




\section{PROCESOS DE DIÁlOGO PARA LA FORMULACIÓN DE POLÍTICAS DE CTI EN AMÉRICA LATINA Y ESPAÑA}


Los trabajos publicados en este libro se encuentran sujetos a un sistema de evaluación por pares independientes y externos, lo que asegura el compromiso de calificación e integridad de parte de los investigadores que aceptaron realizar la evaluación. Éste procedimiento garantiza que los artículos poseen calidad y rigurosidad científica, adecuados a los cánones académicos vigentes en instituciones educativas y de investigación reconocidas internacionalmente.

Procesos de diálogo para la formulación de políticas de CTI en América Latina y España / Gabriela Dutrénit ... [et al.] ; editado por Gabriela Dutrénit ; José Miguel Natera. - 1a ed . - Ciudad Autónoma de Buenos Aires : CLACSO ; Madrid : CYTED ; México : LALICS, 2017.

Libro digital, PDF - (Grupos de trabajo / Atilio Alberto Boron, )

Archivo Digital: descarga y online

ISBN 978-987-722-282-1

1. Políticas Públicas. 2. Ciencia y Tecnología. 3. Información. I. Dutrénit, Gabriela II. Dutrénit, Gabriela, ed. III. Natera, José Miguel, ed. CDD 320.6

Otros descriptores asignados por CLACSO:

Ciencia y Tecnología / Estado / Políticas Públicas / Ciencia / Empresas / Impacto / Innovación / Evaluación / América Latina / España 


\title{
PROCESOS DE DIÁLOGO PARA LA FORMULACIÓN DE POLÍTICAS DE CTI EN AMÉRICA LATINA Y ESPAÑA
}

\author{
Gabriela Dutrénit \\ José Miguel Natera \\ (Editores)
}

Gabriela Dutrénit | José Miguel Natera | Martín Puchet Anyul | Arturo Torres | Alexandre O. Vera-Cruz | Isabel Álvarez | Melissa Ardanche | Florencia Barletta | Mariela Bianco | Iván de la Vega | Ileana Díaz Fernández | María Goñi | Carlos Nupia | Jeffrey Orozco Barrantes | Fernando Prada | Fernando Romero | Lucía Simón | Diana Suárez | Marcela Suárez | Judith Sutz | Víctor Gómez-Valenzuela | Leonie Zapata | Myrna Juan | Celia Torrecillas | Nadia Albis | Romilio Labra | Luis M. Barboza-Arias | Ricardo Torres Pérez | Oscar Fernández Estrada | Mario Bazán | Adriana Martínez-Maestre | Claudia Cohanoff| Soledad Contreras | Nydia Ruiz | María Antonia Cervilla | Marcelo Pessoa de Matos | José Eduardo Cassiolato | Helena M. M. Lastres | Gabriel Yoguel
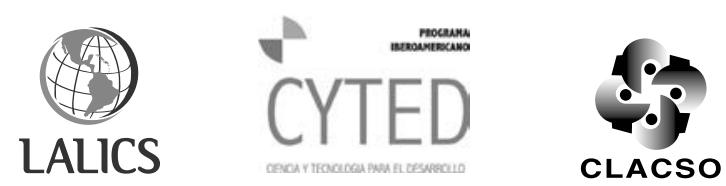


\section{CLACSO 50 AÑOS}

Consejo Latinoamericano de Ciencias Sociales

\section{Colección Grupos de Trabajo}

\section{CLACSO - Secretaría Ejecutiva}

Pablo Gentili - Secretario Ejecutivo

Pablo Vommaro - Director de Grupos de Trabajo, Investigación y Comunicación

Nicolás Arata - Director de Formación y Producción Editorial

Núcleo de producción editorial y biblioteca virtual

Lucas Sablich - Coordinador Editorial

Núcleo de diseño y producción web

Marcelo Giardino - Coordinador de Arte

Sebastián Higa - Coordinador de Programación Informática

Jimena Zazas - Asistente de Arte

Rosario Conde - Asistente de Programación Informática

Equipo Grupos de Trabajo

Rodolfo Gómez, Giovanny Daza, Alessandro Lotti, Teresa Arteaga

\section{Producción Paula D'Amico}

Creemos que el conocimiento es un bien público y común. Por eso, los libros de CLACSO están disponibles en acceso abierto y gratuito. Si usted quiere comprar ejemplares de nuestras publicaciones en versión impresa, puede hacerlo en nuestra Librería Latinoamericana de Ciencias Sociales.

Biblioteca Virtual de CLACSO www.biblioteca.clacso.edu.ar

Librería Latinoamericana de Ciencias Sociales www.clacso.org.ar/libreria-latinoamericana

\section{CONOCIMIENTO ABIERTO, CONOCIMIENTO LIBRE.}

\section{Primera edición}

Procesos de diálogo para la formulación de políticas de CTI en América Latina y España (Buenos Aires: CLACSO, noviembre de 2017)

ISBN 978-987-722-282-1

(c) Consejo Latinoamericano de Ciencias Sociales I Queda hecho el depósito que establece la Ley 11723.

\section{CLACSO}

\section{Consejo Latinoamericano de Ciencias Sociales - Conselho Latino-americano de Ciências Sociais}

Estados Unidos 1168 I C1023AAB Ciudad de Buenos Aires I Argentina

Tel [54 11] 43049145 I Fax [54 11] 43050875 I <clacso@clacsoinst.edu.ar> I <www.clacso.org>

No se permite la reproducción total o parcial de este libro, ni su almacenamiento en un sistema informático, ni su transmisión en cualquier forma o por cualquier medio electrónico, mecánico, fotocopia u otros métodos, sin el permiso previo del editor. 


\section{ÍNDICE}

Gabriela Dutrénit y José Miguel Natera

Procesos de diálogo para el diseño de políticas de CTI

I. ASPECTOS TEÓRICOS Y METODOLÓGICOS DE LOS PROCESOS

DE DIÁLOGOS PARA EL DISEÑO DE POLÍTICAS DE CTI

Gabriela Dutrénit, José Miguel Natera, Martín Puchet Anyul, Arturo Torres y Alexandre O. Vera-Cruz

Dimensiones y atributos relevantes de los procesos de diálogo entre comunidades para el diseño de políticas públicas de CTI

Gabriela Dutrénit et al.

Lineamientos metodológicos para procesos de diálogo orientados

a la formulación de políticas de CTI en América Latina, El Caribe y España

II. PROCESOS DE DIÁLOGOS PARA EL DISEÑO DE POLÍTICAS

DE CTI DE ALCANCE NACIONAL

Víctor Gómez-Valenzuela y Leonie Zapata

Diálogos de Ciencia, Tecnología e Innovación

en la República Dominicana 
Isabel Álvarez, Myrna Juan, Celia Torrecillas, Nadia Albis

y Romilio Labra

Procesos de diálogo en la definición de políticas de Ciencia,

Tecnología e Innovación en España

Jeffrey Orozco Barrantes y Luis M. Barboza-Arias

Diálogos de CTI: hacia la generación de indicadores de Ciencia,

Tecnología e Innovación en Costa Rica

Ricardo Torres Pérez, Ileana Díaz Fernández

y Oscar Fernández Estrada

El contexto para la innovación en Cuba: construcción de consensos

entre comunidades

Mario Bazán y Fernando Romero

Diálogo en el diseño de políticas de Ciencia, Tecnología e Innovación

\section{PROCESOS DE DIÁLOGOS PARA EL DISEÑO DE POLÍTICAS DE CTI ENFOCADAS EN COMUNIDADES ESPECÍFICAS}

\section{Gabriela Dutrénit y Marcela Suárez}

Diálogo entre las comunidades, generación de consensos

y adopción de una perspectiva de género en las políticas públicas

de CTI en México

Carlos Mauricio Nupia y Adriana Martínez-Maestre

La medición de la producción científica de los grupos

de investigación en Colombia

\section{PROCESOS DE DIÁLOGOS PARA EL DISEÑO DE POLÍTICAS DE CTI DE CARÁCTER SECTORIAL}

Melissa Ardanche, Mariela Bianco, Claudia Cohanoff, Soledad Contreras, María Goñi, Lucía Simón y Judith Sutz

Diálogo entre comunidades para la construcción de políticas CTI:

la energía eólica en Uruguay

Iván de la Vega, Nydia Ruiz y María Antonia Cervilla

Hacia la articulación de las políticas públicas en CTI en Venezuela

Marcelo Pessoa de Matos, José Eduardo Cassiolato

y Helena M. M. Lastres

Diálogo para a construção de políticas de CTI para atividades culturais

Florencia Barletta, Diana Suárez y Gabriel Yoguel

Diálogo para la política CTI en el sector de software en Argentina 


\section{ACERCA DE ESTA PUBLICACIÓN}

Con el correr de los años la comunidad de investigadores que estudia el comportamiento de los sistemas innovativos nacionales de Ibero-américa ha ido adquiriendo solidez y comprensión de los aspectos dinámicos, no solo económicos sino también políticos e institucionales, así como sobre la interdependencia sistémica entre los diversos actores que integran dichos sistemas. Hay aprendizaje institucional -tanto en el ámbito privado como en el público-y las empresas, las agencias gubernamentales y la sociedad civil van encontrando nuevas formas de diálogo e interacción que dan forma a la manera como distintas sociedades gestionan su evolución en materia de ciencia, tecnología e innovación. Este libro aporta nuevas pruebas acerca de dichos vínculos sistémicos, así como sobre la creciente solidez y comprensión del papel de lo idiosincrático de la realidad nacional de los distintos países de Ibero-América en este plano. Este libro también nos ayuda a entender lo valioso que son los estudios de casos y la investigación micro para iluminar el papel que la ciencia, la tecnología y la innovación tienen en nuestro medio, y cómo va tomando forma en cada caso la manera en que cada país evoluciona en este campo. Recomiendo la lectura del libro para mejorar nuestra comprensión sobre el papel de la 
participación pública en la formulación de la política de ciencia, tecnología e innovación.

JoRGE Katz

Departamento de Economía, Universidad de Chile Ex Director de la División de Desarrollo Productivo y Empresarial, CEPAL

Las políticas de Ciencia, Tecnología e Innovación (CTI) presentan rasgos que las diferencian fuertemente de otras políticas públicas, siendo tal vez el rasgo más diferenciador la elevada incertidumbre que ronda su diseño e implementación. En efecto, si uno piensa en una intervención típica de Salud Publica, normalmente se tienen una población objetivo relativamente bien definida (aquellos afectados por una cierta patología), una solución más o menos conocida (una vacuna o un antibiótico) y una metodología de aplicación (un protocolo). Esto contrasta fuertemente con el contexto de las políticas de CTI, donde mucha de la población objetivo no está bien definida, existen varias posibles soluciones y el protocolo de intervención es fuertemente específico al contexto. Es más, muchas veces ni siquiera se conoce bien cuál es el problema de fondo. Es por esto que las políticas de CTI, y las instituciones que las implementan, deberían pensarse como "motores de búsqueda", donde el problema, la población objetivo, la solución y su implementación tienen que descubrirse sobre la marcha durante la implementación en un contexto de fuerte aprendizaje institucional y multi-actorial. La efectividad de este aprendizaje depende en forma crítica de la naturaleza de la diálogo que los responsables de las políticas de CTI puedan estructurar con los otros actores del sistema (académicos, empresas, gobierno y ciudadanos). La literatura y también la práctica sobre como estructurar estos procesos de dialogo para que sean reveladores de información constructiva y no reflejen simplemente opiniones sesgadas hacia intereses sectoriales es muy incipiente. En este sentido este libro hace una contribución fundamental para el diseño de la nueva generación de políticas de CTI, no solo porque provee un marco conceptual para entender estos procesos diálogo, sino también porque presenta estudios de casos concretos de estos procesos que pueden alimentar el aprendizaje para los hacedores de política. Es sin duda un libro que recomiendo fuertemente para aquellos colegas involucrados en el diseño e implementación de políticas de CTI en América Latica y El Caribe.

Gustavo Crespi

Especialista Líder en la División de Competitividad e Innovación en el Banco Interamericano de Desarrollo (BID) 
Las políticas de Ciencia, Tecnología e Innovación (CTI) están orientadas a la solución de problemas cada vez más complejos, para los que no hay una sola respuesta desde un único ámbito. Los avances en nuevas tecnologías, los desafíos ambientales y de inclusión social, asi como otro tipo de problemas en torno a los que se diseñan estas políticas no se pueden abordar desde el punto de vista técnico y normativo solamente sino que deben incorporar otras dimensiones, aportadas desde las propias comunidades que de forma directa o indirecta se ven afectadas por estos temas. En este sentido, la participación ciudadana en el diseño de políticas de CTI enriquece el proceso al agregar puntos de vista y voces complementarios a quienes tradicionalmente han participado. Además, el involucramiento de las comunidades en los procesos de toma de decisión repercute en un mayor y mejor ejercicio de la ciudadanía e interés en temas de CTI. Complementariamente, esto se relaciona con la contribución que tenemos que hacer, quienes tenemos algún grado de responsabilidad relacionado con estos procesos, para la consolidación de ámbitos institucionales que permitan que los intercambios fluyan y luego se plasmen en acciones concretas. El Programa CYTED procura articular sus acciones con políticas regionales en el ámbito iberoamericano, con la ejecución de una significativa cantidad de actividades de redes de cooperación académica y empresarial, proyectos de investigación y foros academia-empresa. El fortalecimiento de estas políticas por medio de la participación ciudadana contribuirá también a enriquecer las acciones del Programa y orientarlas aún más a una mejora real de la calidad de vida. La "Red temática para mejorar el diálogo entre las comunidades involucradas en la CTI - COM-LALICS", integrada por expertos de 11 países, hace un aporte muy valioso y oportuno con esta publicación, en la que se presentan casos de procesos de diálogo entre las partes interesadas, lo que permite enriquecer la comprensión sobre los mismos y su relación con los contextos específicos. 



\title{
PROCESOS DE DIÁLOGO PARA EL DISEÑO DE POLÍTICAS DE CTI
}

\section{LA CONSTRUCCIÓN DE UNA RED TEMÁTICA}

\author{
Gabriela Dutrénit ${ }^{*}$ y José Miguel Natera**
}

La participación pública es un principio o práctica política que también puede reconocerse como un derecho (derecho a la participación pública). Más aún, puede considerarse como una forma de empoderamiento de los ciudadanos y como parte vital de la gobernabilidad democrática. Además de otros conceptos, tales como ciudadanos/as o grupos de interés (Crane, Matten y Moon, 2004), la literatura sobre participación pública define a aquellas personas que pueden verse afectadas por las decisiones que toma el gobierno como partes interesadas (stakeholders). En este sentido, se analiza cómo se puede involucrar a las partes interesadas en los procesos de toma de decisiones pues: (i) la construcción de políticas públicas coloca a la participación pública en el centro de estos procesos (Jensen, 2005; Griessler, Biegelbauer y Hansen, 2011); y (ii) existen varios esfuerzos teóricos y metodológicos que están orientados a identificar cómo contribuir a una mayor participación ciudadana (Chilvers, 2008; Griessler, Biegelbauer y Hansen, 2011; Jensen, 2005; Lázaro et al., 2014).

\footnotetext{
* Posgrado en Economía, Gestión y Políticas de Innovación, Universidad Autónoma Metropolitana, Xochimilco

** Catedrático CONACYT, Universidad Autónoma Metropolitana, Xochimilco
} 
Las propuestas para profundizar la participación pública, y/o ciudadana, y/o de los interesados se relacionan con la necesidad de fomentar el diálogo para el proceso de toma de decisiones. Este diálogo puede referirse a temas de interés como los derechos humanos, la salud, el medio ambiente, el agua y los incentivos, entre otros. Aunque ha sido un proceso que inicialmente se dio en los países nórdicos y los Estados Unidos, la naturaleza de los procesos de diálogo entre las partes interesadas y los responsables de la formulación de políticas (los funcionarios públicos) se ha vuelto cada vez más importante en varias regiones del mundo. De hecho, ya hay estudios que han identificado mecanismos para facilitar procesos de diálogo (Jensen, 2005; Rowe, 2005; Mejlgaard, 2009). Los diálogos democráticos, como mencionan Cuentas y Linares Méndez (2013), y los diálogos público-privados en la esfera de la interacción entre el Estado y el sector empresarial (OCDE, 2007)-, recientemente han cobrado relevancia, en particular, por su posibilidad de incidir en las políticas públicas. ${ }^{2}$

Las experiencias de participación pública en la política de ciencia, tecnología e innovación (CTI) han adquirido un interés significativo en las últimas décadas. Para las políticas de CTI, las partes interesadas son un conjunto heterogéneo de actores académicos, del sector privado y ciudadanos que intervienen en esta arena y tienden a interactuar con los responsables de la política pública (actores gubernamentales). Desde una perspectiva sistémico-evolutiva (Woolthuis, Lankhuizen y Gilsing, 2005; Smits, Kuhlmann y Shapira, 2010), la participación pública es fundamental para encontrar soluciones a los problemas políticos determinados durante el establecimiento de la agenda de la política de CTI; en particular para superar las brechas asociadas a fallas sistémicas de los sistemas nacionales de innovación, tales como en el funcionamiento de las redes, limitaciones institucionales y contextuales. Más recientemente, la justificación de la intervención pública asociada a la política de CTI también se ha relacionado con objetivos sociales como el medio ambiente, la salud, la seguridad alimentaria, la sociedad inclusiva, entre otros (European Union, 2013). La participación pública juega un papel destacado en la identificación de estos objetivos.

En este libro, las partes interesadas que participan en la política pública se organizan en comunidades, las cuales se definen desde las personas. Las comunidades son el resultado de la interacción de dos procesos: (i) la socialización de las personas, en la medida en que expresan un origen común y valores compartidos que acentúan los

2 Si bien las políticas diseñadas por los gobiernos también pueden ser gubernamentales, estatales, públicas, o una mezcla de las tres, los diálogos para diseñar las políticas están asociados principalmente con la política pública. 
determinantes de su mentalidad económica, social y cultural, y (ii) la formación de redes, asumiendo la pertenencia, pero también generando relaciones entre las personas que influyen y condicionan las conductas y formas de actuación de las otras (Barboza, 2016; Dutrénit, Natera y Suárez, 2014).

En las actividades de CTI, la formación de comunidades resulta tanto de las actividades mismas como de los incentivos que provienen de la formulación e implementación de políticas. Siguiendo a Dutrénit, Natera y Suárez (2014), en este libro se presentan cuatro comunidades claramente identificadas en el ámbito de la CTI: académica, empresarial, del sector público y otras integradas por personas de la sociedad civil. Dentro de estas comunidades emergen grupos, conjuntos de personas o entidades asociadas, los que ejercen el papel de actores en la formulación de políticas. Como plantean Álvarez et al. (2016), entendemos a las comunidades de CTI como el conjunto de actores en los que existe un alto nivel de cohesión y articulación, así como atributos en común. Entre ellas se establecen distintos diálogos y, de entre todos ellos, nos hemos enfocado en los relacionados con la formulación de política de CTI.

Con el objetivo de analizar procesos de diálogo orientados a la formulación de política de CTI, este trabajo recoge la definición de diálogo democrático propuesta por Cuentas y Linares Méndez (2013). ${ }^{3}$ Sin embargo, Goñi, Bianco y Puchet (2015) hicieron un trabajo de adaptación para hacer que esta definición pudiera contemplar las características de la política de CTI. La propuesta de definición, en la cual se ha basado este libro, es la siguiente:

Los procesos de diálogo relativos a las políticas públicas de CTI son, al igual que los del diálogo democrático, auténticos ejercicios de interacción y conflicto. En ellos cada uno de los participantes aprende e internaliza argumentos de los demás sosteniendo su identidad y está ubicado, desde la perspectiva comunicativa, en una posición resultante del poder o de las capacidades que tiene. Los participantes son actores que emergen de distintas comunidades de agentes de las actividades de CTI. Tienen, por lo tanto, una relación de representación con su comunidad y, a su vez, pertenecen a organizaciones académicas, productivas, gubernamentales o de la sociedad civil que los dotan de diferentes grados de poder y de distintas capacidades. (Goñi, Bianco y Puchet, 2015)

3 "El diálogo es un proceso de genuina interacción mediante el cual los seres humanos se escuchan unos a otros con tal profundidad y respeto que cambian mediante lo que aprenden. Cada uno de los participantes en un diálogo se esfuerza para incorporar las preocupaciones de los otros a su propia perspectiva, aun cuando persista el desacuerdo. Ninguno de los participantes renuncia a su identidad, pero cada uno reconoce la validez de las reivindicaciones humanas de los demás y en consecuencia actúa en forma diferente hacia los otros" (Cuentas y Linares, 2013). 
En los procesos de diálogo orientados a la formulación de políticas de CTI, uno de los desafíos que enfrentan países de América Latina y el Caribe (ALC), y también España, es cómo generar consenso entre las partes interesadas; y cómo traducir las propuestas en un lenguaje institucional y/o gubernamental que esté al día con los programas y esfuerzos actuales.

La participación de las partes interesadas, por sí misma, no garantiza la mejora de la toma de decisiones, del diseño y de la implementación, o de las prácticas públicas en la gobernanza de los sistemas de CTI. Sin embargo, es un paso necesario para una mayor democratización de la CTI. Varios autores sostienen que la diferencia entre la política gubernamental y la política pública radica precisamente en la capacidad de participación de las partes interesadas en sus procesos de formulación (Aguilar, 1992; Valenti y Flores, 2009). Esta participación requiere legislación, arreglos institucionales, normas y reglas del juego. Vale la pena destacar que en algunos países la participación pública se ha convertido en un principio central de la formulación de políticas públicas. Eso ha conducido a un esfuerzo constante por crear formas de participación de las/os ciudadanas/os o de las partes interesadas en el proceso de formulación de políticas. En este marco, se han documentado un conjunto de mecanismos, tales como consultas a gran escala, generación de consensos, u otras formas de participación pública. Nuestro conocimiento sobre estos temas es aún limitado, sobre todo en el ámbito de las políticas de CTI y en contextos específicos, donde los sistemas nacionales de innovación y sistemas políticos siguen siendo inmaduros, como en los países de ALC, y probablemente en menos medida en España.

Los países de ALC han avanzado en la construcción de sistemas de innovación, pero aún están en una fase inmadura y emergente (Dutrénit y Sutz, 2014). La región tiene características comunes y diferencias. Entre los rasgos comunes, destacan: las universidades tienen una fuerte presencia en los sistemas de innovación, en la mayoría de los países hay consejos nacionales de CTI, y algunos han avanzado hacia la creación de ministerios de CTI, el gobierno es el principal financiador del gasto en investigación y desarrollo experimental (GIDE) mientras que el gasto privado continúa siendo menor. La política de CTI en la región ha seguido el marco analítico promovido por los organismos internacionales. En esta senda de construcción, los países han adoptado, a diferentes ritmos y con disímil intensidad, un enfoque sistémico de la política de CTI, aunque básicamente persiste un modelo lineal de innovación (Crespi y Dutrénit, 2014). La formulación de la política de CTI en la región ha pasado de ser una política gubernamental, a definir elementos de política de estado, que trascienda los horizontes 
de cada gobierno. En la última década ha avanzado hacia la construcción de políticas públicas (Ordoñez-Matamoros et al., 2013). Es en este último contexto, donde la participación de las partes interesadas se convirtió en un tema relevante. España es un país recurrido para las comparaciones con ALC. Comparten una historia próxima y la misma lengua. Si bien España ha avanzado más rápidamente en todo este proceso de construcción de sistemas de innovación, aún persisten rasgos que la asemejan a los países más avanzados de ALC.

La confluencia de casos de procesos de diálogo de ALC y de España ha brindado una gran riqueza para entender diferentes aspectos de los procesos de diálogo y de la relación con los contextos específicos. La Red temática para mejorar el diálogo entre las comunidades involucradas en la CTI - COM-LALICS, fue financiada por CYTED (Programa Iberoamericano de Ciencia y Tecnología para el Desarrollo) en el período 2014-2017. Está integrada por investigadores de once países: Argentina, Brasil, Colombia, Costa Rica, Cuba, España, México, Perú, República Dominicana, Uruguay y Venezuela. El objetivo de esta Red ha sido conceptualizar los procesos de diálogo relacionados con la formulación de la política de CTI. En el marco del trabajo de la Red se ha recogido y sistematizado evidencia empírica de quince casos de participación pública que nutren el proceso de formulación de políticas de CTI. Los casos representan un proceso completo de diálogo, que ha tenido como resultado: documentos, acuerdos o recomendaciones. En algunos casos también se implementaron medidas de política.

Uno de los retos planteado fue definir una serie de lineamientos metodológicos para mejorar estos procesos en los países de ALC y en España. Estos lineamientos emergieron de la evidencia, de un análisis sistemático de los casos. El proceso de construcción de conocimiento de la Red fue un reto en sí mismo, en la medida en que confluyeron investigadores de diferentes disciplinas y experiencias, desde realidades comunes -las de ALC y España-, pero con especificidades. El resultado se construyó a través de un proceso de aproximaciones sucesivas, revisitando continuamente la evidencia. En otras palabras, fue un proceso de construcción gradual de conocimiento a partir de la evidencia, donde el énfasis central estuvo en la documentación de los casos y la construcción conjunta del marco teórico-metodológico. Los talleres en México, Montevideo, Lima, Santo Domingo jugaron un papel central en el proceso de construcción conjunta de conocimiento. Nos beneficiamos del hecho de que en la mitad de los procesos de diálogo analizados hubo una participación activa de miembros de la red, lo cual enriqueció la discusión de los lineamientos metodológicos. El anexo 1 lista las referencias de las matrices de información por países que sistematizan el mapeo de los procesos de diálogo de CTI en los países. 
El proceso de construcción de conocimiento incluyó las siguientes actividades:

- Primer taller del equipo de investigación realizado en la Ciudad de México, donde se discutió el marco conceptual, se elaboró una primera versión del marco metodológico, que incluyó dos formularios: el formulario 1 (anexo 2) y el 2 (anexo 3);

- Elaboración de un documento de trabajo (WP) que sintetiza las primeras ideas del proyecto (Dutrénit, Natera y Suárez, 2014);

- Levantamiento de los casos y llenado de los formularios 1 y 2;

- Segundo taller del equipo en Montevideo, donde se discutió la evidencia recolectada de acuerdo a los formularios, y se reformuló el marco metodológico;

- Nueva visita a los casos y revisión del formulario 2 de cada país;

- Elaboración de WP que contienen los resultados de la construcción conceptual y metodológica: Goñi, Bianco y Puchet (2015), Nupia y Martínez (2015), Alvarez et al. (2016), Barboza (2016) y Dutrénit et al. (2016);

- Tercer taller en Lima, dedicado a la elaboración de la primera versión de los lineamientos metodológicos;

- Redacción de los casos, ya enfocados a la elaboración de documentos publicables;

- Cuarto taller en Santo Domingo, donde se discutieron los documentos para su publicación y se revisaron los lineamientos metodológicos; $\mathrm{y}$

- Publicación de los documentos.

Este libro recoge los resultados de la investigación de la Red. Está organizado en tres secciones. La primera es una sección conceptual y metodológica. La segunda y la tercera presentan y discuten la evidencia empírica compuesta por 11 casos de procesos de diálogo.

La sección 1 se compone de dos capítulos. El capítulo 2 se titula "Dimensiones y atributos relevantes de los procesos de diálogo entre comunidades para el diseño de políticas públicas de CTI". Este documento discute un conjunto de conceptos que contribuyen a caracterizar los procesos de diálogo en torno a las políticas de CTI. Gabriela Dutrénit, José Miguel Natera, Martín Puchet Anyul, Arturo Torres Vargas y Alexandre O. Vera-Cruz proponen un marco analítico 
de los procesos de diálogo, a partir de sistematizar los 15 casos incluidos en la Red. El marco analítico se basa en una tipología de las dimensiones y condiciones de los diálogos. Se describe la metodología propuesta por la Red, que constituye una herramienta para analizar otros procesos de diálogo, y un conjunto de recomendaciones para el diseño y la implementación de procesos de diálogo que sean adecuados para la formulación de políticas de CTI. El capítulo 3 contiene una propuesta de "Lineamientos metodológicos para procesos de diálogo orientados a la formulación de políticas de CTI en ALC y España", y fue escrito por un conjunto amplio de miembros de la Red. El propósito es sistematizar un conjunto de lineamientos para orientar a las personas interesadas en el desarrollo de procesos de diálogos para la política pública de CTI en la región. Los lineamientos cubren tres aspectos: (i) consideraciones sobre las comunidades y el proceso de diálogo; (ii) una propuesta de organización del proceso de diálogo en cinco fases; y (iii) una serie de lecciones aprendidas que han sido recolectadas de la evidencia empírica. La sección 2 integra cinco capítulos que describen procesos de diálogo sobre la política de CTI. El capítulo 4, titulado "Diálogos de ciencia, tecnología e innovación en la República Dominicana: análisis de su impacto y repercusiones en políticas públicas", es elaborado por Víctor Gómez-Valenzuela y Leonie Zapata. En este trabajo se re-construye la experiencia del diálogo de políticas de CTI desarrollado en 2014. Este diálogo condujo a que la comunidad pública y empresarial reconocieran la necesidad de fomentar un marco estructurado de políticas de CTI en la República Dominicana, así como a la habilitación de la Ventanilla de Financiamiento de Proyectos de Innovación.

En el capítulo 5, Isabel Álvarez, Myrna Juan, Celia Torrecillas, Nadia Albis y Romilio Labra presentan el trabajo titulado "Procesos de diálogo en la definición de políticas de ciencia, tecnología e innovación en España". En este capítulo se analizan dos diálogos en el ámbito de la política CTI, relacionados con el "Plan de Ciencia y Tecnología de Andalucía" y la "Mejora de la movilidad de personal investigador en formación entre Universidades y Empresas (el caso de IBERDROLA)".

El capítulo 6, "Diálogos de CTI: hacia la Generación de Indicadores de Ciencia, Tecnología e Innovación en Costa Rica", de Jeffrey Orozco Barrantes y Luis M. Barboza-Arias, describe los procesos institucionales que condujeron al establecimiento de un Diálogo para la Generación de Indicadores de CTI en Costa Rica, y sus efectos en la identificación de política pública.

El capítulo 7, titulado "El contexto para la innovación en Cuba: construcción de consensos entre comunidades", analiza un proceso 
de diálogo sobre innovación en Cuba. Este diálogo se inserta en un contexto que combina subdesarrollo, socialismo de planificación central y, más recientemente, el inicio de un proceso de transformaciones definido inicialmente como una partida hacia un nuevo modelo. La innovación se ha incluido como uno de los seis ejes estratégicos para el Plan Nacional de Desarrollo Económico y Social hasta 2030; asimismo, los cambios que se están introduciendo en la economía cubana demandan un enfoque moderno sobre la innovación, que otorgue un lugar diferente a las diferentes formas productivas. Esto requiere construir consensos para alimentar el diseño de las políticas de CTI. En este contexto complejo, Ricardo Torres Pérez, Ileana Díaz Fernández y Oscar Fernández Estrada analizan las condiciones para el diálogo, con especial atención a las especificidades del contexto en el cual se desarrolla, y los actores involucrados.

En el capítulo 8, "Diálogo en el diseño de políticas de Ciencia, Tecnología e Innovación: La experiencia en el Perú de la Agenda Nacional de Competitividad 2014-2018", Mario Bazán y Fernando Romero describen el proceso de diálogo para construir la Agenda de competitividad, particularmente para el diseño del componente de CTI, y discuten las lecciones aprendidas de este proceso. Estas lecciones de la experiencia peruana contribuyen al debate sobre la aplicación de metodologías para involucrar a una gran diversidad de actores en el diseño y monitoreo de políticas en CTI.

La sección 3 se compone de seis capítulos que describen procesos de diálogo sectoriales o temáticos. En el capítulo 9 titulado "Diálogo entre las comunidades, generación de consensos y adopción de una perspectiva de género en las políticas públicas de CTI", Gabriela Dutrénit y Marcela Suárez discuten la incidencia que pueden tener los procesos de diálogo entre comunidades en el diseño de la política pública. El caso analizado es una experiencia de diálogo y generación de consensos desarrollado durante 2013 y 2014 para proponer recomendaciones orientadas hacia la adopción de una perspectiva de género en la política de CTI en México.

El capítulo 10 es "La medición de la producción científica de los grupos de investigación en Colombia: del diálogo experto a nuevas prácticas representativas", donde Carlos Mauricio Nupia y Adriana MartínezMaestre analizan las condiciones que afectan el diálogo entre los científicos y los tomadores de decisiones cuando está en juego una política pública para medir la productividad científica. El proceso de diálogo analizado está relacionado con la construcción del Modelo Colombiano de Medición de la Producción Científica de los Grupos de Investigación.

En el capítulo 11, titulado "Diálogo entre comunidades para la construcción de políticas CTI: la energía eólica en Uruguay”, donde 
Melissa Ardanche, Mariela Bianco, Claudia Cohanoff, Soledad Contreras, María Goñi, Lucía Simón y Judith Sutz analizan los diálogos que se establecieron en torno al proceso de cambio de la matriz energética. Las autoras ponen especial atención en los roles y características de las comunidades que participaron en este diálogo.

El capítulo 12 contiene el trabajo "Hacia la articulación de las políticas públicas en CTI en Venezuela. La implicación de los diálogos para avanzar en el proceso de gestión del conocimiento en el área de la energía”, elaborado por Iván de la Vega, Nydia Ruiz y María Antonia Cervilla.

El capítulo 13 se titula "Diálogo para a construção de políticas de CTI para atividades culturais: a experiência dos Arranjos Produtivos Locais do Carnaval no Brasil". Este documento elaborado por Marcelo Pessoa de Matos, José Eduardo Cassiolato y Helena M. M. Lastres presenta un conjunto de evidencia empírica y críticas acerca de la experiencia do proceso de diálogo para la creación e implementación de políticas de CTI en los Arreglos Productivos Locales (APLs) del Carnaval en Brasil. El objetivo central es discutir las características y determinantes del proceso de diálogo, con especial atención en la interfaz entre la capacidad de agencia de los beneficiarios, los intereses políticos y las relaciones de poder.

Finalmente, el capítulo 14 contiene el documento "Diálogo para la política CTI en el sector de software en Argentina. Orígenes, evolución y desafíos del FONSOFT como herramienta de promoción sectorial". Allí, Florencia Barletta, Diana Suárez y Gabriel Yoguel analizan el proceso de diálogo para la política de CTI en el sector de software y servicios informáticos. Los autores estudian y sistematizan las características del diálogo (en términos de organización, equilibrios y asimetrías de poder entre las comunidades involucradas, forma de implementación, etc.) que condujeron al diseño de una política específica de promoción del sector: el Fondo Fiduciario de Promoción de la Industria del Software.

Este trabajo forma parte de un esfuerzo más amplio de reflexión sobre Ciencia, Tecnología y Sociedad en América Latina, que viene desarrollando el Grupo de trabajo "Ciencia y Sociedad" de CLACSO. En particular, este libro contribuye a alimentar el pensamiento en torno a la generación de políticas de CTI basadas en la evidencia, a partir de la discusión de estudios de caso sobre los procesos de diálogo de las comunidades para construir política pública.

Esperamos que la recopilación de estos casos de estudios, estructurados a través del marco analítico que proponemos, sean considerados como un aporte a la construcción de políticas públicas de CTI, basadas en la participación pública, que logren contribuir al desarrollo de ALC y España. En este sentido, queremos agradecer el financiamiento de CYTED (Programa Iberoamericano de Ciencia y Tecnología 
para el Desarrollo) a la "Red temática para mejorar el diálogo entre las comunidades involucradas en la CTI - COM-LALICS”. Particularmente, el apoyo crítico y constructivo del gestor del área de Ciencia y Sociedad, Sandro Mendonça.

\section{BIBLIOGRAFÍA}

Aguilar, L. 1992 La hechura de las políticas públicas (México: Miguel Ángel Porrúa).

Álvarez, I.; Barletta, F.; Suarez, D.; Yoguel G. 2016 "Marco analítico para la tipificación de diálogos para las políticas de CTI" en Working paper 3 (Red CYTED COM-LALICS). Disponible en <http://lalics.org/images/CYTED/DT3-DimensionesDialogo.pdf> acceso 15 de abril de 2017.

Barboza, L. 2016 "Algunas consideraciones en torno al concepto de comunidad" en Working paper 6 (Red CYTED COMLALICS). Disponible en <http://lalics.org/images/CYTED/DT6DefinicionComunidad.pdf $\geq$ acceso 15 de abril de 2017 .

Chilvers, J. 2008 "Deliberating Competence: Theoretical and Practitioner Perspectives on Effective Participatory Appraisal Practice" en Science, Technology \& Human Values (SAGE Journals) $\mathrm{N}^{\circ} 33$, pp. 421-451.

Crane, A.; Matten, D.; Moon, J. 2004 "Stakeholders as Citizens? Rethinking Rights, Participation, and Democracy" en Journal of Business Ethics (Springer) N ${ }^{\circ}$ 53/1-2, pp. 107-122.

Crespi, G.; Dutrénit, G. (eds.) 2014 Science, Technology and Innovation Policies for Development: The Latin American Experience (London: Springer).

Cuentas, M. A.; Linares Méndez, A. 2013 Guía práctica de diálogo democrático (Organización de Estados Americanos - Programa de las Naciones Unidas para el Desarrollo).

Dutrénit, G.; Sutz, J. (eds.) 2014 National Innovation Systems, Social Inclusion and Development: The Latin American Experience (Cheltenham: Edward Elgar).

Dutrénit, G.; Álvarez, I.; Ardanche, M.; Barletta, F.; Bianco, M.; Cortés, R.; Cummings, A.; de la Vega, I.; Díaz, I.; Fernández, O.; Gómez, V.; Goñi, M.; Natera, J. M.; Nupia, C.; Orozco, J.; Prada, F.; Puchet, M.; Romero, F.; Simón, L.; Suárez, D.; Suárez, M.; Sutz, J.; Vera-Cruz, A. (2016) "Matriz de Información para el mapeo de procesos de diálogo de CTI en España, América Latina y el Caribe" en Working paper 5 (Red CYTED COMLALICS). Disponible en <http://lalics.org/images/CYTED/DT5Formulario2.pdf > acceso 15 de abril de 2017. 
Dutrénit, G.; Natera, J. M.; Suárez, M. 2014 “Lineamientos para la caracterización de las Comunidades y sus Procesos de Diálogo" en Working paper 1 (Red CYTED COM-LALICS). Disponible en <http://alics.org/images/CYTED/DT1ComunidadesDialogo\%201.pdf> acceso 15 de abril de 2017.

EU 2013 Horizon 2020 - Excellent Science, Competitive Industries, Better Society (Bruselas).

Goñi, M.; Bianco, M.; Puchet, M. 2015 “Elementos para caracterizar los procesos de diálogo en políticas de CTI" en Working paper 7 (Red CYTED COM-LALICS). Disponible en <http://lalics.org/images/ CYTED/DT7-ConfianzaPoder.pdf> acceso 15 de abril de 2017.

Griessler, E.; Biegelbauer, P.; Hansen, J. 2011 “Citizen’s Impact on knowledge intensive policy: introduction to a special issue" en Science and Public Policy (Reino Unido: Oxford University Press) $\mathrm{N}^{\circ}$ 38(8), pp. 583-588.

Jensen, C. 2005 "Citizen Projects and Consensus-Building at the Danish Board of Technology: On Experiments in Democracy" en Acta Sociológica (México: UNAM) N 48(3), pp. 221-235.

Lázaro, M.; Trimble, M.; Umpiérrez, A.; Vásquez, A.; Pereira, G. 2013 Juicios Ciudadanos en Uruguay. Dos experiencias de participación pública deliberativa en ciencia y tecnología (Montevideo: PNUD/ Universidad de la República).

Mejlgaard, N. 2009 "The trajectory of scientific citizenship in Denmark: changing balances between public competence and public participation" en Science and Public Policy (Reino Unido: Oxford University Press) $\mathrm{N}^{\circ} 36 / 6$, pp. 483-496.

Metcalfe, J. 1995 "Technology systems and technology policy in an evolutionary framework" en Cambridge Journal of Economics (Reino Unido: Oxford University Press) Nº 19/1, pp. 25-46.

Nupia, C.; Martínez A. 2015 "Revisión de metodologías de procesos de diálogo" en Working paper 4 (Red CYTED COMLALICS). Disponible en <http://lalics.org/images/CYTED/DT4MetodologiasDialogo.pdf> acceso 15 de abril de 2017.

OECD 2007 Public-Private Dialogue in Developing Countries Opportunities and Risks (Paris: OECD Development Centre).

Ordónez-Matamoros, G.; Tadlaoui, S.; Porras, S.; Duarte, J.; López, L.; Martínez, L.; Calderón, G. 2013 Manual de Análisis y Diseño de Políticas Públicas (Bogotá: Editorial Universidad Externado de Colombia).

Rowe, G. 2005 "A Typology of Public Engagement Mechanisms" en Science, Technology \& Human Values (SAGE Journals) N $\mathrm{N}^{\circ}$ 30/2, pp. 251-290. 
Smits, R.; Kuhlmann, S.; Shapira, P. 2010 The theory and practice of innovation policy: an international research handbook (Cheltenham: Edward Elgar).

Valenti, G.; Flores, U. 2009 "Ciencias sociales y políticas públicas" en Revista Mexicana de Sociología (México: UNAM) № 71,pp. 16791.

Woolthuis, R.; Lankhuizen, M.; Gilsing, V. 2005 “A system failure framework for innovation policy design" en Technovation (Estados Unidos) $\mathrm{N}^{\circ}$ 25/6, pp. 609-619. 


\section{ANEXO 1 MATRICES DE INFORMACIÓN POR PAÍSES PARA EL MAPEO DE LOS PROCESOS DE DIÁLOGO DE CTI}

Álvarez, I; Juan, M; Torrecillas, C; Albis, N; Labra, R. 2016a. Plan regional de $I+D+i$ para la Comunidad Autónoma de Andalucía (PAIDI). Working paper (WP), Red CYTED COM - LALICS. En $<$ http://lalics.org/index.php?option=com_content\&view=category \&layout=blog\&id=63\&Itemid=321\&lang=es $>$ (España-Andalucía). Álvarez, I; Juan, M; Torrecillas, C; Albis, N; Labra, R. 2016b. Diálogos y Políticas para la Investigación, Innovación, Ciencia y Tecnología (España: Iberdrola). Working paper (WP), Red CYTED COM LALICS. En <http://lalics.org/index.php?option=com_content \&view $=$ category\&layout $=$ blog\&id $=63 \&$ Itemid $=321 \& l a n g=e s>$ (España: Iberdrola).

Ardanche, M; Bianco, M; Cohanoff, C; Conteras, S; Goñi, M; Simón, L; Sutz, J 2016a Cambio en la matriz energética uruguaya con especial énfasis en el desarrollo de la energía eólica. Working paper (WP), Red CYTED COM - LALICS. En <http://alics.org/ index.php?option $=$ com_content $\&$ view $=$ category\&layout $=$ blog\&i $\mathrm{d}=63$ \&Itemid=321\&lang=es $>$ (Uruguay: Viento).

Ardanche, M; Bianco, M; Cohanoff, C; Conteras, S; Goñi, M; Simón, L; Sutz, J 2016b Juicios Ciudadanos en Uruguay. Una experiencia de participación pública deliberativa en Ciencia y Tecnología. WP, Red CYTED COM - LALICS. En <http://lalics.org/index. 
php?option=com_content\&view=category\&layout $=$ blog\&id $=63 \&$ Itemid=321\&lang=es $>$ (Uruguay: Ciudadanos).

Barletta, F; Suárez, D; Yoguel, G. 2016 Promoción de la innovación en la industria del software y los servicios de TI - El caso de FONSOFT. WP, Red CYTED COM - LALICS. En <http://lalics. org/index.php?option=com_content\&view $=$ category\&layout $=$ blo g\&id=63\&Itemid=321\&lang=es $>$ (Argentina: FONSOFT).

Bazán, M; Prada, F; Romero, F. 2016 Matriz de Información para el mapeo de procesos de diálogo de CTI: Diálogos para el desarrollo de la Agenda de Competitividad 2014-2018 en el Eje Estratégico de Ciencia, Tecnología e Innovación en Perú. WP, Red CYTED COM - LALICS. En <http://lalics.org/index.php?option=com_conten t\&view $=$ category\&layout $=$ blog\&id $=63 \&$ Itemid $=321 \&$ lang $=e s>$ (Peru: Agenda).

Cortes, R. 2016 Creación de instituciones públicas para el desarrollo de la ciencia en Chile. WP, Red CYTED COM - LALICS. En <http:// lalics.org/index.php?option=com_content\&view=category\&layou $\mathrm{t}=\mathrm{blog} \& \mathrm{id}=63 \&$ Itemid $=321$ \&lang $=\mathrm{es}>$ (Chile: Ciencia) .

De la Vega, I; Ruiz, N; Cervilla, M.A . 2016. STI desde la gestión del conocimiento. El caso de la política pública en el área de energía en Venezuela. WP, Red CYTED COM - LALICS. En <http://lalics. org/index.php?option=com_content\&view=category\&layout=blo g\&id=63\&Itemid=321\&lang=es $>$ (Venezuela: Energía) .

Dutrénit, G, Suárez, M. 2016a Propuestas para adoptar una perspectiva de género en las políticas de CTI en México. WP, Red CYTED COM - LALICS. En <http://lalics.org/index. php?option=com_content $\&$ view $=$ category\&layout $=$ blog\&id $=63 \&$ Itemid=321\&lang=es $>$ (Mexico: Género).

Dutrénit, G, Suárez, M. 2016b Desafíos empresariales basados en el conocimiento en México. WP, Red CYTED COM - LALICS. En $<$ http://lalics.org/index.php?option=com_content\&view $=\mathrm{c}$ ategory\&layout $=$ blog\&id $=63 \&$ Itemid $=321 \& l a n g=e s>$ (México: Emprendedores).

Gómez-Valenzuela, V; Zapata, L. 2016 Matriz de Información para el mapeo de procesos de diálogo de CTI: Diálogo nacional sobre políticas de innovación: fomento de la innovación, la creatividad y la creación de nuevos negocios en República Dominicana. WP, Red CYTED COM - LALICS. En <http://lalics.org/index. php?option=com_content\&view $=$ category\&layout $=$ blog\&id $=63 \&$ Itemid=321\&lang=es $>$ (República Dominicana: Política). 
Nupia, C, Martínez, A. 2016a El desarrollo participativo de la innovación en politicas sociales en Colombia. WP, Red CYTED COM - LALICS. En <http://lalics.org/index.php?option=com_co ntent\&view=category\&layout=blog\&id=63\&Itemid=321\&lang= es> (Colombia: Social).

Nupia, C, Martínez, A. 2016b Medición y reconocimiento de grupos de investigación en Colombia. WP, Red CYTED COM - LALICS. En $<$ http://lalics.org/index.php?option=com_content\&view=category \&layout=blog\&id $=63 \&$ Itemid $=321 \&$ lang=es $>$ (Colombia: Grupos de investigación).

Orozco, J; Barboza-Arias, L. 2016 Sistema de Indicadores Nacionales de Ciencia, Tecnología e Innovación en Costa Rica. WP, Red CYTED COM - LALICS. En <http://lalics.org/index. php?option=com_content\&view=category\&layout $=$ blog $\& i d=63 \&$ Itemid=321\&lang=es $>$ (Costa Rica: Indicadores).

Pessoa de Matos, M; Cassiolato, J. E.; Lastres, H. 2016 Construcción de politicas STI: diálogo de políticas públicas en los Sistemas Locales de Innovación y Producción del Carnaval en Brasil. WP, Red CYTED COM - LALICS. En <http://lalics.org/index. php?option=com_content\&view $=$ category\&layout $=$ blog\&id $=63 \&$ Itemid=321\&lang=es $>$ (Brasil: Carnaval).

Suárez, D; Barletta, F; Yoguel, G. 2016 Promoción de la innovación a nivel sectorial - El caso de FONARSEC. WP, Red CYTED COM - LALICS. En <http://lalics.org/index.php?option=com_conten t\&view=category\&layout=blog\&id=63\&Itemid $=321 \&$ lang $=e s>$ (Argentina: FONARSEC).

Torres Pérez, R; Díaz Fernández, I.; Fernández Estrada, O. 2016 Arreglos institucionales e incentivos para la innovación en Cuba. WP, Red CYTED COM - LALICS. En http://lalics.org/index. php?option $=$ com_content \&view $=$ category $\&$ layout $=$ blog $\& i d=63 \&$ Itemid=321\&lang=es (Cuba: Instituciones). 



\section{ANEXO 2 \\ FORMULARIO 1}

El Formulario 1 está orientado a listar las comunidades identificadas en los procesos de diálogo.

\begin{tabular}{|l|l|l|l|l|}
\hline \multicolumn{5}{|c|}{ Formato 1: Listado de Comunidades Identificadas } \\
País: \\
\hline $\begin{array}{l}\text { Comunidad } \\
\text { Académica }\end{array}$ & $\begin{array}{c}\text { Comunidad } \\
\text { Empresarial }\end{array}$ & $\begin{array}{c}\text { Comunidad } \\
\text { Sector Público }\end{array}$ & $\begin{array}{c}\text { Otros sectores } \\
\text { de la Comunidad } \\
\text { Civil }\end{array}$ & $\begin{array}{c}\text { Comunidad } \\
\text { Mixta }\end{array}$ \\
\hline & & & & \\
\hline & & & & \\
\hline & & & & \\
\hline & & & & \\
\hline
\end{tabular}

Fuente: Adaptado de Dutrénit, G.; Natera, J. M.; Suárez, M. 2014 "Lineamientos para la caracterización de las Comunidades y sus Procesos de Diálogo" en Working paper 1 (Red CYTED COM-LALICS). Disponible en <http://lalics. org/images/CYTED/DT1-ComunidadesDialogo\%201.pdf> acceso 15 de abril de 2017. 



\section{ANEXO 3 \\ ESTRUCTURA DEL FORMULARIO 2 - MATRIZ \\ DE INFORMACIÓN PARA EL MAPEO \\ DE PROCESOS DE DIÁLOGO DE CTI \\ EN ESPAÑA, AMÉRICA LATINA Y EL CARIBE}

Instrumento diseñado para analizar la heterogeneidad de los procesos de diálogo en Iberoamérica. La versión detallada del instrumento se encuentra en el Documento de Trabajo de la RED CYTED: Dutrénit, G.; Álvarez, I.; Ardanche, M.; Barletta, F.; Bianco, M.; Cortés, R.; Cummings, A.; de la Vega, I.; Díaz, I.; Fernández, O.; Gómez, V.; Goñi, M.; Natera, J. M.; Nupia, C.; Orozco, J.; Prada, F.; Puchet, M.; Romero, F.; Simón, L.; Suárez, D.; Suárez, M.; Sutz, J.; Vera-Cruz, A. 2016 “Matriz de Información para el mapeo de procesos de diálogo de CTI en España, América Latina y el Caribe" en Working paper 5 (Red CYTED COM-LALICS). Disponible en <http://lalics.org/images/CYTED/DT5Formulario2.pdf> acceso 15 de abril de 2017.

\begin{tabular}{|l|l|}
\hline \multicolumn{2}{|c|}{ SECCIONES, SUBSECCIONES } \\
\hline \multicolumn{4}{c}{\begin{tabular}{c} 
EL TEMA \\
\multirow{4}{*}{$\begin{array}{c}\text { 1. Contexto del } \\
\text { tema }\end{array}$}
\end{tabular}} & 1.1 Breve historia del tema \\
\cline { 2 - 2 } & 1.2 Contexto político \\
\cline { 2 - 2 } & 1.3 Retos del tema \\
\cline { 2 - 2 } & 1.4 Avances significativos \\
\hline
\end{tabular}




\section{EL PROCESO DE DIÁLOGO}

\begin{tabular}{|c|c|}
\hline \multirow{2}{*}{$\begin{array}{l}\text { 2. El Proceso de } \\
\text { Diálogo }\end{array}$} & 2.1 Breve historia y principales actores involucrados en el proceso (si hay antecedentes) \\
\hline & 2.2 Contexto político (incluir la legislación sobre la participación de las comunidades) \\
\hline \multirow{2}{*}{ 3. Propósito } & 3.1 Propósito de iniciar el diálogo (de los convocantes y de los participantes) \\
\hline & 3.2 Alcance \\
\hline \multirow{5}{*}{$\begin{array}{l}\text { 4. Comunidades } \\
\text { Identificadas } \\
\text { (incluir el número } \\
\text { de participantes } \\
\text { en cada } \\
\text { comunidad) }\end{array}$} & 4.1. Comunidad Académica \\
\hline & 4.2. Comunidad Empresarial \\
\hline & 4.3. Comunidad Sector Público \\
\hline & 4.4. Otros sectores de la Comunidad Civil \\
\hline & 4.5. Descripción del involucramiento de las comunidades \\
\hline \multirow{12}{*}{$\begin{array}{l}\text { 5. Características } \\
\text { del proceso de } \\
\text { diálogo }\end{array}$} & 5.1 Promotores. \\
\hline & 5.2 Lideres. \\
\hline & 5.3 Convocantes. \\
\hline & 5.4 Donantes. \\
\hline & 5.5 Facilitadores, traductores, mediadores. \\
\hline & 5.6 Gestores. \\
\hline & 5.7 Expertos. \\
\hline & 5.8 Espacio en donde se celebra el diálogo (organización, territorio) \\
\hline & 5.9 Criterios para la selección de los actores \\
\hline & 5.10 Fases/etapas/hitos (relación con la línea del tiempo). \\
\hline & 5.11 Metodología \\
\hline & 5.12 Evaluación y retroalimentación del proceso de diálogo por parte de los actores \\
\hline \multirow{7}{*}{$\begin{array}{l}\text { 6. Retos del } \\
\text { proceso de } \\
\text { diálogo }\end{array}$} & 6.1 Existencia (o no) de un nivel homogéneo de capacidades entre las comunidades \\
\hline & 6.2 Existencia (o no) de un lenguaje común entre las comunidades \\
\hline & 6.3 Grupos de poder e intereses de conflicto (si los hay) \\
\hline & 6.4 Desarrollo de los procesos de creación de espacios de confianza entre las comunidades \\
\hline & $\begin{array}{l}\text { 6.5 Relaciones / instituciones /reglas de juego formales (declaradas en el proceso } \\
\text { de diálogo) e informales (que surgen del proceso de diálogo aun cuando no estén } \\
\text { declaradas) }\end{array}$ \\
\hline & 6.6 Intensidad de las interacciones entre las comunidades \\
\hline & $\begin{array}{l}\text { 6.7 Otros retos enfrentados relacionados con el tema/comunidades/ otro tipo de } \\
\text { naturaleza }\end{array}$ \\
\hline
\end{tabular}




\begin{tabular}{|c|c|}
\hline \multirow{3}{*}{ 7. Resultados } & 7.1 Resultados del proceso de diálogo (intermedios o finales) \\
\hline & 7.2 Trabajo de seguimiento y compromisos por parte de los actores \\
\hline & 7.3 Impacto del proceso de diálogo sobre el tema del diálogo (énfasis en la política de CTI) \\
\hline \multicolumn{2}{|r|}{ LAS LECCIONES APRENDIDAS } \\
\hline \multirow{4}{*}{$\begin{array}{l}\text { 8. Lecciones } \\
\text { aprendidas en } \\
\text { la definición de } \\
\text { las comunidades } \\
\text { participantes en } \\
\text { el proceso de } \\
\text { diálogo }\end{array}$} & 8.1 Representatividad \\
\hline & 8.2 Heterogeneidad de los actores \\
\hline & 8.3 Emergencia de nuevas comunidades \\
\hline & 8.4 Otras lecciones aprendidas acerca de las comunidades \\
\hline \multirow{22}{*}{$\begin{array}{l}\text { 9. Lecciones } \\
\text { aprendidas } \\
\text { del proceso de } \\
\text { diálogo (destacar } \\
\text { las buenas } \\
\text { prácticas versus } \\
\text { aquellas fallas del } \\
\text { proceso que lo } \\
\text { obstaculizaron) }\end{array}$} & 9.1 Promotores \\
\hline & 9.2 Convocantes \\
\hline & 9.3 Líderes \\
\hline & 9.4 Donantes \\
\hline & 9.5 Facilitadores, traductores, mediadores. \\
\hline & 9.6 Gestores \\
\hline & 9.7 Expertos de proceso \\
\hline & 9.8 Espacio en donde se celebra el diálogo (organización, territorio) \\
\hline & 9.9 Criterios para la selección de los 9 \\
\hline & 9.10 Fases/etapas/hitos (relación con la línea del tiempo) \\
\hline & 9.11 Metodología \\
\hline & 9.12 Evaluación y retroalimentación del proceso de diálogo por parte de los actores \\
\hline & 9.13 Existencia (o no) de un nivel homogéneo de capacidades entre las comunidades \\
\hline & 9.14 Existencia (o no) de un lenguaje común entre las comunidades \\
\hline & 9.15 Grupos de poder e intereses de conflicto (si los hay) \\
\hline & $\begin{array}{l}\text { 9.16 Desarrollo de los procesos de creación de espacios de confianza entre las } \\
\text { comunidades }\end{array}$ \\
\hline & $\begin{array}{l}9.17 \text { Relaciones / instituciones /reglas de juego formales (declaradas en el proceso } \\
\text { de diálogo) e informales (que surgen del proceso de diálogo aun cuando no estén } 7\end{array}$ \\
\hline & 9.18 Intensidad de las interacciones (baja, media, alta) entre las comunidades \\
\hline & $9.19 \mathrm{a}-$ Retos enfrentados relacionados con el tema \\
\hline & $9.19 b$ - Retos enfrentados relacionados con las comunidades \\
\hline & $9.19 \mathrm{c}$ - Retos enfrentados con otro tipo de naturaleza \\
\hline & 9.20 Otras lecciones aprendidas del proceso de diálogo \\
\hline
\end{tabular}




\begin{tabular}{|l|l|}
\hline $\begin{array}{c}\text { 10. Lecciones } \\
\text { aprendidas en } \\
\text { los resultados } \\
\text { e impactos del } \\
\text { proceso de } \\
\text { diálogo }\end{array}$ & 10.1 Lecciones aprendidas en los resultados e impactos del proceso de diálogo \\
\hline \multirow{4}{*}{$\begin{array}{c}\text { 11. Clasificación } \\
\text { general del } \\
\text { diálogo }\end{array}$} & 11.1 Origen \\
\cline { 2 - 3 } & 11.2 Temporalidad \\
\cline { 2 - 2 } & 11.3 Alcance \\
\cline { 2 - 2 } & 11.5 Balance entre actores \\
\cline { 2 - 3 } & 11.6 Resultados \\
\hline
\end{tabular}

Fuente: adaptado de Dutrénit, G.; Álvarez, I.; Ardanche, M.; Barletta, F.; Bianco, M.; Cortés, R.; Cummings, A.; de la Vega, I.; Díaz, I.; Fernández, 0.; Gómez, V.; Goñi, M.; Natera, J. M.; Nupia, C.; Orozco, J.; Prada, F.; Puchet, M.; Romero, F.; Simón, L.; Suárez, D.; Suárez, M.; Sutz, J.; Vera-Cruz, A. 2016 "Matriz de Información para el mapeo de procesos de diálogo de CTI en España, América Latina y el Caribe" en Working paper 5 (Red CYTED COM-LALICS). Disponible en <http://lalics.org/images/CYTED/DT5-Formulario2.pdf> acceso 15 de abril de 2017. 


\section{ASPECTOS TEÓRICOS Y METODOLÓGICOS DE LOS PROCESOS DE DIÁLOGOS PARA EL DISEÑO DE POLÍTICAS DE CTI}





\title{
DIMENSIONES Y ATRIBUTOS RELEVANTES DE LOS PROCESOS DE DIÁLOGO ENTRE COMUNIDADES PARA EL DISEÑO DE POLÍTICAS PÚBLICAS DE CTI
}

\author{
Gabriela Dutrénit,* José Miguel Natera, ${ }^{* *}$ Martín Puchet \\ Anyul, ${ }^{* * *}$ Arturo Torres, ${ }^{*}$ y Alexandre O. Vera-Cruz*
}

\section{INTRODUCCIÓN}

Recientemente ha cobrado importancia el tema de la definición, diseño e implementación de política pública en la arena de ciencia, tecnología e innovación (CTI). A este tema contribuye, por un lado, la teoría de la política pública (Aguilar, 1992, 2006; Valenti, 2008; Ordoñez-Matamoros et al., 2013) y, por otro, los avances y las reflexiones sobre la naturaleza, alcances y metodologías de la participación pública (Chilvers, 2008; Griessler, Biegelbauer y Hansen, 2011; Jensen, 2005). La incorporación de las voces de los sectores interesados, es decir de aquellos involucrados o afectados por, conocedores de, o que tienen experiencia relevante en el tema en cuestión (Cuppen, 2012) en el diseño de política pública de CTI es un tema aun poco analizado (Jasanoff, 2003; Irwin, 2006; Bruce y Whatmore, 2010). La forma práctica de incorporar esas voces en la política pública de CTI ha sido a través de formas sencillas de consulta, como los métodos de participación política basados en audiencias públicas o grupos

\footnotetext{
* Posgrado en Economía, Gestión y Políticas de Innovación, Universidad Autónoma Metropolitana, Xochimilco

**Catedrático CONACYT, Universidad Autónoma Metropolitana, Xochimilco

***Facultad de Economía, Universidad Nacional Autónoma de México
} 
focales, y algunos instrumentos de larga escala, consulta y asesoría basados en encuestas de consulta, comités asesores ciudadanos o cumbres ciudadanas. Estos métodos permiten recoger la opinión de las partes interesadas, pero no aseguran la inclusión de las opiniones en el diseño de la política. El uso de instrumentos de generación de consenso es más limitado.

La evidencia en ALC y España muestra que, más allá de los discursos, en el diseño de las políticas de CTI predomina un enfoque de arriba hacia abajo, basado en políticas gubernamentales, y existen dificultades para recoger la voz de los sectores interesados. El conocimiento sobre la participación pública en el diseño de política pública de CTI es aún limitado, particularmente en el caso de sistemas de innovación emergentes. Sabemos poco sobre los procesos de diálogo en los cuales participan los formuladores de la política y las partes interesadas (stakeholders), tanto de los sectores académico y empresarial, como de otros sectores de la sociedad civil.

Este trabajo se inserta en esta discusión y analiza las dimensiones, condiciones y desafíos que presentan los procesos de diálogo entre comunidades para contribuir a la formulación de políticas en los sistemas de innovación de ALC y de España. Se propone un marco conceptual basado en las relaciones entre los sistemas de innovación, las políticas públicas de CTI y el papel de los procesos de diálogo que surgen en esos sistemas a propósito de las políticas. Para el análisis de los procesos se propone una perspectiva analítica que considera dimensiones y condiciones del diálogo. Se basa en evidencia empírica sobre quince casos de diálogo, trece de países de ALC y dos de España.

El análisis de la evidencia a partir del marco analítico propuesto permite extraer tres principales recomendaciones de política: i) es crucial entender cuál es el objeto del diálogo y quienes son las comunidades y actores participantes, ii) es importante identificar claramente las tres dimensiones del diálogo -objeto, espacio y temporalidad- y los atributos específicos de cada una y iii) es necesario identificar diferencias en las condiciones de cada diálogo respecto tanto a las capacidades de las comunidades participantes como a las asimetrías de poder entre ellas, con la finalidad de instrumentar acciones correctivas y de alentar la generación de consensos.

Después de esta introducción, la sección 2 contiene una revisión crítica de literatura sobre los sistemas de innovación, las políticas de CTI, la participación pública y los procesos de diálogo. La sección 3 describe la metodología utilizada para sistematizar casos de procesos de diálogo y los casos analizados. La sección 4 propone un marco analítico para organizar información sobre procesos de 
diálogo, basado en dimensiones y atributos. La sección 5 explora algunos aspectos metodológicos que se derivan del análisis realizado y, finalmente, la sección 6 presenta un conjunto de reflexiones finales e implicaciones para la política pública de CTI.

\section{SISTEMAS DE INNOVACIÓN, POLÍTICAS DE CTI, PARTICIPACIÓN PÚBLICA Y PROCESOS DE DIÁLOGO}

Desde una perspectiva operativa, un sistema de innovación (SI) es una entidad compuesta por cuatro sectores: académico, productivo, gubernamental y de la sociedad civil. Cada sector reúne organizaciones-universidades, centros de investigación, empresas, administraciones públicas del estado, entidades civiles, etc., donde se desempeñan individuos como científicos, tecnólogos, empresarios, funcionarios, activistas, etc. En esos cuatro sectores se realizan las actividades y procesos que, en interacción y retroalimentándose, conducen a las innovaciones y a la formación de conductas, hábitos y rutinas de agentes y organizaciones.

La evolución de los SI requiere concebir tanto las acciones (A) como las instituciones (I) de la innovación. El cuadro 1 representa este enfoque dual de los sistemas y la ubicación, en su seno, de procesos y reglas. Del lado de las acciones se concatenan y relacionan procesos que hacen emerger comunidades y actores -columna A del cuadro-; del lado de las instituciones surgen reglas que conforman los marcos que regulan las acciones de agentes y organizaciones -la columna I del mismo-. Es, en paralelo, que se desarrolla: (i) la configuración y emergencia de comunidades y actores, y (ii) la constitución de marcos institucionales, lo cual hace posible concebir la participación (P) y el diálogo (D) entre actores y comunidades en relación con políticas de CTI.

La perspectiva evolutiva de los SI tiende puentes entre agentes, organizaciones e interacciones en los procesos de innovación. Muestra como la interacción entre agentes y entre estos y organizaciones posibilita la innovación. Los agentes de una organización hacen acciones sujetas a las reglas internas de la organización y fijan modos de conducta que les permiten adaptarse, hacer sus funciones y lograr sus objetivos, También, las organizaciones, en cuanto conjuntos de agentes, fijan sus reglas inter-organizacionales para relacionarse con otras y alcanzar sus metas. Es así que, en todo proceso, está el aspecto de la acción -columna A del cuadro 1-y, simultáneamente, el de la estipulación de reglas -columna I del mismo cuadro- tanto por medio de la estabilización de hábitos y rutinas como mediante convenciones entre agentes, entre ellos y las organizaciones, o entre estas últimas.

La caracterización de los SI reconoce modos de comportamiento de agentes y organizaciones que supera los límites de individuos que deciden contando con un conocimiento completo de las reglas y con 
información perfecta sobre sus opciones de acción y aquellas que tienen los demás. Esta caracterización incorpora elementos de aprendizaje, racionalidad acotada y reconocimiento de los otros en la toma de decisiones (Lundvall, 2007).

Los SI operan a partir de y en las intersecciones de intercambios de carácter mercantil y acciones que responden a políticas de las distintas organizaciones, en particular, de aquellas gubernamentales y estatales. Es factible afirmar que los SI han articulado los procesos de innovación en la evolución de las economías y las sociedades dándole mayor concreción, en ese aspecto, a la conjunción y la interdependencia de mercados y estados.

Analíticamente, los SI explican la innovación basándose: i) en rutinas y en comportamientos de los agentes que suponen acciones intencionales y ii) en relaciones mutuas que fijan instituciones convencionales -la línea 1) del cuadro 1-. Los procesos que ocurren en las organizaciones son, de manera concomitante, productores de reglas; en dichos procesos sujetos a reglas, los agentes operan con un umbral limitado de reflexividad de la conciencia sobre la acción -la línea 2) del mismo cuadro-. Las condiciones de configuración de entidades e instituciones de índole más compleja que suponen, por un lado, una capacidad de agencia de personas y organizaciones con participación activa y colectiva y, por otro, ensamblajes armónicos de reglas intra e interorganizacionales, se presentan cuando hay heterogeneidad de miembros de las organizaciones y de ellas mismas. La línea 3) del cuadro 1 representa estas condiciones. La transformación de los ámbitos y las actividades iniciales de la innovación hasta convertirse en aquellos que son desarrollados requieren de dichas entidades e instituciones complejas.

La revisión de un conjunto de actividades de participación y diálogo en torno a las políticas condujo a la necesidad de ampliar este marco para mostrar y concebir la emergencia de comunidades y de actores y, a la vez, de marcos institucionales correspondientes -la línea 4) del cuadro 1-. A diferencia de enfoques que usan el término comunidades para conjuntos o poblaciones de agentes que se comunican entre sí, o que consideran sinónimos los términos agentes y actores, el análisis de las prácticas de participación y diálogo obligó a precisar los rasgos distintivos de ambos conceptos. En particular, se requirió precisar el papel que juega el hacer más allá de una actividad específica como innovar y los grados de conocimiento, planeación de acciones e intervención en la formulación de políticas que tiene una persona para ser calificado no solo como agente sino también como actor (Giddens, 1984).

Las comunidades de CTI se definen aquí desde las personas que tienen funciones de agentes en las organizaciones. Resultan de la interacción de dos procesos en tensión: (i) la socialización de los individuos 
que, en la medida en que exprese la procedencia común y los valores compartidos, acentúa la pertenencia de las personas a categorías económicas, sociales y culturales, y (ii) la formación de redes que presupone alguna pertenencia pero que, sobre todo, genera relaciones interindividuales que influyen y condicionan la configuración de conductas y modos de acción de las personas (Barboza, 2016; Dutrénit, Natera y Suárez, 2014).

En las actividades de CTI, la formación de las comunidades resulta tanto de las actividades mismas como de los estímulos y condicionamientos provenientes de la formulación e implementación de políticas (Dutrénit et al., 2017). A partir de esas características se define a las comunidades como aquellas entidades colectivas basadas, por un lado, en esos procesos de socialización y formación de redes y, por el otro, en la necesidad de los agentes de participar en las políticas intra e interorganizacionales, con particular fuerza en aquellas donde intervienen organizaciones de instancias gubernamentales. El proceso de constitución de comunidades supone no solo la suma de las voluntades de las personas sino la formación de algunos rasgos volitivos de la comunidad misma que sus miembros reconocen como extensiones e intensificaciones de los que ellos mismos ostentan.

La aparición de las comunidades por medio de la emergencia también es acompañada por un escalamiento de las reglas. Estas pasan de ser relativas a los agentes, y a su pertenencia a las organizaciones, para trascender, mediante la articulación de diferentes niveles de reglas, en marcos institucionales que se refieren a las comunidades. Estos marcos son, de manera concomitante, instituciones emergentes.

La necesidad de acciones de los agentes que van de las actividades de CTI a la integración en la formulación y puesta en práctica de políticas supone que hay una reflexividad del conocimiento y la ideación sobre la acción misma, que trasciende el grado de conciencia circunscrito a los procesos de innovación. Los actores son aquellos agentes cuya capacidad de agencia es tal que no solo se relaciona con las actividades de CTI sino con la que se requiere para hacer e instrumentar políticas que abarcan a la organización de pertenencia, pasan al ámbito de las relaciones con otras organizaciones sectoriales, al sector respectivo y llegan hasta el SI en su conjunto. La emergencia de los actores supone que estos tienen una capacidad representativa de otros agentes, de grupos de ellos o de comunidades. De manera paralela, este carácter representativo es adquirido por organizaciones que se constituyen en actores respecto de otras que son sus pares dentro del mismo sector $\mathrm{y}$, también, es posible que a sectores distintos. 
Cuadro 1. Sistema de innovación: acciones e instituciones

\begin{tabular}{|c|c|c|c|c|c|c|c|}
\hline \multirow{2}{*}{ 1) } & \multirow{2}{*}{$\begin{array}{l}\text { Acciones } \\
\text { (A) }\end{array}$} & \multirow{2}{*}{$\begin{array}{l}\text { Componentes de } \\
\text { los sectores }\end{array}$} & \multicolumn{4}{|c|}{ Organizaciones } & \multirow{2}{*}{$\begin{array}{l}\text { Instituciones } \\
\text { (l) }\end{array}$} \\
\hline & & & Académicas & Productivas & Gubernamentales & Societales & \\
\hline 2) & Procesos & $\begin{array}{l}\text { Miembros de las } \\
\text { organizaciones }\end{array}$ & \multicolumn{4}{|c|}{$\begin{array}{l}\text { Actividades de innovación } \\
\text { Formación de conductas hábitos y rutinas }\end{array}$} & Reglas \\
\hline 3) & \multirow{4}{*}{$\begin{array}{l}\text { Condiciones de } \\
\text { configuración } \\
\text { de entidades } \\
\text { complejas } \\
\text { Emergencia } \\
\text { de entidades } \\
\text { colectivas y } \\
\text { representativas }\end{array}$} & $\begin{array}{l}\text { Agentes: } \\
\text { científicos, } \\
\text { tecnólogos, } \\
\text { emprendedores, } \\
\text { productores, } \\
\text { artesanos, } \\
\text { empresarios, } \\
\text { directivos, } \\
\text { funcionarios, } \\
\text { usuarios, } \\
\text { consumidores, } \\
\text { ciudadanos }\end{array}$ & \multicolumn{4}{|c|}{$\begin{array}{l}\text { Intra instituciones: } \\
\text { códigos y normas de actuación de agentes, usos y costumbres } \\
\text { relativas a la interacción y comunicación entre agentes, normas } \\
\text { formales intra - organizacionales }\end{array}$} & $\begin{array}{l} \\
\text { Condiciones de } \\
\text { configuración } \\
\text { de } \\
\text { instituciones } \\
\text { complejas }\end{array}$ \\
\hline \multirow[t]{3}{*}{ 4) } & & $\begin{array}{l}\text { Comunidades: } \\
\text { identidades, } \\
\text { redes }\end{array}$ & \multicolumn{4}{|c|}{$\begin{array}{l}\text { Inter instituciones: códigos y normas de actuación de } \\
\text { organizaciones, hábitos, usos y costumbres relativas a la } \\
\text { interacción y comunicación entre organizaciones, normas } \\
\text { jurídicas, reglamentos y leyes a diversas escalas }\end{array}$} & $\begin{array}{l}\text { Emergencia } \\
\text { de marcos } \\
\text { institucionales }\end{array}$ \\
\hline & & $\begin{array}{l}\text { Actores: } \\
\text { representación, } \\
\text { poder }\end{array}$ & \multicolumn{4}{|c|}{$\begin{array}{l}\text { Participación (P) y diálogo (D): } \\
\text { instituciones de P y D }\end{array}$} & \\
\hline & & \multicolumn{5}{|c|}{$\begin{array}{l}\text { Procesos de participación y diálogo } \\
\text { Instituciones de Py D inter organizacionales e intersectoriales en entornos sociales }\end{array}$} & \\
\hline
\end{tabular}

Fuente: elaboración propia.

La descripción de un SI obliga a trazar un cuadro conceptual más específico, particularmente si se considera su operación y la constitución y emergencia de entidades que incidan, mediante formas asociativas y representativas, en la formulación de políticas. Este cuadro conceptual se presenta y explica a continuación (cuadro 2).

El SI de innovación tiene aspectos que resultan más visibles (+) en las descripciones habituales y otros que son menos aparentes (-). Entre los primeros están la estructura y el funcionamiento con sus distintos componentes. Por ejemplo, la estructura compuesta de sectores que reúnen distintos tipos de organizaciones donde se ubican agentes que realizan funciones específicas es un aspecto visible y, por lo general, es presentada en su funcionamiento como la que genera los procesos de innovación. Los procesos de formación por asociación de distintos tipos de consorcios de organizaciones o de diversas comunidades de agentes son, junto con la constitución de actores que representan conjuntos tanto de organizaciones como de agentes, aspectos mucho menos visibles en las concepciones teóricas de los SI. 
La actividad misma de innovar origina las relaciones de los agentes dentro de las distintas organizaciones y de estas en sus respectivos sectores; a su vez, los procesos innovadores muestran relaciones inter organizacionales en un sector y, también, entre sectores en el funcionamiento de un SI. Los procesos de consorciar entre organizaciones o entre agentes y de, mediante la representación, constituir actores tanto a nivel de organizaciones como de agentes son aspectos más difíciles de identificar y describir.

Los aspectos más visibles están asociados a la estructura y al funcionamiento de los componentes de los sistemas con el objetivo de innovar. La consorciación que origina nuevas formas asociativas y la constitución de actores que ostentan carácter representativo, suponen la emergencia de entidades que trascienden organizaciones y agentes. Consorcios de organizaciones y comunidades de agentes, actores tanto consorciados como comunitarios, resultan de la evolución de un SI para lograr una mejor coordinación de actividades e interacciones que supongan mayor conciencia de sus fines.

Cuadro 2. Sl: componentes, estructura y funcionamiento como bases de procesos emergentes

\begin{tabular}{|c|c|c|c|c|c|}
\hline $\begin{array}{l}\text { Visibilidad de } \\
\text { los aspectos }\end{array}$ & \multicolumn{4}{|c|}{ (+) Estructura y funcionamiento } & $\begin{array}{l}\text { (-) Constitución de } \\
\text { actores: }\end{array}$ \\
\hline (+) Componentes & \multicolumn{4}{|l|}{ Sectores } & en general \\
\hline $\begin{array}{l}(-) \\
\text { Consorciación:1 }\end{array}$ & Académico & Productivo & $\begin{array}{l}\text { Gubernamental/ } \\
\text { estatal }\end{array}$ & Sociedad civil & $\begin{array}{l}\text { por emergencia2 de } \\
\text { organizaciones (o de agentes) } \\
\text { que adquieren carácter } \\
\text { representativo de otras ( } 0 \\
\text { de otros) respecto a las } \\
\text { actividades de un sector }\end{array}$ \\
\hline $\begin{array}{l}\text { de forma } \\
\text { asociativa }\end{array}$ & \multicolumn{4}{|l|}{ Organizaciones } & consorciados \\
\hline $\begin{array}{l}\text { por emergencia } \\
\text { de conjuntos de } \\
\text { organizaciones } \\
\text { con fines } \\
\text { comunes de CTI: } \\
\text { Asociaciones } \\
\text { Federaciones } \\
\text { Confederaciones, } \\
\text { sectoriales } \\
\text { (frecuentes), } \\
\text { intersectoriales } \\
\text { (infrecuentes) }\end{array}$ & $\begin{array}{l}\text { Universidades } \\
\text { Centros de } \\
\text { investigación } \\
\text { Centros de } \\
\text { formación } \\
\text { de recursos } \\
\text { humanos }\end{array}$ & $\begin{array}{l}\text { Establecimientos } \\
\text { (campos, } \\
\text { talleres, fábricas, } \\
\text { plantas) } \\
\text { Empresas (por } \\
\text { tamaño y rama } \\
\text { de actividad) } \\
\text { nacionales, } \\
\text { transnacionales }\end{array}$ & $\begin{array}{l}\text { Administraciones } \\
\text { (nacionales, } \\
\text { sub-nacionales, } \\
\text { centralizadas, } \\
\text { descentralizadas, } \\
\text { federales, } \\
\text { estaduales) } \\
\text { Consejos } \\
\text { Agencias } \\
\text { Institutos }\end{array}$ & $\begin{array}{l}\text { No } \\
\text { gubernamentales } \\
\text { Corporativas } \\
\text { (cámaras, } \\
\text { sindicatos) } \\
\text { Sociales } \\
\text { Civiles }\end{array}$ & $\begin{array}{l}\text { por emergencia del carácter } \\
\text { representativo de una } \\
\text { organización (o de un } \\
\text { consorcio de ellas) ante } \\
\text { otra/s (u otro/s) respecto } \\
\text { a las actividades de CTl; } \\
\text { son supervinientes3 de la } \\
\text { interacción y comunicación } \\
\text { entre organizaciones; realizan } \\
\text { la capacidad de agencia de } \\
\text { las organizaciones o de los } \\
\text { consorcios }\end{array}$ \\
\hline en comunidades & \multicolumn{4}{|l|}{ Agentes4 } & comunitarios \\
\hline
\end{tabular}




\begin{tabular}{|c|c|c|c|c|c|}
\hline Visibilidad de & \multicolumn{4}{|c|}{ (+) Estructura y funcionamiento } & \multirow[b]{2}{*}{$\begin{array}{l}\quad \begin{array}{c}\text { (-) Constitución de } \\
\text { actores: }\end{array} \\
\text { por emergencia del carácter } \\
\text { representativo de un agente } \\
\text {-actor individual- o de un } \\
\text { grupo de agentes -actor } \\
\text { colectivo- ante una o varias } \\
\text { comunidades respecto } \\
\text { a las actividades de CTI; } \\
\text { son supervinientes de la } \\
\text { interacción y la comunicación } \\
\text { entre agentes; son quienes } \\
\text { realizan la capacidad de } \\
\text { agencia que tengan los } \\
\text { agentes de los procesos de } \\
\text { innovación }\end{array}$} \\
\hline $\begin{array}{l}\text { por emergencia } \\
\text { del sentido de } \\
\text { pertenencia de } \\
\text { los agentes de } \\
\text { manera } \\
\text { sectorial (por } \\
\text { columna, más } \\
\text { frecuente) 0 } \\
\text { transversal (por } \\
\text { filas, menos } \\
\text { frecuente) } \\
\text { respecto a las } \\
\text { actividades de CTI }\end{array}$ & $\begin{array}{l}\text { Funcionarios } \\
\text { directivos } \\
\text { Administradores } \\
\text { Académicos } \\
\text { Científicos } \\
\text { Tecnólogos } \\
\text { Trabajadores }\end{array}$ & $\begin{array}{l}\text { Empresarios } \\
\text { Directivos } \\
\text { Administradores } \\
\text { Gerentes } \\
\text { Científicos } \\
\text { Tecnólogos } \\
\text { Ingenieros } \\
\text { Trabajadores } \\
\text { Artesanos }\end{array}$ & $\begin{array}{l}\text { Funcionarios } \\
\text { directivos } \\
\text { Administradores } \\
\text { Gerentes } \\
\text { Científicos } \\
\text { Tecnólogos } \\
\text { Comunicadores } \\
\text { Trabajadores }\end{array}$ & $\begin{array}{l}\text { Ciudadanos } \\
\text { Dirigentes } \\
\text { Líderes } \\
\text { Activistas }\end{array}$ & \\
\hline \multicolumn{6}{|c|}{ Socialidad5 por interacción, comunicación y coordinación de agentes, organizaciones, sectores; actores y comunidades } \\
\hline $\begin{array}{l}\text { Procesos y sus } \\
\text { resultados }\end{array}$ & \multicolumn{4}{|c|}{ Innovación que genera productos, técnicas, rutinas organizacionales, servicios } & $\begin{array}{l}\text { Diálogo que produce políticas } \\
\text { e instituciones públicas de CTI }\end{array}$ \\
\hline
\end{tabular}

Notas:

${ }^{1}$ Consorciar: unir o convertir en consorcio entidades u organizaciones 0 agentes; consorciación: proceso de consorciar.

${ }^{2}$ Emergencia: resultado de un proceso en que intervienen distintas entidades o componentes y cuyo resultado

trasciende sus características individuales. ${ }^{3}$ Supervenir: suceder, acaecer, sobrevenir; superviniente: relativo al acto de supervenir.

${ }^{4}$ Agente: persona que tiene capacidad de hacer una función en un proceso dentro de una organización.

${ }^{5}$ Socialidad: capacidad de asociarse con otros o de representarlos.

Fuente: elaboración propia.

Las interacciones entre actores están en el centro de los SI. En los sistemas inmaduros y aún emergentes, la interacción de actores tiende a ser más limitada, e incluso se presentan obstáculos a la interacción, obstáculos para la comunicación entre los actores, o comportamientos que dificultan la interacción. En otras palabras, se tienden a reforzar las fallas sistémicas (Chaminade et al., 2009).

Como argumentan Chaminade et al. (2009), es la participación y el diálogo lo que puede conducir a transformar los sistemas emergentes en sistemas maduros. Pero es necesario tomar en cuenta algunas especificidades. Las condiciones iniciales de los SI de los países en desarrollo, particularmente en ALC, son diferentes a las observadas en las economías desarrolladas. Hay dos rasgos que es necesario destacar: (i) hay una mayor diversidad de organizaciones y actores (Cimoli, 2000; Cassiolato, Lastres and Maciel, 2003; López, 2007; Dutrénit et al., 2010; Dutrénit y Sutz, 2014), y (ii) hay una variedad institucional que proviene tanto de los procesos de creación de las organizaciones como de comunidades que se desarrollan a través de una colisión de culturas y la subordinación de unas a otras y que conforman la diversidad cultural de las sociedades (Ostrom, 2005). Estos rasgos determinan 
que el proceso de adaptación al entorno, que está en el origen de los SI en estos países, impone ciertas características a las condiciones de participación y a los procesos de diálogo diferentes a las observadas en muchos países desarrollados.

Para estimular el desarrollo de los SI y su gobernanza a diferentes niveles se requiere una política de CTI. Este enfoque justifica la intervención pública no solo para introducir incentivos que promuevan la innovación sino para dar solución a fallas sistémicas. El funcionamiento sin interferencias y obstáculos de las redes de agentes y organizaciones, y de las instituciones y el marco regulatorio en el que operan, es el centro de atención de la concepción sistémica de la innovación (Chaminade y Edquist, 2006).

La formulación de políticas de CTI en ALC ha transitado por fases que comprenden, sucesivamente, políticas gubernamentales, de estado y públicas. En la primera fase, la responsabilidad de formular las políticas residía enteramente en el gobierno y se concebía el proceso general de innovación de forma lineal, como una trasferencia de resultados de la ciencia y la tecnología hacia la generación de innovaciones. Por ello, se diseñaban y ponían en práctica instrumentos y medidas de política para mejorar cada etapa de esa transferencia secuencial (Crespi y Dutrénit, 2014; Dutrénit y Puchet, 2017). Las acciones de coordinación entre políticas, base de la gobernanza del sistema, eran resultado del funcionamiento centralizado de las administraciones públicas.

Las políticas de estado en CTI incorporaron a los tres poderes constitucionales, a otros organismos subordinados o autónomos, vinculados a la promoción y el fomento de CTI, y a universidades, institutos y centros de investigación con funciones de investigación científica y de educación superior. También abarcaron a los niveles sub-nacionales de gobierno y supusieron periodos de mayor duración que los de una administración (Puchet y Ruiz, 2003; Vera-Cruz et al., 2011; Kreimer et al., 2014).

La coordinación de las políticas de estado ya no tenía la posibilidad de ser jerárquica e imperativa e introdujo modalidades de cooperación o concertación contrastantes con la lógica de arriba hacia abajo, peculiar del poder ejecutivo. Se pusieron en práctica instrumentos y medidas que no solo actuaron directamente sobre los participantes y destinatarios (stakeholders) sino que se crearon instituciones que, indirectamente, establecieron condiciones y marcos de acción para inducir conductas adecuadas a los objetivos de las políticas, o para regular los intercambios favoreciendo múltiples formas de interacción y comunicación.

La fase de las políticas públicas está, en esencia, caracterizada por la participación de las partes interesadas en la formulación de 
políticas (Aguilar, 1992 y 2006; Valenti, 2008; Ordoñez-Matamoros et al., 2013). En ellas participan aquellas personas que pueden ser afectadas por las decisiones que toma el gobierno, o aquellos involucrados en las acciones de política que están informados sobre sus consecuencias, o individuos o entidades que tienen conocimientos especializados pertinentes o experiencia sobre el tema en cuestión (Cuppen, 2012). Las políticas incorporan entonces, en su hechura y puesta en práctica, la participación pública y su creciente institucionalización. Se configuran mecanismos que rigen la inclusión de una variedad de personas, grupos sociales y entidades civiles (Nupia y Martínez, 2015). La construcción de políticas públicas tiene en su centro la participación pública en el proceso de toma de decisiones (Jensen, 2005; Griessler, Biegelbauer y Hansen, 2011).

La gobernanza se transforma en un proceso que integra, por un lado, la configuración de normas de conducta y modos de acción de quienes deben acordar para orientar las actividades hacia metas comunes y, por el otro, requiere que surjan las formas de autoconducción y autocontrol de los SI (Türke, 2008).

En este marco de SI, sectores, agentes y organizaciones es que surgen las comunidades y actores de CTI. La formación de comunidades resulta tanto de los procesos mismos de producción de conocimientos, técnicas e innovaciones como de la formulación e implementación de las políticas.

Las cuatro principales comunidades identificadas en el ámbito de la CTI corresponden a los sectores académico, productivo, gubernamental -compuesto por entidades tanto de los poderes o niveles de gobierno como de las instancias estatales- y de la sociedad civil (Dutrénit, Natera y Suárez, 2014). En estas comunidades emergen personas, grupos de personas, o entidades asociativas que juegan el papel de actores en la formulación de políticas. Algunas de las comunidades están compuestas por destinatarios de las políticas (stakeholders), o por quienes serán influidos por las decisiones gubernamentales. Tales son los casos de las comunidades académica, del sector productico o de la sociedad civil; en tanto que la comunidad del sector gubernamental tiene la iniciativa en la formulación de políticas.

La participación pública abre espacios para un diálogo entre comunidades, de un lado, de los participantes interesados y, del otro, del sector gubernamental. Cada comunidad interviene con distinta intensidad en cada etapa del ciclo de la política. La evidencia muestra una participación más intensa en las etapas de definición de la agenda y de diseño (Jensen, 2005; Rowe, 2005; Mejlgaard, 2009; Lázaro el al, 2014). Esfuerzos teóricos y metodológicos se han orientado a la identificación de los medios para contribuir a una mayor participación 
pública en los procesos de toma de decisiones (Chilvers, 2008; Jensen, 2005; Griessler, Biegelbauer y Hansen, 2011). La compatibilidad de los diálogos forma parte de las capacidades de gobernanza de los SNI en la época actual.

\section{METODOLOGÍA PARA SISTEMATIZAR CASOS DE PROCESOS DE DIÁLOGO}

La evidencia empírica de este trabajo se recolectó mediante la "Red temática para mejorar el diálogo entre las comunidades involucradas en las políticas de CTI (COM-LALICS)", financiada por CYTED (Programa de Ciencia y Tecnología para el Desarrollo). Los casos de estudio se sistematizaron mediante un instrumento metodológico desarrollado para este proyecto llamado "Matriz de Información para el mapeo de procesos de diálogo de CTI en España, América Latina y el Caribe" (véase anexo 1 del capítulo 2 de este libro). Se basa en la propuesta hecha por el PNUD para ubicar procesos de diálogo de la región (PNUD, 2003). La guía inicial fue modificada para adecuarse a los temas de CTI en la región (Dutrénit et al., 2016).

La estructura de esta matriz está compuesta por tres grandes bloques que se desagregan en secciones para ofrecer mayor detalle de los procesos de diálogo. A continuación, se hace una breve descripción de estos bloques y sus contenidos.

El tema. Se refiere al objeto sobre el cual se dialoga. Incluye una breve historia del tema, su contexto político, los retos relacionados con su definición, los problemas científicos o tecnológicos que involucra y los avances significativos que su abordaje ha tenido.

El proceso de diálogo. Contiene la descripción de todo el proceso de diálogo de CTI; es el aspecto más extenso y rico en términos de la información que contiene el instrumento; combina datos de las comunidades participantes y de sus acciones durante el diálogo. Los contenidos del bloque están organizados en seis secciones:

1. Codifica el origen del proceso de diálogo, su historia, contexto y retos enfrentados para iniciar su desarrollo;

2. Contiene la información del propósito del diálogo y su alcance en el tiempo;

3. Describe las comunidades; se listan los actores de cada una de ellas que están involucrados y el nivel de involucramiento durante las distintas fases del proceso de diálogo; 
4. Describe las características del proceso; los roles de las comunidades; el criterio para la selección de los actores; la existencia de facilitadores, traductores o mediadores; los espacios donde se produjeron los encuentros; las fases del proceso de diálogo (ordenadas en el tiempo); la metodología empleada y la existencia de evaluación y retroalimentación del proceso de diálogo por parte de los actores;

5. Caracteriza las interacciones del proceso de diálogo: existencia de un nivel homogéneo de capacidades, un lenguaje común y de grupos de poder e intereses en conflicto; el desarrollo de los procesos de creación de confianza; las reglas del juego formales e informales; la intensidad de las interacciones;

6. Tipifica los resultados e impactos del proceso diálogo; se discrimina si estos han logrado entendimientos generales, acuerdos específicos o acciones implementadas; quiénes se han encargado de dar seguimiento a los resultados y qué acciones han tomado; cuáles han sido los impactos del proceso de diálogo sobre el tema.

Lecciones aprendidas. El bloque final recoge los aprendizajes obtenidos durante el proceso de diálogo. Por un lado, clasifica los aprendizajes en cuanto a las comunidades, en concreto, en términos de la representatividad de los actores participantes en el diálogo, la heterogeneidad que tienen y la emergencia de nuevas comunidades. Del otro lado, este bloque recoge los aprendizajes sobre cada una de las características del proceso de diálogo descritas en el bloque anterior.

Basado en las matrices, los cuadros 3 y 4 describen brevemente las características clave de los quince casos de estudio. En el cuadro 3 , la columna 1 enlista los casos por sus códigos y la columna 2 describe brevemente su objetivo. Las columnas 3 y 4 listan las principales comunidades involucradas en cada proceso de diálogo y el número de actores participantes. En el cuadro 4, la columna 1 enlista los casos por sus códigos, la columna 2 clasifica los resultados de los diálogos en tres categorías principales de productos o resultados: (i) documentos públicos, (ii) entrega de recomendaciones para los hacedores de políticas y (iii) acciones de política de los hacedores de políticas. La columna 3 describe el principal efecto de los diálogos. 
Cuadro 3. Características clave de los casos de procesos de diálogo: objetivo y comunidades

\begin{tabular}{|c|c|c|c|}
\hline $\begin{array}{l}\text { País y casos } \\
\text { (código) }\end{array}$ & Objetivo del diálogo & $\begin{array}{l}\text { Principales } \\
\text { comunidades, } \\
\text { en orden de } \\
\text { participación en } \\
\text { el diálogo }\end{array}$ & $\begin{array}{l}\text { \# de actores } \\
\text { involucrados }\end{array}$ \\
\hline $\begin{array}{l}\text { Argentina- } \\
\text { FONARSEC }\end{array}$ & $\begin{array}{l}\text { Identificar problemas que limitan } \\
\text { competitividad a nivel sectorial }\end{array}$ & $\begin{array}{l}\text { Gubernamental } \\
\text { Productivo } \\
\text { Académico }\end{array}$ & $\begin{array}{l}\text { Diálogo a nivel } \\
\text { nacional con } \\
\text { varios actores }\end{array}$ \\
\hline $\begin{array}{l}\text { Argentina- } \\
\text { FONSOFT }\end{array}$ & $\begin{array}{l}\text { Promover el diseño y la implementación } \\
\text { de una política de fomento del sector del } \\
\text { software y servicios de información }\end{array}$ & $\begin{array}{l}\text { Productivo } \\
\text { Gubernamental } \\
\text { Académico } \\
\text { Sociedad Civil }\end{array}$ & 21 actores \\
\hline Brasil-Carnaval & $\begin{array}{l}\text { Creación de un plan nacional de apoyo a la } \\
\text { cadena productiva del Carnaval }\end{array}$ & $\begin{array}{l}\text { Productivo } \\
\text { Sociedad Civil } \\
\text { Gubernamental } \\
\text { Académico } \\
\end{array}$ & 51 actores \\
\hline Chile-Ciencia & $\begin{array}{l}\text { Discutir y crear una instancia de reflexión } \\
\text { sobre la necesidad de fortalecer la } \\
\text { institucionalidad responsable para la ciencia } \\
\text { y la tecnología }\end{array}$ & $\begin{array}{l}\text { Académico } \\
\text { Gubernamental }\end{array}$ & 105 actores \\
\hline $\begin{array}{l}\text { Colombia-Grupos } \\
\text { de investigación }\end{array}$ & $\begin{array}{l}\text { Construir un modelo para la medición de la } \\
\text { calidad de los grupos de investigación }\end{array}$ & $\begin{array}{l}\text { Gubernamental } \\
\text { Académico }\end{array}$ & 4 actores \\
\hline Colombia-Social & $\begin{array}{l}\text { Contribuir a la definición de las } \\
\text { orientaciones y las acciones estratégicas } \\
\text { en el marco de formulación de la política de } \\
\text { innovación social }\end{array}$ & $\begin{array}{l}\text { Gubernamental } \\
\text { Académico } \\
\text { Sociedad Civil }\end{array}$ & 77 actores \\
\hline $\begin{array}{l}\text { Costa Rica- } \\
\text { Indicadores }\end{array}$ & $\begin{array}{l}\text { Generar un Sistema nacional de indicadores } \\
\text { de CTI para apoyar políticas públicas y } \\
\text { estrategias de diferentes actores }\end{array}$ & $\begin{array}{l}\text { Gubernamental } \\
\text { Académico } \\
\text { Productivo }\end{array}$ & $\begin{array}{l}\text { Más de } 400 \\
\text { actores }\end{array}$ \\
\hline $\begin{array}{l}\text { Cuba- } \\
\text { Instituciones }\end{array}$ & $\begin{array}{l}\text { Contribuir a la modificación o la creación } \\
\text { de regulaciones y normas que alienten la } \\
\text { innovación en las empresas }\end{array}$ & $\begin{array}{l}\text { Académico } \\
\text { Gubernamental } \\
\text { Productivo }\end{array}$ & $\begin{array}{l}98 \text { participantes } \\
\text { de diferentes } \\
\text { actores } \\
\text { institucionales }\end{array}$ \\
\hline España-lberdrola & $\begin{array}{l}\text { Lograr cambios en la regulación para } \\
\text { integrar investigadores en los procesos de } \\
\text { I+D+i en las empresas }\end{array}$ & $\begin{array}{l}\text { Productivo } \\
\text { Gubernamental } \\
\text { Académico } \\
\end{array}$ & 12 actores \\
\hline $\begin{array}{l}\text { España- } \\
\text { Andalucía }\end{array}$ & $\begin{array}{l}\text { Construir un plan regional de } \mathrm{I}+\mathrm{D}+\mathrm{i} \text { en } \\
\text { concordancia con políticas nacionales y } \\
\text { europeas }\end{array}$ & $\begin{array}{l}\text { Gubernamental } \\
\text { Académico } \\
\text { Productivo } \\
\end{array}$ & $\begin{array}{l}\text { Más de } 100 \\
\text { actores }\end{array}$ \\
\hline $\begin{array}{l}\text { México- } \\
\text { Emprendedores }\end{array}$ & $\begin{array}{l}\text { Identificar los desafíos del desarrollo de } \\
\text { emprendimientos basados en conocimiento }\end{array}$ & $\begin{array}{l}\text { Productivo } \\
\text { Gubernamental } \\
\text { Académico }\end{array}$ & $\begin{array}{l}440 \\
\text { participantes } \\
\text { individuales de } \\
13 \text { actores }\end{array}$ \\
\hline México-Género & $\begin{array}{l}\text { Generar un conjunto de recomendaciones } \\
\text { para adoptar una perspectiva de género en } \\
\text { las políticas de CTI }\end{array}$ & $\begin{array}{l}\text { Académico } \\
\text { Gubernamental } \\
\text { Productivo }\end{array}$ & $\begin{array}{l}350 \\
\text { participantes } \\
\text { individuales de } \\
15 \text { actores }\end{array}$ \\
\hline
\end{tabular}




\begin{tabular}{|l|l|l|l|}
\hline $\begin{array}{l}\text { País y casos } \\
\text { (código) }\end{array}$ & Objetivo del diálogo & $\begin{array}{l}\text { Principales } \\
\text { comunidades, } \\
\text { en orden de } \\
\text { participación en } \\
\text { el diálogo }\end{array}$ & $\begin{array}{l}\text { \# de actores } \\
\text { involucrados }\end{array}$ \\
\hline Perú-Agenda & $\begin{array}{l}\text { Generar consensos para la formulación de } \\
\text { la política de CTI como base de la agenda } \\
\text { de competitividad }\end{array}$ & $\begin{array}{l}\text { Gubernamental } \\
\text { Productivo } \\
\text { Académico }\end{array}$ & $\begin{array}{l}\text { Más de 42 } \\
\text { actores }\end{array}$ \\
\hline $\begin{array}{l}\text { Rep. } \\
\text { Dominicana- } \\
\text { Política }\end{array}$ & $\begin{array}{l}\text { Construir un espacio de encuentro } \\
\text { y discusión para acordar sobre las } \\
\text { necesidades de la política de innovación }\end{array}$ & $\begin{array}{l}\text { Gubernamental } \\
\text { Académico }\end{array}$ & $\begin{array}{l}\text { Más de 200 } \\
\text { actores }\end{array}$ \\
\hline Uruguay-Viento & $\begin{array}{l}\text { Generar propuestas para contribuir al } \\
\text { cambio de la matriz energética }\end{array}$ & $\begin{array}{l}\text { Gubernamental } \\
\text { Académico } \\
\text { Sociedad Civil }\end{array}$ & 20 actores \\
\hline $\begin{array}{l}\text { Uruguay- } \\
\text { Ciudadanos }\end{array}$ & $\begin{array}{l}\text { Incorporar la visión ciudadana sobre un } \\
\text { tema controversial de ciencia y tecnología: } \\
\text { energía termonuclear }\end{array}$ & $\begin{array}{l}\text { Sociedad Civil } \\
\text { Académico } \\
\text { Gubernamental }\end{array}$ & 36 actores \\
\hline $\begin{array}{l}\text { Venezuela- } \\
\text { Energía }\end{array}$ & $\begin{array}{l}\text { Diseñar una metodología para documentar } \\
\text { los activos de conocimiento de los actores } \\
\text { y su contribución para el diseño de políticas } \\
\text { públicas }\end{array}$ & $\begin{array}{l}\text { Académico } \\
\text { Productivo } \\
\text { Gubernamental }\end{array}$ & 18 actores \\
\hline
\end{tabular}

Fuente: Elaboración propia basado en Alvarez et al. (2016a), Alvarez et al. (2016b), Ardanche et al. (2016a), Ardanche, et al. (2016b), Barletta, Suárez y Yoguel (2016), Bazán, Prada y Romero (2016), Cortes (2016), De la Vega, Ruiz y Cervilla (2016), Dutrénit y Suárez (2016a), Dutrénit y Suárez (2016b), Gómez-Valenzuela y Zapata (2016), Nupia y Martínez (2016a), Nupia y Martínez (2016b), Orozco y Barboza-Arias (2016), Pessoa de Matos, Cassiolato y Lastres (2016), Suárez, Barletta y Yoguel (2016), y Torres Pérez, Díaz Fernández y Fernández Estrada (2016).

\section{Cuadro 4. Características clave de los casos de procesos de diálogo: resultados e impactos}

\begin{tabular}{|l|l|l|}
\hline Caso de diálogo & Productos/Resultados & \multicolumn{1}{c|}{ Efecto/impacto } \\
\hline $\begin{array}{l}\text { Argentina- } \\
\text { FONARSEC }\end{array}$ & $\begin{array}{l}\text { Documentos públicos } \\
\text { Entrega de } \\
\text { recomendaciones } \\
\text { Acciones de políticas }\end{array}$ & $\begin{array}{l}\text { Nuevos programas de financiamiento público para } \\
\text { la realización de proyectos de desarrollo tecnológico } \\
\text { en consorcios público - privados }\end{array}$ \\
\hline $\begin{array}{l}\text { Argentina- } \\
\text { FONSOFT }\end{array}$ & $\begin{array}{l}\text { Documentos públicos } \\
\text { Entrega de } \\
\text { recomendaciones } \\
\text { Acciones de políticas }\end{array}$ & $\begin{array}{l}\text { Instrumentos de apoyo público para innovación en } \\
\text { software y servicios de información }\end{array}$ \\
\hline Brasil-Carnaval & Documentos públicos & $\begin{array}{l}\text { Reconocimiento de las actividades culturales como } \\
\text { un área de acción para el ministerio de CTI }\end{array}$ \\
\hline Chile-Ciencia & $\begin{array}{l}\text { Documentos públicos } \\
\text { Entrega de } \\
\text { recomendaciones }\end{array}$ & $\begin{array}{l}\text { Introducir en la agenda legislativa la necesidad de } \\
\text { crear un ministerio de C\&T }\end{array}$ \\
\hline $\begin{array}{l}\text { Colombia-Grupos } \\
\text { de investigación }\end{array}$ & $\begin{array}{l}\text { Documentos públicos } \\
\text { Entrega de } \\
\text { recomendaciones } \\
\text { Acciones de políticas }\end{array}$ & $\begin{array}{l}\text { Construcción de un modelo de medida más } \\
\text { complejo que incluya productos de nuevos tipos } \\
\text { de conocimiento y legitimación de la comunidad } \\
\text { científica }\end{array}$ \\
\hline
\end{tabular}




\begin{tabular}{|c|c|c|}
\hline Caso de diálogo & Productos/Resultados & Efecto/impacto \\
\hline Colombia-Social & $\begin{array}{l}\text { Documentos públicos } \\
\text { Entrega de } \\
\text { recomendaciones } \\
\text { Acciones de políticas }\end{array}$ & $\begin{array}{l}\text { Propuesta de una política de innovación social y } \\
\text { definición de un plan de acción hacia } 2023\end{array}$ \\
\hline $\begin{array}{l}\text { Costa Rica- } \\
\text { Indicadores }\end{array}$ & $\begin{array}{l}\text { Documentos públicos } \\
\text { Entrega de } \\
\text { recomendaciones } \\
\text { Acciones de políticas }\end{array}$ & $\begin{array}{l}\text { Extensión de los procesos de consulta, incluyendo } \\
\text { más sectores económicos y destinatarios de las } \\
\text { políticas de la comunidad del sector productivo }\end{array}$ \\
\hline Cuba-Instituciones & $\begin{array}{l}\text { Documentos públicos } \\
\text { Entrega de } \\
\text { recomendaciones }\end{array}$ & $\begin{array}{l}\text { Generar consensos sobre aspectos nucleares de la } \\
\text { innovación que impactan sobre el funcionamiento } \\
\text { de la economía }\end{array}$ \\
\hline España-Iberdrola & $\begin{array}{l}\text { Documentos públicos } \\
\text { Entrega de } \\
\text { recomendaciones } \\
\text { Acciones de políticas }\end{array}$ & $\begin{array}{l}\text { Incremento del número de becas y de incorporación } \\
\text { de trabajadores más calificados a las empresas }\end{array}$ \\
\hline España-Andalucía & $\begin{array}{l}\text { Documentos públicos } \\
\text { Acciones de políticas } \\
\end{array}$ & $\begin{array}{l}\text { Generación de un plan regional para la mejora de la } \\
\text { I+D+i en Andalucía }\end{array}$ \\
\hline $\begin{array}{l}\text { México- } \\
\text { Emprendedores }\end{array}$ & $\begin{array}{l}\text { Documentos públicos } \\
\text { Entrega de } \\
\text { recomendaciones }\end{array}$ & $\begin{array}{l}\text { Reconocimiento de la carencia de coordinación } \\
\text { entre la política pública y la difusión en los medios } \\
\text { de los emprendimientos basados en conocimiento } \\
\text { con perspectiva con perspectiva de género }\end{array}$ \\
\hline México-Género & $\begin{array}{l}\text { Documentos públicos } \\
\text { Entrega de } \\
\text { recomendaciones }\end{array}$ & $\begin{array}{l}\text { Poner en la mesa de la discusión pública la } \\
\text { necesidad de diseñar las políticas de CTI con una } \\
\text { perspectiva de género y proponer un conjunto de } \\
\text { acciones específicas para los programas de apoyo } \\
\text { a la ciencia }\end{array}$ \\
\hline Perú-Agenda & $\begin{array}{l}\text { Documentos públicos } \\
\text { Entrega de } \\
\text { recomendaciones }\end{array}$ & $\begin{array}{l}\text { Creación de capacidades de los actores, logro de } \\
\text { acuerdos y definición de sus responsabilidades } \\
\text { respecto a las metas de la agenda de competitividad }\end{array}$ \\
\hline $\begin{array}{l}\text { Rep. Dominicana- } \\
\text { Política }\end{array}$ & $\begin{array}{l}\text { Documentos públicos } \\
\text { Entrega de } \\
\text { recomendaciones } \\
\text { Acciones de políticas }\end{array}$ & $\begin{array}{l}\text { Reconocimiento por las comunidades } \\
\text { gubernamental y productivo sobre la necesidad de } \\
\text { promover la CTI }\end{array}$ \\
\hline Uruguay-Viento & $\begin{array}{l}\text { Documentos públicos } \\
\text { Entrega de } \\
\text { recomendaciones } \\
\text { Acciones de políticas }\end{array}$ & Formalización de la política energética \\
\hline $\begin{array}{l}\text { Uruguay- } \\
\text { Ciudadanos }\end{array}$ & $\begin{array}{l}\text { Documentos públicos } \\
\text { Entrega de } \\
\text { recomendaciones }\end{array}$ & $\begin{array}{l}\text { Aproximación de posiciones entre diferentes } \\
\text { comunidades alrededor de la controversia sobre la } \\
\text { generación de energía termonuclear }\end{array}$ \\
\hline Venezuela-Energía & $\begin{array}{l}\text { Documentos públicos } \\
\text { Entrega de } \\
\text { recomendaciones }\end{array}$ & $\begin{array}{l}\text { Poner en la mesa de la discusión pública la } \\
\text { relevancia de la documentación de los activos de } \\
\text { conocimiento para el diseño de políticas públicas }\end{array}$ \\
\hline
\end{tabular}

Fuente: Elaboración propia basado en Alvarez et al. (2016a), Alvarez et al. (2016b), Ardanche et al. (2016a), Ardanche, et al. (2016b), Barletta, Suárez y Yoguel (2016), Bazán, Prada y Romero (2016), Cortes (2016), De la Vega, Ruiz y Cervilla (2016), Dutrénit y Suárez (2016a), Dutrénit y Suárez (2016b), Gómez-Valenzuela y Zapata (2016), Nupia y Martínez (2016a), Nupia y Martínez (2016b), Orozco y Barboza-Arias (2016), Pessoa de Matos, Cassiolato y Lastres (2016), Suárez, Barletta y Yoguel (2016), y Torres Pérez, Díaz Fernández y Fernández Estrada (2016). 


\section{UN MARCO ANALÍTICO PARA ORGANIZAR INFORMACIÓN SOBRE PROCESOS DE DIÁLOGO}

La definición de diálogo utilizada en este trabajo se relaciona con la hechura de las políticas públicas de CTI en el marco de los SI. Se parte de la propuesta para el diálogo democrático hecha por Cuentas y Linares Méndez (2013). Se argumenta que ante este planteamiento se requiere hacer tres precisiones para adaptarla a los procesos de políticas de CTI (Goñi, Bianco y Puchet, 2015).

1. Los participantes son personas (o sujetos colectivos) que adquieren el carácter de actores emergentes de sus respectivas comunidades.

2. En el diálogo se manifiestan intereses y valores que ponen en conflicto a los participantes. Desde este ángulo, los diálogos median conflictos y tienen la posibilidad de resolverlos. Los actores participantes mantienen una relación de representación con las comunidades a las que pertenecen. Entonces, en el diálogo hay, de forma permanente, una tensión entre los intereses y valores de los actores y los de sus comunidades de origen. Los procesos sociales que hacen posible la emergencia y la evolución de los actores marcan también el grado en que se establece esa relación.

3. La conformación de comunidades que participan en distintas organizaciones. Las comunidades son entidades transversales respecto a las organizaciones y, también, respecto a los sectores del sistema de innovación. Esa pertenencia transversal es fundamental para dotar a los actores de distintos tipos y grados de poder según su inserción en diferentes organizaciones.

A partir de estas precisiones se asume la definición de procesos de diálogo propuesta por Goñi, Bianco y Puchet, que señala:

Los procesos de diálogo relativos a las políticas públicas de CTI son, al igual que los del diálogo democrático, auténticos ejercicios de interacción y conflicto. En ellos cada uno de los participantes aprende e internaliza argumentos de los demás sosteniendo su identidad y está ubicado, desde la perspectiva comunicativa, en una posición resultante del poder o de las capacidades que tiene. Los participantes son actores que emergen de distintas comunidades de agentes de las actividades de CTI. Tienen, por lo tanto, una relación de representación con su comunidad y, a su vez, pertenecen a organizaciones académicas, productivas, gubernamentales o de la sociedad civil que los dotan de diferentes grados de poder y de distintas capacidades. (2015)

Los procesos de diálogo tienen un conjunto de dimensiones. Las dimensiones deben, por un lado, posibilitar el análisis de cómo los actores interactúan y se comunican para definir, en esos intercam- 
bios, una acción colectiva y, por otro lado, tienen que ser útiles para identificar fallas, trabas, y obstáculos que se presentan para arribar a un resultado. Es fundamental identificar sobre qué se dialoga (cuáles son los objetos de disputa), dónde tiene lugar el proceso (en qué espacios se realiza) y cuánto dura (cuál es la temporalidad en la que se desenvuelve). Cada una de estas dimensiones tiene a su vez un conjunto de atributos específicos. Dutrénit et al. (2017) presenta una versión más reducida de esta clasificación.

\section{DIMENSIÓN OBJETO}

Los procesos de diálogo tienen por objeto los tipos de política de CTI que se formularán. Estos tipos están caracterizados, como mínimo, por tres atributos: (i) las actividades científicas, tecnológica o de innovación, o alguno de sus componentes, sobre los que se dialoga, (ii) el territorio en el que se hacen esas actividades: el conjunto de un país, una región o una localidad, y (iii) el problema público específico que los actores delimitan, plantean e intentan abordar y las partes que lo integran.

El problema que se pretende abordar es el atributo clave del diálogo. No está planteado de antemano, sino que se irá explorando, delimitando y formulando en el proceso mismo. Sin embargo, para ubicarlo se debe tener en mente si se dialoga sobre aspectos relativos a la oferta o la demanda, o a la interconexión entre ambas, en el marco específico de las actividades y los territorios a las que alude el diálogo.

La interrelación entre problema, territorio y actividad de CTI captura los rasgos y perfiles principales de las políticas públicas que emergen de un proceso de diálogo.

\section{DIMENSIÓN ESPACIO}

El espacio de dialogo existe en donde se dan las condiciones para establecerlo. Es donde los actores logran originar una iniciativa de intercambio, muestran las intenciones con que llegan a la arena, fijan la postura ante el objeto mismo del diálogo y manifiestan los poderes relativos que tienen. Así, se identifican los atributos de: (i) origen, (ii) intenciones, (iii) posturas y (iv) poder.

El origen proviene de quién tiene la iniciativa de dialogar. ¿La iniciativa ha sido promovida por una de las comunidades que actúa como stakeholder en relación a las políticas de CTI (es decir, opera un mecanismo bottom-up), o, por el contrario, es promovida por comunidades del sector gubernamental (es decir, opera un mecanismo topdown)? (Dutrénit et al., 2016). Las intenciones con que arriban los actores al diálogo están delimitadas, en principio, por la convocatoria 
que inicia el proceso. No obstante, es relevante detectar en sus agendas si cada actor considera que el carácter del diálogo es: consultivo, orientado a trazar lineamientos generales de política o a diseñar una política en particular, o a evaluar una política ya existente (Dutrénit et al., 2016).

Las posturas respecto al objeto del diálogo definen el curso que tendrá el proceso. Habrá actores reactivos, otros que tienen una posición tomada y, probablemente, un análisis previo, y otros más favorables a explorar el objeto en conjunto con los demás actores a partir de algunas ideas guía. Las posturas tienen sustento en el conocimiento del objeto del diálogo y, también, en las capacidades de los actores, y en la experiencia participativa en diálogos previos sobre el mismo u otros objetos similares. Finalmente, el poder de los actores depende de las relaciones entre ellos y la comunidad que representan, de la inserción que tienen las comunidades en las organizaciones a las que pertenecen, y de la transversalidad que tengan las comunidades entre organizaciones o, incluso, en distintos sectores del sistema. Las relaciones de poder que subyacen en los procesos deben ser comprendidas más allá de las expresiones evidentes. Como están vinculadas con la iniciativa de los diálogos, vale la pena preguntarse ¿qué actor tiene la iniciativa de dialogar?: un funcionario responsable de una administración pública a nombre de ella misma, o de una coalición de ellas establecida en la ley; un líder de una asociación empresarial; los dirigentes de un movimiento social, etc. La posibilidad de contar con distintos actores en las cuatro comunidades genera un entramado de relaciones de poder en las que diferentes simetrías (o asimetrías) configuran el proceso de diálogo o emergen del mismo. Poderes relativos, intenciones y posturas de los dialogantes mueven el espacio del diálogo y tienden a situarlo en términos de confrontación, equilibrio inoperante, colaboración restringida o concertación activa. Esas situaciones pueden dar lugar a resultados con distintas posibilidades de puesta en práctica.

\section{DIMENSIÓN TEMPORALIDAD}

Es definida como: de una sola vez, por un lapso definido previamente o generado por la dinámica del diálogo, o de forma permanente. Los términos formales de la convocatoria y de las reglas del diálogo acotan la temporalidad. Sin embargo, la temporalidad es un atributo del proceso mismo (Álvarez et al., 2016)

El recuadro 1 define las tres dimensiones y el cuadro 5 describe los atributos de cada dimensión. También incluye una lista de los diferentes niveles que pueden tener estos atributos. 
Recuadro 1. Dimensiones de los procesos de diálogo

\begin{tabular}{|l|l|}
\hline Objeto & Los tipos de política de CTI que se formularán \\
\hline Espacio & $\begin{array}{l}\text { El ámbito social donde los actores logran originar una iniciativa } \\
\text { de intercambio, muestras las intenciones con las que llegan a } \\
\text { la arena, fijan la postura ante el objetivo mismo del diálogo y } \\
\text { manifiestan los poderes relativos que tienen }\end{array}$ \\
\hline Temporalidad & Lapso de tiempo durante el cual se desarrolla el diálogo \\
\hline
\end{tabular}

Cuadro 5. Dimensiones y atributos de los procesos de diálogo en CTI

\begin{tabular}{|c|c|}
\hline \multicolumn{2}{|c|}{ Dimensión Objeto } \\
\hline Atributos & Niveles de los atributos \\
\hline \multirow{2}{*}{ Actividad de CTI } & Actividades generales de CTI \\
\hline & Actividad específica: ciencia, tecnología o innovación \\
\hline \multirow{2}{*}{ Territorio } & Localidad o región específica \\
\hline & País \\
\hline \multirow{3}{*}{ Problema } & Del lado de la demanda \\
\hline & Del lado de la oferta \\
\hline & Interacción de oferta y demanda \\
\hline \multicolumn{2}{|c|}{ Dimensión Espacio } \\
\hline Atributos & Niveles de los atributos \\
\hline \multirow{2}{*}{ Origen } & De abajo arriba (bottom-up) \\
\hline & De arriba abajo (top-down) \\
\hline \multirow{3}{*}{ Intenciones } & Consulta o esbozo de orientaciones generales de política \\
\hline & Evaluación crítica u opuesta de las políticas \\
\hline & Propuesta de una nueva política \\
\hline \multirow{3}{*}{ Posturas } & Posición reactiva \\
\hline & Mantenimiento de la posición establecida \\
\hline & Posición abierta \\
\hline \multirow{2}{*}{ Poder } & Relaciones simétricas \\
\hline & Relaciones asimétricas \\
\hline \multicolumn{2}{|c|}{ Dimensión Temporalidad } \\
\hline \multicolumn{2}{|l|}{ Atributos } \\
\hline \multicolumn{2}{|l|}{ Una sola vez } \\
\hline \multicolumn{2}{|c|}{ Un período limitado } \\
\hline \multicolumn{2}{|l|}{ Permanente } \\
\hline
\end{tabular}


Finalmente, los procesos de diálogo se encuentran determinados por dos condiciones transversales: (i) el contexto y el marco institucional, y (ii) las capacidades de las comunidades.

El contexto se refiere a una serie de circunstancias que rodea física (por ej. el tiempo cronológico, el lugar físico) o simbólicamente un acontecimiento (por ej. el entorno social o económico). No se refiere solo al contexto inmediato de pertenencia de los actores, sino también al contexto amplio en el que se desarrollan los procesos de diálogo, ya que estos tienen intereses distintos y trayectorias diversas. El marco institucional se refiere al ensamblaje de reglas informales (códigos y normas de actuación de los actores, hábitos, usos y costumbres relativas a la interacción y comunicación entre actores) y reglas formales (normas intraorganizacionales, normas jurídicas, reglamentos y leyes a diversas escalas) (North, 1990; Ostrom, 2005). En los procesos de diálogo participan comunidades con diferentes valores, conocimientos y antecedentes, de allí la importancia de las normas y prácticas institucionalizadas que regulan el comportamiento de los participantes.

Las capacidades representan el conocimiento específico de actores y comunidades, son adquiridas a través de experiencias y aprendizajes individuales o colectivos y se acumulan a través del tiempo. El diálogo es esencialmente un proceso basado en conocimiento, comunicación, coordinación y liderazgo, habilidades que llevan a las comunidades a la exploración de los conflictos, resolución de problemas y a la toma de decisiones. Por su naturaleza, las comunidades tienen diferentes capacidades, incluyendo diferentes habilidades para establecer un diálogo. Entre las capacidades de las comunidades que son relevantes para un proceso de diálogo destacan, entre otras, las siguientes: cognitivas, habilidad para identificar y resolver problemas, disposición a vincularse en redes, generadoras de confianza, para compartir conocimiento, para el aprendizaje conjunto, de coordinación y de liderazgo (Álvarez et al., 2016).

Las dimensiones y atributos propuestos son un marco de análisis para entender procesos de diálogo complejos como los que se clasifican en el cuadro 6. En cada dimensión y atributo, de acuerdo a los niveles específicos que se presentaron en el cuadro 5, se clasificaron los casos identificados. Por ejemplo, en la dimensión Objeto, el caso México-Emprendedores se ubica en la clasificación como una Actividad específica de CTI (innovación), su territorio es todo el país y se refiere a un problema que aborda las interacciones oferta-demanda. 
En el cuadro 6, hay un patrón claro en la dimensión relativa al Objeto. La mayoría de los procesos de diálogo están orientados a actividades generales de CTI, a nivel de un país y para problemas del lado de la oferta. Este hecho concuerda con que la construcción de los SNI en América Latina ha sido orientada a generar la infraestructura científica y tecnológica necesaria para aumentar la capacidad del país para participar en procesos de innovación (Crespi y Dutrénit, 2014). Por otro lado, desde el punto de vista temporal, también, la mayoría de los procesos de diálogo tienden a ocurrir en un período limitado.

Cuadro 6. Clasificación de los procesos de diálogo en ALC y España

\begin{tabular}{|c|c|c|c|c|}
\hline Dimensión & Atributos & Niveles de los atributos & $\begin{array}{l}\text { \# de casos } \\
\text { identificados }\end{array}$ & Lista de procesos de diálogo identificados* \\
\hline \multirow{7}{*}{ Objeto } & \multirow[t]{2}{*}{$\begin{array}{l}\text { Actividad } \\
\text { de CTI }\end{array}$} & $\begin{array}{l}\text { Actividades generales } \\
\text { de CTI }\end{array}$ & 12 & $\begin{array}{l}\text { Argentina-FONARSEC, Brasil-Carnaval, Colombia-Social, } \\
\text { Costa Rica-Indicadores, Cuba-Instituciones, , España- } \\
\text { Andalucía, México-Género, Perú-Agenda, RDominicana- } \\
\text { Política, Uruguay-Viento, Uruguay-Ciudadanos, Venezuela- } \\
\text { Energía }\end{array}$ \\
\hline & & $\begin{array}{l}\text { Actividad específica } \\
\text { de CTI }\end{array}$ & 5 & $\begin{array}{l}\text { Argentina-FONSOFT, Chile-Ciencia, Colombia-Grupos de } \\
\text { Investigación, España-Iberdrola, México-Emprendedores, }\end{array}$ \\
\hline & \multirow[b]{2}{*}{ Territorio } & $\begin{array}{l}\text { Localidad o región } \\
\text { específica }\end{array}$ & 2 & Colombia-Social, España-Andalucía \\
\hline & & País & 15 & $\begin{array}{l}\text { Argentina-FONSOFT, Argentina-FONARSEC, Brasil- } \\
\text { Carnaval, Chile-Ciencia, Colombia-Grupos de Investigación, } \\
\text { CostaRica-Indicadores, Cuba-Instituciones, España- } \\
\text { lberdrola, México-Género, México-Emprendedores, Perú- } \\
\text { Agenda, RDominicana-Política, Uruguay-Viento, Uruguay- } \\
\text { Ciudadanos, Venezuela-Energía, }\end{array}$ \\
\hline & \multirow{3}{*}{ Problema } & Del lado de la demanda & 3 & Brasil-Carnaval, Uruguay-Viento, Uruguay-Ciudadanos \\
\hline & & Del lado de la oferta & 9 & $\begin{array}{l}\text { Argentina-FONSOFT, Argentina-FONARSEC, Colombia- } \\
\text { Grupos de investigación, Cuba-Instituciones, España- } \\
\text { Andalucía, México-Género, Perú-Agenda, RDominicana- } \\
\text { Política, Venezuela-Energía }\end{array}$ \\
\hline & & $\begin{array}{l}\text { Interacción de oferta y } \\
\text { demanda }\end{array}$ & 5 & $\begin{array}{l}\text { Chile-Ciencia, Colombia-Social, CostaRica-Indicadores, } \\
\text { España-lberdrola, México-Emprendedores }\end{array}$ \\
\hline
\end{tabular}




\begin{tabular}{|c|c|c|c|c|}
\hline Dimensión & Atributos & Niveles de los atributos & $\begin{array}{l}\text { \# de casos } \\
\text { identificados }\end{array}$ & Lista de procesos de diálogo identificados ${ }^{\star}$ \\
\hline \multirow{10}{*}{ Espacio } & \multirow[b]{2}{*}{ Origen } & De abajo a arriba & 8 & $\begin{array}{l}\text { Brasil-Carnaval, Chile-Ciencia, España-Iberdrola, México- } \\
\text { Género, México-Emprendedores Uruguay-Viento, Uruguay- } \\
\text { Ciudadanos, Venezuela-Energía }\end{array}$ \\
\hline & & De arriba a abajo & 9 & $\begin{array}{l}\text { Argentina-FONSOFT, Argentina-FONARSEC, Colombia- } \\
\text { Social, Colombia-Grupos de investigación, CostaRica- } \\
\text { Indicadores, Cuba-Instituciones, España-Andalucía, Perú- } \\
\text { Agenda, RDominicana-Política }\end{array}$ \\
\hline & \multirow{3}{*}{ Intenciones } & $\begin{array}{l}\text { Consulta o esbozo de } \\
\text { orientaciones generales } \\
\text { de política }\end{array}$ & 2 & Uruguay-Viento, Uruguay-Ciudadanos \\
\hline & & $\begin{array}{l}\text { Evaluación crítica u } \\
\text { opuesta de las políticas }\end{array}$ & 5 & $\begin{array}{l}\text { Colombia-Grupos de investigación, CostaRica-Indicadores, } \\
\text { España-lberdrola, México-Género, México-Emprendedores }\end{array}$ \\
\hline & & $\begin{array}{l}\text { Propuesta de una nueva } \\
\text { política }\end{array}$ & 10 & $\begin{array}{l}\text { Argentina-FONSOFT, Argentina-FONARSEC, Brasil- } \\
\text { Carnaval, Chile-Ciencia, Colombia-Social, Cuba- } \\
\text { Instituciones, España-Andalucía, Perú-Agenda, } \\
\text { RDominicana-Política, Venezuela-Energía }\end{array}$ \\
\hline & \multirow{3}{*}{ Posturas } & Posición reactiva & 5 & $\begin{array}{l}\text { Chile-Ciencia, Colombia-Grupos de Investigación, España- } \\
\text { Iberdrola, México-Género, México-Emprendedores }\end{array}$ \\
\hline & & $\begin{array}{l}\text { Mantenimiento de la } \\
\text { posición establecida }\end{array}$ & 6 & $\begin{array}{l}\text { Argentina-FONSOFT, Argentina-FONARSEC, España- } \\
\text { Andalucia, Perú-Agenda, RDominicana-Política, Venezuela- } \\
\text { Energía }\end{array}$ \\
\hline & & Posición abierta & 6 & $\begin{array}{l}\text { Brasil-Carnaval, Colombia-Social, CostaRica-Indicadores, } \\
\text { Cuba-Instituciones, Uruguay-Viento, Uruguay-Ciudadanos }\end{array}$ \\
\hline & & Relaciones simétricas & 2 & Colombia-Grupos de investigación, México-Género \\
\hline & Poder & Relaciones asimétricas & 15 & $\begin{array}{l}\text { Argentina-FONSOFT, Argentina-FONARSEC, Brasil- } \\
\text { Carnaval, Chile-Ciencia, Colombia-Social, CostaRica- } \\
\text { Indicadores, Cuba-Instituciones, España-Andalucía, } \\
\text { España-lberdrola, México-Emprendedores, Perú-Agenda, } \\
\text { RDominicana-Política, Uruguay-Viento, Uruguay- } \\
\text { Ciudadanos, Venezuela-Energía }\end{array}$ \\
\hline \multirow{3}{*}{ Temporalidad } & & Una sola vez & 1 & Chile-Ciencia \\
\hline & \multicolumn{2}{|c|}{ Un periodo limitado } & 12 & $\begin{array}{l}\text { Argentina-FONSOFT, Argentina-FONARSEC, Brasil- } \\
\text { Carnaval, Colombia-Social, Cuba-Instituciones, España- } \\
\text { Iberdrola, México-Género, México-Emprendedores, } \\
\text { Perú-Agenda, RDominicana-Política, Uruguay-Ciudadanos, } \\
\text { Venezuela-Energía }\end{array}$ \\
\hline & \multicolumn{2}{|r|}{ Permanente } & 4 & $\begin{array}{l}\text { Colombia-Grupos de investigación, CostaRica-Indicadores, } \\
\text { España-Andalucía, Uruguay-Viento }\end{array}$ \\
\hline
\end{tabular}

Fuente: elaboración propia en base a Dutrénit et al (2017), Alvarez et al. (2016a), Alvarez et al. (2016b), Ardanche et al. (2016a), Ardanche, et al. (2016b), Barletta, Suárez y Yoguel (2016), Bazán, Prada y Romero (2016), Cortes (2016), De la Vega, Ruiz y Cervilla (2016), Dutrénit y Suárez (2016a), Dutrénit y Suárez (2016b), Gómez-Valenzuela y Zapata (2016), Nupia y Martinez (2016a), Nupia y Martínez (2016b), Orozco y Barboza-Arias (2016), Pessoa de Matos, Cassiolato y Lastres (2016), Suárez, Barletta y Yoguel (2016), y Torres Pérez, Díaz Fernández y Fernández Estrada (2016). 
La dimensión Espacio es más heterogénea: (i) el Origen está más cercano a los enfoques de top-down, pero hay una amplia posibilidad de encontrar procesos bottom-up, (ii) se muestra que las Posturas varían según los niveles de los diferentes atributos, y (iii) resulta claro que la mayoría de los procesos de diálogo responden a Intenciones de formular nuevas políticas de CTI. Sin embargo, hay un atributo que destaca por encima de los otros, el Poder; al respecto sus relaciones en los procesos de diálogo se caracterizan por una marcada asimetría.

Finalmente, hay dos condiciones transversales de los procesos de diálogo que no se incluyen en los cuadros 5 y 6: el contexto y el marco institucional, por un lado, y las capacidades de las comunidades y actores, por otro. Estas condiciones contribuyen a explicar las asimetrías de poder que puede haber entre comunidades y actores de las mismas.

La evidencia empírica de casos de procesos de diálogo presentada en los diferentes capítulos de este libro ilustra que:

- El cambio del marco institucional en el que se desarrolla un proceso de diálogo es producto tanto de eventos externos y disruptivos, como de cambios incrementales generados durante el propio proceso de diálogo (véase Colombia-Grupos de investigación).

- Modificaciones del contexto y las reglas formales e informales pueden ser determinantes en el desarrollo de los procesos de diálogo (véase Brasil-Carnaval).

- Las capacidades orientadas a identificar y resolver problemas, vincularse en redes y compartir conocimiento, así como aquellas de generación de confianza, aprendizaje conjunto, coordinación y liderazgo pueden jugar un papel central en la construcción de propuestas para los procesos de diálogo. Las capacidades de coordinación y liderazgo también fueron una fuerza importante para avanzar en las diversas etapas que constituyen el proceso de diálogo (véase Brasil-Carnaval).

- La heterogeneidad de los actores y la existencia de brechas más o menos amplias pueden dificultar los procesos de diálogo; diferentes niveles de capacidades intra e intercomunidades demandan esfuerzos adicionales para llevarlo a cabo (véase Argentina-FONSOFT y Argentina-FONARSEC).

- El diálogo es un proceso dinámico; los bloqueos y limitaciones que pueden surgir en su trayectoria derivan no tanto de las características de un único actor sino de la dinámica de la 
interacción (Goñi, Bianco y Puchet, 2015). Ciertas características o dotaciones iniciales de los actores, en términos de capacidades acumuladas de diversa índole, en tanto afectan el diálogo, pueden evolucionar y transformarse eliminando barreras en el proceso.

- Las brechas existentes pueden reducirse al mejorar las capacidades de alguno de los actores como resultado del aprendizaje y la experiencia adquirida, de la práctica, del hacer y de la interacción con otros actores.

- Los actores participantes provienen de diferentes comunidades que poseen tanto motivaciones, prioridades y lógicas como conocimientos, capacidades y recursos diferenciados. Estas diferencias pueden ser usadas como mecanismos de control del diálogo, generando asimetrías de poder que se manifiestan en la interacción (Goñi, Bianco y Puchet, 2015).

- Las asimetrías se refieren a situaciones en las que una de las comunidades participantes en el diálogo, o uno de los actores, posee alguna característica, capacidad o recurso que las otras no tienen. Cuando esa tenencia le permite a quien la posee construir una hegemonía en el dialogo, de manera que priman su voluntad, intereses y valores, se está frente a una asimetría de poder. Es importante dar cuenta de estas situaciones para promover espacios de intercambio real y no de legitimación de rumbos de acción ya establecidos en otra esfera (Goñi, Bianco y Puchet, 2015) (véase México-Emprendedores, ArgentinaFONSOFT, Colombia-Grupos de investigación).

\section{CUESTIONES METODOLÓGICAS RESULTANTES DEL ANÁLISIS}

Algunos temas relativos al marco conceptual para la interpretación de los procesos de diálogo requieren de reflexión y análisis adicionales. En una primera aproximación, el análisis de un proceso considera los elementos que entran y salen del mismo. El cuadro 3 muestra el siguiente esquema del proceso: el diálogo tiene unos objetivos (sus entradas), en él intervienen comunidades y actores, configuraciones emergentes de la estructura y el funcionamiento del SI y, una vez realizado el proceso, se alcanzan unos resultados (o productos) generadores, a su vez, de efectos mediatos (o impactos). Esta lógica de entrada salida se interpreta habitualmente mediante dos dimensiones: espacio y tiempo. No obstante, las dimensiones (y sus atributos) presentados en el cuadro 4 revelan una triple perspectiva analítica que muestra la figura 1. Se observa allí que el espacio del diálogo es el conjunto de condiciones en las que se desempeñan sus actores; hay, de abajo 
hacia arriba, un origen, unas intenciones, unas posturas y unos poderes dados que se manifiestan al inicio, y el proceso transcurre según la temporalidad descrita en el eje que va del comienzo al final.

Figura 1. Perspectivas de las dimensiones del proceso de diálogo

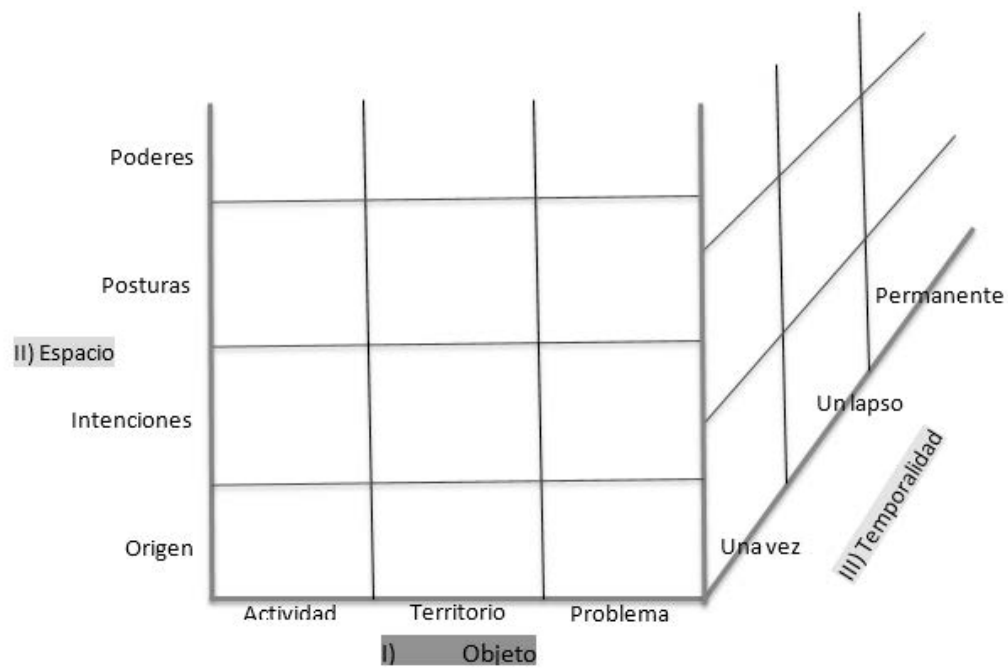

Fuente: elaboración propia.

La aplicación de la matriz del cuadro 1 a los casos observados fue imponiendo que el objeto del diálogo, siempre referido a las actividades sobre las que versan las políticas y su territorialidad, surgiera como una dimensión primigenia e intermedia entre espacio y tiempo. No solo porque esos atributos relativos al objeto y al lugar connotan a los diálogos como relativos a la CTI, sino porque, de manera fundamental, el diálogo constituye el problema mismo de política pública, su planteamiento y sus formas de resolución.

Sin duda, desde el punto de vista descriptivo, ubicar el espacio y la temporalidad del diálogo es crucial. Para la práctica y el seguimiento del proceso y su comprensión, el objeto del diálogo es la dimensión fundamental. La interacción comunicativa sobre el objeto mismo constituye el problema que será, en el transcurso del diálogo, multifacético y cambiante.

La concreción de esta perspectiva analítica hace posible relacionar y comparar procesos y, sobre todo, extraer lineamientos para orientar futuros ejercicios de diálogo. El orden de los atributos de cada dimensión muestra rasgos característicos del diálogo. El objeto se delimita, en primer lugar, respecto a la actividad sobre la que 
versa (o versará) la política, luego en relación al territorio de su instrumentación y, finalmente, acotará el problema a resolver. El espacio se considera, primero, según su origen y, a continuación, respecto a intenciones, posturas y poderes relativos de los actores. Se transita así de la interpretación de lo intencional a la de lo real y efectivo. La temporalidad se ordena desde diálogos en plazos cortos hasta aquellos permanentes.

La identificación de un conjunto relativamente pequeño de atributos que distingue un proceso de otro posibilita hacer su descripción mediante algunos elementos relevantes. Los atributos de las dimensiones para el análisis de cada proceso son complementarios. Si se toma la dimensión objeto se observa que un diálogo puede estar centrado en la resolución de problemas específicos de una actividad en un territorio, como es el caso, por ejemplo, de la política social de innovación en Colombia. México-Emprendedores tiene un origen bottom-up con la intención de evaluar una política pública desde una postura reactiva y tiene lugar en un medio donde las relaciones de poder entre los participantes son asimétricas.

La temporalidad muestra que, cuando los diálogos son permanentes (o abarcan un lapso muy largo), es posible pensar en momentos donde el diálogo coincide, en sus características, con una sucesión de procesos puntuales y, en otros, con los que ocurren en un lapso definido. El caso Uruguay-Viento, diálogo en torno al cambio de la matriz energética hacia la energía eólica, es un ejemplo de una temporalidad permanente con fases de diálogos puntuales y otras que corresponden a intercambios en lapsos prolongados.

Este marco conceptual que incorpora, en su perspectiva, las tres dimensiones, significó un avance para explorar cómo los procesos de diálogo funcionan en ambientes complejos.

Las comunidades emergen en este planteamiento de la interacción de agentes en las organizaciones y de las relaciones entre ellas mismas ubicadas en un sector del sistema. No obstante, resulta evidente que cuando se realizan actividades de innovación hay relaciones entre agentes y organizaciones de distintos sectores. En consecuencia, emergen comunidades de carácter intersectorial que cortan transversalmente los sectores de CTI. Esta visión es relevante para enfocar la construcción de capacidades entre organizaciones y sectores.

Los procesos de diálogo fortalecen vínculos entre comunidades y entre sus actores; la consolidación, permanencia y estabilidad de estos vínculos crea la posibilidad de que emerjan comunidades y actores que sean transversales a los sectores. Muchas de las fallas sistémicas están relacionadas con la incapacidad de los actores de distinto origen sectorial de encontrar mecanismos de coordinación que posibiliten 
flujos de conocimiento duraderos. Por ello, conceptualizar tanto esas comunidades como sus actores no circunscritos sectorialmente y, consecuentemente, entender cómo emergen es una vía para que, en el estudio de los diálogos, se destaque la configuración de comunidades y actores que comiencen a superar esa falla sistémica fundamental.

\section{REFLEXIONES FINALES}

Este capítulo reconoce la importancia de la participación pública en la formulación de la política pública de CTI. La evidencia, basada en quince casos de ALC y España, ha ilustrado la complejidad de estos procesos de diálogo, que se desarrollan en SI que no ostentan todas las características de aquellos que han alcanzado un alto nivel de madurez.

A partir de la bibliografía existente y de la evidencia empírica se ha propuesto un marco para analizar estos procesos de diálogo distinguiendo dimensiones y atributos. Este dimensionamiento permite analizar cómo los actores interactúan y se comunican para definir una acción colectiva e identificar fallas, trabas y obstáculos que se presentan para arribar a un resultado. Es una propuesta que no pretende establecer un estándar normalizador sino, por el contrario, iluminar distintas características que coexisten en las interacciones que ocurren en los diálogos.

La literatura destaca diferencias entre SI de países en desarrollo y desarrollados basadas en el menor número y variedad de los componentes, la escasa cantidad y poca intensidad de los vínculos, las carencias evolutivas de sus partes y la débil co-evolución que prima en los primeros respecto a los segundos (Chaminade et al., 2009). Desde esta perspectiva, los procesos de participación y diálogo de comunidades y actores tendrían que evolucionar, en países como los de ALC y España, según sus trayectorias específicas, sujetas a su inserción en entornos sistémicos inmaduros y enfrentar, por tanto, obstáculos evolutivos específicos. El análisis aquí expuesto complementa y refuerza la perspectiva evolutiva del desarrollo de los SI, e incorpora la dimensión de la acción colectiva y la voluntad de comunidades y actores que opera, de manera reflexiva, sobre la gestación y maduración de los sistemas y sus sectores.

En este trabajo se complementan los aportes de la literatura sobre participación pública en la hechura de las políticas (Jensen, 2005; Griessler, Biegelbauer y Hansen, 2011) con una clasificación de dimensiones y atributos de los procesos de diálogo, la cual resulta relevante cuando estos tienen lugar en la formulación de políticas de CTI.

La definición de diálogos democráticos propuesta por Cuentas y Linares Méndez (2013) para otros procesos de formulación de políticas 
y para la política en general, se retoma en nuestro marco conceptual. Su apropiación y adaptación más adecuada para procesos relativos a las políticas de CTI fue connotada con características tanto diferenciadoras como ampliatorias para abarcar de manera pertinente su nuevo objeto (Goñi, Bianco y Puchet, 2015).

La política pública de CTI supone la participación y el diálogo entre comunidades y sus actores. Si bien existen un conjunto de sistemas de información para captar datos sobre sectores, organizaciones y agentes de la innovación, nuestro trabajo mostró que es necesario implementar procedimientos, dispositivos y sistemas informativos que permitan hacer mapas y relevamientos de comunidades y actores involucrados en los diálogos. Los procesos de diálogo conducen al establecimiento de acuerdos entre los participantes en diferentes etapas. Hay que hacer un seguimiento de cada etapa, basados en las tecnologías de la información y la comunicación. La información sobre las características y las etapas de los diálogos hace posible configurar grupos expertos que estudien su emergencia, evolución y resultados. El seguimiento y análisis de los diálogos es la base para detectar las arenas de vinculación entre sectores en los sistemas de innovación, o las partes de los subsistemas sectoriales donde interactúan y se comunican sus organizaciones y agentes y en donde no han emergido comunidades y actores que participen y dialoguen.

La participación y el diálogo mismo requieren una política pública tendiente a la constitución de órganos que surjan de manera autónoma como resultado de las comunidades y los actores, o que sean establecidos más formalmente, con la finalidad de hacer efectivas esas prácticas. En esta línea, se han dado avances importantes. En varios países de América Latina y el Caribe se han creado organismos de asesoría y consulta para alimentar el proceso de formulación de la política de CTI que tienen entre sus funciones ser órganos de consulta de diferentes comunidades y actores (Dutrénit, 2014).

Sistemas de información y órganos autónomos relativos a la participación y al diálogo son quienes permitirán relevar capacidades de comunidades y actores, grados de conflicto y posibilidades de consensos. Sin que emerjan tales instituciones complementarias es difícil hacer política pública y generar mejor gobernanza de los sistemas de innovación. Como quien se mira en el espejo, qué tanto se han desarrollado las políticas públicas de CTI se puede ver en qué tan evidente es, para la sociedad, la proclividad que estas tienen a la participación pública y el diálogo con sus comunidades y actores. 
El análisis de la evidencia empírica ilustra que los diálogos suceden en condiciones que reflejan circunstancias específicas. Es difícil derivar de esos hechos propuestas estandarizadas para mejorar y promover el diálogo. Sin embargo, en los casos descritos es factible identificar algunas regularidades e imágenes ilustrativas que aportarán elementos de aprendizaje específico para diseñadores de políticas de CTI y otros actores participantes en procesos de diálogo. Las siguientes provienen de la aplicación de la perspectiva analítica tridimensional desarrollada. Primero, es fundamental entender cuál es el objeto del diálogo y quienes son las comunidades y los actores que participan. Segundo, es importante identificar claramente las tres dimensiones del proceso de diálogo y los atributos específicos de cada una, para entender su naturaleza y tomar decisiones apropiadas respecto a la misma. Tercero, es conveniente identificar diferencias en capacidades entre las comunidades que participan y asimetrías de poder, para inducir acciones correctivas y promover la generación de consensos. El capítulo tres de este libro incluye un esfuerzo por sistematizar un conjunto de lineamientos metodológicos para establecer procesos de diálogo para el diseño de políticas de CTI.

\section{BIBLIOGRAFÍA}

Aguilar, L. 1992 La hechura de las políticas públicas (México: Miguel Ángel Porrúa).

Aguilar, L. 2006 Gobernanza y gestión pública (México: Fondo de Cultura Económica).

Álvarez, I.; Barletta, F.; Suarez, D.; Yoguel G. 2016 “Marco analítico para la tipificación de diálogos para las políticas de CTI" en Working paper 3 (Red CYTED COM - LALICS). En $<$ http://lalics.org/images/CYTED/DT3-DimensionesDialogo. pdf $>$ acceso 15 de abril de 2017.

Barboza, L. 2016 "Algunas consideraciones en torno al concepto de comunidad" en Working paper 6 (Red CYTED COM - LALICS). En $<$ http://lalics.org/images/CYTED/DT6-DefinicinComunidad. pdf $>$ acceso 15 de abril de 2017.

Bruce, B.; Whatmore, S. 2010 Political Matter: Technoscience, Democracy, and Public Life (Minnesota: The University of Minnesota).

Cassiolato, J.; Lastres, H.; Maciel, M. (eds.) 2003 Systems of Innovation and Development Evidence from Brazil (Cheltenham: Edward Elgar).

Chaminade, C.; Edquist C. 2006 "Rationales for public policy intervention from a systems of innovation approach: the case of VINNOVA" en Working Papers series (CIRCLE) N 2006/04. 
Chilvers, J. 2008 "Deliberating Competence: Theoretical and Practitioner Perspectives on Effective Participatory Appraisal Practice" en Science, Technology \& Human Values (SAGE Journals) $\mathrm{N}^{\circ} 33(3)$, pp. 421-451.

Cimoli, M. (ed.) 2000 Developing Innovation Systems, Mexico in the Global Context (Londres: Pinter Publishers).

Crespi, G.; Dutrénit, G. (eds.) 2014 Science, Technology and Innovation Policies for Development: The Latin American Experience (Londres: Springer).

Cuentas, M.; Linares Méndez, A. 2013 Guía práctica de diálogo democrático (Organización de Estados Americanos - Programa de las Naciones Unidas para el Desarrollo).

Cuppen, E. 2012 "A quasi-experimental evaluation of learning in a stakeholder dialogue on bio-energy" en Research Policy (Estados Unidos) $\mathrm{N}^{\circ} 41 / 3$, pp. 624-637.

Dutrénit, G.; Sutz, J. (eds.) 2014 National Innovation Systems, Social Inclusion and Development: The Latin American Experience (Cheltenham: Edward Elgar).

Dutrénit, G.; Puchet, M. 2017 “Tensions of STI policy in Mexico: analytical models, institutional evolution, national capabilities and governance" en Kuhlmann, S.; Ordóñez-Matamoros, G. (eds.) International Research Handbook on Science, Technology and Innovation Policy in Developing Countries: Rationales and Relevance (Cheltenham: Edward Elgar) pp. 205-231.

Dutrénit, G.; Álvarez, I.; Ardanche, M.; Barletta, F.; Bianco, M.; Cortés, R.; Cummings, A.; de la Vega, I.; Díaz, I.; Fernández, O.; Gómez, V.; Goñi, M.; Natera, J. M.; Nupia, C.; Orozco, J.; Prada, F.; Puchet, M.; Romero, F.; Simón, L.; Suárez, D.; Suárez, M.; Sutz, J.; Vera-Cruz, A. 2016 "Matriz de Información para el mapeo de procesos de diálogo de CTI en España, América Latina y el Caribe" en Working paper 5 (Red CYTED COM - LALICS). En <http://lalics.org/images/CYTED/DT5-Formulario2.pdf> acceso 15 de abril de 2017.

Dutrénit, G.; Natera, J. M.; Puchet Anyul, M. O.; Vera-Cruz, A.; Torres, A. 2017 "Dialogue processes on STI policy-making in Latin America and the Caribbean: dimensions and conditions", en Science and Public Policy, 1-16. En <doi: 10.1093/scipol/ scx044>.

Dutrénit, G.; Capdeville, M.; Corona, J.; Puchet, M.; Santiago, F.; and Vera-Cruz, A. 2010 El Sistema Nacional de Innovación Mexicano: Instituciones, Políticas, Desempeño y Desafíos (México: UAM-X/ Textual). 
Dutrénit, G.; Natera, J. M.; Suárez, M. 2014 "Lineamientos para la caracterización de las Comunidades y sus Procesos de Diálogo" en Working paper 1 (Red CYTED COM - LALICS). En <http:// lalics.org/images/CYTED/DT1-ComunidadesDialogo\%201.pdf> acceso 15 de abril de 2017.

Giddens, A. 1984 The Constitution of Society. Outline of the Theory of Structuration (Cambridge: Polity Press).

Goñi, M.; Bianco, M; Puchet, M. 2015 “Elementos para caracterizar los procesos de diálogo en políticas de CTI" en Working paper 7 (Red CYTED COM - LALICS). En <http://lalics.org/images/ CYTED/DT7-ConfianzaPoder.pdf> acceso 15 de abril de 2017.

Griessler, E.; Biegelbauer, P.; Hansen, J. 2011 “Citizen's Impact on knowledge intensive policy: introduction to a special issue" en Science and Public Policy (Reino Unido: Oxford University Press) $\mathrm{N}^{\circ}$ 38(8), pp. 583-588.

Irwin, A. 2006 "The Politics of Talk: Coming to Terms with the 'New' Scientific Governance" en Social Studies of Science (SAGE Journals) $\mathrm{N}^{\circ} 36 / 2$, pp. 299-320.

Jasanoff, S. 2003 "Technologies of Humility: Citizen Participation in Governing Science” en Minerva (Springer) N 41/3, pp. 223-44.

Jensen, C. 2005 "Citizen Projects and Consensus-Building at the Danish Board of Technology: On Experiments in Democracy" en Acta Sociológica (México: UNAM) N 48/3, pp. 221-235.

Kreimer, P.; Vessuri, H.; Velho, V.; Arellano, A. (eds.) 2014 Perspectivas latinoamericanas en el estudio social de la ciencia, la tecnología y el conocimiento (México: CYTED, FCCyT, ESOCITE, Siglo XXI Editores).

Lázaro, M.; Trimble, M.; Umpiérrez, A.; Vásquez, A.; Pereira, G. 2013 Juicios Ciudadanos en Uruguay. Dos experiencias de participación pública deliberativa en ciencia y tecnología (Montevideo: PNUD/ Universidad de la República).

López, A. 2007 Desarrollo Económico y Sistema Nacional de Innovación en la Argentina. (Buenos Aires: Consejo Profesional de Ciencias Económicas de la Ciudad Autónoma de Buenos Aires).

Lundvall, B. 2007 "Innovation System Research Where it came from and where it might go", Paper que será presentado en la Fifth Globelics Conference en Saratov, 19-23 de septiembre.

Mejlgaard, N. 2009 "The trajectory of scientific citizenship in Denmark: changing balances between public competence and public participation" en Science and Public Policy (Reino Unido: Oxford University Press) $N^{\circ} 36 / 6$, pp. 483-496. 
North, D. 1990 Institutions, Institutional Change and Economic Performance (Cambridge: Cambridge University Press).

Nupia, C.; Martínez A. 2015 "Revisión de metodologías de procesos de diálogo" en Working paper 4 (Red CYTED COM - LALICS). En <http://lalics.org/images/CYTED/DT4-MetodologiasDialogo. pdf $>$ acceso 15 de abril de 2017.

Ordóñez-Matamoros, G.; Tadlaoui, S.; Porras, S.; Duarte, J.; López, L.; Martínez, L.; Calderón, G. 2013 Manual de Análisis y Diseño de Políticas Públicas (Bogotá: Editorial Universidad Externado de Colombia).

Ostrom, E. 2005 Understanding institutional diversity (Estados Unidos: Princeton University Press).

PNUD 2003 Mapeo de experiencias de diálogo en América Latina y el Caribe. Lineamientos de investigación, matriz y variables de estudio propuestas (Nueva York: UNDP).

Puchet Anyul, M.; Ruiz, P. 2003 Nuevas leyes de ciencia y tecnología y orgánica del CONACYT. Buenos propósitos, cambios institucionales y concentración presidencial de las decisiones (México: Editorial Porrúa y Facultad de Derecho - UNAM).

Rowe, G. 2005 "A Typology of Public Engagement Mechanisms" en Science, Technology \& Human Values (SAGE Journals) N ${ }^{\circ}$ 30/2, pp. 251-290.

Türke, R. 2008 Governance. Systemic Foundation and Framework (Heidelberg: Physica-Verlag).

Valenti, G. (coord.) 2008 Ciencia, tecnología e innovación. Hacia una agenda de política pública (México: FLACSO).

Vera-Cruz, A.; Dutrénit, G.; Ekboir, J.; Martínez, G.; Torres, A. 2011 "El financiamiento de la Investigación y la Innovación Mediante Fondos Competidos: Balance del caso de la Agricultura Mexicana" en Aboites, J.; Corona, J. (coords.) Economía de la Innovación y Desarrollo (México: Siglo XXI) pp. 192-215.

\section{REFERENCIAS DE LAS MATRICES DE INFORMACIÓN POR PAÍSES PARA EL MAPEO DE LOS PROCESOS DE DIÁLOGO DE CTI}

Álvarez, I.; Torrecillas, C.; Albis, N.; Labra, R. 2016a "Plan regional de $\mathrm{I}+\mathrm{D}+\mathrm{i}$ para la Comunidad Autónoma de Andalucía (PAIDI)" en Working paper (España-Andalucía) (Red CYTED COM - LALICS). En <http://lalics.org/index. php?option $=$ com_content $\&$ view $=$ category\&layout $=$ blog $\& i d=63$ \&Itemid $=321 \&$ lang $=$ es $>$. 
Álvarez, I; Juan, M; Torrecillas, C; Albis, N; Labra, R. 2016b "Diálogos y Políticas para la Investigación, Innovación, Ciencia y Tecnología" en Working paper (España-Iberdrola) (Red CYTED COM - LALICS). En <http://lalics.org/index. php?option $=$ com_content $\&$ view $=$ category\&layout $=$ blog $\& i d=63$ \&Itemid $=321$ \&lang $=$ es $>$.

Ardanche, M.; Bianco, M.; Cohanoff, C.; Conteras, S.; Goñi, M.; Simón, L.; Sutz, J. 2016a "Cambio en la matriz energética uruguaya con especial énfasis en el desarrollo de la energía eólica" en Working paper (Uruguay-Viento) (Red CYTED COM LALICS). En <http://lalics.org/index.php?option=com_content $\&$ view $=$ category\&layout $=$ blog\&id $=63 \&$ Itemid $=321 \& l a n g=e s>$.

Ardanche, M.; Bianco, M.; Cohanoff, C.; Conteras, S.; Goñi, M.; Simón, L.; Sutz, J. 2016b “Juicios Ciudadanos en Uruguay. Una experiencia de participación pública deliberativa en Ciencia y Tecnología" en Working paper (Uruguay-Ciudadanos) (Red CYTED COM - LALICS). En <http://lalics.org/index. php?option $=$ com_content $\&$ view $=$ category $\&$ layout $=$ blog $\&$ id $=63$ \&Itemid $=321$ \&lang $=$ es $>$.

Barletta, F.; Suárez, D.; Yoguel, G. 2016 "Promoción de la innovación en la industria del software y los servicios de TI - El caso de FONSOFT" en Working paper (Argentina-FONSOFT) (Red CYTED COM - LALICS). En <http://lalics.org/index. php?option $=$ com_content $\&$ view $=$ category\&layout $=$ blog $\& i d=63$ \&Itemid $=321 \&$ lang $=e s>$.

Bazán, M.; Prada, F.; Romero, F. 2016 "Matriz de Información para el mapeo de procesos de diálogo de CTI: Diálogos para el desarrollo de la Agenda de Competitividad 2014-2018 en el Eje Estratégico de Ciencia, Tecnología e Innovación en Perú" en Working paper (Peru-Agenda) (Red CYTED COM - LALICS). En $<$ http://lalics.org/index.php?option=com_content\&view=categor y\&layout $=$ blog\&id $=63 \&$ Itemid $=321$ \&lang $=e s>$.

Cortes, R. 2016 "Creación de instituciones públicas para el desarrollo de la ciencia en Chile" en Working paper (ChileCiencia) (Red CYTED COM - LALICS). En <http://lalics.org/ index.php?option $=$ com_content $\&$ view $=$ category\&layout $=$ blog $\&$ $\mathrm{id}=63 \&$ Itemid $=321$ \&lang $=\mathrm{es}>$.

De la Vega, I.; Ruiz, N.; Cervilla, M. 2016 "STI desde la gestión del conocimiento. El caso de la política pública en el área de energía en Venezuela" en Working paper (Venezuela-Energía) (Red CYTED COM - LALICS). En <http://lalics.org/index.php?option=com_content\&vie $\mathrm{w}=$ category\&layout $=\mathrm{blog} \& \mathrm{id}=63 \&$ Itemid $=321$ \&lang $=\mathrm{es}>$. 
Dutrénit, G.; Suárez, M. 2016a "Propuestas para adoptar una perspectiva de género en las políticas de CTI en México" en Working paper (México-Género) (Red CYTED COM - LALICS). En $<$ http://lalics.org/index.php?option=com_content\&view=category \&layout=blog\&id=63\&Itemid=321\&lang=es $>$.

Dutrénit, G.; Suárez, M. 2016b “Desafíos empresariales basados en el conocimiento en México" en Working paper (MéxicoEmprendedores) (Red CYTED COM - LALICS). En <http://lalics. org/index.php?option=com_content\&view=category\&layout=blog \&id $=63 \&$ Itemid $=321 \&$ lang $=$ es $>$.

Dutrénit, G.; Suárez, M. 2017 “Involving stakeholders in policymaking: tensions emerging from a public dialogue with knowledgebased entrepreneurs" en Science and Public Policy 1-13. En < doi: 10.1093/scipol/scx043>.

Gómez-Valenzuela, V.; Zapata, L. 2016 "Matriz de Información para el mapeo de procesos de diálogo de CTI: Diálogo nacional sobre políticas de innovación: fomento de la innovación, la creatividad y la creación de nuevos negocios en República Dominicana" en Working paper (RDominicana-Política) (Red CYTED COM LALICS). En <http://lalics.org/index.php?option=com_content\&vi ew $=$ category \&layout $=$ blog $\& i d=63 \& I t e m i d=321 \& l a n g=e s>$.

Nupia, C.; Martínez, A. 2016a "El desarrollo participativo de la innovación en políticas sociales en Colombia" en Working paper (Colombia-Social) (Red CYTED COM - LALICS). En <http://lalics. org/index.php?option=com_content\&view=category\&layout=blog \&id $=63$ \& Itemid $=321$ \&lang $=$ es $>$.

Nupia, C.; Martínez, A. 2016b "Medición y reconocimiento de grupos de investigación en Colombia" en Working paper (ColombiaGrupos de investigación) (Red CYTED COM - LALICS). En $<$ http://lalics.org/index.php?option=com_content\&view=category \&layout $=$ blog $\& i d=63 \&$ Itemid $=321$ \&lang $=e s>$.

Orozco, J.; Barboza-Arias, L. 2016 "Sistema de Indicadores Nacionales de Ciencia, Tecnología e Innovación en Costa Rica” en Working paper (CostaRica-Indicadores) (Red CYTED COM - LALICS). En $<$ http://lalics.org/index.php?option=com_content\&view=category \&layout $=$ blog\&id $=63 \&$ Itemid $=321$ \&lang $=e s>$.

Pessoa de Matos, M.; Cassiolato, J.; Lastres; H. 2016 "Construcción de políticas STI: diálogo de políticas públicas en los Sistemas Locales de Innovación y Producción del Carnaval en Brasil" en Working paper (Brasil-Carnaval) (Red CYTED COM - LALICS). En <http:// lalics.org/index.php?option=com_content\&view=category\&layout $=$ blog\&id $=63 \&$ Itemid $=321 \&$ lang=es $>$. 
Suárez, D.; Barletta, F.; Yoguel, G. 2016 "Promoción de la innovación a nivel sectorial - El caso de FONARSEC" en Working paper (Argentina-FONARSEC) (Red CYTED COM LALICS). En <http://lalics.org/index.php?option=com_content \&view $=$ category \&layout $=$ blog \&id $=63 \&$ Itemid $=321$ \&lang $=e s>$.

Torres Pérez, R.; Díaz Fernández, I.; Fernández Estrada, O. 2016 "Arreglos institucionales e incentivos para la innovación en Cuba" en Working paper (Cuba-Instituciones) (Red CYTED COM - LALICS). En <http://lalics.org/index.php?option=com content $\&$ view $=$ category\&layout $=$ blog $\& i d=63 \&$ Itemid $=321 \& l a n$ $\mathrm{g}=\mathrm{es}>$. 



\section{LINEAMIENTOS METODOLÓGICOS PARA PROCESOS DE DIÁLOGO ORIENTADOS A LA FORMULACIÓN DE POLÍTICAS DE CTI EN AMÉRICA LATINA, EL CARIBE Y ESPAÑA}

Dutrénit, Gabriela ${ }^{1}$; Álvarez, Isabel ${ }^{5}$; Ardanche, Melissa ${ }^{2}$; Barletta, Florencia ${ }^{4}$; Bianco, Mariela ${ }^{2}$; de la Vega, Iván ${ }^{13}$; Díaz, Ileana $^{7}$; Fernández, Oscar6; Gómez, Víctor ${ }^{8}$; Goñi, María ${ }^{2}$; Natera, José Miguel ${ }^{3}$; Nupia, Carlos ${ }^{9}$; Orozco, Jeffrey ${ }^{10}$; Prada, Fernando $^{12}$; Puchet, Martin ${ }^{11}$; Romero, Fernando ${ }^{12}$; Simón, Lucía $^{2}$; Suárez, Diana ${ }^{4}$ S Suárez, Marcela ${ }^{14}$; Sutz, Judith ${ }^{2}$ y Vera-Cruz, Alexandre O. ${ }^{1}$

\section{INTRODUCCIÓN}

Los procesos de diálogo para la formulación de políticas de Ciencia, Tecnología e Innovación (CTI) pueden entenderse y analizarse a partir de la interacción entre las comunidades de un sistema de innovación. Las comunidades relevantes para dichos sistemas suelen ser las siguientes: académica, sector productivo, sector público y otros sectores de la sociedad civil organizada. El proceso de diálogo se desarrolla entre actores que son parte de estas comunidades.

1 Posgrado en Economía, Gestión y Políticas de Innovación, Universidad Autónoma Metropolitana, Xochimilco.

2 Unidad Académica de la Comisión Sectorial de Investigación Científica, Universidad de la República, Montevideo, Uruguay.

3 Catedrático CONACYT, Universidad Autónoma Metropolitana, Xochimilco

4 Centro Interdisciplinario de Estudios en Ciencia, Tecnología e Innovación (CIEC-

TI), Instituto de Industria - Universidad Nacional de General Sarmiento (IdeI-UNGS).

5 Instituto Complutense de Estudios Internacionales (ICEI).

6 Centro de Estudios de la Economía Cubana, de la Universidad de La Habana.

7 Centro de Estudios sobre Administración Pública y Empresarial, de la Escuela Superior de Cuadros del Estado y el Gobierno.

8 Instituto Tecnológico de Santo Domingo (INTEC).

9 Observatorio Colombiano de Ciencia y Tecnología (OCyT).

10 Centro Internacional de Política Económica, Universidad Nacional, Costa Rica.

11 Facultad de Economía, Universidad Nacional Autónoma de México.

12 FORO Nacional Internacional, Perú.

13 CENTRUM Católica Graduate Business School, Pontificia Universidad Católica del Perú.

14 Lateinamerika-Institut, Freie Universität Berlin. 
El diálogo se basa en conocimientos, comunicación, coordinación y habilidades de liderazgo, que lleva a las comunidades a la exploración de conflictos y a la búsqueda de acuerdos para la toma de decisiones en torno a la resolución de problemas comunes. El diálogo es, por ende, un proceso complejo de confrontación de ideas y de construcción colectiva y negociada de un objeto o de una posición. Dicho proceso se caracteriza por la diversidad de comunidades que, por su propia naturaleza, tienen diferentes capacidades, incluyendo diferentes habilidades para establecer el diálogo e intereses, así como por la heterogeneidad de los actores que integran cada comunidad.

Los procesos de diálogo entre las comunidades y sus actores desempeñar un papel fundamental en la construcción de política pública y, por lo tanto, de política pública en CTI. Con diferentes énfasis, esto se conoce como participación pública / participación ciudadana / involucramiento de las partes interesadas (stakeholders).

Como resultado del trabajo de la Red CYTED COM-LALICS, orientada al análisis de los procesos de diálogo para la política pública de CTI, se ha recogido y sistematizado evidencia en once países de América Latina, el Caribe y España. El marco analítico planteado se basa en la literatura de los sistemas de innovación, la perspectiva evolucionista y la aproximación institucional de las políticas públicas de CTI. Como resultado de la reflexión sobre este tema, la red elaboró los siguientes documentos:

Álvarez, I., Barletta, F., Suarez, D. y Yoguel G. 2016 "Marco analítico para la tipificación de diálogos para las políticas de CTI" en Working paper 3 (Red CYTED COM-LALICS). En <http://lalics. org/images/CYTED/DT3-DimensionesDialogo.pdf> acceso $15 \mathrm{de}$ abril de 2017.

Barboza, L. 2016 "Algunas consideraciones en torno al concepto de comunidad" en Working paper 6 (Red CYTED COM-LALICS). En <http://lalics.org/images/CYTED/DT6-DefinicionComunidad. pdf $>$ acceso 15 de abril de 2017.

Dutrénit, G., Álvarez, I., Ardanche, M., Barletta, F., Bianco, M., Cortés, R., Cummings, A., de la Vega, I., Díaz, I., Fernández, O., Gómez, V., Goñi, M., Natera, J. M., Nupia, C., Orozco, J., Prada, F., Puchet, M., Romero, F., Simón, L., Suárez, D., Suárez, M., Sutz, J.; Vera-Cruz, A. 2016 "Matriz de Información para el mapeo de procesos de diálogo de CTI en España, América Latina y el Caribe" en Working paper 5 (Red CYTED COM-LALICS). En $<$ http://lalics.org/images/CYTED/DT5-Formulario2.pdf> acceso 15 de abril de 2017. 
Dutrénit, G., Natera, J. M.; Suárez, M. 2014 “Lineamientos para la caracterización de las Comunidades y sus Procesos de Diálogo" en Working paper 1 (Red CYTED COM-LALICS). En <http:// lalics.org/images/CYTED/DT1-ComunidadesDialogo\%201.pdf> acceso 15 de abril de 2017.

Goñi, M., Bianco, M.; Puchet, M. 2015 “Elementos para caracterizar los procesos de diálogo en políticas de CTI" en Working paper 7 (Red CYTED COM-LALICS). En <http://lalics.org/images/ CYTED/DT7-ConfianzaPoder.pdf> acceso 15 de abril de 2017.

Nupia, C.; Martínez A. 2015 "Revisión de metodologías de procesos de diálogo" en Working paper 4 (Red CYTED COM-LALICS). En <http://lalics.org/images/CYTED/DT4-MetodologiasDialogo.pdf> acceso 15 de abril de 2017.

Estos lineamientos sintetizan la reflexión colectiva, y tienen como objetivo orientar a las personas interesadas en el desarrollo de procesos de diálogos para la política pública de CTI en la región. Están organizados en tres grandes bloques: (i) consideraciones sobre las comunidades y el diálogo; (ii) una propuesta de organización del proceso de diálogo en cinco fases; y (iii) una serie de lecciones aprendidas que han sido recolectadas de la evidencia empírica.

\section{CONSIDERACIONES SOBRE LAS COMUNIDADES}

Las comunidades no son entes homogéneos. Al interior de cada comunidad puede existir una elevada heterogeneidad de los actores que la conforman en cuanto a capacidades, diferencias de lenguaje y asimetrías de poder. Si bien esto no se puede solucionar -en particular, en diálogos de corta duración-, es necesario reconocer y gestionar las diferencias.

Adicionalmente, durante los procesos de diálogo es importante atender a un conjunto de elementos relacionados con las comunidades, como son: (i) las asimetrías de poder, y (ii) la heterogeneidad de capacidades. Estos elementos afectan particularmente el desarrollo del diálogo.

\section{ASIMETRÍAS DE PODER}

En los procesos de diálogo se generan situaciones en las que una de las comunidades que participan en el proceso de diálogo, o uno de los actores de una comunidad, tiene una capacidad, recurso o característica que los demás participantes no poseen. Cuando estas características, recursos o capacidades permiten a quienes los tienen construir hegemonía en el proceso de diálogo donde prevalece su voluntad, intereses o valores, esto conduce a una situación de asimetría de poder. 
Asimismo, en los procesos de diálogo coexisten grupos de poder con intereses en conflicto. Independientemente de si las asimetrías y los conflictos se logran solucionar en el proceso, deben gestionarse de manera que no obstaculicen los entendimientos. Adicionalmente, en tanto cada comunidad tiene un lenguaje propio, será preciso también, mediante acciones deliberadas, crear un lenguaje común y clarificar conceptos que faciliten el entendimiento.

\section{HETEROGENEIDAD DE CAPACIDADES}

Para desarrollar un proceso de diálogo son necesarias diferentes capacidades, tales como la identificación y resolución de problemas, la articulación en redes y la generación de condiciones para compartir conocimiento, generar confianza, aprendizaje conjunto, liderazgo y coordinación. Ninguna comunidad tiene todas las capacidades que se requieren para llevar a término el proceso de diálogo. La heterogeneidad de los actores y la existencia de distancias cognitivas grandes o pequeñas entre las capacidades de los mismos pueden dificultar los procesos de diálogo. Diferentes niveles de capacidades entre comunidades exigen esfuerzos adicionales para la generación de consensos.

Es importante considerar que estos elementos interactúan, en el sentido de que mayores capacidades de una comunidad o de un actor de una comunidad pueden generar asimetrías de poder, y alternativamente, un mayor poder puede conducir a generar mayores capacidades.

\section{CARACTERIZACIÓN DE LOS DIÁLOGOS EN CTI}

\subsection{BASES DEL PROCESO DE DIÁLOGO}

- El foco de estos lineamientos son los actores del proceso de diálogo, organizados en cuatro comunidades: sector académico, sector público, sector productivo, y otros sectores de la sociedad civil organizada.

- El proceso de diálogo puede plantearse en torno a las siguientes dimensiones, así como a los atributos que las caracterizan:

- Objeto. Es el tema de la política de CTI sobre el que se dialogará. En general, los temas pueden referirse a uno o varios de los siguientes tres tipos: (i) la actividad científica, tecnológica o de innovación, o uno de sus componentes; (ii) el territorio donde se desarrollan estas actividades: un país, una región o una localidad; y (iii) el problema público específico que los actores definen, exponen y tratan de abordar; 
- Espacio de interacción. Es la dimensión donde los actores desarrollan el diálogo. Se configura como resultado del origen de la iniciativa, los poderes relativos de los actores participantes, sus intenciones al llegar al diálogo, y la posición que asumen con respecto al objeto del diálogo mismo. Por lo tanto, se pueden identificar cuatro atributos: (i) origen, (ii) intenciones, (iii) posiciones y (iv) poder;

- Temporalidad. Describe el nivel de continuidad del proceso de diálogo, y tiene tres atributos: (i) diálogo puntual, que se desarrolla una sola vez, (ii) diálogo en períodos limitados, o (iii) diálogo de largo plazo o permanente. En tanto todo proceso de diálogo es dinámico, cuanto mayor sea la temporalidad considerada, más probable será que se produzcan cambios a nivel de los actores participantes, sus recursos y las interrelaciones entre ellos, lo que seguramente conduzca a un replanteo de la propia estructura del diálogo y de los resultados esperados.

- Es importante considerar las características culturales y tomar en cuenta el papel de las instituciones informales en cada país.

\subsection{FASES DE UN PROCESO DE DIÁLOGO DE POLÍTICAS DE CTI}

Se propone una estructura secuencial de las fases, desde el punto de vista del diseño del proceso de diálogo y de su sistematización, por lo cual es importante que se sigan de acuerdo al orden que se presentan. Sin embargo, las distintas fases del diálogo de CTI no necesariamente ocurrirán de manera lineal. Cuando tal cosa ocurra, se requerirá de un enfoque adaptativo de conducción que gestione adecuadamente el cambio de las fases y su reconducción a favor de los objetivos y propósitos del mismo.

\section{FASE 1 - IDENTIFICACIÓN DE UNA NECESIDAD, UNA DEMANDA O UN PROBLEMA Y DEFINICIÓN DEL PROPÓSITO DEL PROCESO DE DIÁLOGO}

\subsection{DELIMITAR EL OBJETO:}

- Definir el objeto del proceso de diálogo, es decir, el tema de la política de CTI sobre el que se dialogará.

- Delimitar el objeto de acuerdo a los siguientes atributos:

- Actividades de CTI: generales (por ejemplo, plan nacional de CTI) o específicas (por ejemplo, programas de fomento a la innovación o a la ciencia, consorcios público-privados, desarrollo de un sector estratégico). 
- Territorio: implementación de políticas a nivel nacional o regional/local (por ejemplo, políticas de clusters, desarrollo de un sector estratégico regional).

- Problema público: desde la demanda (por ejemplo, propuesta de un programa de financiamiento a los clusters, facilitar el acceso a fondos para financiar las actividades de innovación en las PYME), desde la oferta (por ejemplo, programa para estimular la innovación de las empresas pequeñas), y de la interacción entre demanda y oferta (por ejemplo, propuesta para articular la oferta y demanda de recursos humanos altamente capacitados).

- Identificar en qué etapa del ciclo de la política de CTI se ubica el objeto del diálogo (diseño, implementación, monitoreo y evaluación).

\subsection{IDENTIFICAR EL ORIGEN DEL DIÁLOGO:}

- Identificar el origen del diálogo, el cual puede emerger de:

- Comunidad del sector público (top-down): El diálogo se origina como una propuesta de la comunidad del sector público.

- Otras comunidades - académica, sector productivo, y otros sectores de la sociedad civil organizada (bottom-up): El diálogo se origina como resultado del interés y de la propuesta de otras comunidades que son beneficiarias potenciales o actuales de la política pública y actúan como partes interesadas.

\subsection{PRECISAR LA POSTURA DEL DIÁLOGO FRENTE A LA POLÍTICA PÚBLICA:}

- Identificar la postura del diálogo en función de:

- Reactivos: surgen en respuesta a políticas existentes. Pueden ser programas implementados que tienen conflictos entre los actores, problemas que requieren soluciones distintas a las planteadas, entre otros.

- Posición ya establecida: surgen para mantener una posición, que puede basarse en análisis previos.

- Posición abierta: los participantes en el diálogo están abiertos a explorar opciones de política pública.

- Conocer cuáles son los procesos de diálogos anteriores o que se están desarrollando en torno a este objeto. 
- Identificar y analizar otras experiencias de diálogos que tengan un nivel de complejidad similar, en relación a: (i) otras arenas de la política pública a nivel nacional, y (ii) experiencias internacionales.

\subsection{DEFINIR EL PROPÓSITO DEL PROCESO DE DIÁLOGO:}

- El propósito está definido por la intención de los actores para sumarse al proceso de diálogo.

- Es importante dejar claro ante las comunidades el propósito del proceso de diálogo. En términos generales, hay tres grandes propósitos de un proceso de diálogo para la formulación de políticas de CTI:

- Concertación: diálogos orientados a concertar acuerdos entre los posibles actores involucrados en el diseño de políticas;

- Consultivos: diálogos orientados a generar las primeras consultas con expertos en temas específicos de la política;

- Generación de propuestas de política: diálogos focalizados en el diseño de una nueva política.

\section{FASE 2 - IDENTIFICACIÓN Y SELECCIÓN DE ACTORES Y COMUNIDADES}

\subsection{IDENTIFICAR ACTORES Y COMUNIDADES:}

- Identificar cuáles de las cuatro comunidades (académica, sector público, sector productivo y sociedad civil organizada) deben estar involucradas en el proceso de diálogo, de acuerdo al objeto y el propósito.

\subsection{CARACTERIZAR LAS COMUNIDADES PERTINENTES Y LOS ACTORES DENTRO DE ESAS COMUNIDADES:}

- Realizar un diagnóstico inicial de los actores existentes dentro de las comunidades identificadas para el diálogo. Pueden usarse metodologías de mapeo de actores (ver anexo 1), que consideren:

- El papel de las instituciones informales y el grado de formalización de cada país y de cada comunidad;

- Características culturales de las comunidades involucradas;

- Los conflictos existentes y los actores con poder; 
- El tipo de recursos clave (materiales y simbólicos) de cada uno de los actores y de las comunidades;

- La identificación de las comunidades que tienen capacidades (expertise) para los distintos aspectos del objeto del diálogo;

- La existencia o no de un lenguaje común entre las comunidades y la necesidad de tomar acciones específicas en ese sentido.

- Dado el carácter transversal de la política de CTI, considerar la inclusión de actores de otras arenas de la política pública, particularmente de la comunidad del sector público.

\subsection{CRITERIOS DE SELECCIÓN DE LOS ACTORES A SER CONVOCADOS:}

- Los principales criterios son:

- Accesibilidad: para participar en el proceso de diálogo;

- Balance entre el conjunto de actores: en cuanto a poder/influencia, conocimiento del objeto y representatividad de sus comunidades;

- Relación entre los actores a ser seleccionado: empatía, buena relación inicial, conflictos (manifiestos o potenciales) entre ellos que puedan afectar el diálogo.

\section{FASE 3 DISEÑO DEL PROCESO DE DIÁLOGO}

El diseño del proceso de diálogo incluye una serie de pasos:

1. Iniciar con la definición del objeto y propósito, y mantener este enfoque.

2. Formar un comité estratégico para elaborar la estrategia de diálogo a partir del objeto y propósito. Este comité estará integrado por representantes de todas las comunidades incluidas en el diálogo, para asegurar legitimidad. Se debe evitar que en este comité se impongan las agendas de sus integrantes en la definición de la agenda del diálogo.

3. Integrar un equipo operativo que ejecute las propuestas del comité estratégico. El equipo operativo debe estar conformado por líderes, promotores, facilitadores, gestores y expertos. Debe estar informado, conocer el medio en el que se desarrolla el diálogo y contar con capacidades metodológicas para la facilitación de procesos de diálogo. Este será responsable del diseño, implementación y seguimiento de los resultados del proceso de diálogo. 
4. Definir a los destinatarios de los resultados.

5. Seleccionar la técnica de diálogo (ver anexo 2), de acuerdo a la temporalidad del proceso.

6. Diseñar la convocatoria del proceso de diálogo:

- Definir quiénes son los convocantes más idóneos, tomando en cuenta criterios como legitimidad y conocimiento técnico;

- Diseñar el contenido y la agenda de la convocatoria de acuerdo a los actores seleccionados.

7. Proponer productos/resultados consistentes con la técnica de diálogo que se seleccione (recomendaciones, acuerdos, consensos, abrir canales). Estos productos/resultados se pueden plantear en dos niveles: (i) el resultado directo del diálogo (por ejemplo, recomendaciones para la política), y (ii) el impacto que tienen esos resultados en las políticas de CTI (por ejemplo, rediseño de un programa).

8. El diseño debe incluir un conjunto de mecanismos:

- De documentación de la información del diálogo: para lograr la legitimidad del proceso;

- De monitoreo y evaluación de las fases del proceso de diálogo (particularmente, participación activa de los actores, legitimidad, apego al objeto y propósito, obtención de resultados): para generar procesos de aprendizajes conjuntos entre las comunidades que lleven a la articulación de las capacidades necesarias para el proceso de diálogo.

9. El diseño debe ser flexible para poder adaptarse a la evolución del diálogo e introducir cambios sin que se pierda la esencia del proceso.

\section{FASE 4: IMPLEMENTACIÓN DEL PROCESO DE DIÁLOGO}

La implementación del proceso de diálogo se organiza en un conjunto de pasos:

1. Implementación de la convocatoria:

- Determinar el medio de convocatoria: correos, llamadas, visitas, medios de prensa, etc.;

- Definir el lugar idóneo donde se realizará el diálogo con criterios que favorezcan la participación de los actores (por ejemplo, confianza, confort, accesibilidad, lugar, etcétera). 
2. Facilitación y gestión del proceso de diálogo:

- Registrar los acuerdos (en textos y videos), sistematizar la información a partir de los mecanismos de documentación seleccionados y construir una memoria;

- Informar a los actores acerca de los acuerdos o arreglos de manera regular y pedir validación de los registros por parte de cada actor;

- Definir estrategias de comunicación diferenciada por actor/ comunidad;

- Asegurar las condiciones para la operación eficiente de la técnica de diálogo, y cambiar las dinámicas y el tiempo de participación en función de la evolución del diálogo;

- Identificar liderazgos y roles de los actores que participan;

- Prestar especial atención a los mecanismos de construcción de legitimidad y de generación de consensos;

- Desarrollar los mecanismos diseñados para fomentar el aprendizaje entre los actores.

3. Monitoreo, evaluación y aprendizaje del proceso de diálogo:

- Aplicar regularmente mecanismos de monitoreo;

- Realizar las evaluaciones diseñadas;

- Identificar la emergencia de algún actor interesado en darle seguimiento al proceso;

- Incorporar los aprendizajes permanentes de la implementación al diseño.

\section{FASE 5 - SEGUIMIENTO DE LOS RESULTADOS DEL PROCESO DE DIÁLOGO Y VALORACIÓN DE SUS IMPACTOS}

- Sistematización del conjunto de resultados:

- Elaborar recomendaciones;

- De acuerdo al propósito, comunicar los resultados a las instituciones capaces de implementar las recomendaciones, o construir arreglos entre instituciones relacionadas para poder implementar las recomendaciones.

- Seguimiento a las recomendaciones:

- Colaborar con el actor interesado en darle seguimiento, y 
brindarle la información necesaria para la tarea. El interés en dar seguimiento a las recomendaciones tiende a ser mayor en los diálogos bottom-up;

- Diseñar un plan de acciones de seguimiento para generar impacto más allá del solo diálogo. En dicho plan de acción se debe dejar claro el trabajo, los pasos y los liderazgos necesarios para llevarlo a cabo.

- Valoración de sus impactos:

- Solicitar a los destinatarios un informe de las acciones emprendidas respecto a las recomendaciones entregadas en un plazo acordado;

- Identificar y documentar otros resultados del proceso (por ejemplo, empoderamiento de comunidades o de actores específicos, difusión de las ideas y su internalización por parte de los actores, aprendizajes, emergencia de diálogos colaterales, etcétera).

- Comunicación de los resultados a las comunidades:

- Informar a los participantes del diálogo y más ampliamente a las comunidades interesadas el conjunto de resultados y los impactos logrados, así como las responsabilidades respecto al seguimiento de los resultados.

- Aprendizajes del proceso de diálogo:

- Extraer las lecciones aprendidas de todo el proceso de diálogo (qué se hizo bien y qué se podría mejorar).

\section{LECCIONES APRENDIDAS DE LOS PROCESOS DE DIÁLOGOS: QUÉ HACER Y QUÉ NO HACER}

\section{IDENTIFICACIÓN DE UNA NECESIDAD, UNA DEMANDA O UN PROBLE- MA Y DEFINICIÓN DEL PROPÓSITO DEL PROCESO DE DIÁLOGO}

- Promover diálogos genuinos y en lo posible vinculantes, y evitar realizar diálogos que tengan por objetivo convalidar decisiones ya tomadas, de manera de salvaguardar la credibilidad de la herramienta;

- Analizar previamente la evidencia existente de otras experiencias análogas en relación a su contexto particular;

- Evitar la generación de falsas expectativas en los actores y comunidades respecto a los resultados que se pueden alcanzar con un diálogo. 


\section{IDENTIFICACIÓN Y SELECCIÓN DE ACTORES Y COMUNIDADES}

- Los actores y las comunidades que integran los procesos de diálogo poseen diversas características que pueden acentuar las relaciones asimétricas de poder durante el desarrollo del diálogo. Tener en cuenta las capacidades de cada uno de los actores involucrados en el diálogo resulta fundamental para generar estrategias que permitan disminuir estas asimetrías y poder llevar adelante un proceso de aprendizaje e interacción fluido.

- Todos los actores relevantes deben estar convocados. Se debe buscar internalizar los eventuales conflictos en torno al propósito del diálogo que puedan emerger, para poder trabajar sobre ellos, de manera de que no atenten contra los acuerdos que se alcancen en el proceso.

- Las comunidades pueden preceder al diálogo, pero también pueden conformarse como emergentes del mismo. Ante la inexistencia de alguna comunidad relevante, es recomendable para el desarrollo del diálogo y en particular para el seguimiento de los resultados, que se fije como objetivo del proceso aportar a la conformación y/o consolidación de la comunidad de que se trate.

\section{DISEÑO DEL PROCESO DE DIÁLOGO}

- Diferenciar entre los convocantes, el comité estratégico y el equipo operativo, y definir desde el inicio sus roles e interacción de manera precisa.

- En cuanto a la dimensión temporal, se recomienda:

- Plantearse objetivos realistas en términos de los plazos de desarrollo del proceso de diálogo y de obtención de los resultados esperados;

- Monitorear el proceso de diálogo para hacer los ajustes necesarios de acuerdo a lo planeado;

- Manejar la intensidad de las interacciones en el tiempo, en función del desarrollo del diálogo.

- Es posible que las comunidades evolucionen durante y después de finalizar el proceso de diálogo, avanzando hacia perfiles específicos o demandas específicas. De la misma forma, el objeto del diálogo puede cambiar y evolucionar. Dependiendo de la duración del proceso de diálogo, particularmente cuando se definen como de largo plazo, puede ser necesario rediseñarlo o contemplar la necesidad de iniciar un nuevo proceso. 
- Cabe anticipar que el proceso de diálogo es dinámico, y se pueden integrar a nuevas comunidades y/o distintos actores a lo largo del proceso. También puedan ocurrir cambios en los roles de liderazgo e incluso a la reducción de las asimetrías de poder.

\section{IMPLEMENTACIÓN DEL PROCESO DE DIÁLOGO}

- Reconocer la falta de un lenguaje común entre las comunidades involucradas y tomar tempranamente acciones específicas. La capacidad de traducción de los facilitadores es muy importante en este proceso para superar la barrera del lenguaje y crear códigos comunes.

- Buscar armonía/equilibrio entre el/los facilitador/es, el equipo operativo, y el comité estratégico, para lograr articulación entre ellos.

- Es importante conocer la agenda propia del facilitador y evitar que esta se sobreponga a las propuestas que emergen de las comunidades.

- Se debe prestar atención a la distribución de la participación durante el diálogo, y evitar que los actores/comunidades con mayores capacidades relevantes para el propósito del diálogo, con lenguaje similar a los convocantes y facilitadores o, en general, con un diferencial en cuanto a recursos de poder, monopolicen la palabra y hagan primar sus visiones en la construcción de los acuerdos, capturando de esta manera al diálogo.

- Es fundamental arribar a compromisos precisos, validados por todos los participantes, y cuyo cumplimiento sea mensurable en alguna medida para poder dar lugar al seguimiento.

\section{SEGUIMIENTO DE LOS RESULTADOS DEL PROCESO DE DIÁLOGO Y VA- LORACIÓN DE SUS IMPACTOS}

- Existe el riesgo de que el seguimiento esté enfocado a los intereses de los actores que asumen esta responsabilidad, en lugar de estar enfocado en los resultados del diálogo. 



\section{ANEXO 1 GLOSARIO}

- Actores: personas, grupos de personas, o entidades asociativas que emergen de las comunidades y que juegan un papel de representación en los procesos de diálogo de CTI.

- Capacidades: representan el conocimiento específico de actores y comunidades, son adquiridas a través de experiencias y aprendizajes individuales o colectivos y se acumulan a través del tiempo. Entre las capacidades de las comunidades que son relevantes para un proceso de diálogo destacan, entre otras, las siguientes: cognitivas, habilidad para identificar y resolver problemas, disposición a vincularse en redes, generadoras de confianza, para compartir conocimiento, para el aprendizaje conjunto, de coordinación y de liderazgo.

- Comunidades de CTI: son aquellas entidades colectivas basadas, por un lado, en esos procesos de socialización y formación de redes y, por el otro, en la necesidad de los agentes de participar en las políticas intra e interorganizacionales, con particular fuerza en aquellas donde intervienen organizaciones de instancias gubernamentales. El proceso de constitución de comunidades supone no solo la suma de las voluntades de las personas sino la formación de algunos rasgos volitivos de 
la comunidad misma que sus miembros reconocen como extensiones e intensificaciones de los que ellos mismos ostentan.

- Destinatarios: también llamados "partes interesadas" (stakeholders), son aquellos que pueden verse afectados por las decisiones que toma el gobierno en materia de políticas de CTI.

- Dimensiones del proceso de diálogo de CTI: son un marco de análisis diseñado para posibilitar el estudio de procesos de diálogo de CTI. Fueron generadas con dos funciones: (i) entender cómo los actores interactúan y se comunican para definir, en sus intercambios, una acción colectiva; y (ii) identificar fallas, trabas, y obstáculos que se presentan para arribar a un resultado.

- Procesos de diálogo: los procesos de diálogo relativos a las políticas públicas de CTI son, al igual que los del diálogo democrático, auténticos ejercicios de interacción y conflicto. En ellos cada uno de los participantes aprende e internaliza argumentos de los demás sosteniendo su identidad y está ubicado, desde la perspectiva comunicativa, en una posición resultante del poder o de las capacidades que tiene. Los participantes son actores que emergen de distintas comunidades de agentes de las actividades de CTI. Tienen, por lo tanto, una relación de representación con su comunidad y, a su vez, pertenecen a organizaciones académicas, productivas, gubernamentales o de la sociedad civil que los dotan de diferentes grados de poder y de distintas capacidades. 


\section{ANEXO 2* \\ REVISIÓN DE METODOLOGÍA DE MAPEO DE ACTORES ${ }^{1}$}

\section{INTRODUCCIÓN}

El presente documento ofrece un panorama de métodos utilizados para la identificación de actores, especialmente cuando se realizan acciones de cooperación para el desarrollo. Estas metodologías pueden ser utilizadas y adaptadas para la implementación de diálogos para el diseño de políticas públicas de ciencia, tecnología e innovación

La Matriz 1 ofrece una descripción de las metodologías mencionadas. Muchas veces la identificación de actores se puede reducir al simple uso de una herramienta de mapeo. Sin embargo, es importante entenderla también en el marco de métodos más complejos de trabajo con comunidades. Por esta razón la Matriz 1 ofrece información de contexto que permite ubicar el mapeo de actores dentro de enfoques metodológicos propuestos por distintas organizaciones que han estudiado el tema.

1 Elaborado por Carlos Mauricio Nupia. 
Matriz 1. Metodologías para la Identificación de Actores

\begin{tabular}{|c|c|c|c|}
\hline Metodología & Contexto & Principales caracteristicas & Referencia \\
\hline $\begin{array}{l}\text { Mapa de Actores } \\
\text {-Capacity } \\
\text { Works - Agencia } \\
\text { de Cooperación } \\
\text { Internacional de } \\
\text { Alemania (GIZ) }\end{array}$ & $\begin{array}{l}\text { Capacity Works es un } \\
\text { modelo de gestión para } \\
\text { el desarrollo sostenible } \\
\text { desarrollado por GIZ. Sirve } \\
\text { para diseñar cooperaciones, } \\
\text { independientemente de las } \\
\text { diferencias que existen entre } \\
\text { distintos paises, culturas y } \\
\text { sectores en los que se llevan } \\
\text { a cabo las actividades de } \\
\text { cooperación internacional. } \\
\text { El modelo ha desarrollado } \\
\text { una caja de herramientas } \\
\text { para cinco factores de éxito } \\
\text { que le dan forma: estrategia, } \\
\text { cooperación, conducción } \\
\text { procesos y aprendizaje e } \\
\text { innovación. Dentro de las } \\
\text { herramientas del factor } \\
\text { de éxito denominado } \\
\text { "Cooperación" aparece una } \\
\text { herramienta denominada } \\
\text { "Mapa de Actores" que } \\
\text { se aplica en situaciones } \\
\text { en la que es importante } \\
\text { hacerse a una idea de los } \\
\text { actores involucrados y se las } \\
\text { actividades que desarrollan a } \\
\text { lo largo del tiempo }\end{array}$ & $\begin{array}{l}\text { Analiza a los actores dentro de un } \\
\text { sistema de proyectos de cooperación } \\
\text { Se compone de seis pasos: } \\
\text { formulación de pregunta clave; } \\
\text { identificación de actores; selección de } \\
\text { forma de visualización; visualización } \\
\text { de actores; visualización de } \\
\text { relaciones entre actores; evaluación } \\
\text { de los resultados } \\
\text { Utiliza dos técnicas de visualización } \\
\text { de actores: tipo "cebolla" y tipo } \\
\text { "arco iris" } \\
\text { Inicia con la formulación de preguntas } \\
\text { clave sobre el mapa de actores } \\
\text { Enfatiza en la visualización de las } \\
\text { relaciones entre actores mediante } \\
\text { símbolos y convenciones } \\
\text { Finaliza con la evaluación de } \\
\text { resultados según las preguntas } \\
\text { formuladas inicialmente }\end{array}$ & $\begin{array}{l}\text { Capacity WORKS. El modelo } \\
\text { de gestión de la GIZ para el } \\
\text { desarrollo sostenible } \\
\text { En <http://www.gizprevenir. } \\
\text { com/documentos/resumen- } \\
\text { de-cw.pdf>. }\end{array}$ \\
\hline $\begin{array}{l}\text { Stakeholder } \\
\text { Analysis (SA) }\end{array}$ & $\begin{array}{l}\text { SA es un proceso de } \\
\text { recolección sistemática } \\
\text { y análisis cualitativo de } \\
\text { información para determinar } \\
\text { qué tipo de intereses deben } \\
\text { tomarse en cuenta cuando } \\
\text { se desarrolla o implementa } \\
\text { una política o un programa. } \\
\text { Los "stakeholders" } \\
\text { son actores (persona u } \\
\text { organizaciones) con un } \\
\text { interés definido para que una } \\
\text { política sea promovida. }\end{array}$ & $\begin{array}{l}\text { El análisis tiene en cuenta } \\
\text { características de los actores como } \\
\text { el conocimiento que tienen sobre } \\
\text { una política específica, sus intereses } \\
\text { en relación con dicha política, el } \\
\text { potencial de alianzas con otros } \\
\text { actores y la habilidad que tienen para } \\
\text { afectar el proceso de política (poder } \\
\text { y liderazgo) } \\
\text { El SA se compone de } 8 \text { pasos: } \\
\text { planeación del proceso, selección } \\
\text { y definición de una política, } \\
\text { identificación de actores claves, } \\
\text { adopción de herramientas, } \\
\text { recolección y grabación de } \\
\text { información, diligenciamiento de la } \\
\text { tabla de actores, análisis de la tabla } \\
\text { de actores y uso de información }\end{array}$ & $\begin{array}{l}\text { Schmeer, K. } 1999 \\
\text { "Stakeholder Analysis } \\
\text { Guidelines" en Policy Toolkit } \\
\text { for Strengthening Health } \\
\text { Sector Reform (Bethesda: } \\
\text { Abt Associates). } \\
\text { En <http://www.who.int/ } \\
\text { workforcealliance/knowledge/ } \\
\text { toolkit/33.pdf>. }\end{array}$ \\
\hline
\end{tabular}




\begin{tabular}{|c|c|c|c|}
\hline Metodología & Contexto & Principales características & Referencia \\
\hline $\begin{array}{l}\text { Stakeholder } \\
\text { Engagement }\end{array}$ & $\begin{array}{l}\text { SE es la creación de } \\
\text { relaciones internas y } \\
\text { externas entre individuos y } \\
\text { grupos, en los niveles local, } \\
\text { nacional e internacional, } \\
\text { con el fin de asegurar la } \\
\text { cooperación y alinear los } \\
\text { intereses de las partes. } \\
\text { El método se compone de } \\
\text { siete pasos que definen } \\
\text { el curso de acción para } \\
\text { comprometer a los } \\
\text { actores en un proyecto o } \\
\text { programa (por ejemplo se } \\
\text { utiliza especialmente en } \\
\text { investigación relacionada } \\
\text { con ensayos clínicos de VIH). } \\
\text { El quinto paso se denomina } \\
\text { identificación y descripción } \\
\text { de stakeholders. }\end{array}$ & $\begin{array}{l}\text { El paso } 5 \text { del método provee una } \\
\text { lista de tareas que orientan cómo } \\
\text { identificar organizaciones e individuos } \\
\text { relevantes para un proyecto } \\
\text { específico: } \\
\text { Lluvia de ideas con gente cercana. } \\
\text { Desarrollar descripciones de los } \\
\text { actores. } \\
\text { Refinar la lista de actores. } \\
\text { Crear bases de datos electrónicas. } \\
\text { Aproximación a los individuos y } \\
\text { organizaciones identificados. } \\
\text { Entrevistas y notas informativas sobre } \\
\text { los actores. } \\
\text { Obtener referencias de otros actores } \\
\text { (bola de nieve). } \\
\text { Clasificación de actores según tipo o } \\
\text { grupos. }\end{array}$ & $\begin{array}{l}\text { MacQueen, K. et al. } 2012 \\
\text { Stakeholder Engagement } \\
\text { Toolkit for HIV Prevention } \\
\text { Trials. FHI } 360 \text { (Durham: } \\
\text { FHI 360). } \\
\text { En <http://www.fhi360. } \\
\text { org/sites/defaultfiles/ } \\
\text { webpages/se-toolkit/SE__ } \\
\text { Toolkit_and_Steps_PDF_files/ } \\
\text { Stakeholder_Engagement_ } \\
\text { Toolkit-Step_5.pdf>. }\end{array}$ \\
\hline $\begin{array}{l}\text { MACTOR: Matriz } \\
\text { de Alianzas } \\
\text { y Conflictos: } \\
\text { Tácticas, } \\
\text { Objetivos y } \\
\text { Recomendaciones }\end{array}$ & $\begin{array}{l}\text { Método de análisis de juego } \\
\text { de actores que busca valorar } \\
\text { las relaciones de fuerza } \\
\text { entre los actores y estudiar } \\
\text { sus convergencias y } \\
\text { divergencias con respecto a } \\
\text { un cierto } \\
\text { número de posturas y de } \\
\text { objetivos asociados. }\end{array}$ & $\begin{array}{l}\text { Es un método que se basa en el } \\
\text { relacionamiento de los intereses de } \\
\text { los actores mediante la identificación } \\
\text { de sus objetivos. } \\
\text { Busca calibrar la posición de la } \\
\text { fuerza de cada actor en el sistema } \\
\text { y posicionarlos frente a los objetivos } \\
\text { que se proponen para conocer } \\
\text { posibilidades de conflictos o alianzas. } \\
\text { El método se compone de siete } \\
\text { fases: } 1 \text {. construcción del cuadro } \\
\text { de "estrategias de los actores"; } 2 \text {. } \\
\text { identificación de retos estratégicos } \\
\text { y objetivos asociados; } 3 \text { situación } \\
\text { de cada actor en relación con los } \\
\text { objetivos estratégicos (matriz de } \\
\text { posiciones); } 4 \text {. jerarquización de } \\
\text { actores según sus prioridades de } \\
\text { objetivos (matriz de posiciones } \\
\text { evaluadas); } 5 \text {. evaluación de las } \\
\text { relaciones de fuerza de los actores; } \\
6 \text {. Integración de relaciones de fuerza } \\
\text { en el análisis de convergencias } \\
\text { y divergencias entre actores; } 7 . \\
\text { Formulación de recomendaciones } \\
\text { estratégicas y preguntas clave de } \\
\text { futuro. }\end{array}$ & $\begin{array}{l}\text { Godet, M. } 2007 \text { "Prospectiva } \\
\text { Estratégica: problemas y } \\
\text { métodos" En Cuadernos } \\
\text { de LIPSOR (Laboratoire } \\
\text { d'Investigation Prospective et } \\
\text { Stratégique) NNo 20. } \\
\text { En <http://archivo.cepal. } \\
\text { org/pdfs/GuiaProspectiva/ } \\
\text { Godet2007.pdf>. }\end{array}$ \\
\hline
\end{tabular}




\begin{tabular}{|c|c|c|c|}
\hline Metodología & Contexto & Principales características & Referencia \\
\hline $\begin{array}{l}\text { Local Systems } \\
\text { for Sustained } \\
\text { Development } \\
\text { - Agencia de } \\
\text { Cooperación } \\
\text { Internacional de } \\
\text { Estados Unidos } \\
\text { (USAID) }\end{array}$ & $\begin{array}{l}\text { Es el método utilizado por } \\
\text { la USAID para implementar } \\
\text { proyectos de desarrollo } \\
\text { sostenible. Se fundamenta } \\
\text { en el hecho de que el } \\
\text { desarrollo se logra a partir } \\
\text { de las contribuciones de } \\
\text { múltiples actores que se } \\
\text { encuentran interconectados. } \\
\text { La visión de sistema } \\
\text { permite apreciar a los } \\
\text { actores como una entidad } \\
\text { global en relación con } \\
\text { sus interrelaciones y los } \\
\text { incentivos que los guían. }\end{array}$ & $\begin{array}{l}\text { La metodología define } 10 \text { principios } \\
\text { que guían el pensamiento sistémico } \\
\text { para comprometer a los actores } \\
\text { locales en acciones sostenibles. } \\
\text { El principio número } 5 \text { se refiere } \\
\text { al mapeo de los sistemas locales, } \\
\text { cuyo objetivo es filtrar las distintas } \\
\text { perspectivas de los actores de un } \\
\text { sistema. } \\
\text { La herramienta utilizada para } \\
\text { este mapeo se denomina "5R" } \\
\text { (resources, roles, relationships, } \\
\text { rules y results), la cual permite } \\
\text { analizar a los actores dentro de un } \\
\text { sistema y su dinámica de múltiples } \\
\text { intervenciones }\end{array}$ & $\begin{array}{l}\text { USAID } 2014 \text { Local } \\
\text { Systems: A Framework } \\
\text { for Supporting Sustained } \\
\text { Development (Washington } \\
\text { D. C.). } \\
\text { En <https://www. } \\
\text { usaid.gov/sites/default/ } \\
\text { files/documents/1870/ } \\
\text { LocalSystemsFramework. } \\
\text { pdf>. }\end{array}$ \\
\hline $\begin{array}{l}\text { Stakeholder } \\
\text { Identification and } \\
\text { Analysis - The } \\
\text { World Bank }\end{array}$ & $\begin{array}{l}\text { Es la aplicación de } \\
\text { las metodologías de } \\
\text { stakeholder analysis } \\
\text { desde la perspectiva del } \\
\text { Banco Mundial. Consiste } \\
\text { en una mirada profunda } \\
\text { a los grupos de intereses, } \\
\text { cómo dichos grupos serán } \\
\text { afectados y qué influencia } \\
\text { podrían tener con una } \\
\text { intervención de desarrollo } \\
\text { (proyecto o programa). }\end{array}$ & $\begin{array}{l}\text { La metodología consta de nueve } \\
\text { pasos que van más allá del simple } \\
\text { mapeo de actores: } \\
\text { identificación de actores que afectan } \\
\text { directa e indirectamente al proyecto. } \\
\text { identificación de los intereses de los } \\
\text { actores. } \\
\text { priorización de actores para la } \\
\text { intervención. } \\
\text { Uso de la información provista por los } \\
\text { actores y consulta a los mismos. } \\
\text { Levantamiento de fichas técnicas } \\
\text { enfocadas en los grupos de actores } \\
\text { más vulnerables. } \\
\text { Verificación de la representatividad de } \\
\text { los actores. } \\
\text { Compromiso con los actores en sus } \\
\text { propias comunidades. } \\
\text { Consideración del gobierno como } \\
\text { un actor. } \\
\text { ONG como actores representativos. } \\
\text { Reconocimiento de la comunidad } \\
\text { como canal de comunicación. }\end{array}$ & $\begin{array}{l}\text { Stakeholder Identification } \\
\text { and Analysis. World Bank } \\
\text { En <https://commdev. } \\
\text { org/userfiles/Part0ne_- } \\
\text { Stakeholderldentification_0. } \\
\text { pdf>. }\end{array}$ \\
\hline
\end{tabular}




\begin{tabular}{|c|c|c|c|}
\hline Metodología & Contexto & Principales características & Referencia \\
\hline $\begin{array}{l}\text { Enfoque de Marco } \\
\text { Lógico - EML }\end{array}$ & $\begin{array}{l}\text { El EML es una de las } \\
\text { metodologías más utilizadas } \\
\text { para el diseño y formulación } \\
\text { de proyectos de cooperación } \\
\text { para el desarrollo. El EML } \\
\text { contribuye } \\
\text { eficazmente a integrar y } \\
\text { darle coherencia a todas las } \\
\text { partes o involucrados en el } \\
\text { proceso de } \\
\text { programación y } \\
\text { administración de la } \\
\text { inversión. }\end{array}$ & $\begin{array}{l}\text { Una de las fases del EML consiste en } \\
\text { el análisis de la participación. Esta } \\
\text { es una especie de diagnóstico social } \\
\text { que permite identificar personas } \\
\text { susceptibles de ser beneficiadas por } \\
\text { la acción del proyecto que se intenta } \\
\text { implementar. } \\
\text { Los objetivos del análisis de } \\
\text { participación son: } \\
\text { Conocer todos los implicados del } \\
\text { proyecto } \\
\text { Desarrollar una imagen global de los } \\
\text { mismos } \\
\text { Análisis sus intereses, expectativas, } \\
\text { problemas y puntos de vista } \\
\text { Identificar conflictos existentes y } \\
\text { prever conflictos futuros } \\
\text { Identificar implicados cuyos } \\
\text { problemas serán priorizados }\end{array}$ & $\begin{array}{l}\text { Ortegón E.; Pacheco J.; } \\
\text { Prieto A. } 2005 \text { Metodología } \\
\text { del marco lógico para la } \\
\text { planificación, el seguimiento } \\
\text { y la evaluación de proyectos } \\
\text { y programas (CEPAL) Serie } \\
\text { Manuales. } \\
\text { En <http://repositorio. } \\
\text { cepal.org/bitstream// } \\
\text { handle/11362/5607/ } \\
\text { S057518_es.pdf>. } \\
\text { Ferrero, G.; de Loma-0sorio, } \\
\text { G. (eds.) 2008 Identificación } \\
\text { y formulación de proyectos } \\
\text { de cooperación para el } \\
\text { desarrollo: gestión del ciclo } \\
\text { del proyecto y enfoque de } \\
\text { marco lógico. Cuadernos } \\
\text { de Cooperación (Valencia: } \\
\text { Editorial de la Universidad } \\
\text { Politécnica de Valencia). } \\
\text { En <http://www.upv.es/upl/ } \\
\text { U0566379.pdf>. }\end{array}$ \\
\hline
\end{tabular}





\section{PROCESOS DE DIÁLOGOS PARA EL DISEÑO DE POLÍTICAS DE CTI DE ALCANCE NACIONAL}





\section{DIÁLOGOS DE CIENCIA, TECNOLOGÍA E INNOVACIÓN EN LA REPÚBLICA DOMINICANA}

\section{ANÁLISIS DE SU IMPACTO Y REPERCUSIONES EN POLÍTICAS PÚBLICAS}

Víctor Gómez-Valenzuela y Leonie Zapata*

\section{INTRODUCCIÓN}

Los diálogos son procesos dinámicos de interacción basada en la comunicación dirigida y la participación, concebidos para facilitar dinámicas de concertación y/o consenso que desde un punto de vista instrumental permiten alcanzar diversos objetivos de acción social, que pueden abarcan desde la mediación y/o resolución de conflictos hasta la construcción de políticas públicas (Fischer \& Gottweis, 2012).

La plasticidad de los procesos de diálogos en buena medida se deriva de la naturaleza comunicativa subyacente a tales dinámicas y por consiguiente para que sean eficaces o lo que es lo mismo, para que se puedan alcanzar los objetivos o resultados esperados, se requieren que concurran condicionantes clave que parten del "reconocimiento mutuo" entre los actores que participan en un dialogo, lo que implica la aceptación implícita o explícita de un conjunto de reglas básicas como la inteligibilidad y la veracidad, entre otras pautas que faciliten la interacción entre los participantes en un diálogo (Díaz Montiel, 2007; Habermas, 2011).

\footnotetext{
* Instituto Tecnológico de Santo Domingo (INTEC)
} 
En otras palabras, para que el diálogo sea efectivo y tenga sentido como un instrumento de gobernabilidad, las partes deben trascender las limitaciones impuestas por sus diferencias para construir un marco de colaboración que parta del reconocimiento mutuo como interlocutores y que se validen los espacios y mecanismos de interacción que sustenten la dinámica del diálogo (Ansell \& Gash, 2008; Dutrenit, Natera, \& Suárez, 2014). Una implicación clave de los proceso de diálogos es la transformación, es decir, en la medida en que determinadas reglas básicas del diálogo son aceptadas por las partes, el desarrollo efectivo del diálogo permite que las partes se acerquen y tal acercamiento puede definirse como un proceso de transformación (Cuentas \& Linares Méndez, 2013; Goñi, Blanco, Andarche, \& Puchet, 2015).

La experiencia de los diálogos en la República Dominicana, como instrumento para facilitar la gobernabilidad no es nueva y ha tenido en el papel mediador de la Iglesia Católica, su máxima expresión (Betances, 2004). La mediación de la Iglesia Católica ha servido tanto para la resolución de conflictos, como para la construcción consensos sobre determinadas políticas.

En el caso de los diálogos de ciencia, tecnología e innovación (CTI), la experiencia tampoco es nueva. En términos de alcance probablemente la experiencia más significativa de un diálogo de CTI en el país, fue la formulación del Plan Estratégico de Ciencia, Tecnología e Innovación 2008-2018, iniciada a mediados del año 2007 y concluida en el mes de octubre del año 2008 (SEESCYT, 2008). En el marco del presente trabajo se pretende analizar el diálogo de políticas de CTI desarrollado del 3 al 4 de septiembre de 2014. El referido diálogo fue convocado por los actores institucionales que integran el Consejo de Innovación y Desarrollo Tecnológico, el cual es presidido por el Ministerio de Educación Superior, Ciencia y Tecnología. Como resultado, se logró que la comunidad pública y la empresarial reconocieran la necesidad de fomentar un marco estructurado de políticas de CTI en la República Dominicana.

En tal sentido, con el presente trabajo se pretende responder a las siguientes preguntas: ¿Cuál ha sido el impacto del diálogo de políticas de CTI acontecido en septiembre de 2014? ¿Cuáles han sido las lecciones aprendidas de la experiencia del referido diálogo? ¿Cómo se puede caracterizar la experiencia de diálogo para la política de CTI de la República Dominicana?

Las preguntas anteriores definen el alcance del presente trabajo, que puede resumirse en términos de un ejercicio de sistematización o recuperación de la experiencia de dialogo de CTI de 2014, que permita avanzar hacia la re-construcción tipológica de dicha experiencia en 
una perspectiva regional (Álvarez et al., 2016). En tanto re-construcción tipológica, el objeto de la misma sería no solo identificar los atributos que permitan establecer una clasificación o tipología de los diálogos de CTI en la región, sino a partir de los casos individuales analizados, utilizar dicha tipología como un herramienta heurística para mejorar la comprensión de la naturaleza e impacto de tales iniciativas (Goñi et al., 2015; Mckinney, 1966; Thomas, 2011).

En el caso dominicano la re-construcción de la experiencia del dialogo de CTI de 2014, permitirá recuperar dicha experiencia como una herramienta de aprendizaje social o lo que es lo mismo, como instrumento para el consenso y/o concertación que faciliten la construcción de políticas basadas en la discusión entre los distintos actores públicos, privados y de la sociedad civil sobre tópicos e intereses comunes en los temas de CTI (Goñi, 2015). Por actores se comprenden las comunidades que participan en la dinámicas y procesos de diálogo, motivadas por los intereses que en determinadas coyunturas políticas pueden ser convergentes o divergentes, o simplemente expresar una situación de confrontación latente o explícita que puede afectar el logro de determinados objetivos de políticas de CTI (Barboza, 2016; Goñi, 2015).

Ciertamente el consenso y la concertación como formatos y esquemas de gobernanza, apuntan a que independientemente del grado de acuerdo o descuerdo en torno a la legitimidad o pertinencia de los resultados de los diálogos de CTI, se espera que al memos los mismos cuenten con una sustentación que los legitime ante la sociedad (Nupia \& Martínez M., 2015; van de Kerkhof, 2006). Por tanto, tal caracterización como caso de estudio puede ser considerada como una re-construcción de la experiencia que permite su síntesis teórica y aprovechamiento heurístico y normativo (Álvarez et al., 2016; Thomas, 2011).

El análisis de los diálogos de CTI no solo se justifica por el interés académico de su sistematización, sino por la necesidad de sentar las bases de un marco de políticas públicas no solo respaldas por el consenso y la concertación como formatos de legitimación pública, sino para asegurar la transparencia y la rendición de cuentas ante la sociedad que tiene que pagar por las medidas y los costes que supone la implementación de las iniciativas de políticas de CTI resultantes de dichos diálogos. En otras palabras, este tipo de ejercicios constituyen un tipo de veeduría académica que además de la intelección de la experiencias de diálogos de CTI, se constituyen en una especie de evidencia para la sociedad de la efectividad de dichos diálogos al menos desde el punto de vista de las expectativas sociales sobre los mimos (Goñi, 2015). 
Finalmente, el presente trabajo se inserta dentro de una iniciativa regional denominada "Red temática para mejorar el diálogo entre las comunidades involucradas en las políticas de CTI (COM-LALICS)", auspiciada por el Programa Iberoamericano de Ciencia y Tecnología para el Desarrollo (CYTED), que precisamente tiene por objeto la sistematización y análisis de las experiencias regionales de diálogos de CTI. En la referida iniciativa se incluyen experiencias de diálogos de CTI de Argentina, Brasil, Chile, Colombia, Costa Rica, Cuba, España, México, Perú, República Dominicana, Uruguay y Venezuela.

El resto de este capítulo se estructura de la siguiente manera. Luego de esta introducción, en la sección 2 se presenta el marco metodológico, a continuación, en la sección 3 , se sintetiza el contexto nacional en el que tiene lugar el diálogo bajo estudio. La sección 4 discute el marco conceptual y seguidamente se presenta el esquema general de políticas CTI en la República Dominicana. La sección 6 consiste en el análisis de la experiencia. En la sección 7 se proveen algunas conclusiones y reflexiones finales.

\section{METODOLOGÍA}

El marco metodológico que sirve de base al presente trabajo, fue el resultado de un proceso construcción colectiva y dialógica entre el conjunto de académicos responsables de la sistematización de las experiencias nacionales que forman parte de la iniciativa COM-LALICS. El marco metodológico concertado se sustentó en dos grandes aproximaciones: la definición del marco conceptual sobre los diálogos de CTI, lo que incluye su sistematización en términos tipológicos, propósitos y alcance (Álvarez et al., 2016; Barboza, 2016; Dutrénit et al., 2017) y luego, la definición de un instrumento de captura de las distintas experiencias objeto de la sistematización (Dutrénit et al., 2016). Como todo proceso de diálogo, las dos aproximaciones no fueron estáticas sino dinámicas, dado que tanto la definición del marco conceptual fue un requerimiento e insumo para el instrumento de captura, como al mismo tiempo la definición del instrumento obligó a revisar el marco conceptual una y otra vez, especialmente en los encuentros y consultas realizadas tanto de manera presencial como por los medios electrónicos. Al final tanto los elementos conceptuales como el instrumento de captura, puede leerse como una sola experiencia narrativa con las discontinuidades que les imprime el proceso de dialogo del que se derivaron, una dinámica propia de instrumentos de construcción de consenso como los diálogos (Thomas, 2011; van de Kerkhof, 2006).

El instrumento de captura tomó la forma de un formulario, que esencialmente permitió reconstruir la experiencia de diálogo y al mismo 
tiempo repensar la misma a la luz de los elementos del marco conceptual (Dutrénit et al., 2016), lo que en cierto sentido implicó algún grado de mutación de la experiencia, es decir, la experiencia re-construida y narrada por medio del formulario no puede asumirse como una versión pura de los diálogos analizados sino como una versión estilizada de los mismos (van de Kerkhof, 2006). El instrumento de captura utilizado muestra la compleja dinámica subyacente al análisis de los procesos de diálogos sociales, especial de los de CTI en los que la construcción de confianza, la gestión de la incertidumbre de corto y mediano plazo constituyen elementos latentes de la trama dialógica (Burgess, 2014). De manera que si bien el presente trabajo en términos generales se sustenta el marco metodológico acordado como parte de la iniciativa COM-LALICS (Nupia \& Martínez, 2015), se ha procurado además un tratamiento que permita visualizar los elementos más realistas de la experiencia dominicana sistematizada o re-construida en este trabajo.

\section{CONTEXTO PAÍS}

La República Dominicana comparte la Isla de la Española con la República de Haití. El país posee una población de alrededor de 10 millones de habitantes y ocupa una superficie de $48,640 \mathrm{~km} 2$, lo que representa aproximadamente 2/3 de la superficie insular (ONE, 2014; PNUD, 2014).

De acuerdo con organismos internacionales la República Dominicana, es definida como una economía de ingreso medio así como la de mayor tamaño relativo de Centro América y el Caribe, con un PIB que en el año 2015 superó los US $\$ 67.1$ billones (World-Bank, 2016). De igual modo y con base en las mismas fuentes, el país ha sido uno de los más rápido crecimiento de América Latina, con un crecimiento promedio anual del 5.4\% entre 1992 y 2014 y con el mayor crecimiento de la región en el año 2015 de un 7\% (Banco-Central, 2016; CEPAL, 2008). En términos de desarrollo humano, desde el año 2014 el país es considerado como de desarrollo humano alto, de acuerdo con el Informe de Desarrollo Humano del Programa de las Naciones Unidas para el Desarrollo (PNUD, 2015).

A pesar de la reconocida dinámica de crecimiento económico experimentado por el país, la economía dominicana no ha sido capaz de reducir la pobreza a la misma velocidad e intensidad con la que ha podido crecer. La población en línea de pobreza en el año 2013 era del $41 \%$ no obstante en los últimos dos años y medio el país ha experimentado una significativa caída de la tasa de pobreza gracias a las mejoras en las políticas de inclusión y a una mejor focalización del gasto social y del gasto en educación, situándose dicha tasa en la actualidad en torno al 30\% (MEPyD, 2014; World-Bank, 2016). 


\section{LOS DIÁLOGOS DE CTI DESDE EL CONCEPTO DE SISTEMA NACIONAL DE INNOVACIÓN}

Los diálogos de políticas de CTI en el contexto regional no son una experiencia reciente. Tal como se indicó, en el caso de la República Dominicana tales experiencias tienen su antecedente histórico inmediato en el proceso de participación que facilitó la construcción del Plan Estratégico de Ciencia, Tecnología e Innovación 2008-2018. No obstante los dialogo relativos a las políticas de CTI en el país pueden rastrearse hasta el denominado "Diálogo Nacional" acontecido en la segunda mitad de los años noventa del siglo XX (Espinal, 2001).

A nivel regional, a lo largo del último lustro (desde el año 2010), llama la atención el papel preponderante del Banco Interamericano de Desarrollo (BID), en la promoción de los diálogos de CTI con un mayor énfasis en la construcción de políticas de innovación para el desarrollo productivo (BID, 2011, 2014, 2016). El énfasis de un organismo multilateral de financiamiento con la reconocida influencia que ejerce el BID en las políticas de desarrollo de la región, es un llamado de atención cuyas raíces pueden ser encontradas en la naturaleza misma de la noción de Sistema Nacional de Innovación (SNI).

Desde el punto de vista del presente análisis, el Sistema Nacional de Innovación puede comprenderse como el arreglo dinámico de instituciones (marco legal, sistemas de incentivos, reglas de juego) y organizaciones (actores públicos, privados, universidades y centros de investigación, entre otros) así como sus interacciones, en torno a la producción y diseminación de conocimiento dentro del sistema económico (Metcalfe, 1994; Metcalfe \& Ramlogan, 2008). El énfasis en la dinámica de las interacciones entre instituciones y actores y luego entre los mismos, de entrada, subraya la naturaleza dialéctica y dialógica de la noción de sistema nacional de innovación.

A partir de la anterior aseveración, el análisis de la experiencia de diálogos de CTI encuentra su sustentación más densa en la noción SNI, que en tanto herramienta heurística parte del análisis de las interacciones sociales, económicas y políticas que pueden explicar los procesos de producción del conocimiento y su relación con el desempeño de una determinada economía (Fagerberg \& Verspagen, 2009). La naturaleza dialéctica y dialógica del concepto viene además marcada por los elementos genéticos compartidos con el enfoque sobre ciencia, tecnología y sociedad o STS por sus siglas en inglés (Science, Technology and Society), derivados del influjo de la teoría fundamentada y la teoría crítica (Shariff, 2006).

La teoría fundamentada le ha aportado a la noción de SNI un enfoque cualitativo que se sustenta en la búsqueda de los elementos teóricos que subyacen en los datos y la teoría fundamentada ha 
contribuido con un enfoque interpretativo de la interacción entre actores y componentes de los sistemas (de la Cuesta, 2006; Lundvall, 2007; Shariff, 2006). Es precisamente en las intenciones entre actores del sistema que el análisis de los diálogos de CTI cobra sentido desde la perspectiva conceptual aportada por la noción de SNI.

Asimismo, un sistema de innovación puede definirse como un "sistema social" (Lundvall, 1992), de carácter "dinámico" debido a que las interacciones que se generan son entre personas, instituciones y organizaciones (perspectiva que corresponde con la influencia de la teoría crítica en la noción de SNI). El objeto de tales interacciones son las dinámicas de producción y gestión del conocimiento. En línea con lo anterior, algunos autores sostienen que las interacciones entre los distintos componentes del sistema y de las instituciones que conforman un SNI pueden condicionar el rendimiento innovador de las organizaciones productivas, especialmente las empresas (Nelson \& Rosenberg, 1993).

La perspectiva anterior sustenta la definición dada al inicio de este apartado, en la que un SNI puede ser comprendido como "un conjunto de instituciones para crear, almacenar y transferir los conocimientos, habilidades y artefactos que definen las oportunidades tecnológicas" (Metcalfe, 1994). Por consiguiente dada la importancia del conocimiento en un SNI, tanto los procesos de aprendizaje como las organizaciones formales de formación e investigación se definen como actores fundamentales de dichos sistemas (Freeman, 1992).

En cuanto a la interacción entre los componentes de un SNI, puede afirmarse que la interacción entre los agentes es la que otorga la forma a las instituciones que conforman un SNI (Malerba, 2002). En un artículo provocador publicado en el año 2002, se argumentó que las instituciones como parte de un SNI, puede definirse como "tecnologías sociales" que permiten la creación de rutinas o "líneas de acción", que facilitan la gobernabilidad y la reducción de los costos de transacción (Nelson \& Nelson, 2002). Dada la importancia de los procesos de aprendizaje así como de las interacciones entre los componentes que integran un SNI, no sería prematuro afirmar que el concepto de SNI puede interpretarse desde la perspectiva de la teoría de la acción comunicativa, una de las modalidades de mayor influencia en el pensamiento filosófico de la teoría crítica contemporánea (Habermas, 2011).

Con arreglo al enfoque de la acción comunicativa, la capacidad de funcionamiento de un SNI estaría condicionada por la calidad de las interfaces comunicativas que vinculan a los distintos actores de un sistema de innovación, de tal suerte que los elementos de una acción comunicativa de calidad vendrían dados por manifestaciones 
particulares de al menos dos de los elementos del diálogo según Habermas (2011): la inteligibilidad y la veracidad. De manera que la emergencia de los diálogos de CTI puede definirse como una suerte de epifenómeno consustancial a la naturaleza dialéctica de los sistemas nacionales de innovación, una cuestión planteada en el capítulo 2 de esta publicación.

El concepto de SNI también ha sido utilizado como un recurso ideológico por representantes de las distintas comunidades que interactúan en el área política de los temas de CTI, especialmente las comunidades académicas y políticas gracias al estatus de "objeto límite" del concepto (Shariff, 2006). La plasticidad del uso del concepto se ha expresado de dos maneras: 1) al utilizarse como contrapeso al dominio de la interpretación neoclásica del desempeño económico y 2) como alternativa política a las recetas neoclásicas de los años noventa del siglo XX, como el denominado "Consenso de Washington" y sus distintas versiones, de gran influencia en América Latina y el Caribe durante el período de reformas estructurales de la primera mitad de los años noventa del siglo XX (Alcorta \& Peres, 1998; Vonortas, 2002). Por consiguiente los esfuerzos de organismos internacionales como el BID para promover los diálogos de CTI y en particular los diálogos de innovación, muestran un cambio de enfoque que les ha permitido ajustar sus agendas programáticas de una manera mucho más efectiva, lo que de alguna manera es un reconocimiento a las ideas relacionadas con el crecimiento endógeno y su relación con las dinámicas de innovación (Acs \& Attila, 2002).

En lo que respecta a la tipologías de diálogos de CTI, y con base en el marco conceptual y metodológico que sustenta la iniciativa regional "Red temática para mejorar el diálogo entre las comunidades involucradas en las políticas de CTI (COM-LALICS)" (ver capítulo 2), se han definido cuatro tipologías de diálogos de CTI: los diálogo reactivos, los propositivos, los enfocados en la detección de demandas y los orientados para la formación de opinión no experta (Álvarez et al., 2016; Goñi et al., 2015). Los diálogos reactivos emergen como una reacción de las comunidades afectadas o implicadas, a determinadas políticas de CTI; los diálogos propositivos se organizan a partir de la necesidad de contribuir con la formulación y/o articulación de determinadas políticas de CTI; por su parte los diálogos para la detección de demandas, tienen un carácter claramente exploratorio que de alguna manera los relaciona con los diálogos propositivos (sin que necesariamente les antecedan) y por último, los diálogos para la formación de opinión se relacionan con proceso de veeduría social y apoderamiento público (Goñi, 2015; Goñi et al., 2015). Tal como se analizará en las secciones siguientes, el diálogo que se re-construye en este capítulo se sitúa 
en un punto intermedio entre un diálogo reactivo y uno propositivo. La convocatoria del diálogo, así como sus atributos formales indican con claridad que dicha experiencia fue el resultado de una reacción positiva de una parte de las comunidades públicas a las propuestas derivadas de iniciativas como el Segundo Congreso de la Industria Dominicana efectuado en el año 2012, entre otras que ocurrieron en el mismo período. Pero también la convocatoria y su desarrollo enfatizaron la necesidad de un marco nacional de políticas de innovación.

Finalmente, la caracterización de un determinado diálogo depende de sus atributos formales, entre los que cabe mencionar: sus objetivos, duración, continuidad, alcance, actores, resultados, evaluación, nivel de seguimiento, entre otras características. No obstante, tal caracterización va más allá de un ejercicio de tipología constructiva y requiere de una intelección más compleja del contexto dialógico en el que discurre la experiencia analizada, en particular por las claves políticas y de gobernanza subyacentes a tales dinámicas (Burgess, 2014). Todo lo cual se discutirá en las secciones siguientes.

\section{LAS POLÍTICAS DE CTI EN LA REPÚBLICA DOMINICANA}

Las políticas de CTI en la República Dominicana en el siglo XXI, se iniciaron formalmente con la promulgación de la Ley 139-01 sobre educación superior, ciencia y tecnología en el año 2001. Ciertamente a lo largo de las tres últimas décadas del siglo XX se generaron iniciativas concretas en materia de políticas de ciencia y tecnología, pero de poca efectividad y alcance. Con anterioridad a dicha ley existieron esfuerzos como el Consejo Nacional de Ciencia y Tecnología creado en 1974, como parte del entonces Secretariado Técnico de la Presidencia. Dicho consejo fue sustituido en 1979 por el Departamento de Ciencia y Tecnología adscrito al referido Secretariado Técnico (Sánchez-Mariñez, 2010). Durante este período el enfoque misional de las políticas tempranas de CTI estuvo vinculado con el desarrollo de capacidades tecnológicas de apoyo a las políticas de industrialización, propias del modelo de sustitución de importaciones extendido por América Latina y el Caribe desde finales de los años sesenta el siglo XX (Alcorta \& Peres, 1998).

Durante el mismo período y hasta mediados de los años ochenta del siglo XX, el Ministerio de Agricultura de la República Dominicana, jugó un papel relevante en la promoción de iniciativas de investigación y transferencia tecnológica del sector agropecuario, pero no fueron parte de una política integral de CTI. Desde la perspectiva del Ministerio de Agricultura el enfoque misional fue garantizar la seguridad agroalimentaria del país, un período dominado por los esfuerzos globales y regionales de Investigación y Desarrollo de la denominada 
"Revolución Verde" que estimuló el desarrollo y la adopción de cultivos de alto rendimiento en los países en desarrollo (Evenson \& Gollin, 2003). El correlato a nivel industrial impulsado por el Banco Central de la República Dominicana fue la creación del actualmente desaparecido Instituto Dominicano de Tecnología Industrial (INDOTEC), concebido para la provisión de servicios tecnológicos y el apoyo a los procesos de transferencia tecnológica del sector industrial (SánchezMariñez, 2010). En el año 2005 el INDOTEC fue reconvertido en el Instituto de Innovación en Biotecnología e Industria (IIBI).

Luego de promulgada la Ley 139-01 y a lo largo de la primera década del siglo XXI se generaron iniciativas de alto valor e impacto institucional que permiten explicar la emergencia de los diálogos de políticas de CTI. En la figura 1 se presenta una línea de tiempo para representar los principales hitos del proceso de construcción de las políticas de CTI en la República Dominicana, ordenándolos por su importancia relativa definida en función de las misiones a las que se pueden orientar las políticas de CTI (Gassler, Polt, \& Rammer, 2008). En este caso el ordenamiento parte de la apreciación de los autores.

Figura 1. Desarrollo histórico de las políticas de CTI en la República Dominicana

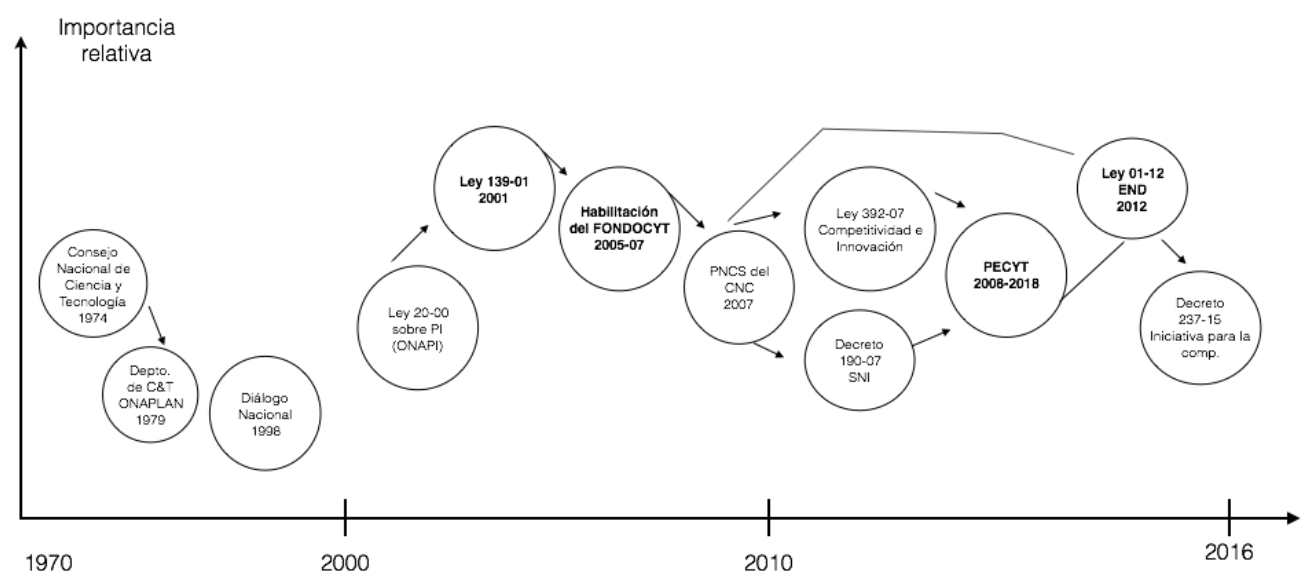

Fuente: elaboración propia.

Dada las limitaciones y alcance de este trabajo aquí se presentan de manera sumaria tres de esos grandes hitos: el lanzamiento del Fondo Nacional de Innovación y Desarrollo Tecnológico (FONDOCYT), el Plan Estratégico de Ciencia, Tecnología e Innovación 2008-2018 referido en la introducción y la Estrategia Nacional de Desarrollo. 


\section{EL FONDOCYT}

El FONDOCYT fue creado mediante la Ley 139-01, como una herramienta de financiamiento de la actividad científica mediante transferencias directas, no obstante, no fue hasta el año 2005 que se realizó la primera convocatoria de proyectos. Esa primera convocatoria se realizó de manera muy elemental mediante un llamado a concurso que incluía líneas de investigación y topes de financiamiento. En esa primera convocatoria se recibieron 29 propuestas y fueron aprobadas 14 , para totalizar un financiamiento de $\mathrm{RD} \$ 16.7$ millones equivalentes a unos US\$ 499 mil. Dos años después, en 2007, inició el proceso de fortalecimiento y reglamentación del FONDOCYT que permitió su consolidación como una herramienta creíble y estable de financiamiento de la actividad científica y tecnológica en la República Dominicana (Ministerio de Educación Superior, Ciencia y Tecnología, 2015).

En la convocatoria del año 2014 se presentaron 145 propuestas de investigación, fueron aprobadas 54 y se facilitó financiamiento por RD\$ 428.7 millones, un monto equivalente a US\$9.7 millones. En otras palabras, la cobertura de financiamiento entre el año 2005 y el 2014 se multiplicó por 19. Hasta el año 2014, se habían financiado unos 256 proyectos de investigación y se había provisto un financiamiento general por $\mathrm{RD} \$ 1,580.5$ millones, lo que equivale a alrededor de US\$ 35.1 millones (MESCYT, 2015). Desde el año 2008 con el lanzamiento del Plan Estratégico de Ciencia y Tecnología e Innovación 2008-2018, proveyó al FONDOCYT de un marco concreto del que se derivan las líneas de investigación y prioridades nacionales de investigación. Es muy probable que el FONDOCYT continúe creciendo durante los próximos años, en la medida en que se consoliden las capacidades nacionales de investigación y transferencia de conocimiento. Dicho crecimiento deberá dar lugar un ritmo más estable en lo que respecta a la cantidad y calidad de las iniciativas objeto de financiamiento.

A este respecto, una de las limitaciones del FONDOCYT ha sido la limitada participación de las empresas en los distintos tipos de proyectos financiados, lo que ha afectado la capacidad de cooperación empresa-universidad y sobre todo la articulación efectiva del sistema de innovación de la República Dominicana (de Groote, 2015; GómezValenzuela, 2014). De hecho la baja capacidad de cooperación entre las empresas dominicanas y las universidades constituye un factor característico del sistema de innovación dominicano, que limita no solo la eficiencia general del sistema, sino también procesos concretos de creación de valor en determinadas actividades y sectores económicos de la manufactura y los servicios (de Groote, 2015). 


\section{EL PLAN ESTRATÉGICO DE CIENCIA, TECNOLOGÍA}

\section{E INNOVACIÓN 2008-2018}

La formulación del "Plan Estratégico de Ciencia, Tecnología e Innovación 2008-2018" (PECYT+I), constituye uno de los hitos relevantes en la historia de las políticas de CTI del país, porque fue el primer marco formalmente construido como un conjunto de políticas explícitamente formuladas para enfocar los desafíos nacionales sobre la materia (Navarro, 2009; UNCTAD, 2012). La formulación del Plan se prolongó por unos 14 meses (iniciando en el último cuarto del año 2007 y concluyendo en octubre del año 2008). El enfoque de la formulación se sustentó una dinámica de diálogo y participación pública de actores gubernamentales, representantes empresariales y determinados actores de la sociedad civil, representantes de las comunidades científicas articuladas alrededor de la Academia de Ciencias de la República Dominicana (OECD, 2012; UNCTAD, 2012). De manera que la génesis de diálogos de CTI en la República Dominicana se encuentra en el proceso público que permitió a la construcción del PECYT+I.

El Plan Estratégico consta de cuatro componentes o ejes de intervención: 1) el fortalecimiento institucional y financiero del sistema nacional de ciencia, tecnología e innovación; 2) el desarrollo de los programas de investigación científica, innovación y transferencia tecnológica; 3) la formación de recursos humanos para la ciencia y la tecnología y 4) un programa de divulgación y apropiación social de la ciencia y la tecnología (SEESCYT, 2008).

Desde el punto del financiamiento de los distintos ejes de políticas de CTI, en el Plan se planteó un inversión global de unos US $\$ 1,450.95$ millones, de los cuales el 38\% corresponden al primer eje de fortalecimiento institucional y financiero; el $40 \%$ al segundo eje sobre programas de investigación; el 14\% al tercer eje sobre formación avanzada en recursos humanos y el restante $8 \%$ al cuarto eje sobre divulgación y apropiación social de la ciencia y la tecnología (SEESCYT, 2008).

Entre las críticas que ha recibido el Plan se encuentran las metas ambiciosas en financiamiento y formación de doctores (unos tres mil doctores al final de los 10 años), así como el bajo impacto en la creación de mercados (UNCTAD, 2012). No obstante, a favor del Plan debe argumentarse que tales metas fueron planteadas con base en un detallado análisis de las condiciones macroeconómicas simuladas durante los 10 años de ejecución del Plan, así como en las capacidades reales de financiamiento del Estado Dominicano (SEESCYT, 2008). A la fecha no se cuenta con los resultados de ningún tipo de evaluación del impacto del Plan Estratégico, una tarea pendiente que tiene que ser enfocada cuanto antes, de tal manera que cualquier estimación de las brechas de logro de las metas del plan debería fundamentarse, en 
el mejor de los casos, en una buena intuición y conocimiento de las condiciones del contexto institucional de la República Dominicana.

En tal sentido si bien es muy probable que no se hayan alcanzado las metas de financiamiento previstas en el Plan durante el período de vigencia del mismo, su mayor logro ha sido sentar las bases de un marco específico de políticas de CTI. En principio puede afirmarse que si las metas de financiamiento no se han alcanzado en la magnitud prevista, no ha sido por un problema de capacidad financiera, sino probablemente por fallas de coordinación a nivel institucional de las políticas de CTI (Magro, Navarro \& Zabala-Iturriagagoitia, 2014). De hecho en el país se han mantenido las condiciones macroeconómicas de crecimiento, con una tasa media de crecimiento del PIB desde el 2008 hasta el 2015 del 5\% (Banco-Central, 2016), la inversión en educación se elevó al 4\% del PIB desde el año 2013 y no se generaron cambios en la administración pública que pudieran afectar la continuidad de las políticas acordadas en el Plan.

¿A caso fue el plan un proceso de dialogo fallido? La respuesta tentativa es que desde el punto de vista de su efecto institucional en el sistema no puede calificarse como un acto fallido, sus avances por modestos o parciales que fueren así lo indican. Por lo demás habría que evaluar las expectativas de los actores que participaron en el dialogo que dio como resultado al Plan, para ver si efectivamente fue un proceso fallido desde la perspectiva de los participantes. Desde el punto de vista de los logros alcanzados y la magnitud de los mismos, los resultados están por verse.

\section{LA ESTRATEGIA NACIONAL DE DESARROLLO}

El proceso de formulación de la Estrategia Nacional de Desarrollo (END), se desarrolló a partir de una dinámica de tipo más consultivo que no puede denominarse como dialogo propiamente dicho. El proceso de formulación tomó alrededor de cuatro años (2006-2010) y concluyó con la promulgación de la Ley 12-01 sobre la Estrategia Nacional de Desarrollo de la República Dominicana (MEPyD, 2016). La END se encuentra articulada en cuatro grandes ejes: 1) el fortalecimiento de las instituciones públicas y la transparencia administrativa del Estado; 2) la cohesión social y la equidad; 3) una economía mucho más articulada e innovadora y 4) el manejo sostenible del medio ambiente (MEPyD, 2011). En este capítulo interesan las consideraciones sobre el tercer eje de la END.

La Comisión Internacional para el Desarrollo Estratégico de la República Dominica (Attali, 2010), elaboró un reporte en el que se destacan las vulnerabilidades de la economía y se sugiere la formulación de una especie de "nuevo contrato social", que estaría sustentado 
en las siguientes iniciativas: 1) "Devolver la confianza en las instituciones"; 2) "Desarrollar servicios públicos de calidad"; 3) "Formar a las futuras generaciones"; 4) "Preparar el país para la competencia internacional"; 5) "Organizar el financiamiento de la Estrategia Nacional de Desarrollo"; 6) "Proteger el medio ambiente y ordenar el territorio" y 7) "Integrar al país en la región y en la competencia internacional" (Attali, 2010).

De igual modo en el denominado "Informe Harvard", se propone una profunda revisión del modelo de crecimiento y se plantea un giro hacia los denominados "sectores transables" de la economía, lo que en sentido general implicaría un nuevo modelo de industrialización basada en la innovación, la transferencia de conocimiento y el fortalecimiento del capital humano, para construir capacidades competitivas de largo plazo (Hausmann et al., 2011).

Los puntos de vistas aportados, tanto por el Informe Attali como por el Informe Harvard, apuntalan la necesidad de avanzar en el fortalecimiento del sistema nacional de innovación, de tal manera que la producción y transferencia de conocimiento constituyan insumos para la creación de valor de manera sustentable.

En el contexto regional las universidades latinoamericanas y caribeñas se están implicando cada vez más en iniciativas conjuntas de producción y transferencia de conocimientos con las empresas y los sectores productivos y se aprecia una tendencia emergente de mayor vinculación, si bien aún queda por superar enormes desafíos (Barro, 2015). En el contexto de los Estados Unidos de Norteamérica, tan solo entre los años 2010 y 2011 el financiamiento a este tipo de actividades se incrementó en un $6.3 \%$ al pasar de US\$ 61.2 billones a US\$ 65.1 billones, incluyendo un mayor número de universidades implicadas en este tipo de dinámicas (Britt, 2012).

Desde la perspectiva anterior, la END abre una ventana de oportunidades para fortalecer el sistema de innovación de la República Dominicana, vinculando de manera más proactiva y productiva a las universidades, con las empresas y con los distintos actores demandantes y oferentes de conocimiento del sector público (Etzkowitz \& Leydesdorff, 2000). En este contexto de políticas la emergencia de las dinámicas dialógicas con respecto a las políticas e iniciativas de CTI es cuanto menos esperable.

\section{LAS POLÍTICAS DE CTI POST PROMULGACIÓN DE LA LEY \\ SOBRE LA ESTRATEGIA NACIONAL DE DESARROLLO}

Desde la promulgación de la Ley 12-01 en enero de 2012, sobre la Estrategia Nacional de Desarrollo, algunos hitos claves marcaron la emergencia de los diálogos de CTI. El primero de ellos fue la realización 
del "Segundo Congreso de la Industria Dominicana", acontecido en abril de 2012 y organizado por la Asociación de Industria de la República Dominicana (Johnson-Laird), el Ministerio de Industria y Comercio, el Consejo Nacional de Competitividad y otras entidades representativas del sector privado dominicano (MIC, 2015).

Dicho congreso estuvo organizado en siete mesas de trabajo: 1) Política Comercial y Exportaciones; 2) Financiamiento para el Desarrollo; 3) Encadenamientos Productivos; 4) Fomento de Empleo Formal; 5) Capital Humano e Investigación + Desarrollo + Innovación; 6) Requerimientos de Infraestructura y Energía y 7) Apoyo Institucional al Sector Manufacturero (MIC, 2015). Al interior de cada una de las mesas interactuaron los representantes de las comunidades del sector público, de los gremios empresariales y los distintos actores gubernamentales relacionados con los tópicos de referencia en cada una de las mesas, es decir las comunidades de interesados en las dinámicas asociadas a los diálogos de CTI (Dutrénit et al., 2014).

Los actores de la mesa 5, al igual que las distintas mesas, generaron una clara dinámica de dialogo consistente en la identificación, discusión y acuerdo sobre determinadas propuestas para la construcción de políticas de CTI, basadas en la idea del consenso previo como reconocimiento de la complejidad y diversidad de actores políticos e institucionales que forman parte de un sistema nacional de innovación (Magro \& Wilson, 2013). Como reacción al conjunto de propuestas generadas en el marco de los trabajos de las distintas mesas, en noviembre de 2012 se instaló una mesa especial de seguimiento a las propuestas del segundo congreso industrial (MIC, 2015).

Algunos meses después del segundo congreso, del 3 al 4 de septiembre de 2014, se realizó el dialogo de políticas de CTI, objeto del presente trabajo, donde se enfatizó el rol de la innovación. Es cierto que en términos formales no fue el primer dialogo de políticas de CTI, pero sí el primero enfocado en políticas de innovación y la primera experiencia de seguimiento al proceso derivado del Segundo Congreso de la Industria Dominicana.

\section{ANÁLISIS DE LA EXPERIENCIA}

En este apartado se sigue en términos generales el proceso de sistematización indicado en el formulario de captura de datos, con la finalidad de reconstruir la experiencia de diálogo de CTI de la República Dominicana, acontecida del 3 al 4 de septiembre de 2014 en la ciudad de Santo Domingo (para un mayor detalle de la documentación del caso ver DT formulario Rep. Dominicana; para un mayor análisis de los aspectos conceptuales y su análisis ver capítulo teórico). La experiencia de diálogo estuvo enfocada en la construcción general para el 
diseño de una política de innovación, siguiendo en términos generales el formato sugerido por organismos como el Banco Interamericano de Desarrollo (BID, 2016). En este primer diálogo participaron unas 58 organizaciones y en el punto de mayor presencia, se registraron alrededor de 120 personas.

\subsection{CONTEXTO}

El diálogo de CTI analizado enfatizó la necesidad de construcción de políticas de innovación, con lo que puede definirse como un diálogo con una clara direccionalidad y propósito político (Álvarez et al., 2016). Se partió del reconocimiento de la necesidad de construcción de espacios que faciliten el encuentro y la comunicación de las empresas, del sector público y de las academias, sobre los tópicos más relevantes de la agenda nacional sobre políticas de innovación. En buena medida este diálogo no solo hereda el legado generado en el proceso de formulación del PECYT+I 2008-2018, sino que además retoma las expectativas generadas en el marco del Segundo Congreso Industrial de la República Dominicana, cuyas implicaciones fueron señaladas anteriormente. Para lograr los objetivos del diálogo, las instituciones miembros del Consejo de Innovación y Desarrollo Tecnológico, se mostraron comprometidas con la divulgación de los resultados obtenidos del diálogo, así como con el despliegue de un esfuerzo sistemático en procura de construir una agenda nacional en materia de políticas de innovación que impacten positivamente en las capacidades competitivas de los sectores productivos de la economía dominicana.

Por consiguiente, el principal reto del proceso de diálogo fue comprender las condiciones requeridas para diseñar una combinación efectiva de políticas que genere las sinergias con otras acciones de gobierno, canalizando recursos para los componentes claves de fomento a la innovación. Otro elemento clave es la identificación de la estructura de gestión adecuada para manejar las políticas de innovación, así como garantizar recursos para la implementación y evaluación de las políticas relacionadas.

\subsection{EL PROCESO DE DIÁLOGO}

Tal como se ha indicado anteriormente, el primer dialogo de políticas de CTI condujo a la formulación del Plan Estratégico de Ciencia Tecnología e Innovación 2008-2018. El dialogo objeto de este análisis se enfocó en planificación del sistema nacional de ciencia, tecnología e innovación. Incluye el fortalecimiento financiero e institucional del sistema. Se construyó consenso entre la comunidad académica, empresarial y pública, pero los medios de comunicación no fueron involucrados. En la República Dominicana, se carece de legislación o normas legales que 
instituya los procesos de diálogos como parte del proceso de construcción de las políticas públicas. No obstante, la experiencia del "Diálogo Nacional" de la segunda mitad de la década de los años noventa del siglo XX, sentó un precedente importante (Espinal, 2001).

\subsection{PROPÓSITO DEL DIÁLOGO Y ALCANCE}

El propósito del diálogo fue fortalecer la capacidad de articulación público-privada en materia de políticas de innovación, permitiendo la definición de una agenda mínima para tal fin, sustentada en los marcos de política existentes. Además, se esperaba que como fruto del diálogo, se pueda dar impulso a los compromisos derivados del Segundo Congreso Industrial Dominicano, celebrado en abril de 2012 y que fueron recogidos en el Decreto 72-14 (MIC, 2015).

El diálogo fue concebido como un proceso de largo plazo, no solo como un espacio para hacer propuestas, sino para que un segundo momento pueda servir como espacio de debate y acompañamiento de las políticas de innovación, así como para generar la confianza y la credibilidad necesarias entre los distintos representantes de las comunidades participantes (Goñi, 2015).

\subsection{COMUNIDADES IDENTIFICADAS}

Se identificaron cuatro grupos de comunidades en interacción: académica, empresarial, del sector público y de la sociedad civil, correspondientes a las distintas categorías identificadas en el marco de la iniciativa de análisis regional sobre diálogos de CTI (Dutrénit et al., 2014). De las aproximadamente 58 organizaciones que participaron en el diálogo, el $29 \%$ correspondió a la comunidad académica, el $45 \%$ a la comunidad empresarial, el 19\% a la comunidad pública y el $7 \%$ a la comunidad de organizaciones de la sociedad civil. En el caso de la comunidad empresarial, se seleccionaron representantes de asociaciones empresariales, economistas y representantes de empresas que han evidenciado interés en innovar. En el caso de la comunidad académica, participaron representantes de áreas de $\mathrm{I}+\mathrm{D}$, de negocios y emprendimiento y principalmente universidades. En lo que respecta a la comunidad pública, se contó con representantes de las instituciones del Consejo de Innovación y Desarrollo Tecnológico y otras relevantes para el proceso de políticas de innovación. Sobre la comunidad civil, no hubo criterios de selección.

\subsubsection{DETALLE DE LAS COMUNIDADES}

En la siguiente tabla se presentan los principales actores del diálogo, concretamente los representantes de las comunidades académica, empresarial y del sector público. 
Tabla 1. Relación de comunidades participantes en el diálogo

\begin{tabular}{|c|c|c|}
\hline $\begin{array}{l}\text { Comunidad de } \\
\text { académica }\end{array}$ & $\begin{array}{l}\text { Comunidad } \\
\text { empresarial }\end{array}$ & $\begin{array}{l}\text { Comunidad del sector } \\
\text { público }\end{array}$ \\
\hline $\begin{array}{l}\text { Instituto Tecnológico de } \\
\text { Santo Domingo (INTEC) }\end{array}$ & $\begin{array}{l}\text { Asociación de Industria } \\
\text { de la República } \\
\text { Dominicana (AIRD) }\end{array}$ & $\begin{array}{l}\text { Banco Central de la } \\
\text { República Dominicana }\end{array}$ \\
\hline $\begin{array}{l}\text { Pontificia Universidad } \\
\text { Católica Madre y Maestra } \\
\text { (PUCMM) }\end{array}$ & $\begin{array}{c}\text { Asociación Dominicana } \\
\text { de Empresas de Zonas } \\
\text { Francas (ADOZONA) }\end{array}$ & Cámara de Diputados \\
\hline $\begin{array}{l}\text { Universidad Autónoma de } \\
\text { Santo Domingo (UASD) }\end{array}$ & $\begin{array}{l}\text { Asociación de Empresas } \\
\text { Industriales de Herrera } \\
\text { y la Provincia de Santo } \\
\text { Domingo (AEIH) }\end{array}$ & $\begin{array}{l}\text { Consejo Nacional de } \\
\text { Competitividad (CNC) }\end{array}$ \\
\hline $\begin{array}{l}\text { Universidad Católica } \\
\text { Tecnológica de Barahona } \\
\text { (UCATEBA) }\end{array}$ & $\begin{array}{c}\text { Asociación de Empresas } \\
\text { de Inversión Extranjera } \\
\text { (ASIEX) }\end{array}$ & $\begin{array}{l}\text { Instituto Dominicano } \\
\text { de Investigaciones } \\
\text { Agropecuarias y } \\
\text { Forestales (IDIAF) }\end{array}$ \\
\hline $\begin{array}{l}\text { Universidad Católica } \\
\text { Tecnológica del Cibao } \\
\text { (UCATECI) }\end{array}$ & $\begin{array}{c}\text { Asociación de Mujeres } \\
\text { Empresarias }\end{array}$ & $\begin{array}{l}\text { Instituto Dominicano } \\
\text { de Telecomunicaciones } \\
\text { (INDOTEL) }\end{array}$ \\
\hline $\begin{array}{c}\text { Universidad Central del } \\
\text { Este (UCE) }\end{array}$ & Canó Industrial & $\begin{array}{c}\text { Ministerio de Economía, } \\
\text { Planificación y } \\
\text { Desarrollo (MEPyD) }\end{array}$ \\
\hline $\begin{array}{l}\text { Universidad Católica } \\
\text { Nordestana (UCNE) }\end{array}$ & $\begin{array}{l}\text { CAPEX (Centro de } \\
\text { capacitación }\end{array}$ & $\begin{array}{l}\text { Ministerio de Educación } \\
\text { Superior, Ciencia y } \\
\text { Tecnología (MESCYT) }\end{array}$ \\
\hline $\begin{array}{l}\text { Universidad APEC } \\
\text { (UNAPEC) }\end{array}$ & CEMEX Dominicana & $\begin{array}{l}\text { Ministerio de Industria y } \\
\text { Comercio (MIC) }\end{array}$ \\
\hline $\begin{array}{l}\text { Universidad Nacional } \\
\text { Evangélica (UNEV) }\end{array}$ & ClusterSoft & $\begin{array}{l}\text { Viceministerio de } \\
\text { Desarrollo Industrial } \\
\text { (MIC) }\end{array}$ \\
\hline $\begin{array}{c}\text { Universidad } \\
\text { Iberoamericana (UNIBE) }\end{array}$ & Coworking.do & $\begin{array}{l}\text { Presidencia de la } \\
\text { República }\end{array}$ \\
\hline $\begin{array}{l}\text { Universidad Instituto } \\
\text { Cultural Dominico } \\
\text { Americano (UNICDA) }\end{array}$ & Deloitte & Prolndustria \\
\hline $\begin{array}{l}\text { Universidad Instituto } \\
\text { Superior de Agricultura } \\
\text { (UNISA) }\end{array}$ & Eaton & \\
\hline $\begin{array}{l}\text { Universidad Nacional } \\
\text { Tecnológica (UNNATEC) }\end{array}$ & $\begin{array}{l}\text { Educa (Acción } \\
\text { Empresarial por la } \\
\text { Educación) }\end{array}$ & \\
\hline
\end{tabular}




\begin{tabular}{|c|c|c|}
\hline $\begin{array}{l}\text { Comunidad de } \\
\text { académica }\end{array}$ & $\begin{array}{l}\text { Comunidad } \\
\text { empresarial }\end{array}$ & $\begin{array}{c}\text { Comunidad del sector } \\
\text { público }\end{array}$ \\
\hline $\begin{array}{l}\text { Universidad Nacional } \\
\text { Pedro Henríquez Ureña } \\
\text { (UNPHU) } \\
\text { Universidad Psicología } \\
\text { Industrial Dominicana } \\
\text { (UPID) } \\
\text { Universidad Tecnológica } \\
\text { de Santiago (UTESA) } \\
\text { Universidad Federico } \\
\text { Henríquez y Carvajal } \\
\text { (UFHEC) }\end{array}$ & $\begin{array}{c}\text { Enlaces (Red de } \\
\text { Inversionistas Ángeles) } \\
\text { ETED (Empresa de } \\
\text { Transmisión Eléctrica } \\
\text { Dominicana) } \\
\text { Grupo Corripio } \\
\text { IMCA (Implementos y } \\
\text { Maquinarias) } \\
\text { INFACA (Industria } \\
\text { Farmacéutica del Caribe) } \\
\text { JMMB Grupo Financiero } \\
\text { Molinos Modernos } \\
\text { NAP del Caribe } \\
\text { RoboTech } \\
\text { Smart Investment } \\
\text { Consulting } \\
\text { Steam Drop } \\
\text { Suprema Qualitas } \\
\text { Tomadachi }\end{array}$ & \\
\hline
\end{tabular}

Fuente: elaboración propia.

Tal como se puede apreciar en la tabla anterior, la comunidad académica estuvo representada por unas 17 universidades del sistema de educación superior de la República Dominicana, las cuales en su conjunto representan entorno al 95\% de la población estudiantil del sistema dominicano de educación superior (MESCYT, 2011). En la tabla también se puede apreciar que la comunidad empresarial estuvo representada por sus gremios más importantes, así como por empresas individuales.

La comunidad de actores públicos estuvo conformada por entidades centralizadas y descentralizadas del gobierno dominicano. Entre las primeras se encuentran los ministerios y entre las segundas, entidades como el INDOTEL, ONAPI y PROINDUSTRIA. La participación de representantes de la Cámara de Diputados (el Congreso de la República Dominicana es bicameral, compuesto por la cámara de Senadores y la de Diputados), constituye un hito importante por sus competencias legislativas (Nupia \& Martínez, 2015). 
Entre los actores de la comunidad civil se pueden mencionar organizaciones como: 1) la Fundación Global, Democracia y Desarrollo (FUNGLODE), 2) Fundación La Trinitaria, 3) el Laboratorio de Innovación Civil, 4) la Fundación CREES (Centro Regional de Estrategias Económicas Sostenibles). La relativa baja cantidad de organizaciones de la comunidad civil participantes en este primer diálogo, puede estar relacionada con el hecho de que en la República Dominicana, a pesar de contar con un conjunto activo e influyente de organizaciones de la sociedad civil, el interés específico en temas de CTI se encuentra en una fase muy emergente entre tales organizaciones (Barboza, 2016).

\subsubsection{DESCRIPCIÓN DEL INVOLUCRAMIENTO DE LAS COMUNIDADES}

Las distintas comunidades mencionadas, se involucraron activamente en el proceso de diálogo, es decir, participaron activamente tanto en las sesiones plenarias como en las mesas de trabajo que se conformaron. De hecho, llamó la atención la activa participación de organizaciones de la sociedad civil, a pesar del relativo bajo grupo de entidades participantes. Las principales inquietudes relativas a la participación, giraron en torno a cuestiones como el fomento de la cultura emprendedora, las políticas y los estímulos a la innovación y los requerimientos para construir una economía basada en el conocimiento, especialmente los tópicos de capital humano y formación avanzada.

\subsection{PRINCIPALES CARACTERÍSTICAS DEL PROCESO DE DIÁLOGO}

El diálogo analizado en este trabajo fue convocado en el marco del denominado "Consejo Nacional de Innovación y Desarrollo Tecnológico", un mecanismo de coordinación inter-institucional creado en virtud del Decreto Presidencial 190-07 y liderado por el Ministerio de Educación Superior, Ciencia y Tecnología. Dicho Consejo fue creado como resultado de la dinámica institucional generada por el Plan Nacional de Competitividad Sistémica, formulado bajo la coordinación del Consejo Nacional de Competitividad (CNC, 2007). Desde su creación en el año 2007, el principal papel del referido Consejo de Innovación fue servir de marco institucional para la formulación del Plan Estratégico de Ciencia, Tecnología e Innovación 2008-2018 (SEESCYT, 2008).

En términos metodológicos, el diálogo partió de la elaboración de un documento o nota conceptual que no solo justificara la realización del diálogo, sino que sirviera como recurso para contextualizar las discusiones, así como las expectativas en términos de resultados (Nupia \& Martínez M., 2015). La actividad se organizó siguiendo un esquema de exposiciones plenarias, paneles de expertos y mesas de trabajo conducidas por un facilitador, seleccionado de cada una de 
las comunidades participantes y de acuerdo con el tema abordado en cada una de las mesas. Las discusiones en las mesas fueron recogidas y sistematizadas y divulgadas posteriormente.

\subsection{PRINCIPALES RETOS DEL PROCESO DE DIÁLOGO}

Uno de los retos principales del proceso de diálogo y que quedó evidenciado durante la realización del mismo, fueron los distintos niveles de capacidades y comprensión entre los miembros de las distintas comunidades representadas sobre el tema de innovación. Entre los expertos que participaron se pudo apreciar un lenguaje común sobre el tema de innovación y las políticas relacionadas, pero en sentido general se evidenció un desconocimiento del tema entre algunos de los actores. Otro reto importante fue el manejo de los intereses en aparente conflicto, derivados de políticas orientadas de manera clientelar y con fuerte sesgo proteccionista, no obstante las interacciones entre las comunidades representadas, transcurrieron de manera cordial (Goñi, 2015). Una evidencia de lo anterior es que los actores participantes defendían los roles tradicionales de las comunidades que representaban.

Otro desafío relacionado con el primer reto enunciado, es la formación de los actores en temas de innovación. Desde el punto de vista del análisis de las políticas de innovación, quedó clara la necesidad de mejorar la comprensión sobre el diseño de instrumentos de políticas como los incentivos a la innovación, así como de los mecanismos de financiamiento, implementación y evaluación de los instrumentos y herramientas. Por último y como parte de los compromisos del diálogo, las discusiones fueron recogidas y sistematizadas y posteriormente distribuidas entre los participantes.

\subsection{PRINCIPALES RESULTADOS E IMPACTOS DEL PROCESO DE DIÁLOGO}

Una de las primeras acciones derivadas de la experiencia de diálogo fue el curso impartido del 3 al 5 de diciembre de 2014 sobre diseño y evaluación de políticas de innovación, dictado por la Universidad de las Naciones Unidas (UNU-MERIT), auspiciado por el Banco Interamericano de Desarrollo y por el Ministerio de Educación Superior, Ciencia y Tecnología. En dicha actividad formativa participaron representantes claves de las comunidades públicas y empresariales que fueron parte de la experiencia de diálogo analizada en este trabajo. Otro de los resultados del diálogo ha sido el reconocimiento de la comunidad pública y empresarial de la necesidad de fomentar un marco de políticas de CTI en la República Dominicana.

En términos de políticas e instrumentos para promover la innovación, uno de los resultados más interesantes de la dinámica del diálogo de CTI fue la habilitación de la Ventanilla de Financiamiento de 
Proyectos de Innovación. Dicha ventanilla estuvo disponible a finales de 2014 y su habilitación fue responsabilidad del Consejo Nacional de Competitividad y del MESCYT. El diálogo le ofreció un gran impulso a dicha iniciativa e indudablemente tanto para la comunidad pública como empresarial, la ventanilla constituyó una oportunidad inmejorable de aprendizaje. Otro resultado posiblemente no tan directo pero derivado de alguna manera del diálogo, fue el Decreto 237-015, que creó la Iniciativa Nacional por la Productividad y Competitividad.

En agosto de 2015 se promulgó el referido Decreto Presidencial, que en el marco de un enfoque de alianzas público-privadas y con una participación importante del sector empresarial, se planteó como objetivo sentar las bases para alcanzar las metas del tercer eje de la Estrategia Nacional de Desarrollo. No obstante, a pesar del rico enfoque basado en alianzas público-privadas, el referido decreto pierde la oportunidad de superar las limitaciones del Decreto 190-07 y articular de manera más consistente un elemento central en la competitividad y la productividad de las empresas: la producción de conocimiento y la articulación con los actores sociales e institucionales responsables de dicha producción, cuestiones centrales a la hora de fortalecer las capacidades nacionales de innovación. Curiosamente dicha iniciativa fue precedida de la presentación de un "Diagnóstico Preliminar del Sistema Nacional de Innovación y Competitividad en la República Dominicana", elaborado para el MEPyD con el apoyo del Banco Interamericano de Desarrollo (de Groote, 2015).

Entre los elementos destacados por el referido diagnóstico y de los cuales se hizo eco la prensa (Mercado, 2015), se encuentra la baja articulación de las universidades y centros tecnológicos con los sectores productivos, los escasos recursos materiales, financieros y humanos dedicados a la investigación y a la innovación en las universidades, el énfasis en innovaciones de tipo incremental (adquisición de bienes y equipos, implantación de software, etc.) que además se realizan de forma aislada, y la consecuente baja productividad científica (publicaciones) y limitados resultados tecnológicos (patentes, modelos de utilidad, entre otros (de Groote, 2015). De hecho, de acuerdo con el referido informe del BID, en el sistema dominicano de universidades, el personal trabajando en investigación e innovación es de alrededor de 450 personas. Se resalta el hecho de que las investigaciones que se realizan se han articulado desde una perspectiva de la oferta y no con base en la demanda de innovación de los sectores productivos (de Groote, 2015).

De manera que iniciativas como la definida en el Decreto 237-015 muestran la apremiante necesidad de que actores del sistema nacional de innovación asuman un compromiso firme y sostenido con los 
procesos y dinámicas productivas que estimulan la innovación, una de las cuestiones medulares discutidas en el marco del diálogo de CTI de septiembre de 2014.

Los resultados anteriores constituyen por sí mismos impactos vitales y directos de la experiencia de diálogo analizada en este trabajo. Tales impactos muestran la pertinencia del mismo al margen de cualquier punto crítico que dicha experiencia pudo tener.

\subsection{ALGUNAS LECCIONES APRENDIDAS}

Una de las lecciones aprendidas desde el punto de vista metodológico, fue la necesidad de implementar una evaluación formal de la experiencia de diálogo. La evaluación conducida se limitó a los aspectos básicos de la experiencia, como la organización y logística de soporte de la misma. Una evaluación más formal, que incluyera aspectos de contenido, hubiese permitido una mejor sistematización de la experiencia.

Otra lección importante, ha sido la necesidad de promover un mayor nivel de participación de la sociedad civil en estos temas. Con base en la relación de participantes, los más interesados en participar fueron los integrantes de la comunidad académica, seguidos de las comunidades pública y empresarial. La convocatoria se enfocó principalmente en las comunidades pública y empresaria, lo que puede explicar la baja participación de la sociedad civil, a pesar de que como se explicó previamente, en el contexto dominicano las organizaciones de la sociedad civil está limitadamente apoderadas de los temas de CTI (Álvarez et al., 2016).

Otras de las lecciones aprendidas, es la necesidad de mejorar la comprensión de los grupos de poder e intereses en potencial conflicto en lo relacionado con el diseño e implementación de las políticas de CTI, para hacer que los futuros de diálogos puedan organizarse de manera mucho más detallada en términos metodológicos y orientados de manera más estratégica (Álvarez et al., 2016; Nupia \& Martínez, 2015).

Probablemente la lección más importante es que los diálogos de CTI no pueden verse como un proceso o ciclo que se cierra al terminar los encuentros formales (Álvarez et al., 2016; Dutrénit et al., 2014). Una vez iniciadas estas dinámicas se requiere un trabajo continuo con los actores de las distintas comunidades para que se sientan parte activa del sistema de innovación del país, un requerimiento ya identificado para el caso dominicano con la finalidad de mejorar la articulación política del sistema de innovación (Gómez-Valenzuela, 2014). Tal como se ha planteado anteriormente, la naturaleza dialéctica de los sistemas nacionales de innovación implica asumir los procesos de diálogos como una dinámica permanente y continua para construir capacidades para el desarrollo productivo. 


\section{CONCLUSIONES}

Es indudable que el proceso de diálogo de CTI iniciado en el año 2007, para la formulación del Plan Estratégico de Ciencia, Tecnología e Innovación 2008-2018, bajo el liderazgo del Ministerio de Educación Superior, Ciencia y Tecnología, tuvo un impacto significativo en las dinámicas posteriores de formulación de políticas de CTI. El diálogo de políticas de innovación objeto de análisis en el presente trabajo, puede considerarse como un legítimo heredero del referido proceso.

Una diferencia con respecto al diálogo del año 2007, es el incremento sustancial de la participación privada. Dicho incremento puede estar relacionado con una mayor madurez del sector empresarial con respecto a las cuestiones de CTI, que se concretó en el Segundo Congreso de la Industria Dominicana, referido anteriormente y acontecido en el año 2012.

Otras de las diferencias notorias con el diálogo del 2007 fue el énfasis en el tema de emprendimiento. En la experiencia del año 2007, los temas de emprendimiento fueron abordados desde la perspectiva de la construcción de una cultura emprendedora, a partir de la puesta en funcionamiento de iniciativas como las incubadoras universitarias. En el diálogo de 2014 se enfatizó la cuestión de la empleabilidad y la relación directa de las dinámicas emprendedoras con los procesos de innovación más de corte disruptivo. La pertinencia o no de tales énfasis es totalmente discutible, pero lo cierto es que de un diálogo a otro se pudo apreciar al menos un interés sustancialmente mayor en los temas de emprendimiento.

Otro de los puntos a resaltar, es que este tipo de diálogos aún no ha llamado la atención de la Iglesia Católica, posiblemente por la relativa baja movilización social que consigan los temas de políticas de CTI en la República Dominicana, además de los procesos de cambios sociales y políticos que vive la sociedad dominicana del siglo XXI. Es probable que en la medida en que se incremente la participación de actores de la comunidad civil en esa misma medida se despierte el interés de la Iglesia, una cuestión interesante y sobre la que habrá que estar atentos.

Un punto final es que en ambas experiencias de diálogo se notó la necesidad de profundizar en aspectos elementales de índole conceptual, sobre la naturaleza y alcance de los procesos de innovación. La necesidad de profundizar en los aspectos conceptuales, va más allá de la perspectiva académica o de cualquier frivolidad pseudo-intelectual, sino que constituye por mérito propio, una demanda tanto de los actores públicos como privados que participaron en la experiencia de diálogo de 2014. De manera que el hecho de que la demanda de clarificación conceptual persistiera siete años después, demuestra las 
debilidades del proceso de implementación del Plan Estratégico de Ciencia, Tecnología e Innovación 2008-2018. Este punto en particular requiere de una reflexión que escapa al alcance del presente trabajo pero que abre una interesante línea de investigación futura.

En cuanto a la naturaleza de los diálogos y siguiendo la tipología básica utilizada en el marco de la iniciativa regional: "Red temática para mejorar el diálogo entre las comunidades involucradas en las políticas de CTI (COM-LALICS)", el diálogo analizado puede situarse en un punto intermedio entre un diálogo reactivo y uno propositivo. Como se mencionara, definitivamente la convocatoria del diálogo así como sus atributos formales (objetivos, comunidades participantes y resultados) apuntan hacia un proceso que más que nada puede definirse como la reacción de una parte de las comunidades públicas (los actores articulados en torno al Ministerio de Educación Superior, Ciencia y Tecnología y al Consejo Nacional de Innovación y Desarrollo Tecnológico), a las presiones derivadas de iniciativas como el Segundo Congreso de la Industria Dominicana, reseñado anteriormente y acontecido dos años antes.

De igual modo los resultados del diálogo, el trabajo de construcción de consenso en torno a las mesas de trabajo, el contenido de los resultados y los compromisos de seguimiento y divulgación, apuntan hacia un claro enfoque propositivo, claramente orientado a la modificación y ajustes del marco vigente de políticas de CTI.

Por último, en lo que respecta a las tendencias futuras de investigación y análisis, la caracterización en un punto intermedio del diálogo analizado, lo hace más complejo desde el punto de vista de su evaluación, lo cual consiste en un reto intelectual por ahora fuera del alcance del presente trabajo, pero que señala una clara tendencia de análisis futuro. De igual modo, la evaluación propiamente dicha de la experiencia constituye una tarea pendiente, a la que indudablemente la re-construcción aportada por este trabajo contribuye de manera importante.

En un nivel teórico más general, es necesario volver sobre las tipologías constructivas utilizadas en el marco regional y que le sirven como elemento conceptual y metodológico. Las distintas tipologías de diálogos tienen que ser elaboradas más detalladamente, repensadas a la luz de las interacciones de sus atributos, de sus posibles combinaciones y las relaciones genéticas entre ellas, pero en especial, a partir de las influencias que los contextos dialógicos pueden tener en la configuración de las dinámicas de diálogos en cada una de sus fases.

Finalmente, los autores agradecemos al equipo de "COM-LALICS" por la oportunidad de aprender y vincularnos con un proyecto que nos ha permitido recuperar una experiencia clave en el proceso de construcción de las políticas de CTI de la República Dominicana. 


\section{BIBLIOGRAFÍA}

Acs, Z.; Attila, V. 2002 "Geography, Endogenous growth, and innovation" en International Regional Science Review (SAGE Journals) $\mathrm{N}^{\circ}$ 25(1), pp. 132-148.

Alcorta, L.; Peres, W. 1998 "Innovation systems and technological specialization in Latin America and the Caribbean" en Research Policy (Países Bajos: Elsevier) No 26; pp. 857-881.

Álvarez, I.; Barletta, F.; Suárez, D.; Yoguel, G. 2016 Marco analítico para la tipificación de diálogos para las políticas de CTI (México) (Red CYTED COM-LALICS).

Ansell, C.; Gash, A. 2008 "Collaborative Governance in Theory and Practice" en Journal of Public Administration Research and Theory (Reino Unido: Oxford University Press) N $\mathrm{N}^{\mathrm{o}} 18$, pp. 543571. En <doi:10.1093/jopart/mum032>.

Attali, J. 2010 República Dominicana 2010-2030 (Santo Domingo) En <http://www.economia.gob.do/UploadPDF/Informe_Attali. pdf $>$.

Banco-Central 2016 Sector Real (República Dominicana). En <http:// www.bancentral.gov.do/estadisticas_economicas/real/>.

Barboza, L. 2016 Algunas consideraciones en torno al concepto de comunidad (México) (Red CYTED COM-LALICS).

Barro, S. 2015 La transferencia de I+D, la innovación y el emprendimiento en las universidades. Educación superior en Iberoamérica. Informe 2015 (Santiago de Chile) (Red CYTED COM-LALICS).

Betances, E. 2004 "The Catholic Church and Political Mediation in the Dominican Republic: A Comparative Perspective" en Journal of Church and State (Reino Unido: Oxford University Press) $\mathrm{N}^{\circ}$ 46, pp. 341-364.

BID 2011 Los Sistemas Regionales de Innovación en América Latina (Washington, D. C.: Banco Interamericano de Desarrollo).

BID 2014 ¿Cómo repensar el desarrollo productivo? Políticas e instituciones sólidas para la transformación económica (Washington, D. C.: Banco Interamericano de Desarrollo).

BID 2016 Red de Innovación. Diálogo Regional de Política (Washington, D. C.: Banco Interamericano de Desarrollo). En $<$ http://www.iadb.org/es/investigacion-y-datos/dialogo-regionalde-politica/red-de-innovacion, 2400.html>.

Britt, R. 2012 Universities Report Highest-Ever R\&D Spending of \$65 Billion in FY 2011 (Arlington: National Center for Science and Engineering Statistics). pp. 1-6. 
Burgess, M. 2014 "From 'trust us' to participatory governance:

Deliberative publics and science policy" en Public

Understanding of Science (SAGE Journals) N $\mathrm{N}^{\circ}$ 23(1), pp. 48-52.

doi:10.1177/0963662512472160

CEPAL 2008 La República Dominicana en 2030: hacia una nación cohesionada (Santiago de Chile: Comisión Económica Para América Latina y el Caribe - CEPAL. Secretaría de Estado de Economía, Planificación y Desarrollo - SEEPyD).

CNC 2007 Plan Nacional de Competitividad Sistémica (Santo Domingo: Consejo Nacional de Competitividad - CNC). En $<$ http://cnc.gov.do/cnc/?cat=12>.

Cuentas, M.; Linares Méndez, A. 2013 Guía Práctica de Diálogo Democrático (Guatemala: Organización de los Estados Americanos). En <http://www.marn.gob.sv/download/Guia_ practica_de_dialogo_democratico.pdf $>$.

de Groote, R. 2015 Apoyo al desarrollo y fortalecimiento del sistema nacional de innovación y competitividad (Santo Domingo).

de la Cuesta B. 2006 "La teoría fundamentada como herramienta de análisis" en Cultura de los Cuidados (Valencia: Consejo de Enfermería de la Comunidad Valenciana). Año X, No 20, pp. 136-140.

Díaz Montiel, Z. 2007 “J. Habermas: Lenguaje y diálogo, el rol del entendimiento intersubjetivo en la sociedad moderna" en Utopía y

Praxis Latinoamericana (Venezuela: REDALYC) No 12(39), pp. 47-72.

Dutrénit, G.; Natera, J. M.; Suárez, M. 2014 Lineamientos para la caracterización de las Comunidades y sus Procesos de Diálogo (México).

Dutrénit, G.; Alvarez, I.; Ardanche, M.; Barletta, F.; Bianco, M.; Cortés, R.; Sutz, J. 2016 Matriz de Información para el mapeo de procesos de diálogo de CTI en España, América Latina y el Caribe (México).

Dutrénit, G.; Natera, J. M.; Puchet Anyul, M.; O. Vera-Cruz, A.; Torres, A. 2017 "Dialogue processes on STI policy-making in Latin America and the Caribbean: dimensions and conditions", en Science and Public Policy, 1-16. En <doi: 10.1093/scipol/scx044>.

Espinal, R. 2001 "La sociedad civil movilizada y las reformas democráticas en la República Dominicana" en Espiral. Estudios sobre Estado y Sociedad (México: Universidad de Guadalajara). $\mathrm{N}^{\mathrm{o}} \mathrm{VII}(21)$, pp. 101-132.

Etzkowitz, H.; Leydesdorff, L. 2000 "The dynamics of innovation: from national systems and 'mode 2' to a triple helix of universityindustry-government relations" en Research Policy (Países Bajos: Elsevier). N 29, pp. 109-123. 
Evenson, R.; Gollin, D. 2003 "Assessing the Impact of the Green Revolution, 1960 to 2000" en Science (Estados Unidos: NCBI). $\mathrm{N}^{\circ} 300$, pp. 758-762. En <doi:10.1126/science.1078710>.

Fagerberg, J.; Verspagen, B. 2009 "Innovation studies- The emerging structure of a new scientific field" en Research Policy (Países Bajos: Elsevier). No 38, pp. 218-233. En <doi:10.1016/j. respol.2008.12.006>.

Fischer, F.; Gottweis, H. 2012 The Argumentative Turn Revisited. Public Policy as Communicative Practice (Durham: Duke University Press).

Freeman, C. 1992 "Formal scientific and technical institutions in the national system of innovation" en Lundvall, B. (ed.) National Systems of Innovation: towards a theory of innovation and interactive learning (Londres: Pinter). pp. 169-187.

Gassler, H.; Polt, W.; Rammer, C. 2008 "Priority setting in technology policy: Historical development and recent trends" en Nauwelaers, C.; Wintjes, R. (eds.) Innovation Policy in Europe: Measurement and Strategy (Reino Unido/ Northampton: Edward Elgar). pp. 203-224.

Gómez-Valenzuela, V. 2014 Análisis del Capital Intelectual de empresas dominicanas: la importancia de las ideas del conocimiento (Santo Domingo: ONAPI-AIRD-CNC-ATABEY).

Goñi, M. 2015 Caracterización de las condiciones de los procesos de diálogo: confianza, conflicto, relaciones de poder (México).

Goñi, M.; Blanco, M.; Andarche, M.; Puchet, M. 2015 Elementos para caracterizar los procesos de diálogo en políticas de CTI (Montevideo).

Habermas, J. 2011 Teoría de la acción comunicativa: complementos y estudios previos (Madrid: Cátedra).

Hausmann, R.; Hidalgo, C.; Jiménez, J.; Lawrance, R.; Levi-Yeyati, E.; Sabel, C.; Schydlowsky, D. 2011 Construyendo un mejor futuro para la República Dominicana: herramientas para el desarrollo (República Dominicana: Harvard University).

Johnson-Laird, P. 1980 "Mental models in cognitive science" en Cognitive Science (Reino Unido: Psychology Press) N ${ }^{\circ}$, pp. 71-115.

Lundvall, B. 1992 "National Systems of Innovation [Introduction]" en Lundvall, B.; Fagerberg, J. (eds.) National Systems of Innovation: toward a theory of innovation and integrative learning (Londres: Pinter). pp. 1-19. 
Lundvall, B. 2007 "National innovation systems. Analytical concept and development tool" en Industry and Innovation (Reino Unido: Routledge). $\mathrm{N}^{\mathrm{o}}$ 14(1), pp. 95-119.

Magro, E.; Navarro, M.; Zabala-Iturriagagoitia, J. 2014 "Coordination-mix: the hidden face of STI policy" en Review of Policy Research (Canadá: Carleton University). N ${ }^{\circ} 31(5)$, pp. 367389. En <doi:10.1111/ropr.12090>.

Magro, E.; Wilson, J. 2013 "Complex innovation policy systems: Towards an evaluation mix" en Research Policy (Países Bajos: Elsevier). No 42, pp. 1647-1656. En <doi:http://dx.doi. org/10.1016/j.respol.2013.06.005>.

Malerba, F. 2002 "Sectoral systems of innovation and production" en Research Policy (Países Bajos: Elsevier). No 31, pp. 247-264.

Mckinney, J. 1966 Constructive Typology and Social Theory (Nueva York: Appleton-Centry-Crofts).

MEPyD 2011 Documento Base de la Propuesta de Estrategia Nacional de Desarrollo (Santo Domingo). En <http://www.end.gov. do/index.php?option=com_content $\&$ view $=$ article $\& i d=47$ :lapropuesta-de-estrategia-nacional\&catid=1:latest-news $>$.

MEPyD 2014 Actualización de las estimaciones oficiales de pobreza monetaria en la República Domininicana (Santo Domingo).

MEPyD 2016 Ley 1-12 (República Dominicana: Estrategia Nacional de Desarrollo). En <http://economia.gob.do/mepyd/wp-content/ uploads/archivos/end/marco-legal/ley-estrategia-nacional-dedesarrollo.pdf $>$.

Mercado 2015 RD invierte $0.01 \%$ del PIB en áreas de investigación $y$ desarrollo (República Dominicana). En $<$ http://www. revistamercado.do/app2/rd-invierte-0-01-del-pib-en-areas-deinvestigacion-y-desarrollo/>.

MESCYT 2011 Informe General sobre Estadísticas de Educación Superior 2006-2009 (Santo Domingo).

MESCYT 2015 [Evolución del FONDOCYT].

Metcalfe, J. 1994 "Evolutionary economics and technology policy" en The Economic Journal (Reino Unido: Wiley). No 104(425), pp. 931-944.

Metcalfe, J.; Ramlogan, R. 2008 "Innovation Systems and the Competitive Process in Developing Countries" en Quarterly Review of Economics and Finance (Países Bajos: Elsevier). $\mathrm{N}^{\mathrm{o}}$ 48(2), pp. 433-446. En <doi:http://dx.doi.org/10.1016/j. qref.2006.12.021>. 
MIC 2015 Informe de Logros de la Mesa de Seguimiento a las Propuestas del Segundo Congreso de la Industria Dominicana (Santo Domingo). En <http://mic.gob.do/media/839649/ logros-de-la-mesa-del-segundo-congreso industrial_06-162015.pdf>.

Navarro, J. 2009 República Dominicana: una revisión de la ciencia, tecnología e innovación (Washinton D. C.: Banco Interamericano de Desarrollo). En <http://www.iadb.org/ en/publications/publication-detail,7101.html?id=8606 $\&$ dcLanguage $=$ es\&dcType $=$ All $>$.

Nelson, R.; Nelson, K. 2002 “Technology, institutions, and innovation systems" en Research Policy (Países Bajos: Elsevier). $\mathrm{N}^{\circ}$ 31(2), pp. 265-272. En <doi:http://dx.doi.org/10.1016/s00487333(01)00140-8>.

Nelson, R.; Rosenberg, N. 1993 "Technical innovation and national systems" en Nelson, R. (ed.) National Innovation Systems. A comparative analysis (Nueva York: Oxford University Press). pp. 3-21.

Nupia, C.; Martínez, A. 2015 Revisión de Metodologías de Procesos de Diálogo (México).

OECD 2012 Reviews of national policies for education: higher education in the Dominican Republic 2012 (OECD Publishing).

ONE 2014 Estadísticas demográficas (República Dominicana). En <http://www.one.gob.do/Estadisticas/6/demograficas $>$.

PNUD 2014 Informe de Desarrollo Humano 2014. Sostener el Progreso Humano: Reducir vulnerabilidades y construir resiliencia (Nueva York).

PNUD 2015 Informe sobre Desarrollo Humano. Trabajo al servicio del desarrollo humano. Panorama general (Nueva York).

Sánchez-Mariñez, J. 2010 "El rol de las universidades en el desarrollo científico-tecnológico en la década de 1998-2007. Caso de la República Dominicana" En Santelices, B. (ed.) El rol de las universidades en el desarrollo científico y tecnológico (Santiago de Chile: Centro Interuniversitario de Desarrollo - CINDA / Universia - Secretaría General Iberoamericana).

SEESCYT 2008 Plan Estratégico de Ciencia, Tecnología e Innovación 2008-2018 (Santo Domingo).

Shariff, N. 2006 "Emergence and development of the national innovation systems concept" en Research Policy (Países Bajos: Elsevier). $\mathrm{N}^{\mathrm{o}} 35$, pp. 745-766. 
Thomas, G. 2011 "A typology of the case study in social science following a review of definition, discourse, and structure" en Qualitative Inquiry (SAGE Journals) N $\mathrm{N}^{\mathrm{0}}$ 17(6), pp. 511-521. En $<$ doi:10.1177/1077800411409884>.

UNCTAD 2012 Examen de las políticas de ciencia, tecnología e innovación. República Dominicana (Nueva York-Ginebra). En <http://unctad.org/es/PublicationsLibrary/dtlstict2012d1_ sp.pdf $>$.

van de Kerkhof, M. 2006 "Making a difference: On the constraints of consensus building and the relevance of deliberation in stakeholder dialogues" en Policy Science (Reino Unido: SpringeR). N ${ }^{\circ} 38$, pp. 279-299. doi:10.1007/s11077-006-9024-5

Vonortas, N. 2002 "Building competitive firms: technology policy initiatives in Latin America" en Technology in Society (Países Bajos: Elsevier). No 24(4), pp. 433-459. En <doi: http://dx.doi. org/10.1016/s0160-791x(02)00034-9>.

World-Bank 2016 The Dominican Republic (Santo Domingo). En $<$ http://www.worldbank.org/en/country/dominicanrepublic $>$. 



\title{
PROCESOS DE DIÁLOGO EN LA DEFINICIÓN DE POLÍTICAS DE CIENCIA, TECNOLOGÍA E INNOVACIÓN EN ESPAÑA
}

\author{
Isabel Álvarez, ${ }^{1}$ Myrna Juan, ${ }^{1}$ Celia Torrecillas, ${ }^{1,2}$ \\ Nadia Albis ${ }^{1,3}$ y Romilio Labra ${ }^{1,4}$
}

\section{INTRODUCCIÓN}

El impulso que en España recibiera la ciencia y la tecnología en los años 80, cuando se aprobó la primera Ley de la Ciencia y el Primer Plan Nacional de Investigación y Desarrollo (I+D), ${ }^{2}$ no ha seguido un ritmo suficientemente intenso ni constante como para que este tema ocupe un lugar central en la agenda política del país. A pesar de que en las últimas décadas España ha realizado un escalamiento de posiciones en $\mathrm{I}+\mathrm{D}$, al compararse con el contexto internacional y con el más reducido ámbito europeo, el sistema español parece haberse quedado más rezagado en su comportamiento tecnológico que al atender a otros elementos de la estructura económica y social del país. En particular, la posición que ha obtenido en las clasificaciones económicas internacionales -ya sea a través de los niveles de renta per cápita y de

(1) Instituto Complutense de Estudios Internacionales (ICEI).

(2) Universidad Europea de Madrid.

(3) Observatorio Colombiano de Ciencia y Tecnología.

(4) Centro de Genómica Nutricional Agroacuicultura, Chile.

2 En España, la primera Ley de la Ciencia se consolidó en 1986 y, desde ese momento, la investigación y el desarrollo (I+D) se ha convertido en un aspecto de los debates sociales y la opinión pública (Arroyo et al., 2007; Sanz \& Muñoz, 1994). 
índices de desarrollo-, no tiene parangón con los indicadores de ciencia, tecnología e innovación (CTI), en los que es persistente el retraso de la economía española respecto a la mayoría de sus competidores internacionales. De hecho, un informe reciente publicado por la Comisión Europea sobre el estado de la investigación y la innovación en España, afirma que no se vislumbran signos de convergencia de España con la UE (Comisión-Europea, 2014b). Tampoco se percibe que la CTI sean elementos que ocupen el lugar que les correspondería en el discurso y en el debate político español (Insenser \& Jiménez, 2014).

De manera ilustrativa, las deficiencias de España se ponen de manifiesto al atender al nuevo índice de innovación lanzado recientemente por la Comisión Europea. Se trata de un indicador de resultados de innovación, el Indicator of innovation output (Comisión Europea, 2013), una iniciativa que tiene como principal objetivo contar con una metodología común que permita la comparación de los países europeos y poder llegar a definir una política de innovación común con más precisión. En la construcción del mismo se han usado cuatro pilares: la innovación tecnológica medida por patentes, el empleo en actividades intensivas en conocimiento como porcentaje del total de empleados, la competitividad de los bienes y servicios intensivos en conocimiento, y las oportunidades de negocio en sectores innovadores y de rápido crecimiento. A pesar de que la información disponible actualmente todavía es escasa, ya que el indicador vio la luz en septiembre de 2013, los datos son bastante expresivos de la preocupante situación española, por cuanto el valor del indicador innovation output en 2012 fue del 80.8 para España, lo que le sitúa a más de 20 puntos del promedio europeo que fue de 101.6 (Comisión-Europea, 2014b). Cabe reseñar la debilidad con la que se cuenta en términos de excelencia en ciencia y tecnología, y la aún tímida inversión pública y privada en $\mathrm{I}+\mathrm{D}$, cuya positiva evolución se ha visto frenada por las restricciones fiscales y financieras de los últimos años.

El acuerdo acerca del papel de las políticas de CTI y la preocupación por la innovación en el desarrollo de los países se ha ido extendiendo de manera generalizada entre académicos y gobiernos, fundamentalmente en las últimas décadas, existiendo consenso sobre los efectos positivos que los gastos en $\mathrm{I}+\mathrm{D}$, la innovación, las patentes, y la cualificación de los trabajadores, ejercen sobre el crecimiento económico. Sin embargo, a pesar de que los resultados eficaces de las políticas de CTI han demostrado ser positivos para los países, el papel que juegan los diversos actores de la sociedad en el proceso de construcción de este tipo de políticas sigue siendo poco conocido, habiéndose dedicado un espacio aún escaso a este asunto en la agenda de investigación. En particular, cabe afirmar que la literatura sobre 
CTI tenga que dedicar una atención aún mayor a la comprensión del proceso de diálogo que hace posible la construcción de una política de CTI robusta (Brown, 2015; Burgess \& Chilvers, 2006; Crespi \& Dutrenit, 2013; Chilvers, 2013; OECD, 2011).

No obstante, esta perspectiva desalentadora, en las últimas décadas ha ido ganando un espacio en la agenda de gobierno como forma de avanzar y superar la situación de retraso relativo. Al respecto, cabe señalar que algunas iniciativas han permitido revelar algunas mejoras y extraer lecciones para seguir en la senda de un mayor desarrollo científico y tecnológico en el país, algunas de las cuales resultaron de procesos de diálogo entre los distintos actores del sistema de innovación. El objetivo de este capítulo es presentar y analizar dos diálogos en el ámbito de la política CTI en España: en primer lugar, el Plan de Ciencia y Tecnología de Andalucía (plan de I+D+i de la Comunidad Autónoma de Andalucía), una región española que tiene un desarrollo -económico y tecnológico- comparable a muchos territorios de América Latina; está caracterizada por una alta participación de industrias con bajo contenido tecnológico y su nivel de desarrollo es intermedio. En segundo lugar, se estudia la propuesta de diálogo para la Mejora de la movilidad de personal investigador en formación entre Universidades y Empresas (el caso de IBERDROLA), en el que se describe como una iniciativa que emerge del sector empresarial y que persigue incrementar la movilidad de jóvenes investigadores, llega a integrarse en el paquete de medidas de la política de CTI en España, siendo integrada en la Ley de la Ciencia, la Tecnología y la Innovación en el país. Ambos diálogos dan cuenta del involucramiento de distintos actores del sistema español en procesos que persiguen superar las debilidades del mismo.

La presentación de los diálogos que a continuación se realiza responde a las pautas de la metodología acordada y desarrollada en el seno de la "Red CYTED COM-LALICS para Mejorar el Diálogo entre las Comunidades Involucradas en las Políticas de CTI" (Dutrénit et al., 2016; Goñi et al., 2015). Los dos diálogos fueron seleccionados de acuerdo a los criterios de la Red en México (Álvarez et al., 2017; Dutrénit et al., 2014, 2017). ${ }^{1}$

La siguiente sección de este capítulo presenta algunas cuestiones generales sobre innovación y orientaciones para la política CTI en España. A continuación, en las secciones tercera y cuarta se presentan los dos diálogos - uno de ellos a nivel regional y el otro a nivel nacionalambos con relevancia en el ámbito de las políticas CTI de los últimos años en el país, para finalizar en la sección quinta con algunas conclusiones.

1 Ver los capítulos 2 y 3 de este libro para una discusión conceptual y metodológica acerca de la selección y análisis de casos de diálogo y las especificidades de los diálogos para la política CTI). 


\section{ANTECEDENTES, CAPACIDADES DE INNOVACIÓN Y RETOS DE POLÍTICA CTI EN ESPAÑA}

El conocimiento científico y tecnológico junto a la capacidad de innovación de un país, son elementos que han ido ganando un peso específico cada vez mayor en el avance de las economías. De hecho, es abundante la evidencia empírica que confirma el papel que juega el progreso técnico en el desarrollo y cómo ese elemento es un factor explicativo de la brecha que separa a las economías más atrasadas del progreso económico y social de aquéllas que se sitúan en la frontera mundial del conocimiento, delimitando su competitividad (Fagerberg et al., 2007; Fagerberg et al., 2010).

No en vano, la Agenda de Desarrollo Sostenible aprobada por los Estados Miembros de la ONU en la Cumbre para el Desarrollo Sostenible en septiembre de 2015, incorpora a la industria y la innovación, junto a las infraestructuras, como reto 9 dentro del conjunto de 17 Objetivos de Desarrollo Sostenible (ODS) para poner fin a la pobreza, luchar contra la desigualdad, y hacer frente al cambio climático. Pero esta no es una prioridad que se vincule solo a problemas de desarrollo y de la que puedan quedar al margen los países industrializados y de ingreso alto. Bien al contrario, en el marco geopolítico de referencia para España, la UE, encontramos una estrategia de política de investigación e innovación orientada a afrontar el reto que supone posicionar a Europa a la cabeza de la economía del conocimiento en el mundo. Algunos de los programas se vuelcan en la construcción de un espacio común de investigación, en el que además de fomentar la movilidad de investigadores e ideas, y la generación de redes y equipos transnacionales, se vaya consolidando una mayor coordinación de las políticas europeas y nacionales en el largo plazo. Además del Espacio Europeo de Investigación, y del nuevo Programa Marco de I+D+i -el Horizonte 2020-, la Estrategia Europa 2020 integra la iniciativa Unión por la Innovación, que tienen como objetivos fundamentales los de encumbrar a Europa como potencia científica mundial, contribuir a reducir los obstáculos a la innovación, y modificar la colaboración público-privada a través de los partenariados europeos de innovación.

Los objetivos prioritarios de competitividad y sostenibilidad que define la estrategia Europa 2020, se combinan en una sucesión de desarrollos normativos que definen una nueva concepción de política industrial (Comisión-Europea, 2010), y entre los que la innovación se concibe como un motor clave de productividad, de mayor eficiencia energética, de mejor aprovechamiento de materiales y de generación de nuevos mercados. La idea es desarrollar una nueva política industrial que agilice el desarrollo y la comercialización de bienes y servicios, al tiempo que garantice el posicionamiento de las empresas de la 
UE en el mercado global, propiciando mejoras en su competitividad. Para ello, se asume que las conocidas como tecnologías facilitadoras robótica, electrónica, nanotecnologías- son esenciales para sentar las bases de desarrollo de una amplia variedad de nuevos procesos, bienes y servicios, incluido el desarrollo de nuevas industrias en el futuro (Comisión Europea, 2014a).

El objetivo de competitividad en la actualidad no puede dejar al margen, por lo tanto, una reflexión acerca de la importancia que tiene el conocimiento, la tecnología y la innovación, en las opciones de cambio productivo que las nuevas tecnologías propician. Así lo confirma el extendido consenso de académicos, y también de gobiernos, acerca de la necesidad de considerar las capacidades de generación y adaptación de innovaciones como objetivo central en la definición de políticas conducentes a mantener los procesos de desarrollo en el largo plazo. No obstante, los indicadores no siempre revelan que estas cuestiones ocupen un lugar central ni tan siquiera explícito en la estrategia nacional de progreso.

Los antecedentes revelan que el profuso desarrollo conceptual en este campo de estudio incorpora los conceptos de progreso técnico y tecnología vinculados a la idea de que la innovación es preferentemente un fenómeno de las empresas -preferente que no exclusivo, si se piensa, por ejemplo, en las innovaciones que se generan en hospitales o centros públicos de investigación o las posibilidades que ofrece la innovación en el tratamiento de problemas sociales-. Es por ello que la innovación ha de entenderse como el resultado de la combinación de una amplia variedad de elementos, tales como las diferentes fuentes y tipos de conocimiento, el desarrollo de capacidades científicotécnicas y habilidades gerenciales, el acceso a la información sobre el mercado, los sistemas de distribución, los recursos financieros e incluso los modelos de negocio. La cuestión es que lo que a simple vista se entiende como una innovación suele ser el resultado de un largo proceso que envuelve una multiplicidad de innovaciones complementarias e interrelacionadas, y que el entorno en el que desarrollan las empresas su actividad y el marco institucional, son ámbitos que no solo justifican adoptar una perspectiva analítica de sistema de innovación en la que se inserta la definición de acciones y políticas, sino que aporta una explicación plausible a las diferencias en el comportamiento innovador de los países (Edquist, 2004; Fagerberg \& Sapprasert, 2011; Freeman, 1987; Lundvall, B, 1988, 2007; Lundvall, B. et al., 2011; Nelson, R., 1992; Nelson, R., 1993).

El actual panorama que describe el retroceso de las manufacturas en la mayoría de los países OCDE, la tendencia a la fragmentación de tareas y actividades en el plano internacional, y la emergencia de nuevas tecnologías, configura un conjunto de retos importantes para la evolu- 
ción de la economía española en el que el desarrollo de capacidades tecnológicas y de innovación, la concepción de nuevos modelos de negocio y el potencial de la internacionalización empresarial pasan a ocupar un lugar muy central. En particular, los desafíos de competitividad de las empresas están estrechamente condicionados por el potencial de rápida penetración de lo que se han vuelto a denominar "nuevas tecnologías", algunas de estas de carácter disruptivo y que integran campos diversos tales como la robótica, las técnicas de inteligencia artificial, la nanotecnologías, los vehículos eléctricos, el Big Data y el internet de las cosas, entre otras (Rubmann et al., 2015). La agenda del World Economic Forum, por ejemplo, incorpora la idea de una cuarta revolución industrial en ciernes, claramente dominada por la irrupción de esas tecnologías en los ámbitos económico y social, que modificará los patrones de competitividad de empresas y países (Sachwald, 2016). Semejantes desafíos en el plano internacional hacen imprescindible contar con una vocación y apoyo gubernamental en el que deliberadamente se definan y se apliquen medidas de acompañamiento para el fomento de la innovación, lo que implica medidas de acceso al conocimiento tecnológico, de gestión, a los recursos humanos con la cualificación técnica adecuada, así como a la financiación de actividades que implican un riesgo elevado.

La situación es ciertamente alarmante si se atiende a que en el contexto europeo, España es tan solo un país "innovador moderado", según la clasificación de la UE que distingue entre países innovadores lideres, seguidores, moderados y modestos (Comisión Europea, 2015). Además, a partir de 2012 la posición relativa española en materia de innovación ha vuelto a retroceder, habiendo perdido el avance de años anteriores, una evolución que es compartida con algunos países en la región tales como Rumanía. Este diagnóstico se realiza a partir del indicador agregado de innovación que genera el EU Innovation Scorboard, construido a partir de tres dimensiones -elementos facilitadores del entorno, actividades empresariales y outputs-, en el que España ocupa una posición inferior al promedio europeo con un valor de 0,38 en 2014 frente al 0,55 de la UE, y muy alejado del 0,74 de Suecia que encabeza el ranking, habiéndose ampliado la brecha con el tiempo al haber perdido 9 puntos porcentuales entre 2008 y 2014. En términos relativos, el rendimiento español es inferior en la mayoría de indicadores, siendo más notable la debilidad que se presenta en los outputs innovadores, a través del indicador de ingresos por licencias y patentes y, mostrando una evolución favorable en las publicaciones científicas con coautoría internacional. Si bien en este último hay claros signos de mejora, hay que hacer notar que la peor evolución es la seguida por los indicadores correspondientes a la inversión de las empresas en $\mathrm{I}+\mathrm{D}$, y a la financiación de la innovación. 
Las debilidades del sistema español de innovación invitan a reflexionar acerca de cuáles son los espacios para mejorar la intervención por parte de todos los agentes que contribuyen a la definición de acciones en el ámbito de la política CTI, lo que justificaría tratar de avanzar en una mejor comprensión de los procesos de diálogo que están en la base de las políticas CTI. ${ }^{2}$

\section{PLAN REGIONAL DE I+D+I PARA LA COMUNIDAD AUTÓNOMA DE ANDALUCÍA}

\subsection{RELEVANCIA Y CONTEXTO DE LA POLÍTICA REGIONAL DE CTI}

Tras décadas de retraso en materia de ciencia y tecnología en España, el restablecimiento de la democracia en el país a finales de los años setenta y el triunfo del primer gobierno socialista en 1982 sirvieron de base para el inicio de una conciencia mayor de la ciencia, la tecnología y la innovación en España. Los trabajos en esa línea condujeron finalmente a la aprobación de La Ley de la Ciencia de 1986 (Ley 13/1986), marco normativo en el que se establecería la elaboración del Primer Plan Nacional de Investigación y Desarrollo, que tenía por objetivo fundamental el crecimiento de España en Ciencia y Tecnología. En esos años también se avanzó políticamente en la descentralización administrativa, que conferiría una mayor autonomía de gobierno a nivel regional, dadas las diferencias históricas, culturales y territoriales de la geografía española. En ese contexto, dicha ley preveía la elaboración de Planes Regionales de Ciencia y Tecnología, concediendo competencias y responsabilidades en materia de CTI a las unidades administrativas regionales, denominadas Comunidades Autónomas. El resultado fue que, en cada una de las 17 Comunidades Autónomas Españolas, se comenzaron a definir políticas CTI más arraigadas en la realidad regional y que quedarían plasmadas en los distintos planes regionales de CTI. El objetivo general de los planes regionales de CTI es la programación plurianual de una serie de actuaciones encaminadas a impulsar la innovación como un factor de crecimiento de las regiones españolas y que, a pesar de la especificidad local, debían estar necesariamente coordinados a nivel estatal y europeo.

El primer plan plurianual de investigación y desarrollo de Andalucía data, por lo tanto, de la década de los ochenta y, desde entonces, se han sucedido otros que han ido adecuándose a la misma evolución de

2 Un ejercicio de tipificación de los diálogos puede encontrarse en el documento de Álvarez et al. (2016), mientras que los dos diálogos que se revisan en este capítulo sirvieron de base para analizar la especificidad y generalización de los procesos cuando éstos pueden generarse bien bottom-up, o bien top-down (Álvarez et al., en prensa). 
la sociedad. Los planes de la última década han sido: el Plan Director de Innovación y desarrollo tecnológico para Andalucía (2001-2003), el III Plan Andaluz de investigación (PAI-2000-2003), el Plan de Innovación y Modernización de Andalucía (PIMA, 2005-2010) y el Plan Andaluz de Investigación, Desarrollo e Innovación (PAIDI, 2007-2013). En la figura 1 se puede apreciar la evolución temporal de estos planes de innovación.

En la actualidad, se está ejecutando el primer año del Plan Andaluz de Investigación, Desarrollo e Innovación (2014-2020) -el PAIDI-. En este plan ya se incorpora la Estrategia de Especialización Inteligente, ${ }^{3}$ que es acorde con los mandatos de la Unión Europea en materia de política CTI. El contexto normativo queda definido entre la primera Ley de Ciencia (Ley 13/1986 de 14 de abril, Ley de Ciencia y Tecnología), y la ley actual, Ley 14/2011 de 1 de junio de la Ciencia, la Tecnología y la Innovación (a partir de ahora CTI).

\subsection{CONTEXTO HISTÓRICO EN EL QUE SE DESARROLLA EL DIÁLOGO}

El análisis de este diálogo se orienta a los acuerdos que anteceden la entrada en vigor del PAIDI 2014-2020. El tema de CTI en el que se clasificaría este diálogo, por la tanto, es la regionalización de la CTI: la principal finalidad del diálogo es la aprobación de un programa o Plan que instrumenta la política regional de CTI en el período 2014-2020, quedando el objetivo del diálogo centrado en los acuerdos para la elaboración de la Estrategia de Especialización Inteligente y la Política Andaluza de CTI. Este diálogo tiene en la base el objetivo fundamental de crecimiento de la región andaluza a partir de la promoción de la innovación y la reorientación de su modelo productivo tradicional; esto es, un objetivo que responde a los desafíos de modernidad y desarrollo de la sociedad andaluza, al tiempo que está en concordancia con la política nacional y europea. Por su propia naturaleza, el PAIDI da cabida a todos elementos que componen el sistema de $\mathrm{I}+\mathrm{D}+\mathrm{i}$ de la región, así como a todos los sectores productivos. No obstante, hace especial énfasis en el fortalecimiento de las tecnologías de la información y las comunicaciones (TIC), la energía y el sector agroalimentario como sectores prioritarios de desarrollo tecnológico.

Los planes regionales tienen carácter de Ley Ordinaria, toda vez que se procede a su publicación en el Boletín Oficial de la región. En concreto, la elaboración del Plan regional actual (PAIDI, 2014-2020) se acordó el 17 de Diciembre de 2013, habiéndose publicado el 9 de Enero de 2014 en el Boletín Oficial de la Junta de Andalucía. ${ }^{4}$

3 Este es un requisito exigido por la Unión Europea para la obtención de los Fondos de Cohesión, dirigidos a las regiones europeas más desfavorecidas.

4 Ver <http://goo.gl/FAiT8o>. El plan anterior, que se desarrolló entre 2007 y 
Hay dos retos principales que están enfrentando en el acuerdo del 17 de diciembre de 2013. El primero de ellos es la conciliación de los intereses regionales y nacional-europeos. El segundo, está relacionado con la prioridad de establecer una Estrategia de Especialización Inteligente. Estos dos retos obligan a fomentar los puntos fuertes de la región y a tratar de sobrepasar las debilidades, mediante la coherencia de las políticas económicas e industriales y las políticas de ciencia, tecnología e innovación.

Entre los hitos de avances significativos que se vislumbran, siendo algunos de ellos incluso anteriores a la publicación del Plan 2014-2020, cabe mencionar los siguientes: 1)acuerdo del 18 de diciembre de 2013 por el que se aprueba la formulación de la Estrategia de Especialización Inteligente; 2) reuniones de expertos de la Comunidad Empresarial y Académica, en abril y diciembre de 2013; 3) apertura al público en diciembre de 2013 de la Estrategia de Especialización Inteligente; 4) aprobación en diciembre de 2013 del acuerdo para formular el plan Andaluz de Investigación, Desarrollo e Innovación (PAIDI 2014-2020); 5) aprobación de la Estrategia de Especialización Inteligente de Andalucía en febrero de 2015.

El Plan 2014-2020 se nutre de los planes anteriores y, en particular, del Plan 2007-2013 que ha tenido como finalidad prioritaria el avance en materia de CTI en dicho período.

Figura 1. Contexto histórico de los planes de innovación regionales en Andalucía

\section{Antecedentes de Planes de Innovación Ciencia y Tecnología en Andalucía}

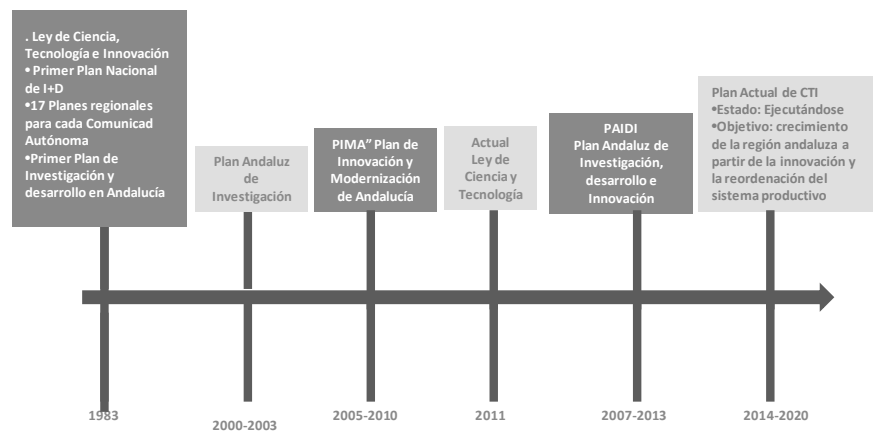

Fuente: elaboración propia.

2013, se publicó el 27 de marzo de 2007. Véase <http://www.juntadeandalucia.es/ boja/2007/72/1>. 


\subsection{PROPÓSITO Y ALCANCE}

El propósito de dar comienzo al diálogo se contiene en el proceso de construcción de un Plan Regional de I+D+i para el período 20142020, de acuerdo a las directrices marcadas por la política nacional y europea en materia de CTI, y a las áreas de especialización de la región andaluza que contribuyan a un mayor crecimiento en la región basado en la innovación y que, por ende, repercuta en el crecimiento de España.

El objetivo de este diálogo es cubrir los desafíos de CTI a largo plazo, en el período 2014 -2020. Su alcance es regional, el de la Comunidad Autónoma de Andalucía que, con una población de 8.450.000 millones de personas, representa el $18 \%$ de la población española y el $13.54 \%$ del valor añadido español, aunque está coordinado con el Plan Nacional de $\mathrm{I}+\mathrm{D}+\mathrm{i}$. El plan regional define los sectores prioritarios a los que dirigir las actuaciones, entendiendo que resultan ser clave para el crecimiento y desarrollo de la región. En particular, se han identificado las siguientes líneas prioritarias: 1) impulso y desarrollo de la movilidad y la logística; 2) consolidación de la industria avanzada vinculada al transporte; 3 ) investigación e innovación en agroindustria y alimentación saludable; 4) fomento de las energías renovables, eficiencia energética y construcción sostenible y; 5) fomento de las TIC y la economía digital.

\subsection{COMUNIDADES IDENTIFICADAS}

Atendiendo al concepto de comunidad que se presenta en Barboza (2016) y Dutrénit et al. (2016, 2017), los principales actores involucrados en este proceso de diálogo son, por un lado, la comunidad del sector público, a nivel regional y nacional, como conductores del proceso; la comunidad académica, como referentes expertos; la comunidad empresarial, a través de las asociaciones y redes que contribuyen en la elaboración y perfeccionamiento de las propuestas; y la comunidad civil, con una participación menos relevante aunque notoria. ${ }^{5}$

Realizando una descripción más detallada de su participación, la correspondiente a la comunidad académica se dio mediante consultas a representantes de universidades y centros públicos de investigación. En Andalucía hay un total de 10 universidades y 24 centros públicos de investigación. Respecto a la comunidad empresarial, que participó en este proceso de diálogo mediante su participación en diferentes re-

5 La participación de las Comunidades viene oficialmente contemplada en la legislación vigente, por lo que es recogida en el Boletín oficial de la Junta de Andalucía (BOJA), donde se plasma el papel que tiene cada comunidad en el proceso de diálogo $<$ http://www.juntadeandalucia.es/boja/2014/5/>. 
uniones de grupos de expertos, formaba parte también de un proceso de codecisión entre los sectores público y privado.

En este proceso de diálogo también participó, y con un peso específico notable, la comunidad del sector público, a nivel regional (Consejería de Economía, Ciencia, Innovación y Empleo), así como con representantes del ámbito nacional e internacional. En particular, como actor internacional intervino el representante que, a nivel europeo, se encarga de que las políticas regionales coincidan con los propósitos de la Unión Europea, recogidos en el Horizonte 2020. Por último, la comunidad civil participó al existir un proceso de apertura pública para emitir sugerencias al final del proceso, que acaba por legitimar con ante ella los acuerdos alcanzados en el proceso de diálogo.

Un aspecto a destacar es que, si bien la iniciativa fue llevada a cabo por parte de la comunidad del sector público regional, también intervinieron las instancias nacionales y europeas, en tanto que las políticas regionales y nacionales en el contexto de la UE han de seguir los criterios aprobados por el marco que en materia de política CTI se define en el ámbito europeo. Por lo tanto, cabe afirmar que la comunidad del sector público ha ostentado un papel preponderante -alta participación- en este proceso de diálogo, la comunidad empresarial y académica tienen una participación media y la comunidad civil tiene una participación baja.

\subsection{CARACTERÍSTICAS DEL PROCESO DE DIÁLOGO}

Cabe destacar que, en este proceso de diálogo, el sector público regional ha actuado como promotor, líder y convocante del diálogo. Por lo tanto, este diálogo siguió una dirección de carácter top-down, es decir, con una estructura de arriba hacia abajo, que abre espacios a los diferentes actores de acuerdo a un cronograma establecido y en función de las tareas definidas en un plan de acción. De manera tal que se fue siguiendo un itinerario altamente estructurado.

El convocante es la Consejería de Economía, Innovación, Ciencia y Empleo de la Junta de Andalucía. Para la elaboración del Plan se creó una Comisión de Redacción interdepartamental y una vez elaborado el primer borrador, se envió a todas las Consejerías de la Junta de Andalucía, al Consejo Andaluz de Universidades, a las universidades y centros de investigación de la Región, así como a las organizaciones empresariales regionales y empresas. La Consejería de Economía, Innovación, Ciencia y Empleo, a su vez, convocó a otras instancias de carácter nacional y el borrador del Plan fue discutido en el Comité Regional a nivel europeo. También se preveía una consulta pública en un período de tiempo específico para que la sociedad manifieste su opinión. Las herramientas utilizadas son los informes, mesas de 
trabajo, debates públicos y privados, sesiones de análisis y consultas a la sociedad.

La organización del diálogo ha sido estructurada, habiendo un equipo de trabajo, agenda, convocatoria, eventos formales e informales y actas. El espacio donde se ha celebrado el diálogo es la sede del Gobierno Andaluz, que está en Sevilla (Andalucía). Aunque de manera complementaria, también se dieron procesos de diálogo descentralizados dirigidos a analizar las problemáticas locales o sectoriales de las provincias andaluzas. En este proceso de diálogo no se detectan donantes, y tampoco facilitadores o gestores. Sí se encuentra, por el contrario, un grupo de expertos formado por las comunidades académica y empresarial.

En cuanto a la relación de fases en el proceso de diálogo, cabe señalar que el proceso de construcción del Plan regional para el período (2014-2020) tiene su origen en diálogos que acontecieron varios años antes de la fecha establecida como inicio del Plan (2014). Este Plan se nutre también de los diálogos correspondientes a los planes regionales y planes nacionales previos: el primer Plan regional data de 1986, y posteriormente se pueden encontrar los planes de 2000-2003, 20052010 y 2007-2013. El proceso más intenso que tuvo mayor influencia en el diálogo es la implementación y evaluación del Plan regional anterior, ya que sirvió como generación de antecedentes relevantes para la propuesta.

Hasta el momento en el que se redacta este capítulo (principios de 2017), el Plan se encuentra elaborado y ya se ha llevado a cabo su publicación, estando en pleno proceso de ejecución. Es por ello que en su conformación pueden identificarse las siguientes fases: evaluación; análisis estratégicos y de futuros; elaboración de borrador; discusión interna; discusión con los representantes a nivel nacional; análisis y propuestas; nueva versión borrador; discusión parlamentaria; discusión y aprobación; implementación, evaluación intermedia; y adecuaciones.

Más particularmente, los hitos en relación con la línea del tiempo que han ocurrido son los siguientes:

- El 18 de diciembre de 2012: Se aprueba en consejo de gobierno la formulación de una Estrategia de Innovación en Andalucía como instrumento fundamental para avanzar hacia la reorientación del patrón de desarrollo económico de la región.

- En abril de 2013: Se iniciaron las reuniones de expertos para el diseño de la Estrategia de Investigación e Innovación de Andalucía (2014-2020) -Estrategia de Especialización Inteligente, RIS3-. 
- En diciembre de 2013: Celebración de la segunda reunión para la definición de la Estrategia de Innovación en Andalucía (2014-2020), y apertura a la opinión pública.

- En febrero de 2015: Aprobación de la Estrategia de especialización inteligente de Andalucía.

- En marzo de 2016: Aprobación del PAIDI por parte del Gobierno de Andalucía. ${ }^{6}$

- El 22 de marzo de 2016 publicado en el BOJA "Boletín de la Junta de Andalucía”, en el número 55.

- El 28 de marzo de 2016 presentado por la presidenta de la Junta de Andalucía: Susana Díaz.

La figura 2 recoge el proceso de diálogo para la elaboración del PAIDI 2014-2020.

En cuanto a los retos del proceso de diálogo, uno de los fundamentales ha sido que se está ante un diálogo en el que no existe un nivel homogéneo de capacidades de las comunidades; la comunidad del sector público tiene más poder durante todo el proceso y, concretamente, tiene más capacidades en la gestión de la política pública. Existe un lenguaje común y no existen grupos de poder e interesas de conflicto. La confianza que se ha creado en el proceso de diálogo es media, siendo las relaciones entre las comunidades intensa.

Figura 2. Diálogo para la elaboración del PAIDI 2014-2020

\section{PAIDI “ Plan Andaluz de investigación desarrollo e innovación” 2014-2020}

Fuente: elaboración propia.

6 Ver $<$ http://www.paidi2020.es $>$. 


\subsection{RESULTADOS}

Los acuerdos específicos que se han obtenido en el proceso de elaboración de la propuesta pueden entenderse como resultados del proceso de diálogo. En particular, cabe identificar tres tipos de resultados: los informes intermedios, las memorias sobre la implementación del Plan y la publicación final del mismo, convirtiéndose así en el documento maestro de la política de CTI en la región.

Como impacto del proceso de diálogo sobre el tema de diálogo puede destacarse la publicación del Plan de Ciencia y Tecnología (2014-2020), con especial énfasis en la Estrategia de Especialización Inteligente. El ámbito del impacto es legislativo, presupuestario y de implementación, y tiene influencia en la generación de la política regional de CTI así como en la generación de instrumentos para poner en práctica dicha política pública.

\subsection{LECCIONES APRENDIDAS DEL PROCESO DE DIÁLOGO Y SUS RESULTADOS E IMPACTOS}

Algunas de las lecciones aprendidas tienen que ver con las comunidades participantes en el proceso de diálogo y, en particular, en que su intervención puede considerarse representativa y heterogénea. Cabe igualmente reseñar entre las lecciones aprendidas dentro del proceso de diálogo un conjunto de buenas prácticas tales como que se está ante un proceso continuo de diálogo, de carácter permanente, con la comunidad empresarial y académica y refrendado por la sociedad civil. Además, hay una involucración horizontal del sector público ya que todos los departamentos del gobierno regional participaron en la elaboración del Plan. Y también se ha dado la involucración del sector público con carácter vertical, en instancias a nivel regional, nacional y europeo.

\section{MEJORA DE LA MOVILIDAD DEL PERSONAL INVESTIGADOR EN FORMACIÓN DE LAS UNIVERSIDADES HACIA LAS EMPRESAS - EL CASO IBERDROLA}

\subsection{RELEVANCIA Y CONTEXTO DE LA MOVILIDAD UNIVERSIDAD/INDUSTRIA}

El asentamiento de la economía basada en el conocimiento requiere la expansión de instrumentos de política pública en ciencia y tecnología orientados específicamente a favorecer tanto la formación como la movilidad de los recursos humanos. El supuesto básico es que la movilidad favorece la trasferencia de conocimiento entre agentes $y$, con ello, se incrementan las sinergias del conocimiento generado y acumulado en el sistema público de I+D. De ahí que el interés en el 
fomento de la movilidad de los recursos humanos en el interior de los sistemas de innovación, que propicie el flujo entre universidades y empresas, haya ido ganando terreno en el seno de las políticas de CTI, fundamentalmente en los últimos años.

Atendiendo al papel clave de la empresa como agente innovador por excelencia dentro de los sistemas de innovación, cabe destacar que entre los mecanismos existentes para la obtención de nuevo conocimiento está la contratación de investigadores científicos, ya formados o en proceso de formación. Ello permite que el capital humano contratado no solo reúna los conocimientos y destrezas necesarias, sino que también aporte conocimientos con valor único y exclusivo, lo que favorece el proceso innovador en el seno de las empresas. Algunos de los ejemplos de empresas que tuvieron una iniciativa similar en el pasado en el contexto español, es la llevada a cabo por el Grupo Santander, que ofertaba becas en prácticas desde 2005. Mediante estas, se conseguía contratar estudiantes en prácticas pero no era posible contratar a aquéllos en formación o potenciar la movilidad de investigadores vinculados a las universidades. ${ }^{7}$

En el caso de España, las políticas de movilidad del personal entre universidades y empresas han estado ligadas a la formulación de los planes nacionales de Ciencia, Tecnología e Innovación. Desde la aprobación del primer Plan Nacional en 1986, han sido numerosos los cambios que se han ido introduciendo de forma progresiva en ese instrumento de planificación, con el objetivo de adaptar las políticas públicas en materia de investigación, desarrollo e innovación (I+D+I) a las necesidades de un entorno dinámico y, especialmente, a las necesidades del propio sistema nacional de CTI. Una de esas necesidades es la de incrementar la movilidad de investigadores desde la universidad a la empresa, por lo que con los años se han ido definiendo acciones encaminadas a la contratación de personal investigador en formación en el sector empresarial.

La legislación y las políticas para fomentar la movilidad de investigadores, empezaron por regular la formación de doctores en empresas, mediante la cofinanciación de los contratos laborales del personal investigador en formación que participaba en un proyecto de investigación industrial o de desarrollo experimental, en el que se enmarcara su tesis doctoral. El fin de esas acciones era favorecer la

7 Los contratos en formación son aquéllos en los que el recurso humano sigue estudiando o investigando, a través de la realización de trabajos vinculados con su especialidad. Asimismo, se suele contratar personal más especializado (con formación de maestría o doctorado). Por su parte, la movilidad es un contrato de investigador a tiempo completo generalmente vinculado a unidades de las empresas que realizan actividades de I+D. 
inserción laboral de los investigadores en el ámbito empresarial desde los inicios de sus carreras profesionales, contribuir a la empleabilidad de estos investigadores y promover la incorporación de talento en el tejido productivo para elevar la competitividad del mismo. ${ }^{8}$

Pese a los avances logrados, siguieron persistiendo algunas lagunas en la regulación que suponían dificultades a la movilidad del recurso humano entre universidades y empresas; problemas que en parte han sido detectados por el sector empresarial al intentar contratar personal investigador. Tal es el caso de Iberdrola, empresa multinacional española líder en el sector energético, que a través de la Fundación Iberdrola puso en marcha un programa de becas y ayudas a la investigación a principios de la década pasada. El objetivo principal consistía en impulsar la formación de nuevos investigadores, fomentar la investigación en el área de energías renovables, promover la movilidad de jóvenes doctores e ingenieros desde la Universidad a la Empresa, y proporcionarles un espacio de creación de competencias mediante un programa de formación entre España y Estados Unidos.

Como resultado de esa experiencia, y con el impulso conferido por Iberdrola, comenzó a desarrollarse un proceso de diálogo entre actores políticos, académicos y empresariales que buscaban superar las dificultades encontradas en la empleabilidad de los investigadores, la incorporación de talento a las empresas, y la legitimidad de los programas de contratación de investigadores formados y en formación, entre universidades y empresas. La necesidad de cambios regulatorios y el diseño de políticas encaminadas a fomentar la movilidad del personal científico en formación son reconocidos por los diversos grupos de interés. Las contribuciones de los sucesivos planes nacionales de $\mathrm{I}+\mathrm{D}$ favorecieron poder avanzar en esa dirección, pero los vacíos normativos y el enfoque de la política en ese momento no permitían corregir acertadamente la problemática reconocida desde la comunidad empresarial y académica. ${ }^{9}$ En ese sentido, el diálogo fue pertinente para tratar de modificar las políticas en materia de ciencia y tecnología, fomentar la colaboración entre sectores y la regulación, acreditación y respaldo del Estado a la financiación de becas de formación, investigación y movilidad de científicos e investigadores a la empresa.

En el actual contexto político y económico, España debe enfrentar el objetivo de impulsar la actividad económica, crear nuevos puestos de trabajo y aumentar la productividad y competitividad del país.

8 Véase, por ejemplo, el Real Decreto 63/2006 y el Plan Nacional de I+D+i para 2004-2007.

9 Véase el concepto de comunidad desarrollado en Barboza et al. (2016). 
Desde un diálogo social permanente, es necesario abordar reformas estructurales que se acerquen a un nuevo modelo económico sostenible y de futuro. En lo que respecta a la gestión de personas y de los recursos humanos, algunos de los ejes de actuación fundamentales son la rotación y la movilidad, la formación, el desarrollo profesional, la conciliación y la igualdad de oportunidades. Dentro de los planes de ciencia y tecnología europeos (programas Marco de la UE y el actual Horizonte 2020) se enmarca la idea de regular y mejorar, mediante la modificación de la legislación de CTI, la inserción laboral de investigadores formados en universidades a las empresas privadas. En este sentido, Iberdrola ha ido anticipando algunas de las medidas estructurales necesarias, habiendo diseñado desde 2002, un modelo propio de relaciones laborales.

Entre los principales resultados de este diálogo cabe mencionar el refuerzo de la política que apoye y regule la movilidad del personal investigador en formación desde la universidad a la empresa, que también ha ayudado a impulsar el número de investigadores contratados en las empresas en el país.

\subsection{CONTEXTO HISTÓRICO DEL PROCESO DE DIÁLOGO}

Los orígenes del diálogo se remontan a 2002, año en el que Iberdrola se planteara realizar un programa de becas de investigación que se publicó en primera convocatoria en 2004. Sin embargo, no fue hasta 2011 cuando el diálogo tuvo efectos directos en materia de política CTI, publicándose en la Ley 14/2011 de Ciencia, la Tecnología y la Innovación, un apartado en el que se modificaban las condiciones bajo las cuales quedaban regulados los contratos predoctorales en las empresas. Este resultado se logró a través de la realización de un sin número de reuniones de expertos, ${ }^{10}$ así como grandes esfuerzos en la búsqueda de los consensos necesarios. Gracias a este proyecto, culminado en ley, los investigadores tienen una nueva plataforma para la formación, la producción de conocimiento científico y su transferencia.

Entre las acciones anteriores cabe mencionar los planes nacionales de I+D que promovían la asignación de becas post-doctorales, así como iniciativas individuales por parte de la empresa privada que no tenían las mismas características que estas ya que no ofrecían movilidad, ni apoyo a la investigación; se trataba, simplemente, de becas de trabajo como, por ejemplo, las mencionadas becas que el Banco Santander asigna desde el 2005.

10 Notas en prensa del 4 de noviembre de 2015 y del 30 de diciembre de 2014, disponibles en <www.iberdrola.com: Sala de Prensa $>$. 
El avance más significativo es, por lo tanto, la adecuación de las normas que regulan la contratación del personal investigador y la creación de becas privadas de inclusión, movilidad y formación, en un entorno y relación contractual más favorable. Los investigadores tienen una nueva plataforma para producir conocimiento científico (Ley 14/2011, de 1 de junio, de la Ciencia, la Tecnología y la Innovación).

El tema del diálogo, por lo tanto, es el fomento del aprendizaje de los jóvenes investigadores, que mueve a las empresas a reforzar la ayuda que prestan a la formación. Este tipo de acciones se hace visible de forma especial en las grandes compañías, tales como Iberdrola, cuya estrategia en este terreno se define en dos líneas esenciales: primera, los programas o contratos específicos destinados a la creación de puestos de trabajo en la propia empresa, sobre todo para universitarios y, segunda, las subvenciones que conceden las firmas para la formación, bien sea a través del patrocinio de actividades educativas, la colaboración con universidades o incluso la existencia de un campus propio.

En colaboración con varias universidades, Iberdrola ha puesto en marcha desde 2002 un plan de acción dirigido a fomentar la contratación de jóvenes y facilitar la movilidad de investigadores desde la Universidad a la empresa. En particular, durante el último año, alrededor de 700 jóvenes se han formado en la empresa como becarios, para luego ser contratados como investigadores. Además, desde 2004 Iberdrola mantiene acuerdos de colaboración con Fundación Carolina (becas de postgrado), Fundación Príncipe de Girona (programa de becas al talento emprendedor), Fundación Universitaria Comillas-ICAI (Programa Ciencia y Tecnología), Fundación Universitat Jaume I Empresa (Programa relación Universidad Empresa), Fundación General de la Universidad de Salamanca (Programa de relación entre Universidad y entidades Públicas y Privadas).

Iberdrola continúa siendo parte de este proceso de diálogo, manteniendo su compromiso, que se hace más notorio al haber suscrito el 20 de mayo de 2013 su adhesión a la Estrategia de emprendimiento y empleo joven 2013-2016 del Gobierno de España. En el marco de este acuerdo, la empresa elaboró un Plan de Acción dirigido principalmente a fomentar la contratación de jóvenes investigadores en su primera experiencia profesional fuera de la universidad. ${ }^{11}$

El proceso de diálogo no fue sencillo. Se hizo necesario un compromiso fuerte por parte de los actores involucrados, sobre todo del promotor del diálogo -Iberdrola-, por el carácter de novedad que suponía en España el hecho de que la empresa privada llevase a cabo iniciativas de diálogo para la generación de una política, de la que no sería la única beneficia-

11 Diario Actualidad Económica del 1 de septiembre de 2013, p. 6. 
da, sino que se extendería al resto de empresas e investigadores. También cabe destacar el gran papel que tuvieron las universidades españolas, ya que a pesar de su inflexible sistema de gobierno contribuyeron en el diálogo y coadyuvaron para lograr los cambios legislativos necesarios para permitir la contratación de jóvenes investigadores en las empresas privadas.

Como ya hemos dicho, existen antecedentes en este proceso de diálogo, pero sus iniciativas se diferenciaban de esta que se analiza en diversos aspectos tales como el énfasis en la contratación del personal directamente relacionado con las actividades de I+D en las empresas, la concesión de becas de prácticas, y no para la formación como ya era tradicional, y la formalización de contratos que no se regían por las mismas normas que los contratos de investigación.

Así también, el capítulo II de la Ley 14/2011, de 1 de junio, de la Ciencia, la Tecnología y la Innovación, contiene el mandato de las Administraciones Públicas de fomentar la valorización del conocimiento, entendida como la puesta en valor del conocimiento obtenido mediante el proceso de investigación, con objeto de que los resultados de la investigación promovidos o generados por ella se transfieran a la sociedad. En este contexto se incluye el fomento de la transferencia inversa del conocimiento liderada por el sector empresarial en colaboración con los agentes de investigación para el desarrollo de los objetivos de mercado basados en dichos resultados.

Gracias a este diálogo impulsado por Iberdrola se han logrado, entre otras, la modificación de diversos ámbitos normativos en los que se apoyan las Políticas en Educación Ciencia y Tecnología:

- La más importante, Ley 14/2011, de 1 de junio, de la Ciencia, la Tecnología y la Innovación, que regula la contratación y movilidad de investigadores, les dota de derechos laborales, ofrece a las empresas ventajas incluso para la divulgación de los avances científicos, entre otros;

- Ley 38/2003, de 17 de noviembre, General de Subvenciones (vigente hasta el 1 de enero de 2016), que regulaba la parte de la actividad financiera del sector público que se canaliza a través de subvenciones, con el objeto de dar respuesta través de medidas de apoyo financiero, a demandas sociales y económicas de personas y entidades públicas o privadas;

- Rea decreto (RD)887/2006, de 21 de julio, por el que se aprueba el Reglamento de la Ley General de Subvenciones 38/2003, de 17 de noviembre, que habilita al Gobierno a aprobar un reglamento general para la aplicación de Ley 38/2003 que integre las previsiones contenidas en la misma; 
- El artículo 20 de la Ley 46/2003, de 25 de noviembre, reguladora del Museo Nacional del Prado, en la que se contempla becas de movilidad y apoyo a la restauración de arte y que también obedece al diálogo promovido por Iberdrola mediante su fundación;

- RD 63/2006, de 27 de enero, por el que se aprueba el Estatuto del personal investigador en formación.

La figura 3 recoge los hitos más importantes de este proceso de diálogo.

Figura 3. Diálogo Iberdrola

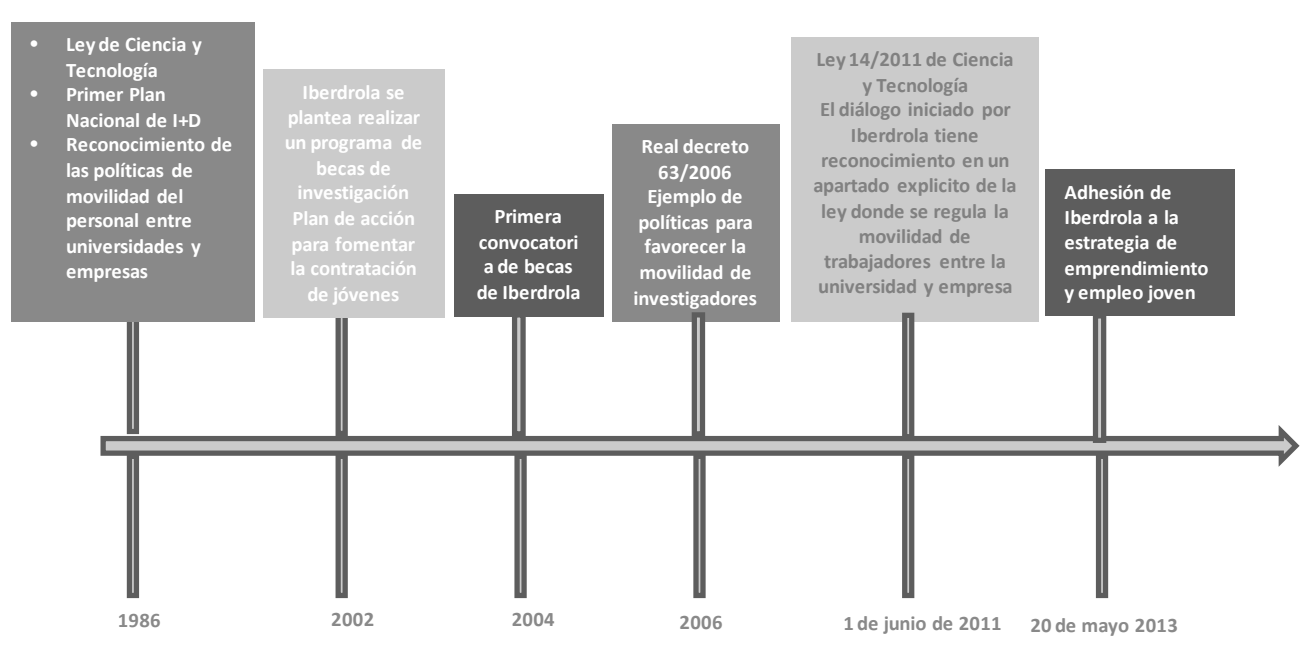

Fuente: elaboración propia

\subsection{PROPÓSITO Y ALCANCE}

El objetivo de los participantes en el diálogo ha sido llegar a acometer cambios en la regulación y en las políticas de fomento a la formación de investigadores, aunando intereses tanto públicos como privados, $\mathrm{y}$ ante la necesidad que tienen las empresas de incorporar y formar investigadores de alto nivel para enriquecer sus procesos de $\mathrm{I}+\mathrm{D}+\mathrm{i}$, generar su propio "know how" e incrementar las innovaciones en temas de interés para las firmas.

Dichos intereses quedaron explicitados en el propósito de conseguir establecer una regulación para la contratación de investigadores que fomente la colaboración entre la universidad y la empresa, con todos los beneficios que esto aportaría (contratación de personal cua- 
lificado, impulso a las actividades de $\mathrm{I}+\mathrm{D}$, mayor número de patentes y publicaciones, además de ventajas fiscales). Es por ello que se puede afirmar que lo novedoso y particular de este diálogo reside en que la iniciativa provino de la empresa privada.

En cuanto al alcance, este se puede describir en tres ámbitos. En primer lugar, el alcance temporal, ya que el diálogo se inició en 2002, habiendo transcurrido casi una década hasta su culminación con la incorporación de la propuesta para la movilidad en la Ley 14/2011. En segundo lugar, su alcance sectorial abarca todos los sectores económicos en los que se pueda llevar a cabo I+D. Dentro de estos, el sector agrícola, con empresas dedicadas a la investigación de nuevos procesos de siembra, cosecha, conservación y mejora de las especies; el sector industrial, con empresas dedicadas a la investigación y desarrollo de nuevos procesos productivos; y, por último, el sector servicios, en el que destacan, sobre todo las empresas dedicadas a la investigación en TIC. En tercer lugar, al atender a su alcance geográfico, cabe decir que este ha sido amplio ya que el diálogo acabó por extenderse a todo el territorio español.

\subsection{COMUNIDADES IDENTIFICADAS}

Este diálogo ejemplifica la colaboración que puede fructificar entre los sectores público, académico y empresarial, y cómo comunidades con perfiles tan diferentes pueden consensuar medidas en la definición de la política pública de CTI que acabe por generar efectos positivos a favor del beneficio común.

En todo caso, la comunidad empresarial en este diálogo ha sido una pieza clave: fue específicamente el sector empresarial quien propusiera y dirigiera el diálogo, aunque claramente apoyado desde sus principios por el sector público y llegándose a promulgar la modificación de la regulación que ampara y da legitimidad a la relación contractual entre los beneficiarios del diálogo (investigadores) y la empresa privada. Iberdrola es una empresa multinacional española que en su estrategia preferente por la innovación detectó que hacía falta renovar su plantilla, y que la mejor opción podía ser atrayendo el talento que se encuentra en las universidades. Con esto, además de beneficiarse contratando jóvenes investigadores (por un coste menor, además de las deducciones fiscales asociadas) también colaboraba en la disminución del número de parados o de jóvenes con alto nivel de cualificación que están emigrando de España en búsqueda de mejores oportunidades profesionales. El fuerte empuje que representa Iberdrola para la inserción de jóvenes doctores e ingenieros en el mundo empresarial es imitable por otras empresas que también pueden obtener similares resultados favorables. 
La comunidad académica tiene una gran relevancia en este diálogo, pues es en las universidades donde se encuentran los jóvenes talentos, doctores, investigadores e ingenieros, dispuestos a incorporarse desde el mundo de la investigación al seno de una empresa. La participación de la academia en el diálogo se define por la aportación del conocimiento sobre las necesidades de los jóvenes investigadores, así como mediante el ajuste de su estructura organizativa y de gestión para facilitar la firma de convenios y contratos de prácticas con empresas.

En cuanto a la comunidad de sector público, cabe valorar que ha sido un sector relevante en el diálogo ya que no solo ha accedido al diálogo promovido desde el sector privado, sino que lo ha apoyado y fomentado mediante la firma de acuerdos, proyectos y leyes. En particular, han intervenido el Ministerio de Educación, Cultura y Deporte; el Ministerio de Ciencia e Innovación; y el Ministerio de Industria, Energía y Turismo. Esto ha dado como resultado la aprobación de nuevas leyes en materia de CTI que incrementan el interés y beneficios de los intervinientes. El sector público ha participado en los debates, incorporando modificaciones y defendiendo los cambios en la Ley de CTI para fomentar y regular la contratación de jóvenes investigadores en las empresas, estando también implicado en el diseño de los instrumentos de política necesarios para implementar la ley y ejecutar los programas de apoyo a las mismas.

Teniendo en cuenta a otros sectores de la comunidad civil, esta es la única comunidad que no ha intervenido, aunque se ve beneficiada por los efectos que estas leyes y proyectos puedan tener en la sociedad.

En definitiva, la iniciativa se generó en la comunidad empresarial, al haber detectado debilidad en su sistema de formación y contratación de personal cualificado, así como habida cuenta del talento que realizan I+D en las universidades y cuyas capacidades y resultados no están suficientemente utilizados en el sistema español. La comunidad académica, con el objetivo de fomentar la investigación e innovación, ha apoyado arduamente al sector empresarial en la búsqueda de acuerdos para llevar a cabo las pertinentes modificaciones en las leyes por parte del sector público y este, a su vez, encontró en esta iniciativa una salida para los jóvenes con altos niveles de cualificación que se encontraban desempleados o subempleados en el país.

\subsection{CARACTERÍSTICAS DEL PROCESO DE DIÁLOGO}

Un aspecto característico de este diálogo es que fuera la comunidad empresarial quien adoptara la iniciativa, en este caso representada por una empresa, Iberdrola. Ello obedece a que son las empresas las entidades que recibirán y financiarán la formación y la movilidad de 
los investigadores procedentes del mundo académico. Estamos, por lo tanto, ante un diálogo que ha seguido una dirección bottom-up, que emerge desde las empresas para tratar de resolver una debilidad que se detecta a nivel del sistema nacional de innovación. Por su parte, el sector con más capacidades ha sido el académico, pues no solo es en el que se forman los nuevos talentos, sino que además tiene en su mano la experiencia en la firma de acuerdos de colaboración y la disponibilidad para facilitar la emergencia de acuerdos y contratos con el sector privado. En cuanto al sector público, es este el que ha aportado los mecanismos de legalidad, dando agilidad a todos los trámites y creando una normativa que reporta beneficios tanto a los jóvenes investigadores (becas, empleo), como a la empresa (know how y mejora de su imagen social corporativa), y a la sociedad (crecimiento del empleo y mejora de los servicios gracias a las innovaciones y mejoras de procesos).

Existe un lenguaje común entre los actores, atendiéndose a que es coincidente la concepción que se tiene, entre otros, sobre la búsqueda de innovaciones, la optimización de los recursos, y el aumento del empleo (de calidad). Por otra parte, cabe afirmar que en el diálogo se detecta el poder de lobby que en particular ejerce la comunidad empresarial, en este caso representado por Iberdrola, siendo la que finalmente financia toda la operación y también la que se verá más claramente beneficiada por los resultados del diálogo. No obstante, el diálogo ha servido para crear espacios de confianza gracias a los beneficios comunes que aporta la propuesta hecha por la comunidad empresarial (por ejemplo, crecimiento del empleo, joven y de calidad), y también gracias a los niveles en los que se llevaba a cabo el diálogo, con la participación de altos cargos que actuaron como representantes de empresas, universidades y de la comunidad del sector público.

Sobre la interacción entre actores, puede destacarse que se fomentó mediante la relación entre las comunidades empresarial y académica a través de reuniones, puesta en común de propuestas, firma de acuerdos de colaboración y apoyo en la elaboración de la estrategia y el posterior desarrollo del marco normativo. Tales relaciones fueron refrendadas y apoyadas mediante la interacción entre el ámbito empresarial y del sector público. Un aspecto a destacar es que el mantenimiento de una agenda a la que contribuyeron todos los actores que han participado en el diálogo sirvió para alimentar la existencia de reglas del juego formales y compartidas por las distintas comunidades involucradas en el proceso. Asimismo, como reglas del juego informales, cabe mencionar las agendas de las reuniones que cada actor mantenía con su sector, así como el feedback que este le proporcionaba y enriquecía el diálogo buscando la optimización de la estrategia a seguir. 
En cuanto a las fases y etapas del proceso de diálogo, la primera fue la detección del problema, a la que siguieron diversas reuniones dentro de la empresa y reuniones con expertos de las universidades. La siguiente fase fue la elaboración de la estrategia y una propuesta. A continuación, se convocaron y se llevaron a cabo reuniones con ministerios, a las que le siguieron la fase de implementación y ejecución.

Respecto al método seguido (Nupia \& Martínez, 2016), cabe destacar, en primer lugar, que se desarrolló a partir de la realización de estudios técnicos, para conocer el estado del arte, el origen del problema así como las soluciones posibles. En segundo lugar, se procedió con la creación de un equipo de expertos; se integraron equipos de expertos para analizar todas las vías posibles, así como los costes y beneficios en los que se incurriría con esta acción. En tercer lugar, el desarrollo del diálogo con los actores involucrados, para llegar a los acuerdos (leyes) necesarios. Y, aunque no ha existido una evaluación como tal, sí que se conocen las opiniones de los actores involucrados y de la sociedad. Además, existen datos que ayudan a evaluar las actuaciones del diálogo, tales como el número de investigadores contratados en las empresas.

Convencionalmente, la visión predominante siempre ha sido que debería ser el Estado quien propusiese este tipo de diálogos y llevara a cabo todas las estrategias, así como la financiación de los programas de becas. No obstante, ha sido valorado muy positivamente por parte de la sociedad, y también por los actores involucrados, que haya sido una empresa como Iberdrola la promotora del diálogo y que con esto se consiga emplear a jóvenes investigadores en temas relevantes para el Horizonte 2020, sin incrementar el coste en las arcas públicas. El fin de este diálogo ha sido el de lidiar con un problema detectado por parte de actores con capacidades no homogéneas y haber conseguido ponerse de acuerdo y llevar a buen fin la propuesta planteada por Iberdrola, elevándola al máximo nivel normativo.

En cuanto a los retos del proceso de diálogo, el principal de ellos consistió en incorporar en la ley de Ciencia, la Tecnología y la Innovación, una propuesta concertada para mejorar la movilidad de estudiantes investigadores desde las universidades a las empresas, ${ }^{12}$ cuya iniciativa provino de una empresa privada (Iberdrola). A pesar de que este no es un tema absolutamente nuevo en el espectro de políticas de formación de capital humano y del fomento a la investigación en España, sí que es ciertamente novedoso que la propuesta haya sido promovida desde la empresa. También lo es que el resultado se haya

12 Informe de Innovación Iberdrola 2009-2011; Informe de Innovación Iberdrola 2011-2013; Informe Fundación I+E: Innovación en España. 
integrado finalmente en las acciones de política pública en CTI, aspecto que confiere un importante grado de novedad al diálogo, habiéndose llegado a modificar la política que apoya y regula la movilidad de investigadores. Este es un hecho que ha generado además efectos positivos en la vinculación e integración de la relación entre la universidad y la empresa dentro del sistema español.

\subsection{RESULTADOS}

El resultado principal del diálogo es la inclusión en la Ley 14/2011 de Ciencia, la Tecnología y la Innovación ${ }^{13}$ de un apartado en el que se modifican las condiciones bajo las cuales se regulan los contratos predoctorales (artículo 21), así como los acuerdos entre todos los agentes involucrados (Universidades, Centros de Formación, Parques Científicos, etc.), dando legitimidad a la contratación, formación y movilidad de investigadores en la empresa privada. En breve, se puede afirmar que este diálogo ha tenido dos grandes resultados: por un lado, un mayor entendimiento entre las partes interesadas y, por otro, la consecución de acuerdos específicos y los cambios en la regulación que afecta al sistema de innovación español.

Sin duda alguna, una de las comunidades más beneficiada ha sido la empresarial, ya que, aunque se fomenta la incursión de jóvenes a sus filas, lo hace otorgando sueldos de becarios a personal cualificado, además de hacer sus procesos más eficientes, cumplir las normativas, buscar soluciones innovadoras (con el beneficio económico que eso conlleva) así como mejorar su imagen ante la sociedad. Para la comunidad del sector público y la académica, los beneficios a corto plazo son menos tangibles. Sin embargo, se trata de resultados muy relevantes en tanto que no se tiene que hacer frente a un incremento de los subsidios o a un incremento de los presupuestos propios para incorporar a los investigadores e ingenieros al mercado laboral. A ello se une el beneficio directo que le aporta a España el mantener personal de alto nivel de cualificación dentro de sus fronteras. A los investigadores les permite incorporarse como trabajadores en áreas estratégicas de las empresas y formarse en entornos creativos tales como, por ejemplo, los departamentos de I+D.

Habiéndose hecho un seguimiento del programa, teniendo en cuenta el número de aspirantes a las convocatorias, así como el out-

13 Capítulo I, Sección $1^{\text {a }}$, artículos 13 (que habla sobre el Personal Investigador), 17 (sobre la Movilidad del Personal Investigador) y 18 (que trata la Autorización para prestar Servicios en Sociedades Mercantiles), así como Sección 2a, Artículos 21 (sobre el Contrato Pre-Doctoral), 22 (que habla sobre el Contrato de Acceso al Sistema Español de Ciencia, Tecnología e Innovación) y 23 (sobre el Contrato de Investigador Distinguido). 
put obtenido (número de artículos, patentes, etc.), cabe reseñar que se ha ido incrementando, año tras año, el número de plazas en las convocatorias y presupuestos, dándose así nuevas oportunidades a más jóvenes investigadores en el país.

El impacto del proceso de diálogo ha sido significativo ya que gracias a este se ha logrado la firma de más acuerdos de colaboración, así como la modificación de las leyes que regulan la formación y contratación de investigadores por parte de las empresas y la movilidad de expertos en $\mathrm{I}+\mathrm{D}+\mathrm{i}$ hacia el sector empresarial. En particular, el impacto se observa en la influencia que ha tenido en la política española de CTI y, específicamente en el ámbito legislativo, ya que se ha conseguido incluir en la Ley de CTI una mayor legalidad a la contratación, formación y movilidad de investigadores desde las universidades a la empresa privada. Igualmente, en el ámbito de la implementación, puesto que además de la empresa promotora que lo ha puesto en marcha, el objeto del diálogo ha alcanzado el rango de ley, pudiendo beneficiar a todas las empresas españolas.

\section{7. LECCIONES APRENDIDAS DEL PROCESO DE DIÁLOGO Y SUS RESULTADOS E IMPACTOS}

En cuanto a las lecciones que pueden ser aprendidas a partir de este diálogo, cabe enunciar la existencia de algunas buenas prácticas, que podrían ser extendidas a otras iniciativas de carácter similar. En primer lugar, el hecho de haberse tratado de una iniciativa de la comunidad empresarial que ha acabado por traducirse en la generación de impactos en el ámbito normativo; esto es, el diálogo ha seguido un enfoque bottom-up y los resultados son exitosos para el ámbito de la política CTI en España. En segundo lugar, la financiación ha recaído en el sector empresarial y ha sido estrecha la colaboración que se ha generado entre la comunidad empresarial, la académica y la del sector el público, habiendo sido activa la participación académica y habiéndose implicado al sector público para que apoyara una iniciativa de origen privado. En tercer lugar, cabría extraer otras lecciones a partir de la observación de cuáles son los obstáculos enfrentados; por un lado, aquéllos que emergieron de la puesta en común de los intereses todos los actores, con la existencia de grupos de poder y ante un conjunto de actores no homogéneos, y que no imposibilitaron la marcha del diálogo y la consecución de los fines.

Finalmente, al atender a los impactos del diálogo, la principal lección aprendida es que el proceso ha sido capaz de conjugar a tres comunidades disímiles y heterogéneas desde un enfoque bottom-up con impactos positivos en el sistema de innovación y la sociedad española. Por una parte, cabe subrayar en este contexto la involu- 
cración y aportación del sector privado en la modificación de la legislación para respaldar la movilidad de la universidad a la empresa. Por otra, cómo la conjugación de intereses a pesar de la diversidad de los diferentes actores, incluso cuando son heterogéneos, jugó un papel fundamental, hasta tal punto que en este diálogo se valora el predominio de los intereses de los investigadores sobre los de las empresas, a pesar de los severos reglamentos internos tanto de estas, que han sabido hacer coordinar los intereses de los primeros con los suyos propios.

\section{CONCLUSIONES}

La descripción de los dos casos que se ha hecho en las páginas anteriores, permite concluir que los diálogos que ocurren en el seno de las distintas comunidades de los sistemas de innovación son clave para la definición de políticas de CTI. El análisis permite diferenciar diálogos que se originan convencionalmente desde el sector público y que se definen como top-down, y otros que emergen por la iniciativa desde más abajo, desde aquéllos actores más cercanos al problema específico que se dirime y que constituye procesos de carácter bottom-up.

Respecto al diálogo generado para la definición del plan regional de CTI en Andalucía, cabe subrayar cómo la construcción de un programa a nivel regional es capaz de incluir y hacer compatible los intereses nacionales y europeos, aunque en última instancia esté orientado a fortalecer el desarrollo de la región. Además, se está ante un diálogo integrador por cuanto se trata de una estrategia que considera sectores y especificidades locales, esto es, un diálogo que atiende temas transversales, específicos y generales. Igualmente, cabe reseñar que, estando dirigido por la demanda de la industria y de la sociedad, incorpora una alta especificidad estructural, a través de la incorporación de sectores "low-tech" en la estrategia de CTI en la región.

El segundo diálogo, el de la movilidad de investigadores desde la universidad hacia la empresa, impulsado por Iberdrola, lleva a resaltar que aunque las dimensiones, campos de acción y prioridades de todos los actores que intervienen en este diálogo sean muy diferentes, es posible contemplar cómo los beneficios de la interacción entre actores de distintas comunidades puede ser extensible al conjunto de la sociedad, al haberse implicado en una iniciativa para fomentar el empleo de investigadores jóvenes, potenciando las relaciones entre la universidad y la empresa. Una de las lecciones aprendidas es que frente a la generalizada convicción y la amplia extensión de diálogos y procesos de carácter top-down en el marco de las políticas CTI, existe la posibilidad cierta de admitir la contribución que puede realizarse desde el sector privado para promover diálogos y acciones a favor de 
la política pública de CTI, lo que finalmente tenderá a favorecer la movilidad de investigadores y la colaboración y la transferencia de conocimiento, reforzando los vínculos aun débilmente consolidados entre los distintos actores del sistema de innovación.

En definitiva, en este trabajo sobre dos diálogos que en el marco de las políticas CTI han tenido lugar en España en las últimas décadas, se ha tratado de describir cuáles son las comunidades involucradas, así como las características de los procesos en los que se relacionan e interactúan actores heterogéneos para resolver problemas complejos y de interés mutuo. El propósito no ha sido otro que arrojar algo de luz sobre las características que han presentado los diálogos, sus objetivos y fines, asumiéndose como elemento común la identificación de un problema de falta de vinculaciones entre comunidades en el seno del sistema nacional. Y cómo esa debilidad justifica la puesta en común de posiciones que $a$ priori no son coincidentes pero que pueden llegar a converger a través de un proceso de aprendizaje interactivo sobre el que acaba avanzando la evolución de los sistemas. A veces es imitativo, cuando se toman prestadas las ideas de las políticas de CTI que han funcionado bien en otros países, en otros contextos o latitudes, o incluso cuando debe adaptarse a las directrices marcadas por alguna institución supranacional. Otras veces, sin embargo, es la resolución de un problema local la que desata un proceso de necesario entendimiento entre comunidades y actores, que lleva a hacer emerger endógenamente novedosas propuestas, instrumentos, normativas e incluso instituciones que promuevan la innovación en el sistema para fortalecer una sociedad basada en el conocimiento.

El análisis y la mejor comprensión de los diálogos se convierte, por todo lo anterior, en un ejercicio académico que debe ser objeto de una mayor atención en la investigación social.

\section{BIBLIOGRAFÍA}

Álvarez, I.; Barletta, F.; Suárez, D.; Yoguel, G. 2016 "Marco analítico para la tipificación de diálogos para las políticas de CTI" en Working paper 3 (Red CYTED COM-LALICS). En <http://lalics. org/images/CYTED/DT3-DimensionesDialogo.pdf $>$.

Álvarez, I.; Juan, M.; Torrecillas, C. "Specificity and pervasiveness of dialogues in Science, Technology and Innovation policies in Spain" en Science and Public Policy (Reino Unido: Oxford University Press). En <https://doi.org/10.1093/scipol/scx055>.

Arroyo, A.; Facal, J.; Muñoz, E.; Sebastián, J.; Tortosa, E. 2007

"Legislar sobre política científica para el siglo XXI en España:

Un nuevo marco normativo para la política de I+ D" en Arbor (España) $\mathrm{N}^{\mathrm{o}}$ 183(727), pp. 637-654. 
Barboza, L. 2016 “Algunas consideraciones en torno al concepto de comunidad” en Working paper 6 (Red CYTED COM-LALICS). En <http://lalics.org/images/CYTED/DT6-DefinicionComunidad. pdf $>$.

Brown, M. 2015 "Politicizing science: Conceptions of politics in science and technology studies" en Social studies of science (SAGE Journals) $\mathrm{N}^{\circ}$ 45(1), pp. 3-30.

Burgess, J.; Chilvers, J. 2006 "Upping the ante: a conceptual framework for designing and evaluating participatory technology assessments" en Science \& Public Policy (Reino Unido: Oxford University Press) $\mathrm{N}^{\mathrm{o}}$ 33(10), pp. 713-728.

Comisión Europea 2010 Una política industrial integrada para la era de la globalización: poner la competitividad y la sostenibilidad en el punto de mira. Comunicación de la Comisión al Parlamento Europeo, al Consejo, al Comité Económico y Social Europeo y al Comité de las Regiones (Bruselas: Comisión Europea).

Comisión Europea 2013 Measuring innovation output in Europe: towards a new indicator (Bruselas: Comisión Europea).

Comisión Europea 2014a Por un renacimiento industrial europeo. Comunicación de la Comisión al Parlamento Europeo, al Consejo, al Comité Económico y Social Europeo y al Comité de las Regiones (Bruselas: Comisión Europea).

Comisión Europea 2014b Research and Innovation performance in Spain. Country Profile, 2014 (Bruselas: Comisión Europea).

Comisión Europea 2015 European Innovation Scoreboard (Bruselas: Comisión Europea).

Crespi, G.; Dutrénit, G. 2013 Politicas de ciencia, tecnología e innovación para el desarrollo: experiencia latinoamericana (México: Foro Consultivo Científico y Tecnológico).

Chilvers, J. 2013 "Reflexive engagement? Actors, learning, and reflexivity in public dialogue on science and technology" en Science Communication (SAGE Journals) No 35(3), pp. 283-310.

Dutrénit, G.; Natera, J. M.; Suárez, M. 2014 "Lineamientos para la caracterización de las Comunidades y sus Procesos de Diálogo" en Working paper 1 (Red CYTED COM-LALICS). En <http:// lalics.org/images/CYTED/DT1-ComunidadesDialogo\%201.pdf $>$.

Dutrénit, G.; Álvarez, I.; Ardanche, M.; Barletta, F.; Bianco, M.; Cortés, R.; Vera-Cruz, A. 2016 “Matriz de Información para el mapeo de procesos de diálogo de CTI en España, América Latina y el Caribe" en Working paper 5 (Red CYTED COM-LALICS). En <http://lalics.org/images/CYTED/DT5-Formulario2.pdf>. 
Dutrénit, G.; Natera, J. M.; Puchet Anyul, M.; O. Vera-Cruz, A.; Torres, A. 2017 "Dialogue processes on STI policy-making in Latin America and the Caribbean: dimensions and conditions", En Science and Public Policy pp. 1-16. En <doi: 10.1093/scipol/ scx044>.

Edquist, C. 2004 "Systems of innovation perspectives and challenges" en Fagerberg, J.; Mowery, D.; Nelson, R. (eds.) The Oxford handbook of innovation (Oxford: Oxford University Press).

Fagerberg, J.; Sapprasert, K. 2011 "National innovation systems: the emergence of a new approach" Science \& Public Policy (Reino Unido: Oxford University Press) $\mathrm{N}^{\circ} 38(9)$, pp. 669-679.

Fagerberg, J.; Srholec, M.; Knell, M. 2007 "The competitiveness of nations: Why some countries prosper while others fall behind" en World development (Países Bajos: Elsevier) No 35(10), pp. 1595-1620.

Fagerberg, J.; Srholec, M.; Verspagen, B. 2010 "The role of innovation in development" Review of Economics and Institutions (Italia: University of Perugia Electronic Press) $\mathrm{N}^{\circ}$ 1(2), pp. 1-29.

Freeman, C. 1987 Technology Policy and Economic Performance: Lessons from Japan (Londres: Frances Pinter).

Goñi, M.; Bianco, M.; Puchet, M. 2015 "Elementos para caracterizar los procesos de diálogo en políticas de CTI” en Working paper 7 (Red CYTED COM-LALICS). En <http://lalics.org/images/ CYTED/DT7-ConfianzaPoder.pdf $>$.

Insenser, J.; Jiménez, J. 2014 La I+D+I en el debate político español (Madrid: Foro de Empresas Innovadoras).

Lundvall, B. 1988 "Innovation as an interactive process: from userproducer interaction to the national system of innovation" en Dosi, C.; Freeman, R.; Nelson, R. (eds.) Technical Change and Economic Theory (Nueva York: Pinter Publishers).

Lundvall, B. 2007 "National innovation systems - analytical concept and development tool" en Industry and innovation (Reino Unido: Routledge) $\mathrm{N}^{\circ}$ 14(1), pp. 95-119.

Lundvall, B.; Joseph, K.; Chaminade, C.; Vang, J. 2011 Handbook of innovation systems and developing countries: building domestic capabilities in a global setting (Cheltenham: Edward Elgar Publishing).

Nelson, R. 1992 "National innovation systems: a retrospective on a study" en Industrial and corporate change (Reino Unido: Oxford University Press) $\mathrm{N}^{\mathrm{o}} 1$ (2), pp. 347-374.

Nelson, R. 1993 National innovation systems: a comparative analysis (Reino Unido: Oxford University Press). 
Nupia, C.; Martínez, A. 2016 "La política de ciencia, tecnología e innovación. Evidencia empírica de un posible campo de investigación en Colombia" en Diana, L.; Pardo, C. (eds.) Análisis de indicadores de ciencia y tecnología (Bogotá: Universidad del Rosario).

OECD 2011 Hacia un mecanismo para el diálogo de políticas de innovación. Oportunidades y desafíos para América Latina y el Caribe (París: OECD).

Rubmann, M.; Lorenz, M.; Gerbert, P.; Waldner, M.; Justus, J.; Engel, P.; Harnisch, M. 2015 Industry 4.0: The future of productivity and growth in manufacturing industries (Boston: Boston Consulting Group).

Sachwald, K. 2016 The Fourth Industrial Revolution (Ginebra: World Economic Forum).

Sanz, L.; Muñoz, E. 1994 "Technology policy in Spain: issues, concerns and problems" en Aichholzer, G.; Schienstock, G. (eds.) Technology policy: towards an integration of social and ecological concerns (Berlín - Nueva York: De Gruyter) pp. 349-349. 



\title{
DIÁLOGOS DE CTI: HACIA LA GENERACIÓN DE INDICADORES DE CIENCIA, TECNOLOGÍA E INNOVACIÓN EN COSTA RICA
}

\author{
Jeffrey Orozco Barrantes y Luis M. Barboza-Arias*
}

\section{INTRODUCCIÓN}

El propósito de este capítulo es describir los procesos institucionales que condujeron al establecimiento de un diálogo para la generación de indicadores de Ciencia, Tecnología e Innovación (CTI) en Costa Rica, así como sus efectos en la identificación de política pública. La investigación propone el estudio de la interacción entre los diferentes actores que participan de la Comisión de Indicadores de Ciencia, Tecnología e Innovación (CICTI), espacio institucional en que se desarrolla esta experiencia de diálogo.

El diálogo analizado es el resultado de la articulación interinstitucional que se formaliza en el año 2008 con la publicación oficial del Decreto 34278-MICITT (Ministerio de Ciencia, Tecnología y Telecomunicaciones). Con la conformación de la CICTI, se origina un espacio de discusión que reúne a las principales instituciones públicas, representantes de la academia y sector privado con competencia en los temas de CTI en el país.

La construcción de indicadores nacionales de CTI surge ante el relativo desconocimiento por parte de las autoridades gubernamentales

* Centro Internacional de Política Económica, Universidad Nacional, Costa Rica 
con respecto a la magnitud de los esfuerzos para desarrollar actividades de CTI en el país. Antes del año 2008, el debate sobre la necesidad de medir esta clase de actividades, en particular la investigación y el desarrollo (I+D) realizados a nivel nacional, ya había cobrado notoriedad. La idea de crear un Sistema Nacional de Ciencia, Tecnología e Innovación había aparecido en la década de 1970, motivada por la ausencia de un marco legal e institucional que incentivara actividades de $\mathrm{I}+\mathrm{D}$, de adquisición de bienes de capital y de bienes de ciencia y tecnología; así como la importancia creciente de contar con mecanismos para fortalecer la interacción entre Estado, sector privado y academia.

Pese a que se hicieron varios esfuerzos no oficiales a lo largo de este período, Costa Rica no contaba con datos oficiales que permitieran determinar cuál era el monto de inversión exacto del país y su contribución al Producto Interno Bruto (PIB). No se disponía de información para caracterizar la situación actual, ni mucho menos los comportamientos y tendencias, incluyendo los efectos derivados de la adopción de estrategias y políticas.

De esta manera, la propuesta de iniciar un proceso de mapeo y divulgación, que permitiera una mayor articulación entre estos actores, toma forma con la creación del Subsistema Nacional de Indicadores de Ciencia, Tecnología e Innovación, que facilita la participación activa de la empresa privada en acciones concretas, como la medición de los montos destinados a estas actividades y su correspondiente registro.

Los datos generados con la publicación de los indicadores demuestran lo relevante que es la innovación para el país. Los indicadores son valiosos porque están basados en normativa internacional, logrando así la comparabilidad a nivel mundial. La medición de la innovación se realiza siguiendo los lineamientos conceptuales y metodológicos establecidos en instrumentos reconocidos como el Manual de Oslo y el Manual de Bogotá, lo cual hace que la información presentada sea comparable con otros países. Además, los indicadores permiten entender el estado de la innovación a nivel nacional, resaltando los esfuerzos, públicos y privados, que se llevan a cabo en esta línea; así como los principales tipos de innovación a los que apuesta el parque empresarial localizado en el territorio de Costa Rica.

Por otra parte, el aporte de los indicadores a la Política Pública de Ciencia, Tecnología e Innovación refleja la importancia de un mejor entendimiento del tema de la innovación en el país, en particular en aspectos tales como la demanda social de conocimiento y la articulación con otras políticas sectoriales, coadyuvando a orientar su alcance de forma más clara y sistemática. 
Con la incorporación de este esfuerzo político e institucional, el MICITT vino a llenar un espacio que no estaba totalmente satisfecho. Además, se propicia más apoyo a las interacciones y se profundiza en los hallazgos y recomendaciones, de forma que el proceso se encuentra mejorando continuamente.

Dos elementos de particular relevancia en el proceso de concertación de actores y en el diseño de las fases de trabajo tempranas de la CICTI han sido su carácter dinámico, en ruta al establecimiento de un proceso de diálogo, y la eficiencia de la interacción entre los actores que la conforman. Desde su creación, los participantes de la CICTI han sido conscientes de la necesidad de adaptación, manteniendo un interés prioritario en acercar a más actores e instituciones, de manera que haya más y mejor interacción. Se trata de un proceso evolutivo nacional que, si bien no siempre ha ocurrido en los tiempos adecuados, permite al país aprovechar el tiempo presente y "marcar la cancha" en el tema de innovación.

En este contexto, caracterizado por la inquietud sobre el estado de la CTI en Costa Rica, la ambigüedad de las políticas del sector y una preocupación creciente respecto al nuevo escenario económico y los retos futuros, es que el diálogo en estudio comienza a configurarse. Cabe resaltar, no obstante, que para muchos de los actores consultados el espacio institucional de la CICTI se ha convertido en un escenario propicio para ampliar el debate, incorporando discusiones sobre temáticas que, si bien están ligadas a las discusiones sobre CTI, no forman parte de la agenda de trabajo. De esta forma, más que un foro consultivo, la interacción entre los actores ha dado lugar al proceso de diálogo que se retoma cada año en diferentes momentos, tanto para dar inicio a la recolección de los indicadores, como para hacer otro tipo de propuestas derivadas del análisis de los mismos.

El análisis de este proceso de diálogo surge como resultado del trabajo de la "Red temática para mejorar el diálogo entre las comunidades involucradas en las políticas de CTI (COM-LALICS)", financiada por CYTED e integrada por más de una decena de países de Iberoamérica (Argentina, Brasil, Chile, Colombia, Costa Rica, Cuba, El Salvador, España, México, Perú, República Dominicana, Uruguay y Venezuela). El marco metodológico con el que se aborda el estudio del diálogo en cuestión surge de la propuesta contenida en Dutrénit, Natera y Suárez (2014), y en la Matriz de Información para el mapeo de procesos de diálogo de CTI en España, América Latina y el Caribe descrita en Dutrénit et al. (2016). Una síntesis y discusión de ambos documentos puede encontrarse en el capítulo 2 de este libro.

El presente capítulo se estructura de la siguiente forma: luego de esta introducción, la sección 2 presenta el abordaje teórico de los procesos de diálogo para la CTI; en la sección 3 se describe la 
metodología con la que se analiza el caso del diálogo para la generación de indicadores CTI en Costa Rica; en las secciones 4 a 6 se describe el proceso de diálogo; y en la sección 7 se ofrecen algunas conclusiones.

\section{ABORDAJE TEÓRICO DE LOS PROCESOS DE DIÁLOGO DE CIENCIA, TECNOLOGÍA E INNOVACIÓN \\ De acuerdo con Cuentas y Linares Méndez:}

El diálogo es un proceso de genuina interacción mediante el cual los seres humanos se escuchan unos a otros con tal profundidad y respeto que cambian mediante lo que aprenden. Cada uno de los participantes en un diálogo se esfuerza para incorporar las preocupaciones de los otros a su propia perspectiva, aun cuando persista el desacuerdo. Ninguno de los participantes renuncia a su identidad, pero cada uno reconoce la validez de las reivindicaciones humanas de los demás y en consecuencia actúa en forma diferente hacia los otros. (2013: 9)

Los procesos de diálogo pueden albergar tanto conflictos resultantes de posiciones e intereses disímiles de los actores, como ubicaciones asimétricas en la interacción comunicativa que son resultantes de relaciones de poder o de desiguales distribuciones de recursos entre los participantes. Las relaciones de poder entre los diversos actores están presentes en el diálogo. Estas se originan tanto por características de los actores como por el hecho de que, en el espacio común de interacción, uno de los actores influye de forma asimétrica en las decisiones de otros de modo que prime su voluntad, intereses y valores.

En sentido weberiano, esta influencia diferencial se da por imposición de la voluntad en contra de toda resistencia o por obediencia del resto de los actores a un mandato. Los liderazgos y las asimetrías de conocimiento en torno al objeto del diálogo también se constituyen en factores de poder, afectando las relaciones entre los actores participantes. La eventual presencia de líderes en algunos procesos puede provocar/destrabar conflictos a lo largo del proceso (Goñi, Bianco y Puchet, 2015).

El peso y la inserción institucional de cada actor definen su situación de poder en los diálogos y, por ende, su capacidad de injerencia en el proceso (Weber, 2002: 43). En el estudio de los diálogos debe tenerse en cuenta tanto las posibles fuentes de conflicto como el poder relativo de cada uno de los actores.

Según Goñi, Bianco y Puchet (2015), todo diálogo de comunidades para la política de CTI es un proceso que adquiere características propias en función de: los objetivos del proceso de diálogo (¿para qué? y ¿para quiénes?); la duración (puntual, corto plazo -menos 
de un año- o mediano/largo plazo -más de un año-); la continuidad temporal (continuo o discontinuo); el alcance (política global, políticas sectoriales o políticas regionales de CTI); quiénes lo impulsan (comunidades del sector público en instancias nacionales, estatales o locales, comunidad académica, comunidad empresarial o comunidad sociedad civil); la existencia o no de un marco institucional donde se inserta (puede acompañar el "ciclo de la política" buscando contribuir a su desarrollo o a su consolidación, puede darse por fuera del ámbito de la política pública planteando aportes o alternativas a esta, o surgir de la crítica a esta); la combinación de comunidades que está presente en el proceso, pudiendo clasificarse su heterogeneidad en alta, media o baja; la metodología que desarrolla (promoción de procesos participativos de gran alcance o consultas puntuales, de legitimación de decisiones tomadas, o de generación de consensos); y los productos (resultados vinculantes o no vinculantes para el desarrollo de las políticas en CTI).

Teniendo en cuenta combinaciones de estas características, Goñi, Bianco y Puchet (2015) distinguen varios tipos de procesos de diálogo, a saber:

a) Diálogos reactivos: surgen en respuesta a una política/acción concreta. Se organizan buscando modificar/incidir/corregir el contenido de una política;

b) Diálogos propositivos: buscan aportar a la construcción de nuevas políticas y acciones, y tienen como objetivo desarrollar discusiones para diseñar de forma colectiva un producto relativamente concreto, que es construir alternativas a políticas existentes;

c) Diálogos para la detección de demandas que permitan orientar políticas de CTI, son de carácter exploratorio, buscan evidenciar posibles cursos de acción para la política con base en temas, situaciones, problemáticas desatendidas; y

d) Diálogos para formar opinión no experta en torno a temas concretos que son objeto de las políticas de CTI (como por ejemplo, juicios ciudadanos).

\subsection{LOS PROCESOS DE DIÁLOGO COMO PRINCIPAL FUNDAMENTO DEL DISEÑO DE POLÍTICAS DE CTI}

Los principales avances dirigidos a establecer una conceptualización clara y acorde con la realidad regional de Latinoamérica respecto a la generación de políticas de CTI, derivan del enfoque de los Sistemas de 
Innovación. Un aspecto medular de este enfoque es que reconoce un alto grado de complejidad y la participación de un conjunto variado de actores (Edquist, 1997; Lundvall, 1992; Nelson, 1993). La innovación de hecho se entiende como la búsqueda interactiva en constante evolución y en la que la ciencia y la tecnología juegan un papel fundamental (Smits, Khulmann y Teubal, 2010).

La construcción de políticas CTI se caracteriza por ser un proceso creativo, una dinámica de confluencias en el tiempo/espacio que deriva de encuentros y acercamientos y que, por tanto, depende de procesos de diálogo. Es importante la existencia de un contexto institucional determinado, cuyos cambios y variaciones afectan de formas diversas la identificación de estrategias oportunas y la capacidad de los actores para adaptar los instrumentos con los que disponen a realidades emergentes o en transformación, lo cual hace evidente la necesidad de fortalecer las redes de colaboración (Crespi y Dutrénit, 2013; Edquist, 2014). Asimismo, su principal amenaza proviene de los riesgos imperantes y la incertidumbre que afecta los niveles de vinculación de actores y la eficiencia en el intercambio de información.

En la formulación de políticas CTI se requiere de una amplia gama de políticas expresadas en un conjunto amplio de instrumentos, específicas a cada contexto y orientadas por una concepción holística (Chaminade y Edquist, 2010). Por tanto, es necesario contar con una estrategia que favorezca la articulación de actores y las alianzas entre sector público, empresa y academia. Es importante por tanto plantearse como objetivo explícito la creación de los mecanismos de diálogo apropiados para la concertación de ideas y la definición de canales de cooperación para el cumplimiento de agendas conjuntas que lleven a propuestas consensuadas.

El modelo de la triple hélice es útil para entender las transformaciones en la producción del conocimiento científico y tecnológico ocurridas en las últimas décadas, y cómo las organizaciones establecen estrategias para adaptarse a estos cambios a través de dinámicas de acoplamiento (Etzkowitz y Leydesdorff, 1995; Isaza, 2006). La vinculación estrecha entre estos actores ha promovido diversos tipos de iniciativas, generando un interés creciente en los investigadores que abordan este tema y un nuevo punto de partida para la construcción de modelos interpretativos en América Latina (Sutz, 1998; Ibarra-Colado, 2006; Pérez-Bustos et al., 2012).

El aporte principal de estos estudios consiste en haber evidenciado la importancia de las interacciones entre la academia, la industria y el sector público para el fomento de la ciencia y la tecnología, esquema que en América Latina se asocia a una nueva posibilidad para acceder al desarrollo socioeconómico (Piñon, 2004). En esta línea, 
Estrada y Pacheco-Vega (2009) señalan que se requiere avanzar en habilitar las opciones de colaboración que garanticen el compromiso de las tres instancias. Dada la ausencia de una línea directriz que establezca los mecanismos de colaboración, se deben realizar esfuerzos para definir metodologías flexibles que contribuyan a "identificar el amplio espectro de personas y organizaciones vinculadas de una forma u otra con la innovación, sus demandas y objetivos, sus capacidades, sus debilidades, el tipo de relaciones de cooperación y conflicto que mantienen" (Sutz, 2010: 11).

En palabras de Sutz (1995), los procesos innovativos se desarrollan en un tejido institucional, donde "la capacidad de aprendizaje institucional y la influencia de lo institucional sobre los procesos de aprendizaje de otros actores" (Sutz, 1995: 22), constituyen un factor determinante para el diseño de políticas CTI exitosas.

Las organizaciones que intervienen en los procesos de aprendizaje pueden convertirse en verdaderas redes institucionalizadas de interacción social (Arocena y Sutz, 2004). En concordancia con esta idea, Alzugaray, Mederos y Sutz (2013), plantean que tanto el conocimiento como la innovación deben establecer formas de colaboración explícita y directa que permitan la inclusión social, con miras a establecer un sistema democrático y con garantías de representación para todos los actores involucrados.

Otra contribución relevante de los estudios sobre interacciones, precisamente, ha sido la discusión acerca de las condiciones institucionales en las que se produce y distribuye el conocimiento. Las instituciones ejercen una fuerte influencia sobre el acceso al conocimiento a través de sus impactos sobre el aprendizaje (Sutz, 1993).

Además, está claro para la discusión sobre diálogos políticos de CTI que las organizaciones no deben ser vistas como redes de expertos, pues, más allá del conocimiento especializado, es fundamental la identificación del conocimiento no codificado o derivado de la experiencia para el establecimiento de procesos de diálogo para políticas de CTI más inclusivas (Lam, 1999). Estos cambios requieren de un abordaje sistémico que debe partir desde el interior mismo de los sistemas de innovación que desarrollan las actividades de ciencia y tecnología, y que debe priorizar la creación de criterios participativos de inclusión y organización de la información (Sutz, 1998).

\section{METODOLOGÍA}

Se utiliza para el estudio el enfoque cualitativo de investigación, a través del cual es posible la exploración en profundidad del fenómeno en estudio según un proceso inductivo y de análisis de la realidad que considera múltiples realidades subjetivas (Hernández, 2010). El marco 
interpretativo de este método permite comprender en mayor detalle la construcción de significados compartidos por parte de los actores involucrados y el modelaje de un espacio común para la ejecución de prácticas determinadas, lo cual convierte al estudio del presente diálogo en un ejercicio creativo de etnografía institucional.

Para el análisis del estudio de caso, la construcción del diseño incorpora elementos del método analítico-inductivo de investigación social. Es decir, mediante el empleo de una técnica que va de lo particular a lo general, permitiendo al investigador la realización de generalizaciones con base en lo observado.

Considerando el carácter novedoso de este ejercicio, resulta oportuno identificar algunos supuestos previos que orientan el trabajo práctico de la investigación. Si bien no se plantea una hipótesis, in stricto sensu, sobre el impacto de la CICTI en el diseño de instrumentos de políticas de CIT, se proponen a continuación líneas específicas para el abordaje conceptual de la experiencia de diálogo surgida a partir de su conformación y establecidas a partir del componente teórico:

1. En línea con lo planteado por Álvarez et al. (2016), los diálogos para las políticas de CTI se caracterizan por ser procesos articulados que permiten la concertación de actores, se fundamentan en niveles de interacción y cohesión que facilitan, además del establecimiento de un lenguaje común y el descubrimiento de intereses compartidos, la transferencia de conocimiento y la promoción de dinámicas de aprendizaje. Así, en el caso de la CICTI se debe encontrar evidencia sobre la existencia de mecanismos que permitan el entendimiento entre actores, potenciando el conocimiento con que cada uno cuenta dada su experiencia inmediata y las competencias que podrían favorecer al diálogo.

2. Un elemento clave para la consolidación y el éxito de los diálogos para las políticas de CTI es la confianza establecida entre los actores que lo conforman (Nupia y Martínez, 2015). De esta manera, la generación de bases de confianza debe ser un objetivo central desde las primeras fases de exploración e involucramiento de nuevos actores. A nuestro entender, este aspecto debe estar visible en los lineamientos concernientes a la resolución de cualquier conflicto y, a la vez, formar parte de las estrategias dirigidas a legitimar el diálogo ante los actores, en especial aquellos que se integran de forma tardía o solo participan en momentos específicos. Se considera que, en este caso de diálogo, la CICTI dispone de procesos de creación de 
la confianza que facilitan, además de un mayor entendimiento entre los actores, una apropiación efectiva del espacio en que interactúan.

3. Derivado de lo anterior, para el caso del MICITT, en su rol de organización gubernamental competente en materia CTI, se espera identificar en este actor los elementos básicos de legitimidad y credibilidad que garantizan su liderazgo. Goñi, Bianco y Puchet (2015) señalan que los liderazgos pueden afectar las relaciones entre los actores participantes. Sin embargo, Nupia y Martínez (2015) y Dutrénit, Natera y Suárez (2014) profundizan en esta idea al proponer que los liderazgos son necesarios para orientar con claridad el direccionamiento, e incluso, en contextos determinados constituyen a dar seguimiento a la correcta implementación del proceso de diálogo.

4. Otro supuesto con el que se da inicio a la descripción del diálogo derivado de la conformación de la CICTI es la realización de evaluaciones del proceso. Se considera que un componente fundamental del diálogo lo constituye la transparencia y la revisión constante de los criterios que rigen las discusiones. Así, las evaluaciones pueden contribuir a mejorar el diseño y la efectividad del diálogo y, en general, a garantizar la democracia dentro del mismo (Nupia y Martínez, 2015).

Para dar cumplimiento al objetivo de la descripción del diálogo como proceso interactivo derivado de la articulación interinstitucional, una tarea que se realiza por primera vez desde la creación de la CICTI, se identificaron un conjunto de variables que fueron utilizadas posteriormente para la elaboración de una guía de preguntas. Si bien en este tipo de diseños de investigación no existe un instrumento fijo de recolección de datos, la identificación de variables de interés facilitó el planteamiento de preguntas relevantes, un hecho clave que permitió la sistematización de la experiencia sin menosprecio de su base empírica.

Se partió de una revisión de los documentos relevantes, tanto de la base institucional que se ha ido conformando para la generación de indicadores de CTI, como de los productos del proceso, identificando en cada uno los aspectos relevantes que dan evidencia del proceso de diálogo.

Durante los meses de mayo y abril de 2016 se realizó la aplicación de ocho entrevistas a actores clave miembros de la CICTI y, por ende, la participación en el proceso de diálogo generado en este espacio. Pese a que en un inicio se consideró un número mayor de participantes, muchos de los consultados declinaron la solicitud, aduciendo que su vinculación a la CICTI era poco relevante y no conocían en profundidad 
el proceso de diálogo, pues se habían integrado en etapas muy recientes. Este aspecto se analiza más adelante, dado que tiene implicancias directas sobre las dinámicas internas de trabajo. También es importante aclarar que, desde un punto de vista cronológico, la experiencia del diálogo se analiza a partir del año 2008 hasta el presente, de ahí la validez de contar con la perspectiva de actores que formaron parte del proceso en períodos específicos y que, en la actualidad, no mantienen grado alguno de vinculación directa.

Finalmente, una vez que la información fue recopilada se procedió con la transcripción de las grabaciones y el uso de variables-descriptores para obtener una mayor homogeneidad en el análisis de los datos.

\section{EVOLUCIÓN HISTÓRICA DEL SUBSISTEMA NACIONAL DE INDICADORES DE CIENCIA, TECNOLOGÍA E INNOVACIÓN}

La creación de un Subsistema Nacional de Indicadores de Ciencia, Tecnología e Innovación responde al interés explícito del MICITT. Su evolución histórica, sin embargo, atraviesa diferentes etapas, empezando con la discusión con participación de distintos actores, en el año 2007, hasta su consolidación con el Decreto 34278-MICIT, en el año 2008. En un primer momento, la entonces Ministra a cargo de esta cartera ministerial, Eugenia Flores, jerarca de la institución durante la Administración Arias Sánchez, 2006-2010, inició conversaciones con distintos actores, en particular con el Ministerio de Hacienda de Costa Rica. Si bien el Plan Nacional de Desarrollo propuesto por el Gobierno de turno establecía metas claras, por ejemplo, la asignación del $1 \%$ del PIB para actividades de I+D, no se disponía de estrategias claras para su ejecución.

En una segunda etapa, en el año 2008, después de tener el decreto firmado, el MICITT convocó a diferentes organizaciones del sector para generar estadísticas que permitieran clarificar el panorama actual de cara a los nuevos desafíos y a la agenda pendiente. Originalmente, la meta consistió en la medición de la I+D que se realizaba en el país. No obstante, después de diversas discusiones, se decidió promover la generación de un conjunto más amplio de indicadores de CTI. Durante las primeras fases de conformación de la CICTI, el diálogo se organizó como una iniciativa top-down, a la vez que incorporaba a más comunidades, representantes del sector privado y empresas, academia y otros actores gubernamentales, incluyendo a las principales organizaciones que generan indicadores económicos en el país.

De esta manera, se consolidó la conformación de la CICTI con actores clave que entendían la importancia de la elaboración de indicadores. La participación sectorial fue clave desde el principio, pues 
el enfoque multisectorial ha enriquecido el proceso con la diversidad de perspectivas, siendo la representación público-privada completa.

Durante la fase temprana de preparación, el proceso de discusión se construyó con la invitación a las organizaciones a ser parte de un grupo que tomaría decisiones sobre cómo medir las actividades científicas y tecnológicas a nivel país, y con la concientización de la responsabilidad que tenía cada ente relacionado en la construcción de los datos sobre la situación particular de Costa Rica. Se inició, además, con las fases centrales del proceso de diálogo para la creación de un Comité Técnico, entre ellas, determinar quiénes eran los actores, entender la naturaleza de cada uno de ellos en el tema y consensuar un proceso que contemplara lo anterior. El Comité Técnico de Indicadores de Ciencia, Tecnología e Innovación (COTECTI) constituyó, a su vez, un mecanismo de asesoría y concertación entre los sectores público, privado y académico, cuyas funciones también se encuentran definidas por el Decreto 34278-MICIT, en donde participan, además de representantes técnicos altamente calificados de cada una de las organizaciones que conforman la CICTI, todas aquellas instancias directamente relacionadas con los procesos propios del cálculo de indicadores, como es el caso del Centro Internacional de Política Económica de la Universidad Nacional (CINPE-UNA), el cual está encargado, mediante el establecimiento de un Convenio de Cooperación, de servir de enlace con las empresas consultadas, facilitar la recopilación de la información y, finalmente, elaborar el cálculo de los indicadores.

Fue así como se consolidó la estructura que permitiría posteriormente la discusión de agendas y temáticas específicas, por ejemplo, la selección de sectores a estudiar en cada medición. Dicho de otra manera, la creación de la estructura organizativa de la CICTI y el COTECTI permitió la coordinación entre los diferentes sectores del país relacionados con la producción de Indicadores de Ciencia, Tecnología e Innovación, con el fin de establecer políticas que guíen al sector científico y tecnológico en las áreas estratégicas del país.

En la tercera fase, también en el año 2008, el MICITT fue designado oficialmente, mediante el Decreto 34278-MICIT, como la institución competente para la creación de la CICTI. Esta incluye a representantes de la comunidad del sector público en el nivel del estado central y la comunidad empresarial, así como organizaciones de la sociedad civil, con interés en los indicadores. También fue creado el COTECTI con representantes de las mismas agencias y organizaciones.

En la cuarta etapa, se diseñaron un conjunto de indicadores para ser calculados y discutidos como forma de evaluar la metodología para generarlos. 
El Decreto 34278-MICIT, del 11 de enero de 2008, fue publicado por La Gaceta, diario oficial de Costa Rica, a inicios de febrero de ese mismo año. Ahí se estableció la creación del Subsistema Nacional de Indicadores de Ciencia, Tecnología e Innovación.

La CICTI, además del MICITT, está integrada por representantes de una amplia red de actores de las distintas comunidades:

a) Sector público: Instituto Nacional de Estadística y Censos (INEC), Consejo Nacional para Investigaciones Científicas y Tecnológicas (CONICIT), Ministerio de Hacienda, Banco Central de Costa Rica (BCR), y varios entes públicos, como el Ministerio de Comercio Exterior (COMEX), que se han incorporado al proceso de forma posterior, con el objetivo de brindar capacitación técnica y asesoría sobre la orientación y el alcance de la CICTI.

b) Sector empresarial: Unión Costarricense de Cámaras y Asociaciones de la Empresa Privada (UCCAEP), Cámara Costarricense de Tecnologías de Información y Comunicación (CAMTIC), y Cámara de Industrias de Costa Rica (CICR). Asimismo, se considera la convocatoria a otras instituciones afines que, desde su área profesional y competencia, pueden aportar elementos a la discusión de temas específicos, o bien, contribuir al cumplimento de sus fines y funciones.

c) Sector académico: Consejo Nacional de Rectores (CONARE), Universidades Privadas de Costa Rica -a través de un representante general-y el CINPE-UNA, como un instituto que forma parte de una de las principales universidades públicas.

Para el año 2016, ya se habían publicado seis versiones del Informe de Indicadores Nacionales de Ciencia, Tecnología e Innovación, en los que se consideraron los sectores empresariales de Manufactura, Energía y Telecomunicaciones (2006-2007, 2008, 2009, 2010-2011, 2012-2013), Servicios (2012) y Agropecuario (2013-2014).

La diferenciación entre la CICTI y el COTECTI, encargado de la presentación anual del Informe Nacional de Indicadores, es oportuna porque permite la evaluación minuciosa del proceso, no solo en su estructura formal, sino también en su esquema operativo, lo cual conduce a la identificación objetiva de conclusiones y contribuciones, que pueden servir como elementos de mejora sustancial en la planificación de su diseño organizativo y en la toma de decisiones con respecto a posteriores procesos de medición.

La Figura 4.1 presenta de forma gráfica dicha diferenciación y contribuye a identificar la relación entre los principales objetivos de la CICTI y entre las mediciones anuales de Ciencia, Tecnología e Innovación. En principio, la CICTI funciona como una estructura formal que 
reúne al conjunto de instituciones involucradas en el proceso de medición de indicadores de CTI, siendo esta una plataforma reconocida a nivel legal, que goza de un estatus jurídico dado por el decreto que la crea. La medición, por otra parte, constituye un proceso que atraviesa distintas etapas, una fase de identificación a nivel de la caracterización del sector en estudio para cada año, una fase de aplicación metodológica donde se establece un marco poblacional y su respectiva muestra, el proceso de consulta a empresas e instituciones y la posterior sistematización y publicación de los datos recolectados.

Figura 4.1. Subsistema Nacional de Indicadores de Ciencia, Tecnología e Innovación
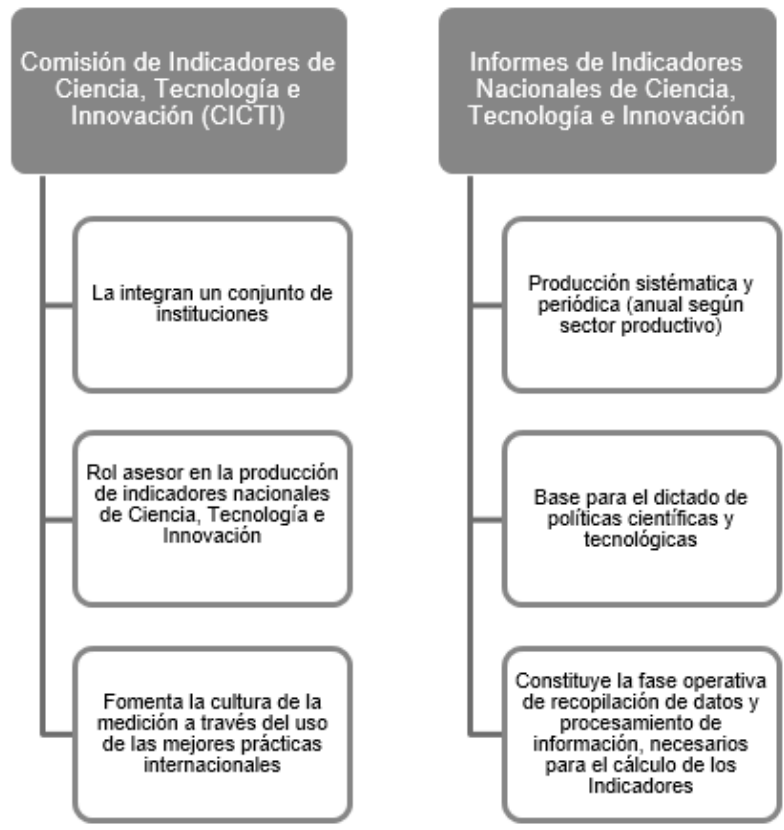

Fuente: elaboración propia.

\section{GÉNESIS DEL DIÁLOGO PARA LA GENERACIÓN DE INDICADORES DE CTI EN COSTA RICA}

El establecimiento de los diálogos de política para la innovación impacta sobre el entorno, incidiendo incluso más allá del área de acción sustantiva de las organizaciones, con lo cual se fortalece el ideal democrático a través de la práctica deliberativa (Badallo, 2008). Diálogos más inclusivos, en palabras de Delgado (2009), favorecen procesos políticos más reflexivos. El pluralismo de perspectivas, considerando 
la dimensión política de las comunidades involucradas, contribuye a la construcción de ciudadanía al habilitar los mecanismos necesarios para que nuevos actores se integren a los procesos de producción del conocimiento, pasando de la tradición de grupos de expertos a un escenario de coproducción de conocimiento (Palacio Sierra, 2011).

La medición es importante porque las economías locales se mueven en un mercado global (Umaña, 2016). Para el caso costarricense, la necesidad de competir con otras naciones ha posicionado un debate que antes no se tenía claro. El país necesita saber cómo monitorear las actividades científicas, tecnológicas y de innovación. Es decir, desarrollar metodologías para identificar quiénes realizan estas actividades y en qué sectores se encuentran ubicados. De esta manera, se puede invertir recursos, políticas y lineamientos de forma más focalizada.

En la misma línea, Giralt (2016) explica que los indicadores permiten evidenciar la inversión que se hace a nivel país en el desarrollo de la ciencia y tecnología, convirtiéndose, de esta manera, en un elemento importante para poder definir una directriz de Política Pública, y, al mismo tiempo, fortalecer o mantener el nivel de inversión a través de las diferentes administraciones.

"Lo que no se mide no mejora", es la frase utilizada por Fervoy (2016) al señalar la relevancia de los Indicadores Nacionales de Ciencia, Tecnología e Innovación. Los indicadores, en palabras de Porras (2016), permiten tener números, un aspecto fundamental al momento de la toma de decisiones.

En este sentido, no puede subestimarse el aporte que los indicadores han hecho a la definición de una Política Nacional de Ciencia, Tecnología e Innovación. Cruz (2016) resalta la importancia de una política pública de CTI al señalar que el país está en transición a una economía que se basa en los componentes de innovación e I+D, donde la experiencia de las empresas, además de ser un factor de diferenciación, representa un proceso que debe ser identificado y utilizado para generar directrices y programas con base en la información de los indicadores.

La política de innovación, en particular, define claramente la interacción entre academia, empresas e instituciones públicas, así como el tipo de innovación al que se debería apostar, las posibilidades de su financiamiento y los sectores en los que se requiere incidir con mayor fuerza, considerando las necesidades más importantes del país. De acuerdo con Vargas (2016), la política de innovación es una hoja de ruta para orientar los esfuerzos que hacen las empresas, la academia y el sector público. Un modelo orientador de los esfuerzos de innovación, cuya aplicación debe hacerse de forma articulada entre empresa, 
academia y universidad, a través del establecimiento de sinergias entre esta "triple hélice".

Los indicadores reflejan, por otro lado, la necesidad de acercar el conocimiento producido en las aulas a las empresas, y viceversa. Dado que en las empresas existe el conocimiento por la experiencia, que da pautas, es importante identificarlo y analizar su potencial (Cruz, 2016). Aspecto en el que coincide Porras (2016), indicando que deben aprovecharse las competencias de las nuevas generaciones que "nacen ya con la tecnología", así como las oportunidades que ofrecen aquellas áreas de alto valor agregado que podrían generar el empleo que el país requiere en la actualidad. Así, la "apuesta a la innovación", citada por Vargas (2006), considera que no solamente se debe hacer innovación para subsistir, sino también para ponerse a tono con el crecimiento y la evolución de la economía mundial.

Promover las actividades científicas y tecnológicas y, en particular, la inversión en innovación, es un elemento esencial para obtener desarrollos económicos sostenidos y más acelerados que aquellos crecimientos obtenidos a través del incremento solamente en los factores de producción.

Meneses (2016) señala que el proceso de creación del COTECTI respondió a la necesidad de concertar posiciones, metodologías y colaboraciones de todos los entes del país involucrados en el desarrollo científico y tecnológico. Por ende, mediante un Convenio de Cooperación, el CINPE-UNA se convirtió en el instituto de investigación encargado de llevar a cabo la fase operativa del proceso.

Flores (2016), señala además que, antes de la primera medición, realizada en el 2006-2007, solamente se contaba con estimaciones generales. De ahí la pertinencia de contactar al CINPE-UNA para sistematizar la información y establecer un método unificado.

Durante la primera fase del proceso, lo más importante fue aclarar de qué se estaba hablando cuando se hablaba de innovación (Umaña, 2016), motivando de esta forma un esfuerzo a nivel conceptual que facilitó el origen del diálogo. Un diálogo liderado, según la perspectiva de Fervoy (2016), por el MICITT, en su calidad de entidad rectora, y con el apoyo técnico del CINPE-UNA.

Para Porras (2016), la metodología utilizada para la generación de indicadores está relacionada con el insumo técnico que proveen los investigadores del CINPE-UNA, un proceso abierto a la realimentación de los otros actores y acompañado por una agenda de temas a desarrollar en las reuniones de la Comisión que está en constante actualización y que, por otra parte, constituye la justificación principal del diálogo emergente (Meneses, 2016).

Entender lo anterior, la génesis del diálogo a partir de la experiencia empírica del proceso de las mediciones, es clave para identificar 
por qué se considera que el tipo de diálogo originado es propositivo, aspecto que se analiza en el siguiente sub-apartado.

\subsection{EL DIÁLOGO PROPOSITIVO}

Siguiendo la clasificación de Goñi, Bianco y Puchet (2015), se puede afirmar que, por la metodología que se desarrolla, el diálogo para la generación de un sistema de indicadores de CTI en Costa Rica, representa un proceso participativo orientado a la generación de consensos y a la legitimación de líneas de acción que ha querido impulsar el MICITT. Los productos resultantes han servido como insumo para el desarrollo de políticas de CTI, pero no de una forma directamente vinculante.

Se desprende que se trata de un diálogo propositivo (Goñi, Bianco y Puchet, 2015), en tanto se impulsó para aportar a la construcción de nuevas políticas y acciones. En concreto, el proceso se generó con el objetivo específico de desarrollar un sistema de indicadores de CTI en Costa Rica, visualizado como un producto concreto, aunque tiene un alto grado de complejidad. El objetivo final de contar con el sistema de indicadores es el de tener insumos para construir políticas alternativas a las existentes. Una vez cumplida la primera etapa de generación del sistema de indicadores, el proceso de diálogo dentro de la CICTI ha continuado para dar paso a la generación de nuevas rondas de actualización de indicadores. Por tanto, se puede caracterizar como un proceso de largo plazo que, si bien no ha sido completamente continuo, se ha retomado año a año para discutir sobre el tipo de indicadores a generar, los sectores a ser estudiados y las implicaciones de los resultados. El proceso ha sido coordinado por una instancia gubernamental, el MICITT, pero han participado actores de distintas comunidades. Después de una primera etapa de discusiones, se generó un marco institucional que estableció las reglas del juego sobre los actores participantes, los propósitos del proceso y los alcances.

No obstante, debemos ser críticos al valorar el alcance propositivo del diálogo en cuestión y su relación con el establecimiento de un espacio de diálogo en el país. Si bien la experiencia que analizamos ha sido enriquecida por la diversidad de actores que lo integran, no debe perderse de vista la viabilidad operativa de las discusiones, el seguimiento de los objetivos y el contexto político en que surgen las propuestas para fortalecer el Subsistema Nacional de Indicadores de Ciencia, Tecnología e Innovación de Costa Rica.

Partiendo de los planteamientos elaborados por Goñi, Bianco y Puchet (2015) y de las reflexiones derivadas de nuestro caso específico de estudio, en el Cuadro 1 se incorpora una serie de elementos que consideramos oportuno integrar al análisis del concepto de diálogo propositivo. 
Cuadro 1. Dimensiones de análisis para experiencias de diálogo propositivo

\begin{tabular}{|c|c|c|c|}
\hline $\begin{array}{c}\text { Disponibilidad de los } \\
\text { actores }\end{array}$ & Estructura formal & Entorno institucional & $\begin{array}{l}\text { Imparcialidad de los } \\
\text { instrumentos }\end{array}$ \\
\hline $\begin{array}{l}\text { Competencias } \\
\text {-Esfera de acción/ } \\
\text { participación } \\
\text { - Nivel de } \\
\text { conocimientos } \\
\text { individual } \\
\text { - Capacidad para } \\
\text { interactuar con } \\
\text { empatía }\end{array}$ & $\begin{array}{l}\begin{array}{r}\text { Inclusión vs } \\
\text { colectividad }\end{array} \\
\text { - Fortalecimiento } \\
\text { de competencias } \\
\text { institucionales } \\
\text { - Integralidad de } \\
\text { enfoques } \\
\text { - Capacidad de } \\
\text { influencia sobre el } \\
\text { contexto } \\
\text {-Gestión del } \\
\text { aprendizaje }\end{array}$ & $\begin{array}{l}\begin{array}{r}\text { Complejidad de } \\
\text { escenarios }\end{array} \\
\text { - Necesidades y } \\
\text { prioridades } \\
\text { - Agendas amplias y } \\
\text { temas puntuales } \\
\text { - Estímulos para la } \\
\text { investigación } \\
\text { - Acompañamientos } \\
\text { - Conflicto }\end{array}$ & $\begin{array}{r}\begin{array}{r}\text { Verticalidad/ } \\
\text { horizontalidad del } \\
\text { sistema }\end{array} \\
\text { Marco analítico de las } \\
\text { discusiones }\end{array}$ \\
\hline
\end{tabular}

Fuente: elaboración propia.

La experiencia del diálogo para la generación de indicadores de CTI en Costa Rica se ajusta al modelo conceptual de diálogo propositivo porque comparte cuatro criterios centrales, los cuales son detallados a continuación:

\section{a) Disponibilidad de los actores}

La evidencia encontrada nos permite identificar la existencia de un diálogo propositivo, no solo en su proceso formal de construcción, sino también en la diversidad de comunidades 
que lo integran. Así, la inclusión de actores procedentes del sector público, del ámbito empresarial y de la academia ha tenido un impacto positivo en la propuesta de acciones novedosas, dada la riqueza de enfoques y competencias. El conjunto de actores comparte ciertas características, tales como la procedencia de esferas de acción vinculadas de forma directa o indirecta con el tema central del diálogo, lo cual hace que la integración se realice en un marco de entendimiento general. No obstante, no existe una base de conocimiento común a nivel individual de las personas que representan a las respectivas organizaciones, hecho que influye en su capacidad para apropiarse del espacio e interactuar de forma empática con los otros participantes.

Por otra parte, los actores se refieren a su participación en el proceso a partir de los aportes que cada uno realiza. Aún en los casos donde la interacción no ha resultado sencilla, es posible evidenciar la motivación inicial como uno de los componentes principales. De igual manera, se discute la permanencia de los actores en el diálogo; pues muchos consideran que se trata de un factor decisivo para alcanzar un espacio articulado con incidencia efectiva. La salida o ausencia de actores específicos, por el contrario, es considerada como un elemento que afecta de forma negativa al desempeño del conjunto.

\section{b) Estructura formal del diálogo propositivo}

Lo anterior guarda relación con las características de la estructura formal del diálogo, que en episodios específicos limitan la integración de los actores. En esta dimensión de análisis, la conformación del Subsistema Nacional de Indicadores de CTI en Costa Rica, si bien ha favorecido la inclusión de actores a partir del reconocimiento de sus competencias institucionales, muestra debilidades respecto a la identificación de estrategias que permitan integrar los distintos enfoques y perspectivas de las organizaciones sobre temas específicos. Si bien el propósito no es uniformar posiciones, deben existir mecanismos claros para que el establecimiento dé consensos que contribuyan a potenciar el carácter propositivo del diálogo.

Por otra parte, la instancia de discusión se concibe como una estructura cerrada que no facilita a los actores la disposición de espacios informales para el debate de nuevas ideas. La rigurosidad del método de interacción, si bien no origina asimetrías significativas en la capacidad de los actores para discutir 
nuevas propuestas o acciones, limita la ampliación de espacios no planificados, en los cuales se podrían generar lógicas de discusión paralelas. Es decir, la capacidad de los actores para influir sobre el entorno nacional y la política de CTI, más allá de los límites de la estructura formal del diálogo, es reducida y tiene efectos negativos en los mecanismos que utilizan para articularse entre sí. La continuidad de ideas queda sujeta al desarrollo de reuniones formales, cuya distancia en el tiempo afecta la calidad argumentativa, fluencia analítica y el seguimiento de planteamientos valiosos para el debate.

\section{c) Entorno institucional}

El entorno institucional está determinado por el contexto político en que el proceso de diálogo se lleva a cabo. Al ser liderado por una institución pública, sus directrices se encuentran condicionadas por el mandato político. En este sentido, las necesidades inmediatas que el diálogo busca atender están sujetas al establecimiento de las prioridades identificadas por la administración en turno. En consecuencia, el establecimiento de agendas puede afectar el desarrollo de los temas centrales, pues existe la amenaza de la escasez de recursos financieros y técnicos para apoyar la ejecución de actividades cuando se producen cambios en el Gobierno Central.

Aunado a ello, la construcción de alternativas debe lidiar con el ámbito regulatorio del país, quedando sujeta a los plazos y a la institucionalidad vigentes para la aprobación de planes específicos de trabajo. Asimismo, cabe cuestionarse si, en el largo plazo, las acciones que sí son ejecutadas tienen un nivel mayor de articulación con otras políticas sectoriales.

\section{d) Imparcialidad de los instrumentos}

En relación con lo anterior, cabe plantearse la objetividad de los aportes realizados por el diálogo. En particular, si los instrumentos utilizados por los actores del diálogo son integrados al Subsistema Nacional de Indicadores de CTI de manera neutral y representan el interés colectivo de los actores involucrados. En nuestro caso específico, se destaca que la experiencia de construcción de los indicadores es la fase en que el diálogo se muestra más activo, dado el interés nacional que guía la generación periódica de los indicadores. Así, se dispone de un marco analítico que brinda confianza a los actores, el cual permite, además de discusiones horizontales, espacios para valorar la viabilidad de las alternativas y realizar ajustes anteriores 
a la publicación final. La transparencia con que este proceso se lleva a cabo garantiza la objetividad técnica y un procedimiento orientado a resultados visibles en el corto plazo.

La apuesta a la medición de las actividades CTI, como la define Vargas (2008), constituye hoy en día la principal experiencia en materia de diálogos políticos para la ciencia, tecnología e innovación que se ha realizado en Costa Rica. En la actualidad, los actores que participan tienen claro su rol y están comprometidos con el desempeño de su función.

Para los actores consultados, un aspecto positivo de la participación de las instituciones en el Comité Técnico es la representatividad, lo cual enriquece los puntos de vistas y ayuda a realizar un mejor trabajo. Dicho de otra manera, la alta representación de personas de diferentes disciplinas y de diferentes organizaciones enriquece las discusiones y el análisis de propuestas de cambio y mejoras. Las visiones técnicas de las organizaciones son fundamentales en la discusión de los Informes Finales de Indicadores, contribuyendo además a tomar ciertas decisiones de muy alto nivel.

Empero, existen también debilidades del proceso que pueden afectar próximas mediciones. La relativa poca anticipación con que se convoca a las reuniones para evaluar los Informes Finales, de acuerdo con Giralt (2016), afecta la calidad de la revisión. Por lo general, el tiempo de reacción es muy corto, no es posible realizar una lectura en profundidad que permita valorar detenidamente las variables en estudio. Además de ello, las organizaciones no siempre participan en todas las sesiones $\mathrm{y}$, en algunos casos, las personas encargadas de su representación varían según las directrices internas. Si bien existe poder de convocatoria a estas reuniones, la ausencia de instancias clave o la incorporación de representantes institucionales sin conocimiento de las discusiones anteriores tienen efectos negativos sobre la fluidez del diálogo, dado que la nivelación de nuevos actores, al menos en dinámicas específicas del diálogo, amenaza con provocar una involución en el proceso.

\subsection{DESAFÍOS AL LIDERAZGO Y PREVISIÓN DE RIESGOS FUTUROS}

Dada su responsabilidad de ser líder en la materia e impulsar una mejor calidad de la información, así como reflejar importancia de la inversión en ciencia y tecnología tanto a nivel público como privado, el liderazgo del MICITT es reconocido por la totalidad de actores. No obstante, el MICITT también enfrenta riesgos políticos importantes 
que, en períodos específicos desde creación del Subsistema Nacional de Indicadores de CTI, han comprometido su liderazgo. Cuestiones como los cambios de administración en el Gobierno Central, el ingreso de nuevos jefes con visiones distintas, o reajustes presupuestarios, se encuentran entre las amenazas que pueden entorpecer la calidad de este liderazgo. Aunque también, en condiciones específicas, estas amenazas pueden convertirse en oportunidades estratégicas para mejorar el diálogo, a través de la apertura de nuevos espacios para la discusión, o, como indica Fervoy (2016), incluyendo cambios en la coordinación que permitan el paso de sesiones de trabajo informativas a sesiones participativas, abiertas y consensuadas.

Si bien se requiere de mecanismos reconocidos a nivel institucional que faciliten los encuentros, el exceso de formalidad en las sesiones de trabajo reduce el potencial creativo y la inventiva de quienes asisten a ellos. Como refleja la teoría, la concertación de ideas y la definición de canales de cooperación para el cumplimiento de agendas conjuntas, es un requisito indispensable de cualquier diálogo de política CTI que tenga por finalidad la consolidación de un proceso de diálogo permanente. Por ende, estos procesos deben ocurrir de forma natural, en un espacio de intercambio horizontal que no coaccione la participación de los actores o, más importante aún, que no disminuya su motivación principal.

Para Vargas (2016), representante de MICITT, las sesiones no son formales, mientras que para los representantes de las otras organizaciones sí lo son. Sin embargo, más allá de la naturaleza de las reuniones, preocupa su periodicidad y seguimiento, pues si bien es cierto que se tiene más conocimiento del proceso, las reuniones son cada vez más espaciadas en el tiempo. Umaña (2016), señala que al principio se realizaban reuniones cada dos meses, en cambio, actualmente se realizan una o dos cada año.

Consultado por la existencia de una agenda de actividades, Fervoy (2016) explica que hay un calendario al que se responde. En palabras suyas, es como el ciclo del diseño de la investigación, análisis y publicación de los indicadores. Atender este calendario permite atender las necesidades del momento en que se está.

Con respecto al seguimiento, las actas de reunión se comparten. Se cuenta con un registro de lo que se hizo y de lo que viene. En las sesiones, los temas están planteados de forma cíclica, lo cual facilita que los actores recuerden los pormenores de la sesión pasada, dando lugar a una dinámica de mejora y evolución continua.

Porras (2016), añade que, por lo general, no quedan tareas pendientes para las reuniones siguientes, lo cual contradice en cierto sentido lo planteado con anterioridad. Esta observación es respaldada por Morales (2016), quien argumenta que no hay una continuidad de 
lo que se acordó en reuniones anteriores, ni tampoco un sitio electrónico o repositorio para consultar los documentos producidos.

A este respecto, los actores consultados sugieren la necesidad de incorporar mecanismos interactivos para socializar la información de forma efectiva, así como la convocatoria a reuniones con regularidad, incluso para debatir agendas con puntos limitados. Desde su perspectiva, estos encuentros servirían, entre otros beneficios, para discutir la introducción de mejoras al diálogo y dar continuidad a los resultados generados por los indicadores, evaluando su utilidad o el uso dado por los actores. Existe también un interés por parte de algunos actores del diálogo en determinar cuál es el uso que las empresas dan a los Informes, si estos son utilizados para mejorar algún aspecto del proceso productivo o son tomados como referencia en la toma de decisiones sobre estrategias de inversión o desarrollo de programas de capacitación en las universidades. Teniendo presente para qué se usó el informe, indica Giralt (2016), es posible trabajar en la viabilidad de las propuestas de mejora del proceso.

Otro tema relevante lo constituye la gestión de capacidades. A partir de lo señalado por Sutz (1995), queda claro que un componente central de la interacción entre actores lo constituyen los procesos de aprendizaje. Para la autora, se trata de un factor determinante en el diseño de políticas CTI exitosas, dado que involucra el establecimiento de canales para el intercambio de conocimiento que facilita también la generación de puentes para la colaboración.

Este planteamiento general puede ser aplicado al caso específico de las experiencias de diálogo, pues la gestión de capacidades, además de facilitar el aprendizaje de los actores, implica el fortalecimiento de las bases de confianza con el fin de promover una articulación proactiva y un diálogo democrático (ver Dutrenit, Natera, Suarez, 2014).

No obstante, otra de las grandes debilidades encontradas en este proceso es la ausencia de mecanismos para la gestión de capacidades en los actores que lo conforman, en especial cuando se trata de nuevos integrantes que no tienen conocimiento del sistema de generación de indicadores y de los indicadores mismos. Se determinó que el ingreso de nuevos actores que participan por primera vez, ya sea por la incorporación tardía de su organización al COTECTI o por un cambio de representante designado por la organización, implica un obstáculo a la eficiencia del diálogo, pues la persona desconoce el estado actual de las discusiones y puntos acordados en agenda.

Morales (2016) destaca que las personas, las primeras veces que forman parte de las reuniones, por lo general están desorientadas, y no cuentan con los canales de confianza adecuados para exponer sus dudas. En el COTECTI se carece de mecanismos institucionales para 
la creación de capacidades y, a la fecha, no se han realizado esfuerzos para desarrollar capacitaciones formales o espacios que contribuyan a la actualización de saberes y conocimientos. El tema de las capacitaciones, de acuerdo con Vargas (2016), tampoco ha sido propuesto. El proceso de aprendizaje se ha realizado, en la mayoría de casos, de forma autodidacta, y surge principalmente desde el interés de los actores en conocer más sobre los temas abordados. Además, el hecho de que cada organización aporte desde su especificidad, restringe la participación al aporte técnico.

Sin embargo, para los actores está claro que se trata de una cuestión fundamental. Fervoy (2016) comenta que se carece de instrumentos y mecanismos para nivelar las experiencias o conocimientos de quienes forman parte del grupo, lo cual provoca que las personas con menos experiencia se sientan cohibidas para expresar su criterio. Aunado a ello, la asistencia irregular de algunos de los actores, a pesar de los esfuerzos de convocatoria, tiene efectos sobre la estrategia de comunicación y sobre la calidad de los vínculos establecidos. La asistencia ocasional de ciertas instancias imposibilita la organización de seminarios o talleres, pues se ha llegado a la conclusión de que estos espacios podrían correr el riesgo de ser desaprovechados por los supuestos involucrados, o bien, no generar suficiente interés entre quienes participan del COTECTI.

Cabe discutir entonces la calidad del diálogo, y su cualidad propositiva, pues, al entender de Goñi et al. (2015), una característica de los diálogos es la facilidad que brindan a los actores para intercambiar mientras aprenden. Se debate además la garantía de representación para todos los actores involucrados que menciona Edwards et al. (2004), pues la barrera para el aprendizaje de actores que recién se incorporan al diálogo se contrapone a los valores humanistas reconocidos en un proceso democrático de diálogo, basado en niveles altos de apertura y acceso a la información.

Por último, si bien existe un proceso de retroalimentación entre los participantes del Comité Técnico, siendo este un factor clave en la perduración del proceso de medición, se carece de un mecanismo de evaluación institucional que permita conocer la evolución y el estado actual de este diálogo.

Las sugerencias de los actores son retomadas en las reuniones y se realiza la atención de comentarios por parte de los encargados. Sin embargo, no se da un seguimiento significativo, dando paso al cumplimiento de la agenda prevista en cada sesión.

Para Umaña (2016), la retroalimentación técnica es la que más resultados concretos alcanza. Esta se realiza mediante la exposición de metodologías, resultados, nuevas técnicas, nuevos instrumentos o 
modificaciones de procesos, los cuales se exponen a los actores y se abre el espacio para la discusión y retroalimentación. Es en esta clase de espacios consultivos donde se crean mayores afinidades entre actores, en los que puede descubrirse perspectivas de mundo compartidas. Además, esto solo es posible por la permanencia de ciertos actores en el grupo, que deriva en que algunas discusiones ocurran fuera del espacio establecido para la retroalimentación y derive en colaboraciones puntuales (Fervoy, 2016).

La evaluación del diálogo, en cambio, para algunos actores no es lo suficientemente explicita como acción del grupo, pero consideran que ocurre paralela al proceso, cuando este es continuamente modificado por los mismos procesos normales de la dinámica.

En Costa Rica, por otra parte, es muy poca la evaluación que se hace. No se dispone de evaluación del impacto o de los resultados alcanzados a partir del proceso de medición de CTI en el país. Unas de las razones por las que se carece de evaluación es la ausencia de actores que la realicen y, además, porque no se cuenta con el suficiente presupuesto para hacerla.

\section{ALCANCE DEL DIÁLOGO E IMPLICACIONES DE LA POLÍTICA PÚBLICA DE CTI}

Los esfuerzos para articular el proceso de diálogo establecido por la CICTI con la formulación del marco jurídico-institucional y con el diseño de política pública de CTI han tenido un resultado medio. Si bien desde la Dirección de Innovación del MICITT se ha establecido un Comité de Buenas Prácticas para alcanzar este propósito, el proceso no ha mostrado a la fecha los efectos esperados.

En el último período, un creciente acercamiento del país a la Organización para la Cooperación y el Desarrollo Económicos (OCDE) ha permitido evidenciar el interés de Costa Rica en orientar sus esfuerzos hacia una economía basada en el conocimiento y con visión de largo plazo. Sin embargo, actividades como la revisión y reformulación de la normativa vigente, así como la vinculación con otros actores, han experimentado dificultades para impactar de forma positiva en la consolidación de una agenda general para el diseño de Política Pública de CTI.

No obstante, la Dirección de Innovación cuenta con plataformas para promover las actividades científicas y tecnológicas, así como la innovación en el país. Programas específicos como Innovación Joven, Huella PYME e Innovación de Base Tecnológica, constituyen iniciativas importantes que tienen por objetivo impulsar la cultura de innovación en diferentes actores del sector productivo y también de la sociedad en su conjunto. 
Enfocadas en fortalecer la idea de "aprender haciendo", estas iniciativas se proponen la generación de confianza a través de la identificación de redes para el trabajo con diferentes actores. Es el caso de la vinculación empresario-emprendedor que define el marco de acción del Programa Innovación de Base Tecnológica, y que brinda, entre otros beneficios al emprendedurismo costarricense, fuentes de fondos para apoyar procesos de innovación.

De acuerdo con Bullón (2016), la disposición de información estadística presente en los Indicadores Nacionales de CTI permitió sustentar estas iniciativas, pues los informes publicados sirven como datos de trasfondo para justificar las necesidades reales del país. Sin embargo, no han tenido la misma utilidad con relación al afianzamiento de una Política Pública de CTI acorde con las demandas científico-tecnológicas y de conocimiento de los diferentes sectores productivos. Bullón (2016) señala que el insumo de los indicadores ha impactado de forma positiva en la generación de programas de gestión del conocimiento y en diferentes iniciativas para la creación de nuevos programas, no obstante, ha tenido poca incidencia en el establecimiento de un diálogo amplio que permita, precisamente, abrir el debate en el sector público. La ausencia de proyectos de ley sobre planes, programas o mecanismos para apoyar la CTI en la Asamblea Ejecutiva de Costa Rica es un ejemplo del poco respaldo político.

Desde el MICITT, la vinculación con otros Ministerios Públicos ha tenido altibajos, pese a que, de forma general, ha permitido alianzas efectivas para el desarrollo de programas. En el caso del Ministerio de Economía, Industria y Comercio (MEIC) y COMEX, la relación ha dado origen, en el primer caso, a las plataformas de apoyo a emprendimientos y PYMEs. Mientras que, en el segundo caso, ha sido provechosa para apoyar la competitividad y el pensamiento global de aquellas empresas locales que buscan la internacionalización.

De igual manera, otros Ministerios Públicos que no forman parte de la CICTI, como el Ministerio de Agricultura y Ganadería (MAG), el Ministerio de Salud, e institutos como el Instituto Costarricense de Turismo (ICT), han incrementado su nivel de involucramiento con la Dirección de Innovación en actividades específicas. Sin embargo, para Bullón (2016), es la institucionalidad de espacios formales como la CICTI la que no favorece vinculaciones más estrechas, dando paso a la dificultad de vincular los datos estadísticos con la agenda particular de los actores institucionales y obstaculizando, a la vez, el establecimiento de recomendaciones de mejora conjunta que contribuyan a delinear de forma clara el rol de cada organización. 
La inexistencia de una base de datos unificada constituye uno de los principales cuellos de botella que dificulta un mayor alcance del diálogo, pues si bien el aporte de los indicadores, como se ha mencionado, es fundamental para entender la realidad del entorno socioproductivo del país y el estado de la CTI, existen juegos en poder en el suministro y posesión de la información primaria que permite generar el Informe Final. La desconfianza de algunos actores radica en el tratamiento dado a los datos, en especial, en los criterios de anonimato y confidencialidad.

Para Bullón (2016), este escenario plantea dos desafíos principales: el primero de ellos, la necesidad de fortalecer la articulación institucional entre los actores; el segundo, la emergencia de un mejor entendimiento de los roles específicos que cada actor cumple en el contexto del diálogo promovido por la CICTI.

Resulta pertinente, por lo tanto, continuar avanzando en el diseño de procesos para la transferencia de conocimientos entre los actores, incluyendo el fortalecimiento de los flujos de información horizontal. Se debe, además, impulsar condiciones para generar el "pensamiento fuera de la caja", aspecto que resulta crucial para promover procesos de $\mathrm{I}+\mathrm{D}+\mathrm{I}$.

Por último, las propuestas para avanzar en esta línea deben conllevar al análisis del diseño institucional de la CICTI, de manera que el problema de ejecución evidenciado en el manejo de la información no afecte los usos potenciales de los indicadores por parte de los actores participantes.

Estas propuestas, además, deben servir como base instrumental para el modelaje de una agencia híbrida de innovación que genere mayores recursos y motive nuevas alianzas público-privadas para la promoción de la CTI en Costa Rica. Esta idea no es nueva en el contexto nacional, pues diversas organizaciones presentes en la CICTI consideran la creación de una Agencia de Innovación Nacional como un requisito previo al establecimiento de una política pública de CTI. Por ende, los esfuerzos institucionales se han centrado en fortalecer las alianzas con los actores presentes y en motivar un nuevo diálogo dentro de la CICTI que genere las pautas y mecanismos propicios para un rediseño institucional de este espacio.

\section{CONCLUSIONES}

Se ha identificado algunos obstáculos para continuar con el proceso de diálogo y para que los productos del mismo tengan mejores impactos en la generación de políticas de CTI. Una situación problemática es la constante incertidumbre sobre el presupuesto para continuar con el esfuerzo de generación de indicadores. Aunque se ha generado 
cierta estabilidad, todos los años hay una lucha de los personeros del MICITT, encargados de coordinar el esfuerzo, para garantizar que el presupuesto efectivamente se canalice al proyecto.

Por otra parte, algunos de los actores señalaron otros problemas como la poca continuidad de algunos actores, pues son cambiados por las organizaciones que representan, por lo que se desnivela el nivel de conocimiento necesario para un diálogo más productivo y profundo. Sería necesario establecer mecanismos para generar capacidades en el tema a las personas que se van sumando tardíamente. Por otra parte, se señala reiteradamente la necesidad de espacios de tiempo más amplios para analizar los indicadores generados antes de los talleres de socialización y discusión.

Es importante también generar espacios paralelos para la discusión explícita de políticas de CTI. Por lo general, los esfuerzos que impulsa el MICITT en esa línea están bastante separados de los esfuerzos para generar los indicadores, por lo que la mayoría de los actores en los otros procesos no maneja adecuadamente los indicadores que ha generado el sistema. Por ejemplo, el esfuerzo para generar el plan de CTI reunió a un grupo de actores, pero muy pocos conocían los indicadores de CTI, por lo que no se usaron adecuadamente para plantear las discusiones respectivas. Es importante también repensar los espacios de intercambio para abrir una participación más preparada de los actores, generando por ejemplo insumos previos sobre las líneas de discusión en que cada actor quisiera profundizar y sobre los alcances del proceso de diálogo.

El hecho de haber institucionalizado el esfuerzo incluso con un decreto legal, ha generado un espacio importante de continuidad. Ya se han elaborado varios informes de indicadores que, en sí mismos, son resultados tangibles de gran relevancia. Se ha generado, además, una cultura explícita de innovación y de mayor atención a los temas de CTI. Tanto las empresas como los actores académicos y las entidades públicas, así como las no estatales, se han apropiado del proceso y aportan la información necesaria para generar los indicadores, a pesar de que no es obligatorio hacerlo. Se cuenta, además, con un sistema de indicadores que da base para discusiones profundas sobre la realidad en materia de CTI y que da espacios para el diseño de nuevas políticas.

Otro de los desafíos fundamentales es el de consolidar el Subsistema de Indicadores de CTI, de forma que contribuya a identificar políticas y acciones por parte de los distintos actores, que permitan fortalecer el sistema nacional de innovación. Las discusiones del COTECTI deben trascender a espacios más amplios de generación de políticas. El MICITT tiene el reto paralelo de vincular sus consultas 
públicas en materia de políticas a los esfuerzos de generación de indicadores. En lo concreto, se deben establecer mejores mecanismos de retroalimentación de los participantes del COTECTI, para que se genere más motivación y aportes basados en un mayor nivel de profundización del conocimiento necesario. Se tiene también el desafío de generar instrumentos y mecanismos para nivelar las experiencias o conocimientos de quienes forman parte de las comunidades que integran el diálogo, evitando de esa forma que las personas con menos experiencia se sientan cohibidas para expresar su criterio.

Es de gran relevancia contar con un espacio de diálogo que tiene los objetivos muy claramente definidos y que ha ido generando, a lo largo del tiempo, una serie de reglas del juego que permiten aprovechar la experiencia individual de cada participante. Se rescata la necesidad de contar con una retroalimentación técnica solvente y fundamentada en la experiencia internacional. Pero es importante seguir innovando en la metodología del proceso, para generar mejores condiciones y para mejorar los impactos del diálogo en materia de políticas y acciones de CTI. Una acción concreta para avanzar al respecto, es plantear de forma explícita una evaluación del proceso en forma colectiva, para abrir espacio a que, dentro del proceso mismo del diálogo, se definan acciones de mejora.

Este documento sistematiza la experiencia del proceso de diálogo y rescata la opinión de una serie de actores que han jugado un papel fundamental en el proceso. Además, permite visualizar el cumplimiento del objetivo de generación de indicadores, pero aún falta mucho para que ese sistema genere mejores resultados en términos de generación de políticas de CTI.

\section{BIBLIOGRAFÍA}

Álvarez, I.; Barletta, F.; Suarez, D.; Yoguel G. 2016 "Marco analítico para la tipificación de diálogos para las políticas de CTI" en Working paper 3 (Red CYTED COM-LALICS). En <http://lalics. org/images/CYTED/DT3-DimensionesDialogo.pdf> acceso $15 \mathrm{de}$ abril de 2017.

Alzugaray, S.; Mederos, L.; Sutz, J. 2013 “Investigación e innovación para la inclusión social: la trama de la teoría y de la política" en Isegoría (Madrid: Consejo Superior de Investigaciones Científicas) $\mathrm{N}^{\circ} 48$, pp. 25-50.

Arocena, R.; Sutz, J. 1999 “Mirando los sistemas nacionales de innovación desde el sur. In Ponencia presentada en la Conferencia 'Sistemas Nacionales de Innovación, Dinámica Industrial y Políticas de Innovación'” en Danish Research Unito Industrial Dynamics (Dinamarca: Rebild). 
Arza, V. 2010 "Interactions between public research organisations and firms: channels, benefits and risks in developing countries. A conceptual framework. In this Special Issue" en Science \& Public Policy (Londres: Oxford University Press) N 37, pp. 473484.

Avellaneda, M. F., \& von Linsingen, I. R. L. A. N. 2011 "Una Mirada a la Educación Científica Desde los Estudios Sociales de la Ciencia y la Tecnología Latinoamericanos: abriendo nuevas ventanas para la educación" en Alexandria: Revista de Educação em Ciência e Tecnologia (Florianópolis: UFSC) N 4 (2), pp. 225246.

Badallo, A. C. 2008 "Conocimiento científico, ciudadanía y democracia" en CTS: Revista iberoamericana de ciencia, tecnología y sociedad (Buenos Aires: Centro REDES) $\mathrm{N}^{\circ} 4$ (10), pp. 67-83.

Bergek, A.; Jacobson, S.; Hekkert, M.; Smith, K. 2010

"Functionality of Innovation Systems as a Rationale for and

Guide to Innovation Policy" en Smits, R.; Kuhlmann, S.;

Shapira, P. (ed.) The theory and practice of innovation policy.

(Cheltenham: Edward Elgar Publishing).

Chaminade C.; Edquist, C. 2010 "Rationales for public policy intervention in the innovation process: A systems of innovation approach" en Smits, R.; Kuhlmann, S.; Shapira, P. (ed.) The Theory and Practice of Innovation Policy, An International Research Handbook (Cheltenham: Edward Elgar).

Córdova, P. 2008 "Marcos de acción para la popularización y visibilidad de la ciencia y tecnología" en Bitácora-e Revista Electrónica Latinoamericana de Estudios Sociales, Históricos y Culturales de la Ciencia y la Tecnología (Mérida, Venezuela: Universidad de los Andes) No 1, pp. 183-194.

Crespi, G.; Dutrénit, G. 2014 "Introduction to Science, Technology and Innovation Policies for Development: The Latin American Experience" en Science, Technology and Innovation Policies for Development (Nueva York: Springer International Publishing).

Delgado, A. 2010 “¿Democratizar la Ciencia? Diálogo, reflexividad y apertura" en CTS: Revista iberoamericana de ciencia, tecnología y sociedad (Buenos Aires: Centro REDES) $\mathrm{N}^{\circ} 5$ (15), p. 1.

Dutrénit, G.; Álvarez, I.; Ardanche, M.; Barletta, F.; Bianco, M.; Cortés, R.; Cummings, A.; de la Vega, I.; Díaz, I.; Fernández, O.; Gómez, V.; Goñi, M.; Natera, J. M.; Nupia, C.; Orozco, J.; Prada, F.; Puchet, M.; Romero, F.; Simón, L.; Suárez, D.; Suárez, M.; Sutz, J.; Vera-Cruz, A. O. 2016 “Matriz de 
Información para el mapeo de procesos de diálogo de CTI en España, América Latina y el Caribe" en Working paper (Red CYTED COM-LALICS) $\mathrm{N}^{\circ}$ 5. En <http://alics.org/images/ CYTED/DT5-Formulario2.pdf> acceso 15 de abril de 2017.

Dutrénit, G.; Natera, J. M.; Suárez, M. 2014 "Lineamientos para la caracterización de las Comunidades y sus Procesos de Diálogo" en Working paper (Red CYTED COM-LALICS) $\mathrm{N}^{\circ} 1$. En <http:// lalics.org/images/CYTED/DT1-ComunidadesDialogo\%201.pdf> acceso 15 de abril de 2017.

Echevarría, J. 2010 "De la filosofía de la ciencia a la filosofía de la tecnociencia" en Daimon Revista Internacional de Filosofía (Murcia : Universidad de Murcia) $\mathrm{N}^{\circ}$ 50, pp. 31-41.

Edquist, C. 1997 Systems of Innovation. Technologies, Institutions and Organizations. (London: Pinter).

Edquist, C. 2014 "Striving Towards a Holistic Innovation Policy in European Countries - But Linearity Still Prevails!" en Science, Technology and Innovation Policy Review, (Ghana: UNCTAD) $\mathrm{N}^{\circ}$ 5 (2), pp. 1-19.

Edwards, M.; Vilches, A.; Gil, D.; Praia, J. 2004 "La atención a la situación del mundo en la educación científica" en Enseñanza de las Ciencias (Barcelona: Universitat Autónoma de Barcelona) $\mathrm{N}^{\circ} 22$ (1), pp. 47-64.

Estrada, S.; Pacheco-Vega, R. 2009 "Sistemas y políticas de investigación, desarrollo e innovación: Algunas propuestas" en Espiral (Guadalajara: Universidad Nacional de Guadalajara), $\mathrm{N}^{\circ} 15$ (44), pp. 31-76.

Etzkowitz, H.; Leydesdorff, L. 1995 “The Triple Helix of UniversityIndustry-Government Relations: A laboratory for Knowledge Based Economy Development" en EASST Review N ${ }^{\circ} 14$ (1), pp. 11-19.

Gibbons, M.; Limoges, C.; Nowotny, H.; Schwartzman, S.; Scott, P.; Trow, M. 1994 The new production of knowledge: The dynamics of science and research in contemporary societies (California: Sage).

Goñi, M.; Bianco, M.; Puchet, M. 2015 "Elementos para caracterizar los procesos de diálogo en políticas de CTI" en Working paper (Red CYTED COM-LALICS) $\mathrm{N}^{\circ} 7$. En $<$ http:// lalics.org/images/CYTED/DT7-ConfianzaPoder.pdf> acceso 15 de abril de 2017.

Gras, N. 2012 Innovación orientada a la inclusión social: un modelo basado en agentes. (México: Maestría en Economía y Gestión de la Innovación, Universidad Autónoma Metropolitana). 
Hernández, R. 2010 Metodología de la Investigación (McGRAW-Hill Interamericana) Quinta edición.

Ibarra-Colado, E. 2008 "Regulación social de la 'triple hélice' en América Latina: Diálogos en busca de un proyecto distinto" en Revista mexicana de investigación educativa, (México: Consejo Mexicano de Investigación Educativa) N 13 (36), pp. 319-327.

Isaza, G. A. L. 2006 "Perspectivas para el análisis de la innovación: un recorrido por la teoría" en Cuadernos de Administración (Colombia: Pontificia Universidad Javeriana) No 19 (31).

Invernizzi, N. 2004 "Participación ciudadana en ciencia y tecnología en América Latina: una oportunidad para refundar el compromiso social de la universidad pública" en CTS: Revista iberoamericana de ciencia, tecnología y sociedad (Buenos Aires: Centro de Estudios sobre Ciencia, Desarrollo y Educación Superior) $N^{\circ} 1$ (2), pp. 67-83.

Lam, A. 1999 "Tacit Knowledge, Organisational Learning and Societal Institutions: An Integrated Framework. Paper presented in the Conference on National Innovation System, Industrial Dynamics and Innovation Policy" en Danish Research Unit for Industrial Dynamics (DRUID) (Dinamarca: Rebild) junio, pp. 9-12.

Lundvall, B. Å. 1992 National System of Innovation: Towards a Theory of Innovation and Interactive Learning (Londres: Pinter).

Nelson, R. 1994 "The Co-evolution of Technology, Industrial Structure, and Supporting Institutions" en Industrial and Corporate Change (Londres: Oxford University Press) $\mathrm{N}^{\circ} 3$, pp. 47-63.

Nupia, C.; Martínez A. 2015 "Revisión de metodologías de procesos de diálogo" en Working paper (Red CYTED COM-LALICS) $\mathrm{N}^{\circ} 4$. En <http://lalics.org/images/CYTED/DT4-MetodologiasDialogo. pdf $>$ acceso 15 de abril de 2017.

Orozco, J. 2016 Políticas para promover innovación: reflexiones para países en desarrollo (Mimeo - CINPE-UNA).

Orozco, J.; Ruiz, K. 2010 "Quality of interactions between public research organizations and firms: lessons from Costa Rica" en Science and Public Policy (Londres: Oxford University Press) $\mathrm{N}^{\circ} 37$ (7), pp. 527-540.

Sierra, M. C. P. 2011 "La construcción de la sociedad del conocimiento y las políticas públicas de apropiación social de la ciencia, la tecnología y la innovación" en Revista Trilogía (Medellín: Instituto Tecnológico Metropolitano) $\mathrm{N}^{\circ}$ 5, pp. 17-39. 
Pérez-Bustos, T. 2012 "Iniciativas de Apropiación Social de la Ciencia y la Tecnología en Colombia: tendencias y retos para una comprensión más amplia de estas dinámicas" en História, Ciências, Saúde (Manguinhos, Río de Janeiro) $\mathrm{N}^{\circ} 1$ (19), pp. 115-137.

Piñón, F. 2004 Ciencia y tecnología en América Latina: una posibilidad para el desarrollo en <www.campus-oei.org/salactsi/ pinon.pdf $>$.

Smits, R.; Kuhlmann, S.; Teubal, M. 2010 "A system-evolutionary approach for innovation systems" en Smits, R. (ed.) The theory and practice of innovation policy (Cheltenham: Edward Elgar).

Sutz, J. 1995 "La innovación en Uruguay. Problemas, instituciones, perspectivas" en Revista Perfiles Latinoamericanos (México: FLACSO) $\mathrm{N}^{\circ} 4$ (7), pp. 9-41.

Sutz, J. 1998 "La caracterización del Sistema Nacional de Innovación en el Uruguay: enfoques constructivos "en Nota Técnica (Río de Janeiro: IE/UFRJ) N 19, p. 98.

Sutz, J. 2010 "Ciencia, tecnología, innovación e inclusión social: una agenda urgente para universidades y políticas" en Psicología, Conocimiento y Sociedad (Uruguay: Facultad de Psicología de la Universidad de la República) Nº 1 (1), pp. 3-49.

\section{COMUNICACIONES PERSONALES}

Patricia Meneses. Representante del Consejo Nacional de Rectores en los períodos 2011-2012 y 2015-2016, y miembro de la Subcomisión de Indicadores de la Investigación en dicha institución.

Ana Mercedes Umaña. Coordinadora de Estadísticas Económicas del Instituto Nacional de Estadística y Censo.

Alejandro Cruz Molina. Se desempeñó como Rector del Instituto Tecnológico de Costa Rica desde 1995 hasta 2003, y como Ministro de Ciencia, Tecnología y Telecomunicaciones en el período comprendido entre 2011 y 2014.

Diego Vargas. Actual Jefe de Indicadores del Ministerio de Ciencia, Tecnología y Telecomunicaciones.

Eugenia Flores. Ministra de Ciencia, Tecnología e Innovación durante el período 2006-2010. Fue miembro destacado de todas las comisiones inherentes al cargo, como el Consejo de Competitividad, gobierno digital, pymes y otras.

Paul Fervoy. Representante de la Cámara de Tecnología de Información y Comunicación (CAMTIC). 
Natalia Porras. Encargada del Área de Propiedad Intelectual del Ministerio de Comercio Exterior (COMEX).

Franklin Giralt. Departamento de Gestión de Calidad del Banco Central de Costa Rica.

Ricardo Morales. Departamento de Gestión de Calidad del Banco Central de Costa Rica. 



\title{
EL CONTEXTO PARA LA INNOVACIÓN EN CUBA
}

\author{
CONSTRUCCIÓN DE CONSENSOS \\ ENTRE COMUNIDADES
}

\author{
Ricardo Torres Pérez, * Ileana Díaz Fernández* \\ y Oscar Fernández Estrada**
}

\section{INTRODUCCIÓN}

Ninguna sociedad ha logrado alcanzar elevadas cuotas de desarrollo económico y social sin fomentar adecuadamente la innovación y la acumulación social de conocimientos que permiten dar solución a los desafíos que supone satisfacer las necesidades materiales y espirituales de las sociedades. Su rol en las economías contemporáneas se hace cada vez más prominente.

Hay varias señales que indican que la innovación es clave para el desarrollo sostenible de las economías en el largo plazo. Los análisis formales nos indican que, de forma creciente, no son los factores físicos (trabajo, capital), sino las maneras en que se combinan, lo que constituye la clave del crecimiento a largo plazo. Hoy se invierte deliberadamente en ciencia y desarrollo tecnológico más que nunca antes en la historia. Los gobiernos prestan una renovada atención a las políticas para fomentar la innovación y facilitar el acceso y la difusión del conocimiento.

\footnotetext{
* Profesores del Centro de Estudios de la Economía Cubana, de la Universidad de La Habana.

** Profesor del Centro de Estudios sobre Administración Pública y Empresarial, de la Escuela Superior de Cuadros del Estado y el Gobierno.
} 
El conocimiento es el instrumento más potente de que disponemos para aumentar de forma sostenible la producción, nos permite comprender las leyes naturales y atender nuestras necesidades. La innovación es el conocimiento puesto en acción para dar respuesta a un problema de naturaleza socioeconómica. La innovación es un proceso esencial para el desarrollo de las fuerzas productivas, y en las condiciones cubanas, para garantizar la capacidad del país de generar un desarrollo sostenible sobre la base de potenciar las fuerzas endógenas. Solo una sociedad y economía innovadoras garantizará amplios grados de independencia y movilidad económica, financiera, política y cultural; que brinden la capacidad de rehacer trayectorias, buscando revertir procesos seculares de inserción externa subalterna en el marco del sistema de relaciones internacionales vigente.

En este trabajo se asume que la innovación es un proceso de naturaleza estratégica que, aunque tiene una direccionalidad definida, transcurre de forma iterativa, no lineal, y es altamente sensible al contexto histórico y las condiciones socioeconómicas y políticas en que tiene lugar. En la práctica, la innovación abarca dimensiones tecnológicas (procesos, productos), pero desborda ampliamente este ámbito y se extiende hacia aspectos vinculados a las organizaciones y la conducción del cambio en las mismas, así como las personas y sus interrelaciones.

Algunas características centrales de la innovación son: (i) acumulativa; y (ii) interactiva. Lo acumulativo se refiere a que las capacidades de innovación se construyen, no surgen espontáneamente; el proceso de innovación es costoso, deliberado y toma tiempo, por lo que la trayectoria importa a la hora de describir la situación en el presente. Además, las innovaciones en ciertas áreas abren la posibilidad para innovar en otras, las que, a su vez, proveen oportunidades que antes no se hubiesen considerado. Lo interactivo supone la existencia de distintos tipos de agentes o actores, que tienen funciones relativamente bien definidas, que comparten un espacio socioeconómico común y que están llamados a establecer vínculos de relación y/o competencia. A partir de esto, ellos son capaces de acumular conocimientos e información que ha sido recabada a través de las interacciones entre los mismos. Por ejemplo, empresas con clientes, proveedores y academia; universidades y centros de investigación con empresas innovadoras; y empresas y universidades con gobiernos para diseño e implementación de políticas.

Los elementos y características anteriores han llevado a considerar el análisis de los procesos de innovación en el marco de los denominados sistemas nacionales de innovación (SNI), con sus derivaciones a nivel regional o local, y sectorial. Una definición amplia en este sentido sería: 
el sistema nacional de innovación es un sistema abierto, complejo y en constante evolución, que integra instituciones y estructuras económicas. Los atributos de sus componentes y las relaciones entre estos determinan el volumen y la dirección de la innovación y la construcción de competencias que surge de la combinación del aprendizaje basado en la ciencia y la experiencia. (Lundvall, 2007)

En el contexto de las economías en desarrollo, con frecuencia los elementos del SNI aparecen distorsionados o desarticulados (Dutrénit \& Sutz, 2014). La enorme inercia asociada a la condición del subdesarrollo secular implica que la transformación de estas condiciones no ocurre espontáneamente, incluso en un escenario de crecimiento de la renta per cápita. Este último proceso, aunque deseable, como norma genera una reproducción de escala ampliada de las debilidades estructurales, por lo que se requiere de una acción deliberada del Estado para iniciar y sostener la transformación por un período suficientemente largo. Esta necesidad genera el espacio para las políticas públicas en ciencia, tecnología e innovación (CTI). A su vez, estas se han ido transformando desde un estilo "top-down", de tipo ofertista, hasta un esquema más complejo $\mathrm{y}$, sobre todo, crecientemente participativo, mediante el cual el ente público interactúa y construye los marcos de acción en conjunto con actores de las diversas comunidades, a saber, académica, empresarial y otras de la sociedad civil.

Este proceso de inclusión y creciente participación de otros actores igualmente relevantes ha atravesado diferentes etapas. Como respuesta a las necesidades de proveer un marco claro y estructurado se han venido sistematizando varios métodos para contribuir al éxito de estos esfuerzos, de gran importancia socioeconómica. Entre ellos se puede encontrar el diálogo.

Existen diversas definiciones de diálogo público. La más difundida es la propuesta del PNUD que plantea que es un

Proceso de genuina interacción mediante el cual los seres humanos se escuchan unos a otros con tal profundidad y respeto que cambian mediante lo que aprenden. Cada uno de los participantes en un diálogo se esfuerza para incorporar las preocupaciones de los otros a su propia perspectiva, aun cuando persista el desacuerdo. Ninguno de los participantes renuncia a su identidad, pero cada uno reconoce la validez de las reivindicaciones humanas de los demás y en consecuencia actúa en forma diferente hacia los otros. (Cuentas y Linares, 2013: 9) ${ }^{1}$

1 Otras definiciones de diálogo se pueden encontrar en Nupia \& Martínez (2015). 
Pero, para analizar las especificidades de los procesos de diálogo para la formulación de políticas públicas de CTI, la "Red temática para mejorar el diálogo entre las comunidades involucradas en las políticas de CTI”, de CYTED, desarrolló una propuesta teórico-metodológica, que se resume en Dutrénit, Natera y Suarez (2014), Goñi, Bianco y Puchet (2015), Alvarez et al. (2016) y Dutrénit et al. (2016, 2017). En particular, se adapta la definición de diálogo al contexto analizado las políticas de CTI-. Sobre esta base, Goñi, Bianco y Puchet (2015) plantean que

los procesos de diálogo relativos a las políticas públicas de CTI son, al igual que los del diálogo democrático, auténticos ejercicios de interacción y conflicto. En ellos cada uno de los participantes aprende e internaliza argumentos de los demás sosteniendo su identidad y está ubicado, desde la perspectiva comunicativa, en una posición resultante del poder o de las capacidades que tiene. Los participantes son actores que emergen de distintas comunidades de agentes de las actividades de CTI. Tienen, por lo tanto, una relación de representación con su comunidad y, a su vez, pertenecen a organizaciones académicas, productivas, gubernamentales o de la sociedad civil que los dotan de diferentes grados de poder y de distintas capacidades.

La definición de comunidades de CTI a que se hace referencia, parte de los individuos, las comunidades son resultado de la interacción de 2 procesos conflictivos: la socialización de individuos y la formación de redes (Barboza, 2016; Dutrénit, Natera \& Suárez, 2014). Las cuatro principales comunidades identificadas en la esfera de la CTI son: académicos, empresas, sector público, y otros agentes de la sociedad civil (Dutrénit, Natera \& Suárez, 2014). Los actores en los diálogos en CTI son así grupos de individuos o de organizaciones que emergen dentro de esas comunidades.

La concepción de diálogo incluye el aprendizaje, lo cual es especialmente importante en los diálogos que se efectúen mediante las interacciones entre los actores en los procesos de innovación. Según Lundvall "el recurso más importante es el conocimiento y el proceso más importante es el aprendizaje” (2007: 5).

El diálogo se convierte en un instrumento poderoso sobre todo en los países en desarrollo donde los sistemas nacionales de innovación son más formales que reales y por tanto las interconexiones son débiles y las relaciones e interacciones entre actores suelen ser más dispersas, por tanto, más necesitadas de procesos de diálogo que contribuyan a generar consensos. El estudio de tales procesos ayuda a perfeccionarlos y contribuiría a alcanzar acuerdos de calidad y alto impacto en los procesos de innovación y en las políticas de CTI que los favorecen. 
Según Álvarez et al. (2016), los elementos fundamentales del diálogo serían los siguientes i) el contexto, porque da cuenta del entorno del sistema y las reglas de juego; ii) los principales actores involucrados: actores clave dentro de cada comunidad, intereses, relaciones de poder; iii) el alcance, en términos de sus límites tanto geográficos como relativos a la población objetivo del diálogo político; iv) los objetivos; v) la dinámica del proceso; y vi) sus resultados: tipo de política, mecanismo de monitoreo y ajuste, e impacto.

Este trabajo analiza un proceso de diálogo sobre innovación en Cuba. El objetivo es discutir las condiciones para el diálogo que incluirían, particularmente el contexto y los actores involucrados (en términos de competencias dialógicas y de reconocimiento de los otros).

Después de esta introducción, la sección dos justifica la importancia de un diálogo sobre innovación en la Cuba de hoy, la sección tres presenta el marco teórico que ubica conceptualmente el problema, la sección cuatro describe la metodología, la sección cinco analiza las condiciones para el diálogo sobre innovación en Cuba, la sección seis describe las comunidades, la sección siete discute la evidencia, y por último la sección ocho contiene las conclusiones.

\section{EL DIÁLOGO SOBRE INNOVACIÓN EN CUBA}

Cuba se ha constituido a lo largo de las últimas cinco décadas en una realidad socioeconómica singular. Como en pocos países, en la Isla se superponen los rasgos de al menos tres realidades con un largo recorrido en la conceptualización de las ciencias sociales: subdesarrollo, socialismo de planificación central, y más recientemente, el inicio de un proceso de transformaciones, definido inicialmente como una partida hacia un nuevo modelo, que todavía se halla difuso en términos tanto de sus características como del camino a seguir. Todo esto conforma una realidad compleja, donde existen ausencias de certidumbre respecto a los cursos del cambio. Esta mutación conlleva una transformación intensa, profunda y progresiva, inabarcable para el investigador actual, sobre la expresión y el contenido de los actores, comunidades y las interacciones entre los mismos.

La conceptualización del modelo económico y social del desarrollo socialista, intenta dibujar el punto de llegada, que se describe -todavía con trazos muy gruesos- como una sociedad socialista, democrática, soberana, próspera y sustentable. Todos estos cambios en marcha condicionan el espacio para las políticas públicas en general, y para las políticas de CTI en particular. Es, por tal razón, que el tema de la innovación adquiere relevancia y es necesario lograr consensos entre las comunidades que influyan en las decisiones de política. Ese 
consenso solo se logra por el intercambio e interacción entre las partes involucradas, es decir, mediante el diálogo.

Todo lo anterior nos conduce a que sea indispensable plantearse como un problema del proceso de diálogo ¿Cómo aprovechar las condiciones para el diálogo en un proceso de diálogo sobre innovación?

Las políticas de CTI existen para conducir, de manera general, los procesos de la misma, que transcurren en un espacio y tiempo determinado, por lo que es indispensable conocer y evaluar el contexto económico, político y sociocultural en el que deben actuar, tanto para el diseño como para su desenvolvimiento. Por otra parte, los decisores de políticas y quienes están sujetos a ellas deben interactuar con sistematicidad y para ello es necesario que posean capacidades comunicativas y se reconozcan unos a otros, como una vía de lograr el consenso.

Este estudio del proceso de diálogo en Cuba se centra en las condiciones para el diálogo debido a que:

1) El contexto cubano actual se encuentra en cambios mediante la actualización del modelo económico y social, que se caracterizan por una diversidad de formas de propiedad, aceptación del mercado como complemento de la planificación central y reconocimiento de la innovación como base de la modernización y desarrollo económico.

2) La importancia de los actores de las comunidades del gobierno, empresas y centros de generación de conocimientos, todos jugando roles diferentes en el proceso de diálogo sobre innovación.

3) El mecanismo de funcionamiento de la economía cubana centralizado, hace complejo el consenso entre los actores involucrados en la innovación, pues la Comunidad del Sector Público tiene una presencia y una influencia desproporcionada, lo que requiere de un gran esfuerzo inicial para crear las condiciones mínimas para un diálogo efectivo.

4) Cada uno de los actores poseen competencias dialógicas basadas en ejes cognitivos diferentes, así las empresas tienen la experiencia práctica, los centros académicos el conocimiento formal y el gobierno, la capacidad de diseñar y poner en prácticas las políticas públicas. Es importante conocer por anticipado con qué competencias cuenta cada actor y de qué modo lograr el aprendizaje en el proceso de diálogo. 
En estos momentos es más que oportuno el diálogo sobre innovación, en primer lugar, porque se ha incluido como uno de los seis ejes estratégicos para el Plan Nacional de Desarrollo Económico y Social hasta 2030 (PCC, 2016). Específicamente, se incorpora dentro del eje denominado "potencial humano, ciencia, tecnología e innovación"; y, en segundo lugar, debido a los cambios que se están introduciendo en la economía, que demandan un enfoque moderno sobre la innovación, que otorgue su justo lugar a las diferentes formas productivas. Esto requiere construir consensos sobre los fundamentos conceptuales de la innovación y otros aspectos medulares a refrendarse en las políticas. Conviene apuntar que esta forma de construir políticas públicas no tiene muchos antecedentes en Cuba, donde ha predominado un modelo centralizado de toma de decisiones. Por este motivo, lograr consenso entre los diversos actores, incluido el gobierno, es un paso importante que pudiera servir de ejemplo para otras políticas.

Este es uno de los aportes más importantes de esta sistematización. A partir de la documentación de la experiencia de diálogo, puede ser difundida para que sirva a los decisores como base de análisis para los próximos temas de discusión, mucho más en momentos en que se están acometiendo un conjunto de tareas, la mayoría enfocadas a la modificación o elaboración de políticas en diversas áreas de la vida socio-económica del país, en muchas de las cuales sería posible y beneficioso el uso de métodos más participativos.

El conjunto de elementos expuestos anteriormente, determina el limitado desarrollo de este campo del conocimiento, por lo que este trabajo contribuye a llenar un vacío práctico, que debe ser entendido sobre todo, como un punto de partida.

Para presentar de manera lógica la respuesta al problema de investigación, se han formulado las siguientes preguntas, que contribuyen a guiar el avance de este ejercicio:

1) ¿Qué importancia le otorga la literatura a las condiciones de diálogo?

2) ¿Por qué es necesario en Cuba prestarles atención a las condiciones de diálogo en la conformación de los consensos para la construcción de políticas para la innovación?

3) ¿Qué papel juegan las condiciones en el proceso de diálogo sobre innovación en Cuba?

4) ¿Cómo contribuyen las condiciones de diálogo al cumplimiento de los objetivos del proceso de diálogo en innovación en Cuba? 


\section{REVISIÓN DE LA LITERATURA SOBRE DIÁLOGO}

La necesidad que tuvieron los seres humanos de relacionarse para sobrevivir condiciona la existencia del lenguaje y de ahí la conversación, el intercambio como una forma de dialogo. El diálogo es un proceso totalmente social de interacción en el cual intervienen dos o más personas, existe un tema a discusión, una "forma de conducir" el diálogo y un resultado que debe corresponderse con el objetivo esperado.

No existe una teoría completa o acabada de diálogo, sino enfoques sobre el mismo, de modo que la literatura refiere a la mirada filosófica, que abarca la visión fenomenológica, hermenéutica y la ética dialógica. También se expone el diálogo como herramienta de interacción social utilizado en la terapéutica, la resolución de conflictos y en general en la interacción.

Existen autores (Cuentas y Linares, 2013) que diferencian el diálogo del debate y la negociación, en tanto otros (Velasco \& Alonso, 2009; Ermida, 2006) incluyen la negociación como una forma de dialogo. Para adentrarnos en el estudio del diálogo, a continuación, se presentan algunas definiciones en la Tabla 1:

Tabla 1: Definiciones de diálogo

\begin{tabular}{|c|c|}
\hline Autores & Definiciones \\
\hline $\begin{array}{l}\text { OCDE. Hacia un mecanismo para el } \\
\text { diálogo de políticas de innovación: } \\
\text { oportunidades y desafíos para América } \\
\text { Latina y el Caribe. Marzo } 2011 \text { (p. 29). }\end{array}$ & $\begin{array}{l}\text { "Aquellos espacios en que ejecutivos públicos en ejercicio, } \\
\text { a cargo del diseño o la ejecución de políticas, interactúan } \\
\text { con ejecutivos en posiciones análogas de otros países, } \\
\text { para intercambiar experiencias prácticas derivadas de } \\
\text { su desempeño laboral, con el fin de obtener ideas para } \\
\text { nuevas iniciativas, soluciones a problemas prácticos en la } \\
\text { implementación de sus programas o concertar iniciativas } \\
\text { conjuntas de mutuo beneficio. Permite una transferencia } \\
\text { directa de información valiosa y difícil de codificar, sobre } \\
\text { el quehacer propio de la gestión de políticas públicas. No } \\
\text { es este el espacio privilegiado para la discusión teórica ni } \\
\text { requiere de interfaces de tipo académico. Su ventaja está } \\
\text { más en la posibilidad de ser inspirado por el quehacer de } \\
\text { otros para realizar ciertas iniciativas en el propio país, y } \\
\text { en la oportunidad en que las ideas Ilegan, más que en la } \\
\text { precisión o elaboración de la información". }\end{array}$ \\
\hline $\begin{array}{l}\text { Mirna Cuentas y Ana Linares. PNUD. } \\
\text { Guía práctica del diálogo democrático. } \\
\text { Febrero 2013. (p. 9). }\end{array}$ & $\begin{array}{l}\text { "Proceso de genuina interacción mediante el cual los seres } \\
\text { humanos se escuchan unos a otros con tal profundidad y } \\
\text { respeto que cambian mediante lo que aprenden. Cada uno } \\
\text { de los participantes en un diálogo se esfuerza para incorporar } \\
\text { las preocupaciones de los otros a su propia perspectiva, aun } \\
\text { cuando persista el desacuerdo. Ninguno de los participantes } \\
\text { renuncia a su identidad, pero cada uno reconoce la validez de } \\
\text { las reivindicaciones humanas de los demás y en consecuencia } \\
\text { actúa en forma diferente hacia los otros". }\end{array}$ \\
\hline
\end{tabular}




\begin{tabular}{|c|c|}
\hline Autores & Definiciones \\
\hline $\begin{array}{l}\text { Alexander Rayo. CEPAL. Espacios de } \\
\text { diálogo para construir estrategias de } \\
\text { desarrollo público-privadas: Una guía } \\
\text { metodológica. Octubre } 2013 \text {. }\end{array}$ & $\begin{array}{l}\text { "Los espacios de diálogo constituyen un proceso de } \\
\text { comunicación y cooperación entre diferentes actores } \\
\text { relevantes para un tema, que deben colaborar para el } \\
\text { desarrollo mutuo y del propio sistema relacional al que } \\
\text { pertenecen (identificar soluciones e implementar acciones). } \\
\text { A través del diálogo se reúnen capacidades, recursos, } \\
\text { ideas y perspectivas de los diversos actores, lo que facilita } \\
\text { la búsqueda de soluciones que individualmente no serían } \\
\text { pensadas ni alcanzables. El diálogo implica que ninguna } \\
\text { postura es concluyente hasta que no hay un consenso } \\
\text { general, de manera que de la conversación en una sesión } \\
\text { de trabajo pueden surgir ideas o nuevos acuerdos. Se } \\
\text { trata de establecer un modelo de pensamiento conjunto } \\
\text { donde todos pueden opinar y colaborar abiertamente. Estos } \\
\text { diálogos deben estar estructurados como un proceso de } \\
\text { trabajo y tener un objetivo común compartido por todos } \\
\text { los actores. También deben tener como base de trabajo la } \\
\text { búsqueda de consensos, el diseño conjunto de acciones y } \\
\text { su respectiva implementación". }\end{array}$ \\
\hline $\begin{array}{l}\text { Antonio Velasco Castro y Leonor Alonso } \\
\text { González. Una síntesis de la teoría del } \\
\text { dialogo. } 2009 \text { (p. 110). }\end{array}$ & $\begin{array}{l}\text { "interrelación comunicativa entre dos o más sujetos, que } \\
\text { cumple ciertas características mínimas: } \\
\text { (1) tendencia al tratamiento de un mismo tema; (2) } \\
\text { ocurrencia de emisiones por cada una de las partes; (3) } \\
\text { tendencia a la simetría en la participación;(4)interacción } \\
\text { según turnos alternativos; (5) cortesía mínima; (6) } \\
\text { búsqueda de comprensión mutua; (7) lenguaje en común; } \\
\text { y (8) existencia de retroalimentación, para-alimentación y } \\
\text { prealimentación". }\end{array}$ \\
\hline $\begin{array}{l}\text { Ana María García Femenía, Emilio } \\
\text { Morgado Valenzuela y Marleen } \\
\text { Rueda Catry. OIT. Dialogo social } \\
\text { institucionalizado en América Latina. } \\
\text { Estudio comparado de Argentina, Brasil, } \\
\text { Ecuador, México y Perú. } 2007 \text { (p. 12). }\end{array}$ & $\begin{array}{l}\text { "El dialogo social comprende un intercambio de } \\
\text { informaciones acerca de las visiones, aspiraciones y } \\
\text { proposiciones de quienes participan en él, respecto de las } \\
\text { materias objeto de ese intercambio". }\end{array}$ \\
\hline $\begin{array}{l}\text { María Goñi, Mariela Bianco y Martín } \\
\text { Puchet (2015), "Elementos para } \\
\text { caracterizar los procesos de diálogo en } \\
\text { políticas de CTI”, Documento de trabajo } \\
\text { núm. 1, Red CYTED COM - LALICS. }\end{array}$ & $\begin{array}{l}\text { "Los procesos de diálogo relativos a las políticas públicas } \\
\text { de CTI son, al igual que los del diálogo democrático, } \\
\text { auténticos ejercicios de interacción y conflicto. En ellos } \\
\text { cada uno de los participantes aprende e internaliza } \\
\text { argumentos de los demás sosteniendo su identidad y } \\
\text { está ubicado, desde la perspectiva comunicativa, en una } \\
\text { posición resultante del poder o de las capacidades que } \\
\text { tiene. Los participantes son actores que emergen de } \\
\text { distintas comunidades de agentes de las actividades de } \\
\text { CTI. Tienen, por lo tanto, una relación de representación } \\
\text { con su comunidad y, a su vez, pertenecen a organizaciones } \\
\text { académicas, productivas, gubernamentales o de la } \\
\text { sociedad civil que los dotan de diferentes grados de poder } \\
\text { y de distintas capacidades". }\end{array}$ \\
\hline
\end{tabular}

Fuente: elaboración de los autores a partir de las fuentes mencionadas. 
Si se analizan las definiciones presentadas sobre la base de tres dimensiones, a saber, esencia del dialogo, el proceso y lo que se espera de ese proceso, se puede apreciar lo siguiente:

\section{SOBRE LA ESENCIA DEL DIÁLOGO}

Están referidos en lo fundamental a la interacción, intercambio e interrelación, ya sea de experiencias o de información, aunque también se vincula a la comunicación y colaboración.

\section{SOBRE EL PROCESO DE DIÁLOGO}

La OCDE plantea "transferencia directa" sin más detalles y en García et al. (2007) no se traza una postura al respecto. En Velasco y Alonso (2009) se enumeran un conjunto de aspectos, entre los cuales se encuentra el de "búsqueda de comprensión mutua" que está presente en los dos trabajos restantes, que apuntan con mucha fuerza hacía aspectos tales como: "se escuchan unos a otros", "profundidad y respeto", "se esfuerza para incorporar las preocupaciones de los otros", así como "ninguna postura es concluyente hasta lograr el consenso". Todo lo expuesto refuerza lo iterativo de este proceso, de volver una y otra vez y tantas veces como sea necesario para encontrar las bases del acuerdo o del logro de los objetivos, sin la supremacía de unos actores frente a otros. Es por eso que Cuentas y Linares (2013), así como Goñi, Bianco y Puchet (2015), proponen que sea un proceso de aprendizaje, ya que los diversos actores participantes, en su interacción, van creciendo respecto a la comprensión del tema que se dialoga y a las capacidades para dialogar.

\section{SOBRE LO QUE SE ESPERA DEL PROCESO}

Lo más significativo es lo formulado por Rayo (2013): el consenso. Cualquiera que sea el tema y los objetivos propuestos, el dialogo debe alcanzar el consenso, de lo contrario las posturas de unos actores se habrán impuesto sobre otras y no se lograría un diálogo. Las soluciones o acciones, como exponen algunos autores como resultado, deben ser consensuadas, de lo contrario no estaríamos en presencia de un dialogo.

Por supuesto todas las definiciones hacen mención a los sujetos de diálogo o actores, que son condición necesaria para la interacción social que toma la forma de dialogo.

Si bien ninguna definición expone de forma abierta y directa las condiciones para el diálogo (y no tendrían por qué incluirlo), de hecho, los participantes o actores son parte de esas condiciones toda vez que se asume la propuesta de Velasco y Alonso sobre las condiciones de diálogo" 
Competencia comunicativa. Cognitiva: de producción de significados; intraindividual: facultad de adquirir y usar el lenguaje; e interindividual: competencia para comunicarse en la lengua. Reconocimiento mutuo: aceptación de la presencia del otro, comprensión psicológica del otro, y ejecución de acciones en función de las del Otro. Contexto de reconocimiento: condiciones sociales y ambientales que permiten reconocer al otro como semejante. (2009: 109)

De las definiciones, por tanto, se pueden inferir ciertos aspectos generales respecto a las condiciones, uno de ellos es que los actores deben saber o aprender en el proceso a: escuchar, respetar, ser cortés, incorporar puntos de vistas, etc. Es decir, es importante que existan o se desarrollen ciertas capacidades o competencias de diálogo en los actores, y en quienes facilitan el proceso y la aceptación de unos respecto a los otros.

En la revisión bibliográfica se precisa que en la fase exploratoria del proceso de diálogo se tenga en cuenta tanto a los actores como al contexto. Conocer las condiciones de partida en cuanto a los actores y el contexto para el diálogo sobre un tema en particular es premisa para poder continuar en las siguientes fases.

¿Cuál es la importancia de evaluar las condiciones para el diálogo? Las condiciones políticas, económicas y socioculturales en las cuales se debe desarrollar el diálogo y en las cuales se contextualiza el tema son decisivas para determinar los actores que participan, su comportamiento, los intereses o posturas que defienden, y sus motivaciones.

Respecto de los actores, es necesario conocer sus competencias para el diálogo, que están relacionadas con la capacidad para comunicarse, para valorar e incorporar criterios de otros. Saber escuchar, no aferrarse a sus propias opiniones y todas estas habilidades pueden estar presentes o matizarse en dependencia de los intereses y metas, así como de la postura respecto al tema y el nivel de conocimiento. Por otra parte, reconocer a otros en el diálogo se relaciona con la capacidad de apertura e involucramiento, el poder o papel en el tema, así como con el tipo de relaciones que se tiene con el resto de los actores.

Rayo (2013) muestra algunos factores de éxito, el primero de ellos es el conocimiento de los actores Se le otorga también una gran relevancia al fortalecimiento de las relaciones, que debe lograrse, sino desde el inicio, al menos mediante el aprendizaje durante el proceso de diálogo.

Por lo anterior, si en el diálogo se debe alcanzar consenso, es importante, mediante un mapeo u otra técnica, conocer las capacidades de los actores y sus intereses en el tema a discutir, para poder ubicar roles, saber las necesidades de aprendizaje e identificar las limitaciones. 


\section{METODOLOGÍA}

La metodología designa la forma en que enfocamos los problemas y buscamos respuestas (Taylor \& Bogdan, 2000). La metodología en que se basa la investigación que sustenta este trabajo es el estudio de caso; el caso es un proceso de diálogo sobre la innovación en Cuba.

Existe un gran número de definiciones sobre estudios de caso (Yin, 1997; Tellis, 1997; Rodríguez, Gil, García, 2004) pero existe cierto consenso en resaltar que consiste en una lógica de investigación que permite comprender los significados de determinados comportamientos en un sistema de acción. Los estudios de caso se caracterizan por el examen detallado, comprehensivo, sistemático y en profundidad del caso (o los casos) objeto de interés (Rodríguez, Gil, García, 2004).

Una de las características fundamentales de un estudio de caso consiste en la búsqueda de la comprensión holística de un sistema cultural de acción, entendido este último como un grupo de actividades interrelacionadas y desarrolladas por un grupo de actores en una situación social (Feagin, Orum, \& Sjoberg, 1990; citado por Tellis, 1997).

Estas particularidades del estudio de caso son muy valiosas para desarrollar los objetivos de investigación propuestos en el presente trabajo ya que permite la comprensión de las relaciones que se establecen en el proceso de diálogo a lo largo de un período de tiempo dado, partiendo de un contexto singular que ha conformado una forma específica de los actores, las comunidades y su comportamiento.

En el caso del proceso de diálogo sobre la innovación en Cuba participaron 53 personas de diferentes comunidades de CTI: 39 del sector empresarial, 6 del sector académico, 6 del gobierno, 2 por la Asociación Nacional de Economistas y Contadores de Cuba. El diálogo se desarrolló a lo largo de once sesiones. Se usaron técnicas de trabajo en grupo para organizar la discusión.

En el proceso de diálogo para alcanzar el consenso se pueden aplicar técnicas como: reducción de listado, Pareto, hoja de balance, positivo y negativo, votación ponderada, discusiones reiteradas, siendo esta última la más utilizada en este trabajo.

Para realizar el análisis holístico del caso se utilizó el formulario propuesto por la RED (Dutrénit et al., 2016).

\section{LAS CONDICIONES PARA UN DIÁLOGO SOBRE POLÍTICAS PARA LA INNOVACIÓN EN CUBA}

La economía cubana, luego de cincuenta años de Revolución, no ha logrado corregir la mayoría de los desequilibrios estructurales que la mantienen en una senda de bajo crecimiento potencial a pesar de 
haber creado grandes oportunidades de desarrollo a partir de las enormes inversiones en infraestructura educativa y sanitaria, que incluye la formación de recursos humanos de alta calificación para estos sectores. En el plano productivo, existen complejos problemas que podemos sintetizar en un conjunto de deformaciones estructurales que socavan el avance de las fuerzas productivas. Algunas de ellas están directamente relacionadas con el tema del dialogo, entre ellas tenemos, siguiendo a Torres (2011):

1) Inexistencia de un desarrollo industrial pretérito que haya posibilitado ubicar a una proporción significativa de la fuerza de trabajo en trayectorias ascendentes de aprendizaje y dominio de nuevas tecnologías.

2) Elevado desaprovechamiento relativo de los recursos laborales del país (15\% de los trabajadores generan 90\% del valor de las exportaciones (níquel, turismo, servicios médicos, industria farmacéutica).

3) Los servicios productivos tienen un escaso desarrollo lo cual denota el bajo nivel de especialización, a lo que se suma el escaso despliegue de formas avanzadas de organización de la producción, como los clústeres y parques industriales.

4) Escasa diversificación y sofisticación de la oferta exportable (solo un 10\% de las exportaciones de bienes se clasifican como de alta tecnología, cuatro conceptos concentran alrededor del $60 \%$ de las exportaciones de bienes).

5) Oferta de servicios transables que se concentra en los rubros menos dinámicos del comercio internacional.

Una parte significativa de las insuficiencias que muestra la transformación estructural del país puede explicase a partir de las características generales del sistema empresarial cubano. En un estudio de los sistemas de dirección de la economía después de 1959 y su impacto sobre la trayectoria productiva de las empresas, se destacan dos elementos esenciales (Díaz, 2010). Primeramente, los mecanismos de regulación se han caracterizado por su centralización y verticalidad, definiendo un rol menor para la empresa, con predominio de la gran empresa estatal y con un papel casi ceremonial para las cooperativas, quedando el emprendimiento individual relegado a un papel virtualmente marginal.

El criterio básico de eficiencia dinámica se identificó con la generación de rentas basadas en unas pocas actividades productivas, 
esencialmente vinculadas con la exportación de recursos naturales y más recientemente los servicios médicos. Esto explicaría el hecho de que la innovación y el cambio tecnológico de base amplia no formen parte orgánica del funcionamiento de un sistema económico enfocado hacia el corto plazo. Por su propia naturaleza, los procesos innovadores tienen un carácter acumulativo y una clara orientación de largo plazo. La inercia y el inmovilismo de los sistemas de dirección en Cuba han retardado el proceso de innovación, impidiendo el descubrimiento continuo de nuevas fuentes de acumulación y creación de riqueza. En la mayoría de los casos, para cuando el ente central advierte una oportunidad, es demasiado tarde para competir exitosamente en el mercado.

En segundo lugar, el surgimiento de nuevas empresas y ramas ha dependido de la prioridad establecida centralmente, incluso la estructura interior de los sectores responde más a la necesidad de maximizar las rentas que a otros criterios de eficiencia o al fomento de derrames. En el contexto de mayor dependencia de los resultados propios para financiar la acumulación y la sostenibilidad de las prestaciones sociales, consecuencia de la crisis económica de principios de los noventa, tampoco las sucesivas actualizaciones del marco regulatorio aplicable a la empresa lograron introducir mecanismos propicios para el estímulo de los procesos innovadores sobre el que descansa el proceso de redistribución de la riqueza.

El diálogo sobre innovación en Cuba se inserta en este contexto. Para un análisis riguroso del contexto, es preciso comprender a cabalidad cuáles son los rasgos fundamentales que caracterizan el funcionamiento del sistema y marcan por tanto una diferencia determinante respecto a otros contextos.

1) Economía planificada. El primero y más general rasgo del sistema socioeconómico cubano es su atribuida condición de economía planificada. Esta condición, entendida como la sustitución de las relaciones de intercambio mercantil entre los agentes, y por tanto la anulación del mecanismo de mercado para la asignación de recursos en la economía, conduce a efectos significativos. La estatización completa y el manejo centralizado de todas las actividades productivas se fueron consolidando durante varias décadas. En esas condiciones, en vez de orientar el curso general de la economía, la planificación fue empujada a realizar una misión que no podía cumplir: la centralización de todas las decisiones de producción, distribución e intercambio de bienes en un comando rector: el plan. 
2) La tiranía de los productores. La intención de establecer exante las proporciones productivas a escala nacional y de encomendar su cumplimiento a través de las órdenes contenidas en el plan -gracias a la omnipresencia del Estado como propietario de los medios de producción- conducen a una economía cuyo rasgo fundamental ha sido acuñado como la "tiranía de los productores". En este modelo, la demanda tiene un papel pasivo en la asignación de recursos, en tanto la estructura de la producción ha sido decidida con anterioridad y los mecanismos de retroalimentación no se basan en la información de los precios, los que, por lo tanto, no envían señales a los distintos agentes económicos.

3) Estructura de mercado cuasi-monopólica. Aunque la causa determinante en esta situación pareciera hallarse en limitaciones productivas reales, el hecho se agrava cuando la producción de cada renglón se concentra en una o muy pocas empresas, persiguiendo supuestos beneficios de escala derivados de la especialización, pero sobre todo facilitando la toma de decisiones de manera centralizada. Esta tendencia genera al mismo tiempo una estructura de mercado que garantiza condiciones cuasi-monopólicas a determinados productores estatales y les otorga un poder de mercado virtualmente absoluto. Lo anterior profundiza una relación de fuerza favorable al productor -respecto al consumidor-, influye negativamente sobre la cantidad, calidad, variedad y precio de las producciones, y constituye un inhibidor por excelencia de cualquier potencialidad innovadora.

4) Inhibición del emprendimiento. Para contrarrestar el poder de los productores, los órganos estatales superiores intentan un diseño con la intención de suplantar el papel del inexistente control horizontal de los consumidores, y tienden con ello a un sobredimensionamiento de los mecanismos de control vertical de la economía. Como consecuencia, la autonomía decisoria de las empresas se reduce a la mínima expresión, al ser sustituida por normas o regulaciones altamente detalladas y rígidas, y cualquier actitud emprendedora queda inmediatamente neutralizada ante los elevados riesgos personales que se enfrentan.

La forma en que se regulan actualmente los procesos productivos a escala nacional, si bien constituye un esfuerzo por manejar las presiones de los constantes desequilibrios generados por las debilidades 
estructurales latentes, a su vez se convierte en un factor que atenaza el despliegue pleno de las fuerzas productivas, con lo cual constituye un cabestro para el crecimiento económico y el desarrollo.

Se ha entendido por planificación una lógica que predetermina a priori la gran mayoría de las relaciones a establecer entre los actores económicos, normando y restringiendo proveedores, clientes, cantidades a producir y a consumir, variedades, precios, estándares tecnológicos, inversiones, condiciones de financiamiento, estructura de costos, estructuras organizativas, plantillas, formas y montos de retribución, entre otros muchos elementos.

Con todo esto se consolida un contexto perfecto para contaminar, enfermar y terminar neutralizando cualquier idea con capacidad para convertirse en innovación. Los empresarios, los técnicos, los trabajadores, más que no tener incentivos para la innovación, enfrentan un marco institucional perfectamente alineado (lamentablemente) para inhibir la innovación.

La permanencia de este modelo inhabilita cualquier posibilidad -en materia de CTI- de avanzar hacia una configuración sistémica diferente de un modelo ofertista rígido. En una economía cuyos mercados están dominados por la oferta, la demanda está imposibilitada para desempeñar papel alguno como motor de la innovación. Mucho menos puede aspirarse a un sistema que innove sobre la base de interacciones sinérgicas entre los actores, pues estas interacciones están centralmente preestablecidas, y como no se determinan por la iniciativa de los actores no poseen adaptabilidad y son relativamente inamovibles en el tiempo. Los resultados de las dos encuestas nacionales de innovación aplicadas al sector empresarial cubano ilustran estas características (Chía, 2004: 65; CITMA, 2008).

Más allá del polo biofarmacéutico, las capacidades científico-técnicas de la nación son débiles, lo que repercute en su habilidad para transformar sostenidamente las bases de su inserción internacional y su potencial de crecimiento a largo plazo. Una parte del éxito de este enclave, el "Polo Científico", es que ha operado bajo reglas muy diferentes al resto de actividades. Entre ellas cabe destacar la posibilidad de completar internamente el ciclo productivo desde la fase de investigación básica hasta la comercialización de los productos en el mercado externo, permitiendo acceder a la necesaria retroalimentación de los clientes, a la vez que retiene una parte sustancial de los recursos generados. Por sus propias características, el sector ha estado obligado a generar permanentemente nuevas innovaciones para sostener su cartera de productos y conformar una imagen a tono con los mejores estándares a nivel internacional (Lage, 2004). Asimismo, se han conformado alianzas entre los distintos tipos de organizaciones 
para alcanzar objetivos comunes, incluyendo el desarrollo de nuevos productos; y el sector se ha beneficiado del alto nivel alcanzado por el sistema de salud cubano, que constituye el destino priorizado de sus fármacos.

A partir de 2010, este escenario se torna aún más complejo con la emergencia de nuevas formas de propiedad. El creciente espacio del sector no estatal cubano y su impacto en la generación de nuevas fuerzas impulsoras de la innovación es un asunto de gran actualidad. Este segmento está creciendo rápido y es esperable que juegue un papel fundamental en la economía de los años venideros. Ya absorbe casi el 30\% de los ocupados hacia fines de 2016, aunque su presencia se despliega, fundamentalmente, en actividades de bajo valor añadido que no aprovechan aún el potencial humano formado.

En general, los intentos de diseño sistémicos respecto a la CTI en Cuba han padecido predominantemente de un enfoque de oferta. Los centros generadores de conocimiento se encuentran, por lo general, desarticulados del mundo empresarial; con excepción del Polo Científico anteriormente señalado.

Sin embargo, existen indicios concretos que denotan que la actividad innovadora en Cuba ha formado y forma parte de una práctica cotidiana y que se resumen en:

- La superación de importantes escollos en el desarrollo de la isla a través de acciones innovadoras que han posibilitado mantener funcionando fábricas y otras empresas productivas o de servicios.

- La constante actitud innovadora de obreros, técnicos e ingenieros que ha posibilitado sustituir materias primas, hacer reconversiones y ajustes tecnológicos, racionalizar combustibles y solucionar carencias diversas.

- La existencia de diferentes organizaciones con niveles participativos muy altos en las acciones innovadoras expresadas en los puntos anteriores y que involucran a millones de cubanos que manifiestan una actitud creativa que puede ser canalizada a través de formas colectivas (Asociación Nacional de Innovadores y Racionalizadores, Brigadas Técnicas Juveniles, Fórum de Ciencia y Técnica, etc.), en las que los objetivos se materializan, fundamentalmente, vía innovación como solución de problemas apremiantes de la producción, los servicios y la sociedad (Escobar, 2007). 
La innovación se ha conducido en las empresas mediante las Brigadas Técnicas Juveniles, Asociación Nacional de Innovadores y Racionalizadores y los Fórums de Ciencia y Técnica, lo que ha provocado que sea un proceso más bien concentrado en la solución de pequeños problemas productivos, que no son generalizables y tienen un impacto limitado en la generación de cambios radicales y en la estructura productiva.

El Gobierno reconoce la importancia de la innovación en los procesos productivos en la actualidad y también la necesidad de superar el viejo modelo ofertista que caracteriza al sistema. Sin embargo, su enfoque es relativamente contradictorio puesto que no internaliza a la empresa como el centro fundamental de generación de innovaciones. Aunque el discurso político aboga constantemente por impulsar la innovación en las empresas, el mecanismo prevaleciente de asignación de recursos inhibe el desarrollo de una mayor autonomía empresarial con un diseño de incentivos coherentemente alineados en el objetivo de la innovación. Las autoridades temen que un proceso descentralizador pueda conducir a una pérdida del control sobre los recursos y actividades de las empresas estatales.

Por otra parte, aunque se han dado pasos relativamente significativos, el sector no estatal aún es muy limitado como para convertirse en referente innovador y mecanismo de presión hacia la competitividad de todo el sistema empresarial. La legislación vigente es la normativa del Sistema de Ciencia e Innovación Tecnológica y la política en desarrollo se corresponde con los Lineamientos de la Política Económica y Social aprobados en 2011.

\section{LAS COMUNIDADES Y ACTORES PARTICIPANTES EN EL DIÁLOGO Y SUS PRINCIPALES INTERACCIONES}

\subsection{DESCRIPCIÓN DE LAS COMUNIDADES}

Como se señaló en la sección 1, los participantes de un proceso de diálogo son actores que emergen de distintas comunidades de CTI. Las cuatro principales comunidades identificadas en la esfera de la CTI son: académicos, empresas, sector público, y otros agentes de la sociedad civil. Los actores en los diálogos en CTI son así grupos de individuos o de organizaciones que emergen dentro de esas comunidades. A continuación, se describen brevemente las comunidades que participan en el sector de CTI.

\section{LAS EMPRESAS}

Las empresas estatales cubanas se caracterizan por su obsolescencia tecnológica; la desmotivación de los trabajadores; los débiles 
incentivos que ofrece el plan anual para mejorar eficiencia y productividad, la formación centralizada de precios y la aplicación de tasas de cambio sobrevaluadas; la pobre infraestructura de calidad; y la falta de recursos materiales y financieros, lo que determina niveles de inversión que se ubican por debajo de las necesidades de reemplazo o ampliación de capacidades productivas. El tamaño de las estructuras empresariales es grande y registran baja productividad (Alonso, 2013).

Las insuficiencias de la gestión económica interna se aprecian, entre otras, en la existencia de 151 empresas que cerraron con pérdidas su gestión y acumularon un saldo negativo de 439 millones de pesos en el año 2015, mayormente en el Ministerio de la Agricultura, con 71 entidades con saldos deficitarios. Adicionalmente, hubo 320 empresas que pagaron 189 millones de pesos de salarios sin el indispensable respaldo productivo (Rodríguez, 2015).

Las empresas estatales han sufrido frecuentes procesos de reestructuración desde el triunfo de la revolución, lo que no les ha permitido estabilidad para su desempeño. En los momentos actuales, también están sometidas a nuevos cambios con la creación de los Grupos Empresariales (OSDE) cuyas funciones (según Decreto 303) en temas de gestión son similares a las de los Ministerios con funciones productivas, al tiempo que las actividades productivas se organizan en Unidades empresariales de base (UEB), sin personalidad jurídica, lo que ha conllevado a la reducción de la cantidad de empresas y a que las mismas cumplan una función más de control, junto a las OSDE. Tal forma de reestructuración igual para todo tipo de sector, tamaño, fortaleza económica, presencia nacional e internacional reafirma la jerarquía vertical y no promueve ni la flexibilidad para la adaptación al cambio, ni la autonomía donde se crea la riqueza, ni las redes empresariales, todos aspectos básicos para la innovación.

Diversos estudios sobre cultura (Díaz, 2005; Gutiérrez, 2002; González, 2012; Sotolongo, 2009; Díaz, 2013) muestran que, para distintos tipos de organizaciones en diferentes épocas en Cuba:

- Las características de las empresas no se correspondían con las necesarias para la innovación y muestran unos rasgos culturales que no son malos en sí mismos, solo que no se corresponden con aquellos que la literatura y la realidad confirma como más adecuados para la innovación.

- No se reconoce o estimula el riesgo, así como se considera que predomina la rigidez y centralización. 
- Las empresas no asumen riesgos, ni estimulan la mejora, ni se aceptan errores, ni es muy favorable a reconocer criterios diferentes. Esto se considera como una señal de que no existe estímulo a la innovación.

Lo anterior es coherente con los criterios que se emiten sobre las señales del entorno antes analizadas, y que se muestran en los resultados de la encuesta como son: sobre las barreras y los rasgos de la cultura, se observa que, el $48,4 \%$ plantean que la innovación no se prioriza por los niveles superiores, el $42 \%$ se refieren a que los incentivos no se vinculan a la innovación, el $33 \%$ que existe falta de recursos y tiempo y el $48,4 \%$ plantea la falta de autonomía.

\section{CENTROS GENERADORES DE CONOCIMIENTOS}

El Sistema de la Ciencia Cubana contaba al cierre del 2015 con aproximadamente 200 centros de investigación y 30 centros de educación superior. Se cuenta con 82.471 trabajadores físicos, de los cuales 3.853 son investigadores categorizados (descendió un 21\% respecto al 2010). En estas cifras se incluyen todos los trabajadores de las 232 ECIT (30.694), del CITMA (11.191) y todos los de los demás centros de educación superior del país, adscritos o no al MES. Se incrementa poco a poco el número de doctores en ciencia que ya abarca a 14.601.

En términos agregados, existen 1,9 científicos e ingenieros por cada 1.000 habitantes, $8,1 \%$ de la población es universitaria y el $15 \%$ de los trabajadores son universitarios. El por ciento de trabajadores físicos en actividades científico-técnicas con respecto a la población económicamente activa en Cuba está sobre el 1,6, con una cierta tendencia a reducirse.

Mucho se ha realizado en el país con el desarrollo del polo científico biotecnológico con un fuerte énfasis en el área de la salud, así como es loable el esfuerzo que han realizado otros centros de investigación en invenciones que, en algunos casos, como biotecnología, han tenido éxito en el mercado, sobre todo entre gobiernos. Sin embargo, la acción por parte de las empresas no ha tenido la misma evolución, lo que se puede deducir de por la baja proporción de recursos de las empresas dedicado a las actividades de ciencia y técnica.

Del total de gastos en actividades de ciencia y técnica alrededor del $60 \%$ es en $\mathrm{I}+\mathrm{D}$, que no significa necesariamente innovación y dicha cifra representa alrededor del 0,5\% del PIB en los últimos años.

A pesar de contar con una masa crítica importante, esta comunidad presenta debilidades importantes tales como (Cabal \& Rodríguez, 2015): 
- El éxodo y envejecimiento de investigadores y doctores y el lento reemplazo por la insuficiente formación de doctores.

- Se ha reducido el financiamiento a la ciencia y tecnología.

- Es notable el retraso en el acceso y utilización de las TIC.

- La productividad científica medida en artículos y patentes es muy baja.

- La desarticulación entre los diferentes actores: centros de investigación y universidades.

- El sistema ha tenido un marcado enfoque de "empujón de la ciencia", lo que ha desconectado a las empresas del mundo de la ciencia.

Se puede afirmar que la educación ha sido un logro de la Revolución, pero poseer fuerza de trabajo calificada es condición necesaria pero no suficiente para la innovación y por otra parte se hace necesario que la enseñanza desde los niveles de primaria, hasta el superior se enfoque más hacia el pensamiento creativo.

Diversos trabajos (Díaz, 2011; Pino \& Quevedo, 2009; Torres, 2011) permiten arribar a las siguientes conclusiones:

- No existe una adecuada articulación entre intensidad de la formación - producción del conocimiento y crecimiento económico.

- Desvinculación entre demanda del conocimiento y las necesidades y estrategias de desarrollo de la actividad económica.

- La asimetría entre el potencial científico "dormido" en las instituciones y la debilidad presentes en el sistema nacional de innovación tecnológica, expresado en las escasas investigaciones de tipo aplicada.

- Desconexión práctica entre las políticas de formación, evaluación y promoción del personal y la gestión de la innovación.

\section{GOBIERNO}

El organismo de la administración central del estado (OACE) es el encargado de definir la política y estrategia de ciencia y tecnología, así como de diseñar, coordinar y facilitar el Sistema Nacional de Ciencia e Innovación Tecnológica (SCIT) es el Ministerio de Ciencia, Tecnología y Medio Ambiente (CITMA). Por supuesto, el resto de los OACE deben tener una participación en tanto incluyan en sus polí- 
ticas sectoriales o globales el impacto de la ciencia y tecnología, así como la innovación. El CITMA al igual que la mayoría de los OACE posee funciones estatales de política y también se le subordinan centros de investigación.

Existe una Estrategia de Ciencia e Innovación Tecnológica 20112015, la síntesis que se posee plantea los siguientes objetivos:

- Aumentar a corto plazo el impacto de los resultados científicos y tecnológicos, en especial, en el incremento de la productividad, las exportaciones, la sustitución de importaciones, la sostenibilidad energética, el ahorro de recursos y el mejoramiento de la calidad de vida de la población.

- Elevar el impacto estratégico de los resultados científicos y tecnológicos en el desarrollo económico y social sostenible del país, favoreciendo el tránsito de la estructura productiva hacia bienes y servicios de alto valor agregado.

- Orientar el incremento cualitativo y cuantitativo del capital humano en correspondencia con el papel actual y perspectivo de la I+D y la innovación en sectores clave para el desarrollo económico y social sostenible del país.

El SCIT, en Cuba, fue rediseñado en 1995 (donde se incorpora el término de innovación) y se concibió como

forma organizativa que permite la implantación participativa de la política científica y tecnológica que el estado cubano y su sistema de instituciones establecen para un período determinado, de conformidad con la estrategia de desarrollo económico y social del país y de la estrategia de ciencia y tecnología que es parte consustancial de la anterior. (CITMA, $2000-2001)^{2}$

Existen un conjunto de políticas explícitas en forma de leyes, normativas y resoluciones permiten hablar de un sistema de innovación formal.

Los actores contemplados en dicho sistema son todos los reconocidos en cualquier sistema nacional de innovación, con excepción de los siguientes: Fórum, Sindicato Nacional de Trabajadores de la Ciencia, sistema bancario, Academia de Ciencias, ANIR y BTJ.

Un aspecto importante es lo relacionado con el ambiente laboral y las costumbres asimiladas por las personas en la dinámica institucional,

2 Documentos Rectores de la Ciencia y la Innovación Tecnológica en Cuba 
las cuales pueden constituir un freno o un impulso al desarrollo de una mentalidad y una práctica innovadora.

\section{OTROS AGENTES}

Existen otros agentes económicos, como las cooperativas, sobre todo las agropecuarias que tienen más años de experiencia en la economía cubana, pero no por ello se le ha fortalecido y estimulado producir por vías intensivas, teniendo en cuenta las condiciones de suelo y fuerza de trabajo de este sector. Es bueno señalar que existe un lineamiento dirigido a lograr aplicación de la ciencia e innovación en esta rama.

\subsection{LAS INTERACCIONES ENTRE LOS AGENTES}

Ante todo, es importante analizar las interacciones entre los actores, que son base del conocimiento y del proceso de aprendizaje. El aprendizaje, además de recibirse por vías formales, es decisivo cuando se obtiene por la interacción con clientes, proveedores, centros de generación del conocimiento.

La interacción con proveedores y clientes, en muchos casos predeterminados por los niveles superiores, no promueve más que un acto de compraventa, no exento de complejidad y asimetrías. Esta situación comienza desde la planificación y el plan como mecanismo, casi absoluto, de asignación de recursos a entidades, no vistas íntegramente, ni por cadenas productivas. Las organizaciones no son autónomas de organizar sus propias cadenas con los agentes que considere.

Existen diversos trabajos que muestran la pobre o nula importancia que se otorga a los clientes y sus requerimientos, sean estas organizaciones o la población dado el carácter monopólico de la oferta y la poca prioridad que se confiere incluso en las regulaciones de gobierno. Por supuesto que tampoco se logra interacción con empresas que producen lo mismo, no hay colaboración, ni intercambios de experiencias, buenas prácticas o sinergias productivas.

Las organizaciones de interface como empresas de consultorías, consorcios de I+D, Incubadoras de empresas, etc., no han tenido un fuerte desarrollo en el país, salvo las consultorías.

Los vínculos con los centros de generación del conocimiento no son estables, ni esenciales para las organizaciones, varios aspectos han incidido en esto:

- El enfoque ofertista de ciencia y tecnología que ha primado en el país. 
- La empresa no ha necesitado de la ciencia e innovación para existir.

- Las empresas no poseen autonomía, son monopolios y tienen que cumplir el plan.

- Los mecanismos de financiamiento e incentivos a la ciencia y universidades no han promovido el acercamiento a las empresas y viceversa.

La segunda encuesta a las empresas muestra que la cooperación entre la empresa, universidades, entidades de investigación, consultorías y otras entidades de gestión tecnológica, en asuntos relacionados con la innovación, es un elemento que favorece la capacidad innovadora de la empresa al aprovechar sinergias. No obstante, en este aspecto el porcentaje de empresas que cooperaron para innovar es aún insuficiente, pues solamente $41 \%$ considera que el nivel de cooperación es frecuente (CITMA, 2008).

Por otra parte, los vínculos con los organismos del Gobierno que regulan las políticas de CTI (CITMA, MES, etc.), se supone, se lograrían mediante el funcionamiento del Sistema Nacional de Ciencia, Tecnología e Innovación, pero el mismo posee, según Pérez (2014), insuficiencias estructurales tales como:

- Burocrático y descalificado.

- No da solución oportuna a los problemas.

- Reducción potencial científico (envejecimiento, migración, etc.).

- Débil conexión con empresas e internacionalmente.

- Retraso tecnológico para la investigación.

- Problemas de financiamiento.

- Bajo impacto económico.

En sentido general, las innovaciones que se realizan son del tipo topdown, es decir, aquellas que los niveles superiores (Ministerios sectoriales) exigen para reducir gastos de energía, costos de importación, etcétera.

Finalmente, nos parece oportuno tener en cuenta a las personas que trabajan en cualquiera de los sectores y tipos de agentes económicos. 


\subsection{LAS CONDICIONES DE CADA COMUNIDAD PARA EL DIÁLOGO: CONOCIMIENTO, CAPACIDADES, LENGUAJE, PODER Y LEGITIMIDAD}

Teniendo en cuenta lo anterior se analizan las capacidades, el poder, la confianza, y otros rasgos entre los diferentes actores de las comunidades de CTI. La existencia de capacidades, poder y conocimientos no homogéneos constituyó un obstáculo para el avance del proceso de diálogo, esto es producto de que cada actor cumple un rol diferente en la sociedad respecto al tema de la innovación.

El gobierno posee capacidades para el diseño de políticas, además tiene el poder de decisión producto de la centralización; sus enfoques sobre la innovación han sido muy estrechos y por tanto su lenguaje se correlaciona con ello. La empresa posee capacidades reales o potenciales para desarrollar en la práctica la innovación, su poder está limitado por la falta de autonomía debido a la centralización de la economía, sus conocimientos sobre innovación están signados por lo pragmático y por tanto su lenguaje se corresponde con ello. Por último, los centros generadores de conocimiento poseen capacidades en ese sentido, es decir generadores de conocimiento sobre innovación, lo cual no quiere decir que haya homogeneidad en cuanto a los enfoques, su lenguaje es científico y su poder es el que le otorga la ciencia, que no es un poder de decisión real, pero importante en un proceso de diálogo.

La legitimidad de los actores participantes de las comunidades fue un hecho asumido por todos debido a que cada uno ocupa una posición importante en relación a la innovación, de igual forma la legitimidad de la institución líder, por ser referente científico. Todos estos aspectos constituyeron la base de la creación de confianza.

Inicialmente las comunidades se enrolan en este diálogo a partir de una solicitud expresa de un representante de la Comunidad del Sector Público. El propio desarrollo del diálogo favoreció el establecimiento de relaciones equilibradas entre las comunidades. Se manifestaron intereses heterogéneos, lo que resulta entendible a partir de los diversos roles que desempeñan en la sociedad. No obstante, estos no se manifestaron especialmente contradictorios. El propio origen del diálogo revela una cierta relación de subordinación del resto de las comunidades a la Comunidad del Sector Público, sin embargo, se pudo apreciar como emergen configuraciones sociales diferentes, a partir de las transformaciones que tienen lugar en Cuba. Esto fue especialmente cierto para la Comunidad Empresarial. 


\section{DISCUSIÓN DE LA EVIDENCIA}

El proceso de diálogo realizado será presentado a través de las etapas transitadas de exploración, diseño, implementación y seguimiento.

\section{ETAPA DE EXPLORACIÓN}

El tema consiste en una propuesta de cambios de políticas para promover comportamientos de innovación en las empresas, sobre la base de las experiencias internacionales atemperadas a las particularidades del contexto cubano.

Su relevancia estriba en una contribución potencial a la discusión de los cambios que se deben introducir en el marco regulatorio y la estructura de incentivos para estimular la innovación a nivel empresarial. Hoy se cuenta con un conjunto de medidas normativas, más relacionadas con el campo de la ciencia y la técnica que de la innovación, donde se observan carencias de un marco jurídico, normativo, financiero y de estimulación a la innovación. Las acciones más actuales están contenidas en los Lineamientos de la Política Económica y Social, la que se ha propuesto mejorar los vínculos entre los centros generadores de conocimientos y los centros productivos, y aunque las medidas implementadas no están exentas de discusión, al menos envían señales sobre la importancia que el nuevo modelo otorga a la innovación.

El análisis del contexto, presentado en la sección 5, muestra dos aspectos significativos, el primero, respecto al sistema nacional de innovación y el segundo, sobre la forma de funcionamiento de la economía y su efecto en el crecimiento económico. Todo ello referido al papel que ha ocupado la innovación. El sistema nacional de innovación ha tenido un carácter ofertista y desarticulado, mientras que, por otra parte, las características del modelo de funcionamiento de la economía tendentes a producir mercados dominados por los vendedores, eximen a los productores de la búsqueda constante de competitividad, consolidando un modelo de innovación "por generalización desde arriba".

Todo ese contexto influye, directamente, en el comportamiento de los diferentes actores involucrados con el tema, que tienen diferentes tipos de conocimiento, intereses y enfoques sobre el tema: el sector público como ente regulador en el cumplimiento de políticas, los empresarios que son los que deben ejecutar con necesidades más operativas y la academia con el bagaje teórico, cierta experiencia práctica como consultor y una visión más holística. Los intereses son diversos, de ahí la importancia de lograr un lenguaje común de partida, que permitiera conducir el diálogo sin agendas ocultas. 
El poder del sector público, típicamente preponderante en Cuba, podría ser un actor que desbalanceara e incluso abortara el diálogo, por lo que la elección de los roles en el proceso de diálogo era decisiva.

Aspectos tan importantes como saber escucharse, valorar e incorporar criterios de otros, no aferrarse a sus propias opiniones, fueron competencias dialógicas que no estaban incorporados en el comportamiento de alguno de los actores, por lo que el rol de facilitación y las reglas de juego fueron muy importantes para ello. Por último y no menos importante, era la legitimidad de los actores y el reconocimiento de unos y otros, lo que permitiría la interacción indispensable y el aprendizaje en el proceso de diálogo.

Todos estos factores referidos a los actores (legitimidad, intereses, poder, reconocimiento de los unos con los otros, etc.) se tuvieron en consideración, se valoraron y definieron las guías de actuación.

\section{ETAPA DE DISEÑO}

A partir del 2011, en el contexto de la Actualización del Modelo Económico y Social y la implementación de los Lineamientos de la Política Económica y Social, la alta dirección del país puso el tema a discusión y la Universidad de La Habana, la universidad más antigua y de mayor reputación en el país, asumió la iniciativa para desarrollarlo.

El Centro de Estudios de la Economía Cubana, se convierte en el líder del proceso de diálogo por ser un referente en los estudios sobre economía cubana y poseer una línea de investigación sobre la innovación y el emprendimiento, con múltiples publicaciones. La facilitación del proceso la asumieron profesores expertos en tales roles también del mismo centro.

El hecho de que la dirección y facilitación del proceso de diálogo fuera responsabilidad de la academia, fue un aspecto importante de confianza entre los diferentes actores, ante posibles suspicacias respecto al poder del sector público, así como balance de influencias.

El proceso de diálogo no contó con recursos financieros específicos para su desenvolvimiento, aunque se tuvo en todo momento el apoyo en infraestructura en áreas académicas y en los talleres en provincia. No se concibió en esta etapa ninguna estrategia de comunicación.

El diálogo pretendió alcanzar un consenso en aspectos neurálgicos de la gestión innovadora empresarial. Todo este proceso, al final, deberá contribuir a la promulgación de políticas de incentivos y/o cambios en las regulaciones actuales, ya que de no lograrse es 
probable que las leyes o políticas que se promulguen no ayuden a las empresas. El diálogo buscó generar consensos en soluciones de largo alcance que impacten en las futuras políticas de innovación en Cuba, con propuestas de modificaciones institucionales que permitan verdaderamente desatar las fuerzas productivas.

Los criterios para seleccionar los actores dialogantes tuvieron que ver esencialmente con garantizar la presencia de diferentes enfoques sobre la innovación, a partir del rol que juegan cada uno respecto al tema. Entre los principales actores en el tema se encuentran: el Centro de Estudios de la Economía Cubana, líderes del proyecto de diálogo; el Centro de Estudios sobre Administración Pública y Empresarial de la Escuela Superior de Cuadros del Estado y el Gobierno; el Centro de Investigaciones de la Economía Internacional; el Centro de Estudios de Técnicas de Dirección; empresarios del sector estatal; emprendedores privados y cooperativos; funcionarios de gobiernos locales; especialistas del Ministerio de Ciencia, Tecnología y Medioambiente; miembros de la directiva de la Asociación Nacional de Economistas y Contadores de Cuba (ANEC).

\section{ETAPA DE IMPLEMENTACIÓN}

La convocatoria realizada por la academia fue muy bien recibida. Si bien la participación de todos los actores no siempre fue de forma estable, el diálogo se realizó siempre en áreas de la academia, generalmente en el Centro de Estudios de la Economía Cubana, lo cual ayudó a generar confianza por ser considerado un espacio neutral.

El proceso de diálogo se desarrolló en varias sesiones, con la técnica de discusiones reiteradas y con las siguientes reglas de juego: todos tienen derecho a opinar, no se enjuicia la opinión de otros cuando se emite la de uno, escucharnos los unos a los otros, no se permiten conversaciones independientes cuando se trabaja en grupo, no tomar la discusión como algo personal, etc. Existían relaciones personales anteriores entre algunos de los miembros de grupo y los funcionarios, lo cual contribuyó a crear un clima de confianza.

Otro de los encargos explícitos a los participantes fue que estos deben desempeñar un rol dual: exponer opiniones que necesariamente reflejan una experiencia personal específica y, por otro, representar los intereses más amplios de la comunidad a la que pertenecen.

La ruta metodológica seguida se puede resumir como sigue: El reto inicial era lograr un lenguaje común para alinear los intereses 
sobre bases esenciales, sin dejar de tener en cuenta lo específico. Esto se alcanzó mediante la discusión y acuerdo en el enfoque teórico sobre innovación (dar el lugar que corresponde a las pequeñas soluciones operativas con un impacto marginal despreciable en la productividad), el concepto de innovación empresarial y el de sistema nacional de innovación y sus componentes. Este primer paso fue muy importante pues supuso una senda conceptual de esclarecimiento y generación de un clima de confianza.

En un principio no había toda la confianza necesaria entre los actores, sobre todo con funcionarios del sector público, pues sus puntos de vistas no siempre eran concordantes, no había en todo momento un lenguaje común. La creación de la confianza se logró sobre la base de la discusión científica y de los propósitos que nos llevaban al diálogo, los que deben estar por encima de nuestras posiciones personales. También gracias a la legitimidad social y académica de los líderes del diálogo

El segundo paso supuso defender la idea de otorgar el lugar central a las empresas (y en general, a otros agentes económicos) en la innovación y desmitificar algunas ideas que prevalecen tales como: la calidad de la educación cubana y el desarrollo de centros de investigación como ejes prioritarios sin otorgarle la importancia necesaria a la empresa u otros usuarios activos de los nuevos avances; creer que solo por contar con una fuerza de trabajo calificada ya se garantizan las condiciones para la innovación; asociar innovación con alta tecnología, especialmente en el caso cubano donde el desarrollo de la biotecnología se asoció a alta tecnología. Esta sería una de las fases complicadas ya que se manifestaron puntos de vistas contrapuestos. Varias rondas de análisis con presentación de evidencias fueron permitiendo lograr el consenso.

El tercer paso fue realizar un diagnóstico que les permitiera a todos comprender la situación existente en el país respecto a la innovación, sobre la base de evidencias y no de criterios subjetivos o experiencia práctica particular.

Se distribuyeron tareas tales como: recopilar experiencias internacionales, describir el contexto de la empresa cubana actual, describir la situación de los centros de generación del conocimiento, realizar un estudio de las regulaciones, políticas y legislación sobre CTI, y análisis del sistema de CTI. Esta fase fue la más larga, se tuvieron varias sesiones para consensuar el diagnóstico. Se complicó con las posiciones respecto a las regulaciones sobre las empresas; fue necesario realizar encuentros sucesivos con el grupo de empresarios (que se habían mantenido al tanto participando en algunas sesiones) para que evidenciaran las situaciones que enfrentan por las regulaciones existentes. 
El último paso fue elaborar una propuesta de dirección de los cambios que impulse a las empresas a la innovación, sobre la base de las experiencias internacionales y atemperadas al contexto cubano.

Al valorar la dinámica de diálogo, es necesario apuntar algunas cuestiones respecto a los actores y su papel en el proceso:

1) en realidad, no había grupos de poder, ni en conflicto, solo puntos de vista divergentes;

2) la facilitación permitió que los actores se condujeran según las reglas establecidas y se pudo observar algunos cambios de conducta, por lo que se puede asegurar que se alcanzaron progresos en el aprendizaje;

3) las diferentes áreas de formación de la cual provienen los participantes conducen a disímiles enfoques; el diálogo fue conduciendo hacia los puntos convergentes postergando aquellos que evidenciaban posiciones contradictorias.

Una de las premisas del diálogo ha sido la pluralidad de los participantes, con el objetivo principal de garantizar una heterogeneidad real, que legitime la discusión y disminuya el peso relativo de cada opinión individual.

\section{ETAPA DE SEGUIMIENTO}

Durante todo el proceso se realizaron evaluaciones parciales, se elaboraron memorias de las sesiones y el documento final con la propuesta consensuada.

Finalmente, una valoración general del caso destaca que, dadas las características de Cuba, un tanto sui generis, las condiciones para el diálogo tienen su especificidad. El entorno económico-político y social del país respecto al tema que se discuta, y las particularidades de los actores, en específico: a) la preponderancia del sector público; b) la confusión sobre el sector empresarial estatal y sus bajos niveles de productividad; c) la pobre participación que aún tienen otras formas productivas; y d) el papel prestigioso de la academia, muestran un mosaico complejo y por tanto es obligado contextualizarlo y precisarlo, para definir alternativas de conducción del diálogo.

En el caso que nos ocupa, la línea de dirección fue el enfoque científico sobre la innovación, sin perder de vista los aspectos prácticos del proceso de innovación en el mundo empresarial. 


\section{CONCLUSIONES Y CONTRIBUCIONES AL CAMPO DE ESTUDIO}

El desarrollo del dialogo documentado ha permitido confirmar en la práctica el objetivo propuesto en la investigación sobre la importancia del contexto en el que ha de desarrollar el diálogo, ya que el mismo moldea los roles de actuación de los actores en el proceso de dialogo. De no tenerse en cuenta contexto y actores, en un estudio previo y sostenido durante todo el proceso, pudiera abortarse el proceso en sí y no arribar a los objetivos deseados.

En el caso cubano en particular, es de suma importancia tomar en consideración el contexto debido a sus particularidades, que difieren de las referidas en la literatura sobre economías de mercado. Se han advertido especificidades de tal magnitud en el caso cubano, que se hace difícil la aplicación de teorías e instrumentos, que se han desarrollado en otros contextos, incluso para países en desarrollo. En este mismo caso, al menos se superponen dos esquemas analíticos diferentes: (i) país pequeño y subdesarrollado del área latinoamericana; y (ii) economía centralmente planificada que inicia un cambio fundamental hacia otro modelo con mayor espacio para el mercado, expansión de la propiedad privada y creciente interacción con la economía mundial.

Las capacidades dialógicas de los actores, así como la legitimidad son aspectos que en el caso de Cuba adquieren especial interés ya que se desdibujan con mucha frecuencia las diferencias entre las comunidades del sector público y empresarial, dado que, por ejemplo, todas las empresas son estatales. Esto creó dificultades para analizar el fenómeno desde roles realmente diferentes. Por ello, fue muy útil aclarar desde el principio la naturaleza del diálogo e incorporar a la mayor variedad de actores posible dentro de la comunidad empresarial.

El mayor elemento perturbador respecto a las comunidades estuvo vinculado a la necesidad de convencerlas de su rol en el diálogo, el que está más allá de la posición en que se encuentran respecto al gobierno. Todos los actores son legítimos y no se ubican en una situación de subordinación. Este cambio gradual de actitud se logró a partir de constatar las ventajas de un nuevo tipo de interacciones basadas en la reciprocidad y la horizontalidad.

Una de las lecciones básicas aprendidas es que no existen a priori consensos generales ni siquiera al interior de cada una de las comunidades, especialmente en la comunidad académica. Las diferentes áreas de formación de la cual provienen los participantes conducen a disímiles enfoques. El diálogo fue conduciendo hacia los puntos convergentes postergando aquellos que evidenciaban posiciones contradictorias. 
El reto principal respecto al tema en este ámbito tuvo que ver con la falta de consenso inicial respecto a ciertos aspectos conceptuales (innovación, sistema nacional de innovación, políticas CTI, lugar de la empresa en el sistema nacional de innovación) así como los postulados teóricos de referencia. Finalmente, los argumentos proporcionados por la comunidad académica contribuyeron a establecer una base conceptual mínima común para el diálogo.

Se demostró que, por las condiciones particulares de este diálogo en Cuba, una regla que fue a la vez formal e informal, resultó esencial: conducir el diálogo sobre la base de la equiparación real de la participación y las opiniones de los distintos actores, aun cuando existe un liderazgo definido. La tarea del líder no tiene que ver con imponer o convencer al resto de los participantes de sus propios puntos de vista.

Entre los resultados más importantes del diálogo se pueden apuntar:

- Se ha logrado comenzar a instalar en todas las comunidades la importancia de la innovación y las políticas CTI para un país en desarrollo como Cuba.

- Se ha empezado a esclarecer que los diseños contemporáneos de política CTI en Cuba deben incorporar las dinámicas que se están generando en el sector privado y cooperativo, los que desempeñarán un papel crecientemente importante en el desarrollo económico y social de la nación.

- Se han advertido especificidades de tal magnitud en el caso cubano, que se hace difícil la aplicación de teorías e instrumentos, que se han desarrollado en otros contextos, incluso para países en desarrollo. En el caso cubano, al menos se superponen dos esquemas analíticos diferentes: país pequeño y subdesarrollado del área latinoamericana y economía centralmente planificada que inicia un cambio fundamental hacia otro modelo con mayor espacio para el mercado, expansión de la propiedad privada y creciente interacción con la economía mundial. La superposición de estos dos esquemas requiere más investigación.

\section{BIBLIOGRAFÍA}

Álvarez, I.; Barletta, F.; Suarez, D.; Yoguel G. 2016 "Marco analítico para la tipificación de diálogos para las políticas de CTI" en Working paper 3 (Red CYTED COM-LALICS). En <http://lalics. org/images/CYTED/DT3-DimensionesDialogo.pdf $>$ acceso $15 \mathrm{de}$ abril de 2017. 
Baltera, P; Morales, G. 2010 Las condiciones para el diálogo social en la pequeña empresa: la perspectiva de los actores. Un estudio de caso (Santiago de Chile). En <http://www.dt.gob.cl/ documentacion/1612/articles-99097_recurso_1.pdf>.

Barboza, L. 2016 "Algunas consideraciones en torno al concepto de comunidad" en Working paper 6 (Red CYTED COM-LALICS). En <http://lalics.org/images/CYTED/DT6-DefinicinComunidad. pdf $>$ acceso 15 de abril de 2017.

Cabal, C.; Rodríguez, C. 2015 "Una visión de la ciencia en Cuba. Pasos y caminos" en Revista Anales (Cuba: Academia de Ciencias en Cuba). Vol. 5, $\mathrm{N}^{\circ} 2$.

CITMA 2008) Segunda encuesta nacional sobre la actividad de innovación. Informe de los resultados 2003-2005 (La Habana).

Cuentas, M.; Linares, A. (comps.) 2013 Guía práctica de diálogo democrático (Organización de los Estados Americanos). En $<$ https://www.oas.org/es/sap/dsdme/pubs/guia_s.pdf >.

Dutrénit, G.; Sutz, J. (eds.) 2014 National Innovation Systems, Social Inclusion and Development: The Latin American Experience (Cheltenham: Edward Elgar).

Dutrénit, G.; Álvarez, I.; Ardanche, M.; Barletta, F.; Bianco, M.; Cortés, R.; Cummings, A.; de la Vega, I.; Díaz, I.; Fernández, O.; Gómez, V.; Goñi, M.; Natera, J. M.; Nupia, C.; Orozco, J.; Prada, F.; Puchet, M.; Romero, F.; Simón, L.; Suárez, D.; Suárez, M.; Sutz, J.; Vera-Cruz, A. 2016 "Matriz de Información para el mapeo de procesos de diálogo de CTI en España, América Latina y el Caribe" en Working paper 5 (Red CYTED COM-LALICS). En <http://lalics.org/images/CYTED/DT5Formulario2.pdf> acceso 15 de abril de 2017.

Dutrénit, G.; Natera, J. M.; Suárez, M. 2014 "Lineamientos para la caracterización de las Comunidades y sus Procesos de Diálogo" en Working paper 1 (Red CYTED COM-LALICS). En <http:// lalics.org/images/CYTED/DT1-ComunidadesDialogo\%201.pdf> acceso 15 de abril de 2017.

Dutrénit, G.; Natera, J. M.; Puchet Anyul, M.; O. Vera-Cruz, A.; Torres, A. 2017 "Dialogue processes on STI policy-making in Latin America and the Caribbean: dimensions and conditions". En Science and Public Policy, 1-16. En <doi: 10.1093/scipol/ scx044>.

Echevarría, D. 2008 "Estilos para dirigir: los factores personales y la cultura organizacional desde la perspectiva de género. Estudio de casos en empresas cubanas", Tesis de doctorado en Ciencias Sociológicas (La Habana). 
Ermida, U. 2006 Diálogo Social: Teoría y práctica (Barcelona: Universitat Pompeu Fabra). En <https://www.upf.edu/iuslabor/_ pdf/2006-1/ErmidaUriarteDialogoSocial.pdf $>$.

Escobar, A. 2007 “Es Posible Otro Sur? La Política Cubana De Ciencia Y Tecnología”, Tesis de Doctoral (San Sebastián).

European Academies Science Advisory Council 2012 EASAC Guidelines: Good Practice in the Dialogue between Science Academies and Policy Communities (Saale: EASAC).

García, A.; Morgado, E.; Rueda, M. (comps.) 2007 Diálogo social institucionalizado en América Latina. Estudio comparado de Argentina, Brasil, Ecuador, México y Perú (OIT). En <http:// www.oit.org.pe/WDMS/bib/publ/doctrab/dt_207.pdf>.

Goñi, M.; Bianco, M.; Puchet, M. 2015 "Elementos para caracterizar los procesos de diálogo en políticas de CTI" en Working paper 7 (Red CYTED COM-LALICS). En <http://lalics.org/images/ CYTED/DT7-ConfianzaPoder.pdf> acceso 15 de abril de 2017.

Lundvall, B. 1992 National System of Innovation: Towards a Theory of Innovation and Interactive Learning (Londres: Pinter).

Lundvall, B. 2007 "National innovation system-Analytical concept and development tool" en Industry and innovation (Reino Unido: Routledge). Vol. 14, $\mathrm{N}^{\mathrm{o}}$ 1, pp. 95-119.

Nupia, C.; Martínez A. 2015 "Revisión de metodologías de procesos de diálogo" en Working paper 4 (Red CYTED COM-LALICS). En <http://lalics.org/images/CYTED/DT4-MetodologiasDialogo. pdf $>$ acceso 15 de abril de 2017.

Organización para la Cooperación y el Desarrollo Económico 2011 Hacia un mecanismo para el diálogo de políticas de innovación: oportunidades y desafíos para América Latina y el Caribe (París: Centro de Desarrollo de la OCDE). En <http://www.oecd.org/ centrodemexico/47435448.pdf>.

PCC 2016 Conceptualización del modelo económico y social cubano de desarrollo socialista (Cuba).

PCC 2016 Plan Nacional de Desarrollo Económico y Social hasta 2030: Propuesta de visión de nación, ejes estratégicos y sectores económicos estratégicos (Cuba).

Quiñones, M. 2005 Las nuevas dimensiones del diálogo social (ASET). En <http://www.aset.org.ar/congresos/7/07002.pdf>.

Rayo, A. 2013 Espacios de diálogo para construir estrategias de desarrollo público-privadas: una guía metodológica (México). En <http:// www.cepal.org/es/publicaciones/27169-espacios-de-dialogo-paraconstruir-estrategias-de-desarrollo-publico-privadas>. 
Rodríguez, G.; Gil, J.; García, E. 2004 Metodología de la investigación cualitativa (España: Aljibe).

Taylor, S.; Bogdan, R. 2000 Introducción a los métodos cualitativos de investigación (España: Paidós).

Tellis, W. 1997 "Introduction to Case Study" en The Qualitative Report (Florida: Nova Southeastern University). Vol. 3, Nº 2. En <http://www.nova.edu/ssss/QR/QR3-2/tellis1.html> acceso enero 2005

Torres, R. 2011 Crecimiento económico y cambio estructural en Cuba (La Habana: Centro de Estudios de la Economia Cubana).

Velasco, A.; Alonso, L. 2009 "Una síntesis de la teoría del diálogo" en Argos (Caracas). Vol. 26, N 50, pp. 100-114. 



\title{
DIÁLOGO EN EL DISEÑO DE POLÍTICAS DE CIENCIA, TECNOLOGÍA E INNOVACIÓN
}

\section{LA EXPERIENCIA EN EL PERÚ DE LA AGENDA NACIONAL DE COMPETITIVIDAD 2014-2018}

\author{
Mario Bazán* y Fernando Romero
}

\section{INTRODUCCIÓN ${ }^{2}$}

La incorporación de procesos de diálogos en el diseño de políticas de ciencia, tecnología e innovación (CTI) en el Perú ha sido compleja por los cambios en el contexto político y por la diversidad de actores con sus propios intereses y posiciones. Las políticas nacionales se caracterizan por ser sectoriales, con poca capacidad de articulación entre estos sectores y con mayor dificultad de articulación con los gobiernos a nivel territorial (sub-nacionales).

El Perú está relativamente atrasado en la movilización de recursos financieros y en la implementación de políticas de CTI con respecto a otros países de igual nivel de desarrollo y de América Latina (Crespi \& Dutrénit, 2014; Sagasti, 2011). Sin embargo, en los últimos años se han realizado esfuerzos para mejorar la institucionalidad, definir instrumentos de política, movilizar recursos y organizar los esfuerzos en función de metas nacionales. Uno de los actores que ha contribuido a esta tarea ha sido el Consejo Nacional de la

\footnotetext{
* Mario Bazán es docente de la Universidad Antonio Ruiz de Montoya e Investigador Principal de Foro Nacional Internacional, Perú.

** Fernando Romero es Investigador Principal de Foro Nacional Internacional, Perú.

2 Este trabajo contó con el apoyo de Fernando Prada.
} 
Competitividad (CNC). El CNC es una institución adscrita al Ministerio de Economía y Finanzas que ha cumplido con la tarea de articular las acciones de varios sectores que contribuyen a mejorar la competitividad del país.

Las políticas CTI han alcanzado consenso como instrumento para mejorar la competitividad del país, lo cual se refleja en los acuerdos del CNC y en acuerdos políticos de largo plazo como el Acuerdo Nacional. Para lograr estos consensos, el marco del diseño de la Agenda Nacional de Competitividad 2014-2018 tomó en cuenta metodologías de consulta y diálogo para involucrar a actores claves.

Este estudio recupera el proceso que el CNC aplicó para la elaboración de la Agenda Nacional de Competitividad 2014-2018 -desde ahora la Agenda- y lo contrasta con un marco teórico sobre la naturaleza de los procesos de diálogo para la formulación de políticas públicas de CTI, desarrollado por la Red temática para mejorar el diálogo entre las comunidades involucradas en las políticas de CTI, financiada por CYTED. Dutrénit, Natera y Suarez (2014), Goñi, Bianco y Puchet (2015), Álvarez et al. (2016) y Dutrénit et al. $(2016,2017)$ resumen las ideas desarrolladas por esta Red.

El objetivo de este documento es describir el proceso de diálogo para construir la Agenda, particularmente para el diseño del componente de CTI, y extraer las lecciones aprendidas de este proceso. Las lecciones de la experiencia peruana contribuyen al debate sobre la aplicación de metodologías para involucrar a una gran diversidad de actores en el diseño y monitoreo de políticas en CTI.

Después de esta introducción, la segunda sección revisa el uso del diálogo como herramienta para el diseño de políticas públicas. En la tercera sección se describe el contexto de la política de CTI en el año 2014, año en que se diseñó la Agenda Nacional de Competitividad. En la cuarta sección se describe brevemente el contexto del sector de CTI en Perú. En la sección quinta se presenta el caso de estudio y las implicancias de política para la promoción del diálogo y concertación en el caso de CTI. La sección sexta extrae las lecciones aprendidas, y finalmente la sección sétima presenta las reflexiones finales.

\section{DIMENSIONES DE UN PROCESO DE DIÁLOGO}

Cuentas y Linares Méndez (2013), Goñi, Bianco y Puchet (2015), argumentan que "los procesos de diálogo relativos a las políticas públicas de CTI son, al igual que los del diálogo democrático, auténticos ejercicios de interacción y conflicto. En ellos cada uno de los participantes aprende e internaliza argumentos de los demás sosteniendo su identidad y está ubicado, desde la perspectiva comunicativa, en 
una posición resultante del poder o de las capacidades que tiene. Los participantes son actores que emergen de distintas comunidades de agentes de las actividades de CTI. Tienen, por lo tanto, una relación de representación con su comunidad y, a su vez, pertenecen a organizaciones académicas, productivas, gubernamentales o de la sociedad civil que los dotan de diferentes grados de poder y de distintas capacidades".

La definición de comunidades de CTI parte de los individuos, y son resultado de la interacción de dos procesos en conflicto: (i) la socialización de los individuos; y (ii) la formación de redes (Barboza, 2016; Dutrénit, Natera \& Suárez, 2014). En este marco, las cuatro comunidades principales identificadas en la esfera de las políticas CTI son el sector académico, negocios, sector público (conformado por el gobierno nacional y los sub-nacionales), y otros agentes de la sociedad civil (Dutrénit, Natera, y Suárez, 2014). Estos grupos o conjuntos de personas al interior de estos grupos genéricos pueden unirse al interior de las comunidades, con el fin de convertirse en actores en el diseño de políticas.

Álvarez, et al. (2016) identifican seis dimensiones analíticas para los procesos de diálogo: origen, temporalidad, alcance, relaciones de poder entre actores, organización y resultados, los que se encuentran resumidos en el cuadro 1 .

Cuadro 1. Dimensiones analíticas

\begin{tabular}{|c|c|c|c|c|c|}
\hline 1. ORIGEN & $\begin{array}{c}2 . \\
\text { TEMPORALIDAD }\end{array}$ & 3. ALCANCE & $\begin{array}{l}\text { 4. BALANCE } \\
\text { ENTRE } \\
\text { ACTORES }\end{array}$ & $\begin{array}{c}5 . \\
\text { ORGANIZACIÓN }\end{array}$ & 6. RESULTADOS \\
\hline $\begin{array}{l}\text { 1.1 Comunidad } \\
\text { 1.2 Relación } \\
\text { con la política: } \\
\text { reactivo } \\
\text { /proactivo } \\
1.3 \text { Enfoque: } \\
\text { Oferta / } \\
\text { demanda } \\
1.4 \\
\text { Direccionalidad } \\
\text { Bottom-up / } \\
\text { Top-down }\end{array}$ & $\begin{array}{l}\text { 2.1 Puntual / } \\
\text { Corto plazo / } \\
\text { Mediano-largo } \\
\text { Plazo } \\
\text { 2.2 Continuo / } \\
\text { Discontinuo }\end{array}$ & $\begin{array}{l}3.1 \text { Ámbito: } \\
\text { general / } \\
\text { sectorial/ } \\
\text { temático/ } \\
\text { regional. } \\
3.2 \text { Propósito: } \\
\text { acuerdos / } \\
\text { consultivos / } \\
\text { propuestas }\end{array}$ & $\begin{array}{l}\text { 4.1 Relaciones } \\
\text { de poder } \\
4.2 \text { Relación } \\
\text { entre } \\
\text { capacidades } \\
4.3 \text { Lenguaje } \\
\text { común }\end{array}$ & $\begin{array}{l}\text { 5.1 Definición } \\
\text { de la agenda } \\
5.2 \text { Estructura } \\
\text { del } \\
\text { proceso: } \\
\text { etapas/ } \\
\text { participación } \\
\text { de } \\
\text { comunidades } \\
5.3 \text { Liderazgo } \\
5.4 \text { Intensidad } \\
\text { de las } \\
\text { interacciones }\end{array}$ & $\begin{array}{l}6.1 \text { Acciones / } \\
\text { acuerdos } \\
\text { específicos/ } \\
\text { entendimientos } \\
6.2 \text { Impacto: } \\
\text { existencia / } \\
\text { ámbito } \\
6.3 \\
\text { Externalidades } \\
\text { / creación de } \\
\text { capacidades }\end{array}$ \\
\hline
\end{tabular}

Fuente: Álvarez et al. (2016) 
El proceso de diálogo para la construcción de la Agenda Nacional de Competitividad en CTI busca la definición de una política basada en el consenso entre diferentes actores: altos funcionarios del gobierno, las principales universidades productoras de conocimiento y usuarias de los fondos otorgados por el gobierno, las empresas más grandes, academia y organizaciones privadas especializadas en el tema. Tipificar el proceso de diálogo sirve como marco para analizar el caso del Perú e identificar sus aciertos y espacios de mejora.

\section{EL USO DEL DIÁLOGO COMO HERRAMIENTA PARA DISEÑAR POLÍTICAS PÚBLICAS EN EL PERÚ}

El diálogo ha sido un medio utilizado durante los gobiernos democráticos en el Perú para arribar a consensos sobre el desarrollo y la elaboración de políticas públicas. El Perú tiene desde el año 2001 más de tres lustros continuos de gobiernos democráticos, lo que ha permitido que el diálogo se convierta en un medio efectivo para construir consensos sobre políticas de estado con una visión de largo plazo.

El uso del diálogo tiene varios ejemplos en la historia de la gestión pública y ha estado sujeto al clásico péndulo entre autoritarismo y democracia que el país ha experimentado. Por ejemplo, en el año 1980 se recuperó la democracia luego de más de doce años de dictadura militar. Durante el gobierno del Presidente Fernando Belaunde Terry (1980-1985), se buscó la construcción de consensos políticos al más alto nivel como medio para enfrentar algunos problemas sociales graves. Los más emblemáticos se relacionaron con las gestiones entre empresarios, trabajadores y el estado con el fin de negociar políticas salariales y beneficios sociales. La cooperación bilateral hizo esfuerzos para reforzar este proceso y varias instituciones como la Universidad del Pacífico, Grade y la Fundación Friedrich Ebert realizaron eventos para promover el diálogo (Hernández, 2014).

En el decenio de 1990 los esfuerzos continuaron, aunque el contexto político cambió. En 1992, el presidente Alberto Fujimori, elegido en elecciones democráticas dos años antes, hizo un golpe de Estado al disolver ilegalmente el Congreso de la República y gobernar con el apoyo de las fuerzas armadas para mantener un régimen dictatorial con elecciones populares seriamente cuestionadas en noviembre de 2000. En este año, el Presidente abandona el cargo, se fuga del país y renuncia por fax a la Presidencia de la República para no responder por cargos de corrupción. Durante este período presidencial, las políticas públicas dejaron de ser consensuadas, se debilitaron las instituciones de intermediación política como los partidos, y se limitó la participación ciudadana -incluso las reuniones de personas podían ser intervenidas por el gobierno bajo el pretexto de combatir el terrorismo, lo cual limitó expresiones ciudadanas como marchas, vigilias, y huelgas inclusive-. 
A pesar del contexto adverso al diálogo, algunas iniciativas desde la sociedad civil buscaron recuperar las prácticas democráticas en el país, y con ello, el diálogo como medio para alcanzar concesos en el diseño de políticas de largo plazo. Una de estas iniciativas fue Agenda: Perú. En una primera etapa (1994 y 1995) sus actividades se centraron en la elaboración de "un diagnóstico de la gobernabilidad democrática y a identificar una agenda de temas para lograr el buen gobierno y el desarrollo en el Perú, así como en el diseño de estrategias de desarrollo que permitan avanzar hacia la prosperidad y el bienestar para todos los peruanos" (Sagasti et al., 1999). A partir de este diagnóstico se realizó un proceso de consultas a diversos tipos de profesionales, líderes de opinión de la sociedad civil -desde las Fuerzas Armadas hasta de la Iglesia- y consultas a los ciudadanos.

El gobierno de transición democrática de Valentín Paniagua, tras la renuncia de Alberto Fujimori, reanudó los esfuerzos para reconstruir la institucionalidad del diálogo. Durante el gobierno de transición se creó el Acuerdo Nacional (2001) que se institucionalizó en 2002. Dos fueron sus objetivos: generar consensos sobre políticas públicas que debería continuar el Perú en el largo plazo, mirando hacia el año 2021 (Bicentenario de la Independencia); y constituir un respaldo para la continuidad democrática, el diálogo de política al más alto nivel, y la prevención de la instauración de gobiernos dictatoriales.

El Acuerdo Nacional generó un espacio para el diálogo y la concertación efectiva. En un inicio se pensó en involucrar a los partidos políticos, pero su situación de debilidad institucional hizo que se ampliara la convocatoria. En los años siguientes, el diálogo se extendió a la sociedad civil y el gobierno tomó parte del proceso, con igual poder de participación que todos los actores en las negociaciones y los acuerdos colectivos (Hernández, 2014).

Estas entidades suscribieron un Compromiso de Diálogo y se integraron a un Foro de Gobernabilidad que constituyó el núcleo gestor del proceso en el que los temas de democracia y Estado de derecho, equidad, competitividad, institucionalidad, ética pública, modernización del Estado y descentralización se fueron perfilando como los objetivos principales a los que debían apuntar las políticas de Estado. (Hernández, 2014)

El Acuerdo Nacional tiene más de 15 años y ha fortalecido la institucionalidad del diálogo cuando se ha utilizado como un instrumento, pero es un fin en sí mismo como instrumento de concertación democrática. El Objetivo 1, referido a la Democracia y Estado de Derecho, promueve la institucionalización del diálogo y la concertación. En este marco, el Perú ha logrado incorporar el diálogo no solo como herramienta para el diseño de políticas de Estado, como las del Acuerdo Nacional; sino de 
gobierno, tales como los planes concertados de largo plazo que realizan las regiones y distritos del país, y los presupuestos participativos con propuestas de ciudadanos organizados y elegidos a través de procesos públicos, entre otros instrumentos y mecanismos formales para orientar el diálogo en las decisiones de gobierno.

\title{
4. EL CONTEXTO DE LA DE CTI EN EL PERÚ
}

Invertir en CTI es parte del Acuerdo Nacional. La política de Estado 20 "Desarrollo de la ciencia y tecnología" establece el siguiente objetivo:

\begin{abstract}
Nos comprometemos a fortalecer la capacidad del país para generar y utilizar conocimientos científicos y tecnológicos, para desarrollar los recursos humanos y para mejorar la gestión de los recursos naturales y la competitividad de las empresas. De igual manera, nos comprometemos a incrementar las actividades de investigación y el control de los resultados obtenidos, evaluándolos debida y puntualmente. Nos comprometemos también a asignar mayores recursos financieros mediante concursos públicos de méritos que conduzcan a la selección de los mejores investigadores y proyectos, así como a proteger la propiedad intelectual [...] Con este objetivo el Estado: (a) asignará mayores recursos, aplicará normas tributarias y fomentará otras modalidades de financiamiento destinado a la formación de capacidades humanas, la investigación científica, la mejora de la infraestructura de investigación y la innovación tecnológica; (b) creará mecanismos que eleven el nivel de la investigación científica y el desarrollo tecnológico de las universidades, los institutos de investigación y las empresas; (c) procurará la formación de recursos humanos altamente calificados en los sectores productivos más promisorios para la economía nacional; (d) desarrollará programas nacionales y regionales de impacto productivo, social y ambiental; y (e) promoverá en toda la población, particularmente en la juventud y la niñez, la creatividad, el método experimental, el razonamiento crítico y lógico así como el afecto por la naturaleza y la sociedad mediante los medios de comunicación". (Acuerdo Nacional)
\end{abstract}

Pese a esta voluntad política, el Perú se encuentra rezagado en los resultados de CTI con respecto a otros países de igual nivel de desarrollo y con los de América Latina. La inversión en investigación y desarrollo ( $\mathrm{I}+\mathrm{D})$, así como en actividades de ciencia y tecnología (ACT) son bajos. En 2014, Perú había invertido 0.13\% del PBI en $\mathrm{I}+\mathrm{D}$, mientras que Brasil invirtió casi 10 veces más, México 4 veces más, Chile y Uruguay 3 veces más, y Colombia 2 veces más en relación a su PBI (RICYT, 2017).

El Perú también muestra un retraso en innovación. El Foro Económico Mundial muestra que el índice de competitividad de Perú se ha mantenido a la zaga en los factores de innovación, lo cual retiene la competitividad del país. Según el índice de competitividad global 
el Perú ha perdido competitividad entre 2014 y 2016. El país se encuentra en el puesto 67 de 138 países que han sido considerados para el informe del 2016-2017, lo cual es un retroceso del puesto 65 del 2014. En innovación la tendencia ha sido también negativa. El año 2016 se encontraba en el puesto 119, lo cual representó un retroceso de tres puestos con respecto del año anterior.

El resultado total del pilar de innovación se correlaciona con el puntaje de sus componentes. Estos sub-pilares para el último año, muestran, en relación con los otros 138 países, falencias en: provisión del gobierno de productos de alta tecnología (en el puesto 125), la capacidad para innovar (111), aplicación a patentes por cada millón de pobladores (79), calidad de los científicos de los institutos de investigación (114), gasto en I+D (122), colaboración entre industria y universidad en I+D (110) y disponibilidad de científicos e ingenieros (114). En todos estos indicadores el Perú está detrás de la mayoría de los países considerados (World Economic Forum, 2016).

La debilidad en el pilar de innovación es efecto de la escasez de conocimiento tecnológico y no tecnológico. Este último proviene del aprendizaje, las habilidades y las condiciones del trabajo. En Perú, ninguno de estos conocimientos se ha afianzado. Las innovaciones e invenciones son adquiridas normalmente desde afuera; y aunque son aprovechables, no son suficientes para competir en el mercado global. En este pilar el país más cercano en Latinoamérica, Colombia, está por delante que el Perú en casi 40 puestos, y muy por debajo de México, Chile, Panamá y Costa Rica. Estos dos últimos países lideran en innovación en la región. Según el Foro Económico Mundial, el Perú se encuentra en el segundo nivel de desarrollo, aquel basado en el uso eficiente de sus recursos, aunque todavía sigue basado en los recursos naturales (primer nivel). Muchos de los países que lo sobrepasan están en el tercer nivel, el basado en la innovación, o están en un estado de transición.

En este contexto se han venido realizando varios esfuerzos para aumentar las capacidades del país en este campo. A partir del 2006 se han movilizado muchos más recursos nacionales e internacionales para apoyar las inversiones en CTI. Además, en el año 2012, el Presidente Ollanta Humala creó una Comisión Consultiva para evaluar la posibilidad de crear un ministerio de CTI, y proponer lineamientos para repotenciar las capacidades del país en este campo. En el 2014 se realizó, como parte de la Agenda Nacional de Competitividad, un capítulo dirigido a dar seguimiento a los esfuerzos en CTI que los distintos actores estaban realizando con un horizonte 2014-2018. Es este último proceso que se ha seleccionado para analizar el impacto de la participación y el diálogo en el diseño de políticas y estrategias de CTI en el Perú. 


\section{CASO DE ESTUDIO: EL USO DEL DIÁLOGO PARA EL DISEÑO DEL COMPONENTE DE CTI DE LA AGENDA NACIONAL DE COMPETITIVIDAD 2014-2018}

\subsection{REQUERIMIENTO}

El CNC tiene una tradición de involucrar a los diversos actores de interés en sus procesos de rendición de cuentas. Cada seis meses, el CNC convoca a los representantes de los distintos sectores, del empresariado, la academia y la sociedad civil para presentar los avances de sus compromisos y luego mostrar los resultados a toda la comunidad interesada en el desempeño de la competitividad del país. A principios del año 2014, el CNC inició un proceso de actualización de la Agenda Nacional de Competitividad para 2014-2018. Mediante licitación pública, la firma de consultoría Apoyo Consultoría se adjudicó el contrato para realizar este proceso de actualización de la Agenda. La tarea implicaba hacer una propuesta de la Agenda Nacional de Competitividad para varios de los capítulos de este documento de política. Una de las condiciones metodológicas era la consulta con actores relevantes para el diseño de la Agenda Nacional de Competitividad 2014-2018.

La consultora Apoyo contrató a un grupo de consultores de Foro Nacional Internacional (FNI) para realizar la investigación, consultas y propuestas para el capítulo de CTI de la Agenda. FNI es un centro de investigación aplicada que ha desarrollado una línea de investigación en CTI y contaba con la información, contactos y conocimiento del procedimiento de consultas requerido para el diseño la Agenda.

La metodología de diálogo aplicada por FNI se ha utilizado a lo largo de veinticinco años en distintos procesos de planeamiento, diseño, reflexión y evaluación de políticas, programas y proyectos. FNI considera que el diálogo es un instrumento tanto para el diagnóstico como para el análisis de políticas y estrategias de desarrollo. Se considera que el diálogo cumple dos funciones para implementar políticas y estrategias: la primera es la apropiación por parte de los actores clave (stakeholders), y la segunda consiste en facilitar el acceso a información útil para realizar diagnósticos, proponer metas y realizar seguimiento y evaluación de la implementación. Está implícito en la promoción del diálogo que los actores más cercanos a las situaciones de análisis por lo general tienen información más detallada de las condiciones, procesos y resultados.

\subsection{LA PROPUESTA DE CONSULTA Y DIÁLOGO CON ACTORES CLAVES}

El proceso de involucramiento de actores contó con diversas metodologías de consultas que se detallan en la siguiente secuencia de fases del proceso de diálogo: Entrevistas y consultas, Taller, Proceso de diálogo y Resultados de diálogo. 


\section{a) Entrevistas y consultas}

Se realizaron entrevistas a profundidad a representantes del sector público, el sector privado, la academia y organizaciones de la cooperación internacional que tienen experiencia en el tema de CTI. Las consultas a más de veinte actores claves buscaron identificar los temas prioritarios a considerar. Se realizó un taller en el Hotel los Delfines en Lima, donde se revisó el conjunto de indicadores presentados y se establecieron metas viables en el horizonte temporal de la Agenda.

Las entrevistas fueron abiertas y se centraron en dos preguntas: la primera sobre la experiencia de la Agenda 2012-2013 y las principales lecciones de su participación en ese proceso. La segunda pregunta se refería a cuáles deberían ser los temas a considerar en la nueva agenda 2014-2018. Se les pidió considerar los siguientes criterios para sus propuestas: que el objetivo o acción tuviera un vínculo explícito de contribución a la competitividad del país, que implique la articulación de varios actores, y que sea un objetivo estratégico para el país. Cada reunión duró entre treinta minutos y una hora.

En las consultas se buscó incluir a todos los actores del Sistema Nacional de Ciencia, Tecnología e Innovación Tecnológica del Perú (SINACYT), creado mediante la ley $\mathrm{N}^{\circ} 28303$, y definido como "el conjunto de instituciones y personas naturales del país dedicadas a la investigación, desarrollo e innovación tecnológica (I+D+I) en ciencia y tecnología; y a su promoción". Según esta ley, el SINACYT está compuesto por los siguientes agentes:

- el Consejo Nacional de Ciencia, Tecnología e Innovación Tecnológica (CONCYTEC), como organismo rector del SINACYT;

- el Fondo Nacional de Desarrollo de la Ciencia, Tecnología e Innovación Tecnológica (FONDECYT) para fomentar proyectos del SINACYT;

- el Consejo Consultivo Nacional de Investigación y Desarrollo para CTI (CONID), órgano consultivo intersectorial del SINACYT;

- el Instituto Nacional de Defensa de la Competencia y de la Protección de la Propiedad Intelectual (INDECOPI), para proteger y difundir los derechos intelectuales en CTI, y registrar normas técnicas y metrológicas;

- las instancias de los gobiernos regionales y locales dedicadas a las actividades de CTI en sus respectivas jurisdicciones; 
- las universidades públicas y privadas, empresas, programas nacionales y especiales de CTI, instituciones e integrantes de la comunidad científica; y

- las comunidades campesinas y nativas, como espacios de preservación y difusión del conocimiento tradicional, cultural y folclórico del país.

Las entrevistas individuales previas a los talleres permitieron llevar ejemplos que facilitaban la participación activa de los mismos actores ante otros actores que no conocían. Asimismo, al presentar algunos resultados preliminares, donde se podían elegir o reforzar algunas ideas, se ayudaba a focalizar en los puntos centrales del diálogo. No se utilizó mucho tiempo en lluvias de ideas, porque estas se recogían previamente y se presentaban para acotar la discusión con todos los participantes.

\section{b) El taller}

Definir preguntas puntuales para cada etapa del taller ayudó a tener claro un objetivo y la tarea. Esto permitió regresar al objetivo cuando existía algún tipo de distracción (diálogos por anécdotas puntuales, cambios de tema, entre otros). Resumir los aportes al final de cada etapa del taller permitió validar y asegurarse de tomar en cuenta la mayor parte de las propuestas de los participantes.

\section{c) Proceso del diálogo}

Los actores eran decisores directos o influyentes en las decisiones de las instituciones a la que pertenecían. Sin embargo, en las universidades y empresas las acciones no aseguraban replicarse entre sus pares, porque no se contaba con una representatividad suficiente de estas comunidades.

Estuvieron ausentes en el diálogo las comunidades nativas y los gobiernos sub-nacionales. No obstante, hubo mucha diversidad, la cual favoreció en algunos puntos el proceso de diálogo, pero lo retrasó en punto discordantes por falta de conocimiento de acciones de unos actores sobre otros. Al final hubo explicaciones cruzadas y diálogos que permitieron arribar a un mensaje común.

Durante el diálogo, en las mesas más heterogéneas los participantes buscaban explicar el porqué de ciertas restricciones en 
materia de política, las cuáles eran solo conocidas por ciertas comunidades. Este caso sucedió, en especial, con los participantes del Ministerio de Economía, que explicaban los conceptos financieros y las necesidades normativas para cumplir con las demandas de las comunidades demandantes de la política en CTI. Finalmente, entender los procesos financieros para apoyar iniciativas de todos los actores contribuyó a un mejor diálogo.

En las mesas de diálogo no se mostró desconfianza, pero las participaciones se relacionaban con diferentes grados de capacidad de expresión y comunicación, lo cual no se atribuía a la confianza sino a la personalidad. No obstante, el facilitador jugó un papel importante para que los actores menos participativos también dieron sus puntos de vista.

\section{d) Resultados del diálogo}

El resultado principal del diálogo fue una agenda consultada con la participación de más de treinta actores de entidades públicas, académicas, consultoras, cooperación internacional y empresarios. Después de la elaboración y presentación de la Agenda 2014-2018 se definieron las reuniones para las rendiciones de cuenta. La Primera Rendición de Cuentas se realizó aproximadamente a 6 meses de entregado el documento a la opinión pública. Las siguientes reuniones también estarían programadas cada 6 meses.

\subsection{POLÍTICA RESULTANTE DEL DIÁLOGO EN EL DISEÑO DE LA AGENDA}

Como se señaló anteriormente, con la finalidad de promover la competitividad del país, el Perú desarrolló como instrumento la Agenda de Competitividad (dos agendas a la fecha, empezando en el 2012). Dentro de las líneas estratégicas se encuentra la promoción de la CTI, la cual va anudada a las otras seis líneas con metas intersectoriales. Los estamentos de la sociedad congregados por el gobierno central buscaban estar comprometidos en actividades que impactaran, en diferentes plazos, en la competitividad del país: las instituciones educativas público y privadas, las universidades, los institutos de investigación, las incubadoras, los centros proveedores de servicios tecnológicos y de gestión, los gobiernos regionales y locales inversores en CTI y las otras instituciones nacionales e internacionales de financiamiento e intermediarios.

La vinculación entre la línea estratégica de la CTI y la competitividad es central para la sostenibilidad del crecimiento económico, atender los desafíos sociales y ampliar las posibilidades de un desarrollo sostenible 
para el país. La competitividad en las empresas es la capacidad para propiciar su crecimiento, rentabilidad y alcance en el mercado. Estos fines se logran en parte a través del aumento de su productividad. La generación y adquisición de conocimientos, la adopción y creación de tecnologías y la innovación tecnológica en los procesos productivos contribuyen al aumento de la productividad. La inversión constante en CTI impulsa la mejora y renovación de bienes y servicios que constituyen la estructura productiva de un país.

El gráfico 1 muestra la relación causal entre la CTI y la competitividad. El Estado es el primer propulsor de la CTI. La inversión del Estado y los incentivos que facilitan la inversión del sector privado generan un conjunto de conocimientos. Este conjunto de conocimientos aplicados origina innovaciones. Las innovaciones se dan en nuevos productos o los mejorados. En el Perú, la inversión del Estado y de las empresas es reducida y por ende las innovaciones y los nuevos productos han sido escasos. El bajo nivel de tecnología ocasiona una baja productividad a través de este factor y afecta negativamente a la competitividad del país. La idea central es avanzar en mejorar la productividad mediante políticas consensuadas.

Gráfico 1: Relación causal entre la inversión en CTI y la Competitividad

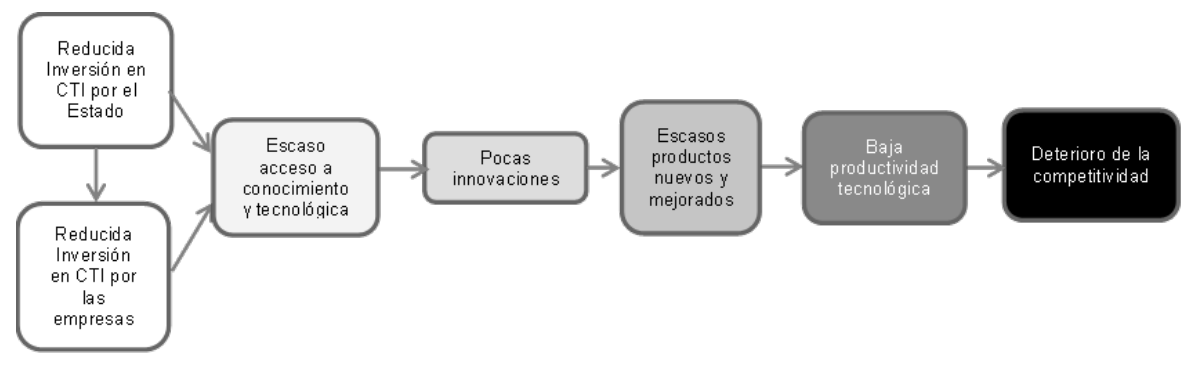

Elaboración: propia

El diseño de la Agenda de Competitividad en CTI siguió las propuestas de planes anteriores. Los planes para la inversión en CTI están estipulados en el Plan Nacional Estratégico de CTI para la Competitividad y el Desarrollo Humano 2006-2021 y en el proyecto de inversión pública "Innovación para la Competitividad". Sin embargo, la atención que se le ha puesto a las estrategias de CTI para alcanzar estos objetivos de desarrollo ha sido muy limitada.

La Agenda de Competitividad en CTI buscó solucionar un problema central: la limitada capacidad en CTI, tanto capacidades ins- 
titucionales, recursos humanos y financieras. Dicho problema es originado por cuatro causas directas: i) la baja articulación de actores involucrados; ii) las capacidades de emprendimiento e innovación desfortalecidas; iii) la base científica-tecnológica desfortalecida; y iv) la inadecuada movilización de recursos financieros.

La baja articulación de actores involucrados empieza entre las entidades del sector público. Con un sector público desarticulado, su conexión con el sector privado y las universidades también se limita. La información inadecuada y desactualizada para la toma de decisiones debilita mucho más la articulación entre los actores. Muchos de los problemas que enfrenta el sistema de la CTI se muestran en el gráfico 2, el árbol de problemas muestra la relación de estas causales con el problema central y los efectos que tienen en la competitividad del país. Así, las limitadas capacidades de emprendimiento e innovación se manifiestan en la debilidad de los ecosistemas para emprendimientos basados en innovación, en el bajo conocimiento de la demanda y oferta de productos y servicios tecnológicos e innovadores, en la provisión de servicios públicos inadecuados para la innovación y la transferencia tecnológica, y en el bajo nivel de innovación de las empresas.

La débil base científica-tecnológica implica una baja producción científica ocasionada por la escasez de recursos humanos dedicados a la producción de CTI. La falta de infraestructura institucional y física se conjuga negativamente con la capacidad desfortalecida de producción científica de los institutos públicos de investigación. Asimismo, la insuficiente movilización o inadecuada asignación de recursos financieros de la CTI, en los últimos años, contrasta con varios países de la región latinoamericana y países desarrollados, quienes han invertido en promedio muchos más recursos para esta tarea. Esto genera una brecha creciente con respecto a la capacidad de innovación de otros países. Esta tendencia ha cambiado en los últimos dos años, sin embargo, el retraso es significativo. En el caso de los recursos provenientes del canon y regalías de las actividades extractivas han sido subutilizados por las universidades públicas, las cuales han invertido poco y de manera poco eficiente en investigación. Respecto al sector privado, este ha tenido pocos incentivos para invertir en procesos de investigación, desarrollo tecnológico e innovación.

Revertir estas bajas capacidades involucra la intervención en cuatro ejes estratégicos con el objetivo de aumenta la competitividad del país: articulación de actores, la base científico-tecnológica, el emprendimiento y la innovación, y el financiamiento. 


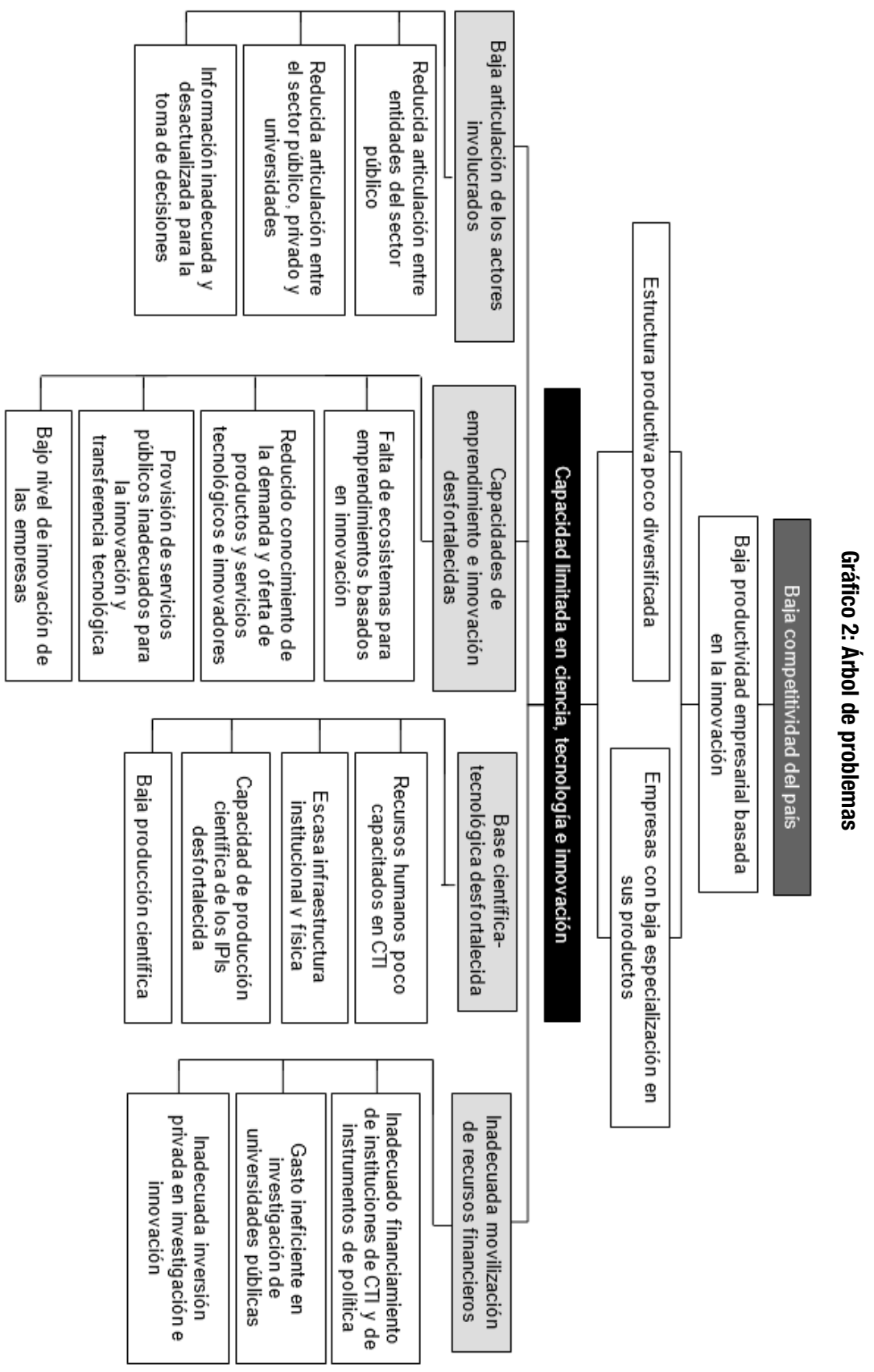




\section{ARTICULACIÓN DE ACTORES}

El objetivo de este eje es aumentar la articulación entre los actores del Sistema Nacional de CTI, que incluye mejorar la vinculación entre los diversos actores del sector público, la vinculación del sector público con el sector académico y sector empresarial, la articulación entre el sector académico y el sector empresarial, dentro del sector académico y dentro del sector empresarial, y las acciones de cooperación internacional en CTI. La articulación se realiza a través de la formalización de la implementación de políticas e instrumentos de políticas entre los diversos actores del sector público, la promoción e incentivos del sector público hacia el sector académico y empresarial, la implementación de oficinas de transferencia tecnológica entre el sector académico y el sector empresarial, entre otros.

\section{BASE CIENTÍFICO-TECNOLÓGICA}

El objetivo es formar y atraer talento dedicado a la producción de CTI, así como mejorar el acceso a conocimiento, infraestructura, equipamiento y tecnología adecuada para realizar actividades de ciencia, tecnología e innovación. Mejorar la base científico-tecnológica implica aumentar y consolidar el sistema de becas en ciencia, tecnología e innovación, promover la producción de conocimiento, incentivar la capacidad inventiva, y mejorar la transferencia de tecnologías de punta hacia el sector productivo. Además, se requiere de un sistema de información adecuada para medir los alcances de las acciones realizadas y contar con información relevante para la toma de decisiones.

\section{CAPACIDADES DE INNOVACIÓN}

El objetivo en este eje es generar las condiciones adecuadas e incentivos para generar innovaciones que puedan llegar al mercado. Para conseguir este objetivo es necesario incentivar la incorporación en los modelos de negocio de las empresas peruanas unidades orientadas a la innovación, mejorar el entorno para que los emprendimientos innovadores consigan la escala necesaria para acceder a mercados, y promover la existencia de infraestructura, servicios y mecanismos para promover la innovación en el sector productivo.

\section{MOVILIZACIÓN DE RECURSOS FINANCIEROS}

El objetivo es movilizar recursos financieros orientados a generar capacidades de CTI, con el fin de potenciar las oportunidades futuras de desarrollo. Este objetivo implica que el sector público asigne de manera adecuada recursos crecientes para promover la producción de ciencia y tecnología y nuevas innovaciones, que el sector privado invierta una mayor proporción de sus ingresos en generar nuevos 
procesos y productos para el mercado, que el sector académico dedique parte de sus recursos para entrenar al recurso humano altamente calificado y promover la producción, adaptación y uso de conocimiento y tecnologías, y movilizar recursos de cooperación internacional en oportunidades de interés global.

La Agenda de Competitividad en la línea estratégica de CTI agrupó los objetivos y las metas a cumplir en los cuatros ejes descritos. En el documento el objetivo es descrito como:

Fortalecer las capacidades científicas tecnológicas y de innovación para apuntalar el cambio en la estructura productiva hacia una economía basada en el conocimiento. Agenda de Competitividad 2014-2018.

Mientras que las ocho metas a alcanzar, del total de 65 metas en competitividad, incluyendo todas las líneas estratégicas fueron las siguientes:

1. Triplicar el número de proyectos de $\mathrm{I}+\mathrm{D}+\mathrm{i}$ que acceden a fondos públicos, en los que exista una alianza entre las empresas y la academia.

2. $100 \%$ de indicadores de CTI actualizados y reportados de acuerdo con los estándares internacionales (RICYT, WEF, OCDE, entre otros).

3. Triplicar los investigadores activos inscritos en el directorio de CONCYTEC.

4. Elevar el Coeficiente de Invención (patentes solicitadas por residentes entre población) de 0.65 a 0.84 .

5. Quintuplicar (al 1.5\%) el monto invertido por las empresas en I+D respecto de sus ventas.

6. Lograr que al menos $20 \%$ de 500 emprendimientos innovadores de alto impacto que recibieron apoyo público estén en el mercado.

7. Quintuplicar la inversión pública en I+D como porcentaje del PBI.

8. Elevar de $2.3 \%$ al $30 \%$, el porcentaje de ejecución de los fondos provenientes del Canon para proyectos de $\mathrm{I}+\mathrm{D}+\mathrm{i}$ en universidades públicas.

(Agenda de Competitividad 2014-2018)

\section{DISCUSIÓN SOBRE EL CASO}

La aplicación de una metodología de investigación ex-post tiene limitaciones y ventajas. Si bien no es posible incorporar cambios y evaluar los efectos de esos cambios, al mismo tiempo se posee información del proceso y resultado del diálogo, que permite ver hacia atrás y tener aprendizajes contrastados con los resultados. En esta sección presenta una clasificación del proceso de diálogo de acuerdo a las categorías analíticas planteadas en la sección 2 y los aprendizajes según las etapas de preparación y convocatoria, facilitación del diálogo, limitaciones encontradas y los resultados, y devolución de los mismos a quienes participaron del proceso. 


\subsection{CARACTERIZACIÓN DEL PROCESO DE DIÁLOGO PARA CONSTRUIR LA AGENDA NACIONAL DE COMPETITIVIDAD}

Este proceso de diálogo tenía un fin bastante preciso: convocar a una diversidad de actores para organizar un marco de políticas que alineen los esfuerzos de impulsar las políticas CTI con aquellos de mejorar la competitividad de la economía. Sin embargo, este proceso de diálogo consolidó una serie de asociaciones entre los actores alrededor del proceso de rendición de cuentas de las políticas alcanzadas por consenso. Por tanto, es importante señalar que los actores que organizaron el diálogo aprovecharon una serie de circunstancias favorables para consolidar un espacio de coordinación y rendición de cuentas - que permitió obtener resultados adicionales. Resumimos estas características de acuerdo a las seis dimensiones analíticas para los procesos de diálogo descritas en la tabla 1 de la sección 2.

1. Origen. El proceso de diálogo para la construcción de la Agenda se origina en el gobierno central a través del CNC, adscrito al Ministerio de Economía y Finanzas, el cual tenía la capacidad de convocatoria suficiente para reunir a los más altos funcionarios del gobierno y otras instituciones. El objetivo del diálogo era proactivo, porque tenía la misión de elaborar una política de CTI orientada hacia el logro de la competitividad del país. En este caso, hubo convergencia entre demanda y oferta. La demanda estaba representada por los beneficiarios de esta política, tales como las empresas a través de los incentivos tributarios y las universidades usuarias de los fondos concursables CTI; mientras que la oferta estaba representada por el gobierno central, que quería definir una política a favor de la competitividad, la cual no podía pasar por alto la política de CTI. Este tipo de diálogo lo consideramos top-down pues fue diseñado para organizar una política nacional en CTI con una misión clara y objetiva, relacionado con el aumento de la productividad y de la competitividad en el país a través del consenso en política de CTI.

2. Temporalidad. La Agenda fue elaborada en cuatro meses, tiempo que incluye las consultas y el taller de validación. Como tal, es un proceso de diálogo de corto plazo, aunque originó reuniones de rendición de cuentas, establecidas cada seis meses después de terminada la Agenda. Por esta razón, se le puede considerar como un proceso de diálogo de mediano plazo, pero discontinuo. Cada taller de rendición de cuentas permite el seguimiento de la política y las acciones de los actores, principalmente 
públicos, quienes comparan si avance de acuerdo a los plazos y objetivos de la Agenda.

3. Alcance. El ámbito del proceso de diálogo para el diseño de la Agenda Nacional de Competitividad es general, ya que busca el diseño de la política nacional de CTI relacionada con la promoción de la competitividad y el aumento de la productividad de las empresas y la economía en general.

4. Balance entre actores. A pesar de la diversidad de actores en la formulación de la política de CTI, en la Agenda CTI no hubo mayor conflicto de interés ni grupos de poder que tomaran control del proceso de diálogo. Una de las explicaciones es el nivel de consenso técnico entre la relación de las políticas CTI y de competitividad: es posible mejorar la eficiencia en el uso de recursos mediante la inversión en tecnología. Sin embargo, hubo un grado de heterogeneidad entre los objetivos de la comunidad empresarial y de las otras comunidades. Por ejemplo, el sector privado tomó un papel más neutral por los beneficios propios que le proporcionaba la política; mientras que las universidades, la academia y el sector público buscaban hacer coincidir la demanda con la oferta en la formulación de la política. Para ello, el Ministerio de Economía y Finanzas identificó un interés común en el aspecto de financiamiento, por lo que utilizó una estrategia clara para explicar los instrumentos financieros de la política en un lenguaje común para entender las trabas, dificultades y oportunidades para el financiamiento en CTI.

5. Organización. Al inicio del proceso de diálogo estaba previsto solo convocar a altos funcionarios, representantes de las empresas de mayor tamaño, representantes de la academia y universidades con mayor producción de conocimiento. La Agenda no consideraba la participación de gobiernos sub-nacionales, ya que se definiría la política de CTI desde el gobierno central y los otros niveles del gobierno se adecuarían a la misma. El proceso previo de diagnóstico permitió identificar actores relevantes para la política, que serían congregados para el diálogo. Las consultas, como primer paso, permitieron recibir el punto de vista de todos los actores, y de esta forma diseñar una política previa que sería discutida y validada en un taller grupal, con todos los actores reunidos. El liderazgo lo tomó el gobierno central a través del CNC, quien era el convocante con legitimidad. En este contexto, Foro Nacional Internacional sirvió como intermediario para la convocatoria al diálogo, en 
tanto su rol independiente podía conectar a varias de las comunidades de actores.

6. Resultados. El resultado fue el diseño de la línea estratégica de CTI en la Agenda de Competitividad 2014-2018, que determina políticas, acciones y responsables. El impacto se dio a lo largo de la formulación de las políticas de CTI: la normativa, los mecanismos operativos (dentro de ellos el financiamiento) y la definición de actores participantes. Finalmente, la Agenda originó una práctica poco común en el gobierno peruano: el seguimiento y la retroalimentación de la política de CTI, cada seis meses, en las reuniones grupales de rendición de cuentas.

La metodología propuesta por la Red COM-LALICS-CyTED establece criterios para tipificar las experiencias de diálogo en Iberoamérica a partir del grado de semejanza (diversidad) y homogeneidad (heterogeneidad). Respecto a estos criterios, los diálogos de CTI en Perú se caracterizan como diálogos adaptativos, emergentes, de convergencia y vinculantes. El proceso de diálogo para la elaboración de la Agenda de Competitividad 2014-2018 en CTI recae dentro de la categoría de un diálogo adaptativo, porque el proceso de diálogo es top-down y su contribución para la disminución de la heterogeneidad de sus actores es baja.

\subsection{LECCIONES APRENDIDAS DEL PROCESO DE DIÁLOGO}

\section{PREPARACIÓN Y CONVOCATORIA}

Con un mandato claro proveniente del $\mathrm{CNC}$, los organizadores del diálogo CTI preparan los materiales y sistematizan el conocimiento existente. Para el diseño de políticas públicas se requiere un proceso de preparación detallado, que incluye: conocer las publicaciones formales de demandas, necesidades y debates existentes en el campo de estudio. Además, se debe conocer o tener una idea de las posiciones centrales de los actores, los intereses formales e informales, así como la secuencia de hechos previos a la reunión que se está organizando, y de preferencia conocer las actas o acuerdos que hayan podido llegar. Una buena herramienta preparatoria es tener algunas entrevistas personales previas al encuentro, que permita hacer consultas, preguntar referencias de otros actores y acceder a documentos que tienen los actores y los consideran clave tomarlos en cuenta.

Los resultados de las convocatorias son influenciados por la credibilidad de quien convoca, la experiencia previa de diálogos con la entidad convocante, la agenda, el horario y lugar de reunión propuesto, la duración de las reuniones, la anticipación con que se convoca 
y los mecanismos de verificación de la participación de los invitados (cartas de invitación, correos electrónicos recordatorios, llamadas de teléfono tanto directas como a las secretarias o asistentes que llevan la agenda de los actores). Existen otros factores externos, como un evento inesperado que complica la participación de los actores, por ejemplo, una emergencia nacional puede que todo el sector público se concentre en las acciones para remediar y no atiendan otras agendas que son importantes, pero no urgentes.

Tener varias estrategias de convocatoria ayuda a ir adaptando los mejores mecanismos para cada tipo de actor o grupo de actores alrededor de un tema específico. Por ejemplo, si la composición del grupo a convocar tiene un sesgo más de funcionarios públicos, hacerlo durante el horario laboral es más conveniente, mientras que si el grupo está compuesto por empresario las preferencias pueden ir por realizar un desayuno de trabajo o al final de la tarde, luego del horario laboral, podría tener más éxito.

En suma, la descripción del proceso muestra un mandato claro y medible a través de resultados, que contó con la participación de organizadores que sistematizaron la información y convocaron al diálogo sobre la base de un mapa de actores que podían aportar.

\section{FACILITACIÓN DEL DIÁLOGO E INTEGRACIÓN DE IDEAS}

La adecuada facilitación del diálogo a través de un actor independiente de los stakeholders, que conozca la temática y de ser posible a los actores y cuente con una posición independiente y con ánimo de crear una atmósfera de diálogo hacia la construcción de consensos operativos para la implementación de la política pública, es clave para lograr acuerdos, así como para identificar los temas en los que no los hay, y proponer una agenda de futuros diálogos sobre esos temas. La ausencia de un facilitador puede implicar que los acuerdos se rompan fácilmente, que si existen tensiones durante el diálogo se rompa la dinámica y no se retome, o que ciertas personalidades acaparen el proceso y exista un sesgo en los acuerdos que no represente la integración de los intereses. Asimismo, contar con una de las partes de interés como facilitador (por ejemplo, cuando un sector convoca y facilita) puede limitar las propuestas de otros actores, y la orientación de la discusión estaría más sesgada hacia los intereses e impactos, como resultado, los resultados mostrarían sesgos.

La facilitación debe incluir un balance en la convocatoria sobre actores que tienen posiciones distintas. Por ejemplo, saber que hay un tema tenso, y tener una audiencia donde pocos defienden una posición y muchos la otra, el resultado podría ser contraproducente. Si se conoce del tema, es posible desde la convocatoria buscar grupos similares 
que defiendan cada una de las posiciones para tener un balance de intervenciones. Sin embargo, también el facilitador puede neutralizar las situaciones que no participen igual número de representantes de ambas posiciones, lo cual se presenta de manera no prevista, dando la palabra a los representantes de distintas posiciones de manera intercalada e identificando explícitamente los argumentos y contrastarlos.

El facilitador también debe tener herramientas para salir de situaciones tensas y convertirlas en una oportunidad de identificar acciones para avanzar sobre los acuerdos y proponer estudios más profundos sobre los temas que no son claros para todas las posiciones que contribuyan a futuros acuerdos. Estas herramientas incluyen pausas para síntesis de las posiciones o un café, que luego se retoman con un resumen de las ideas redactadas y se inicia un diálogo para hacer explícitos los argumentos y dejarlos claros para todos, aunque no haya un consenso en ese momento. También, sirve hacer énfasis en la discusión sobre las ideas y no sobre las personas que lo proponen (cuando existen críticas personales y no sobre el contenido del debate). Asimismo, cuando al final del diálogo no existen acuerdos, sino por el contrario hay posiciones encontradas, se acuerdan los textos de cada posición para que sean desarrolladas por cada equipo y conocidos por todos. Conocer estos disensos también es útil para la división de funciones, la posibilidad de probar mecanismos alternativos y la oportunidad de profundizar en las ideas en un diálogo de más largo plazo.

Las actas del proceso de diálogo son una herramienta central para el seguimiento a los compromisos acordados. Las actas deben revelar el procedimiento de convocatoria, la agenda, los temas tratados en la reunión, las ideas principales expuestas por los actores, los temas de acuerdo, los temas que quedaron en debate, la propuesta de ideas para futuros diálogos, un cronograma de actividades futuras y la firma de los asistentes con la conformidad de los contenidos del acta y en caso no lo estén incluir alguna nota al respecto.

\section{LIMITACIONES Y BARRERAS}

Los diálogos no son panacea para los temas y/o problemas que abordan, pues no garantizan la implementación de los acuerdos. Una barrera que enfrentan los diálogos es que la participación de muchos actores puede no incluir la participación del actor más influyente. En efecto, cuando existe un actor que es muy influyente en un tema, puede preferir no participar en un diálogo abierto, porque aprovecha su posición y grado de influencia y/o poder para incidir directamente sobre las acciones que se realizan, y garantiza un resultado más acorde con sus intereses que los del consenso que se puede generar en el 
proceso de diálogo. A la larga, estos resultados no son sostenibles si no coinciden con los de otros actores, pero en el corto plazo suelen tener más éxito. La importancia de la estrategia de convocatoria y convencer a estos actores influyentes de participar del diálogo es central.

La garantía de implementar los acuerdos es un factor relevante para ir construyendo confianza en los procesos de diálogo, pero no siempre sucede. El diálogo es un insumo, y no es vinculante, por lo tanto, entre los resultantes del diálogo y lo que se implementa pueden existir brechas significativas. Esta práctica ha desprestigiado los procesos participativos y luego la implementación de acciones puede traer conflictos o poca apropiación de los actores a la hora de mantener o valorar los esfuerzos. Sin embargo, aún persisten las imposiciones de los grupos de interés más influyentes de filtrar los resultados de los diálogos desde sus puntos de vista y no desde la viabilidad y conveniencia del conjunto de actores.

Coincidir agendas y tener un espacio neutral para realizar los procesos de diálogo es sumamente complejo, y en la medida que el número de actores sea mayor se complejiza aún más. Además, si los actores provienen de lugares muy distintos y tienen actividades distintas no es fácil hacer coincidir fechas, horarios y ubicación para que todos puedan asistir. Por eso, es siempre útil tener una estrategia para optimizar el tiempo de los actores y poder obtener una participación amplia. Por ejemplo, realizar pequeños diálogos territoriales para luego ir agregando en diálogos por representantes de los territorios para un proceso más integral reduce el número de personas por espacio y va construyendo consensos representativos que luego pasan a plataformas más amplias. O realizar mesas de diálogo por tipos de actor, para luego hacer una mesa multiactor con algunos de los representantes de cada mesa. Esas estrategias dependen de cada caso.

\section{RESULTADOS Y DEVOLUCIÓN}

Los resultados de los diálogos son de varios tipos. El primero es la formación de una red de actores que participan, porque se conocen personalmente, tienen contacto directo y fortalecen sus lazos. El segundo es sobre el proceso, que implica movilizar información, explicitar posiciones y organizar el conjunto de ideas que representan al conjunto de actores que participan del diálogo. Tercero, se encuentran los registros de las ideas organizadas en las actas, la asistencia y el contacto de los participantes. Parte de esta información debería ser devuelta al público participante. Algunas veces es un activo poder compartir la información de contacto de los participantes con todos los participantes, de manera que se promuevan asociaciones y coordinaciones espontáneas -fuera del espacio del 
diálogo-. El acta de la reunión debería ser firmada y hacer que cada participante cuente con una copia. Finalmente, los diálogos son un insumo, hacer llegar a los participantes de los espacios de diálogo los resultados finales, sean estos un informe, una nueva normativa, o las declaraciones políticas del líder del sector ayudan a afianzar la confianza en la participación porque hace visibles las contribuciones del diálogo.

Por lo tanto, la comunicación posterior al diálogo con los participantes es clave. Es necesario además hacer un seguimiento a los acuerdos y poder informar cada cierto tiempo los avances de los mismos. Esta tarea facilitará además diálogos futuros al crear una comunidad activa alrededor de un tema específico.

\section{CONCLUSIONES Y REFLEXIONES FINALES}

El ejercicio de la red temática del CYTED sobre diálogos en la construcción de políticas de CTI ha sido una excusa de este documento para sistematizar una metodología y aplicarla a un proceso de diálogo específico que ha sido el observado en la elaboración de la Agenda Nacional de Competitividad del Perú para los años 2014-2018. Al revisar la experiencia nacional e internacional, así como el marco conceptual se afianza la necesidad de transitar hacia diseños de política pública y de instrumentos con el uso del diálogo como una herramienta para hacer mejores políticas e instrumentos, que sean posibles de aplicar y que beneficien a la sociedad en su conjunto.

El uso del diálogo contribuye a contar con mejor información y a afianzar el proceso de apropiación de la población sobre las políticas específicas en CTI. Asimismo, contribuye a lograr consensos y acuerdos operativos que facilitan la implementación. Permiten identificar barreras y proponer medidas habilitantes para la superación de las trabas existentes. Ayuda a proponer hojas de ruta a distintos actores que desde sus propias posiciones pueden contribuir a mejorar las condiciones específicas y los resultados de la política de CTI.

El objetivo de este documento ha sido describir el proceso de diálogo para construir la ANC particularmente para el diseño del componente de CTI, y extraer las lecciones aprendidas de este proceso. La experiencia del caso de la ANC es un ejemplo de cómo el diálogo ha contribuido a proponer metas conjuntas entre distintos actores, y darle seguimiento a los acuerdos y a los resultados con respecto a las metas propuestas. Durante este proceso interactuaron los distintos actores del sistema nacional de CTI, quienes se apropiaron de metas comunes, y asumieron sus responsabilidades en el camino al cumplimiento de esas normas. El Consejo Nacional de Competitividad jugó 
un papel facilitador del proceso de diálogo y del seguimiento de la implementación de los acuerdos.

La literatura difícilmente destaca los aspectos operativos de estos procesos de diálogo. En este trabajo se hizo un esfuerzo por listar un conjunto de lecciones aprendidas, que contribuyen a hacer más eficiente e incluyente este proceso. Entre las principales lecciones aprendidas destacan:

- Contar con un objetivo claro para la convocatoria. El diseño original del diálogo buscaba acordar puntos generales sobre la política CTI y su aporte a la competitividad del país. Este objetivo se logró en cuatro meses con un proceso bien diseñado y con el apoyo de organizadores independientes con llegada y prestigio al mayor número de actores. Sin embargo, esta tarea se completó al haber podido insertar este proceso de diálogo en una convocatoria más amplia de seguimiento de las metas y de rendición de cuentas de los actores. Tener el objetivo claro, y haber identificado a los actores, permitió un proceso de planificación del diálogo que dejó la sensación de una buena organización que hizo que los actores se enganchen al proceso y aporten.

- Definir los temas de consenso y empezar a forjar acuerdos a partir de ellos. Uno de los temas que concitó el interés común de varios actores tenía que ver con la propuesta del Estado de utilizar fondos adicionales para apoyar las iniciativas CTI futuras. Esta propuesta fue creíble pues el Estado ya había aumentado el volumen de recursos disponibles a través de diversos fondos. Alrededor del tema de financiamiento fue posible convocar a varios actores y a través de la explicación de los objetivos del Estado para el uso de esos recursos fue posible lograr que muchos de ellos participaran activamente.

- Prestar atención a los procesos logísticos alrededor del diálogo. Si bien se puede argumentar que el proceso fue fluido, el trabajo detrás del escenario fue importante y es un aspecto central de haber logrado los objetivos. Cada mesa, diálogo, aporte, fue adecuadamente recogido y se utilizó como manera de propiciar los aportes, pero también como una manera de contrastar nuevas ideas -o evitar que hayan aportes repetidos-. No es solo trabajo de facilitación del diálogo, sino de preparación de todo el entorno para que los actores participen de manera fluida. 
El diálogo es una herramienta útil para el diseño de políticas públicas, pero aún es poco extendido como práctica en otros sectores. La necesidad de extender esta práctica para el diseño de otras políticas institucionaliza el diálogo y genera soporte para el cumplimiento de las políticas de mediano y largo plazo. Para el Perú, considerado como un país donde existe una muy alta rotación de los ejecutores de política, especialmente dentro de los ministerios del poder ejecutivo, se abriría un espacio independiente al cambio de funcionarios y se mantendría la estabilidad de los acuerdos de relevancia para el país. Esto contribuiría a diseñar políticas de estado, que trascienden a las administraciones en turno.

\section{BIBLIOGRAFÍA}

Agenda: PERÚ 2001 Perú: Agenda y Estrategia para el Siglo 21 (Lima: Foro Nacional Internacional - APOYO Editores).

Álvarez, I.; Barletta, F.; Suarez, D.; Yoguel G. 2016 "Marco analítico para la tipificación de diálogos para las políticas de CTI" en Working paper 3 (Red CYTED COM-LALICS). En <http://lalics. org/images/CYTED/DT3-DimensionesDialogo.pdf> acceso $15 \mathrm{de}$ abril de 2017.

Barboza, L. 2016 "Algunas consideraciones en torno al concepto de comunidad" en Working paper 6 (Red CYTED COM-LALICS).

En <http://alics.org/images/CYTED/DT6-DefinicinComunidad. pdf $>$ acceso 15 de abril de 2017.

Comisión Consultiva para la Ciencia, Tecnología e Innovación 2012 "Nueva política e institucionalidad para dinamizar la CTI peruana", Informe final de la Comisión creada por R. S. N. ${ }^{\circ} 038$ 2011-ED (Lima).

CONCYTEC 2005 Plan Nacional Estratégico de Ciencia, Tecnología e Innovación para la Competitividad y el Desarrollo Humano-PNCTI 2006-2021 (Lima: CONCYTEC).

Consejo Nacional de Ciencia, Tecnología e Innovación Tecnológica 2013 "Doctorados: Garantía para el Desarrollo Sostenible del Perú", Documento de trabajo (Lima: CONCYTEC) septiembre. Consejo Nacional de la Competitividad - Ministerio de Economía y Finanzas 2014 Agenda de Competitividad 2014-2018: Rumbo al Bicentenario (Perú) 27 de junio

Crespi, G.; Dutrénit, G. (eds.) 2014 Science, Technology and Innovation Policies for Development: The Latin American Experience (Londres: Springer).

Cuentas, M.; Linares, A. 2013 Guía práctica de diálogo democrático (Organización de Estados Americanos - Programa de las Naciones Unidas para el Desarrollo). 
Dutrénit, G.; Natera, J. M.; Suárez, M. 2014 "Lineamientos para la caracterización de las Comunidades y sus Procesos de Diálogo" en Working paper 1 (Red CYTED COM-LALICS). En <http:// lalics.org/images/CYTED/DT1-ComunidadesDialogo\%201.pdf> acceso 15 de abril de 2017.

Dutrénit, G.; Álvarez, I.; Ardanche, M.; Barletta, F.; Bianco, M.; Cortés, R.; Cummings, A.; de la Vega, I.; Díaz, I.; Fernández, O.; Gómez, V.; Goñi, M.; Natera, J. M.; Nupia, C.; Orozco, J.; Prada, F.; Puchet, M.; Romero, F.; Simón, L.; Suárez, D.; Suárez, M.; Sutz, J.; Vera-Cruz, A. 2016 "Matriz de Información para el mapeo de procesos de diálogo de CTI en España, América Latina y el Caribe" en Working paper 5 (Red CYTED COM-LALICS). En $<$ http://lalics.org/images/CYTED/DT5-Formulario2.pdf> acceso 15 de abril de 2017.

Dutrénit, G.; Natera, J. M.; Puchet Anyul, M.; O. Vera-Cruz, A.; Torres, A. 2017 "Dialogue processes on STI policy-making in Latin America and the Caribbean: dimensions and conditions". En Science and Public Policy, 1-16. En <doi: 10.1093/scipol/ scx044>.

Goñi, M.; Bianco, M.; Puchet, M. 2015 "Elementos para caracterizar los procesos de diálogo en políticas de CTI" en Working paper 7 (Red CYTED COM-LALICS). En <http://lalics.org/images/ CYTED/DT7-ConfianzaPoder.pdf> acceso 15 de abril de 2017.

Hernández, M. 2014 Doce años del Acuerdo Nacional (Lima). Primera edición, noviembre. En <http://franciscosagasti.com/descargas/ eventos/ff-informe-comision-consultiva-cti.pdf $>$.

PNUD 2014 Acuerdo Nacional: Consensos para enrumbar al Perú (Lima: Secretaría Ejecutiva del Acuerdo Nacional). Primera edición.

Sagasti, F. 2011 Ciencia, tecnología, innovación: Políticas para América Latina (México: Fondo de Cultura Económica).

Sagasti, F.; Patrón, P.; Hernández, M.; Lynch, N. 1999 "Democracia y Buen Gobierno" en Agenda: PERÚ (Lima: Editorial Apoyo). Tercera edición.

World Economic Forum 2016 The Global Competitiveness Report 2016-2017 (Génova). En <www.weforum.org/gcr>. 


\section{PROCESOS DE DIÁLOGOS PARA EL DISEÑO DE POLÍTICAS \\ DE CTI ENFOCADAS EN COMUNIDADES ESPECÍFICAS}





\section{DIÁLOGO ENTRE LAS COMUNIDADES, GENERACIÓN DE CONSENSOS Y ADOPCIÓN \\ DE UNA PERSPECTIVA DE GÉNERO EN LAS POLÍTICAS PÚBLICAS DE CTI EN MÉXICO}

Gabriela Dutrénit* y Marcela Suárez ${ }^{* *}$

\section{INTRODUCCIÓN}

La política de ciencia, tecnología e innovación (CTI) en México enfrenta el reto de convertirse en política pública, y para ello se requiere la participación de los diversos actores interesados. En el diseño de la política de CTI predomina aún un enfoque de arriba hacia abajo, de política gubernamental, en contraposición al de política pública, y hay dificultades para reconocer las voces de las comunidades. El carácter público de la política se refiere a incrementar la participación de las comunidades en el proceso de formulación (Aguilar, 1992; Valenti \& Flores, 2009; Ordoñez-Matamoros et al., 2013). Una de las voces se refiere a adoptar una Perspectiva de Género (PEG) para reducir asimetrías.

En América Latina se están llevando a cabo esfuerzos por analizar y conceptualizar los procesos de diálogo entre las diversas comunidades de CTI (Álvarez et al. 2016; Dutrénit, Natera, \& Suarez, 2014). En México hay una creciente discusión en torno a la necesidad de incrementar el carácter público de las políticas a través

* Posgrado en Economía, Gestión y Políticas de Innovación, Universidad Autónoma Metropolitana, Unidad Xochimilco

** Lateinamerika-Institut, Freie Universität Berlin 
de una mayor participación de las comunidades en su proceso de formulación. Sin embargo, la participación de las comunidades no es suficiente ni para asegurar que todas las voces estén siendo escuchadas o incluidas ni para que eso se refleje en un cambio en el diseño de la política.

Los ejercicios de participación pública en materia de CTI en México han sido reducidos. Se refieren principalmente a: (i) informar o involucrar a la gente en actividades de CTI (tipo popularización de la CTI); y (ii) hacer consultas (como la agenda ciudadana, o la consulta del Sistema Nacional de Investigadores). Pero, para diseñar una política que, en definitiva, sea pública, se requiere la participación, negociación y consenso de propuestas de parte de las diferentes comunidades y actores involucrados; el ejercicio más sistemático en esta dirección fue la generación de consensos para emprendedores basados en conocimiento reportado en Dutrénit y Suárez (2016).

Existen asimetrías en relación al género en el sector de CTI, se requiere introducir políticas más consistentes que estimulen la participación igualitaria de las comunidades en términos de género. Entre estas asimetrías se encuentran, por un lado, un elevado número de mujeres en comparación con el de hombres en el sector académico de la CTI, tanto de estudiantes como de investigadoras y docentes, y por otro la poca presencia de mujeres en mandos directivos tanto en el sector académico, empresarial y público. Las tensiones que se generan desde la misma política contribuyen a acentuar la desigualdad de género.

El tema de la PEG se incorporó en el Plan Nacional de Desarrollo (documento rector de las políticas públicas en México) como un eje transversal en todos los planes sectoriales desde diciembre de 2012. Si bien se han dado avances significativos en la adopción de marcos legales que favorezcan la incorporación de PEG en México, la política pública de CTI, y en otros ámbitos, ha introducido lentamente estos cambios legales; no se puede argumentar que la política de CTI en México tenga una PEG.

Este artículo tiene como objetivo discutir las características de los procesos de diálogo entre comunidades y la incidencia que pueden tener en el diseño de la política pública. El trabajo se basa en una metodología de estudio de caso. El caso es una experiencia de diálogo y generación de consensos para proponer recomendaciones orientadas hacia la adopción de una PEG en la política de CTI en México, es decir se analiza participación pública para el diseño de la política pública. Dicha experiencia está basada en un proyecto realizado por el Foro Consultivo Científico y Tecnológico (FCCyT) en conjunto con el Consejo Nacional de Ciencia y Tecnología (CO- 
NACYT), el Instituto Nacional de las Mujeres (INMUJERES) y la Organización para la Cooperación y Desarrollo Económico (OCDE). El proyecto lleva por título "Una mirada a la ciencia, la tecnología y la innovación con perspectiva de género. Hacía un diseño de políticas públicas". El objetivo del proyecto fue generar un espacio de diálogo y discusión entre las comunidades científica, académica, gubernamental y empresarial, en torno a los retos y oportunidades que representa la adopción de una PEG en el diseño e implementación de políticas públicas en CTI. Asimismo, se buscó articular los puntos de vista de actores interesados y llegar a un consenso sobre una serie de recomendaciones para la política pública.

Este trabajo se basa en un marco teórico y metodológico sobre la naturaleza de los procesos de diálogo para la formulación de políticas públicas de CTI, desarrollado por la Red temática para mejorar el diálogo entre las comunidades involucradas en las políticas de CTI, financiada por CYTED. Dutrénit, Natera y Suarez (2014), Goñi, Bianco y Puchet (2015), Álvarez et al. (2016) y Dutrénit et al. (2016, 2017) resumen las ideas desarrolladas por esta Red.

Después de esta introducción, la sección 2 analiza el ciclo de la política públicas con PEG, y la relación entre diálogo de las comunidades y etapas del ciclo. La sección 3 describe brevemente tanto las metodologías de diálogos y participación pública, así como la metodología de este trabajo. La sección 4 presenta el caso de diálogo para el diseño de la política de CTI con PEG. La sección 5 discute los resultados de diálogo y su impacto en el diseño de la política pública de CTI. La sección 6 presenta las reflexiones finales.

\section{POLÍTICAS PÚBLICAS CON PERSPECTIVA DE GÉNERO}

Este documento analiza procesos de diálogo de las comunidades de CTI y la adopción de una PEG en las políticas de CTI. En este sentido, se basa en literatura sobre diálogo y participación pública (Brown, 2014; Carsten et al., 2013; Voss et al., 2014) y sobre PEG en las políticas (Fraser \& Honneth, 2006; Harding, 1992; Ortiz et al., 2013).

\subsection{COMUNIDADES, DIÁLOGO Y POLÍTICA PÚBLICA}

Tradicionalmente, las políticas gubernamentales definían las acciones a seguir con un enfoque desde arriba hacia abajo, es decir desde el gobierno hacia la sociedad. Hoy, se ha pasado del concepto de gobierno de arriba hacia abajo a un concepto de gobernanza del sistema con un nuevo estilo de gobierno, distinto del control jerárquico, caracterizado por un mayor grado de cooperación y de interacción entre el gobierno y los actores no estatales (Ortegón Quiñones, 2008). 
Como han argumentado algunos autores, la diferencia entre política gubernamental y pública se encuentra precisamente en la capacidad del público/partes interesadas ${ }^{1}$ de participar en el proceso de toma de decisiones (Aguilar, 1992; Cabrero, 2000; Valenti \& Flores, 2009). Esto ha promovido esfuerzos teóricos y metodológicos centrados en identificar los medios para contribuir a una mayor participación pública en los procesos de toma de decisiones (Chilvers, 2008; Griessler, 2011; Jensen, 2005; Lázaro et al., 2014), lo cual pone sobre la mesa el tema del proceso de diálogo.

¿Diálogo entre quién? entre las partes interesadas, los formuladores de política, los congresistas y otros actores relacionados. ¿Diálogo para qué? Para alimentar la formulación de la política pública. Como señalan Goñi, Bianco y Puchet (2015: 3 y 4)

los procesos de diálogo pueden albergar tanto conflictos resultantes de posiciones e intereses disímiles de los actores como ubicaciones asimétricas en la interacción comunicativa que son resultantes de relaciones de poder o de desiguales distribuciones de recursos entre los participantes. Por tanto, en el estudio de los diálogos debe tenerse en cuenta tanto las posibles fuentes de conflicto como el poder relativo de cada uno de los actores. En particular, se deberá observar la eventual existencia de algún actor con capacidad de imposición o de bloqueo del proceso, la existencia de tendencias en algunos o en todos los demás actores que expresen un acompañamiento disciplinado al mandato de un actor determinado, y el grado de apertura que exhiban los actores con mayor poder relativo para incorporar las sugerencias resultantes del diálogo. El proceso se refiere a cómo en el diálogo se presenta y evoluciona el conflicto, cómo se construyen las posiciones y al grado relativo de fuerza que cada una de ellas adquiere.

En el ámbito de la política de CTI participan un conjunto heterogéneo de actores públicos y privados, que interactúan, pero que tienen diferentes motivaciones, intereses, prioridades y lógicas. Estos actores corresponden a diferentes comunidades y responden a diferentes racionalidades, intereses, prioridades y lógicas. ${ }^{2}$ Más aún, los actores

1 Hay por lo menos tres conceptos interrelacionados: ciudadanos, grupos de interés/partes interesadas (stakeholders), y constituyentes (Crane, Matten \& Moon, 2004). Siguiendo a Dutrénit, Natera y Suárez, (2014), en este trabajo, se usa el concepto de comunidades, las que se definen a partir de individuos, y son el resultado de la interacción de dos procesos conflictivos: (i) la socialización de los individuos; (ii) la formación de redes, asumiendo pertenencia, pero también generando relaciones entre individuos que influyen y condicionan las conductas y formas de actuación de las personas. Algunas de estas comunidades son partes interesadas, ya que pueden verse afectadas por las decisiones que hace el gobierno. En este sentido, se usa indistintamente partes interesadas y comunidades,

2 Dentro de cada comunidad emergen grupos o conjuntos de personas o entidades asociadas que se convierten en actores en la formulación de políticas. 
participan de diferente forma y con distinta intensidad en cada etapa (agenda, formulación, decisión, implementación y evaluación) del ciclo de la política. Crecientemente se discute la inclusión de una amplia gama de actores en todo el ciclo de la política de CTI, incluyendo las fases de diseño, implementación y evaluación. Esta participación abre espacios para un diálogo entre comunidades, de un lado las partes interesadas, y del otro los funcionarios públicos.

Siguiendo a, Dutrénit, Natera y Suárez (2014) y a Dutrénit et al. (2017) en este documento entendemos a las comunidades de CTI como el conjunto de actores en CTI en el que hay un nivel de cohesión, articulación y atributos en común. Las cuatro principales comunidades identificadas dentro de la esfera de la CTI son los sectores: académico, empresarial, público (integrado por organismos gubernamentales y estatales) y otros agentes de la sociedad civil.

La noción de diálogo que se utiliza aquí es estrecha, en el sentido a aquella proporcionada por Cuentas y Méndez (2013), y se entiende como un proceso de interacción genuina mediante el cual los seres humanos se escuchan unos a otros con tal profundidad y respeto que cambian a partir de lo que aprenden. La noción de diálogo público parte de los esfuerzos actuales para conceptualizar los diálogos entre las comunidades de CTI en América Latina (Dutrénit, Natera y Suárez, 2014). Siguiendo a Goñi, Bianco y Puchet (2015):

los procesos de diálogo relativos a las políticas públicas de CTI son, al igual que los del diálogo democrático, auténticos ejercicios de interacción y conflicto. En ellos cada uno de los participantes aprende e internaliza argumentos de los demás sosteniendo su identidad y está ubicado, desde la perspectiva comunicativa, en una posición resultante del poder o de las capacidades que tiene. Los participantes son actores que emergen de distintas comunidades de agentes de las actividades de CTI. Tienen, por lo tanto, una relación de representación con su comunidad y, a su vez, pertenecen a organizaciones académicas, productivas, gubernamentales o de la sociedad civil que los dotan de diferentes grados de poder y de distintas capacidades.

Boekholt y den Hertog (2004) destacan que la participación de las partes interesadas en el ciclo de la política en los Países Bajos ha mostrado un conjunto de aspectos positivos y otros negativos. Entre los aspectos positivos destacan:

- aumenta la orientación al usuario de las políticas y en consecuencia su eficacia;

- promueve una mayor transparencia en las reglas del juego;

- despolitiza algunas decisiones controvertidas; 
- evita conflictos entre territorios o departamentos gubernamentales; y

- facilita la creación de redes entre las diferentes partes interesadas.

Entre los aspectos negativos señalan que:

- alarga el proceso de toma de decisiones;

- aumenta los costos de transacción de la formulación de políticas; $y$

- tiene el riesgo de que la composición de las partes interesadas pueda sesgarse en favor de determinadas partes interesadas o posiciones.

En América Latina existen un conjunto de organismos de asesoría y consulta para alimentar el proceso de diseño, implementación y evaluación de la política de CTI. El más antiguo data de 1999 y el más reciente fue creado en 2005. Algunas de estos organismos son:

- Foro Consultivo Científico y Tecnológico (FCCyT), México.

- Consejo Nacional de Innovación para la Competitividad (CNIC), Chile.

- Centro de Gestión y Estudios Estratégicos (CGEE), Brasil.

- Foro Nacional Internacional, Perú.

- Fundación Comisión Asesora en Alta Tecnología (CAATEC), Costa Rica.

Todos estos organismos cumplen la función de consulta con las comunidades, y por lo tanto promueven el diálogo en el ámbito de las políticas de CTI, pero se diferencian en el énfasis que asignan a otras funciones desarrolladas. De acuerdo a Dutrénit (2014), las funciones importantes en todos los organismos son: ser un órgano de consulta de diferentes actores (gobierno, comunidades de CTI); dar respuesta a demandas de las agencias de CTI; y constituirse como un think tank para la estrategia de CTI. Estos organismos de asesoría y consulta también llevan a cabo funciones de articulación entre actores, cabildeo y persuasión, y generación de indicadores.

\subsection{LA PERSPECTIVA DE GÉNERO EN LAS POLÍTICAS PÚBLICAS}

Para llevar a cabo el objetivo de este artículo es necesario aclarar algunos conceptos en torno al género y la PEG. La igualdad es un principio 
universal que establece la igualdad de derechos y oportunidades entre mujeres y hombres. Para poder lograrla se debe reconocer la existencia de desigualdad y las diferencias entre ciertos grupos. La atención de estas especificidades es lo que da lugar a la equidad como principio de justicia. Esto implica un trato diferenciado de grupos específicos de mujeres y de hombres para corregir desigualdades de origen por medio de las acciones de la política pública (INMUJERES, 2013).

El concepto de género es una categoría explicativa que da cuenta del proceso social y discursivo que construye la diferencia entre los sexos, así como de las representaciones de lo femenino y masculino (INMUJERES, 2008; citado por Ortiz et al. 2013). La categoría de género tiene diferentes interpretaciones como herramienta teóricometodológica, como manera de reinterpretar la ciencia y el mundo (Muñiz, 2013), o como perspectiva crítica que visibiliza las relaciones de poder y procesos desiguales.

Con base en lo anterior, la igualdad de género, según Cozzens (2008), sería un punto ideal en que tanto hombres como mujeres pueden alcanzar sus potencialidades. La contribución de la literatura de género en la discusión de las políticas públicas ha sido visibilizar las relaciones de poder, buscar un mayor equilibrio de género en la toma de decisiones, problematizar la clásica división entre la esfera pública y privada para visibilizar las relaciones de desigualdad en el ámbito familiar, cuestionar la objetivación de los sujetos a los que va dirigida la política, y disputar los valores universalistas que son transferidos e integrados en las políticas (Ackerly, 2000; Fraser \& Honneth, 2006; Harding, 1992). Por ello, una PEG en las políticas públicas implica la promoción de políticas incluyentes desde diferentes epistemologías, voces, miradas y experiencias que se armonicen con acciones hacia la igualdad.

La PEG es la herramienta teórica-metodológica que permite generar una comprensión de la compleja problemática que representan las asignaciones sociales en torno al sexo y, con ella, una reflexión respecto de cómo se pueden transformar dichas asignaciones, de modo que tejan una sociedad más inclusiva. La PEG ofrece las herramientas para analizar la desigualdad social, e identificar las inequidades sobresalientes que pueden ser abordadas como un tema de política pública.

Como argumenta Miyares (2013), hay cuatro rasgos indispensables que definen la ciudadanía plena en una sociedad democrática e incluyente: la participación, la capacidad de elegir y la capacidad de ser electas, la distribución de la riqueza y el reconocimiento. Las mujeres sufren tanto de desigualdad (no se valora de igual forma el trabajo productivo que el reproductivo, por ejemplo), como de discriminación por la valoración inferior que se hace de su género: las 
normas y símbolos culturales privilegian los rasgos asociados con la masculinidad.

Esto mismo sucede en el terreno de la CTI, del cual las mujeres habían sido excluidas por mucho tiempo, o no consideradas cabalmente. Aunque han accedido a recursos y conquistado espacios políticos y laborales dentro del sector, aún falta mucho por lograr en términos de reconocimiento de sus capacidades. No es suficiente con que haya presencia femenina en cuanto a números, sino que se redefina la ciencia y la tecnología como espacios igualmente abiertos a hombres y mujeres. En el marco de un Estado liberal, se considera que la política pública es el conjunto de instrumentos adecuado para corregir estas desigualdades a través de acciones afirmativas y perspectiva de género desde el diseño hasta la evaluación de la política pública.

El compromiso con la incorporación de la PEG en el proceso de políticas públicas ha sido un objetivo creciente de los gobiernos del mundo gracias al impulso de los movimientos de mujeres o personas que asumen liderazgos o participan en la transformación social de género desde mitad del siglo XX. En América Latina y el mundo este proceso adquiere una dinámica mayor en los últimos veinte años a partir de la Conferencia Internacional de la Mujer en Beijing en 1995, que impulsa el enfoque conocido como transversalidad de género. Uno de los mayores aciertos de este proceso ha sido la búsqueda por incorporar en los distintos niveles de gobierno, en sus acciones, planes y programas la PEG, mediante lo que se define como transversalidad de género. Según el Consejo Económico y Social de las Naciones Unidas (1997), transversalidad es definida como: "el proceso de evaluar la implicación que tiene para hombres y mujeres, cualquier acción que se planifique, incluyendo las de tipo legislativo, las políticas o los programas de todas las áreas y a todos los niveles". La transversalidad involucra una visión basada en la comprensión y búsqueda de aplicación de que se requiere que la igualdad y la equidad figuren en la acción de gobierno. Debido a la actualidad de este proceso es necesario comprender cuál o cuáles son los enfoques de transversalidad vigentes y adoptados por los gobiernos, y cuál es el grado de diálogo con los movimientos de mujeres y sus aliadas e interlocutoras, personas afines o expertos(as).

\section{LA INSTITUCIONALIDAD DE LA PEG EN MÉXICO}

En enero de 2001 se aprobó la Ley de Creación del Instituto Nacional de las Mujeres (INMUJERES) en México. A través de INMUJERES se opera el Programa Nacional para la Igualdad de Oportunidades y no Discriminación contra las Mujeres (PROIGUALDAD). Este programa 
obedece a la obligación señalada en el plan nacional de desarrollo 2012-2018 de contar con una estrategia transversal de PEG en todos los programas, acciones y políticas de gobierno.

Como una acción transversal, la aplicación de la PEG es adoptada en el programa de PROIGUALDAD, pero también se desarrolla un marco jurídico que permite avances significativos en la materia. Actualmente en el país se cuenta con un conjunto de leyes a favor de la igualdad de género en la administración pública federal:

- Constitución Política de los Estados Unidos Mexicanos (reforma a los Artículos $1^{\circ}, 4^{\circ}$ y $26^{\circ}$ ).

- Ley General para la Igualdad entre Mujeres y Hombres.

- Los artículos 2, 9 y 14 de la Ley de Planeación plantean la incorporación de la perspectiva de género en la planeación nacional.

- Ley Federal del Trabajo.

- Ley Federal para Prevenir y Eliminar la Discriminación.

- Ley General de Acceso de las Mujeres a una Vida Libre de Violencia.

- Ley General para Prevenir, Sancionar y Erradicar los Delitos en Materia de Trata de Personas y para la Protección y Asistencia a las Víctimas de estos Delitos.

- Ley para la Protección de los Derechos de Niñas, Niños y Adolescentes.

Asimismo, en junio del 2013 se realizaron varios cambios a la Ley de Ciencia y Tecnología, creada en el 2002, que regula al sector de CTI:

- Se añadió la Fracción VIII al Artículo 2 de la Ley de Ciencia y Tecnología para "promover la inclusión de la perspectiva de género con una visión transversal en la ciencia, la tecnología y la innovación, así como una participación equitativa de mujeres y hombres en todos los ámbitos del Sistema Nacional de Ciencia, Tecnología e Innovación".

- Se reforma la fracción V del artículo 12, que señala: "Las políticas instrumentos y criterios con los que el gobierno federal fomente y apoye la investigación científica, el desarrollo tecnológico y la innovación deberán buscar el mayor efecto benéfico, de estas actividades, en la enseñanza y el aprendizaje de la ciencia y la tecnología, en la calidad de la educación, particularmente de la educación superior, en la vinculación con el sector productivo 
y de servicios, así como incentivar la participación equilibrada y sin discriminación entre mujeres y hombres y el desarrollo de las nuevas generaciones de investigadores y tecnólogos".

- Se agregó un tercer párrafo al artículo 14 que ahora señala: "En la medida de lo posible el sistema deberá incluir información de manera diferenciada entre mujeres y hombres a fin de que se pueda medir el impacto y la incidencia de las políticas y programas en materia de desarrollo científico, tecnológico e innovación".

- Se reformó el primer párrafo del artículo 42, que ahora dice: "El gobierno federal apoyará la investigación científica y tecnológica que contribuya significativamente a desarrollar un sistema de educación formación y consolidación de recursos humanos de alta calidad en igualdad de oportunidades y acceso entre mujeres y hombres.

A pesar de los cambios en la legislación, y de la incorporación de la PEG en el plan nacional de desarrollo, ha habido un lento proceso de incorporación de la PEG en la política pública, particularmente en los programas de gobierno, incluyendo a la política de CTI.

\section{NOTAS METODOLÓGICAS}

\subsection{MECANISMOS DE PARTICIPACIÓN CIUDADANA}

El interés en la participación pública en CTI ha abierto una amplia discusión sobre los mecanismos de participación y su impacto en las políticas de CTI (Jasanoff, 2003). Los mecanismos desarrollados por la Danish Board of Technology se convirtieron en un punto de referencia a nivel internacional. Los mecanismos se pueden clasificar en tres grupos según su orientación: 1) los centrados en la participación pública que tienen como objetivo promover la discusión y debate público de una determinada audiencia (Abelson et al., 2003); como instrumentos específicos en esta categoría destacan, por ejemplo: las audiencias públicas, que son presentaciones de expertos y actores interesados en un evento abierto al público y a la prensa, así como grupos focales que son discusiones abiertas de 6 a 12 participantes; 2) los orientados a la realización de actividades consultivas a gran escala o de asesoría para el gobierno que tienen como principal objetivo informar acerca de las nociones, percepciones, deseos y preocupaciones de los involucrados, así como guiar el proceso de toma de decisiones de los formuladores de política (Abelson et al., 2003; Rowe, 2005); en esta categoría destacan instrumentos como las encuestas de opinión y las conferencias para votar sobre una determinada controversia o 
problema; y 3) los mecanismos generadores de consenso que tienen como objetivo identificar las necesidades y preferencias de los ciudadanos, así como promover consensos en la toma de decisiones sobre determinadas controversias o problemas (Jensen, 2005; Lázaro et al., 2014; Mejlgaard, 2009); en esta categoría destacan como instrumentos el congreso de consensos que se basa en reuniones con expertos, discusiones y votaciones para la generación de consensos; las observaciones y conclusiones son presentadas a los medios y públicos en general. Otro instrumento es el de juicios ciudadanos que consta en una reunión de un grupo de 12 a 25 de actores seleccionados arbitrariamente que representen un microcosmo de su comunidad. Hay reuniones en diferentes días para debatir sobre un asunto de política.

Los mecanismos de participación pública no garantizan ni que haya diálogo ni la mejora en la toma de decisiones o en las prácticas públicas en la gobernanza de la CTI dentro de un sistema político vertical, donde existen pocos canales y experiencias de participación pública. En este sentido, uno de los problemas a que se enfrentan países como México es la manera de promover la participación pública, generar consenso entre las partes interesadas, y traducir las propuestas en un lenguaje institucional/gubernamental que sea coherente con la utilizada en los programas de gobierno existentes. De esta forma se podría conectar más fácilmente los esfuerzos y las necesidades de las comunidades. Más aún, se requiere un lenguaje que ayude a definir las necesidades para facilitar el diálogo.

\subsection{ESTUDIO DE CASO: CONGRESO DE CONSENSOS Y AUDIENCIA PÚBLICA SOBRE PEG EN LAS POLÍTICAS DE CTI}

Esta investigación se basa en una metodología cualitativa; se analiza un caso de participación ciudadana, a partir de un diálogo que se organiza en torno a la combinación de dos mecanismos de participación pública: un congreso de consensos y una audiencia pública. La evidencia y los datos recolectados provienen de un proyecto de diálogo llevado a cabo entre septiembre de 2013 y abril de 2014 en la Ciudad de México, titulado "Una mirada a la ciencia, tecnología e innovación con perspectiva de género: hacia un diseño de políticas públicas". El proyecto buscaba realizar una consulta para informar acerca de las preocupaciones de los involucrados en el tema de la PEG, llegar al consenso sobre algunas propuestas que guiaran el proceso de toma de decisiones de los formuladores de política de CTI. Por ello, el instrumento principal utilizado es un congreso de consensos, pues se basa justamente en la discusión de un problema para buscar un consenso en torno a medidas de política que son necesarias, en este caso como incorporar una PEG en la política de CTI, y emitir recomendaciones 
para guiar la toma decisiones de los formuladores de política (Guston, 1999). Por ello, se combina el congreso de consensos con la audiencia pública, para completar un diálogo de mayor alcance.

Este proyecto se desarrolló en seis etapas: i) la integración de un grupo de trabajo de veintidós expertas; ii) la elaboración de un documento de trabajo; iii) la definición de un acuerdo sobre cinco temáticas y la elección de facilitadoras; iv) la organización de una audiencia pública y la aprobación de un conjunto de recomendaciones; v) la publicación en la prensa de once recomendaciones; y vi) la implementación de acciones de seguimiento.

Las fuentes de evidencia recolectadas fueron de diversa índole: (i) documentos nacionales e internacionales sobre el tema de la PEG; (ii) una serie de documentos producidos en el marco del proyecto, como el documento de trabajo; (iii) minutas de las reuniones preparativas; (iv) las ponencias realizadas por expertas en la audiencia pública; (v) los lineamientos y conclusiones de las mesas de diálogo del proyecto; y (vi) las transcripciones de las cinco mesas de diálogo y de la audiencia pública del proyecto, que recogían el punto de vista de todos los participantes. Para analizar estas fuentes de evidencia, se procedió a agrupar y organizar toda la información.

Posteriormente, con base en una estrategia de análisis de contenido y del discurso, los documentos se exploraron, codificaron y categorizaron con la ayuda de un software de análisis cualitativo. El objetivo de esta estrategia es identificar los segmentos relevantes de los datos a través de categorizarlos con la ayuda de códigos para identificar patrones en los datos, relacionar las categorías y generar nuevas dimensiones y explicaciones acerca del fenómeno. Durante el proceso de análisis, las reflexiones, dudas, posibles explicaciones y nuevas dimensiones del fenómeno fueron escritos en memorándums.

\section{EL CASO: DISEÑO DE POLÍTICAS PÚBLICAS DE CTI CON PEG}

El caso es una experiencia de diálogo basada en un congreso de consensos y audiencia pública para proponer recomendaciones orientadas hacia la adopción de una PEG en la política de CTI en México, es decir se analiza participación pública para el diseño de la política pública. Dicha experiencia está basada en un proyecto liderado por el FCCyT en conjunto con el CONACYT, el INMUJERES y la OCDE. El proyecto lleva por título "Una mirada a la ciencia, la tecnología y la innovación con perspectiva de género. Hacía un diseño de políticas públicas". El objetivo del proyecto fue generar un espacio de diálogo y discusión entre las comunidades científica, académica, gubernamental y empresarial, en torno a los retos y oportunidades que representa la adopción de una PEG en el diseño e implementación de políticas públicas en CTI. 
Asimismo, articular los puntos de vista de actores interesados y llegar a un consenso sobre una serie de recomendaciones para la política pública.

El FCCyT es un organismo de asesoría y consulta para alimentar el proceso de diseño, implementación y evaluación de la política de CTI. De acuerdo al artículo 36 de la Ley de Ciencia y Tecnología de 2002 de México, se crea el FCCyT, como un órgano autónomo de consulta permanente del Poder Ejecutivo, el Consejo General de Investigación Científica, Desarrollo Tecnológico e Innovación y la Junta de Gobierno de CONACYT. De acuerdo a esta normativa, el FCCyT tiene la función de ser un organismo asesor autónomo; promover la expresión de la comunidad científica, académica, tecnológica y del sector productivo para la formulación de propuestas en materia de políticas y programas; así como ser un órgano de expresión y comunicación de las diversas comunidades con autoridades federales. El FCCyT está integrado por una Mesa Directiva conformada por instituciones clave del sector académico y empresarial. Un coordinador general es elegido cada dos años para liderar las actividades del FCCyT.

El FCCyT tiene experiencia en realizar investigaciones, estudios, propuestas y análisis que después se entregan a los tomadores de decisiones para convertirlos en instrumentos de política o programas. ${ }^{3}$ En las instalaciones del FCCyT se llevan a cabo reuniones entre las diferentes comunidades involucradas en CTI para cabildear políticas. Ha jugado un papel determinante, por ejemplo, en convocar a las comunidades de CTI para hacer propuestas y discutirlas en la formulación del Programa Especial de Ciencia, Tecnología e Innovación (PECITI) en los años 2002-2006, 2008-2012 y 2014-2018.

Justo diez años después de su creación, en el 2012 el FCCyT fue por primera vez coordinado por una mujer. Esto coincidió con una efervescencia en el discurso público sobre la necesidad de implementar políticas públicas con PEG en el sector de CTI, materializada en la introducción de una estrategia transversal sobre PEG en el Plan Nacional de Desarrollo 2013-2018. Estos dos factores despertaron un gran interés sobre todo desde la comunidad académica para visibilizar la dimensión de la problemática y levantar el tema para su potencial discusión entre las diferentes comunidades. Asimismo, el interés del FCCyT en el tema se conectó también con discusiones a nivel internacional sobre mecanismos de diálogo y participación ciudadana en el proceso de diseño y formulación de políticas públicas (Jensen, 2005; Nupia \& Martínez, 2015).

En agosto de 2013, el FCCyT materializó su cometido de poner sobre la mesa de discusión las políticas de públicas con PEG en el

3 Véase <http://www.foroconsultivo.org.mx/FCCyT3/index.php/que-es-el-foro-consultivo $>$. 
proyecto: "Una mirada a la ciencia, tecnología e innovación con perspectiva de género: hacía un diseño de políticas públicas". El objetivo fue generar un espacio de diálogo y discusión entre las comunidades científica, académica, gubernamental y empresarial, en torno a los retos y oportunidades que representa la adopción de una PEG en el diseño e implementación de políticas públicas en CTI, así como en el fortalecimiento de los procesos democráticos inclusivos que se llevan a cabo en este sector, y la forma como se debe atender a los problemas locales de la igualdad de género en CTI.

La metodología del proyecto estuvo inspirada en los mecanismos de participación ciudadana, denominados también diálogos públicos para la toma de decisiones. Se escogieron como instrumentos para promover el diálogo un congreso de consensos en combinación con una audiencia pública, para discutir un tópico e impulsar decisiones que puedan guiar a los hacedores de política.

Las comunidades de CTI participantes fueron: académica (investigadores de Instituciones de Educación Superior, y de Centros de Investigación públicos y privados), gubernamentales (titulares de Consejos Estatales de Ciencia y Tecnología, CONACYT, INMUJERES, incluyendo al sector legislativo), empresarial (Cámaras empresariales), y organismos no gubernamentales de la sociedad civil. El proyecto se dividió en seis fases.

\section{FASE I: INTEGRACIÓN DE UN GRUPO DE TRABAJO DE EXPERTAS}

Se conformó un grupo de trabajo de expertas en el tema de género de la Universidad Nacional Autónoma de México (UNAM), la Universidad Autónoma Metropolitana (UAM), la Universidad del Claustro de Sor Juana y la Universidad Iberoamericana, a las que se sumaron líderes del proyecto del FCCyT, INMUJERES, CONACYT y OCDE. Las expertas fueron convocadas por sus publicaciones en el tema, buscando un equilibrio institucional. Desde septiembre hasta diciembre de 2013, este grupo llevó a cabo cuatro reuniones con el objetivo de dimensionar la problemática y discutir la estructura de la audiencia pública a llevarse a cabo el 6 de diciembre de 2013, que sería el principal producto del proyecto.

\section{FASE II: ELABORACIÓN DE UN DOCUMENTO DE TRABAJO}

El grupo de trabajo acordó realizar un documento que brindará un diagnóstico de la problemática de incorporar una PEG en las políticas públicas de CTI, así como un glosario de términos relevantes y dimensiones del análisis necesarias para llevar a cabo una evaluación de dicha problemática. El documento llevo por título el mismo nombre del proyecto: "Una mirada a la Ciencia, la Tecnología e Innovación con Perspectiva de Género: Hacía un Diseño de Políticas 
Públicas (Ortiz et al., 2013). El trabajo consta de tres partes. La primera parte brinda un panorama general de la PEG en el sector de CTI, además de que identifica las principales problemáticas y plantea recomendaciones a nivel internacional. La segunda parte identifica los antecedentes legales y definiciones del género en el escenario jurídico y político actual, así como resume las principales estadísticas que visibilizan la problemática de las mujeres en la educación básica, superior e investigación. En la última parte se presentan algunas conclusiones y un glosario de términos.

El documento aclara la diferencia entre conceptos como igualdad y equidad. De acuerdo a este, la igualdad se refiere a un principio que establece la igualdad de derechos y oportunidades entre hombres y mujeres tomando como referencia la desigualdad, así como la diferencia de individuos y sus entornos locales. Por su parte la equidad es un principio de justicia. Esto implica entonces aspirar a la igualdad a través de la equidad (Ortiz et al., 2013: 10). El documento de trabajo jugó un importante papel para brindar una base común de conceptos y estadísticas para alimentar la dinámica de las mesas temáticas de diálogo que se establecieron para abordar aspectos específicos.

\section{FASE III: DEFINICIÓN DE CINCO TEMÁTICAS Y CONFORMACIÓN DE ME- SAS DE DIÁLOGO}

La siguiente etapa del proyecto fue la elección de temáticas, la integración de mesas de trabajo y la redacción de una primera propuesta de recomendaciones de política. De acuerdo a las reuniones del grupo de trabajo, se acordó hacer mesas de trabajo en las siguientes cinco temáticas: la PEG en la educación superior; una mirada a la investigación con PEG; la PEG en la dirección de las instituciones de CTI; la PEG en la cultura organizacional e innovación; y la PEG en la implementación de políticas públicas. Se acordó también invitar a expertas en dichos temas para que facilitarán el proceso, redactaran un conjunto de recomendaciones, moderaran el diálogo durante la audiencia pública, así como hicieran una relatoría de las sesiones durante la audiencia pública. Las facilitadoras actuaron como articuladoras de ideas, opiniones, propuestas y recomendaciones. Al final de la discusión elaboraron las conclusiones de cada mesa de trabajo. Los productos clave de esta fase fueron una primera propuesta de recomendaciones de política de cada una de las mesas de trabajo.

\section{FASE IV: ORGANIZACIÓN DE UNA AUDIENCIA PÚBLICA}

El evento final consistió en una audiencia pública que tuvo un doble propósito: discutir las propuestas de las recomendaciones emanadas de las mesas de trabajo de las expertas y entablar un diálogo con un público 
más amplio, para acordar un conjunto de recomendaciones finales. El evento se llevó en a cabo en la Universidad del Claustro de Sor Juana, como lugar simbólico de la participación de las mujeres en la vida académica ${ }^{4}$. En la primera parte de la audiencia tuvieron lugar conferencias magistrales que analizaron el marco nacional e internacional en cuánto a la problemática del género, además de brindar los elementos conceptuales y legales en relación al género en las políticas públicas en México. Posteriormente, tuvieron lugar cinco mesas de diálogo simultáneas, que discutieron las propuestas emanadas de las mesas de trabajo de las expertas y ampliaron las propuestas. Cada participante podía elegir a cuál entrar. La dinámica de las mesas de diálogo consistió, como procedimiento general, en que se leyeron las propuestas que emanaron de las mesas de trabajo de las expertas, y se abrió la discusión para retroalimentar el documento con el objetivo de profundizar su discusión o bien incorporar nuevas problemáticas o recomendaciones. Sin duda, uno de los principales retos de las dinámicas de las mesas de diálogo fue condensar en breves propuestas la problemática, experiencias y diversas propuestas discutidas.

Finalmente se realizó una audiencia pública, donde las facilitadoras de las mesas de diálogo presentaron las propuestas y recomendaciones de política consensuadas. En el evento participaron alrededor de 340 miembros de la comunidad académica (investigadoras e investigadores de diferentes instituciones de educación superior mexicanas), empresarial (la Cámara Nacional de la Industria de Transformación), sector público (CONACYT e INMUJERES), organismos internacionales (OCDE), otros miembros de la sociedad civil interesados en el tema, así como medios de comunicación.

\section{FASE V: PUBLICACIÓN EN LA PRENSA DE UN CONJUNTO DE 11 RECOMENDACIONES}

Al término de la audiencia pública, el FCCyT realizó una reunión de evaluación que permitió reflexionar sobre las lecciones aprendidas y la riqueza del evento en términos de la generación de entrelazamientos y canales de comunicación entre las comunidades para seguir cabildeando las recomendaciones. Posteriormente el grupo de trabajo a través de diversas discusiones y sesiones elaboró un listado de recomendaciones por temática y un listado general de 11 recomendaciones.

4 Sor Juana Inés de la Cruz fue una poeta, dramaturga, filósofa, ensayista y monja mexicana del siglo XVII. Desafió las costumbres de su época y produjo una amplia e influyente obra en un ambiente hostil para el desarrollo intelectual de las mujeres. Toda su obra es un acto de afirmación de la libertad de pensamiento y de la dignidad de la mujer. 
El 8 de marzo de 2014 se publicó en los principales periódicos de circulación nacional el conjunto de 11 recomendaciones como producto final del proyecto (Tabla 1). Después de la publicación, estas recomendaciones fueron entregadas de manera formal mediante un oficio a funcionarios públicos e instituciones clave, como por ejemplo los titulares de las instituciones de CTI, principales secretarías de estado involucradas en CTI y legisladores.

\section{Tabla 1. Recomendaciones finales del proyecto}

1. Que se revisen y actualicen los reglamentos institucionales a fin de que incluyan las modificaciones que por ley se establecen en cuanto a igualdad de género.

2. Que se promueva la presencia de mujeres en cargos de toma de decisión y se procure que en las comisiones evaluadoras, congresos, paneles y demás eventos académicos 0 institucionales exista representatividad de ambos sexos.

3. Que se consolide la perspectiva de género (PEG) como campo de conocimiento inter y transdisciplinario en todas las instituciones del sector.

4. Que se revisen los planes de estudio para que la bibliografía, programas y métodos de enseñanza recojan las contribuciones de las mujeres, así como los resultados de las investigaciones sobre el género.

5. Que se propicie que empresas privadas e instituciones públicas establezcan un compromiso con las iniciativas de certificación en igualdad de género, en concreto con el modelo de igualdad laboral. 6. Que se solicite a las cámaras de diputados y senadores armonizar los reglamentos y legislación del sector de CTI de manera que se logren alinear las nociones de igualdad entre mujeres y hombres en las diversas leyes.

7. Que se instrumente un observatorio ciudadano para monitorear los avances en la igualdad de oportunidades y la no discriminación para mujeres y hombres.

8. Que se promueva el uso de imágenes asertivas e igualitarias de la mujer y del hombre en mensajes de difusión masiva, para modificar los estereotipos de género de manera que disminuyan las brechas y se elimine la segregación por áreas de estudio.

9. Que se utilice un lenguaje no sexista e incluyente.

10. Que se fortalezcan los mecanismos de evaluación con una perspectiva de género.

11. Que todos los datos institucionales, así como producción de estadísticas, garanticen la desagregación por sexo, lo cual permitirá diseñar y monitorear la política nacional de igualdad de género en todos los ámbitos y con las desagregaciones temáticas y geográficas necesarias.

Fuente: minutas del evento, FCCyT.

\section{FASE VI: RESULTADOS Y SEGUIMIENTO}

Existen al menos cuatro resultados exitosos del proyecto:

1) La generación de consenso entre las comunidades participantes en torno a las once recomendaciones de políticas específicas listadas en la tabla 1.

2) La difusión pública de las recomendaciones en los medios y la entrega a autoridades de instituciones de sector de CTI. Durante ocho meses se hizo seguimiento a las recomendaciones enviadas a las instituciones. Dando respuesta a los oficios de las instituciones que lo contestaron. 
3) La generación de recomendaciones puntuales a CONACYT y la creación de un grupo de trabajo que diera seguimiento a las propuestas hechas. Este grupo de trabajo, coordinado por el FCCyT, elaboró un conjunto de propuestas puntuales referidas a la incorporación de la PEG en el Sistema Nacional de Investigadores, las que se listan en la tabla 2. Las propuestas buscaban que CONACYT reconociera los estudios de género como un campo de conocimiento interdisciplinario, lo que ayudaría a empoderar y visibilizar el conocimiento producido, así como evaluar mejor al personal investigador que trabaja en esta área de conocimiento.

\title{
Tabla 2 Propuesta de incorporación de elementos para una PEG en el Sistema Nacional de Investigadores
}

\begin{abstract}
1. En las áreas de Humanidades y Sociales (Áreas IV y V), los estudios de género deben de reconocerse como un campo de conocimiento (no una disciplina). Esto es importante porque el enfoque de estudios de género es distinto desde las Ciencias sociales que, desde las Humanidades, pero en ambas áreas el género es un campo de conocimiento que permite producir investigación de calidad que forma un cuerpo teórico.

2. Acuerdo: Que se incorpore en el formato del CVU del SNI, en el catálogo que se despliega para las áreas IV y V, sobre campos de conocimiento, el correspondiente a "Estudios de género" para identificar a quienes tienen este tema como principal línea de investigación.

3. En el área de Ciencias Biológicas y de las Salud (Área III), el cruce con temas de género es sumamente relevante y resulta ser un enfoque para la investigación, aunque no sea de carácter teórico/analítico como en caso de las Ciencias Sociales y las Humanidades.

4. Acuerdo: Que se incorpore en el formato del CVU del SNI, en el catálogo que se despliega para el área III, sobre campos de conocimiento, el correspondiente a "Salud y Género", para identificar a quienes tienen este, como una de sus líneas principales de investigación.

5. Adicionalmente, hay mucha investigación que trata cuestiones de género en diversos contextos y que se da en las demás áreas del conocimiento (Áreas I, II, VI y VII). Estas investigaciones por lo general son interdisciplinarias e incluyen los estudios de género, entre otras disciplinas. Es deseable que dichos productos de investigación sean evaluados por una comisión multi/inter/transdisciplinaria del SNI, que deberá contar con expertos en el tema de género.
\end{abstract}

Fuente: oficio del FCCyT enviado a la Dra. Julia Tagüeña, Directora Adjunta de Desarrollo Científico de Conacyt, el 17 de junio de 2014.

4) El fortalecimiento de una red académica e interinstitucional que asumió la función de dar el seguimiento de actividades para promover políticas públicas con PEG. Las académicas de esta red, principalmente la red "Mujer y Ciencia", asumieron el liderazgo y le dieron continuidad al trabajo realizado anteriormente. De esta forma mantuvieron vivo el tema a través de realizar talleres para elaborar y dar seguimiento a las propuestas emanadas. En particular se organizó el "Taller Superando la inequidad. Acciones para Impulsar y Reconocer las Investigaciones de Ciencia y Género 
en México", realizado el 27 de octubre del 2015. Las principales recomendaciones se presentan en la Tabla 3, y fueron enviadas a CONACYT.

\section{Tabla 3. Recomendaciones del taller de octubre del 2015}

1. El campo de ciencia y género, incluye investigaciones en:

a.Investigaciones de género de las áreas de las humanidades (IV) y las ciencias de sociales (V); b.Investigaciones de ciencia y género de integrantes de las áreas I, II, III, VI y VII del Sistema Nacional de Investigadores (SNI); y c.Investigaciones de género y salud de integrantes de las áreas II, III y VI.

La realización de estas investigaciones podrá ser de tiempo total, parcial u ocasional, dependiendo de las áreas de las ciencias.

2. Se recomienda crear una Subcomité de género para las diferentes áreas del SNI (ver, anexo 1), a fin de reconocer las investigaciones de ciencia y género de todas las áreas de las ciencias reconocidas por este sistema.

3. Continuar con la actualización de la información requerida en el CVU a fin de incorporar información que permita generar indicadores de la productividad de género para la evaluación.

4. Recomendar la obligatoriedad en la visibilidad de información útil para fines de investigación de las bases de datos científicos, tales como el CVU del CONACyT, la ANUIES, Instituciones de Educación Superior (IES), Academias, o Sociedades en seguimiento a las recomendaciones emitidas en el Foro de género FCCyT, 2013.

5. Recomendar a las revistas mexicanas indexadas y reconocidas por el CONACyT el incluir artículos en materia de ciencia y género entre sus temas de interés, a fin divulgar estas investigaciones.

6. Crear fondos para la investigación en el campo de ciencia y género

7. Valoración de la docencia, y en particular la de género en el subsistema de CTI a fin de que la enseñanza de la ciencia en todos los niveles educativos de acuerdo al mandato de la ley incluya la perspectiva de género (PEG).

8. Se recomienda que el CONACyT, el INMUJERES, la ANUIES así como las IES y los CPIs, impulsen una campaña a nivel nacional para modificar los estereotipos de género actualmente incluidos en los libros de la SEP en particular, $y$ en otros documentos del gobierno en general.

9. Armonizar las reformas en materia de perspectiva de género y CTI de las leyes de estatales con las federales

10. Recomendar a las IES la creación de Comisiones de Género (CGe) en cada una de las dependencias de las IES, con representación en sus consejos técnicos y universitarios a fin de impulsar la inclusión de la PEG en los procesos institucionales.

11. Crear instancias científicas especializadas de género en las IES y CPIs, así como en el SNI para el reconocimiento y denuncia en casos de discriminación y/0 acoso.

12. Crear una Comisión de Seguimiento en el CONACyT para observar la instrumentación por parte del subsistema de CTI de las recomendaciones de políticas de CTI con PEG, emitidas en los encuentros de género y CTI convocados por el FCCyT y otras instituciones en el 2013 y 2015

13. Recomendar a los diferentes actores del sector CTI, el revisar y uniformar la semántica de género a fin de llegar a acuerdos.

14. Recomendar al CONACyT, IES y CPIs el elaborar campañas de comportamiento de género para su distribución en medios masivos de comunicación del sector CTI.

15. Se recomienda al sector CTI, analizar con PEG los criterios de inclusión para la pertenencia a los diferentes niveles del SNI de las diferentes áreas, así como la evolución cronológica de los mismos en cada área.

Fuente: minutas del "Taller Superando la inequidad. Acciones para Impulsar y Reconocer las Investigaciones de Ciencia y Género en México”. 
La Tabla 4 sintetiza la participación que jugó cada una de las comunidades que participaron en el diálogo, y sus actores, y la figura 1 sintetiza los principales hechos de la evolución del proceso de diálogo y del contexto en el cual se realizó.

Tabla 4. Comunidades y actores del proceso de diálogo.

\begin{tabular}{|c|c|c|}
\hline Comunidades y actores & Tipo de actor & Tipo de participación \\
\hline \multicolumn{3}{|l|}{ Comunidad académica } \\
\hline $\begin{array}{l}\text { Universidad Autónoma } \\
\text { Metropolitana (UAM). } \\
\text { Instituto Politécnico Nacional } \\
\text { (IPN). } \\
\text { Universidad del Claustro de Sor } \\
\text { Juana. } \\
\text { Universidad Iberoamericana } \\
\text { y otras varias instituciones de } \\
\text { educación superior y centros de } \\
\text { investigación. }\end{array}$ & $\begin{array}{l}\text { Instituciones de educación } \\
\text { pública e investigación. }\end{array}$ & $\begin{array}{l}\text { Integrantes del grupo de trabajo } \\
\text { que conformaron } 22 \text { instituciones } \\
\text { junto con instituciones del sector } \\
\text { público y empresarial. } \\
\text { Elaboración de un documento de } \\
\text { trabajo y un glosario con términos } \\
\text { relevantes y dimensiones de } \\
\text { análisis necesarias. } \\
\text { Definición de cinco temáticas y la } \\
\text { elección de facilitadoras para la } \\
\text { audiencia pública. } \\
\text { Organización de la audiencia } \\
\text { pública } \\
\text { Discusión por grupos y } \\
\text { generación de consensos sobre } \\
\text { las propuestas de política. } \\
\text { Implementación de acciones de } \\
\text { seguimiento. }\end{array}$ \\
\hline \multicolumn{3}{|l|}{ Comunidad Empresarial } \\
\hline $\begin{array}{l}\text { Cámara Nacional de la Industria } \\
\text { en Transformación. }\end{array}$ & Asociación de empresas. & $\begin{array}{l}\text { Parte del grupo de trabajo de } \\
\text { expertas. }\end{array}$ \\
\hline \multicolumn{3}{|l|}{ Comunidad del Sector Público } \\
\hline $\begin{array}{l}\text { Consejo Nacional de Ciencia y } \\
\text { Tecnología, CONACYT } \\
\text { Instituto Nacional de las } \\
\text { Mujeres, INMUJERES } \\
\text { Organización para la } \\
\text { Cooperación Económica y el } \\
\text { Desarrollo, OCDE. }\end{array}$ & $\begin{array}{l}\text { Gobierno Federal e Organización } \\
\text { Internacional Gubernamental. }\end{array}$ & $\begin{array}{l}\text { Líderes del proyecto y parte del } \\
\text { grupo de trabajo de expertas. }\end{array}$ \\
\hline \multicolumn{3}{|l|}{ Comunidad de la Sociedad Civil } \\
\hline $\begin{array}{l}\text { Foro Consultivo Científico y } \\
\text { Tecnológico (FCCyT). }\end{array}$ & Asociación Civil. & $\begin{array}{l}\text { Líder del proyecto. } \\
\text { Convocante y promotor del } \\
\text { diálogo. } \\
\text { Organizador y convocante } \\
\text { del grupo de trabajo de } 22 \\
\text { expertas. }\end{array}$ \\
\hline
\end{tabular}



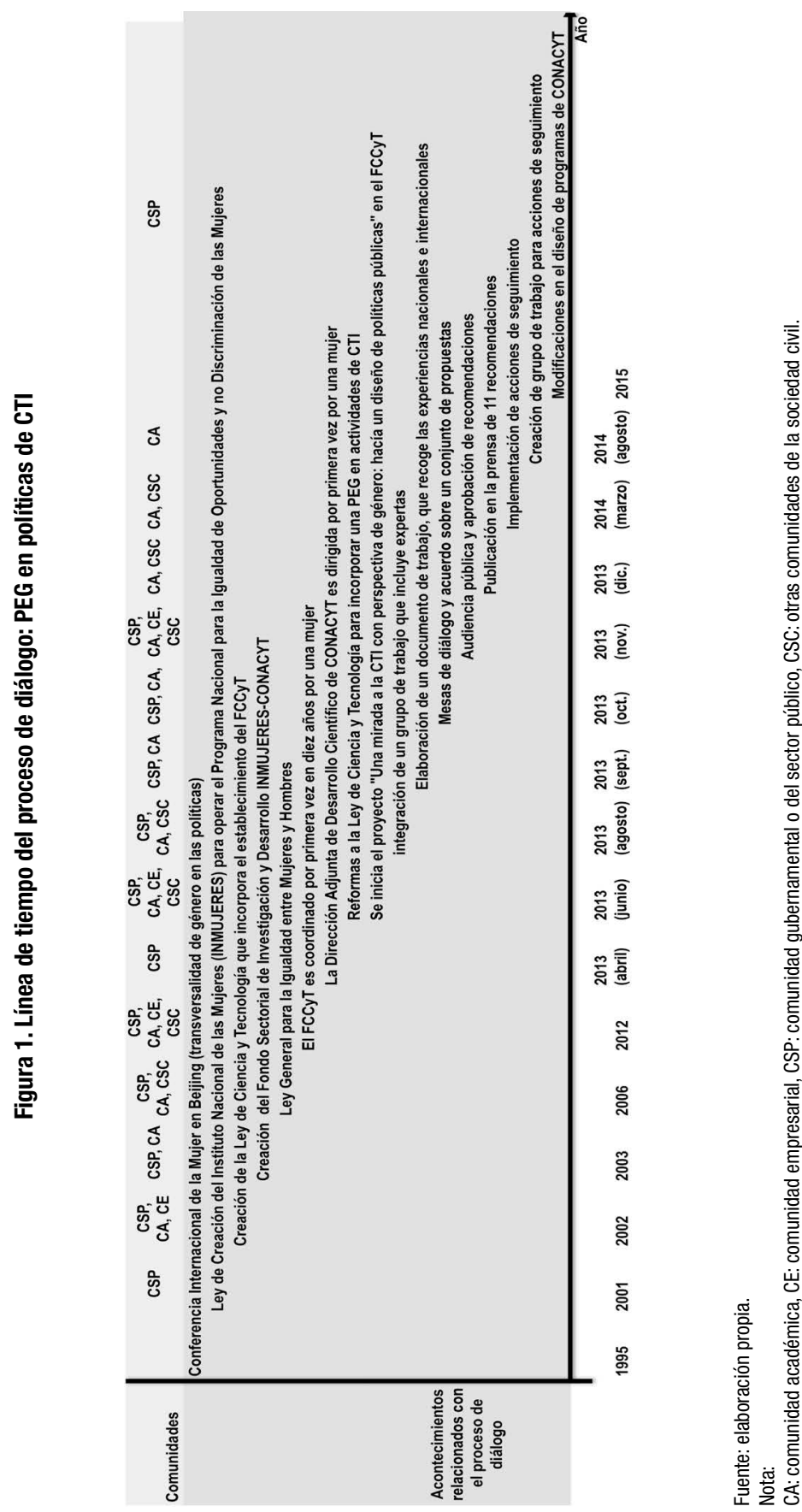


\section{DEL DIÁLOGO A LA INCIDENCIA EN EL DISEÑO DE LAS POLÍTICAS}

El proceso de diálogo analizado en este documento fue exitoso, tanto en términos de la participación de diferentes comunidades de CTI como en los impactos en el corto y mediano plazo. El congreso de consensos, la audiencia pública y las acciones de seguimiento contribuyeron a consolidar un canal de diálogo directo para cabildear estas y otras propuestas. Además, se abrió un espacio de interacción y diálogo entre personal experto de diferentes instituciones y grupos. Más aún, junto a otras acciones relacionadas, logró impactar en el diseño de instrumentos de la política de CTI. Esta sección discute diferentes aspectos que explican la incidencia en el ciclo de la política.

\section{1) SOBRE LOS RESULTADOS DEL PROCESO DE DIÁLOGO}

El caso analizado es parte de un conjunto de acciones promovidas para fomentar la PEG en el país, y también en el sector de CTI. Es difícil afirmar que un solo proyecto ha generado todos los impactos observados, pero con certeza el caso analizado jugó un papel importante en los resultados observados.

El principal resultado observado es la introducción de modificaciones en el diseño de los siguientes programas de CONACYT:

\section{A) FONDO SECTORIAL DE INVESTIGACIÓN EN SALUD}

\section{Y SEGURIDAD SOCIAL-FOSISS (SS/IMSS/ISSSTE-CONACYT)}

Este es un fondo sectorial de CONACYT con la Secretaría de Salud, y dos instituciones de investigación y atención a la salud (IMSS/ ISSSTE). El FOSISS opera desde el 2002, cuando fue introducido junto al paquete de fondos sectoriales, acordados con diferentes secretarías de estado. A partir de la convocatoria 2015 se incorporó el siguiente requisito:

"Cuando sea pertinente, las propuestas que obtengan datos de seres vivos, deberán incluir en los estudios que se realicen la perspectiva de género, i.e., que se desagreguen los datos según el sexo e incluirlos en los análisis correspondientes, así como reportar el impacto en la salud en hombres y mujeres".

\section{B) FONDO SECTORIAL DE INVESTIGACIÓN Y DESARROLLO INMUJERES-CONACYT}

Este fondo se creó en 2003 y tiene como objeto apoyar proyectos de investigación científica y tecnológica que contribuyan a generar el conocimiento requerido por el Sector para atender los problemas, necesidades u oportunidades en los temas que requiera el 
INMUJERES. Estos resultados se unen a una mayor preocupación por la igualdad de género en los programas de CONACYT, o al menos por un incremento de la participación femenina. Los resultados de todos los programas se presentan ahora sistemáticamente diferenciando por sexo.

Hay cuatro factores que explican estos resultados:

- Desde hace años hay grupos de investigación que promueven la igualdad de género en el país.

- La Directora Adjunta de Desarrollo Científico es una mujer, con sensibilidad sobre el tema del género, la cual se sentó a dialogar, participó en el diálogo analizado, y de hecho CONACYT también fue convocante del diálogo.

- El proceso de diálogo contribuyó a detonar acciones concretas.

- Ha habido acciones de seguimiento de las recomendaciones que emergieron del proceso de diálogo, lo que mantuvo vivo el tema y la exigencia de respuestas. En el caso analizado, la emergencia de actores que dieran seguimiento a los resultados del proceso de diálogo, como fue el caso del grupo "Mujer y Ciencia", contribuyó a mantener viva esta iniciativa de participación.

\section{2) SOBRE LAS CARACTERÍSTICAS DEL PROCESO DE DIÁLOGO}

Si bien los mecanismos de participación pública descritos en la literatura brindan una herramienta metodológica fundamental, las especificidades de los procesos de diálogo y los problemas específicos de su implementación trascienden cualquier clasificación de herramientas.

\section{QUÉ HERRAMIENTA DE DIÁLOGO ESCOGER}

La literatura diferencia las herramientas que son apropiadas de acuerdo a los mecanismos de participación según su orientación: 1) los centrados en el debate público en la CTI; 2) los orientados a la realización de actividades consultivas o de asesoría para el gobierno; y 3) los generadores de consenso. Pero, las especificidades del proceso de diálogo analizado llevaron a la combinación de herramientas que corresponden a diferentes orientaciones. Se combinó un congreso de consensos, que tiene como base la discusión de una problemática para lograr consensos en las propuestas que guíen la toma de decisiones, con una audiencia pública, que 
es apropiada para levantar un tema para su debate público. La utilización flexible de las herramientas permitió llegar a resultados tangibles.

\section{CÓMO LOGRAR UNA PARTICIPACIÓN ACTIVA DE FUNCIONARIOS PÚBLICOS}

A lo largo de todo el proceso de diálogo hubo dificultades para lograr la participación activa de los funcionarios públicos en el ejercicio de diálogo. En muchos casos, sus tareas regulares asociadas con la implementación de la política no les dejan espacios para pensar estratégicamente y participar en ejercicios de esa naturaleza. En el caso analizado, el hecho de que la Directora Adjunta de Desarrollo Científico de CONACYT sea una mujer, con sensibilidad sobre el tema del género es que el diálogo tuvo una fuerte incidencia en su participación en el diálogo.

\section{IMPACTO EN LA ETAPA DE DISEÑO DE LA POLÍTICA DE CTI}

El impacto observado se ubica en la etapa del diseño de la política de CTI, pero hay que considerar que el diseño de la política no es una actividad continua, tiene sus tiempos. Si se refiere a un nuevo programa/instrumento, depende de que la agencia, en este caso CONACYT, tome la decisión de diseñar el programa. Esto ocurre mayormente en los inicios de un nuevo gobierno. El primer año tiene un fuerte componente de diseño, por el contrario, en los últimos años esta actividad decae. Este proceso de diseño requiere involucrar a las autoridades; la propuesta inicial debe ser analizado por el área legal, aprobado por la Junta de Gobierno, se le tienen que asignar recursos, para entonces pasar a la implementación. Todo este proceso consume tiempo, involucra a muchos funcionarios diferentes, cada uno con sus opiniones. Si se refiere a una mejora de un instrumento, como es el caso del FOSISS, el proceso puede ser más rápido, pero aún requiere los pasos legales para poder incluir los cambios en una convocatoria pública. Muchas veces un cambio en un instrumento afecta a otros instrumentos, lo cual es un desincentivo para llevarlo a cabo. Por ejemplo, aún no se han introducido cambios sustanciales en el programa SNI, de acuerdo a los cambios en la Ley de Ciencia y Tecnología. En las recomendaciones del diálogo desarrollado también se incluyeron sugerencias de cambios a este programa. Pero el SNI es un programa muy importante, con cruces transversales que afectan a muchos otros programas (por ejemplo, en el Fondo de Ciencia Básica se incluyen requerimientos respecto a la pertenencia al SNI, o en el Padrón de Programas de Posgrado). Cambios en este programa 
requieren un esfuerzo de diseño significativo. En este sentido, sin duda las pequeñas modificaciones del FOSISS son un resultado importante, y lleva tiempo evaluar otros impactos en el diseño de la política de CTI.

\section{LA ENTREGA DE LOS RESULTADOS A LOS FUNCIONARIOS PÚBLICOS}

Durante las últimas etapas se presentaron dificultades para entregar los resultados a los funcionarios públicos. Aquí se generaron varias enseñanzas: (i) no basta entregar las recomendaciones del diálogo, hay que darle seguimiento para tener impacto en la política de CTI, y (ii) se requiere liderazgo institucional, es decir una institución con liderazgo para darle seguimiento a las recomendaciones. El proceso de diálogo falló en asegurar ese liderazgo institucional, ya que una vez que la coordinación general del FCCyT se transfirió a un hombre, éste perdió interés en el proyecto y en su seguimiento.

\section{LA ADAPTACIÓN DE LAS RECOMENDACIONES AL LENGUAJE DE LAS POLÍTICAS PÚBLICAS}

Difícilmente las recomendaciones pueden ser incorporadas como tales en el diseño/rediseño de un instrumento. Para serlo deberían ser elaboradas por especialistas en diseño de política. En el caso analizado, las recomendaciones fueron filtradas por algunos especialistas para ponerlas en el lenguaje del diseño de programas de política, se tomó más el espíritu de la propuesta que el texto de la recomendación. Estas modificaciones hicieron difícil medir el impacto del ejercicio de diálogo, particularmente para los ojos de las comunidades participantes.

\section{REFLEXIONES FINALES}

Este documento discutió la incidencia que pueden tener los procesos de diálogo entre comunidades en el diseño de la política pública, en particular se analizó un proceso de diálogo para promover una PEG en la política de CTI.

Hay cuatro lecciones aprendidas:

- La sola participación de las partes interesadas no es suficiente para generar impacto en el diseño de la política de CTI. Se necesitan establecer mecanismos que anclen estos ejercicios y permitan su continuidad más allá de los intereses de las autoridades de paso de los organismos líderes.

- Se requiere liderazgo de alguna institución que consolidé el grupo de trabajo (quizá dando mayor formalidad o estructura) 
y establezca un plan de trabajo para dar seguimiento a las actividades ya iniciadas.

- A diferencia de otros ejercicios de participación realizados en México (por ejemplo, "Hablan los emprendedores" discutido en Dutrénit y Suárez (2017), en donde los facilitadores y traductores fueron clave, en este proyecto parece ser que el liderazgo y la negociación son las piezas claves.

- El interés de funcionarios públicos de alto nivel contribuye a la inclusión de las recomendaciones en el diseño de programas de la política.

- Las recomendaciones deben ser expresadas en el lenguaje del diseño de programas de política, lo cual hace difícil tanto que las comunidades sientan como suyos los resultados como medir el impacto de los ejercicios de diálogo, en términos de sus resultados.

Otros aspectos relevantes que merecen ser destacados se refieren al proceso de diálogo en sí. Se observó una empatía en las problemáticas discutidas entre las comunidades. Las facilitadoras tuvieron el papel de moderar las varias intervenciones, opiniones, problemáticas que se hacían visibles. Sin embargo, a pesar de que los participantes en la audiencia pública tenían cierto grado de homogeneidad en términos de su interés por el tema de la desigualdad de género, había una gran heterogeneidad de sus diversas experiencias, temáticas, intereses y perspectivas particulares, lo que representó un desafío para generar consensos. Había, por un lado, académicas dedicadas a género, sobre todo de ciencias sociales y humanidades, por otro lado, personal académico de otros campos de conocimiento que se preocupan por el tema de género sin que esta sea su especialidad, y finalmente los funcionarios públicos con un enfoque de políticas.

Uno de los principales desafíos en las mesas de diálogo fue cómo entablar realmente un diálogo que generara consenso en términos de propuestas y entendimiento (Dutrénit et al., 2014). Se observó que una de las mayores dificultades fue precisamente encontrar un punto común para hacer propuestas ante una gran cantidad de problemáticas planteadas en la intersección de varias dimensiones que cruzan el género como etnia, clase, violencia y estéreo tipo sociales y diversas experiencias. En ese sentido, se observó que en las mesas de diálogo las facilitadoras se enfrentaron al arduo reto de ajustarse al tiempo y tratar de enfocar la discusión de experiencias personales para redirigirla a la generación de propuestas concretas. 
Respecto al carácter estratégico de las propuestas, cuando se proponían iniciativas concretas algunos participantes mostraban su preocupación porque no veían representada su institución o área de conocimiento. Esto hace que emerjan preguntas sobre las posibilidades reales de discusión de puntos estratégicos para la toma de decisiones.

En las mesas de diálogo hubo también asimetrías en cuanto participantes de ciertos sectores y regiones que no pudieron participar en las primeras fases del proyecto y cuyas voces no fueron escuchadas. Por ello, una lección para futuros ejercicios de este tipo es que es necesario buscar una mayor inclusión de diferentes especialistas y hacedores de política, por ejemplo, de regiones fuera de la Ciudad de México, para que se visibilicen los problemas particulares a los que se enfrentan diferentes grupos.

La importancia del diálogo y las propuestas que resultaron del proyecto fungieron como un mecanismo para acortar la distancia entre los marcos legales y las estrategias para lograr una incidencia real. En este ejercicio, el involucramiento de las comunidades resulta de suma importancia. Otro elemento en el proyecto fue que el tener documentos de trabajo previos al proyecto, incluyendo una propuesta de recomendaciones, ayudó a centrar las temáticas y enfocar la discusión para plantear un terreno en común de diálogo y propuestas.

Se observó también el hecho de que había mujeres ocupando puestos de liderazgo tanto en el FCCyT, CONACYT y la OCDE, instituciones clave entre las comunidades, fue un factor importante para posicionar el tema en el diálogo público y llevar a cabo el proyecto.

Por otro lado, se observa que los mecanismos de participación pública pueden llegar a ser inflexibles y lineales y por lo tanto hasta cierta medida llegar a limitar la propia dinámica de los procesos de diálogo. Es necesario entonces no solo combinar diferentes mecanismos, sino evaluar claramente desde el principio de los proyectos las ventajas y desventajas, así como su pertenencia de acuerdo a las necesidades propias de cada proyecto. Es también prudente considerarlos como propuestas generales de buenas prácticas y apropiarlos y situarlos en sus particulares de los contextos locales. En ese ejercicio de apropiación, debe haber espacios no solo para la adaptación sino para la creación y propuesta de nuevos mecanismos.

Finalmente, en términos de recomendaciones generales para promover procesos de diálogo para el diseño de la política pública de CTI, es importante promover redes de trabajo a través de la integración de grupos de actores de diversas comunidades que estén 
involucrados en los temas. También, es necesario contar con mediadores o traductores que funjan como enlaces de comunicación entre las diversas comunidades. Por último, es necesario que se lleven medidas necesarias para institucionalizar de alguna manera las actividades de seguimiento. Esto les brinda legitimidad y motivación a los grupos de trabajo, además de que permite visibilizar los alcances que pueden y van siendo alcanzados a través de los diálogos.

\section{BIBLIOGRAFÍA}

Abelson, J.; Forest, P.; Eyles, J.; Smith, P.; Martin, E.; Gauvin, F. 2003 "Deliberations about deliberative methods: issues in the design and evaluation of public participation processes" en Social Science \& Medicine (Países Bajos: Elsevier) No 57(2), pp. 239-51.

Ackerly, B. 2000 Political Theory and Feminist Social Criticism (Cambridge y Nueva York: Cambridge University Press).

Aguilar, L. 1992 El estudio de las Políticas Públicas (México: Miguel Angel Porrua).

Álvarez, I.; Barletta, F.; Suarez, D.; Yoguel G. 2016 "Marco analítico para la tipificación de diálogos para las políticas de CTI" en Working paper 3 (Red CYTED COM-LALICS). En <http://lalics. org/images/CYTED/DT3-DimensionesDialogo.pdf> acceso $15 \mathrm{de}$ abril de 2017.

Brown, M. 2014 "Politicizing science: Conceptions of politics in science and technology studies" en Social Studies of Science (SAGE Journals) No 45(1), pp. 3-30. En <http://doi. org/10.1177/0306312714556694>.

Cabrero, E. 2000 “Usos y costumbres en la hechura de las políticas públicas en México. Límites de las policy sciences en contextos cultural y politicamente diferentes" en Gestión y Política Pública (México: CIDE) Nº IX(2), pp. 180-229.

Carsten, M.; Voss, J.; Amelung, N.; Simons, A.; Runge, T.; Grabner, L. 2013 Challenging futures of citizen panels. Critical issues for robust forms of public participation. A report based on an interactive, anticipatory assesment of the dynamics of governance instruments (Berlín: Innovation in Governance).

Chilvers, J. 2008 "Deliberating Competence: Theoretical and Practitioner Perspectives on Effective Participatory Appraisal Practice" en Science, Technology \& Human Values (SAGE Journals) $\mathrm{N}^{\mathrm{o}} 33(3)$, pp. 421-451. En <http://doi. org/10.1177/01622439073075941>. 
Cozzens, S. 2008 "Gender Issues in US Science and Technoogy Policy" en Science and Engineering Ethics (Reino Unido: Springer) $\mathrm{N}^{\circ} 14(3)$, pp. 345-356.

Dutrénit, G. 2014 “Experiencias de Organismos Latinoamericanos de asesoría y consulta para construir políticas de Ciencia, Tecnología e Innovación", Documento de trabajo (FCCyT).

Dutrénit, G.; Natera, J. M.; Suárez, M. 2014 "Lineamientos para la caracterización de las Comunidades y sus Procesos de Diálogo" Working paper 1 (Red CYTED COM-LALICS). En <http:// lalics.org/images/CYTED/DT1-ComunidadesDialogo\%201.pdf> acceso 15 de abril de 2017.

Dutrénit, G.; Álvarez, I.; Ardanche, M.; Barletta, F.; Bianco, M.; Cortés, R.; Cummings, A.; de la Vega, I.; Díaz, I.; Fernández, O.; Gómez, V.; Goñi, M.; Natera, J. M.; Nupia, C.; Orozco, J.; Prada, F.; Puchet, M.; Romero, F.; Simón, L.; Suárez, D.; Suárez, M.; Sutz, J.; Vera-Cruz, A. 2016 "Matriz de Información para el mapeo de procesos de diálogo de CTI en España, América Latina y el Caribe" en Working paper 5 (Red CYTED COM-LALICS). En <http://alics.org/images/ CYTED/DT5-Formulario2.pdf> acceso 15 de abril de 2017.

Dutrénit, G.; Suárez, M. 2017 "Involving stakeholders in policymaking: tensions emerging from a public dialogue with knowledge-based entrepreneurs". En Science and Public Policy, 1-13. En <doi: 10.1093/scipol/scx043>.

Dutrénit, G.; Natera, J. M.; Puchet Anyul, M.; O. Vera-Cruz, A.; Torres, A. 2017 "Dialogue processes on STI policy-making in Latin America and the Caribbean: dimensions and conditions". En Science and Public Policy, 1-16. En <doi: 10.1093/scipol/scx044>.

Fraser, N.; Honneth, A. 2006 ¿Redistribución o reconocimiento? Un debate político-filosófico (Madrid: Morata).

Goñi, M.; Bianco, M.; Puchet, M. 2015 “Elementos para caracterizar los procesos de diálogo en políticas de CTI" en Working paper 7 (Red CYTED COM-LALICS). En <http://lalics. org/images/CYTED/DT7-ConfianzaPoder.pdf> acceso $15 \mathrm{de}$ abril de 2017.

Griessler, E. et al. 2011 “Citizen's impact on knowledge intensive policy: introduction to a special issue" en Science and Public Policy (Reino Unido: Oxford University Press) $\mathrm{N}^{\circ}$ 38(8), pp. 583-588.

Guston, D. 1999 "Evaluating the First U.S. Consensus Conference: The Impact of the Citizens' Panel on Telecommunications and the Future of Democracy" en Science, Technology \& Human Values (SAGE Journals) No 24(4), pp- 451-482. En <http://doi.or $\mathrm{g} / 10.1177 / 016224399902400402>$. 
Harding, S. 1992 "After the Neutrality: Ideal: Science, Politics and 'Strong Objectivity"' en Social Research (Nueva York: The New School) No 59(3), pp. 567-587.

INMUJERES 2013 Compendio normativo para la construcción de la Igualdad sustantiva en la Administración Pública Federal (México).

Jensen, C. 2005 "Citizen Projects and Consensus-Building at the Danish Board of Technology: On Experiments in Democracy" en Acta Sociologica (México: UNAM) No 48(3), pp. 221-235. En $<$ http://doi.org/10.1177/0001699305056564>.

Lázaro, M.; Trimble, M.; Umpiérrez, A.; Vasquez, A.; Pereira, G. 2014 Juicios Ciudadanos en Uruguay. Dos experiencias de participación pública deliberativa en ciencia y tecnología (Montevideo: PNUD - Universidad de la República).

Mejlgaard, N. 2009 "The trajectory of scientific citizenship in Denmark: changing balances between public competence and public participation" en Science and Public Policy (Reino Unido: Oxford University Press) $\mathrm{N}^{\circ} 36(6)$, pp. 483-496. En $<$ http://doi.org/10.3152/030234209X460962>.

Muñiz, E. 2013 El género como concepto teórico crítico (México: UACJ).

Nupia, C.; Martínez A. 2015 "Revisión de metodologías de procesos de diálogo" en Working paper 4 (Red CYTED COM-LALICS). En <http://lalics.org/images/CYTED/DT4-MetodologiasDialogo. pdf $>$ acceso 15 de abril de 2017.

Ortegón-Quiñones, E. 2008 Guía sobre diseño y gestión de la política pública (Bogotá: Convenio Andrés Bello).

Ortiz, A.; Carrillo, N.; Gómez, M.; Ávila, B.; Suárez, M. 2013 Una mirada a la ciencia, tecnología e innovación con perspectiva de género: Hacía un diseño de políticas públicas (México: FCCyT).

Rowe, G. 2005 “A Typology of Public Engagement Mechanisms" en Science, Technology \& Human Values (SAGE Journals) $\mathrm{N}^{\circ} 30$ (2), pp. 251-290. En <http://doi.org/10.1177/0162243904271724>.

Valenti, G.; Flores, U. 2009) "Ciencias sociales y políticas públicas" en Revista Mexicana de Sociología (México: UNAM) N ${ }^{\circ}$ 71, pp. 167-191.

Voss, J.; Amelung, N.; Mann, C.; Simons, A. 2014 Innovation in Governance (Berlín). 


\title{
LA MEDICIÓN DE LA PRODUCCIÓN CIENTÍ- FICA DE LOS GRUPOS DE INVESTIGACIÓN EN COLOMBIA
}

\author{
DEL DIÁLOGO DE EXPERTOS A LA INCORPORA- \\ CIÓN DE PRÁCTICAS MÁS REPRESENTATIVAS
}

\author{
Carlos Mauricio Nupia* y Adriana Martínez-Maestre ${ }^{* *}$
}

\section{INTRODUCCIÓN}

El objetivo de este capítulo es analizar el proceso de diálogo que dio lugar al Modelo Colombiano de Medición de la Producción Científica de los Grupos de Investigación (MCMPCGI). Diseñado como un instrumento de política para fortalecer el Sistema Nacional de Ciencia y Tecnología (SNCyT), el MCMPCGI evidencia una transformación en relación con la estructura interna de las comunidades que participan y de las dimensiones del diálogo involucradas a lo largo de un proceso de quince años. En particular, se reflexiona sobre las condiciones que afectaron el diálogo entre dos de las comunidades reconocidas en la literatura sobre sistemas de innovación (comunidad académica y sector público) cuando está en juego el diseño e implementación de una política pública para medir la productividad científica.

El caso fue sistematizado según los lineamientos para identificar diálogos de ciencia, tecnología e innovación (Dutrénit, Natera \& Suárez, 2014; Dutrénit et al., 2016) definidos en el marco de las actividades de la "Red temática para mejorar el diálogo entre las comunidades

\footnotetext{
* Investigador. Observatorio Colombiano de Ciencia y Tecnología (OCyT)

** Asistente de investigación. Observatorio Colombiano de Ciencia y Tecnología (OCyT)
} 
involucradas en las políticas de CTI - CYTED COM-LALICS", financiada por CYTED e integrada por más de una decena de países de Iberoamérica (Argentina, Brasil, Chile, Colombia, Costa Rica, Cuba, El Salvador, España, México, Perú, República Dominicana, Uruguay y Venezuela).

Después de esta introducción, la sección 2 reseña conceptos básicos de diálogo en el marco de la relación entre ciencia y sociedad, en términos de la literatura empírica, el abordaje más académico, el enfoque de los problemas complejos y la relación con la política de ciencia, tecnología e innovación. En la sección 3 se describen las principales características y condiciones que restringen el diálogo político en el caso del MCMPCGI. Finalmente, la sección 4 ofrece algunas conclusiones.

\section{EL DIÁLOGO EN EL CONTEXTO DE LA CIENCIA Y LA SOCIEDAD}

\subsection{DEFINICIONES DE DIÁLOGO}

Desde el punto de vista empírico, un diálogo es a la vez un proceso de interacción y una construcción colectiva de significados compartidos. Las organizaciones internacionales han abordado este problema mediante el desarrollo de marcos metodológicos que explican el diálogo. El diálogo se concibe como un instrumento para resolver una variedad de desafíos que se abordan mediante lineamentos técnicos (Cuentas \& Linares Méndez, 2013; Rayo, 2013). Estos lineamientos proporcionan información sobre los actores, etapas, principios y otras cuestiones operacionales que afectan el rendimiento de diálogo. La tabla 1 muestra distintas definiciones de diálogo propuestas por algunas organizaciones internacionales.

Tabla 1. Definiciones de diálogo según tres organizaciones internacionales revisadas

\begin{tabular}{|c|c|}
\hline $\begin{array}{l}\text { Organización } \\
\text { internacional }\end{array}$ & Definición de diálogo \\
\hline $\begin{array}{l}\text { Secretaría General de } \\
\text { la Organización de los } \\
\text { Estados Americanos } \\
\text { (SG/OEA) y el Centro } \\
\text { Regional del PNUD } \\
\text { para América Latina y } \\
\text { el Caribe }\end{array}$ & $\begin{array}{l}\text { Un diálogo democrático se define como aquel que respeta y fortalece la } \\
\text { institucionalidad democrática y busca transformar las relaciones conflictivas } \\
\text { para evitar las crisis y la violencia y contribuir a la gobernabilidad } \\
\text { democrática. Un diálogo democrático es siempre un proceso de cooperación } \\
\text { y trabajo conjunto y puede incluir una o más reuniones de los actores del } \\
\text { diálogo. Un diálogo opera con una mirada sistémica de la problemática en } \\
\text { cuestión y por ende busca incluir a un grupo diverso de actores relacionados } \\
\text { con dicha problemática, y no solamente a partes que buscan negociar un } \\
\text { tangible (Cuentas \& Linares Méndez, 2013). }\end{array}$ \\
\hline
\end{tabular}




\begin{tabular}{|c|c|}
\hline $\begin{array}{l}\text { Organización } \\
\text { internacional }\end{array}$ & Definición de diálogo \\
\hline $\begin{array}{l}\text { Comisión Económica } \\
\text { para América Latina } \\
\text { y el Caribe (CEPAL) y } \\
\text { la Agencia Alemana } \\
\text { para la Cooperación } \\
\text { Internacional (GIZ) }\end{array}$ & $\begin{array}{l}\text { Proceso de comunicación y cooperación entre diferentes actores relevantes } \\
\text { para un tema, que deben colaborar para el desarrollo mutuo y del propio } \\
\text { sistema relacional al que pertenecen (identificar soluciones e implementar } \\
\text { acciones). A través del diálogo se reúnen capacidades, recursos, ideas } \\
\text { y perspectivas de los diversos actores, lo que facilita la búsqueda de } \\
\text { soluciones que individualmente no serían pensadas ni alcanzables. El diálogo } \\
\text { implica que ninguna postura es concluyente hasta que no hay un consenso } \\
\text { general (...) Estos diálogos deben estar estructurados como un proceso de } \\
\text { trabajo y tener un objetivo común compartido por todos los actores. También } \\
\text { deben tener como base de trabajo la búsqueda de consensos, el diseño } \\
\text { conjunto de acciones y su respectiva implementación (Rayo, 2013). }\end{array}$ \\
\hline $\begin{array}{l}\text { Agencia Alemana } \\
\text { para la Cooperación } \\
\text { Internacional (GIZ) }\end{array}$ & $\begin{array}{l}\text { Los diálogos con actores clave (stakeholder dialogues) son un método } \\
\text { para la gestión de los procesos de cambio a través de la cooperación. Su } \\
\text { característica distintiva es que involucran a actores relevantes para definir } \\
\text { una medida concreta. Los diálogos con actores clave aportan diferentes } \\
\text { perspectivas, y facilitan la búsqueda de soluciones conjuntas que no sean } \\
\text { parciales y que no ignoren las dificultades (Petra Künkel et al., 2011). }\end{array}$ \\
\hline
\end{tabular}

Fuente: elaboración propia a partir de (Künkel et al., 2011; Cuentas \& Linares Méndez, 2013; Rayo, 2013)

Las metodologías para abordar diálogos de políticas públicas en CTI podrían agruparse en tres tipos: i) metodologías abiertas: enfocadas en resolución de conflictos para la construcción de la democracia. Reconocen la participación de actores y representantes de los sectores gobierno, academia, sociedad civil e industria. No son restrictivas en cuanto a los problemas que abordan; ii) metodologías específicas: se concentran en el diálogo entre científicos expertos y formuladores de política. Se presenta generalmente en la asesoría experta que los científicos aportan en las distintas etapas del ciclo de una política pública; iii) metodologías de articulación internacional: escenario enfocado en formuladores y responsables de política de distintos países con el fin de intercambiar experiencias y buenas prácticas de política en CTI (Nupia \& Martínez-Maestre, 2015).

En términos generales, el diálogo se fundamenta en la disminución de la propensión al conflicto e implica el establecimiento de canales de comunicación para hacer frente a problemas complejos. Los diálogos mejoran la interacción entre actores, fomentan su participación -basada en responsabilidades individuales y compartidas- y reducen los conflictos (Rayo, 2013). La comunicación se convierte en una fuente de confianza y crea interfaces de cooperación entre los actores. Cuando se alcanzan niveles óptimos de comunicación, los actores involucrados establecen acuerdos y compromisos robustos y sostenibles. 


\subsection{EL SIGNIFICADO DEL DIÁLOGO EN LAS POLÍTICAS PÚBLICAS DE CTI}

El sentido de lo público en la estructuración y diseño de las políticas de CTI en Iberoamérica fue uno de los temas de reflexión de la Red CYTED COM-LALICS. Específicamente para el caso de CTI, la Red entendió el diálogo como la interacción entre las comunidades de un sistema de innovación (académica, sector productivo, sector público y sociedad civil), basada en conocimientos, comunicación, coordinación y habilidades de liderazgo para la exploración de conflictos y la búsqueda de acuerdos que fundamenten la toma de decisiones y resuelvan problemas comunes (Dutrénit et al., 2017: 1).

Una forma de abordar teóricamente el tema es asociándolo al enfoque de los sistemas de innovación y de las fallas sistémicas que en ellos se presentan. Dado que este tipo de fallas se deben a bloqueos y limitaciones del proceso de innovación, originados a su vez en dinámicas poco virtuosas entre actores, se requieren intervenciones sistémicas que conduzcan a mejorar las capacidades de los actores y a promover su interconexión resultados (Álvarez et al., 2016: 2).

En este orden de ideas, el estudio de los diálogos cumplió un doble objetivo en la Red CYTED COM-LALICS: entender cómo en el diseño de políticas públicas participan actores con intereses diferentes a los del gobierno, y analizar las potencialidades de una herramienta de intervención que facilite la interacción mediante el enfoque de sistemas de innovación. Para ello, la Red diseñó un instrumento metodológico que sirvió para documentar distintos casos de diálogos en políticas de CTI presentados por los países Iberoamericanos participantes (Dutrénit et al., 2016) y posteriormente definió un marco analítico para estudiar procesos de diálogo, compuesto por tres dimensiones: objeto, espacio de interacción y temporalidad. Dentro de este marco existen dos elementos relacionados con las comunidades involucradas que afectan el desarrollo del diálogo: las asimetrías de poder y la heterogeneidad (Dutrénit et al., 2017: 3-4).

El objeto del diálogo es el tema de la política de CTI sobre el cual se dialogará. Puede ser una actividad de CTI o un problema público definido por los actores. La dimensión del espacio de interacción es el resultado del origen de la iniciativa y las intenciones y posiciones de los actores durante el diálogo (Dutrénit et al., 2017: 4). El origen de la iniciativa son las razones por las cuáles surge el diálogo y su relación con las fallas sistémicas. En este sentido, los diálogos pueden clasificarse como reactivos o proactivos (dependiendo de si surgen como respuesta a políticas existentes o si por el contrario buscan construir nuevas alternativas de política) o como de oferta y demanda (dependiendo de si son planteados a manera de oferta o si se originan a par- 
tir de la detección de una demanda pública o privada). El origen del diálogo también está relacionado con la direccionalidad desde la cual es impulsado (top-down, cuando se impulsa y coordina por instancias gubernamentales que tiene la competencia de definir y aplicar políticas, o bottom-up cuando se impulsa y coordina por actores tradicionalmente receptores de políticas como el sector privado o las ONG) (Álvarez et al., 2016: 6-7).

Las intenciones, posiciones e intereses de los actores también hacen parte de la dimensión del espacio de interacción y están estrechamente relacionadas con el concepto de asimetrías de poder. Dichas asimetrías se presentan cuando una comunidad específica tiene una capacidad, recurso o característica que otra no posee y por ello hace prevalecer su voluntad (Dutrénit et al., 2017: 3). También están relacionadas con elementos como las generación de capacidades y la existencia de un lenguaje común (Álvarez et al., 2016: 8-9). Dado que ninguna comunidad que interviene en un diálogo cuenta con todas las capacidades para desarrollarlo, es necesario hacer esfuerzos adicionales para generar consensos (Dutrénit et al., 2017: 3).

Por último, la dimensión de temporalidad se refiere al nivel de continuidad del diálogo. Se compone de dos elementos: dimensión temporal (puntual, corto plazo, mediano y largo plazo) y continuidad temporal (si las actividades del diálogo se desarrollaron de manera continua o interrumpida). El alcance del diálogo es definido a partir del ámbito temático (generales, sectoriales, regionales/territoriales y temáticos) y de su propósito (concertación, consultivo, generador de propuestas de política) (Álvarez et al., 2016: 7-8).

Aunque la definición del marco analítico permite comparar los casos de diálogo presentados entre los países, metodológicamente sigue existiendo un desafío para identificar los conflictos y la definición de consensos al interior de cada caso. Precisamente al respecto, Goñi, Bianco y Puchet (2015) llaman la atención sobre la necesidad de acotar la definición general de diálogo para que se convierta en una guía analítica que observe aspectos como la construcción de consensos sociales y la participación social en el diseño e implementación de políticas públicas. En este sentido, abogan por analizar las variaciones del diálogo en función del contexto en el cual se realiza (Goñi, Bianco, \& Puchet, 2015: 2)

\subsection{ASIMETRÍAS DE PODER, CAPACIDADES Y CONOCIMIENTO EXPERTO}

El conocimiento que poseen los expertos sigue siendo un factor clave para la toma de decisiones de política pública. Algunos diálogos requieren conocimientos técnicos como condición esencial para manejar problemas complejos (wicked issues). Por problemas complejos 
se entienden situaciones que abarcan altos niveles de incertidumbre (científica) en el marco de un proceso participativo (Cuppen, 2012).

El conocimiento científico juega un papel crucial en informar algunas de las decisiones políticas más importantes en las sociedades modernas (EASAC, 2012: 1). Sin embargo, cuando actúan en calidad de expertos, los científicos no responden a preguntas elegidas por ellos mismos, como sí ocurre en sus investigaciones, y se ven obligados a transgredir los límites de su competencia (Nowotny, 2003: 152). Dado que el estado administrativo y científico es cada vez más cuestionado, una "nueva" política posmoderna promete aprovechar las necesidades sociales y mejorar el aporte y gestión de la formulación de políticas a través de un aprendizaje político y socialmente orientado (Hoppe, 2011: 29).

Uno de los aspectos más desafiantes de los problemas complejos, es que cualquier intento por abordarlos termina dejando por fuera otras dimensiones o aspectos del problema. Los problemas complejos solo pueden ser definidos, pero nunca solucionados (Hoppe, 2011: 9). Esta condición implica que el uso del conocimiento experto ya no es una forma efectiva de resolver los problemas y que las consecuencias no deseadas en un problema social, no tienen una explicación racional. Helga Nowotny se ha referido a este fenómeno como la "transgresión de la experticia". La experticia es transgresora, ya que debe ser capaz de entender los vínculos que unen a diversas prácticas, instituciones y redes de actores; y porque se dirige a un público que no está compuesto exclusivamente por colegas expertos (Nowotny, 2003: 152).

La crisis en la experticia afecta la credibilidad, legitimidad y el tiempo de la asesoría científica. Cuando se pone en duda la credibilidad científica, las posibilidades de diálogo incrementan porque emerge el conocimiento de nuevos actores. La modificación de los elementos típicos de la asesoría científica abre un espacio al conocimiento socialmente robusto y a nuevos escenarios de diálogo. Dado que el conocimiento fiable validado en su contexto disciplinario (es decir, los comités de expertos) ya no es autosuficiente debido a que sus productos son criticados o rechazados, los expertos deben tender lazos y establecer relaciones con otro tipo de conocimiento, experiencia y experticia. La robustez de este nuevo conocimiento será el resultado de una interacción constante con la sociedad. La interacción crea un espacio de diálogo para la definición y solución de problemas, en los que la contextualización de la producción de conocimiento es esencial (Nowotny, 2003: 156).

A pesar de esta nueva conceptualización reclamando una apertura del diálogo experto, la literatura sobre diálogos todavía concede 
un lugar importante a la evidencia científica. De hecho, se identifica la falta de conocimiento de expertos como uno de los factores de riesgo ${ }^{2}$ del proceso (Rayo, 2013) derivados de un fallo en la interacción de los actores. Desde su posición, dejar de lado a los expertos en el marco de un diálogo es un factor de riesgo que puede conducir a una decisión equivocada o al estancamiento del proceso. El conocimiento experto puede reducir este riesgo, basado en la evidencia científica.

En un diálogo de política de CTI el conocimiento experto juega un papel relevante ya que, por la misma naturaleza del tema, la comunidad científica es la primera llamada a ser consultada. Sin embargo dado que los investigadores no hacen parte de una comunidad científica homogénea a la cual se pueda aplicar la estructura normativa de la ciencia, sino que están influenciados por sus entornos locales (Vinck, 2010: 39), el conocimiento experto que se requiere para fundamentar una política pública requiere de la representación de distintas disciplinas, aspecto que supera a la simple asesoría de los comités de expertos conformados por científicos.

La participación del conocimiento experto en este tipo de procesos plantea de entrada una asimetría de poder entre los comités de expertos, que conocen de primera mano los distintos temas que la política busca regular, y el Estado, que no dispone del conocimiento suficiente para entender la amplia variedad de temas científicos y técnicos implicados en diferentes disciplinas (Callon, 2003: 33). Sin embargo, esta asimetría se puede contrarrestar cuando el Estado aduce el cumplimiento de la ley como fundamento para desconocer o cuestionar la asesoría de los expertos. Este último caso puede dar lugar a diálogos que son decididamente direccionados desde el sector público, y que tienen por objeto desarrollar normas y darle forma a los lineamientos que desean implementar los gobiernos en materia de política pública.

Otro caso de asimetría ocurre cuando entre los mismos comités o grupos de expertos no existen posiciones unificadas para hacer recomendaciones a la política pública, debido a diferencias disciplinares o de aproximación conceptual al tema. En dichos casos, la posibilidad de que se presenten sub-grupos o asociaciones de carácter representativo, que lideren posiciones e intereses distintos, podría generar nuevos matices al diálogo entre las comunidades de un sistema de innovación.

2 Otros riesgos identificados por (Rayo, 2013) son: intereses ocultos (diálogo para buscar objetivos distintos a los definidos inicialmente); burocratización (alta concentración de poder en un grupo y escasa representación de otros); falta de credibilidad y liderazgo (carencia de confianza en el proceso y en el líder-convocante del mismo). 


\subsection{TEMPORALIDAD, DIÁLOGO Y CAMBIO INSTITUCIONAL}

La temporalidad es una dimensión del diálogo que resulta relevante para observar transformaciones en el objeto del diálogo y especialmente en la interacción de las comunidades participantes. Si se analizan diálogos que se desarrollan a lo largo de períodos largos de tiempo, podrían entenderse como instituciones, es decir como "reglas básicas de juego" o "bloques de construcción del orden social", sobre los que se construyen normas que restringen el comportamiento de los actores. Dichas normas representan sanción social y expectativas definidas colectivamente (Nelson, 2008: 2; Streeck \& Thelen, 2005: 9).

Streeck y Thelen afirman que los actores crean instituciones sin importar lo que les gustaría hacer para alcanzar sus propias metas (Streeck \& Thelen, 2005: 10). Esto es muy similar a lo que ocurre con los diálogos. Un diálogo se establece para resolver problemas delimitados por sus participantes y para transformar las relaciones entre los actores involucrados. Sin embargo, no todos los participantes cuentan con un nivel simétrico de información que les permita tomar decisiones y definir previamente sus objetivos.

El diálogo también presenta características muy similares a las de las instituciones, dado que facilitan arreglos institucionales que se renegocian periódicamente. Esto podría reflejarse en el cambio de intereses de los actores debido a modificaciones en las condiciones del contexto del diálogo. La base de este argumento es que el cambio institucional se produce a lo largo del tiempo, no solo como resultado de acontecimientos exógenos y disruptivos, sino de cambios incrementales con resultados transformadores (Streeck \& Thelen, 2005: 19).

Streeck y Thelen proponen cinco modos de cambio institucional que podrían aplicarse a la evolución de los conflictos en el marco de un diálogo en ciencia, tecnología e innovación (CTI), especialmente cuando este se desarrolla en largos períodos de tiempo:

El primer modo se denomina desplazamiento y ocurre en la medida en que surgen y se difunden nuevos modelos, que ponen en cuestión formas y prácticas organizacionales previamente existentes. El cambio institucional no se produce mediante la revisión explícita o modificación de los acuerdos existentes, sino más bien a través de cambios en la importancia relativa que asumen los diferentes arreglos institucionales dentro de un "campo" o "sistema" establecido (Streeck \& Thelen, 2005: 19-22). El segundo modo se denomina estratificación o cambio por capas y ocurre cuando los actores o reformadores desatan dinámicas que alteran las trayectorias y permiten un crecimiento diferencial. Estos actores introducen modificaciones a manera de capas o estratos que en principio se presentan como refinamientos o correctivos a las instituciones existentes (Streeck \& Thelen, 2005: 22-24). 
El tercer modo se denomina cambio por desvío y se produce cuando las instituciones se reorientan o recalibran para responder al entorno político y económico en el que están inmersas. Sin este tipo de "mantenimiento activo" las instituciones pueden estar sujetas a erosión o atrofia por quedar a la deriva en relación con sus objetivos (Streeck \& Thelen, 2005: 24-25).

La conversión es el cuarto modo de cambio institucional. Se produce cuando las instituciones son redirigidas a nuevos objetivos, funciones o fines. Este cambio de dirección puede ser el resultado de por lo menos dos factores: 1) nuevos desafíos de entorno a los que los tomadores de decisiones responden mediante el despliegue de recursos institucionales ya existentes pero los utilizan para nuevos fines; 2) los cambios en las relaciones de poder como un producto de la participación de actores que no fueron involucrados en el diseño institucional original y cuya participación en un momento posterior, les permite controlar la institución y orientarla hacia nuevos fines (Streeck \& Thelen, 2005: 26-29). Finalmente, el quinto modo de cambio se denomina agotamiento. Este modo conduce a la ruptura institucional más que a un cambio en sí mismo. Es diferente al cambio por desvío. Mientras que en este último las instituciones conservan su integridad formal, el agotamiento institucional es un proceso en el que los comportamientos permitidos por las normas existentes terminan por socavar la identidad de las instituciones (Streeck \& Thelen, 2005: 29-30).

La constante "renegociación" de los arreglos institucionales sugiere que los actores que participan de un proceso de diálogo experimentan cambios incrementales en sus posiciones e intereses. Estos cambios pueden rastrearse a lo largo del tiempo para identificar el origen y la dinámica de nuevos acuerdos institucionales que definen a una política pública. Los diálogos que se desarrollan en períodos largos de tiempo, como es el caso del MCMPCGI, ofrecen una oportunidad para identificar estas variaciones.

\section{LA TRANSFORMACIÓN DEL DIÁLOGO EN LA CONSTITUCIÓN DEL MODELO DE MEDICIÓN DE LA PRODUCCIÓN CIENTÍFICA EN COLOMBIA}

\subsection{CONSIDERACIONES METODOLÓGICAS DEL CASO}

Para la identificación de los cambios institucionales ocurridos en el MCMPCGI y de las transformaciones del diálogo ocurridas durante su consolidación, se definió un período de observación de quince años comprendidos entre 2000 y 2015. Esta periodización, coincide con la segunda etapa de la política de promoción de grupos de investigación en Colombia identificadas por Orozco et al., en la que es posible ver 
la puesta en práctica de los debates conceptuales sostenidos en Colombia durante la década de los noventa (Orozco, Ruiz, Bonilla, \& Chavarro, 2013: 649).

La elección de este período de observación se basa en los siguientes argumentos relacionados con las dimensiones y elementos del diálogo para políticas de CTI desarrollados por la Red CYTED COMLALICS:

- La interacción entre la comunidad científica y el sector público para la definición de una política pública de calidad de la investigación se hizo más evidente debido a la sofisticación del registro de las actividades de los grupos de investigación del país, mediante sistemas de información como el software Caldas, CvLAC y GrupLac. ${ }^{3}$

- La institucionalización del MCMPCGI como política de investigación obliga al sector público a definir unas normas producto de la interacción entre gobierno y comités de expertos. Dichas normas se ofrecen en formato de convocatorias cuyos anexos técnicos explican detalladamente la estructura del modelo de medición. Antes de 2000, el contenido y los términos de estas convocatorias no se dieron a conocer públicamente y los investigadores e instituciones tenían escasa información sobre el tema. Sin embargo, después de dicho año la asimetría de información que existía entre comunidad científica y sector público se ve disminuida y las posibilidades de réplica y participación a las decisiones del gobierno son más posibles.

- Los conflictos entre comunidad científica y sector público reciben un mayor cubrimiento por parte de los medios de comunicación colombianos, particularmente de la prensa, aspecto que facilita el seguimiento de las posiciones de los actores involucrados. Esta visibilidad pública de la política de calidad de la investigación incide sobre el espacio de interacción del

3 El software Caldas mejoró los procedimientos para recopilar información relacionada con los grupos de investigación y sus miembros. Este software fue desarrollado por Colciencias entre 1998 y 2000 (Orozco, Ruiz, Bonilla, \& Chavarro, 2013: 652). Posteriormente en 2002, Colciencias integró el software Caldas a CvLAC y GrupLAC, dos aplicaciones de la Plataforma Lattes. Dicha plataforma fue adaptada a partir de la experiencia desarrollada por el Consejo Nacional de Desarrollo Científico y Tecnológico $(\mathrm{CNPq})$ de Brasil. La transferencia técnica de esta experiencia para Colombia, estuvo a cargo del Grupo Stela de la Universidad de Santa Catarina en Brasil, en alianza con Colciencias y el Grupo de investigación de Ciencia, Tecnología y Sociedad de la Universidad Nacional de Colombia. 
diálogo, ya que permite identificar cambios en la interrelación de los actores y en el enfoque del objeto del diálogo y de la política pública que de él se deriva.

- La comunidad científica de universidades y centros de investigación e innovación participó decididamente de las convocatorias realizadas por el sector público (Colciencias) y de los incipientes espacios de consulta abiertos por el gobierno para recibir realimentación sobre el modelo de medición.

- El MCMPCGI se convirtió en una política fundamental que sirvió de base para la implementación de otras políticas públicas como la definición de los salarios de los docentes, el acceso de los científicos a la financiación del gobierno y el cumplimiento de requisitos para obtener la acreditación de las universidades. En este sentido, el modelo logró consolidarse como un asunto sensible para la comunidad científica y para el sector público. Los ajustes al modelo, surgidos de un eventual diálogo con expertos o con sub-grupos específicos de la comunidad científica, significaban una alta repercusión económica y de credibilidad.

Para este estudio de caso se analizaron los documentos técnicos de doce convocatorias organizadas por Colciencias entre 2000 y 2015. La información fue recolectada a partir de revisión de archivos de Colciencias, el Observatorio Colombiano de Ciencia y Tecnología (OCyT), archivos privados facilitados por algunos de los entrevistados e información de la prensa local y nacional tomada de revistas y periódicos colombianos. Dicha información se contrastó con entrevistas realizadas a tomadores de decisiones y a algunos miembros de la comunidad científica que participaron como expertos en la conceptualización e implementación de las diferentes convocatorias lideradas por Colciencias.

\subsection{ANTECEDENTES: LAS CONVOCATORIAS DE MEDICIÓN DE GRUPOS DE INVESTIGACIÓN ANTES DEL AÑO 2000}

Desde mediados de los años noventa Colciencias, la agencia gubernamental para la promoción de la CTI en Colombia, manifestó su interés en identificar las capacidades de investigación disponibles en el país. Tras el reconocimiento de la CTI como una política pública nacional relevante, apoyada por la promulgación de la Ley 29 de 1990, Colciencias diseñó una política para identificar la estructura de la comunidad científica colombiana y establecer quiénes producían conocimiento siguiendo estándares científicos. 
Entre 1991 y 1998 Colciencias organizó cuatro convocatorias para recoger información sobre la actividad de los grupos de investigación en Colombia. Estas convocatorias fueron diseñadas por los tomadores de decisiones de una forma intuitiva. De hecho, fue necesario ofrecer incentivos económicos para obtener un mayor nivel de respuestas. Estos incentivos se convirtieron en premios y contribuyeron a reconocer el trabajo científico en un momento en que la investigación era incipiente (Colciencias, 2008: 6; Villaveces, 2016). ${ }^{4}$

A partir de 1994 el Programa Nacional de Ciencia Sociales y Humanas de Colciencias orientó la reflexión sobre el "grupo" como forma distintiva de la organización de la investigación en el país. Ese mismo año el Ministerio de Educación Nacional exigió la existencia de grupos de investigación como un requisito para la creación de maestrías. Y entre 1997 y 1999 se diseñaron los primeros modelos de análisis para evaluar el comportamiento de los grupos de una manera más sistemática, con la utilización de herramientas como indicadores, índices y sistemas de información (Orozco et al., 2013: 649-653). En la convocatoria de 1996 se invitó a un grupo de expertos externo a Colciencias para que ayudara en la construcción técnica de un modelo de medición de las actividades de los grupos de investigación. Este grupo contaba con personas expertas en publicaciones, estadística y matemática. Con ellos se tenían reuniones de trabajo dos o tres veces por semana para construir un documento que definiera el modelo (Castro, 2015).

La primera versión de un modelo de medición fue diseñada para la convocatoria de 1998. Tuvo por objeto ayudar a los expertos de los comités de evaluación en la selección de grupos que recibirían apoyos económicos. Fue un escalafón basado en la producción de los científicos (artículos indexados, patentes, etc.) e incluyó información sobre financiación y equipos e instrumentos disponibles en los grupos. Estos dos últimos aspectos se omitieron en convocatorias posteriores debido a la dificultad de recoger información sobre el particular (Colciencias, 2008: 7).

Al final de la década de los noventa, lo que inició como una es-

4 La selección de los grupos premiados estaba a cargo de un comité de expertos formado por científicos independientes y reconocidos que fueron convocados por Colciencias. Durante este tiempo los términos de las convocatorias y el modelo para construir escalafones (rankings) de grupos de investigación fueron desarrollados por Colciencias y por investigadores a los que dicha institución pidió colaborar. Los términos no habían sido discutidos públicamente ni antes ni después de dichas convocatorias y los investigadores e instituciones del país tenían escaso conocimiento de ellos (Colciencias, 2001: 1). 
pecie de encuesta para identificar las capacidades de investigación del país se transformó en un modelo de medición de la producción científica en Colombia. Conceptos como "grupo de investigación", "centros de investigación", "personas que participan en los procesos de investigación" y algunos indicadores e índices iniciales para medir la actividad científica sirvieron para sustentar el modelo (Colciencias, 2008) y poner en marcha sistemas de información que garantizaran una "representación fiable" de las actividades científicas y tecnológicas en Colombia (Charum, Usgame, \& Chavarro, 2006: 73).

La construcción de este modelo requirió de un diálogo entre gobierno y comunidades científicas. Si bien a lo largo de los años 90 las interacciones entre estos actores se habían fortalecido gracias a la creación del Sistema Nacional de Ciencia y Tecnología (SNCyT) y de los Programas Nacionales de Ciencia y Tecnología, cuya secretaría técnica está a cargo de Colciencias, la construcción de un modelo de medición de la calidad científica requería de un trabajo más sistemático y riguroso entre las partes. El modelo necesitaba de acuerdos en los conceptos de medición que se utilizarían para definir quiénes estaban realizando investigación en Colombia y cuáles eran los criterios de calidad con que lo hacían.

\subsection{EL PROCESO DE DIÁLOGO DESPUÉS DEL AÑO 2000}

Desde el año 2000, la sofisticación de los instrumentos para medir el desempeño de los grupos de investigación fue evidente, demostrando que la política de calidad de la investigación era un tema importante tanto para el gobierno como para la comunidad científica. El producto principal de dicha sofisticación es lo que en términos generales podríamos denominar el Modelo Colombiano de Medición de la Producción Científica de los Grupos de Investigación (MCMPCGI). ${ }^{5}$ Entre 2000 y 2015 Colciencias lideró once convocatorias para recoger información que alimentara el modelo. Durante dicho período, se mantuvieron tres objetivos básicos que guiaron al MCMPCGI como política pública: 1) la actualización de la información sobre grupos y centros de investigación del país; 2) la consolidación de un mecanismo para clasificar los grupos de investigación de manera que se determine su trayectoria, productividad y madurez; 3) el diseño de políticas de promoción y fortalecimiento a grupos de

5 La expresión "grupos de investigación" se refiere en este texto a todos los grupos que realizan proyectos de investigación tanto en ciencia, tecnología e innovación en Colombia. En los textos técnicos de las convocatorias revisadas es común encontrar la diferenciación entre estas tres áreas. Sin embargo, para efectos de este análisis se utilizará esta expresión general para referirse a los grupos que realizan investigación en cualquiera de ellas. 
investigación en Colombia basadas en la evidencia de la información recolectada.

Sin embargo, la definición del MCMPCGI requería de un proceso de validación con expertos y de un mecanismo que les diera legitimidad a las decisiones del gobierno frente a la comunidad científica. En consecuencia, Colciencias le dio mayor relevancia y continuidad al diálogo con grupos de expertos provenientes de la comunidad científica. Siguiendo una práctica que ya había experimentado en la década de los noventa, invitó a investigadores de reconocida trayectoria en el país a que aportaran su conocimiento y le dieran credibilidad a la construcción de un modelo de medición de la calidad científica para dar cumplimiento a la ley.

A pesar del interés de la comunidad científica la definición del MCMPCGI, el diálogo con los expertos fue originado y liderado por Colciencias, constituyéndose en una iniciativa de carácter top-down. El propósito del diálogo se planteó en términos consultivos más que en términos de concertación. Los conceptos técnicos de los expertos con relación al modelo se constituían en argumentos importantes, sin embargo, Colciencias siempre mantuvo la posibilidad de tomar las decisiones finales, debido al mandato que le otorga la ley. En este sentido, el papel de los comités de expertos ha sido netamente consultivo y Colciencias es finalmente quien decide a partir de las recomendaciones que ellos hacen (Castro, 2015).

Los grupos de expertos han contribuido tradicionalmente a la consolidación del modelo. Se trata grupos ad-honorem, conformados por personas externas a Colciencias y seleccionados por su trayectoria académica y científica. Son referentes en sus respectivos campos disciplinares (Villaveces, 2016). Colciencias ha procurado que exista una representatividad de sus miembros según disciplinas (Castro, 2015). El poder de elegirlos es exclusivamente de Colciencias, aspecto que refuerza el carácter de un diálogo con direccionalidad de arriba a abajo (top-down).

En cuanto a la implementación del diálogo, a partir del año 2000 Colciencias afrontó una mayor interacción con la comunidad científica. La consolidación del MCMPCGI obligó a que la institución adoptara distintos mecanismos de difusión para explicar mejor los términos de cada convocatoria. Prácticas como charlas informativas en distintas regiones del país, consultas electrónicas abiertas sobre los términos de referencia de las convocatorias, reuniones con vicerrectores de investigación de las universidades y la publicación de análisis sobre los resultados de las convocatorias se volvieron más comunes y se sumaron a la tradicional consulta al comité de expertos. 
La producción de documentos técnicos y conceptuales que explicaban a la comunidad científica el complejo modelo de medición también motivaron la discusión y el análisis. A partir del año 2000 las diferencias entre gobierno y comunidad científica se hicieron más visibles (Orozco et al., 2013: 655) y los actores involucrados en la política pública que dictaba el MCMPCGI expresaron con mayor evidencia sus posiciones.

La forma como interactuaron gobierno y comunidad científica en torno a la construcción del MCMPCGI, durante el período 20002015, demuestra que existió una transformación de mecanismos de diálogo en la medida en la que los conflictos entre las partes se fueron evidenciando. Dichos conflictos fueron producto de los cambios en los conceptos de medición de la calidad de los grupos de investigación, de la concentración de poder en el gobierno para tomar decisiones al respecto y del poder de los comités de expertos para introducir o validar ideas en torno a la medición de la calidad. En la Tabla 2 puede apreciarse una descripción más detallada de las transformaciones al modelo de medición que proponía cada convocatoria realizada por Colciencias y de las prácticas y conflictos que incidían en el diálogo entre el sector público y la comunidad científica.

El diálogo en torno al MCMPCGI es un caso particular ya que no se previó con antelación un proceso amplio de consulta con la comunidad científica, sino que en la medida en que las convocatorias fueron avanzando se fueron implementando distintos mecanismos de difusión que facilitaron la participación de dicha comunidad y la realimentación del modelo.

En este diálogo tampoco se definió previamente un horizonte de tiempo. La misma constitución de una política pública de fomento a grupos de investigación y su transformación a lo largo del tiempo en un modelo de control de calidad fue lo que llevó a la creación de mecanismos de diálogo que, según la evidencia revisada, fueron cerrados y jerárquicos en un principio (figura de los comités de expertos) y paulatinamente dieron espacio a expresiones más horizontales y abiertas (incorporación de nuevos actores gubernamentales y mesa de concertación). Esto permite analizar la evolución del MCMPCGI como un diálogo de largo plazo donde las posiciones e interacciones de los actores involucrados (sector público y comunidad científica) se reconfiguran a lo largo del tiempo. 
Tabla 2. Principales cambios del MCMPCGI y conflictos que afectaron el diálogo

\begin{tabular}{|c|c|c|}
\hline $\begin{array}{c}\text { Año } \\
\text { Convocatoria }\end{array}$ & $\begin{array}{l}\text { Principales transformaciones } \\
\text { en la medición de los grupos de } \\
\text { investigación }\end{array}$ & $\begin{array}{c}\text { Prácticas y conflictos que influyeron en } \\
\text { el diálogo }\end{array}$ \\
\hline 2000 & $\begin{array}{l}\text { - Establecimiento de un modelo único } \\
\text { con umbrales fijos. } \\
\text { - Primera recolección de información } \\
\text { en plataforma electrónica (software } \\
\text { Caldas). } \\
\text { - Utilización índice de excelencia } \\
\text { (calidad, pertinencia, visibilidad y } \\
\text { estabilidad de grupos). } \\
\text { - Validación de artículos científicos } \\
\text { según Science Citation Index, Social } \\
\text { Science Citation Index ; índice de } \\
\text { Colciencias. }\end{array}$ & $\begin{array}{l}\text { - No se utilizó comités de expertos para } \\
\text { organización del ranking, pero sí para } \\
\text { discusión del modelo. } \\
\text { - Publicación del escalafón en la página } \\
\text { web de Colciencias. } \\
\text { - Acto oficial de presentación de } \\
\text { resultados. } \\
\text { - Debates de los resultados de la } \\
\text { aplicación del modelo en universidades e } \\
\text { instituciones de investigación. }\end{array}$ \\
\hline \multicolumn{3}{|c|}{ Punto Crítico 1} \\
\hline 2002 & $\begin{array}{l}\text { - Se abandona la idea de establecer } \\
\text { un ranking basado en un solo índice } \\
\text { de productividad o de excelencia y se } \\
\text { identifican "grupos de referencia". } \\
\text { - Recolección de información vía } \\
\text { plataforma electrónica con un nuevo } \\
\text { software (CvLAC y GrupLAC). } \\
\text { - Utilización índice Icol. } \\
\text { - Validación de artículos científicos } \\
\text { con "Publindex". }\end{array}$ & $\begin{array}{l}\text { - Discusión del modelo con la comunidad } \\
\text { científica. } \\
\text { - Debates presenciales en foros } \\
\text { regionales, medios electrónicos a nivel } \\
\text { nacional y en Programas Nacionales de } \\
\text { Ciencia y Tecnología. } \\
\text { - Establecimiento "Comités de Alto } \\
\text { Nivel" para revisar perfiles de grupos y } \\
\text { seleccionar grupos de referencia. } \\
\text { - Conformación "Comisiones de Pares" } \\
\text { para supervisar y evaluar el proceso de } \\
\text { convocatoria. }\end{array}$ \\
\hline 2005 & $\begin{array}{l}\text { - Se abandona la idea de "grupo de } \\
\text { referencia" y se propone un "servicio } \\
\text { de reconocimiento permanente". } \\
\text { - Se sigue tomando a Publindex } \\
\text { como referencia para la verificación } \\
\text { de artículos científicos, en conjunto } \\
\text { con ISI y Scielo. }\end{array}$ & $\begin{array}{l}\text { - La convocatoria no suministra } \\
\text { información al respecto, pero por las } \\
\text { características del modelo expuesto en la } \\
\text { convocatoria se deduce que los comités } \\
\text { de expertos continuaron con un papel } \\
\text { importante en el diálogo. } \\
\text { - Primeras advertencias a representantes } \\
\text { legales sobre importancia de la veracidad } \\
\text { de la información de los grupos que } \\
\text { avalan. }\end{array}$ \\
\hline 2006 & $\begin{array}{l}\text { - Se retoma la idea de clasificar a los } \\
\text { grupos en un ranking. } \\
\text { - Uso nuevo índice (ScientiCOL). } \\
\text { - Se agrega una nueva categoría de } \\
\text { productos: productos o resultados } \\
\text { artísticos que generan nuevo } \\
\text { conocimiento. } \\
\text { - Se sigue utilizando Publindex como } \\
\text { referencia para la verificación de } \\
\text { artículos científicos. }\end{array}$ & $\begin{array}{l}\text { - Denuncias de la comunidad científica } \\
\text { sobre inconsistencia en el reporte de } \\
\text { datos al sistema. } \\
\text { - Conformación en Colciencias de comité } \\
\text { asesor que revise el proceso de la } \\
\text { convocatoria. } \\
\text { - Se evidencia procedimiento para } \\
\text { solicitud de aclaraciones. }\end{array}$ \\
\hline
\end{tabular}




\begin{tabular}{|c|c|c|}
\hline $\begin{array}{c}\text { Año } \\
\text { Convocatoria }\end{array}$ & $\begin{array}{l}\text { Principales transformaciones } \\
\text { en la medición de los grupos de } \\
\text { investigación }\end{array}$ & $\begin{array}{c}\text { Prácticas y conflictos que influyeron en } \\
\text { el diálogo }\end{array}$ \\
\hline \multicolumn{3}{|c|}{ Punto Crítico 2} \\
\hline 2008 & $\begin{array}{l}\text { - Cambio significativo en el modelo } \\
\text { de medición: construcción de un } \\
\text { nuevo ranking con cinco categorías. } \\
\text { - Se generan índices y perfiles } \\
\text { estadísticos para cada grupo de } \\
\text { investigación. } \\
\text { - Establecimiento de umbrales } \\
\text { movibles. } \\
\text { - Se mantiene el índice SientiCoL con } \\
\text { pequeñas modificaciones. } \\
\text { - Desaparece la categoría de } \\
\text { productos o resultados artísticos. } \\
\text { - Se consolida Publindex como } \\
\text { referencia para la verificación de } \\
\text { artículos científicos. }\end{array}$ & $\begin{array}{l}\text { - Por solicitud de universidades y del } \\
\text { Ministerio de Educación se revisa el } \\
\text { modelo que se tenía en la convocatoria } \\
\text { de } 2006 \text {. } \\
\text { • Grupo de expertos de alto nivel } \\
\text { participa de este trabajo y sugiere: } \\
\text { volver al concepto de "productividad" } \\
\text { en lugar del de "producción" y clasificar } \\
\text { las editoriales nacionales para verificar } \\
\text { su calidad. Colciencias decide aplazar } \\
\text { las recomendaciones dos años más por } \\
\text { considerar que se afectaría radicalmente } \\
\text { el ranking. } \\
\text { - La convocatoria hace explícito que el } \\
\text { nuevo modelo fue aprobado por el Consejo } \\
\text { Nacional de Ciencia y Tecnología. }\end{array}$ \\
\hline 2010 & $\begin{array}{l}\text { - Se mantiene el modelo de medición } \\
\text { utilizado en } 2008 \text {. } \\
\text { - Colciencias inicia reflexión sobre el } \\
\text { modelo de medición de } 2008 \text {. }\end{array}$ & $\begin{array}{l}\text { - Críticas al modelo más visibles en } \\
\text { medios de comunicación. } \\
\text { - Colciencias inicia construcción } \\
\text { conceptual de un nuevo modelo. } \\
\text { - Aparece figura de Veedurías Ciudadanas } \\
\text { (Ley } 850 \text { de 2003). }\end{array}$ \\
\hline 2011 & $\begin{array}{l}\text { - Se mantiene el modelo de medición } \\
\text { utilizado en } 2008 . \\
\text { - Se inicia el diseño de un modelo de } \\
\text { reconocimiento de editoriales nacionales. }\end{array}$ & $\begin{array}{l}\text { - Se mantiene la figura de la Veeduría } \\
\text { Ciudadana. } \\
\text { - Colciencias inicia socialización nuevo } \\
\text { modelo de medición. }\end{array}$ \\
\hline 2012 & $\begin{array}{l}\text { - Se mantiene el modelo de medición } \\
\text { utilizado en } 2008 \text {. } \\
\text { - Primera convocatoria de } \\
\text { reconocimiento de editoriales } \\
\text { nacionales. } \\
\text { - Segunda convocatoria de } \\
\text { reconocimiento de editoriales } \\
\text { nacionales. }\end{array}$ & $\begin{array}{l}\text { - Primera versión del modelo para } \\
\text { modificar el de } 2008 \text {. } \\
\text { - Reuniones de socialización con } \\
\text { académicos en } 13 \text { ciudades. } \\
\text { - Comunidad científica manifiesta } \\
\text { desconocimiento del nuevo modelo y } \\
\text { cuestiona su pertinencia. }\end{array}$ \\
\hline
\end{tabular}




\begin{tabular}{|c|c|c|}
\hline $\begin{array}{c}\text { Año } \\
\text { Convocatoria }\end{array}$ & $\begin{array}{l}\text { Principales transformaciones } \\
\text { en la medición de los grupos de } \\
\text { investigación }\end{array}$ & $\begin{array}{l}\text { Prácticas y conflictos que influyeron en } \\
\text { el diálogo }\end{array}$ \\
\hline \multicolumn{3}{|c|}{ Punto Crítico 3} \\
\hline 2013 & $\begin{array}{l}\text { - Cambio en filosofía del modelo } \\
\text { de medición de 2008: Teoría del } \\
\text { Conocimiento de Paul Romer, Ley } \\
1286 \text { de 2009; Documento CONPES } \\
3582 \text { de 2009; Cuadrante de Pasteur } \\
\text { - Donald Stokes). } \\
\text { - Normalización de la productividad } \\
\text { de los grupos y uso de indicadores de } \\
\text { cohesión y cooperación. } \\
\text { - Establecimiento de categorías para } \\
\text { los investigadores (Senior, Asociado, } \\
\text { Junior). } \\
\text { - Presentación de la información en } \\
\text { perfiles de grupos. } \\
\text { - Tercera convocatoria de registro de } \\
\text { editoriales nacionales. } \\
\text { - Validación de artículos con ISI-Web } \\
\text { of Knowledge y Scopus, en cambio de } \\
\text { Publindex. } \\
\text { - Creación inventario de "Servicios de } \\
\text { Indexación y Resumen (SIR). }\end{array}$ & $\begin{array}{l}\text { - Finaliza proceso de socialización de la } \\
\text { segunda versión del modelo. } \\
\text { - Auditorías de Colciencias para verificar } \\
\text { veracidad de la información. } \\
\text { - Espacios de diálogo con otros actores } \\
\text { académicos (ej.: ASEUC, ACOFARTES, } \\
\text { ACFA, RAD) y gubernamentales } \\
\text { (MinEducación, MinCultura y CONACES). } \\
\text { - Constitución comité asesor de expertos } \\
\text { en libros resultados de investigación y } \\
\text { editoriales. } \\
\text { - Constitución comité veedor para } \\
\text { homologación de editoriales extranjeras } \\
\text { en el marco de esta convocatoria } \\
\text { (representación multidisciplinar). } \\
\text { - Experto en propiedad intelectual para } \\
\text { verificar cumplimiento de patentes y } \\
\text { modelos de utilidad. } \\
\text { - Experto en validación de algoritmos: } \\
\text { asesor experto externo al grupo técnico. } \\
\text { - Creación de la mesa de Trabajo de } \\
\text { Arte, Arquitectura y Diseño (MTAAD) y } \\
\text { construcción de criterios de valoración de } \\
\text { productos. }\end{array}$ \\
\hline 2014 & $\begin{array}{l}\text { - Se mantiene el modelo de medición } \\
\text { utilizado en } 2013 \text {. } \\
\text { - Línea base para productos en arte, } \\
\text { arquitectura y diseño con tres tipos } \\
\text { de productos. } \\
\text { - Guías de verificación más } \\
\text { detalladas para los productos de } \\
\text { nuevo conocimiento. }\end{array}$ & $\begin{array}{l}\text { - La MTAAD aparece al mismo nivel de } \\
\text { comité de expertos. } \\
\text { - Se sigue haciendo explícita la } \\
\text { responsabilidad de las instituciones que } \\
\text { avalan los grupos de investigación sobre } \\
\text { las inconsistencias de la información } \\
\text { recopilada. } \\
\text { - Se anuncia un futuro diálogo entre } \\
\text { Colciencias, la Agencia Nacional para } \\
\text { la Superación de la Pobreza Extrema } \\
\text { (ANSPE), el Departamento Nacional de } \\
\text { Planeación (DNP), el Servicio Nacional } \\
\text { de Aprendizaje (SENA) y el Ministerio } \\
\text { de Tecnologías de Información y las } \\
\text { Comunicaciones para formular una Política } \\
\text { Nacional de Innovación social. } \\
\text { - Revisión de la convocatoria de } \\
\text { editoriales universitarias con el comité } \\
\text { asesor de expertos y otros actores: la } \\
\text { Asociación de Editoriales Universitarias } \\
\text { de Colombia (ASEUC) y grupos de } \\
\text { universidades como el G8 de Medellín. }\end{array}$ \\
\hline
\end{tabular}




\begin{tabular}{|c|c|c|}
\hline $\begin{array}{c}\text { Año } \\
\text { Convocatoria }\end{array}$ & $\begin{array}{l}\text { Principales transformaciones } \\
\text { en la medición de los grupos de } \\
\text { investigación }\end{array}$ & $\begin{array}{l}\text { Prácticas y conflictos que influyeron en } \\
\text { el diálogo }\end{array}$ \\
\hline 2015 & $\begin{array}{l}\text { - Se mantiene el modelo de medición } \\
\text { utilizado en } 2013 \text {. } \\
\text { - Inclusión de las industrias creativas } \\
\text { y su importancia para el crecimiento } \\
\text { económico. } \\
\text { - Se reconoce que las áreas de arte, } \\
\text { arquitectura y diseño evidencian } \\
\text { una forma propia de generación de } \\
\text { conocimiento. } \\
\text { - Se limita el proceso de registro } \\
\text { exclusivamente a investigadores } \\
\text { vinculados contractualmente } \\
\text { a instituciones colombianas y } \\
\text { residentes en el país. }\end{array}$ & $\begin{array}{l}\text { - Se reconoce a la MTAAD como mesa } \\
\text { permanente. } \\
\text { - Se recomienda a universidades e } \\
\text { instituciones de investigación que } \\
\text { constituyan un archivo de depósito de } \\
\text { evidencias de la información que registran } \\
\text { sus grupos. Se reconoce que se ha } \\
\text { repostado información falsa. } \\
\text { - Se anuncia proceso de diálogo con } \\
\text { representantes de las Ciencias Sociales y } \\
\text { Humanas. }\end{array}$ \\
\hline
\end{tabular}

Fuente: elaboración propia con base en (Colciencias, 2002, 2005, 2006a, 2006b, 2006c, 2008, 2010, 2011, 2013a, 2013b, 2014, 2014, 2015, 2015, 2015, 2016)

Nota: se utilizaron los textos oficiales de las convocatorias y en algunos documentos oficiales de evaluación o de realimentación sobre las mismas elaborados por Colciencias. En algunas ocasiones los términos técnicos utilizados por los textos no son uniformes, en cuyo caso se acudió a los documentos técnicos de los modelos de medición para resolver la diferencia de términos.

\subsection{LA TEMPORALIDAD Y LOS PUNTOS CRÍTICOS EN LA TRANSFORMA- CIÓN INSTITUCIONAL DEL DIÁLOGO}

Como se ha argumentado en la parte conceptual de este capítulo, el MCMPCGI puede ser entendido como una institución en la medida en que fue construyendo gradualmente unas reglas de juego para definir quién era investigador y cuáles eran los criterios para medir la calidad de su trabajo. Durante este proceso, experimentó cambios producto de la interacción entre el gobierno y la comunidad científica.

Estos cambios están estrechamente ligados con la dimensión de temporalidad del diálogo.

¿Por qué el MCMPCGI se ha mantenido vigente durante los últimos quince años? Siguiendo el enfoque de Streeck y Thelen, una posible respuesta es porque ha desarrollado un tipo de adhesión a la realidad social que le permite que permanecer en el tiempo. A partir de la revisión de las convocatorias implementadas entre 2000 y 2015, podría afirmarse que los componentes del MCMPCGI que han persistido a lo largo de este tiempo y que han contribuido a dicha adhesión son:

- La actualización información para la identificación de capacidades de los grupos de investigación. 
- La utilización de métricas sofisticadas (indicadores, índices compuestos) para la medición de la calidad de los grupos de investigación a partir del análisis de su producción.

- La consideración de al menos tres dimensiones en las que se observan los productos: nuevo conocimiento, formación de recursos humanos para investigación, extensión y apropiación del conocimiento.

La perspectiva institucionalista también facilita el análisis de diálogos de largo plazo. En el caso analizado, dicha perspectiva permite identificar puntos críticos en los que la política pública, representada en el modelo de medición, sufrió cambios significativos en las reglas de juego, aspecto que incidió en el desarrollo del diálogo y la confianza entre los actores. Así mismo determinaron el cambio de posiciones de los actores participantes, el uso de sus recursos y las interrelaciones entre ellos. A continuación, se describen tres puntos críticos ${ }^{6}$ donde dichos cambios se reflejaron con mayor intensidad:

- Punto crítico 1. Se identifica en la Convocatoria de 2002, cuando el MCMPCGI abandonó la idea de la clasificación jerárquica de los grupos de investigación que se había planteado en la convocatoria del año 2000 y la reemplazó por la selección de un conjunto de "grupos de referencia" cuyos perfiles servirían para hacer comparaciones "en" y "entre" los Programas Nacionales de Ciencia y Tecnología coordinados desde Colciencias. El objetivo fue promover la idea de la comparación entre los grupos, antes que la de determinar su orden en un ranking de calidad. El diálogo entre gobierno y comunidad científica se implementó a través de debates, consultas presenciales y distintos tipos de comités de expertos (alto nivel, comisión de pares) conformados por investigadores nacionales e internacionales de reconocida trayectoria. Estos comités analizaban los perfiles de los grupos de referencia con el fin de dar transparencia al proceso de la convocatoria. Los mecanismos de participación

6 La propuesta de estos puntos críticos fue hecha de manera preliminar para facilitar la identificación de cambios en el MCMPCGI y está basada en la comparación de las convocatorias, teniendo en cuenta los siguientes aspectos: a) utilización o no de la idea de ranking; b) diferenciación en la medición de los productos de distintas disciplinas; c) uso de índices compuestos; d) cambios en las categorías de productos de investigación que se miden; e) formas de validación de los productos registrados por los grupos; f) formas en que se recolecta y presenta la información de los grupos; g) mecanismos de diálogo entre gobierno y comunidad científica. 
de la comunidad científica eran incipientes o estaban restringidos al desempeño de los miembros de los comités de expertos, los cuales eran elegidos únicamente por Colciencias. En este punto crítico puede apreciarse una asimetría en el diálogo ya que el sector público concentraba la capacidad y el poder de elegir a los expertos con los que dialogaba más directamente.

- Punto crítico 2. Se identifica en la Convocatoria de 2008, cuando se consolida la idea de un ranking de grupos que fue implementada nuevamente en la convocatoria de 2006 y se incorpora en la medición el concepto de "umbral móvil", que clasifica a los grupos según sus proyectos por área de investigación (ciencias básicas, ciencias sociales, ingeniería, etc.) y tomando como referencia los grupos que se presentan a cada convocatoria. ${ }^{7}$ En términos de diálogo, el comité de expertos de la convocatoria tuvo una notoria influencia e hizo recomendaciones técnicas, de alta sensibilidad en el proceso de diálogo, como la medición de la "productividad de los grupos"8 y la definición de un mecanismo para evaluar la calidad de las editoriales locales. También se destacó el nivel de atención pública que logró el tema, ya que las mismas universidades y el Ministerio de Educación Nacional solicitaron revisar el modelo de 2006. El resultado de esta interacción quedó plasmado en el modelo de medición de 2008 en el que desapareció la categoría de productos o resultados artísticos que se había implementado en 2006 y se regresó a la clasificación tradicional: nuevo conocimiento,

7 Un umbral define el valor más alto esperado para un indicador determinado (por ejemplo, nuevos conocimientos, formación en investigación o difusión del conocimiento). En 2002, los umbrales se definieron tomando como referencia valores previamente establecidos por los expertos (Colciencias, 2008: 11). A partir de 2008 el método de cálculo de los umbrales cambió y pasaron a definirse según los valores más altos en los indicadores presentados por los grupos dentro de la misma convocatoria. En este sentido, en 2008 se produjo una transformación de "umbrales fijos" (que se definen a partir de datos externos) a "umbrales móviles" (definidos de acuerdo a los valores que se encuentran en cada convocatoria específica).

8 El concepto de "productividad" es el resultado de la división de la producción del grupo durante un período de observación determinado entre el número de investigadores con dedicación de tiempo completo en el mismo período de tiempo. El comité de expertos de la convocatoria de 2008 argumentó que el tiempo de dedicación a las actividades del grupo de investigación no significaba que el investigador fuera más productivo. Por ello, el comité recomendó incluir los pesos estadísticos del índice de acuerdo con el nivel de educación de los investigadores (por ejemplo, PhD, maestría, pregrado). Colciencias no puso en práctica esta recomendación de inmediato debido a la existencia de un alto porcentaje de grupos registrados con baja o nula producción (Colciencias, 2008: 14). 
formación de investigadores, y divulgación y extensión. En términos de diálogo, en este punto crítico se sigue apreciando una asimetría de poder que favorece al sector público, aunque se aprecian rasgos de una mayor presión de la comunidad científica a través de otras instituciones tradicionales como las universidades y el Ministerio de Educación.

- Punto crítico 3. Ocurrió en la Convocatoria de 2013, cuando se produjo una evidente reorientación del modelo como producto de la interpretación de la nueva normatividad sobre ciencia, tecnología e innovación (Ley 1286 de 2009). La convocatoria enfatizó la necesidad del uso del conocimiento para resolver problemas sociales. En términos técnicos, utilizó técnicas estadísticas para normalizar la productividad de los grupos, priorizó métricas internacionales para validar la producción de artículos científicos y enfatizó el uso de mecanismos de verificación de información. El diseño y la implementación de esta convocatoria fueron muy criticados por la comunidad científica, lo que motivó diversas reacciones: desde cartas de queja suscritas por académicos de distintas disciplinas, hasta el anuncio de demandas legales por considerar que los términos de la convocatoria atentaban contra los derechos fundamentales de los científicos. La posición de la comunidad científica tuvo una mayor visibilidad en medios de comunicación y se dio lugar a nuevas formas de diálogo, de carácter más horizontal y representativo, como fue el caso de la Mesa de Trabajo de Arte, Arquitectura y Diseño (MTAAD). A pesar de esta apertura en términos de interlocución, el funcionamiento de los tradicionales comités de expertos continuó. Sin embargo, a partir de este punto crítico se puede identificar una mezcla de mecanismos de diálogo que son producto de cambios incrementales en las condiciones del modelo de medición.

\subsection{CONFLICTO Y DIÁLOGO A PARTIR DEL MODELO DE MEDICIÓN 2013}

La convocatoria del año 2013 representó un punto de quiebre importante para entender la aparición de mecanismos más participativos de diálogo, si se quiere sub-diálogos, como fue el caso de la MTAAD. La exacerbación de las críticas al MCMPCGI y la radicalización de las posiciones entre sector público y comunidad científica fueron un punto de partida importante para que se abrieran nuevos espacios de interacción. Los medios de comunicación dieron una mayor visibilidad al debate y contribuyeron a identificar las posiciones de los actores. 
Desde el año 2000, la comunidad científica colombiana manifestó sus críticas, principalmente a través de medios internos de las universidades (Wasserman, 2001) y medios de comunicación nacional (Dinero, 2001). En medios de circulación nacional el tema fue informado a la opinión pública resaltando la existencia de una comunidad científica en Colombia que requería de mayores recursos financieros para su consolidación. También se visibilizaron las capacidades de investigación de las universidades, la posibilidad de abordar temas críticos para el país con dichas capacidades y la importancia del MCMPCGI para la consolidación de la comunidad científica (El Tiempo, 2000, 2003, 2004; Semana, 2006; Dinero, 2009). Igualmente, la discusión generó reflexiones de tipo técnico y conceptual en las que se planteó la posibilidad de diseñar métodos de medición alternativos al MCMPCGI (Soto Mejía, Giraldo Tascón, \& Arenas Valencia, 2007).

En términos generales, las críticas al modelo se enfocaron en cómo adaptar el reconocimiento de productos a la dinámica propia de la ciencia internacional y a la incorporación de nuevos productos que reflejaran otras actividades como la innovación (Fog, 2010), el impacto social de las investigaciones o la inclusión de productos de investigación de áreas tan específicas como las artes. Con respecto a este tema, la Convocatoria de 2006 incluyó el reconocimiento de los nuevos productos de investigación en artes siempre y cuando tuvieran derechos de autor o fueran aprobados por cualquier institución autorizada $^{9}$, sin embargo el modelo de 2008 no tomó en cuenta este avance conceptual y volvió a la tipología tradicional de productos empleada desde 2002.

En febrero de 2010 Colciencias inicia otra revisión del MCMPCGI para incluir nuevos productos de grupos que trabajaban con el sector productivo, principalmente de investigación y desarrollo tecnológico, y para ajustar los requerimientos de existencia y calidad. El proceso generó nuevamente inquietud entre la comunidad científica y se volvió a plantear la discusión sobre la pertinencia de mantener una categorización absoluta (ranking) de los grupos (EAFIT, 2012).

Colciencias acudió nuevamente al mecanismo de construcción conceptual validada con los tradicionales comités de expertos (Col-

9 Para este caso, el producto tendría el mismo peso relativo en el índice como un artículo de investigación en una revista, una patente de invención o un producto tecnológico. En la Convocatoria de 2006, los productos de investigación de artes incluyen: arreglos musicales, composición musical, obras de arte visual y otra producción artística y cultural (Colciencias, 2006b: 8-9). Los pesos relativos asignados por el modelo para los productos de investigación de artes aparecen en la Tabla 1 del documento técnico de la Convocatoria. 
ciencias, 2013a: 12). Los principales cambios producto de esta discusión implementados en la convocatoria de 2013 fueron:

- El establecimiento de una tipología de integrantes de los grupos (Senior, Asociado, Junior).

- La incorporación de nuevos productos relacionados con gestión empresarial, apropiación social del conocimiento y participación en proyectos de extensión universitaria.

- La implementación del índice de productividad con perfiles de grupo por área de conocimiento.

- La visibilización de productos, proyectos y líneas de investigación para observar relaciones entre distintos grupos.

- El fortalecimiento de medios de validación y verificación de la información registrada.

- La actualización de la tipología para la clasificación de productos: incorporación de productos resultados de actividades de desarrollo tecnológico e innovación.

A partir de la convocatoria del año 2013, el aparente equilibrio entre Colciencias y la comunidad científica se rompió. El nuevo modelo de medición tenía cambios que generaron reacciones en contra de una buena parte de la comunidad científica. Entre los cambios más polémicos estaban: 1) la inclusión de sistemas internacionales de indexación y homologación (Web of Science y Scopus) como referencia para definir la calidad y el impacto de los artículos de investigación, decisión que implicó el desplazamiento del índice de publicación nacional (Publindex) como principal referencia de la calidad; 2) el establecimiento de un registro oficial de las editoriales nacionales para validar la calidad de los libros de investigación presentados por los grupos.

Como resultado, de 412.540 documentos registrados como "artículos científicos" en la convocatoria de 2013, solamente 287.713 cumplieron con los requisitos de existencia, y de 38.322 libros de investigación reportados, solamente 30.322 tuvieron los mismos criterios (Colciencias, 2014a: 10-12). En cuanto al producto denominado "libros resultado de investigación", la convocatoria recibió 74.909 registros de los cuales solo 38.552 fueron reconocidos como tales. ${ }^{10}$

10 Entre 2011 y 2013 se organizaron tres convocatorias para reconocimiento de editoriales nacionales con el fin de verificar la calidad de los libros resultados de investigación. A partir de 2013 la homologación de una editorial por Colciencias era un paso previo para el reconocimiento de dicho tipo de libros (Colciencias, 2013a: 119). 
La disminución en los productos de investigación fue interpretada por algunos sectores como la extinción de la comunidad científica en Colombia (Vallejo, 2013). Para los tomadores de decisiones de Colciencias era cuestión de ser coherentes con el discurso de la calidad de la investigación (Delgado, 2016).

En lo que respecta a los mecanismos de diálogo y generación de confianza, a pesar del establecimiento de nuevos comités de expertos ${ }^{11}$ para atender las demandas de la comunidad científica de ciencias sociales y humanas (Por ejemplo, una evaluación más cuidadosa de los libros resultado de investigación y capítulos de libro), los textos de las convocatorias de 2013, 2014 y 2015 estuvieron llenos de advertencias sobre las consecuencias jurídicas de reportar información falsa. Colciencias anunció la asignación de "mecanismos simples y eficientes" para fortalecer el control de la ciudadanía sobre la información reportada por los grupos de investigación. Asimismo, invitó a las universidades e instituciones de investigación a reportar casos de fraude ante las autoridades de control pertinentes (Colciencias, 2014a: 18).

Entre 2014 y 2015, la crisis de confianza entre las partes se hizo aún más evidente. Cartas abiertas a las directivas de las universidades y de Colciencias, artículos en revistas y periódicos, y actas de los foros académicos circulaban criticando el modelo. Colciencias fue acusado de ignorar el consenso académico y de promover la aplicación del Modo 2 de producción de conocimiento, siguiendo las directrices internacionales de la OCDE. La inclusión de índices internacionales (WoS y Scopus) como indicadores de la calidad de los artículos de investigación significaba la "mercantilización de la investigación". La construcción de un "ciencia propia para Colombia" era imposible si el gobierno promovía criterios anglosajones anclados en la lógica del mercado. Además, la disminución en el número de artículos de investigación afectó directamente el salario de los investigadores (Espinosa Menéndez \& Insuasty Rodríguez, 2015; Vallejo, 2013).

En 2014 Colciencias realizó una nueva convocatoria con algunas modificaciones producto de observaciones de la comunidad y del comité de expertos, pero manteniendo en esencia los criterios del modelo establecido en 2013 (Colciencias, 2014: 5). Entre las principales novedades estaban:

11 A partir de la convocatoria de 2013 se organizaron una serie de nuevos comités y equipos técnicos. En la Convocatoria de 2015, el comité tradicional de expertos de grupos de investigación, desarrollo e innovación, estaba acompañado por dos nuevos comités (revisión de los aspectos conceptuales del MCMPCGI, y comité asesor para la evaluación de libros y capítulos de libros resultado de investigación), dos equipos técnicos (construcción del modelo y escritura conceptual del modelo) y una mesa de trabajo (artes, diseño y arquitectura). 
- La construcción de una línea de base para medir productos derivados de investigación/creación en arte, arquitectura y diseño, incorporando por primera vez tres tipos de productos acordados con la Mesa de Trabajo de Arte, Arquitectura y Diseño (MTAAD).

- La reformulación de la estrategia de validación de libros resultados de investigación. Se crearon dos guías: una para libros publicados antes de diciembre de 2006 y otra para los que se publicaron después de esa fecha.

- La redacción de guías de verificación más detalladas para los productos de nuevo conocimiento.

Algunos grupos de investigación de universidades reconocidas en el campo de las ciencias sociales y humanas, decidieron no participar en la convocatoria de 2014 (Arango, 2015; Arias et al., 2015; Fernández Moreno, 2015; Pérez et al., 2015; Profesores y profesoras Departamento de Literatura, 2014). Las críticas al MCMPCGI que sustentaron dicha decisión fueron de distinta índole:

- Desconocimiento de la dinámica de la investigación en ciencias sociales y humanas.

- Predominancia de estándares de investigación de las "ciencias duras y aplicadas" en el modelo de medición.

- Procedimientos burocráticos excesivos (por ejemplo, exigencia de certificaciones para cada producto de investigación).

- Principio de desconfianza en la información proporcionada por los grupos de investigación.

- Existencia de problemas técnicos y obsolescencia del software de registro (plataforma ScienTI).

- Falta de criterios para medir la actividad de los grupos de investigación interdisciplinarios e interinstitucionales.

- Falta de argumentos para justificar los cambios frecuentes en los criterios de medición y ventanas de observación de los productos de investigación.

- Dudas sobre los criterios para asignar los pesos relativos de los productos de investigación.

- Falta de instancias reales de participación en las que se cumplieran las exigencias de los académicos.

- Promoción del "colonialismo académico" y la privatización de la circulación del conocimiento, a través de la asignación de los 
valores más altos a los productos registrados en índices internacionales como WoS y Scopus.

Otras instituciones de investigación también adoptaron posiciones críticas (Facultad de Educación \& Facultad de Ciencias Sociales y Humanas, 2015; Zambrano, 2014) pero de alguna manera contribuyeron a definir alternativas para la medición de las actividades de investigación, especialmente en las ciencias sociales y humanas:

- Dar prioridad a la producción de libros por encima de artículos en revistas como un indicador de la producción científica.

- Entender el ritmo lento en la dinámica de las citaciones académicas debido al tiempo extenso que demanda la escritura de libros de investigación.

- Ponderar en el modelo la baja representación de revistas en idioma español registradas en WoS y Scopus, aspecto que es fundamental en la misión de las ciencias sociales y humanas y especialmente en áreas como el estudio de la lengua española.

- Incluir asociaciones académicas y facultades en la construcción de un nuevo modelo de medición.

- Iniciar una reflexión sobre la necesidad de reconocer proyectos de investigación que contribuyan a solucionar los problemas sociales de una manera inmediata.

- Fortalecer la calidad del Sistema Nacional de Indexación (Publindex).

- Reemplazar el MCMPCGI por un programa de investigación con una lógica de trabajo en red y no de competencia entre los grupos de investigación.

Colciencias aceptó invitaciones de universidades para discutir el inconformismo de los investigadores como producto de los resultados de la convocatoria de 2013 y respondió a las comunicaciones oficiales enviadas principalmente por las universidades. Lucy Gabriela Delgado, Directora de Fomento a la Investigación de Colciencias (septiembre de 2013 - julio de 2015) manifestó que después de la presentación de los resultados de la convocatoria de 2013, Colciencias tuvo que responder alrededor de 7.000 reclamaciones en tres días. Posteriormente, tuvo que asistir a una reunión con el Ministerio de Educación para explicar a los rectores de las universidades acreditadas, por qué sus grupos de investigación aparecían en los puestos 
más bajos del escalafón, en comparación con las antiguas convocatorias. En su concepto la comunidad científica tuvo la oportunidad de discutir y aportar al modelo aplicado en 2013 durante los tres años anteriores a su aplicación, pero solo hasta el momento en que el modelo fue implementado y la clasificación no favoreció a los grupos se empezaron a recibir la mayoría de las observaciones (Delgado, 2016).

La crisis de confianza alcanzó uno de sus puntos más altos con el anuncio de una demanda legal en contra de la convocatoria de 2014, por considerar que violaba los principios de equidad y buena fe promulgados en la Constitución de Colombia, instaurada por uno de los miembros del grupo de investigación Constitucionalismo Comparado de la Facultad de Derecho de la Universidad Nacional de Colombia. Según dicho grupo, las convocatorias de 2013 y 2014 vulneraban la autonomía universitaria y el derecho a la igualdad de los investigadores en ciencias sociales, humanidades y artes porque partían de la mala fe de los investigadores y porque los requisitos de acreditación de los productos académicos se aplicaban retroactivamente. Adicionalmente, la posición del grupo criticaba el uso de las bases de datos que utilizaba Colciencias para validar artículos científicos y libros resultados de investigación ya que todas ellas eran propiedad de Thomson Reuters (El Espectador, 2015). ${ }^{12}$

De parte de Colciencias la desconfianza se basaba en que los criterios de existencia de algunos productos científicos no estaban claros o no habían sido reportados adecuadamente por los investigadores en la plataforma de la convocatoria. En la convocatoria de 2014 se encontró que de un total de 468.149 registros de artículos científicos, 65.918 no cumplieron los requisitos de existencia (Colciencias, 2014: 6). Las razones para el no reconocimiento iban desde no diligenciar la información completa en una de las casillas del software hasta la no aparición en revistas indexadas en los índices bibliográficos ISI o Scopus (Colciencias, 2014: 10). Colciencias realizó auditorías al azar para identificar inconsistencias. A partir de las muestras seleccionadas por un software especializado, el personal de Colciencias verificaba la existencia de los artículos científicos reportados por los grupos incluidos en la muestra (Delgado, 2016).

12 El líder del Grupo de Constitucionalismo Comparado de la Universidad Nacional de Colombia, Profesor Bernd Marquardt, figura como uno de los miembros del Comité Asesor de Revisión para la Valoración de Libros Resultado de Investigación y Capítulo en Libro Resultado de Investigación conformado por Colciencias para la aplicación del MCMPCGI en 2014 (Colciencias, 2014: 3). Esto sugiere que el conflicto entre gobierno y comunidad científica se reflejó también los mecanismos de diálogo tradicionales en este proceso como fue el caso de los comités de expertos. 
La convocatoria del MCMPCGI para el año 2015 continuó con los criterios determinados por el modelo de 2013 y con los tradicionales ajustes producto de las consideraciones expuestas por la comunidad científica y por algunos de los comités de expertos que acompañaban el proceso (Colciencias, 2015: 1). La crisis en el diálogo entre gobierno y comunidad científica tuvo dos frentes distintos de desarrollo: uno en el que gobierno y distintos sectores de investigadores de ciencias sociales y humanidades no lograban establecer un punto de encuentro con el gobierno sobre un modelo genérico que pudiera medir la calidad de la investigación en todas las disciplinas, y otro en el que el gobierno y los investigadores en artes, arquitectura y diseño exploraban un nuevo mecanismo de diálogo y negociación para que los productos de investigación de sus disciplinas fueran reconocidos por el MCMPCGI. ${ }^{13}$

\subsection{LA INCORPORACIÓN DE UNA PRÁCTICA MÁS REPRESENTATIVA DE NEGOCIACIÓN: LA MESA DE CONCERTACIÓN EN ARTES, ARQUITECTURA Y DISEÑO}

Paradójicamente, al mismo tiempo que el conflicto se hizo más agudo como producto de las modificaciones incluidas al MCMPCGI en 2013, en ese mismo año se instauró un nuevo mecanismo de diálogo: la Mesa de Arte, Arquitectura y Diseño (MTAAD). La MTAAD podría ser considerada como mecanismo específico de diálogo que coexiste con los comités de expertos o como una especia de sub-diálogo que plantea una comunicación más horizontal entre comunidad científica y sector público.

La MTAAD fue un grupo de trabajo creado en 2013 para incorporar en el MCMPCGI los productos de investigación derivados de las artes, la arquitectura y el diseño. Fue conformada por representantes de las tres asociaciones de facultades en estas áreas, funcionarios de Colciencias, los Ministerios de Educación Nacional y Cultura, y la Secretaría de Cultura de Bogotá. La mesa contó también con la participación de invitados ocasionales (Colciencias, 2015: 124).

La conformación de la MTAAD no fue un asunto inmediato. Con motivo de la presentación de los resultados de la convocatoria de 2012, asociaciones como la Asociación Colombiana de Facultades y Programas de Arte (ACOFARTES), la Asociación Colombiana de Facultades y Programas de Arquitectura (ACFA) habían manifestado no reconocerse en el MCMPCGI y planteando la necesidad de establecer

13 En la información analizada se encontraron algunas evidencias de que los investigadores de "áreas duras de la ciencia" también manifestaron su descontento por la implementación del MCMPCGI. Sin embargo, dicha evidencia (comunicaciones abiertas y artículos de prensa) no fue tan abundante como la proveniente de las disciplinas de ciencias sociales y humanidades. Por esta razón, el tema no se revisa a profundidad en este capítulo y queda pendiente para análisis posteriores. 
un nuevo modelo de medición propio y un programa nacional para artes, arquitectura y diseño (Bonilla, 2016; Mesa Artes, Arquitectura y Diseño, 2016). La vacilación de la inclusión de los productos de arte en el modelo de medición, reflejada en su aparición dentro de la convocatoria de 2006 y su posterior retiro en la convocatoria de 2008, significaba una nueva demanda de modificación al modelo de medición. Aunque Colciencias no aceptó abrir un nuevo programa nacional de ciencia y tecnología para estas áreas, solicitud que fue manifestada por las asociaciones mencionadas, se acordó iniciar un proceso de conversación a través de una mesa de trabajo.

En septiembre de 2013 iniciaron los diálogos en la MTAAD y en diciembre del mismo año ACOFARTES, ACFFA y la Red Académica de Diseño (RAD) presentaron ante la mesa un documento para la creación del Sistema Nacional de Artes, Arquitectura y Diseño (Colciencias, 2014: 14). La identificación de un lenguaje común fue uno de los primeros desafíos. Al principio fue una especie de "diálogo sordo". "La Directora de Fomento a la Investigación de Colciencias venía de las ciencias básicas. No la entendíamos y ella no nos entendía a nosotros" (Bonilla, 2016). La desconfianza entre las partes era el punto de partida. "Usted viene de las ciencias duras, entonces por eso usted no nos entiende. Y tenían razón. A mí me tocó sentarme a leer documentos de historia del arte y de ciencia del arte para poder entenderlos" (Delgado, 2016).

Las dos partes reconocieron la voluntad de trabajo conjunto a pesar de las dificultades. Una de las estrategias principales de las asociaciones fue enfocarse en demostrar a Colciencias que el arte también produce nuevo conocimiento, solo que lo hace a través de métodos distintos al tradicional "método científico". Adicionalmente, incorporaron a su argumentación el discurso de las "industrias creativas", y su impacto en el crecimiento de la economía nacional y mundial. ${ }^{14}$ De esta manera se fue construyendo un lenguaje común que es uno de los elementos clave para resolver asimetrías de poder y clarificar conceptos que faciliten el entendimiento entre las partes.

14 El anexo 4 de la convocatoria del MCMPCGI para el año 2015 argumentaba: "Las artes, la arquitectura y el diseño constituyen un campo sinónimo de creación e innovación, que aporta formas alternativas de investigación y generación de nuevo conocimiento en sus objetos de estudio, metodologías, formas de desarrollo de pensamiento, así como en la naturaleza y variedad de sus producciones [...] es necesario destacar que uno de los sectores con mayor potencial de crecimiento y aporte es el de la Cultura, el cual en los últimos años ha tenido una participación en el PIB importante; de hecho en el 2013 el sector cultural generó $\$ 20$ billones COP que representaron un aporte del 3,3\% en el PIB nacional (Morales, 2013), mientras que crece en un 5\% en el promedio global" (Colciencias, 2015: 122). 
Según Bonilla, existieron cuatro factores que fueron fundamentales para que el diálogo surtiera efecto utilizando como mecanismo la mesa de trabajo: la voluntad de iniciar el diálogo; el reconocimiento de que en artes también se produce nuevo conocimiento; el acuerdo sobre cómo evaluar los tipos de obras que se producen en artes, arquitectura y diseño; y la forma en que se incorporaron al modelo de medición criterios, valoraciones y pesos de los productos en artes (Bonilla, 2016).

Los dos últimos puntos mencionados por Bonilla son esenciales para la estructura del MCMPCGI. El desafío de "tipificar" productos de investigación y, adicionalmente, darle pesos, es uno de los puntos más sensibles en el modelo de medición. Colciencias reclamó una definición clara y exacta de los productos, acorde a lo que tradicionalmente el modelo había contemplado, es decir, un modelo muy codificado desde las ciencias duras. Sin embargo, el reconocimiento de que las artes producían conocimiento con un método distinto al científico obligaba también a pensar los productos en este sentido. Un ejemplo de ello eran los eventos que denotaban apropiación social del conocimiento y que en el MCMPCGI tenían un peso específico dentro del índice de medición:

Lo normal es que para eso (medir la apropiación social del conocimiento) se hable mucho de los eventos. Pero en artes hay unos eventos que son bastante diferentes a los que se hacen en ciencia y tecnología. Estos últimos generalmente son eventos pequeños, específicos, con unas temáticas muy cerradas, muy claras, porque los públicos son muy escasos. Los lectores de un artículo de ciencia no tienen un volumen muy grande, las reuniones de científicos sobre un tema no son de un volumen muy grande. En cambio, la puesta en escena de una obra de arte es masiva. Entonces las medidas de apropiación del conocimiento tienen características distintas en las unas y en las otras [...] En algún momento se llegó a pensar en cosas tan absurdas como crear una lista de salones o auditorios indexados. (Bonilla, 2016)

Finalmente, la mesa llegó a acuerdos claves que contribuyeron a la generación de un lenguaje común. Conceptos como "investigacióncreación", "tipología de obras/productos de investigación" formaron parte de un nuevo vocabulario común. Así mismo, bajo el concepto de "industrias creativas" se reconocieron los emprendimientos (spinoff) en artes. De esta manera las partes llegaron a un acuerdo para dar visibilidad a un conjunto de productos que antes no la tenían en el modelo de medición, a pesar de los intentos hechos en 2006 y 2008 por incorporar dichos productos. Un ejemplo de los acuerdos conceptuales logrados en la MTAAD se puede apreciar en la Tabla 3, en la que aparecen las definiciones de tres tipos de productos que reflejan 
el consenso de las partes en cuanto a la producción investigativa en artes, arquitectura y diseño. Este consenso permitió un mayor reconocimiento de la productividad de los investigadores en estas áreas.

Tabla 3. Tipología de productos de investigación en artes, arquitectura y diseño según su relación con el tiempo

\begin{tabular}{|l|l|}
\hline \multicolumn{1}{|c|}{ Tipo de producto } & \multicolumn{1}{c|}{ Descripción } \\
\hline Obra o creación efímera & $\begin{array}{l}\text { Son las obras, diseños o productos, materiales e inmateriales, } \\
\text { cuya existencia es de una duración limitada en el tiempo y el } \\
\text { espacio y cuya evidencia depende, por lo tanto, de la memoria } \\
\text { reconstructiva. Son sus huellas, rastros, o registros lo que } \\
\text { corroboran su existencia y las hacen reconocibles. El registro } \\
\text { deber ser repetible, exportable y verificable. }\end{array}$ \\
\hline Obra o creación permanente & $\begin{array}{l}\text { Son obras, diseños o productos -materiales e inmateriales- cuya } \\
\text { existencia pretende ser ilimitada en el tiempo. La presencia y } \\
\text { persistencia del objeto que registra la obra o producto demuestra } \\
\text { su existencia. Sin embargo, la obra o producto mismo predomina } \\
\text { sobre el valor del registro. }\end{array}$ \\
\hline Obra o creación procesual & $\begin{array}{l}\text { Son aquellas obras, diseños o productos materiales o } \\
\text { inmateriales, en cuya naturaleza predomina la dinámica } \\
\text { transformadora, sistemática y relacional; por esta razón tienen un } \\
\text { carácter abierto y no están sujetas a un marco espacio temporal } \\
\text { predeterminado. Generan un impacto verificable pero previsible } \\
\text { material e inmaterial. El reconocimiento de este tipo de producto } \\
\text { se basa en la existencia de indicadores cualitativos o cuantitativos } \\
\text { que den cuenta de las dinámicas del proceso. }\end{array}$ \\
\hline
\end{tabular}

Fuente: (Colciencias, 2015: 125)

Por las características del proceso de medición, la realización de un simulacro para probar la respuesta de los grupos de artes, arquitectura y diseño fue fundamental para asegurar la confianza en la negociación. En la convocatoria de 2014 se incorporaron en la medición los productos de estas áreas (Colciencias, 2014: 18) y se hizo un simulacro cuyos resultados fueron analizados por fuera del análisis global de la convocatoria. Solo hasta la convocatoria de 2015 se hizo un análisis desagregado donde se visibilizaron los nuevos productos. Las categorías tradicionales del modelo registraron por primera vez de manera específica 1.246 obras o productos de arte, arquitectura y diseño como productos de nuevo conocimiento; 156 registros de acuerdos de licencia para la explotación de obras y 21 empresas creativas y culturales como productos e desarrollo tecnológico e innovación; 108 talleres de creación y 456 eventos artísticos como productos de apropiación social del conocimiento y 252 proyectos de investigación-creación como productos de formación de recurso humano (Colciencias, 2016: 5-7). 
En la actualidad la MTAAD es reconocida como una mesa permanente. La visibilización de los productos de investigación lograda en la convocatoria de 2015 generó una sensación de reconocimiento en las comunidades vinculadas a estas áreas. Las asociaciones que participaron de la MTAAD informaron constantemente a sus afiliados sobre los resultados que se iban alcanzando en cada reunión de Colciencias y se recogían los aportes para llevarlos a discusión con Colciencias. Algunas universidades no afiliadas a las asociaciones buscaron participar de manera independiente en la mesa, sin embargo el principio de representatividad de las asociaciones fue respetado por las partes, aspecto que facilitó avanzar en el diálogo (Bonilla, 2016).

El resultado concreto del diálogo con la MTAAD se reflejó en la inclusión de los productos de arte, arquitectura y diseño en el modelo. De igual forma contribuyó a que el trabajo de investigación de estas áreas fuera tomado más en cuenta al interior de las propias universidades donde el MCMPCGI tiene un peso importante debido que sus resultados inciden en la acreditación de programas de pregrado y posgrado. En cuanto a acceso a recursos, Colciencias tiene como requisito para participar en sus convocatorias de proyectos que los grupos estén registrados en la plataforma ScienTI y, en algunos casos, que los líderes de investigación tengan una categoría específica dentro del modelo de medición (junior, senior, asociado). El MCMPCGI también se ha tomado como referencia para la definición del régimen salarial y prestacional de los docentes de las universidades estatales. ${ }^{15}$ Todavía está por analizarse cómo estos aspectos influyen en el proceso de diálogo ya iniciado. Precisamente la falta de financiación por parte del Estado ha sido uno de los factores que más ha disgustado a la comunidad científica en relación con un modelo que para su alimentación demanda mucho del tiempo que debieran dedicar a la investigación.

\section{CONCLUSIONES}

En el presente capítulo se ha analizado un proceso de diálogo de largo plazo, reflejado en el marco del MCMPCGI como política pública.

15 El decreto estipula que los docentes que ingresen a la carrera docente reciben un puntaje salarial de productividad académica según las modalidades académicas, sus criterios y diversos topes. Aunque el decreto no se refiere explícitamente al MCMPCGI, menciona que el "índice de Colciencias" es el que se toma como referencia para definir los puntos por artículos y otras modalidades de publicaciones en revistas especializadas (Presidencia de la República, 2002: 5). Actualmente existe un debate sobre la pertinencia de vincular los resultados de un modelo de calidad con una política salarial de docentes. El hecho de ligar estos dos instrumentos de política pública, imprime presión a un modelo que debería servir más para promover el trabajo en red que para la competencia abierta por financiación. 
A partir de las definiciones de algunas organizaciones internacionales sobre lo que significan los diálogos y de la metodología para identificar procesos de diálogo avanzada por la Red CYTED COM-LALICS, se revisaron las transformaciones del diálogo ocurrido en el MCMPCGI y se identificaron características de su ocurrencia en ejercicios de largo plazo (Ver Tabla 4).

Tabla 4. Características del diálogo según metodología CYTED COM-LALICS

\begin{tabular}{|c|c|}
\hline Dimensión & Característica del MCMPCGI \\
\hline Origen & $\begin{array}{l}\text { Se trata de un caso reactivo ya que se trataba de implementar una política } \\
\text { previamente definida en la ley colombiana. Fue iniciado y convocado por } \\
\text { una instancia de gobierno (Colciencias) aspecto que lo caracteriza como un } \\
\text { diálogo impulsado desde arriba abajo. }\end{array}$ \\
\hline Temporalidad & $\begin{array}{l}\text { Se puede definir de largo plazo, aunque en un principio no haya sido } \\
\text { pensado un mecanismo de diálogo para tal fin. }\end{array}$ \\
\hline Alcance & $\begin{array}{l}\text { Es un diálogo temático en el ámbito nacional, concentrado en la medición } \\
\text { de la calidad de los grupos de investigación. Sin embargo, dado que esta } \\
\text { medición fue ligada posteriormente a otras políticas públicas (asignación } \\
\text { salarial de docentes, acreditación de programas universitarios) logró } \\
\text { expandirse hacia otros temas. El propósito fue variando a lo largo del } \\
\text { tiempo: inicialmente fue netamente consultivo y a partir de } 2014 \text { adquirió } \\
\text { algunos rasgos de concertación entre las partes. }\end{array}$ \\
\hline $\begin{array}{l}\text { Balance entre actores / } \\
\text { asimetrías }\end{array}$ & $\begin{array}{l}\text { Fue otro aspecto que varió con el tiempo. A pesar de que Colciencias } \\
\text { siempre ha tenido el control del MCMPCGl, la ruptura presentada } \\
\text { en } 2013 \text { dio espacio a manifestaciones de diálogo más equilibradas } \\
\text { entre las partes. De todos modos, Colciencias siempre ha mantenido } \\
\text { la información recopilada bajo control y tiene la discrecionalidad de } \\
\text { tomar decisiones finales. Aunque durante todo el proceso se observaron } \\
\text { prácticas de información a la comunidad científica sobre los resultados de } \\
\text { las convocatorias, en las últimas convocatorias se observaron prácticas } \\
\text { para facilitar la presentación de resultados a la sociedad en general y } \\
\text { para facilitar la consulta abierta. La creación de la MTAAD significó una } \\
\text { diminución de asimetrías entre las comunidades involucradas en el diálogo } \\
\text { y permitió la generación de un lenguaje común a partir de un problema } \\
\text { complejo como es la medición de los productos de investigación en artes, } \\
\text { arquitectura y diseño. }\end{array}$ \\
\hline Organización & $\begin{array}{l}\text { Hasta } 2013 \text { la agenda fue controlada principalmente por Colciencias. } \\
\text { Esta situación cambió ligeramente a partir de } 2014 \text { cuando existe una } \\
\text { interacción diferente con un segmento especial de la comunidad científica } \\
\text { (artes, arquitectura y diseño) que genera una dinámica de concertación de } \\
\text { agendas y pasos en la negociación más conjunta. }\end{array}$ \\
\hline
\end{tabular}




\begin{tabular}{|l|l|}
\hline \multicolumn{1}{|c|}{ Dimensión } & \multicolumn{1}{c|}{ Característica del MCMPCGI } \\
\hline Resultados & $\begin{array}{l}\text { Son incrementales a medida que avanzaron las convocatorias. La } \\
\text { incorporación de nuevos productos de investigación fue un logro importante } \\
\text { desde las primeras etapas donde predominó el diálogo con los comités } \\
\text { de expertos. La variación en los pesos de los productos en el modelo, la } \\
\text { configuración del algoritmo y los índices para la medición y la definición } \\
\text { de medios de verificación fue siempre potestad del grupo técnico de las } \\
\text { convocatorias, buscando responder a observaciones de la comunidad } \\
\text { científica. La incorporación de los productos de arte, arquitectura y diseño y } \\
\text { la forma como lo lograron fueron logros importantes para dicha comunidad. }\end{array}$ \\
\hline
\end{tabular}

Fuente: elaboración propia

En términos de su evolución institucional, el diálogo revisado no tuvo una fase de exploración para identificar potenciales actores clave. Por el contrario, la relación entre el gobierno y los científicos comenzó como una consulta de expertos y evolucionó hacia mecanismos más horizontales de diálogo, como fue la MTAAD, en los que la representatividad adquirió mayor relevancia y se pudo observar al menos una disminución de las asimetrías en las comunidades involucradas en el diálogo. El objetivo de transformar las relaciones conflictivas fue evidente, sobre todo debido a la naturaleza de un tema como la medición de la calidad científica, que es un problema complejo y altamente controversial.

Las preocupaciones en torno a la generación de consenso, estuvieron inicialmente asociadas a la función de los comités de expertos que ofrecían su asesoría técnica y en algunos casos terminaban legitimando las decisiones gubernamentales. Sin embargo, los nuevos enfoques para la medición de la calidad de la investigación, introdujeron gradualmente mecanismos de diálogos horizontales, basados en el aprendizaje y la negociación con las comunidades involucradas. En ese sentido, el MCMPCGI mostró características de estratificación y de desplazamiento, según el modelo de Streeck y Thelen, porque a lo largo del tiempo se introdujeron modificaciones al modelo y fueron incorporadas por grupos que en el año 2000 no contaban con un alto reconocimiento como pares científicos.

Este caso muestra la influencia de la incertidumbre y las consecuencias no deseadas en la negociación entre el gobierno y la comunidad científica. Aunque el MCMPCGI no es propiamente un caso en el que los científicos hacen predicciones respecto a problemas complejos que afectan inmediatamente a la sociedad (Por ejemplo, el calentamiento global, las pandemias o los desastres naturales), sí aborda conceptos relativos a la calidad de su trabajo, que varían de acuerdo con la percepción de los actores de turno. Como se apreció en las manifestaciones de la comunidad científica a través de los medios de comunicación, 
existen voces que reclaman revisar al MCMPCGI como política pública, ya que no existe la certeza de sus beneficios en términos de calidad. Sin embargo, el modelo se ha mantenido por más quince años logrando una adherencia institucional como política pública.

Otro aspecto planteado en el análisis del diálogo como institución, es el hecho de las consecuencias indeseadas o inesperadas de un arreglo o institucional. En términos del diálogo entre comunidad científica y sector público, esto significó un cambio en el espacio de interacción. El MCMPCGI fue concebido inicialmente como una estrategia de identificación de capacidades del país y terminó siendo un modelo de acreditación de la calidad científica. Esto generó que otras políticas del gobierno terminaran ligadas al modelo y le imprimieran una presión que afectó y seguirá afectando el diálogo: los salarios de los docentes, el reconocimiento de grupos y la obtención de acreditaciones de programas y posiblemente el acceso a recursos ofrecidos por fondos gubernamentales.

El análisis de diálogos de largo plazo plantea la pregunta sobre la posibilidad de hacer ejercicios prospectivos de visualización de fases. Los enfoques del institucionalismo histórico y del cambio institucional podrían tomarse como base para pensar en metodologías que no solo revisen casos de diálogos de corto plazo, sino que diferencien las fases de un "único" diálogo que se desarrolla a lo largo del tiempo de una manera incremental.

El análisis del MCMPCGI permitió ver rupturas producto del cambio de intereses y del balance de poder entre los actores. El caso muestra cómo una política pública que se plantea con un enfoque topdown puede adquirir rasgos diferentes a lo largo del tiempo y transformar dimensiones del diálogo en política de CTI como son el espacio de interacción y la temporalidad.

Precisamente sobre este último punto, los cambios progresivos en el MCMPCGI afectaron los mecanismos de diálogo e incidieron su transformación como política pública. A pesar de que estos cambios muestran un desplazamiento del modelo, debido a la inclusión de mecanismos de diálogo más horizontales o sub-diálogos más directos con las comunidades involucradas, la evidencia muestra que el diálogo de expertos sigue teniendo un alto nivel de influencia y que el tema de la representatividad de los actores se constituye en un desafío importante al momento de definir quiénes deben participar en un proceso de diálogo para formular políticas de CTI.

En el caso revisado, las negociaciones con instancias más representativas de la comunidad (asociaciones de facultades u otras instancias de organización de la comunidad científica) apenas comienzan y tendrán que acomodarse con los tradicionales mecanismos de diálogo, 
vía expertos, que venían de tiempo atrás. La MTAAD es un ejemplo de que se pueden presentar variaciones a los mecanismos tradicionales de diálogos, especialmente cuando se analizan casos de largo plazo. Su ejemplo está siendo analizado por otro tipo de sectores dentro de la comunidad científica (Por ejemplo, ciencias sociales y humanidades) para ver si puede ser ajustado. Sin embargo, la complejidad del tema involucra debates epistemológicos tan antiguos como la diferencia de métodos entre las ciencias sociales y las ciencias naturales. El MCMPCGI sigue asociado a este último tipo de ciencias y es posible que el diálogo deba continuar para encontrar nuevos conceptos que permitan el reconocimiento de la diversidad de la producción científica.

\section{BIBLIOGRAFÍA}

Álvarez, I.; Barletta, F.; Suarez, D.; Yoguel, G. 2016 "Marco analítico para la tipificación de diálogos para las políticas de CTI" en Working paper 3 (Red CYTED COM-LALICS).

Arango, L. 2015 Retiro medición de grupos de investigación. Grupo Interdisciplinario de Estudios de Género (Bogotá: Facultad de Ciencias Humanas. Escuela de Estudios de Género. Universidad Nacional de Colombia).

Arias, J.; Castiblanco, L.; Castro-Gómez, S.; del Valle, M.; Escobar, A.; Ojeda, D.; Rojas, A. 2015 Convocatoria 693-2014. Retiro Grupo de Investigación en Estudios Culturales de la Facultad de Ciencias Sociales y el Instituto de Estudios Sociales y Culturales Pensar (Colombia: COLCIENCIAS).

Beeseley, L. 2003 "Science policy in changing times: are governments poised to take full advantage of an institution in transition?" en Research Policy (Países Bajos: Elsevier) N ${ }^{\circ} 32$, pp. 1519-1531.

Bonilla, H. 2016 Interview with Hector Bonilla. President of the Colombian Association of Faculties and Programs of Arts (ACOFARTES) and Member of the Work Table on Arts, Architecture and Design (WTAAD).

Castro, L. 2015 Entrevista con Liliana Castro. Asesora Dirección de Fomento a la Investigación de Colciencias.

Charum, J.; Usgame, D.; Chavarro, D. 2006 Evaluación del Sistema Nacional de Ciencia y Tecnología e Innovación. Componente: desarrollo de un sistema de información de ciencia y tecnología del Programa Colciencias BID III y de la construcción de servicios y sistemas nacionales de información (Colombia: Observatorio Colombiano de Ciencia y Tecnología).

Colciencias 2001 Las convocatorias de grupos y centros de investigación (Colombia). 
Colciencias 2002 VI Convocatoria a grupos colombiano de investigación científica o tecnológica (Colombia: COLCIENCIAS).

Colciencias 2005 Convocatoria nacional para el reconocimiento de grupos registrados por Colciencias (Colombia: COLCIENCIAS).

Colciencias 2006a Índice para la medición de grupos de investigación, tecnológica o de innovación. Convocatoria nacional para la medición de grupos reconocidos por Colciencias (Colombia: COLCIENCIAS).

Colciencias 2006b Convocatoria nacional para la medición de grupos reconocidos por Colciencias (Colombia: COLCIENCIAS).

Colciencias 2006c Resultados de la convocatoria nacional para el reconocimiento y la medición de grupos (Colombia: COLCIENCIAS).

Colciencias 2008 Modelo de medición de grupos de investigación, tecnológico o de innovación (Colombia: COLCIENCIAS).

Colciencias 2010 Convocatoria nacional para la medición de grupos de investigación en ciencia, tecnología e innovación (Colombia: COLCIENCIAS).

Colciencias 2011 Convocatoria nacional para reconocimiento de grupos de investigación en ciencia, tecnología e innovación (Colombia: COLCIENCIAS).

Colciencias 2013a Modelo de medición de grupos de investigación, desarrollo tecnológico y/o de innovación (Colombia: COLCIENCIAS). Versión II.

Colciencias 2013b Convocatoria nacional para el reconocimiento y medición de grupos de investigación, desarrollo tecnológico y/o innovación y para el reconocimiento de investigadores del sistema nacional de ciencia, tecnología e innovación (Colombia: COLCIENCIAS).

Colciencias 2014 Convocatoria nacional para el reconocimiento y medición de grupos de investigación, desarrollo tecnológico y/o innovación y para el reconocimiento de investigadores del sistema nacional de ciencia, tecnología e innovación. Informe proceso y resultados. Convocatoria 640 de 2013 (Colombia: Dirección de Fomento a la Investigación - COLCIENCIAS).

Colciencias 2014 Convocatoria nacional para el reconocimiento y medición de grupos de investigación, desarrollo tecnológico o de innovación y para el reconocimiento de investigadores del sistema nacional de ciencia, tecnología e innovación (Colombia: COLCIENCIAS). 
Colciencias 2014 Modelo de medición de grupos de investigación, desarrollo tecnológico o de innovación y reconocimiento de investigadores del sistema nacional de ciencia, tecnología e innovación (Colombia: COLCIENCIAS).

Colciencias 2015 Convocatoria nacional para el reconocimiento y medición de grupos de investigación, desarrollo tecnológico o de innovación y para el reconocimiento de investigadores del sistema nacional de ciencia, tecnología e innovación 2014. Informe proceso y resultados. Convocatoria 693 de 2014 (Colombia: COLCIENCIAS).

Colciencias 2015 Modelo de medición de grupos de investigación, desarrollo tecnológico o de innovación y de reconocimiento de investigadores del sistema nacional de ciencia, tecnología e innovación (Colombia: COLCIENCIAS). En <http://www. colciencias.gov.co/sites/default/files/upload/convocatoria/ m304pr05g01-modelo-medicion-grupos-v3.pdf > .

Colciencias 2015 Anuncio de corte para el proceso de la convocatoria nacional para el reconocimiento y medición de grupos de investigación, desarrollo tecnológico o de innovación y para el reconocimiento de investigadores del sistema nacional de ciencia, tecnología e innovación (Colombia: COLCIENCIAS). En <http:// www.colciencias.gov.co/sites/default/files/upload/convocatoria/ tdr-VC_17.pdf >.

Colciencias 2016 Convocatoria nacional para el reconocimiento y medición de grupos de investigación, desarrollo tecnológico o de innovación y para el reconocimiento de investigadores del sistema nacional de ciencia, tecnología e innovación 2015. Informe de análisis Convocatoria 737 de 2015 (Colombia: COLCIENCIAS). En <http://www.colciencias.gov.co/sites/default/files/analisisconv737-2015.pdf $>$.

Cuentas, M.; Linares Méndez, A. (eds.) 2013 Practical Guide on Democratic Dialogue (Washington, D. C.: General Secretariat of the Organization of American States and United Nations Development Program - UNDP). En <https://www.oas.org/es/sap/ dsdme/pubs/guia_e.pdf>.

Cuppen, E. 2012 "Diversity and constructive conflict in stakeholder dialogue: considerations for design and methods" en Policy Sciences (Reino Unido: Springer) No 45(1), pp. 23-46. En $<$ https://doi.org/10.1007/s11077-011-9141-7>.

Delgado, L. 2016 Interview with Lucy Gabriela Delgado. Director for Research Promotion (Colombia: COLCIENCIAS) septiembre. 
Dinero 2001 "Los mejores centros de investigación” (Bogotá). En $<$ http://www.dinero.com/confidencias/edicion-impresa/articulo/ los-mejores-centros-investigacion/9670>.

Dinero 2009 "Grupo de investigación de la EAN recibe reconocimiento de Colciencias" (Bogotá). En <http://www. dinero.com/actualidad/noticias/articulo/grupo-investigacion-eanrecibe-reconocimiento-colciencias/81768>.

Dutrénit, G.; Álvarez, I.; Ardanche, M.; Barletta, F.; Bianco, M.; Cortés, R.; Vera-Cruz, A. 2017 Lineamientos metodológicos para procesos de diálogo relacionados/orientados a la formulación de políticas de CTI en América Latina, El Caribe y España (Red CYTED COM-LALICS).

Dutrénit, G.; Álvarez, I.; Ardanche, M.; Barletta, F.; Bianco, M.; Cortés, R.; Sutz, J. 2016 "Matriz de Información para el mapeo de procesos de diálogo de CTI en España, América Latina y el Caribe" en Working paper 5 (Red CYTED COMLALICS).

EAFIT 2012 A los grupos de investigación los quieren medir de forma diferente (Colombia: Agencia de Noticias Universidad EAFIT). En <http://www.eafit.edu.co/agencia-noticias/historiconoticias/2012/marzo/Paginas/investigacion-nueva-mediciongrupos-investigacion.aspx $>$.

EASAC 2012 EASAC Guidelines: Good Practice in the Dialogue between Science Academies and Policy Communities (Saale: European Academies Science Advisory Council). En <http:// www.easac.eu/fileadmin/ppt/Science-Policy-Dialogue/Short_ EASAC_Guidelines_PDF.pdf>.

El Espectador 2015 "Una demanda contra la convocatoria 693" (Colombia). En <http://www.elespectador.com/noticias/judicial/ una-demanda-contra-convocatoria-693-articulo-559495>.

El Tiempo 2000 "La comunidad científica colombiana ya está censada” (Colombia). En <http://www.eltiempo.com/archivo/ documento/MAM-1285846>.

El Tiempo 2003 "Crece la comunidad científica" (Colombia). En <http://www.eltiempo.com/archivo/documento/MAM-967888>.

El Tiempo 2004 "Sigue crecimiento en investigación" (Colombia). En $<$ http://www.eltiempo.com/archivo/documento/MAM-1523081>.

Espinosa Menéndez, N.; Insuasty Rodríguez, A. 2015 “El conocimiento inventariado. Apuntes críticos sobre el modelo de indexación de las publicaciones académicas en Colombia" en AGO.USB (Colombia: Bonaventuriana) $\mathrm{N}^{\circ} 15(1)$, pp. 95-113. 
Facultad de Educación; Facultad de Ciencias Sociales y Humanas 2015 Carta abierta a Colciencias. Modelo de medición de Colciencias en la convocatoria 693 de 2014 para las ciencias sociales, humanidades y artes (Colombia: Universidad de Antioquia).

Fernández Moreno, A. 2015 Retiro medición grupos de investigación. Grupo de Investigación en Discapacidad, Inclusión y Sociedad (Colombia: Facultad de Medicina de la Universidad Nacional de Colombia).

Fog, L. 2010 "Colombia: controversia por medición de grupos de ciencia" en Sci Dev Net (Londres). En <http://www.scidev.net/ america-latina/innovacion/noticias/colombia-controversia-pormedici-n-de-grupos-de-ciencia-.html>.

Goñi, M.; Bianco, M.; Puchet, M. 2015 "Marco analítico para la tipificación de diálogos para las políticas de CTI" en Working paper 3 (Red CYTED COM-LALICS).

Guston, D. 2000 Between politics and science. Assuring the integrity and productivity of research (Estados Unidos: Cambridge University Press).

Hoppe, R. 2011 The governance of problems. Puzzling, powering and participation (Reino Unido: The Policy Press).

Koremenos, B.; Lipson, C.; Snidal, D. 2001 "The Rational Design of International Institutions" en International Organization (The MIT Press) $\mathrm{N}^{\circ}$ 55(4), pp. 761-799.

Künkel, P.; Gerlach, S.; Frieg, V.; Görg, C.; Ferguson, M.; Kohler, J.; Herde, J. 2011 Stakeholder Dialogues Manual (Eschborn: GIZ). En <http://www.mspguide.org/sites/default/files/resource/giz stakeholder_dialogues_kuenkel.pdf $>$.

Mesa Artes, Arquitectura y Diseño 2016 La medición de grupos en la creación artística: apuntes sobre el debate académico en Colombia en el proceso de reconocimiento gubernamental de la creación como práctica de generación de nuevo conocimiento. Documento de Trabajo (Colciencias, Bogotá).

Nelson, R. 2008 "What enables rapid economic progress: what are the needed institutions?" en Research Policy (Países Bajos: Elsevier) $\mathrm{N}^{\circ} 37$, pp. 1-11.

Nowotny, H. 2003 “Dilemma of expertise. Democratising expertise and socially robust knowledge" en Science and Public Policy (Reino Unido: Oxford University Press) No 30(3), pp. 151-156.

Nupia, C.; Martínez-Maestre, A. 2015 "Revisión de metodologías de procesos de diálogo" en Working paper 4 (Red CYTED COM-LALICS). En <http://lalics.org/images/CYTED/DT4MetodologiasDialogo.pdf $>$. 
Orozco, L.; Ruiz, C.; Bonilla, R.; Chavarro, D. 2013 “Los grupos de investigación en Colombia. Sus prácticas, su reconocimiento y su legitimidad" en Salazar, M. (ed.) Colciencias cuarenta años: entre la legitimidad, la normatividad y la práctica (Bogotá: Observatorio Colombiano de Ciencia y Tecnología - OCyT) pp. 634-687

Pérez, A.; Hering, M.; Ortega, F.; Borja, J.; Guarín, O.; Martínez, A.; Lasso, M. 2015 Decisión no participación en Convocatoria 693. Grupo de investigación Prácticas Culturales, Imaginarios y Representaciones.

Presidencia de la República 2002 Decreto 1279 por el cual se establece el régimen salarial y prestacional de los docentes de las universidades estatales (Bogotá). En <http://www.mineducacion. gov.co/1621/articles-86434_Archivo_pdf.pdf>.

Profesores y profesoras Departamento de Literatura 2014 Retiro grupos de investigación Departamento de Literatura (Bogotá: Facultad de Ciencias Humanas, Universidad Nacional de Colombia).

Rayo, A. 2013 Espacios de diálogo para construir estrategias de desarrollo público-privadas: una guía metodológica (México: German Society for International Cooperation and Economic Commission for Latin America and the Caribbean - ECLAC) p. 46. En <http://www.cepal. org/es/publicaciones/27169-espacios-de-dialogo-para-construirestrategias-de-desarrollo-publico-privadas $>$.

Sagasti, F. 2011 Ciencia, tecnología, innovación. Políticas para América Latina (Lima: Fondo de Cultura Económica).

Semana 2006 “¿Qué tanto se investiga?” (Colombia). En <http://www. semana.com/especiales/articulo/que-tanto-investiga/78091-3>.

Soto Mejía, J.; Giraldo Tascón, N.; Arenas Valencia, W. 2007 "Productividad de los grupos de investigación. Enfoque de Colciencias versus el análisis envolvente de datos" en Scientia et Technica (Colombia: Universidad Tecnológica de Pereira) № 35 , pp. 275-280.

Streeck, W.; Thelen, K. 2005 "Introduction: institutional change in advanced political economies" en Beyond continuity. Institutional change in advanced political economies (Reino Unido: Oxford University Press) pp. 3-39.

Vallejo, F. 2013 La extinción en masa de la investigación científica en Colombia (Colombia: Universidad del Cauca).

Villaveces, J. 2016 Interview with Jose Luis Villaveces. Secretary of Colciencias (1991-1994) and Deputy Scientific Director of Colciencias (2000-2001). 
Vinck, D. 2010 The sociology of scientific work. The fundamental relationship between science and society (Cheltenham: Edward Elgar).

Wasserman, M. 2001 "Convocatoria de Grupos y Centros 2000, o la triste historia de una comunidad científica desorientada" en $U N$ Periódico (Colombia) pp. 18-19.

Zambrano, M. 2014 Observaciones sobre nueva reglamentación de certificación de Colciencias. 



\section{PROCESOS DE DIÁLOGOS PARA EL DISEÑO DE POLÍTICAS DE CTI DE CARÁCTER SECTORIAL}





\title{
DIÁLOGO ENTRE COMUNIDADES PARA LA CONSTRUCCIÓN DE POLÍTICAS CTI
}

\section{LA ENERGÍA EÓLICA EN URUGUAY}

\author{
Melissa Ardanche, Mariela Bianco, Claudia Cohanoff, \\ Soledad Contreras, María Goñi, Lucía Simón \\ y Judith Sutz
}

\section{INTRODUCCIÓN}

A partir del año 2005, y en el transcurso de pocos años, Uruguay puso en marcha un proceso de diversificación y cambio de su matriz energética basada tradicionalmente en combustibles fósiles y energía hidráulica, los primeros importados en su totalidad y la segunda producida de forma local. Con el objetivo de asegurar el suministro energético, promover la equidad en el acceso a la energía y reducir la dependencia tanto externa como climática, la transformación de la matriz energética apuntó a la diversificación de las fuentes de energía y puso el énfasis en las fuentes autóctonas renovables.

Las principales incorporaciones en la matriz fueron la energía eólica, la biomasa y la energía solar. Así, la matriz eléctrica del año 2015 estuvo conformada de la siguiente manera: un 54\% de hidroeléctrica, $12 \%$ de eólica, 19\% de biomasa, 15\% de petróleo y derivados (MIEMDNE, s/f a). Para dimensionar la magnitud y velocidad del cambio, cabe consignar que hasta el año 2013 la participación de la energía eólica en la matriz eléctrica nacional era inexistente y representó ese primer año un marginal 2\% (MIEM-DNE, s/f b).

* Unidad Académica de la Comisión Sectorial de Investigación Científica, Universidad de la República, Montevideo, Uruguay. 
Contar con una política energética explícita, que reunió a diversos actores, conocimientos y capacidades acumuladas en torno a objetivos y lineamientos compartidos, fue clave para el rápido desarrollo, producción y utilización de nuevas fuentes de energía que integran hoy la arquitectura de la matriz energética. Esto fue posible por una serie de factores, eventos y decisiones que permitieron impulsar el proceso de cambio y que serán objeto de análisis y reflexión en el presente capítulo. Particularmente, se examinan las interacciones y aprendizajes entre actores en diálogo que constituyen el insumo básico para la elaboración de la política pública. Cabe destacar que nuestra mirada estará centrada en el desarrollo de la energía eólica a nivel nacional, por tratarse de la apuesta central de la primera etapa de la política energética, concebida a la vez como una política de Ciencia, Tecnología e Innovación orientada al desarrollo del país.

El cambio de la matriz energética fue posible principalmente por la articulación virtuosa de dos aspectos: i) el conocimiento científico y tecnológico desarrollado y acumulado en la Universidad de la República (en particular en la Facultad de Ingeniería, en adelante FING) en años previos a la decisión acerca de la transformación; ii) el cambio de signo político del gobierno ocurrido en el año 2005, que acarreó una renovación de elencos técnico-políticos y un viraje en la concepción acerca del rol del Estado en la economía y el desarrollo en general, y en particular en relación a lo energético.

La acumulación de conocimientos sobre el sector energético y sobre el potencial del país para la producción de energías renovables, dado a través de estudios e investigaciones realizados principalmente por la academia durante cincuenta años -y en los años previos a la discusión del cambio de política energética, también por algunos esfuerzos en conjunto con otros actores públicos energéticos- y a contrapelo de las tendencias políticas de antaño, permitió contar con diagnósticos e información de base sólida para la rápida construcción y diseño de alternativas energéticas. Esta acumulación cognitiva redundó en el fortalecimiento de las capacidades de la comunidad académica en general y de algunos ingenieros en particular, vinculados principalmente al equipo técnico de la empresa pública estatal encargada de la producción y distribución de energía eléctrica (la Administración Nacional de Usinas y Transmisiones Eléctricas, en adelante, UTE), ${ }^{1}$ que pasan en el año 2005 a ocupar lugares relevantes para la toma de decisiones e

1 La UTE es la empresa estatal que se encarga de la generación y distribución de energía a nivel nacional. Ha sido la encargada de realizar las convocatorias al desarrollo de nuevos parques eólicos por parte de privados, así como la construcción y gestión de parques de las centrales eólicas públicas. 
implementación de acciones específicas. Convergen, de esta manera, capacidades construidas y motivaciones diversas en la necesidad de consensuar salidas compartidas en relación a la producción energética.

Paralelamente, el nuevo gobierno hizo que el Estado asumiera un rol estratégico en la definición y orientación de la política energética; la entonces Dirección Nacional de Energía y Tecnología Nuclear (en adelante, DNE) ${ }^{2}$ del Ministerio de Industria, Energía y Minería (MIEM), resultó un actor fundamental para la toma de decisiones relevantes y para la construcción negociada de la dirección del cambio de la matriz energética.

La apuesta por las energías renovables en base al conocimiento producido disponible, y la modificación del comportamiento de los actores vinculados a la producción y, principalmente, a la dirección en relación al rumbo de la política, fueron factores decisivos para montar un escenario de cambios en que la política energética desempeña un rol de especial significación para el desarrollo del país.

Sobre esta base, dicha política permitió condensar las capacidades acumuladas y reunir a las diferentes comunidades y actores vinculados a la temática, para construir espacios de diálogo a los que se les puede atribuir el éxito relativo producto de las decisiones que se tomaron. Estos espacios de diálogo permitieron al sector público construir y perfeccionar con el correr del tiempo un sistema de incentivos para hacer atractiva -y redituable- la participación de los actores privados en la transformación. La interacción en estos espacios de diálogo se dio entre cuatro "comunidades" (Dutrénit et al., 2016): sector público, sector académico, sector empresarial (público y privado) y sociedad civil. La cohesión -que permite definir a un grupo de actores como comunidad- y el grado de participación de las mismas fue variable; cada una aportó desde su espacio de conocimiento y lugar de pertenencia. Los diversos roles y características de las comunidades, que imprimen a su vez particularidades a los diferentes momentos del proceso de diálogo, serán parte del análisis propuesto. Dicho análisis tiene como base empírica la construcción de datos primarios (a través de entrevistas semiestructuradas a informantes clave de las comunidades mencionadas) y la recopilación de datos secundarios en relación a las diferentes aristas del proceso de transformación (fuentes documentales y bases de datos oficiales, entre otros). ${ }^{3}$

2 En el inicio del proceso de construcción de la política energética, la alternativa nuclear, que formaba parte de los cometidos de la Dirección de Energía y Tecnología Nuclear -como su propio nombre lo indicaba-, fue puesta en consideración. Luego de informes técnicos y valoraciones múltiples a nivel social (incluido un Juicio Ciudadano sobre la posibilidad de incluir la energía nuclear en la matriz) la opción fue descartada, lo que llevó a que la propia denominación de la Dirección se modificara, constituyéndose en Dirección Nacional de Energía.

3 Este documento es parte del trabajo de la Red COM-LALICS, financiada por 
El presente capítulo se estructura de la siguiente manera: en la segunda sección se hará un repaso por algunas categorías conceptuales del enfoque de los Sistemas Nacionales de Innovación, que resultarán de utilidad al momento de analizar el proceso de incorporación de la energía eólica y los diálogos en torno al mismo. En tercer lugar, se presentará el caso en estudio desde los principales antecedentes, que se remontan al siglo pasado, hasta los resultados más significativos a casi diez años del comienzo de la implementación de la Política Energética Nacional. Por último, se mencionarán las implicancias del diálogo en tanto innovación satisfactoria, con impacto en la política pública y en el fortalecimiento de capacidades de investigación, desarrollo e innovación $(\mathrm{I}+\mathrm{D}+\mathrm{i})$ basadas en procesos colectivos.

\section{APRENDIZAJES BASADOS EN LA CONFIANZA}

La transformación de la matriz energética uruguaya puede considerarse una significativa innovación a nivel nacional. Podemos servirnos para su análisis de la perspectiva teórica de los Sistemas Nacionales de Innovación, en particular de la vertiente que pone particular acento en los procesos de aprendizaje (Johnson \& Lundvall, 1994). Desde esta perspectiva, el espacio nacional es importante porque la proximidad histórica y cultural que provee, facilita los procesos de aprendizaje interactivo entre personas pertenecientes a diferentes instituciones que están en el centro de las innovaciones satisfactorias.

De acuerdo con el enfoque de los sistemas de innovación basados en los aprendizajes interactivos, las innovaciones satisfactorias surgen de la construcción de confianza entre los interlocutores que participan del proceso de construcción de soluciones. Cuanto más innovadora es la solución encontrada a un cierto problema, más inciertos serán sus resultados y mayores los requerimientos de pruebas y ajustes. La confianza entre los interlocutores puede llegar a ser así requisito previo a la ocurrencia de la innovación.

Es importante señalar el carácter personalizado de la confianza. En un análisis detallado de las relaciones universidad-empresa en la Universidad de la República (en adelante, UdelaR) se puso en evidencia que los que realmente se relacionaban eran egresados

CYTED. Además de la discusión conceptual que se incluye en el capítulo teórico de este libro, el abordaje metodológico se basa en las discusiones e intercambios de la red, integrada por equipos de investigación de Argentina, Brasil, Chile, Colombia, Costa Rica, Cuba, El Salvador, España, México, Perú, República Dominicana, Uruguay y Venezuela (ver Dutrenit et al., 2014; Álvarez et al., 2016; Nupia \& Martinez, 2015; Goñi et al., 2015 para una síntesis de los diferentes avances en materia conceptual y metodológica). 
universitarios que trabajaban en empresas con sus pares que trabajaban en la universidad, no se vinculaba "la universidad" como institución con "la empresa" como agente productivo (Hein et al., 1996). En el caso de innovaciones asociadas a procesos tecnológicos complejos, la construcción de confianza entre los diversos interlocutores involucrados se ve facilitada cuando existe un lenguaje especializado compartido (Goñi et al., 2015) y un conocimiento recíproco de las capacidades y logros académicos alcanzados.

En este sentido, la transformación de la matriz energética uruguaya puede considerarse una innovación satisfactoria, resultado de diversos procesos de aprendizaje. Dichos aprendizajes, aunque respondieron a lógicas específicas y diferenciadas -en los grupos de investigación universitarios, en la empresa pública dedicada a la producción energética, en la institución dentro del gobierno que asumió nuevos roles respecto de la matriz energética, en los procesos de articulación de múltiples actores promovidos por la política industrialdieron lugar a interacciones que permitieron nuevos aprendizajes, tanto para cada uno de los agentes participantes como de carácter sistémico. Es justamente esto último lo que facilitó la innovación.

Cabe agregar que, en la conceptualización de los sistemas nacionales de innovación a la que hacemos referencia, se pone especial énfasis en que el aprendizaje interactivo surge de diálogos múltiples e involucra a muy variados actores ${ }^{4}$, desde los más orientados hacia un conocimiento formal intensivo, hasta los caracterizados por su conocimiento práctico o su conocimiento en tanto usuarios o afectados de una u otra forma por los procesos de innovación planeados o implementados. Este rasgo es también discernible en el proceso que llevó a innovar en la matriz energética uruguaya.

Conviene analizar, además, hasta qué punto se trata de una innovación de tipo sistémico, es decir, que resulta de coordinaciones múltiples en diversas esferas y, también, que impacta en actividades interrelacionadas. Se visualiza este aspecto mediante el concepto de sistema sectorial de innovación, puesto que lo energético constituye un sector específico, más allá de que incluya componentes muy diversos.

La definición de sistema sectorial de innovación provista por Malerba (2002) es la siguiente:

4 Lundvall y Borrás (2005: 614) catalogan al diálogo y la interacción entre gobierno, comunidad empresarial, sindicatos e instituciones productoras de conocimiento como una condición necesaria para diseñar y desarrollar políticas de innovación claras, socialmente relevantes y que puedan ser implementadas con éxito. 
Un sistema sectorial de innovación es un conjunto de productos nuevos y establecidos orientados a usos específicos, y el conjunto de agentes que llevan a cabo interacciones mediadas o no por el mercado para la creación, producción y comercialización de esos productos. Un sistema sectorial tiene base cognitiva, tecnologías, insumos y una demanda existente, emergente o potencial. Los agentes que componen el sistema sectorial son organizaciones e individuos (por ejemplo, consumidores, empresarios, científicos). Las organizaciones pueden ser firmas [...] y otras organizaciones (universidades, entidades financieras, agencias gubernamentales, sindicatos o asociaciones de carácter técnico) [...] Los agentes están caracterizados por procesos de aprendizaje específicos, competencias, creencias, objetivos, estructuras organizativas y comportamientos. Interactúan a través de procesos de comunicación, intercambio, cooperación, competencia y autoridad y sus interacciones están configuradas por instituciones (reglas y regulaciones). (Malerba, 2002: 250, nuestra traducción)

A partir de esta definición, podemos caracterizar el cambio de la matriz energética en Uruguay como un proceso que presenta varios de los rasgos de un sistema sectorial de innovación. Dicho proceso no está centrado estrictamente en productos sino en la provisión de un servicio a través de productos nuevos, pero son fácilmente reconocibles aspectos que dan cuenta de su carácter sistémico. En torno a productos nuevos orientados a la provisión de un servicio, un conjunto de agentes interactúa, en algunos casos, a través de la mediación del mercado, y en otros no, para producir y comercializar dicho servicio. Los agentes que componen el sistema incluyen científicos, proveedores, usuarios de la energía; están también involucradas organizaciones, como la universidad, diversas empresas, nacionales y extranjeras, empresas públicas, entidades gubernamentales; las interacciones entre los agentes se configuran a través de reglas y regulaciones que implican innovaciones en sí mismas -por ejemplo, la interconexión energética en una red en que pasan a coexistir formas diversas de provisión requiere cambios regulatorios significativos-. Este carácter relativamente sistémico de la transformación de la matriz energética uruguaya contrasta con la tendencia a la fragmentación y a la falta de coordinación en varios aspectos de la política pública nacional, así como de la vinculación de esta con diversos agentes.

La pregunta de hasta qué punto este comportamiento sistémico, centrado en la provisión de un servicio, puede avanzar hacia un sistema sectorial que integre más elementos, por ejemplo, componentes de los sistemas tecnológicos de producción de energía eólica, es de difícil respuesta. Puede sin embargo señalarse que existen elementos que favorecen un posible avance en esa dirección. Uno de particular importancia es el reconocimiento internacional que ha tenido 
Uruguay por la transformación de su matriz energética. Esta visibilidad, sumada a políticas que promuevan y apoyen procesos de aprendizaje múltiples -en la academia, en las empresas, en la formación técnica- permitiría superar las limitaciones de un mercado interno reducido y avanzar en la dirección de agregar productos al proceso, para completar paulatinamente la formación de un sistema sectorial. Esto implicaría hacer de la transformación de la matriz energética una palanca para la transformación productiva. Una vasta literatura aborda el papel del Estado en una transformación de ese tipo, sea a través de la orientación y articulación de sus políticas (Amsden, 1899; Chang, 2003; Evans, 2005; Johnson, 1999; Lundvall \& Borras, 1997;Mazzucatto, 2013;), sea a través directamente de su papel de compra (Edquist $\&$ Hommer, 1998). Es posible encontrar rasgos de un estado desarrollista, de un estado emprendedor, de un estado que usa su poder de compra para estimular ciertas conductas y en particular para fomentar el aprendizaje, en el proceso que es objeto de este estudio.

La interrogante que surge naturalmente es si la experiencia asociada a la transformación de la matriz energética uruguaya, marcada por el logro de una innovación satisfactoria con importante impacto en el desarrollo nacional, podrá ser emulada a partir del reconocimiento de los factores que la hicieron posible. En varios otros campos hay conocimiento acumulado en la academia y también a nivel empresarial que podría, articulado con una combinación de políticas públicas que ofrezca oportunidades para aplicarlo, abrir nuevos caminos de aprendizaje interactivo hacia procesos productivos con alto valor agregado de importancia para el país y con perspectiva de exportación. En este sentido, vale señalar que la transformación de la matriz energética uruguaya ofrece uno de los no tan comunes efectos demostración que pueden estimular futuros caminos virtuosos.

\section{DIÁLOGOS EN TORNO A LA TRANSFORMACIÓN DE LA MATRIZ ENERGÉTICA CON ÉNFASIS EN ENERGÍAS RENOVABLES: EL CASO DE LA ENERGÍA EÓLICA}

En el presente apartado, se partirá de la exposición de las condicionantes de la situación energética uruguaya y de los antecedentes en construcción de confianzas entre academia y sector público que se remontan al siglo pasado y que son bastante previos a la construcción "oficial" de la política, para luego presentar los aspectos más salientes de la Política Energética Nacional, que se formaliza entre 2008 y 2010 y, en particular, de la apuesta específica por la energía eólica. Acto seguido, se realizarán algunos señalamientos en torno a las comunidades participantes del proceso de transformación de la matriz energética y sus interrelaciones crecientes. Por último, se presentarán los principales resultados del 
proceso de diálogo, en lo que tiene que ver con las capacidades políticas y técnicas, de I+D+i, de la producción energética concreta y la generación de una red de actores y comunidades en torno a lo eólico.

\subsection{LÍNEA DE BASE O DE LA CRISIS COMO OPORTUNIDAD}

El proceso de diálogo hacia el cambio de la matriz energética surgió de la necesidad de dar respuesta a la dramática situación del sector. Del estudio de sus características surge un dato evidente: la dependencia energética ha sido estructural en Uruguay. El país dependió enteramente de las importaciones hasta la puesta en marcha de la primera represa hidroeléctrica en 1945 y, hasta los años 70, la dependencia energética estuvo por encima del 90\%. A partir de la crisis del petróleo se produce un progresivo descenso hasta llegar al $75 \%$ a principios del siglo XXI, debido a una reducción obligada de las importaciones de petróleo -por su costo y la situación de crisis del país- que se sustituyen con leña, residuos de biomasa y con la producción de nuevas centrales hidroeléctricas (Bertoni et al., 2009). Por tanto, las condiciones imperantes al momento de concebir el cambio de la matriz energética eran de una fuerte dependencia del exterior para obtener petróleo y dependencia climática para la producción hidroeléctrica. Por citar un ejemplo, en el año 2007 el petróleo representó el 55\% de la energía primaria consumida. Además, la importancia de las fuentes hidroeléctricas en la matriz dejaba al país expuesto a la crisis energética durante los períodos de sequía (Méndez, 2008).

Asimismo, la política energética uruguaya se caracterizaba por ser segmentada y por la falta de visión de largo plazo, lo que intensificaba las mencionadas debilidades del sector. Entre los años 1991 y 2006 no se realizaron inversiones en el sector eléctrico y se sub utilizaron otras inversiones realizadas, como los gasoductos entre Uruguay y Argentina (González \& Méndez, 2014). A esta situación de estancamiento, se le suma el continuo crecimiento económico y, por tanto, el fuerte incremento de la demanda de energía. Si bien durante la crisis económica del año 2002 la demanda baja de forma considerable, desde el año 2004, con la recuperación económica, el sector energético se convierte en uno de los más dinámicos, con un crecimiento de la demanda de un $6,2 \%$ anual en promedio entre 2004 y 2011 (Uruguay XXI, 2013).

\subsection{CONSTRUCCIÓN DE CONFIANZA Y CAPACIDADES A PARTIR DE DIÁLOGOS DE LARGA DATA}

El cambio de la matriz energética puede ser visto como un resultado que sintetiza un conjunto de diálogos, parte significativa de ellos recientes y en torno a la construcción concreta de la política energética como política explícita, pero otra gran parte de larga data, de corte 
más puntual e intermitente, pero que permitieron una acumulación de décadas de conocimiento científico sobre el tema y abonaron a la construcción de relaciones de confianza y espacios de aprendizaje entre personas de instituciones varias. A continuación, se introducen de manera resumida algunos de estos diálogos que ofician de antecedente.

El desarrollo de conocimiento local, que luego haría posible la transición energética en Uruguay, se inicia en la academia en los años 1950 cuando la FING inicia una línea de investigación en estudios eólicos. A partir de allí comienza a conformarse el grupo de investigación en energías renovables, se genera un mapa eólico primario y además se desarrolla el primer túnel de viento del país. Posteriormente la investigación en energía eólica y en energías renovables en general tuvo apoyos de diverso tipo, a partir del relacionamiento de los investigadores con actores e instituciones nacionales. Entre las instituciones que se acercaron a la academia para realizar acuerdos con el objetivo de apoyar la investigación se destaca la UTE. El vínculo formal entre la UdelaR y la UTE en el tema energía fue intermitente hasta fines de la década del 80; allí se firma un acuerdo entre ambas instituciones para la construcción de un mapa eólico mejorado para el que se empleó la tecnología computacional ya disponible. Este fue el inicio de un relacionamiento sistemático entre ambas instituciones que se mantiene hasta el día de hoy (Rodríguez, 2013).

Entre los años 1988 y 2000 se llevaron a cabo una serie de proyectos de la FING en acuerdo con UTE y otras iniciativas financiadas con fondos del entonces Consejo Nacional de Investigaciones Científicas y Técnicas, que generaron un bagaje importante de conocimientos en energía eólica. A partir de esta experiencia acumulada, se propone un proyecto para la construcción de un pequeño parque eólico piloto, que posteriormente dio lugar al primer parque de la UTE. ${ }^{5}$ Hubo acuerdos puntuales con actores diversos en los cuales el grupo de investigación universitario realizó estudios en predios privados, para conocer las posibilidades del abastecimiento con energía eólica, y proyectos financiados por la OEA para la electrificación rural, que incluían la instalación de sistemas autónomos abastecidos por energías renovables (Rodríguez, 2013).

En el año 2003, en el marco de la Comisión Social Consultiva de la UdelaR, tuvo lugar la Mesa de Energía. ${ }^{6}$ A través de varias reuniones

5 Se trata del Parque de la Sierra de los Caracoles, donde aún hoy se encuentra en funcionamiento el primer molino eólico con que contó el país.

6 La Comisión Social Consultiva fue una iniciativa de la UdelaR que en el marco de una profunda crisis económica buscaba poner las capacidades de investigación universitarias al servicio de la sociedad. Se componía de mesas de trabajo (la de energía fue una de ellas) que buscaban favorecer espacios de interacción entre di- 
se discutió sobre la situación del sector, sus principales problemas y posibles alternativas. Este espacio de encuentro entre actores de diferentes ámbitos vinculados al tema energético tuvo como resultado, hacia el año 2004, un documento que actualiza un estudio de prospectiva energética realizado previamente por la FING, realiza un análisis de factibilidad de algunas energías alternativas y plantea escenarios posibles a cinco y treinta años (Bertoni et al., 2010: 36).

Como se puede observar, los principales actores vinculados al sector energético han tenido históricamente lugares de articulación, donde se formaron y fortalecieron las relaciones de confianza y donde se construyó un relato o identificación del dilema energético en tanto problema público. El efectivo proceso de transformación, tuvo como catalizador un cambio de impronta en el rol del Estado en relación al tema energético, que se gesta en el seno de un viraje político a nivel nacional, que coloca al tema en un lugar de destaque de la agenda política uruguaya. ${ }^{7}$

\subsection{LA CONSTRUCCIÓN DE UNA POLÍTICA NACIONAL DE ENERGÍA}

Que una sociedad se plantee la modificación de su matriz energética puede deberse "al imperio de la necesidad" o a la búsqueda de "mejores prácticas"; como señalan Bertoni, et al (2010: 174), "puede deberse a la intención de resolver un problema de optimización en el modelo energético vigente, pero también podría tener el objetivo de inducir un cambio en dicho modelo".

También pueden perseguirse ambos objetivos a la vez, y este parece ser el caso que impulsó en Uruguay a la comunidad política a diseñar y concretar una política pública orientada a diversificar la matriz energética nacional. La asunción del primer gobierno de izquierda en el año 2005, habilitó el diseño e implementación de una política pública para el sector energético, la Política Energética 2005-2030 que, en un tiempo sorprendentemente corto, deviene en Política de Estado.

La literatura de análisis de políticas públicas establece que no basta contar con algunas acciones puntuales, como las relatadas en el apartado anterior, para poder hablar de una política pública. De acuerdo a Subirats et al. (2008: 38), una política pública debe ser entendida como "una serie de decisiones o de acciones, intencionalmente coherentes, tomadas por diferentes actores, públicos y a veces no públicos -cuyos recursos, nexos institucionales e intereses varían- a fin de resolver de manera puntual un problema políticamente definido

versos actores vinculados a sectores particulares (académicos, del sector productivo, organizaciones de la sociedad civil, gobierno y sindicatos).

7 En 2005 asumen al frente de las empresas energéticas del país académicos (ingenieros) provenientes de la FING, del grupo de investigación sobre energías renovables. 
como colectivo", con un objetivo de interés público. Como la definición lo indica, se debe tratar de al menos una serie de acciones que den cuenta de un proceso consciente e intencionalmente coherente, que busca resolver un problema identificado como público y que responde a un modelo causal determinado.

Se podría decir que el diseño de los lineamientos generales de la política pública, se realizó en dos etapas: en primer lugar, al interior del Poder Ejecutivo, entre los actores públicos (políticos y empresariales) con competencias relativas al tema energético y, en segundo lugar, ese acuerdo de gobierno fue rediscutido y legitimado en un espacio de diálogo con otros actores partidarios del sistema político.

A partir de una amplia discusión con la participación de todos los actores públicos involucrados en el tema energético en el país, en el año 2008 la DNE presentó al Poder Ejecutivo una propuesta síntesis de política energética global con una mirada de largo plazo, que resultó aprobada sin mayor discusión. La misma proponía ciertos lineamientos estratégicos, que definían los grandes ejes conceptuales de la política energética (institucional, social, de la oferta y de la demanda), las metas a alcanzar en el corto, mediano y largo plazo (5, 10 a 15, y 20 años y más, respectivamente) y las líneas de acción para alcanzar dichas metas. A su vez, se establecía la necesidad de contar, para orientar la política, con un análisis de situación permanente del tema energético en el país, la región y el mundo (MIEM-DNE, 2008).

El segundo paso en la construcción propiamente "política" -o de la politics-, fue la búsqueda de legitimación de la política energética por parte de actores políticos que no formaban parte del Poder Ejecutivo y que sí contaban con representación parlamentaria: la construcción de una verdadera y poco frecuente política de Estado, que buscaba preservar la estrategia de transformación planteada de los avatares de la alternancia electoral. Es así que, en el año 2010, se convoca desde la Presidencia de la República a una Comisión Multipartidaria de Energía, conformada por representantes del Poder Ejecutivo y de los restantes partidos políticos con representación parlamentaria que, luego de algunas instancias de discusión, avalan unánimemente los aspectos medulares de la política energética propuesta. ${ }^{8}$

En la figura 1 se resumen y agrupan los principales acuerdos de dicha política:

8 Este hito de acuerdo multipartidario es particularmente significativo para el éxito del proceso a la luz de una línea de larga duración, identificada por parte importante de la historiografía política nacional, en que los partidos políticos y la política de partidos ocupan un rol no exclusivo, pero sí central. Este es un fenómeno estructural del conjunto del sistema político; existen otros actores, pero suelen actuar articulados con los partidos (Caetano et al., 1987). 
Figura 1: principales acuerdos de los ejes de la Política Energética 2005-2030

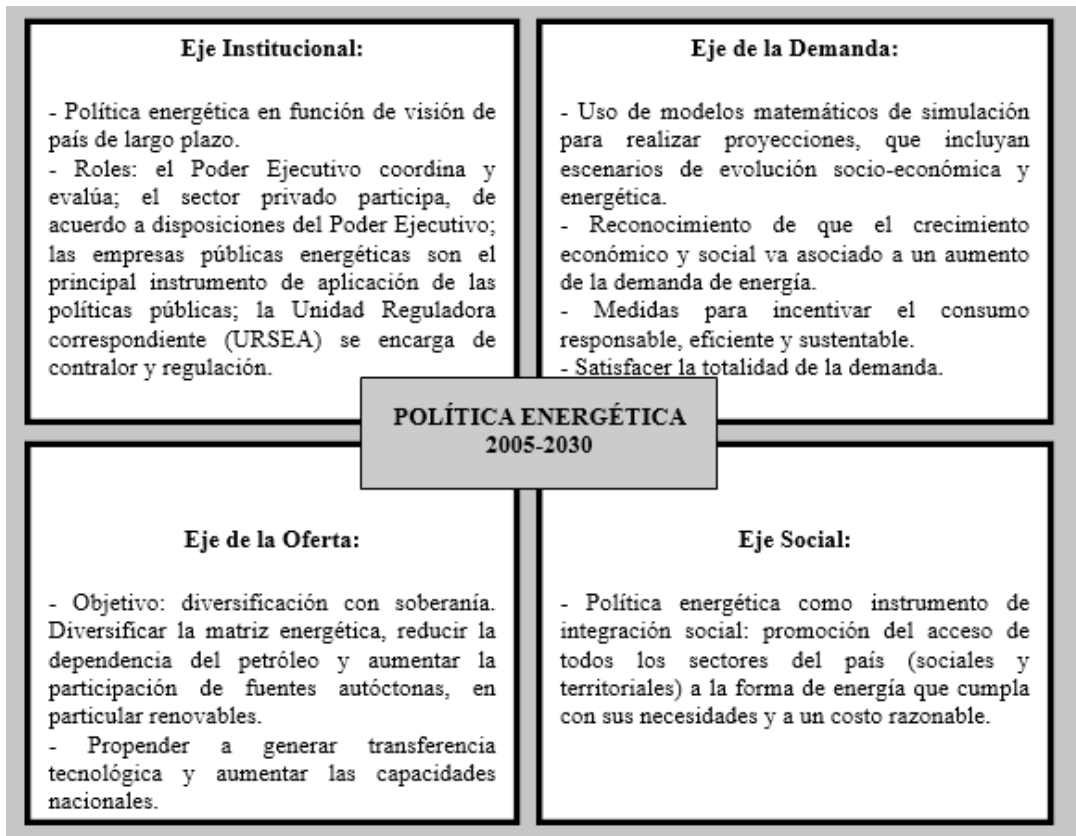

Fuente: elaboración propia en base al "Acuerdo multipartidario sobre política energética 2005-2030" de la Comisión Multipartidaria de Energía (2010).

Para cada uno de los ejes se establecen metas conceptuales y, en algunos casos, numéricas, orientadoras de la acción en el corto, mediano y largo plazo. Por ejemplo, en relación a la instalación de fuentes renovables, se estableció que se debían incorporar a la matriz en el quinquenio 2010-2015 no menos de 300 MW de energía eólica y 200 MW de biomasa.

Este acuerdo político multipartidario, que establece una Política de Estado que va más allá de un simple mandato de gobierno habilitó, producto del marco de estabilidad institucional que se generó, a que se desarrollaran y profundizaran aprendizajes cruzados entre actores diversos en torno al diseño e implementación de la política.

\subsection{EL DESARROLLO DE LA ENERGÍA EÓLICA EN EL MARCO DE LA POLÍTICA ENERGÉTICA NACIONAL}

Como se mencionó anteriormente, dentro de los lineamientos estratégicos de la Política Energética se planteaba la diversificación de la matriz energética y se apuntaba a que al menos el 15\% del consumo eléctrico del país se basara en energía renovable proveniente de fuentes 
no tradicionales (se excluye la producción de energía hidráulica) (DNE-MIEM, 2008). En este contexto se definió apostar a la energía eólica entre las energías renovables. Inicialmente, en el año 2008, la meta de incorporación de energía eólica para el año 2015 se fijó en 300 MW, pero dos años más tarde del acuerdo multipartidario dicha meta fue revisada al alza, situándose en 1.200 MW (DNETN-MIEM, 2009).

Para el caso de la producción de energía eólica, otro antecedente relevante se encuentra en el Programa Energía Eólica en Uruguay (en adelante PEEU), que se extendió entre los años 2007 y 2013, y que tuvo el objetivo de impulsar la producción de energía eólica en el país y de lograr una reducción de gases de efecto invernadero. Se trató de un programa conjunto del Gobierno y del Programa de las Naciones Unidas para el Desarrollo, que fue ejecutado por la Dirección Nacional de Energía (DNE) y contó con una financiación de 7 millones de U\$S del Fondo Mundial para el Medio Ambiente (Global Environment Facility).

El PEEU partió de la identificación de barreras para el desarrollo del sector eólico tanto tecnológicas como a nivel de la política (regulaciones y marco habilitador para la realización de inversiones con expectativas de retorno), de las posibilidades de evaluación del potencial eólico y la información disponible, y de las capacidades y el modelo de negocios de las empresas públicas y privadas. Se orientó la acción del programa a superar estas barreras ${ }^{9}$ y a apoyar la creación de capacidades técnicas en las instituciones del Estado vinculadas a la energía y entre los desarrolladores privados con potencial de provisión (Rodríguez, 2013: 1-2).

En los inicios del PEEU, la mayoría de los actores vinculados a lo eólico eran investigadores de la UdelaR y técnicos de UTE y de la DNE. Se generaron desde el programa espacios de encuentro para promover la interacción entre actores del sector público (Poder Ejecutivo y sus ministerios, gobiernos departamentales), académico (a través de la UdelaR) y empresarial (público, a través de la UTE, y privado, a través de la convocatoria a industriales y emprendedores), ${ }^{10} \mathrm{y}$ se generaron incentivos para favorecer la emergencia del sector empresarial privado. En este proceso de estímulo y atracción de la inversión privada surge, en el año 2009, la Asociación Uruguaya de Energía Eólica (en adelante AUdEE), integrada por personas y empresas

9 Al finalizar la ejecución del programa, consigna la evaluación externa que las barreras habían sido removidas, con la excepción de la político-reguladora, que lo fue parcialmente (las guías medioambientales fueron la pata débil) (Rodríguez, 2013: 47).

10 En abril de 2009 se llevó a cabo el "Primer Encuentro entre Actores de la Energía Eólica en Uruguay: Oportunidades en su Desarrollo", organizado por la DNE en conjunto con la Cámara de Industrias del Uruguay (en adelante CIU); en él participaron 43 actores de diferentes sectores, con un fuerte predominio del sector público y académico (Rodríguez, 2013: 40). 
vinculadas al desarrollo de la energía eólica en el país. Esta organización de segundo grado, que nuclea actores privados, es un emergente claro del proceso de diálogo, y se ha fortalecido en el transcurso del mismo.

El proceso de impulso a la energía eólica implicó importantes cambios a nivel normativo y la reconfiguración dentro del sector eléctrico en general, y en el eólico en particular, de los roles de los actores públicos involucrados (tanto políticos como empresariales), además del surgimiento de nuevos actores.

Para empezar, fue necesario el fortalecimiento de las capacidades técnicas y financieras de la DNE para el correcto desempeño de su rol como diseñador y articulador de la política. El fortalecimiento de la DNE implicó un proceso de profesionalización de sus funcionarios y un trabajo en conjunto de lo técnico y lo político. ${ }^{11}$ Se creó un equipo multidisciplinario de profesionales con formación avanzada en distintas áreas de conocimiento para lo que se contrató egresados de cerca de quince carreras universitarias. Sus perfiles respondían a una visión amplia de la política energética que tiene ribetes tanto tecnológicos como económicos, geopolíticos, ambientales, sociales y éticos; la política fue diseñada en base al conocimiento técnico disponible y se enfatizó en la necesidad de producir nuevo conocimiento para dar continuidad al proceso de transformación.

La UTE, empresa pública que otrora delineara el rumbo de las acciones en materia energética, delega en parte sus funciones de diseño y se fortalece como empresa pública productora, para lo que conserva el monopolio de la red de distribución de energía en el país. Esta empresa tiene como uno de sus cometidos la ejecución de llamados competitivos a empresas para que a través de mecanismos de asociación público-privada construyan los parques eólicos que luego volcarán su producción a la red eléctrica nacional. No obstante, las condiciones de cada llamado o licitación -aspectos vinculados al tipo de tecnología, características de las empresas, porcentaje de componente industrial y de mano de obra nacional requerido, entre otros- las establece el Poder Ejecutivo.

El organismo regulador, la Unidad Reguladora de Servicios de Energía y Agua (en adelante URSEA), existente desde el año 1997, se fortalece en su rol en tanto aumenta la actividad a regular en relación a la calidad y los precios energéticos. La entidad realiza su tarea en cumplimiento de las reglamentaciones establecidas por el Poder Ejecutivo.

11 Tal es así, que al frente de la Dirección que encabezó el cambio de la matriz energética se nombró a un académico de trayectoria, un físico teórico proveniente de la FING, investigador a tiempo completo en la UdelaR hasta esta designación. 
Así, la política pública de cambio de la matriz energética se constituye en esta etapa como una política top-down (de arriba hacia abajo) que, si bien se nutre del fuerte vínculo construido en años anteriores con la academia, está dirigida por el Poder Ejecutivo: diseñada por la DNE, ejecutada por UTE, y regulada por la URSEA. La direccionalidad del diálogo en torno a la alternativa renovable -y en particular eólica- ocurre en el mismo sentido; busca preservar "en manos del gobierno la capacidad de conducir a los actores públicos y privados en el desarrollo de la política, promoviendo la eficiencia sistémica, colocando la lógica del mercado (competencia y maximización de ganancia) al servicio de la política pública" (González \& Méndez, 2014).

A nivel regulatorio, si bien Uruguay ya contaba con un marco legal para la generación y distribución de energía, fue necesaria la creación de uno complementario, compuesto por numerosas resoluciones y decretos, algunos generales para todo el sector eléctrico, y otros tantos específicos para la generación de eólica -regulación de aspectos técnicos, contractuales, medioambientales e impositivos- y de otras energías renovables. ${ }^{12}$ Dicho marco legal, escasamente desarrollado a los inicios de la ejecución del PEEU, es definido hacia el final de la ejecución como "un marco legal habilitante que incluye regulaciones para el acceso a redes y despacho, construcción y operación de centrales eólicas, códigos técnicos, e incentivos financieros para electricidad de generación eólica" (Rodríguez, 2013: 29).

Si bien no se vincula estrictamente al sector energético, en este proceso de construcción normativa se destaca el Régimen General de Promoción de Inversiones, ${ }^{13}$ que establece beneficios fiscales para incentivar la inversión en energías renovables. Entre el 2008 y el 2014, cuarenta y un proyectos energéticos accedieron a beneficios a través de esta vía. El 76\% de los mismos fue impulsado por empresas nuevas y el $66 \%$ se dirigió a la instalación de parques eólicos para la generación de energía (UnASeP, 2014:10).

Algunas características destacables del proceso de incorporación y desarrollo de la energía eólica tienen que ver con: i) un nivel de consenso relativamente amplio, sobre todo político, en torno a la necesidad de dicha transformación, a la orientación tecnológica de la misma y a las modalidades tecno-económicas adoptadas para llevarlas a la práctica; y ii) la rapidez con la cual dicha transformación se produjo,

12 El listado de la normativa vinculada a la transformación energética, junto a una descripción de la sustancia de cada regulación, se encuentra disponible en Rodríguez (2013: 25-29).

13 Este régimen está previsto por la Ley N. ${ }^{\circ} 16.906$ que data del año 1998, en reglamentación dada por el Decreto 002/012 del año 2012. 
lo que redundó en cambios significativos en el origen de la energía consumida en el país.

La rapidez de la transformación, puede ser vista como el emergente de un largo proceso de acumulación de conocimientos y aprendizajes recíprocos a partir de interacciones entre actores diversos. En esto jugaron un papel central múltiples diálogos, sucedidos en diferentes momentos: entre aproximaciones cognitivas diferentes a la temática específica de las energías renovables; entre investigadores en la academia e investigadores académicos que asumieron responsabilidades políticas; entre instituciones tradicionales asociadas a la provisión de energía, con amplia autonomía técnica y política, e instituciones con renovado mandato referido a la energía y más estrecha relación con la política de gobierno.

Es razonable suponer que la construcción de confianza y la facilidad de los intercambios por cercanía cognitiva y espacios compartidos, contribuyeron significativamente a que el diálogo formalmente establecido para el impulso de la energía eólica tuviera un rápido andamiaje y desarrollo.

\subsection{LAS COMUNIDADES EN DIÁLOGO}

Con base en la caracterización de comunidades de CTI de Iberoamérica presentada por Dutrénit, Natera y Suárez (2014), cabe mencionar que en el caso que se presenta son tres las comunidades involucradas y variados los actores que participan en cada una de ellas, a saber:

i) Comunidad Empresarial: está integrada por los actores empresariales (públicos y privados) vinculados a la construcción de la infraestructura para la producción de energía eólica y a la producción en sí misma (AudEE, UTE, CIU y dueños de parques privados);

ii) Comunidad Académica: incluye a instituciones e investigadores del sistema de educación superior (UdelaR y UTEC) y del sistema de educación terciario no universitario (UTU);

iii) Comunidad Sector Público: comprende a los actores vinculados a la movilización de diferentes recursos en torno a la política energética, tanto en su diseño (DNE y Dirección Nacional de Industria del MIEM, Comisión Multipartidaria de Energía) como en su implementación y monitoreo (UTE, Dirección Nacional de Medio Ambiente, Administradora del Mercado Eléctrico, URSEA, Instituto Nacional de Colonización). También incluye a la agencia nacional de fomento y financiación de la I+D+i, la Agencia Nacional de Investigación e Innovación (en adelante, ANII). 
En vinculación con la clasificación utilizada, cabe mencionar que la gran ausente es la sociedad civil entendida en tanto comunidad. ${ }^{14}$ Barboza (2016) recopila diferentes definiciones sociológicas de comunidad; más allá de los matices de los abordajes mencionados, hace mención a características como el reconocimiento (reconocerse como parte de una comunidad y reconocer a otros), el sentido de pertenencia, la construcción colectiva de la identidad, de los objetivos, entre otros. Estos rasgos no están presentes al momento entre los actores de la sociedad civil que de alguna manera han estado vinculados a alguna arista del proceso de diálogo, como no lo estuvieron al inicio del diseño de la política energética entre gran parte de los actores del sector privado.

Los actores de las comunidades mencionadas han sido protagonistas en mayor o menor medida -en función de la etapa del proceso de transformación- de los múltiples diálogos para el desarrollo de la energía eólica. En el Cuadro 1 se presenta, a modo de síntesis, los actores integrantes en cada una de las comunidades, su rol, participación y los aportes más relevantes registrados.

\section{Cuadro 1. Actores participantes en el Diálogo de Energía Eólica. Tipo de participación y aportes específicos.}

\begin{tabular}{|c|c|c|c|}
\hline ACTOR & TIPO DE ACTOR & TIPO DE PARTICIPACIÓN & APORTES \\
\hline \multicolumn{4}{|l|}{ Comunidad Académica } \\
\hline $\begin{array}{l}\text { Universidad de la República: } \\
\text {-Instituto de Ingeniería } \\
\text { Eléctrica, Facultad de } \\
\text { Ingeniería } \\
\text {-Instituto de Mecánica de } \\
\text { Fluidos e Ingeniería Ambiental, } \\
\text { Facultad de Ingeniería } \\
\text {-Grupo interdisciplinario de } \\
\text { Estudios de la Energía }\end{array}$ & $\begin{array}{l}\text { Institución } \\
\text { pública de } \\
\text { educación e } \\
\text { investigación }\end{array}$ & $\begin{array}{l}\text { Generación de } \\
\text { Conocimiento }\end{array}$ & $\begin{array}{l}\text {-Mapas eólicos } \\
\text {-Primer molino de } \\
\text { viento con fines de } \\
\text { investigación } \\
\text {-Estudio de prospectiva } \\
\text { energética } \\
\text {-Primer túnel de viento } \\
\text {-Diagnóstico integral } \\
\text { para el sector } \\
\text { energético }\end{array}$ \\
\hline
\end{tabular}

14 Bertoni et al. (2010: 38), en su estudio sobre la matriz energética de Uruguay, señala que organizaciones ambientalistas como REDES-Amigos de la Tierra y el Centro Uruguayo de Tecnologías Apropiadas (CEUTA) participaron del proceso de producción de conocimiento y de la discusión sobre las alternativas energéticas. Si bien organizan de manera conjunta en 2008 el V Foro Regional de Energías Renovables al que concurren actores públicos y de la sociedad civil (ambientalistas y sindicales), en el proceso de diálogo en torno a la energía eólica en particular, estas organizaciones no están presentes. Una revisión de sus documentos de trabajo revela en el caso del CEUTA -que cuenta con un Programa de Energía- un fuerte trabajo, pero vinculado a la energía solar. 


\begin{tabular}{|c|c|c|c|}
\hline ACTOR & TIPO DE ACTOR & TIPO DE PARTICIPACIÓN & APORTES \\
\hline $\begin{array}{l}\text { Universidad de la República: } \\
\text { Comisión Social Consultiva - } \\
\text { Mesa de Energía }\end{array}$ & $\begin{array}{l}\text { Institución } \\
\text { pública de } \\
\text { educación e } \\
\text { investigación }\end{array}$ & $\begin{array}{l}\text { Generación de espacios } \\
\text { de encuentro }\end{array}$ & $\begin{array}{l}\text { Complemento a } \\
\text { prospectiva energética } \\
\text { de la FING. Análisis } \\
\text { de factibilidad de } \\
\text { energías alternativas } \\
\text { y construcción de } \\
\text { escenarios a } 5 \text { y } 30 \\
\text { años }\end{array}$ \\
\hline $\begin{array}{l}\text { Universidad del Trabajo del } \\
\text { Uruguay (UTU) }\end{array}$ & $\begin{array}{l}\text { Institución } \\
\text { pública de } \\
\text { educación } \\
\text { terciaria }\end{array}$ & $\begin{array}{l}\text { Dictado de cursos } \\
\text { técnicos para el } \\
\text { mantenimiento de } \\
\text { instalaciones de energías } \\
\text { renovables (parques } \\
\text { eólicos) } \\
\end{array}$ & $\begin{array}{l}\text { Formación de técnicos } \\
\text { en el mantenimiento } \\
\text { de instalaciones de } \\
\text { energías renovables } \\
\text { (parques eólicos) }\end{array}$ \\
\hline Universidad Tecnológica (UTEC) & $\begin{array}{l}\text { Institución } \\
\text { pública de } \\
\text { educación } \\
\text { superior }\end{array}$ & $\begin{array}{l}\text { Dictado de cursos } \\
\text { técnicos en energías } \\
\text { renovables }\end{array}$ & $\begin{array}{l}\text { Formación de técnicos } \\
\text { en energías renovables }\end{array}$ \\
\hline \multicolumn{4}{|l|}{ Comunidad Empresarial } \\
\hline $\begin{array}{l}\text { Asociación Uruguaya de } \\
\text { Energía Eólica (AUdEE) }\end{array}$ & $\begin{array}{l}\text { Asociación } \\
\text { Privada }\end{array}$ & $\begin{array}{l}\text { Promoción y articulación } \\
\text { de proyectos vinculados } \\
\text { con la energía eólica }\end{array}$ & $\begin{array}{l}\text { Jornadas técnicas, } \\
\text { diálogo con actores de } \\
\text { otras comunidades, } \\
\text { empresas relacionadas } \\
\text { a la construcción de } \\
\text { parques eólicos } \\
\end{array}$ \\
\hline $\begin{array}{l}\text { Administración de Usinas } \\
\text { y Transmisiones Eléctricas } \\
\text { (UTE) }\end{array}$ & Empresa Pública & $\begin{array}{l}\text { Producción, transmisión, } \\
\text { distribución y } \\
\text { comercialización de la } \\
\text { energía }\end{array}$ & $\begin{array}{l}\text { Construcción de } \\
\text { parques eólicos, } \\
\text { extensión y gestión de } \\
\text { la red energética } \\
\end{array}$ \\
\hline $\begin{array}{l}\text { Cámara de Industrias del } \\
\text { Uruguay (CIU) }\end{array}$ & $\begin{array}{l}\text { Entidad } \\
\text { empresarial }\end{array}$ & $\begin{array}{l}\text { Contribución al } \\
\text { desarrollo e instalación } \\
\text { de parques eólicos; } \\
\text { convocatoria de actores } \\
\text { privados en el marco } \\
\text { del PEEU } \\
\end{array}$ & $\begin{array}{l}\text { Construcción de } \\
\text { parques eólicos, venta } \\
\text { de energía eólica, } \\
\text { jornadas técnicas, } \\
\text { diálogo con actores de } \\
\text { otras comunidades } \\
\end{array}$ \\
\hline Dueños de parques privados & Firmas privadas & Producción energética & Venta de energía \\
\hline \multicolumn{4}{|l|}{ Comunidad Sector Público } \\
\hline $\begin{array}{l}\text { Administración de Usinas } \\
\text { y Transmisiones Eléctricas } \\
\text { (UTE) }\end{array}$ & Empresa Pública & $\begin{array}{l}\text { Administración del } \\
\text { recurso energético }\end{array}$ & $\begin{array}{l}\text { Licitaciones para } \\
\text { parques eólicos, } \\
\text { contratos para la } \\
\text { compra de energía } \\
\text { eólica, convenios } \\
\text { con la academia } \\
\text { para el desarrollo de } \\
\text { conocimiento }\end{array}$ \\
\hline
\end{tabular}




\begin{tabular}{|c|c|c|c|}
\hline ACTOR & TIPO DE ACTOR & TIPO DE PARTICIPACIÓN & APORTES \\
\hline $\begin{array}{l}\text { Dirección Nacional de Energía } \\
\text { (DNE) y Dirección Nacional de } \\
\text { Industria (DNI), del Ministerio } \\
\text { de Industria, Energía y Minería } \\
\text { (MIEM) }\end{array}$ & $\begin{array}{l}\text { Gobierno (Poder } \\
\text { Ejecutivo) }\end{array}$ & $\begin{array}{l}\text { Elaboración y diseño de } \\
\text { política; ejecución } \\
\text { y normativa }\end{array}$ & $\begin{array}{l}\text { Decretos relacionados } \\
\text { con la producción } \\
\text { y uso de la energía } \\
\text { eólica, convocatoria a } \\
\text { actores involucrados } \\
\text { en temas de energía, } \\
\text { facilitador del } \\
\text { diálogo entre actores } \\
\text { de las diferentes } \\
\text { comunidades, } \\
\text { convenios con la } \\
\text { academia para } \\
\text { el desarrollo de } \\
\text { conocimientos }\end{array}$ \\
\hline $\begin{array}{l}\text { Dirección Nacional de } \\
\text { Medio Ambiente (DINAMA), } \\
\text { del Ministerio de Vivienda, } \\
\text { Ordenamiento Territorial } \\
\text { y Medio Ambiente (MVOTMA) }\end{array}$ & Gobierno & $\begin{array}{l}\text { Diseño de políticas } \\
\text { y aplicación de la } \\
\text { regulación vigente }\end{array}$ & $\begin{array}{l}\text { Evaluación ambiental } \\
\text { de los proyectos de } \\
\text { los parques eólicos, } \\
\text { puesta de manifiesto } \\
\text { de proyectos ante la } \\
\text { sociedad en general, } \\
\text { aprobación para } \\
\text { la construcción de } \\
\text { parques }\end{array}$ \\
\hline $\begin{array}{l}\text { Administradora del Mercado } \\
\text { Eléctrico (ADME) }\end{array}$ & $\begin{array}{l}\text { Público no } \\
\text { estatal }\end{array}$ & $\begin{array}{l}\text { Administración del } \\
\text { mercado eléctrico } \\
\text { mayorista }\end{array}$ & $\begin{array}{l}\text { Permitir la ejecución } \\
\text { de contratos de } \\
\text { generadores, } \\
\text { distribuidores y } \\
\text { grandes consumidores } \\
\text { de energía eléctrica, } \\
\text { despacho de energía } \\
\text { según demanda que } \\
\text { optimiza el sistema } \\
\text { interconectado nacional }\end{array}$ \\
\hline $\begin{array}{l}\text { Fondo Sectorial de Energía } \\
\text { (FSE): Agencia Nacional de } \\
\text { Investigación e Innovación } \\
\text { (ANII), DNE-MIEM, } \\
\text { Administración Nacional de } \\
\text { Combustibles (ANCAP) y UTE }\end{array}$ & $\begin{array}{l}\text { Pública de apoyo } \\
\text { a la investigación }\end{array}$ & $\begin{array}{l}\text { Administración de } \\
\text { fondos para proyectos de } \\
\text { investigación y desarrollo } \\
\text { en temas energéticos }\end{array}$ & $\begin{array}{l}\text { Financiación de más } \\
\text { de } 100 \text { proyectos entre } \\
2009 \text { y } 2014\end{array}$ \\
\hline $\begin{array}{l}\text { Comisión Multipartidaria de } \\
\text { Energía }\end{array}$ & Gobierno & $\begin{array}{l}\text { Elaboración y aprobación } \\
\text { de políticas }\end{array}$ & \begin{tabular}{|l} 
Aprobación de la \\
Política Energética \\
Nacional \\
\end{tabular} \\
\hline $\begin{array}{l}\text { Instituto Nacional de } \\
\text { Colonización }\end{array}$ & \begin{tabular}{|l|} 
Institución \\
pública de \\
gestión de tierras \\
(no estatal) \\
\end{tabular} & $\begin{array}{l}\text { Gestión de tierras para } \\
\text { el desarrollo agrario, } \\
\text { algunas de las cuales } \\
\text { alojan parques eólicos }\end{array}$ & $\begin{array}{l}\text { Elaboración y gestión } \\
\text { de convenios de tierras } \\
\text { para parques eólicos }\end{array}$ \\
\hline $\begin{array}{l}\text { Unidad Reguladora de } \\
\text { Servicios de Energía y Agua } \\
\text { (URSEA) }\end{array}$ & $\begin{array}{l}\text { Institución } \\
\text { reguladora } \\
\text { pública (Estado) }\end{array}$ & $\begin{array}{l}\text { Reguladora de servicios } \\
\text { de energía }\end{array}$ & $\begin{array}{l}\text { Regulación, fiscalización } \\
\text { y asesoramiento a } \\
\text { usuarios en temas de } \\
\text { energía }\end{array}$ \\
\hline
\end{tabular}




\begin{tabular}{|l|l|l|l|}
\hline \multicolumn{1}{|c|}{ ACTOR } & TIPO DE ACTOR & TIPO DE PARTICIPACIÓN & \multicolumn{2}{|l|}{ APORTES } \\
\hline Sociedad Civil & Usuarios & $\begin{array}{l}\text { Conexión a la red } \\
\text { eléctrica, uso eficiente } \\
\text { de la energía }\end{array}$ & $\begin{array}{l}\text { Consumo de energía, } \\
\text { volcado a la red } \\
\text { energética }\end{array}$ \\
\hline Usuarios particulares & $\begin{array}{l}\text { Alojamiento de parques } \\
\text { eólicos en predios } \\
\text { particulares y/o } \\
\text { convivencia con parques } \\
\text { cercanos }\end{array}$ & $\begin{array}{l}\text { Información acerca del } \\
\text { viento y los parques } \\
\text { eólicos }\end{array}$ \\
\hline $\begin{array}{l}\text { Comunidades locales cercanas } \\
\text { a parques eólicos }\end{array}$ & Usuarios & &
\end{tabular}

Fuente: elaboración propia en base a información relevada.

Algunas características de los actores y las comunidades, de su rol y participación, marcaron particularidades en distintos momentos del diálogo, entre las que podemos destacar las siguientes:

i) Entre los actores de algunas comunidades pre-existía una relación de confianza que se vio reforzada en el proceso de diálogo específico sobre la energía eólica. Esto se dio particularmente entre la Comunidad Académica y la Comunidad del Sector Público, donde las relaciones de confianza se remontan a diálogos anteriores ya reseñados. Como consecuencia, se produjo un funcionamiento sinérgico entre ambas comunidades para la consecución de sus objetivos, lo que derivó en una suerte de alianza en torno a la relevancia de la producción de conocimiento en vinculación directa con la construcción de la Política Energética Nacional;

ii) Como emergente del propio diálogo, se formó y consolidó la Comunidad Empresarial, que no existía en tanto comunidad antes del mismo. La apuesta por la energía eólica impulsó la conformación de una comunidad de actores del sector, antes disgregados y poco visibles. Los actores energéticos del sector público tuvieron mucho que ver con la construcción de un espacio de confianza para la inversión, a través de la adaptación y creación de normativa legal específica que brindó un marco de estabilidad y de dinamismo para los inversores privados. Desde el año 2006, se sucedieron diferentes eventos con un gradual crecimiento de la presencia de actores del sector privado -junto con el sector público y académico- para el cumplimiento de las metas en torno a la energía eólica. En el año 2009, como ya se mencionó, se crea la AUdEE. Esta organización, que nuclea a las empresas del sector, oficia de punto de encuentro, intercambio y colaboración entre promotores, 
fabricantes e instituciones financieras, los principales actores privados del mercado eólico. Contribuye a la búsqueda de instrumentos financieros para fomentar la presentación de proyectos de energía eólica en el país, promueve espacios de cooperación nacionales e internacionales, participa en los espacios de representación frente a los organismos reguladores y de gobierno (DNE, Administración del Mercado Eléctrico, URSEA) y promueve la generación de flujos de intercambio y la aproximación de sus asociados (AUdEE, s/f);

iii) La sociedad civil es un actor débil en este proceso y, como ya se mencionó, es inexistente en tanto comunidad. No se identifica una comunidad organizada sino tan solo participaciones puntuales y locales de ciudadanos no organizados en talleres convocados por el sector público en localidades cercanas a los puntos de instalación de los parques eólicos. Si bien existen en el país organizaciones sociales ambientalistas, tampoco han tenido una participación activa e influyente en los múltiples diálogos que se han sucedido. Lo cierto es que la política energética, que sí tuvo por objetivo organizar a la comunidad empresarial, no se planteó de manera explícita organizar la participación social en torno a la transformación de la matriz. Se trató de una política construida desde el centro y desde arriba, para la que los ciudadanos son consumidores (cautivos, de acuerdo al marco institucional vigente); esta orientación política (en torno a un "no hacer") tiene claras consecuencias sobre los actores con menos recursos de poder económico, político, informacional y de acceso y control de los factores productivos clave.

A modo de síntesis, la Figura 2 presenta las diferentes comunidades y sus relaciones en una línea de tiempo, a medida que se avanza en el plan de desarrollo eólico y se suceden los principales hitos del diálogo en torno a la construcción de la política energética. Se visualiza en la figura el espacio de interacción de larga data entre las comunidades académica y del sector público, la presencia de la comunidad empresarial desde el momento que surge y se consolida la política energética, y a los actores de la sociedad civil con una participación esporádica y marginal. 
Figura 2. Relacionamiento entre las diferentes comunidades en la incorporación de la energía eólica a la matriz energética de Uruguay en línea de tiempo.

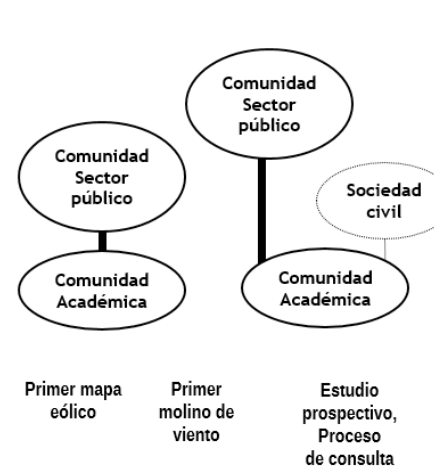

1990

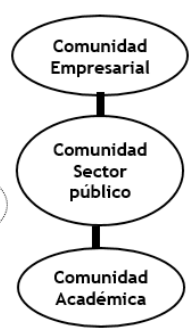

Nueva

Política

Energética

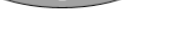

2005

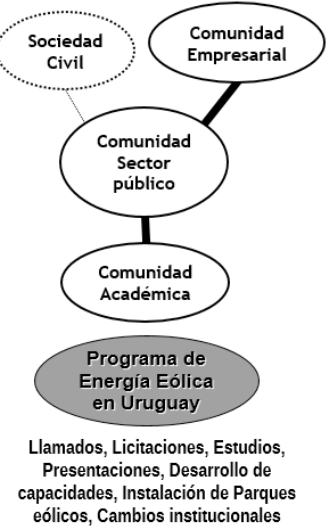

2007-2013

2015

Fuente: elaboración propia en base a información relevada.

Aunque el relacionamiento entre las comunidades varía en el transcurso del diálogo, se destaca un antes y un después de la aprobación de la Política Energética: i) una primera etapa, anterior a la aprobación de la política, en la que la vinculación se produce principalmente entre las comunidades académica y del sector público, aunque los encuentros son intermitentes. La sociedad civil -aunque no en tanto comunidad- aparece vinculada a la academia; $i$ ) una segunda etapa, posterior a la aprobación de la política, en la que además de la comunidad académica y el sector público entra en el juego la comunidad empresarial; los vínculos en esta etapa se mantienen a lo largo del tiempo y el articulador es el sector público, en concreto la Dirección Nacional de Energía, con la que se vinculan el resto de los actores.

\subsection{RESULTADOS DEL PROCESO DE DIÁLOGO EN TORNO A LA ENERGÍA EÓLICA}

A casi diez años del diseño y comienzo de la implementación de la Política Energética Nacional se pueden apreciar algunos resultados, posibles gracias a múltiples procesos de diálogo, tanto en lo que tiene que ver con la participación de la energía eólica en la matriz eléctrica nacional, como en la constitución de una red de comunidades y actores que opera de soporte al proceso y que se ha visto fortalecida por la construcción de nuevas capacidades, tanto políticas como de I+D+i. A continuación, se desarrollan los principales resultados. 
AUMENTO DE PRODUCCIÓN DE ENERGÍA ELÉCTRICA A PARTIR DE LA FUENTE EÓLICA Y REDUCCIÓN DE LA DEPENDENCIA ENERGÉTICA Los procesos de aprendizaje descritos entre las distintas comunidades, las interacciones y diálogos generados entre ellas, han permitido la construcción de una estructura que hoy se hace tangible en los parques eólicos distribuidos en el territorio nacional. Se trata de treinta y cuatro parques instalados hasta el momento, y la producción energética de los mismos representa en la actualidad poco más del $20 \%$ de la energía eléctrica (Gráfico 1).

Gráfico 1. Evolución de la generación de energía eléctrica enero 2009 - julio 2016 en Uruguay. Porcentaje de las diferentes fuentes de energía (térmica, hidráulica, eólica y solar) en Gigavatio-hora (Gwh)

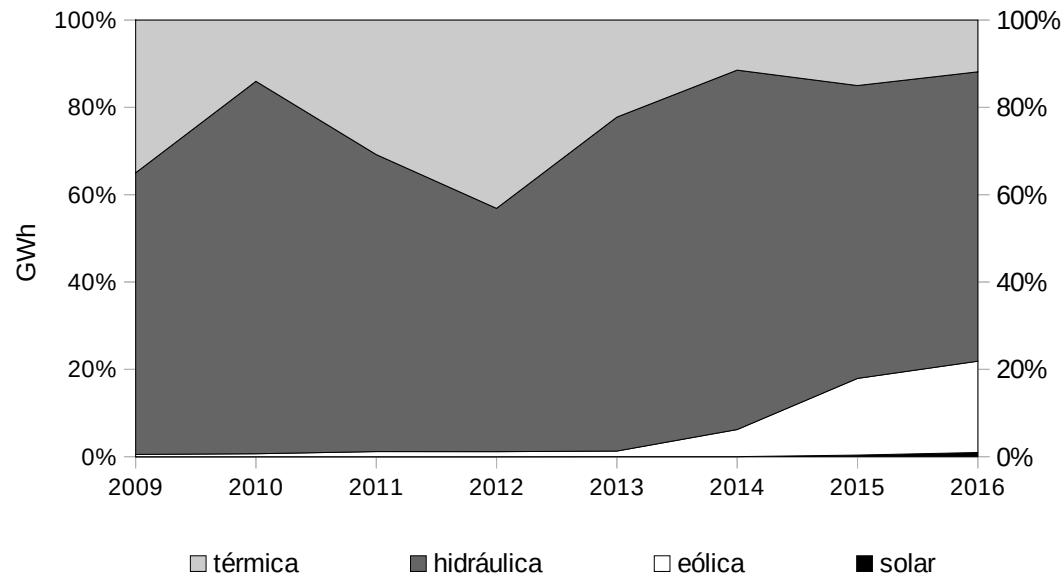

Fuente: elaboración propia en base a serie de datos MIEM-DNE (s/f c).

Se espera que, en el año 2017, el 38\% de la electricidad en Uruguay se genere a partir del viento sobre la base de $1.500 \mathrm{MW}$ de capacidad instalada de energía eólica para el final del año. Según la UTE, la construcción de parques eólicos se detendrá en 2023 ya que la capacidad instalada aumentó desde los 20 MW en 2008, y pronto superará las necesidades internas de Uruguay (GWEC, 2015). La mayoría de las empresas privadas que participan en el negocio de la energía eólica se preparan para exportar su know how a otros países de América Latina con una situación inestable respecto al suministro de energía. 
Los datos mencionados, asociados al desarrollo de la energía eólica, sumado a otros esfuerzos que se realizan en el país también relacionados con la transformación de la matriz energética, han permitido al Uruguay alcanzar una mayor independencia respecto de las fuentes de energía eléctrica.

\section{CONFORMACIÓN DE UNA RED SECTORIAL DE ACTORES Y COMUNIDADES, AÚN INCOMPLETA, EN TORNO AL POTENCIAL EÓLICO}

A pesar de los atributos diferentes de los actores y comunidades -de lenguajes, conocimientos acumulados, capacidades, recursos y experiencias previas compartidas o no- se lograron alcanzar durante el proceso altos niveles de acuerdo y sortear las asimetrías de recursos de poder en los espacios de interacción (Dutrénit, Natera \& Suárez, 2014). Los espacios de confianza -los preexistentes y los nuevos- se fortalecieron entre las comunidades, principalmente entre el sector público, la academia y el sector privado, y habilitaron la conformación de una verdadera red de actores en torno a objetivos compartidos, lo que podríamos identificar como los primeros pasos hacia la conformación de un sistema sectorial de innovación (Malerba, 2002) en torno a la alternativa eólica. Esta red de actores opera de soporte a la transformación energética con énfasis en la producción eólica, aporta sistematicidad e interés en el seguimiento de las metas y un reconocimiento social a la alternativa eólica y al proceso, con el que antes no contaba.

No obstante, resta aún lograr la incorporación de la sociedad civil al diálogo eólico, de manera de poder incorporar la perspectiva ciudadana. Si bien se generaron instancias de intercambio con los ciudadanos que residían en zonas cercanas a los parques eólicos, principalmente por conflictos que se presentaron, ${ }^{15}$ las mismas fueron puntuales. Los usuarios, y la ciudadanía en términos generales, no son hoy verdaderos actores del proceso desarrollado sino espectadores y receptores de las acciones que se sucedieron en los diálogos promovidos entre el resto de las comunidades y actores.

\section{CONSTRUCCIÓN DE CAPACIDADES DE I+D+I}

Las capacidades adquiridas en el correr de los años se han reflejado en gran parte en productos concretos que ya han sido mencionados, como la construcción y el perfeccionamiento del mapa eólico y la

15 Estos conflictos tuvieron que ver con las primeras adjudicaciones de parques eólicos, cuando el proceso iniciaba y se producía el cambio, se vieron demoradas por la oposición de las personas que vivían en las inmediaciones del parque, en un claro proceso de "not in my backyard" que luego fue solucionado mediante talleres organizados por DNE y la UTE. 
disponibilización de esa información relevante para la toma de decisiones en torno a la instalación, la construcción del primer molino de viento con fines de investigación, los estudios de prospectiva energética, la construcción del túnel de viento y el diagnóstico integral para el sector energético.

Pero el proceso de diálogo ha dado también lugar al desarrollo de capacidades que operan de soporte a la continuidad, y que quizás no son aún tan visibles, tanto al interior de la academia como también en el sector público y en el privado. Desde la Agencia Nacional de Investigación e Innovación (ANII), brazo ejecutor de la política de CTI nacional, se crearon en el año 2009 los Fondos Sectoriales, con el objetivo de vincular a agentes de la academia (de todas las instituciones de producción de conocimiento del país) y del sector productivo en líneas estratégicas definidas por las políticas de Estado. Entre estos fondos, que han recibido críticas de protagonistas de las políticas de CTI en relación a la baja y fluctuante participación de las organizaciones del Estado (Ardanche, 2012), configura una excepción el Fondo Sectorial de Energía. Desde su creación hasta 2016, se han realizado cuatro convocatorias ${ }^{16}$ en dos modalidades: proyectos de investigación y proyectos de innovación en articulación con el sector productivo (la línea menos exitosa). Este instrumento ha dinamizado en gran medida la producción de conocimiento en distintas áreas relativas a la energía, ha incentivado vocaciones científicas y ha propiciado la reorientación de agendas de investigación: se financiaron más de cien proyectos en sus cuatro ediciones y se pasó de apoyar a un puñado de investigadores, principalmente de la FING, a que en cada convocatoria se presenten en el entorno de cincuenta proyectos que involucran al menos doscientos investigadores por convocatoria. Las líneas estratégicas de $\mathrm{I}+\mathrm{D}+\mathrm{i}$ de la política energética son acordadas en la dirección del fondo, integrada por la DNE, ANCAP, UTE y la ANII, y comunicadas ante cada convocatoria ${ }^{17}$.

Desde la UdelaR también se han generado instrumentos de I+D, dirigidos a docentes universitarios, en colaboración con las empresas públicas energéticas: existe un programa de colaboración estable con ANCAP, donde en varias de las convocatorias se introdujo la temática energética, a través de problemas de interés como "energías renovables" y "biocombustibles" fijados por el ente (Cohanoff et al., 2014). Recientemente se han establecido contactos con la dirección de

16 Actualmente está en marcha la quinta convocatoria.

17 Más allá del direccionamiento de los temas de la convocatoria, siempre se reserva una categoría libre para eventuales líneas que sean de recibo para la dirección del fondo. 
UTE: se ha direccionado parte del financiamiento universitario para el sector productivo a temas de su interés, se realizaron las primeras jornadas conjuntas entre investigadores de la UdelaR y técnicos de la empresa pública y se está en proceso de establecer un programa de colaboración estable para promover y financiar investigación en torno a temáticas de su interés. Por otra parte, los Convenios de diferentes equipos de investigadores universitarios con las empresas del sector energético son cada vez más numerosos y frecuentes; la percepción de los investigadores lo indica y los técnicos de UTE y de la DNE entrevistados así lo afirman.

Se ha avanzado también en la formación de posgrado. De manera complementaria al aumento general de las becas de posgrado (tanto de la ANII, para realizar estudios en el exterior, como de la UdelaR, para que sus docentes realicen posgrados nacionales), en el año 2008 se instaló en la FING un programa de posgrado en Ingeniería de la Energía que tiene tres niveles: diploma, maestría y doctorado. En un área donde no existían titulaciones nacionales previas, ya se cuenta con cerca de una docena de egresados del programa (aún no doctores).

La carencia más grande a nivel de la construcción de capacidades y lo que más lento ha avanzado es la formación de técnicos, principalmente para operación y mantenimiento de instalaciones eólicas y solares fotovoltaicas. Esto constituye "un cuello de botella" para el desarrollo de la energía eólica y también para la política, puesto que los decretos de convocatoria a licitación establecen que luego del segundo año de instalación del parque eólico, al menos el $80 \%$ del personal involucrado tiene que ser de origen nacional. Desde el 2013 y hasta el momento tan solo existen cursos de técnicos terciarios de especialización en Energías Renovables y Eficiencia Energética, dictados por la Universidad del Trabajo del Uruguay (UTU), pero que constan de módulos de tres meses por cada tipo de fuente energética, cuando la especialización en cada tecnología requiere un entrenamiento que supera con creces dichos tiempos. Este año comenzó a funcionar en la Universidad Tecnológica (UTEC) la carrera de Tecnólogo en Energías Renovables especializado en Energía Eólica, pero los primeros tecnólogos tardarán al menos tres años en egresar.

\section{CONSTRUCCIÓN DE CAPACIDADES TÉCNICAS DE LO POLÍTICO}

Y DE FORTALEZAS DE LA POLÍTICA EN TORNO A LAS ENERGÍAS RENOVABLES

Interrogadas acerca de los fundamentos del éxito de la política, las autoridades del Poder Ejecutivo de la época responden que, a su juicio, la explicación se basa en que hubo un plan, una política a largo plazo y amplios acuerdos validados por todos los actores políticos, que re- 
conocían la necesidad de mirada larga en este tema, aspecto que da garantías para eventuales inversiones, que se requerían y mucho, y que efectivamente llegaron. Así pues, el resultado político más visible y con mayor incidencia en el proceso de diálogo fue la aprobación de la propia Política Energética Nacional. Este acontecimiento marca un hito en el desarrollo de las energías renovables y de la eólica en particular. La política energética, conducida por la DNE, procuró mapear y entender todos los intereses involucrados en el área energía para prevenir enfrentamientos evitables y plantear soluciones ganarganar. Una nota relevante y distintiva de la política es que no recurre a los clásicos subsidios, lo que da estabilidad al precio, y asegura la recuperación de la inversión comprometiéndose el Estado a adquirir toda la energía producida por veinte años, independientemente de su consumo.

La DNE realizó un especial esfuerzo en la generación de competencias internas: se amplió y fortaleció la planta técnica ${ }^{18}$ y se buscó suplir la ausencia de un Instituto de Energía en Uruguay. Para caminar en esa dirección, se tomaron medidas tales como no contratar consultorías independientes sino asociarse con profesionales para desarrollar estudios de forma conjunta, de manera de construir capacidades internas.

Otro resultado a destacar -en buena medida habilitante de los resultados sustantivos en torno a la producción- es la transformación radical del marco legal y regulatorio del sector energético en general y eólico en particular. Entre estas disposiciones legales se destacan decretos que regulan el aporte de información por parte de los actores (series de vientos), establecen los procedimientos para los contratos de energía eólica con privados, incorporan en forma explícita la producción de energía eólica, certifican la incorporación de componentes nacionales en las inversiones de energías renovables (infraestructura, logística y mano de obra) y habilitan la posibilidad de generación de energía por usuarios privados.

El proceso de transformaciones institucionales que ocurrieron en paralelo -y de manera concertada- al diseño e implementación de la política energética, sumado a la excelente respuesta de todas las comunidades involucradas y a los resultados efectivos de las acciones emprendidas, convirtieron a lo que en cierto momento se denominaba "la alternativa eólica" en una de las apuestas energéticas por excelencia del país. Hoy en día el proceso de transformación de la matriz energética con base en fuentes renovables es irreversible y goza de

18 Al respecto, señala el Director de Energía 2008-2015: "tenemos mucho de instituto universitario...". 
cierta inercia, lo que lo preserva de la volatilidad asociada a los ciclos de la política.

\section{REFLEXIONES FINALES}

Cuando hablamos del proceso de diálogo en torno a la energía eólica en Uruguay, recurrimos a una caracterización ex post producto del estudio realizado. No se trata de un diálogo "institucionalizado", formalmente convocado, organizado y definido por las comunidades participantes -o alguna de ellas en particular- a los efectos de alcanzar objetivos negociados, sino que de la observación de la experiencia en torno a la energía eólica es posible reconstruir, a partir del devenir de los acontecimientos, un proceso de diálogo que se desarrolla y cambia de forma en las diferentes etapas que atraviesa. Esta condición hace que sea compleja la caracterización del diálogo en al menos dos sentidos.

En primer lugar, no es posible asignar al diálogo una temporalidad determinada, identificar un comienzo y un fin, puesto que los cimientos del propio proceso (si entendemos, por ejemplo, a la construcción de confianzas intra e intercomunidades como parte fundamental del diálogo) se remontan bastante tiempo atrás de la elaboración y legitimación de la Política Energética Nacional en tanto política explícita.

En segundo lugar, tampoco es posible establecer un estado de situación inmutable sobre las relaciones de los actores y comunidades involucradas: las relaciones entre los actores y el grado de heterogeneidad entre las capacidades de los mismos inciden en las características del diálogo mismo y, junto a él -máxime al tratarse de un diálogo de largo plazo-, pueden sufrir modificaciones, más aún cuando la modificación está incluida entre los objetivos del propio proceso, si se conceptualiza como parte constitutiva del éxito de la política. Lo mismo ocurre con las comunidades: las capacidades y los recursos con que cuenten dependen fuertemente de su grado de constitución y del reconocimiento recíproco entre actores que, debido al largo plazo también, será necesariamente variable. El caso presentado, en particular la transformación de la comunidad empresarial, da cuenta del señalamiento anterior.

El diálogo generado en torno a la incorporación de la energía eólica en Uruguay, como respuesta a la escasez, a la dependencia energética y al alza de los precios internacionales, permitió elaborar y concretar una verdadera política de Estado, estable y con proyección de largo plazo, y aceptada por todas las comunidades involucradas: política, académica y empresarial, con vías a una verdadera apropiación social a pesar de que la participación de la sociedad civil es sin duda el aspecto más débil del proceso. 
En tanto innovación satisfactoria se basó, fundamentalmente, en relaciones estrechas de confianza entre las comunidades, que permitieron procesar un cambio radical en el rumbo energético del país. Como intentamos mostrar a lo largo del texto, estas relaciones de confianza preexistían en gran medida a la formalización de la política energética, y se profundizaron a través de los diálogos acaecidos en torno a la misma extendiéndose hacia actores no tradicionales en el sector. Si bien al inicio fue determinante la confianza y los aprendizajes cruzados entre la comunidad académica y el sector político y los nuevos bríos del sector público en aras de formular y conducir la política energética, el fuerte involucramiento de la comunidad empresarial -novedad relativa en un país de impronta "estatista" y con indiscutido predominio de las empresas públicas en la provisión básica de bienes y servicios- y el desarrollo de la colaboración público-privada, tuvieron como consecuencia altos niveles de efectividad en el cumplimiento de las metas de la política energética.

Adicionalmente, durante el proceso que llevó al cambio de la matriz energética, se desarrollaron vínculos cada vez más sistémicos entre comunidades y comenzaron a configurar un sistema sectorial de innovación. Las distintas comunidades involucradas, a través de vínculos informales y de regulaciones que fueron posteriormente estructuradas y formalizadas, han generado a lo largo del tiempo pequeñas innovaciones en procesos $\mathrm{y}$, sobre todo, han establecido una proyección futura, vinculada con la ampliación de capacidades y con la generación endógena de tecnología. Esto nos permite aventurar la idea de la existencia de un sistema sectorial de innovación en relación a la energía eólica.

La condición particular de este caso de estudio permite extraer lecciones valiosas acerca de las claves de un proceso de generación de sinergias en una situación donde los actores políticos, si bien no se plantearon como objetivo la generación de un espacio vinculante de consulta con otras comunidades, lograron suscitar un proceso virtuoso de alineamiento de intereses y acciones.

Este diálogo sobre un sector particular, pero transversal y a la vez con fuerte base en las competencias de ciencia, tecnología e innovación, que considera las capacidades existentes y mira al futuro para crear nuevas, es evidencia de que es posible pensar la política de CTI en articulación con el desarrollo del país.

\section{BIBLIOGRAFÍA}

Álvarez, A.; Barletta, F.; Suarez, D.; Yoguel, G. 2016 "Marco analítico para la tipificación de diálogos para las políticas de CTI" en Working paper 3 (Red CYTED COM-LALICS). 
Amsden, A. 1989 Asia's Next Giant: South Korea and late industrialization (Nueva York: Oxford University Press).

Ardanche, M. 2012 "Modelos para armar: ciencia, tecnología e innovación en clave de transversalidad", Tesis de grado (Montevideo: Universidad de la República). En <https://www. colibri.udelar.edu.uy/bitstream/123456789/4929/1/TCP_Ardanche FigueredoMar\%c3\%adaMelissa.pdf $>$.

AUdEE (s/f) Asociación Uruguaya de Energía Eólica (AUdEE). En $<$ http://www.audee.org/>.

Barboza, L. 2016 "Algunas consideraciones en torno al concepto de comunidad" en Working paper 6 (Red CYTED COM-LALICS). En $<$ http://lalics.org/images/CYTED/DT6-DefinicinComunidad.pdf>.

Bertoni, R.; Román, C.; Rubio, M. 2009 "El desarrollo energético de España y Uruguay en perspectiva comparada, 1860-2000" en Historia Industrial (Barcelona) No 41, pp. 161-194.

Bertoni, R.; Echinope, V.; Gaudiosso, R.; Laureiro, R.; Lostaunau, M.; Taks, J. 2010 La matriz energética: una construcción social (Montevideo: UdelaR-CSIC).

Caetano, G.; Rilla, J.; Pérez, R. 1987 "La partidocracia uruguaya. Historia y teoría de la centralidad de los partidos políticos" en Cuadernos del CLAEH (Uruguay) $\mathrm{N}^{\circ} 44$.

Chang. H. 2003 Kicking away the ladders. Development strategy in historical perspective (Londres: The Anthem Press).

Cohanoff, C.; Mederos, L.; Simón, L. 2014 "La Universidad vinculada y sus desafíos" en Bianco, M.; Sutz, J. (coords.) Veinte años de politicas de investigación en la Universidad de la República: aciertos, dudas y aprendizajes (Montevideo: Trilce) pp. 85-106.

Comisión Multipartidaria de Energía 2010 Acuerdo multipartidario sobre política energética 2005-2030 (Montevideo: Comisión Multipartidaria de Energía).

DNETN-MIEM 2009 Programa de Energía Eólica (Montevideo). En $<\mathrm{http}: / /$ www.energiaeolica.gub.uy/>.

Dutrénit, G.; Natera, J. M.; Suárez, M. 2014 "Lineamientos para la caracterización de las Comunidades y sus Procesos de Diálogo" en Working paper 1 (Red CYTED COM-LALICS). En <http:// lalics.org/images/CYTED/DT1-ComunidadesDialogo\%201.pdf>.

Dutrénit, G.; Álvarez, I.; Ardanche, M.; Barletta, F.; Bianco, M.; Cortés, R.; Vera-Cruz, A. 2016 "Matriz de Información para el mapeo de procesos de diálogo de CTI en España, América Latina y el Caribe" en Working paper 5 (Red CYTED COM-LALICS). En <http://lalics.org/images/CYTED/DT5-Formulario2.pdf>. 
Edquist, C.; Hommer, L. 1998 "Government Technology

Procurement and Innovation Theory" en Working Paper,

Department of Technology and Social Change (Suecia: Linköping University). En <http://citeseerx.ist.psu.edu/viewdoc/download? doi=10.1.1.203.3198\&rep=rep1\&type $=$ pdf $>$.

Evans, P. 1995 Embedded Autonomy: states and industrial transformation (Princeton: Princeton University Press).

González, R.; Méndez, R. 2014 "Política energética 2005-2030: proceso, sustancia y sostenibilidad" en V Congreso Uruguayo de Ciencia Política (Montevideo).

Goñi, M.; Ardanche, M.; Bianco, M.; Puchet, M. 2015 “Elementos para caracterizar los procesos de diálogo en políticas de CTI" en Working paper 7 (Red CYTED COM-LALICS). En <http:// lalics.org/images/CYTED/DT7-ConfianzaPoder.pdf>.

GWEC 2015 Global Wind Report: Annual Market Update 2015 (Global Wind Energy Council). En <http://www.gwec.net/ wp-content/uploads/vip/GWEC-Global-Wind-2015-Report_ April-2016_22_04.pdf>.

Hein, P.; Mujica, A.; Peluffo, A. 1996 Universidad de la República - Sector Productivo. Análisis de una relación compleja (Montevideo: CIESU/Trilce).

Johnson, B.; Lundvall, B. 1994 "Sistemas Nacionales de Innovación y Aprendizaje Institucional" en Comercio Exterior (México) $\mathrm{N}^{\circ}$ 44(8), pp. 695-704.

Johnson, C. 1999 "The developmental state: Oddyssey of a concept". En Woo-Cumings, M. (ed.) The Developmental State (Nueva York: Cornell University Press) pp. 32-60."

Lundvall, B.; Borras, S. 1997 "The globalising learning economy: Implications for innovation policy" en Report to TSER programme DG XII (Commission of the European Union). En <http://www.globelicsacademy.org/2011_pdf/Lundvall\%20 Borras\%201997.pdf>.

Lundvall, B.; Borras, S. 2005 "Science, Technology and Innovation Policy” en Fagerberg, J.; Mowery, D.; Nelson, R. (eds.) Innovation Handbook (Oxford: Oxford University Press) pp. 599-631.

Malerba, F. 2002 "Sectoral systems of innovation and production" en Research Policy (Países Bajos: Elsevier) N ${ }^{\circ}$ 31, pp. 247-264. Mazzucato, M. 2013 The Entrepreneurial State (Nueva York: The Anthem Press). 
Méndez, R. 2008 Informe final de la consultoría sobre Energía en el marco del Plan Estratégico Nacional en Ciencia Tecnología e Innovación (Uruguay). En <http://www.anii.org.uy/upcms/files/ listado-documentos/focumentos/libro-energia.pdf $>$.

MIEM-DNE (s/f a) Planificación, Estadística y Balance: Balance Energético 2015 (Montevideo: MIEM). En <http:// www.ben.miem.gub.uy/site/descargas/1balance2015/ ben2015informegeneral.pdf $>$.

MIEM-DNE (s/f b) Planificación, Estadística y Balance: Balance Energético 2013 (Montevideo: MIEM). En <http://www.dne. gub.uy/documents/15386/5631903/1.1\%20INFORME\%20 GENERAL20BEN2013.pdf>.

MIEM-DNE (s/f c) Generación Bruta de energía eléctrica por planta (serie de datos). (Montevideo: MIEM). En <http:// www.dne.gub.uy/publicaciones-y-estadisticas/planificaciony-balance/estadisticas?p_p_auth=ej7SYuMD\&p_p_ id $=101 \&$ p_p_lifecycle $=0 \&$ p_p_state $=$ maximized \&_101_ struts_action=\%2Fasset_publisher\%2Fview_content\&_101_ assetEntryId=39886\&_101_type $=$ document $\&$ redirect $=\% 2 \mathrm{~F}-$ $\% 2$ Fseries-estadisticas-de-energia-electrica- $\% 20 \% 3 \mathrm{E}>$.

MIEM-DNE 2008 Política Energética 2005-2030 (Montevideo: MIEM). En <http://www.miem.gub.uy/documents/49872/0/ Pol\%C3\%ADtica\%20Energ\%C3\%A9tica\%202030?version=1.0 $\& \mathrm{t}=1352835007562>$.

Nupia, C.; Martínez, A. 2015 "Revisión de metodologías de procesos de diálogo" en Working paper 4 (Red CYTED COM-LALICS).

Rodríguez, H. 2013 Programa de Energía Eólica en Uruguay (PEEU). Evaluación final (al final del periodo de ejecución). Informe final (con observaciones levantadas: versión 2.0) (Global Environment Facility). En <https://www.thegef.org/sites/fefault/files/project_ documents/2826_UNDP_TE_Informe_Final_PEEU_Espanol. docx $>$.

Subirats, J.; Knoepfel, P.; Larrue, C.; Varone, F. 2008 Análisis y gestión de políticas públicas (Barcelona: Ariel).

UnASeP 2014 Promoción de inversiones: energías renovables (Montevideo: UnASeP). En <https://www.mef.gub.uy/ innovaportal/file/9908/1/20140801_promocion_inv_energ_renov. pdf $>$.

Uruguay XXI 2013 Energías renovables (Uruguay). En <http:// www.dne.gub.uy/documents/112315/1917292/Informe-deenerg\%C3\%ADas-renovables-Abr-20131.pdf>. 


\title{
HACIA LA ARTICULACIÓN DE LAS POLÍTICAS PÚBLICAS EN CTI EN VENEZUELA
}

\section{LA IMPLICACIÓN DE LOS DIÁLOGOS PARA AVANZAR EN EL PROCESO DE GESTIÓN DEL CONOCIMIENTO EN EL ÁREA DE LA ENERGÍA}

\author{
Iván de la Vega, ${ }^{*}$ Nydia Ruiz** \\ y María Antonia Cervilla***
}

\section{INTRODUCCIÓN}

Un indicador de subdesarrollo es la ausencia, o gran debilidad, en el uso de información adecuada para mejorar el proceso de toma de decisiones, tanto organizacionales, como en el caso de las políticas públicas. Precisamente, el SNI venezolano tiene este problema. El esfuerzo por desarrollar una iniciativa en la que, a través de un proceso de diálogo, se articulen capacidades en CTi de los actores del Sistema Nacional de Innovación (SNI) de Venezuela, utilizando el modelo de la gestión del conocimiento para potenciar el uso de la información crítica de las organizaciones y colocarla de forma visible y estructurada, es relevante como caso de estudio. Se generaron diálogos con alto impacto entre los actores participantes y la metodología diseñada es "neutra" en el sentido de que, independientemente

* CENTRUM Católica Graduate Business School, Pontificia Universidad Católica del Perú. Jr. Daniel Alomía Robles 125-129, Los Álamos de Monterrico, Santiago de Surco, Lima 33, Perú. Email: idelavega@pucp.edu.pe

** Centro de Estudios del Desarrollo (CENDES) de la Universidad Central de Venezuela

*** Departamento de Ciencias Económicas y Administrativas de la Universidad Simón Bolívar 
del tema asociado funcione, que pueda ser aplicada en otros sectores. Esos dos aspectos deben considerarse entonces como avances significativos desde la perspectiva de la mejora de la toma de decisiones a distintos niveles.

En los países periféricos como Venezuela se detectan problemas rutinarios que han sido superados hace décadas por los países centrales. Cuando la base del diagnóstico proviene del conocimiento organizacional, uno de estos problemas se hace evidente: la ausencia de la cultura del dato en las organizaciones afecta la toma de decisiones de forma significativa y por ende impacta negativamente en el diseño y aplicación de las políticas públicas (Bemporad, 2003). El ámbito de la ciencia, la tecnología y la innovación en Venezuela no escapa a esa problemática, debido a que no se estructuran apropiadamente los procesos de identificación, recolección y gestión de datos e información dirigidos a mejorar sus propias decisiones (políticas institucionales) ni tampoco se apoya adecuadamente a las políticas públicas en general (De la Vega, 2002).

Un ejemplo claro de ello son los problemas detectados de forma sostenida en la generación de la información emanada de los actores del SNI. En el diseño de las estadísticas e indicadores en CTi es clara la problemática, y cuando eso se traspola al levantamiento de los activos de conocimiento (todos los recursos que de forma explícita existen en una organización), o en la evaluación del uso del conocimiento intangible incorporado en las personas es peor aún. El hecho de que las organizaciones no se conozcan bien a sí mismas las afecta e interfiere negativamente en la estructura de los procesos de diálogo con otros actores, debido a que no existe una sustentación orientada a construir conocimiento para mejorar la toma de decisiones a todo nivel (según el tema y la escala de lo que se esté tratando); bien sea en el marco institucional, en un sector dado, en el ámbito nacional, regional, continental e, incluso, globalmente.

Basado en lo anterior, se ha seleccionado un caso de proceso de diálogo de CTI en Venezuela orientado en la dirección de cerrar la brecha de información organizacional requerida para mejorar la toma de decisiones, al utilizar una metodología que cruza el modelo de la gestión del conocimiento, con el capital intelectual y el enfoque del SNI. En este sentido, el factor diferenciador fue el hecho de impulsar el diálogo constante a todo nivel para ir logrando los consensos respectivos. El centro de gravedad del diálogo seleccionado está en el esfuerzo de diseñar una metodología dirigida a mejorar la toma de decisiones del naciente Ministerio de Ciencia y Tecnología venezolano (2001). Nos referimos a manejar el conocimiento crítico en materia de datos e información que proviene de los propios entes 
gubernamentales. Al detectarse problemas inherentes a la obtención de respuestas a preguntas básicas (como el número de investigadores que trabaja en un área, disciplina o especialidad), surgieron inquietudes e interrogantes sobre otro tipo de información asociada. Era evidente que la información no se tenía estructurada de forma adecuada para ser utilizada al momento de requerirla.

Nydia Ruiz fue la primera Directora General del Programa de Prospectiva del MCT y, al renunciar a su cargo dos años después, tomó la decisión de conformar un equipo en la Universidad Central de Venezuela (UCV) con especialistas de esa casa de estudios y de otras instituciones, incluyendo a personal de alto nivel del propio ministerio, con la finalidad de poner a disposición de la sociedad los conocimientos con valor intelectual o económico de esa universidad. ${ }^{1}$ Así, se esperaba que, con la documentación etnográfica del proceso, se pudiera construir una metodología aplicable en otras organizaciones.

Un esfuerzo de esa magnitud estaba pensado para mejorar la toma de decisiones con el foco en las políticas organizacionales y, de esa manera, comenzando con la línea media de la organización, participar de forma más estructurada en el diseño de las políticas públicas. La metodología fue diseñada por un equipo interdisciplinario y fue pensada desde la perspectiva del manejo del conocimiento crítico de las organizaciones. En esa línea, un diálogo es más efectivo cuando utiliza como apoyo información estructurada para que el proceso de la toma de decisión esté soportado adecuadamente por datos, información y conocimiento en acción.

Una de las barreras o críticas principales al enfoque de los SNI es la dificultad o limitación para operativizarlo. Además, los esquemas de socialización del conocimiento son incipientes en países como Venezuela. En este sentido, este trabajo también busca contribuir en la estructuración del SNI venezolano, al ofrecer una metodología que utiliza un modelo lógico de funcionamiento que se inicia en la organización y que se puede escalar hasta llegar a otros actores. Actuando de esta manera es posible generar taxonomías, mapas de conocimiento y otras definiciones para articular mecanismos institucionales que ayuden en el cierre de esas brechas de conocimiento.

Desde el punto de vista teórico-conceptual, se seleccionó el enfoque del Sistema Nacional de Innovación (SNI), una vez revisados

1 Se trataba de contribuir a la preparación de la UCV para su participación en el proceso de innovación, promoviendo la idea de que la innovación organizacional es una condición previa y necesaria para la participación de esa casa de estudios en dicho proceso. 
otros modelos explicativos sobre las relaciones entre actores sociales vinculados a las actividades en materia de CTi. Este enfoque se articula con los modelos analíticos cercanos a la gestión del conocimiento y del capital intelectual, con el fin de describir el diálogo seleccionado. Esta decisión está fundamentada en la heterogeneidad de los participantes, entre los cuales se cuentan entes gubernamentales, centros generadores de conocimiento (como las universidades e institutos de investigación), las empresas, asociaciones petroleras y ONG. Adicionalmente, fue el uso de este modelo lo que dio sustento a la Ley de Ciencia, Tecnología e Innovación de Venezuela, y por lo tanto el diálogo tratado en este trabajo.

La variedad de temas y posibles implicaciones de políticas generadas por esta falta de conocimiento propio de las organizaciones es amplia. Por ello resulta fundamental entender cuáles pueden ser sus efectos de manera diferenciada. En el caso de Venezuela, la importancia del sector ENERGÍA es indiscutible por el elevado peso que tiene en su economía. Esta es la razón principal por la que se seleccionó un proceso de diálogo en este sector, utilizando la gestión del conocimiento y su relación con el modelo del capital intelectual (aplicado al ámbito de la CTi) como modelo de análisis.

El caso venezolano que se describe a continuación es atípico por cruzar dos variables que intervinieron de forma decidida en la mejora de la toma de decisiones de la política institucional y, a mayor escala, de la política de ciencia, tecnología e innovación del país. En particular, nos referimos a distintos procesos de diálogos ${ }^{2}$ que se desarrollaron para poder llegar a consensos que permitieran crear los mapas de capacidades en Ciencia, Tecnología e innovación (CTi) ${ }^{3}$ en materia de energía y por esa vía gestionar ese conocimiento con novedosos métodos.

El resto del documento está organizado en tres segmentos más. ${ }^{4}$ En un segundo segmento, se describe brevemente el marco metodológico del caso bajo estudio. En el tercer segmento se introducen

2 La definición de diálogos se basa en los documentos elaborados por el equipo de este Proyecto CyTED, específicamente: Álvarez, I., Barletta, F., Suarez, D. y Yoguel G. (2016); Barboza, L. (2016); Nupia, C. y Martínez A. (2015); Goñi, M.; Bianco, M. y Puchet, M. (2015).

3 Mapa de capacidades en $\mathrm{C}+\mathrm{T}+\mathrm{i}$ se refiere al proceso de levantamiento de información en el área de energía y su uso como base para gestionar ese conocimiento entre los stakeholders del sistema nacional de innovación venezolano.

4 También se incluye un anexo III, en el que se examinan los antecedentes de Venezuela mediante la revisión del marco histórico referencial de las políticas en CTi y cómo el contexto de decisiones cambió bajo los dos últimos períodos presidenciales. 
los elementos del caso de la energía en Venezuela y la relación que existió entre los diálogos realizados y su decidida contribución para la conformación de los mapas de capacidades y su posterior gestión entre los stakeholders. En el cuarto y último segmento se presenta los resultados y las lecciones aprendidas.

\section{APRENDIENDO A DIALOGAR. LA IMPORTANCIA ESTRATÉGICA DEL CASO DE LA ENERGÍA EN VENEZUELA}

Venezuela es el mayor productor de petróleo de América Latina, y uno de los más importantes del mundo en este rubro. El sector energético forma parte del corazón de su economía y las trasnacionales más reconocidas han trabajado e invertido mucho dinero en el territorio nacional desde principios del siglo pasado. No obstante, han contado con información limitada de las capacidades que ofrecen los centros generadores de conocimiento del país tales como universidades e institutos de investigación, así como otros actores del SNI venezolano y precisamente por ese problema no han podido aprovechar de forma adecuada esa oferta de servicios y de información. Incluso, en varios casos, la dificultad va más allá del hecho de que las empresas no hayan podido "aprovechar la oferta", pues las Instituciones de Educación Superior (IES) no tienen conocimiento de sus propias capacidades en $\mathrm{CTi}$, a fin de desarrollar productos, servicios y tecnología que puedan ser transferidos a su entorno para resolver problemas de diferente naturaleza. Por otra parte, la interacción con su entorno es limitada, de modo que no tienen conocimiento acerca de las necesidades a atender y problemas a resolver. En buena parte, esto se debe a la historia que ha seguido el desarrollo de la CTI en el país (ver Anexo III).

La importancia de avanzar en la estructuración de mecanismos institucionales de articulación, con incentivos y políticas que favorezcan la transferencia de tecnología y resultados de la investigación desarrollada en las IES, apoyándose en información adecuada acerca de sus capacidades, forma parte del proceso, donde la socialización del conocimiento es el punto de convergencia central.

El ámbito de la CTi en Venezuela no escapa a esa problemática. Por ello, se documentó un caso exitoso que representa un avance en un área estratégica como lo es la energía. Comprender lo que significa cerrar brechas de conocimiento es importante en cualquier momento de la historia reciente. En esa línea, impulsar una iniciativa orientada a mejorar el proceso de toma de decisiones con aportes metodológicos que apunten a optimizar lo que se conoce como el conocimiento crítico en la organización, ayudándolas a identificar y procesar sus datos e información para convertirlos en conocimiento 
en acción, es un avance del que se benefician todos los actores del SNI que participan en procesos como este.

Cerrar una brecha de conocimiento que involucre un volumen de información compleja y estructurarla de forma sencilla y, además, validada con cada uno de los actores mediante múltiples diálogos es una contribución significativa, más aún, si apunta a distintos niveles y actores, hasta escalarlo a las políticas públicas, en este caso, de CTi.

La metodología se fundamenta en un conjunto de diálogos (formales e informales) sostenidos que, además, involucra desde el punto de vista teórico-conceptual, el cruce entre los modelos de la gestión del conocimiento, y del concepto del capital intelectual, con el enfoque del SNI, junto al diseño de taxonomías y conceptos como las estructuras de producción de conocimiento (EPC), las cuales definen el grado de complejidad del grupo de investigación tratado (desde un investigador que trabaja de forma individual, dos o más investigadores formando un grupo disciplinario, hasta llegar a la más complejas, o nodos de conocimiento que involucran a grupos multidisciplinarios e interinstitucionales (ver anexo II).

Múltiples actores del SNI venezolano relacionados con el sector energético participaron en diversos procesos de diálogo (ver tabla $\mathrm{N}^{\circ}$ 2) que se podrían definir a grosso modo mediante la siguiente tipología: 1) hacia el interior de la universidad (UCV): reuniones con las autoridades de distintos niveles, desde el rectorado hasta los decanos y directores de escuelas o departamentos, para dar a conocer el proyecto y buscar su apoyo para el mismo; reuniones de sensibilización y talleres con los investigadores de las diversas facultades involucradas en el tema a tratar, y reuniones para validar los mapas de conocimiento; 2) hacia el exterior de la universidad, reuniones técnicas del equipo ad hoc interdisciplinario; procesos de sensibilización con los diversos actores del SNI participantes en esta iniciativa, organizados por el equipo técnico, con el fin de intercambiar información y dar a conocer la metodología; reuniones de discusión para presentar los mapas de conocimiento elaborados a partir de las entrevistas y talleres, incluso, aprendiendo de las interacciones dinámicas de los actores participantes; presentaciones en eventos científicos; reuniones para discutir los avances y recibir retroalimentación con autoridades del MCT, presidentes de empresas, gerentes y equipos de trabajo de las organizaciones que participaron en las fases de aprendizaje. 


\section{EL CASO: DE LAS POLÍTICAS PÚBLICAS DE CTI, A LA INICIATIVA DE LA ENERGÍA}

El proyecto en el área de energía fue financiado por las empresas Total Oil y Repsol, en el marco de la LOCTI, y tuvo una duración de cinco años (2005-2009). Un elemento clave que afectó a este proyecto, y al propio SNI de Venezuela, fue la modificación que introdujo el gobierno al Reglamento de la LOCTI en el año 2010, el cual derivó en que los recursos recaudados por la contribución de las empresas ya no pudieron ser invertidos en las propias organizaciones, ni asignados a terceros. El nuevo reglamento solo permitía que la contribución pudiese ser entregada, en su totalidad, a los entes gubernamentales competentes. Esa nueva medida, en la práctica, ha dificultado de forma significativa el financiamiento a la CTi en Venezuela y, por esa razón, la articulación de esfuerzos de diálogo se vio afectada de forma significativa. Por otro lado, el uso de los recursos de las empresas para actividades de CTi no ha sido transparente (para entender mejor el contexto venezolano, se recomienda leer el Anexo III de este documento).

En el marco de la Ley Orgánica de Ciencia, Tecnología e Innovación (LOCTI), promulgada en Venezuela en el año 2001 y cuyo reglamento aprobado en 2005 permitió operativizar esa decisión, se desarrolló la iniciativa en el área de Energía con miras a mejorar las políticas públicas en CTi en Venezuela. Los actores que participaron en la prueba piloto fueron: del sector público, el Ministerio de Ciencia y Tecnología como promotor; del sector académico, la Universidad Central de Venezuela (UCV) como promotora y como eje del equipo técnico coordinado por la profesora Nydia Ruiz, la Universidad Simón Bolívar, la Universidad Católica Andrés Bello, la Universidad de Toulouse y la universidad de Puerto Rico; del sector empresarial, las empresas Total Oil \& Gas de Venezuela, Repsol, Banesco, Empresas Polar e ICA2; de otros sectores, la Asociación Venezolana de la Industria Química y Petroquímica (ASOQUIM), la Asociación Venezolana de los Hidrocarburos (AVHI), la Cámara Petrolera de Venezuela (CPV) y el Instituto Francés del Petróleo. 
Tabla $\mathbf{N}^{\circ} 2$

Actores participantes en el diálogo de Venezuela ${ }^{5}$

\begin{tabular}{|c|c|c|c|}
\hline $\begin{array}{l}\text { Comunidad } \\
\text { Académica }\end{array}$ & $\begin{array}{l}\text { Comunidad } \\
\text { Empresarial }\end{array}$ & $\begin{array}{c}\text { Comunidad Sector } \\
\text { Público }\end{array}$ & $\begin{array}{l}\text { Otros sectores de la } \\
\text { Comunidad Civil }\end{array}$ \\
\hline 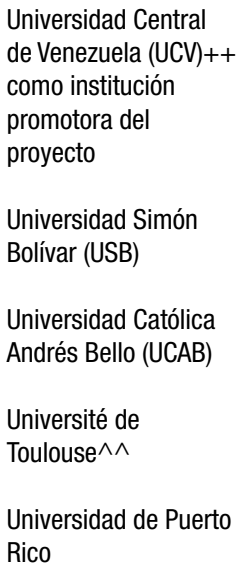 & 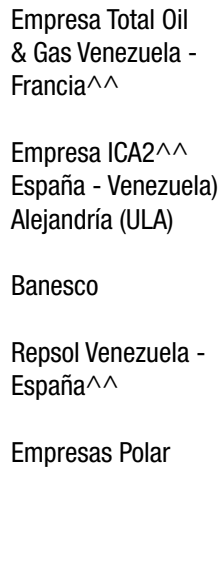 & $\begin{array}{l}\text { Ministerio del Poder } \\
\text { Popular para la Educación } \\
\text { universitaria y para } \\
\text { Ciencia y Tecnología } \\
\text { (MPPEUCT) ++ como } \\
\text { institución promotora del } \\
\text { proyecto } \\
\text { <http://www.mppeuct. } \\
\text { gob.ve/>. } \\
\text { Banco Central de } \\
\text { Venezuela (BCV) }\end{array}$ & $\begin{array}{l}\text { Asociación Venezolana } \\
\text { de la industria química } \\
\text { y petroquímica } \\
\text { (ASOQUIM) } \\
\text { Asociación Venezolana } \\
\text { de los Hidrocarburos } \\
\text { (AVHI) } \\
\text { Cámara Petrolera de } \\
\text { Venezuela (CPV) } \\
\text { Instituto Francés del } \\
\text { Petróleo C.A.^^ }\end{array}$ \\
\hline
\end{tabular}

Clasificación de Comunidades:

$\wedge \wedge$ Organismo Internacional

++ Líderes del Proyecto

${ }^{\star \star}$ Agente Complejo (pertenece a más de una comunidad)

La iniciativa tenía como propósito conocer las capacidades de los centros generadores de conocimientos como las universidades y los centros de investigación, utilizando el modelo de gestión del conocimiento. El área seleccionada fue la Energía y la estrategia utilizada fue la de identificar, recopilar y organizar los activos de conocimiento; diseñar mapas con los datos de las estructuras de producción de conocimientos identificadas y diseñar e implantar un portal de virtual que contiene una taxonomía que permite entender la información de forma sencilla (ver anexo I). Para lograr máxima eficiencia se estructuró un equipo técnico que contó con especialistas de la UCV y de otras instituciones (incluyendo personal de alto nivel de MCT) y se definió un proyecto dirigido a diseñar la metodología necesaria que permitiera estructurar todo el proceso. Finalmente, se hizo un piloto en la UCV, con la finalidad de demostrar que el modelo y metodología diera los resultados esperados. Dentro de los objetivos de esa iniciativa estaban: Articular las capacidades en materia de ciencia, tecnología

5 Elaborado a partir de los documentos diseñados por el equipo del proyecto CyTED, específicamente: Álvarez, I., Barletta, F., Suarez, D. y Yoguel G. (2016); Dutrénit, G. et al. $(2016,2017)$. 
e innovación en Venezuela, a partir del modelo de la gestión del conocimiento y su contribución al diálogo entre actores a partir de información pertinente, tomando como caso piloto el área de la energía. Así mismo, diseñar una metodología a partir de los modelos de la gestión del conocimiento y del capital intelectual que aporte elementos de mejora en la toma de decisiones de las organizaciones. Incidir en el proceso de optimización del uso del conocimiento crítico de las organizaciones al sensibilizar al personal a través de diálogos. Examinar modelos y enfoques teóricos-conceptuales y seleccionar aquéllos que se adecuen mejor a las características del caso venezolano como marco explicativo y aportar al diseño de las políticas públicas utilizando como ejemplo al área de energía en Venezuela.

\subsection{ARTICULACIÓN TEÓRICO-CONCEPTUAL DEL CASO}

En el caso venezolano, el método que se utilizó para rediseñar el desempeño organizacional se basó en el modelo de la gestión del conocimiento y su relación con el capital intelectual. Al trasladar ese esfuerzo a los diálogos relacionados al diseño de las políticas públicas con otros actores, se le correlacionó con el enfoque de SNI y eso permitió que los esfuerzos a distintos niveles se nutrieran de nuevos procesos que optimizaban la identificación del conocimiento crítico de las organizaciones, al mejorar sus rutinas, simplificando pasos y potenciando nuevos sistemas, procesos, productos, normas hasta llegar a modificar su propia infocultura.

$\mathrm{Al}$ escalar los diálogos a otros actores del SNI se apreció un salto cualitativo en términos de contar con mejor argumentación a la hora de avanzar en el proceso de construcción de la política institucional y la contribución que por esa vía se hacía a las políticas públicas. En síntesis, esta es una forma no convencional de abordar los diálogos para el diseño de las políticas públicas en materia de CTi, pero precisamente es ahí donde radica su importancia, corroborada con el éxito obtenido por el caso descrito.

En la literatura especializada no se trata el tema de la gestión del conocimiento y su relación con los diálogos vinculados al diseño de las políticas públicas de forma directa. Se debe insistir que se está abordando un aspecto de ese proceso, referido a la ya mencionada debilidad en las técnicas para identificar, capturar, organizar y almacenar el conocimiento de los trabajadores, con la idea de transformarlo en un activo intelectual que preste beneficios y se pueda compartir. Si las organizaciones mejoran su rendimiento, es evidente que la fase diagnóstica previa a la formulación de la política pública, en cuanto a recoger informaciones e investigar de forma sistemática con el objeto de identificar las problemáticas existentes es más eficiente, al igual que 
mejoraría la fase de aplicación. En esa línea, se presenta la revisión teórica conceptual que sustenta el caso de la Energía en Venezuela.

Al hablar propiamente del modelo de la Gestión del Conocimiento (GC) hay que indicar que no existe un consenso universal sobre esta disciplina (como la denominan algunos especialistas) (Pérez-Montoro, 2010). Esta falta de consenso sobre lo que significa la GC lleva a la revisión de múltiples definiciones y modelos, buscando un referente que permitiera soportar teóricamente el caso de la energía en Venezuela (Sveiby, 1997; Wiig, 1997; Davenport \& Prusak, 1998; Bueno, 1999; Andreu \& Sieber, 1999; Harman \& Brelade, 2000). Las visiones existentes desde diversas disciplinas, las metodologías utilizadas y los hilos conductores de donde parten cada uno de ellos, asociados a los objetivos que se trazaron, permiten seleccionar o integrar perspectivas explicativas diferentes. Por ello, se seleccionó como marco conceptual para este caso la siguiente definición: La GC consiste en un conjunto de procesos sistemáticos (identificación y captación del capital intelectual; tratamiento, desarrollo y compartimiento del conocimiento; y su utilización) orientados al desarrollo organizacional y/o personal y, consecuentemente, a la generación de una ventaja competitiva para la organización y/o el individuo (Valhondo, 2003).

Un grupo de especialistas organizó las aproximaciones teóricoconceptuales sobre los Modelos de la GC y los agrupó en tres tipos según el núcleo, los objetivos, la metodología, los participantes, entre otros aspectos y a grandes rasgos quedó de la siguiente forma:

- Almacenamiento, acceso y transferencia de conocimiento: modelos que no suelen distinguir el conocimiento de la información y los datos y que lo conciben como una entidad independiente de las personas que lo crean y lo utilizan. Este tipo de modelos de GC se centran en el desarrollo de metodologías, estrategias y técnicas para almacenar el conocimiento disponible en la organización en depósitos de fácil acceso para propiciar su posterior transferencia entre sus miembros.

- Sociocultural: modelos centrados en el desarrollo de una cultura organizacional adecuada para el desarrollo de procesos de gestión del conocimiento. Intentan promover cambios de actitudes, fomentar confianza, estimular la creatividad, concienciar sobre la importancia y el valor del conocimiento, promover la comunicación y la colaboración entre los miembros de la organización, etc.

- Tecnológicos: modelos en los que destaca el desarrollo y la utilización de sistemas (por ejemplo: data warehousing, intranets, 
sistemas expertos, sistemas de información, web, etc.) y herramientas tecnológicas (por ejemplo: motores de búsqueda, herramientas multimedia y de toma de decisiones) para la gestión del conocimiento (Rodríguez, 2006).

En la realidad estos modelos no funcionan de forma separada y se mezclan de distintas maneras, integrándose, además, con otras aproximaciones tanto teóricas como conceptuales, incluso con dinámicas endógenas de aprendizaje en las organizaciones.

Dentro de la perspectiva del capital intelectual (CI) se han propuesto varios modelos. Un grupo de expertos desarrolló en la década de los años noventa un cuerpo teórico-conceptual sobre lo que se conoce como la forma en que los factores inmateriales determinan el éxito de las empresas. Sveiby (1997), Edvinson y Malone (1997) son los precursores de la plataforma de los modelos sobre el CI. Esta aproximación explicativa tuvo un desarrollo vertiginoso y aportaciones posteriores refinaron estos primeros aportes sobre la gestión de los activos intangibles. El surgimiento del CI se vincula con la capacidad de manejar y difundir el conocimiento de los empleados en las empresas (Stewart, 1997 y 2001; 2000; Martínez, 2005; Díaz, 2001; entre otros). Un aspecto clave en el desarrollo de este modelo, es el referido a los indicadores del Capital Intelectual. Skandia, Dow Chemicals y el Canadian Imperial Bank ampliaron el radio de acción a todos los activos intangibles al percatarse de que las herramientas que utilizaban no les permitía registrar su valor. Ese nuevo factor requería de indicadores para medir las capacidades que no estaban reflejadas en los registros contables. De esa forma emergió y se posicionó rápidamente el término capital intelectual y se inició el camino al diseño de herramientas para medirlo.

A pesar del esfuerzo de los especialistas, no se ha logrado una definición estandarizada del concepto, similar a lo que sucede con la definición de la gestión del conocimiento, por lo que es un desafío llegar a un marco comprehensivo. La proliferación de definiciones lo enmarcan en lo que se conoce como concepto móvil y sigue la búsqueda para llegar a una conceptualización rigurosa de este tipo de activos.

Una vez revisadas múltiples definiciones de capital intelectual, para el caso de la energía en Venezuela se seleccionó una que integra los elementos de mayor relevancia de varios de los más destacados especialistas. Es la siguiente:

[El capital intelectual] es la combinación de activos inmateriales o intangibles, incluyéndose el conocimiento personal, la capacidad para aprender y adaptarse, las relaciones con los clientes y los proveedores, las marcas, los 
nombres de los productos, los procesos internos y la capacidad de $\mathrm{I}+\mathrm{D}$ de una organización, que aunque no están reflejados en los estados contables tradicionales generan o generarán valor futuro y sobre los cuales se podrá sustentar una ventaja competitiva sostenida. (Sánchez et al., 2007: 102)

Los activos intangibles, aunque no se pueden tocar, si se pueden identificar y clasificarse adecuadamente:

- Activos de competencia individual: Se refieren a la educación, experiencia, "know how", conocimientos, habilidades, valores y actitudes de las personas que trabajan en la empresa. No son propiedad de la empresa/organización. La empresa/organización contrata el uso de estos activos con sus trabajadores. Los trabajadores al marcharse a casa se llevan consigo estos activos. A este conjunto de activos se les denomina también Capital Humano.

- Activos de estructura interna: Se refieren a la estructura organizativa formal e informal, a los métodos y procedimientos de trabajo, al software, a las bases de datos, a la I+D (investigación y desarrollo), a los sistemas de dirección y gestión, y a la cultura de la empresa/organización. Estos activos son propiedad de la empresa/organización y algunos de ellos pueden protegerse legalmente (patentes, propiedad intelectual, etcétera).

- Activos de estructura externa: Se refieren a la cartera de clientes que recibe el nombre de fondo de comercio, a las relaciones con los proveedores, bancos y accionistas, a los acuerdos de cooperación y alianzas estratégicas, tecnológicas, de producción y comerciales, a las marcas comerciales y a la imagen de la empresa/organización. Estos activos son propiedad de la empresa/organización y algunos de ellos pueden protegerse legalmente (marcas comerciales, etcétera).

Estos activos intangibles son conocidos como capital intelectual y pueden ser clasificados de la siguiente manera:

Está formado por:

- Capital Humano: que corresponde con los activos de competencia individual y colectiva.

- Capital Estructural: que corresponde con los activos de estructura internos.

- Capital Relacional: que corresponde con los activos de estructura externos, o como indica): "Es el conocimiento que se 
encuentra incluido en las relaciones de la organización" (Sánchez et al., 2007).

En la literatura especializada existen tres aproximaciones teóricoconceptuales sobre los modelos de Gestión del Conocimiento y el Capital Intelectual. Una de ellas desarrolló el modelo de GC; otra el Modelo del CI y la tercera, integra a ambos modelos y es la que se utilizó en el caso de la energía en Venezuela. A los fines del caso, la gestión del CI se centra en la construcción y gestión de los activos intelectuales desde un perspectiva estratégica y gerencial incluyendo algunos aspectos tácticos. Su función consiste en la consideración global de todos los activos intelectuales de la organización. Por su parte, la GC tiene una perspectiva más táctica y operacional; es más detallada y se centra en facilitar y gestionar actividades relacionadas con el conocimiento tales como su creación, captura, transformación y uso. Su función consiste en planificar, poner en marcha, operar, y monitorizar todas las actividades y programas que requiere la gestión eficaz del CI (Viedma, 1998).

Al escalar el caso de la energía en Venezuela de las organizaciones al resto de actores, se utilizó el enfoque de los SNI (Peña-Cedillo, 2003). Una vez revisada la literatura especializada se seleccionó la definición siguiente: El sistema de innovación de un país constituye el conjunto de agentes, instituciones y prácticas interrelacionadas que conforman, actúan y participan en los procesos de innovación tecnológica y social que suceden en el país, generando un ecosistema favorecedor para las actividades de investigación, desarrollo tecnológico e innovación (OVIT, 2016). El supuesto teórico que se utilizó para el caso de la energía correlaciona a los distintos actores del SNI de Venezuela con el desempeño innovativo, asociado a la mejora sustancial de cada una de ellos (organizaciones) en materia de creación, captura, transformación y uso del conocimiento, con la finalidad de avanzar en la aplicación de los modelos de (GC y CI) y por esa vía apoyarse en las nuevas tecnologías para aportar conocimiento crítico al diseño de las políticas públicas. En el SNI de Venezuela, sin embargo, persisten algunos problemas que pueden ser analizados de acuerdo a los diferentes tipos de capital:

- En cuanto al capital humano: no se conoce adecuadamente el potencial del personal por áreas de conocimiento, disciplinas y especialidades; ni sus niveles académicos; ni los años de experiencia acumulada; ni el proceso de jubilación y la tasa de reposición requerida de personal (en los países en desarrollo puede ser causal de eliminación de líneas de investigación por 
falta de personal); tampoco se conocen en su justa dimensión las competencias de los grupos de investigación para atender demandas o conocer todo el potencial; debilidad en la cultura para mantener actualizadas las líneas de investigación y los proyectos de investigación, entre otros.

- En cuanto al capital estructural: No se conoce adecuadamente el $\mathrm{N}^{\circ}$ de Institutos, Centros y Laboratorios de investigación existentes y las condiciones en las que se encuentran (metros cuadrados utilizados y la capacidad instalada, posibilidad para expandir o iniciar nuevas investigaciones; ni la valuación y valoración tecnológica (es decir la diferencia entre la vida útil estimada de un equipo y la tecnología de punta en el mercado, teniendo en cuenta el valor de reposición y el valor comercial, debido a que en investigación es crucial este aspecto para estar a la vanguardia en determinadas especialidades); ni los insumos requeridos; ni la capacidad para presentar servicios, ni la latencia asociada a las competencias del grupo de investigación. Existen debilidades en la difusión y divulgación de los resultados obtenidos en los productos como papers, patentes o informes técnicos, además de libros, capítulos de libros, trabajos de ascenso, trabajos de grado por nivel académico o, incluso, de las consultorías o asesorías (el impacto social en cuanto a la potencialidad para la resolución de problemas). Esto se vincula al conocimiento que requiere una sociedad dada de todo lo referente a las estructuras de producción de conocimiento y entre oferta y demanda en el interior del SNI.

- En cuanto al capital relacional: Se conoce poco de las relaciones formales e informales del personal a lo interno y externo de las organizaciones, por ejemplo, las coautorías en los productos de investigación permiten realizar mapas de conocimiento de las interacciones internas con otros actores del SNI y con actores de otros países. Las interacciones entre los actores con empresas o con entes gubernamentales se conocen poco, tanto en número como en el requerimiento; así como con las unidades de interfaz o fundaciones y con proveedores.

Por ello, en este caso, la metodología permite estructurar mapas de conocimiento que incorporan esa información (variables, relaciones e interacciones) con la finalidad de articular, a través de múltiples diálogos, todo lo inherente al área de la energía como ancla, para continuar multiplicando esta iniciativa a otras áreas, hasta escalar a la toma de decisiones (políticas públicas en $\mathrm{CTi}$ ). 


\section{DISCUSIÓN DE LA EVIDENCIA. HACIA UNA METODOLOGÍA TRANSVERSAL: EL PROYECTO DE LA GC EN LA UCV}

Partiendo de la noción sobre la ausencia de la cultura del dato en las organizaciones y cómo ella afecta a los SNI débiles, como es el caso de Venezuela, se diseñó, ex profeso, una iniciativa "bottom-up" con la finalidad de mejorar los procesos de toma de decisiones a distintos niveles hasta llegar a incidir en la mejora del diseño y formulación de las políticas públicas.

En esa línea, se desarrolló un macro proyecto que tuvo como punto de partida aplicar la GC y el CI en la Universidad Central de Venezuela (UCV), pensando en desarrollar una metodología meso aplicable a cualquier organización del SNI, tanto de Venezuela, como de cualquier otro país. Se partió del supuesto que una organización compleja como la UCV, de unas 70 mil personas interactuando, dispone de gran cantidad de conocimientos, talento, infraestructura y potencial para generar valor intelectual, servicios y riqueza hacia la sociedad y hacia el interior de la propia organización. Por ello se planteó maximizar el impacto de la UCV seleccionando el área de la Energía, concebida como un área estratégica de la institución y vinculada al corazón de la economía del país, mediante la caracterización de su situación actual y la visualización de las alternativas de evolución más relevantes para la comunidad universitaria. La idea era escalar ese esfuerzo mancomunado con los entes gubernamentales a otros actores del SNI venezolano, a fin de generar un conjunto de propuestas de acción como insumo para la formulación de políticas y la toma de decisiones institucionales y nacionales.

La fase inicial fue de organización del conocimiento, contemplando: recopilación y sistematización de los activos de conocimiento de la UCV en mapas de conocimientos y elaboración de escenarios a futuro para detectar las oportunidades en función de esos activos y las potencialidades institucionales. Los diálogos en esta fase tuvieron formas de encuentros de sensibilización e interacción dinámica de aprendizajes con distintas instancias de conducción de la UCV, sensibilización de los investigadores de las facultades involucradas en el estudio mediante talleres, y entrevistas a los investigadores y grupos para la recolección de información con miras a la institucionalización de los procedimientos de recopilación y sistematización de los activos de conocimiento y validación de los escenarios e incorporación de sus resultados a las políticas institucionales. En la práctica, la primera etapa de la iniciativa se comenzó con la realización de una prueba piloto en el área de Energía, donde se experimentó con conceptos y metodologías novedosas para el manejo de los activos de conocimiento. 
La segunda fase se basó en la incorporación de la información recogida, validada con los stakeholders y producida en sistemas de información de acceso público de cara a la sociedad. Además de continuar con la estrategia clave referida a la importancia que tiene la socialización del valor del conocimiento. Por ello, se instauraron los diálogos a múltiples niveles: negociación de los conocimientos de la UCV con la sociedad mediante investigaciones, asesorías, alianzas estratégicas, contratos de servicio y otras modalidades de cooperación y asociación, como parte de los mecanismos que permiten incentivar la vinculación entre los actores de cara a la solución de problemas de quien lo requiera y por ende de la sociedad.

El punto crítico de la metodología se encuentra en el modelo lógico diseñado para organizar activos de conocimiento en el área de la energía. El esfuerzo debe ser replicable en cualquier institución cuyo foco sea la producción de conocimiento en actividades vinculadas a investigación, desarrollo e innovación. De esta manera, con solo cambiar los valores de los atributos que se definen mediante Tablas de Referencia se puede transferir el uso del modelo a otras instituciones.

\section{EL IMPACTO DE LOS DIÁLOGOS EN LA MEJORA DE DECISIONES DE LAS POLÍTICAS CTI}

El primer impacto tangible de este proceso de diálogo fue la alta receptividad de los stakeholders a la propuesta metodológica diseñada y presentada por el equipo técnico encargado. Incluso, superó las expectativas iniciales dado que la hipótesis previa planteada marcaba un mayor tiempo para las interacciones en el proceso de socialización.

El segundo impacto tangible se expresa en el proceso de aprendizaje bidireccional entre los proponentes y los beneficiarios. Los diálogos permitieron recolectar observaciones que mejoraron la propuesta inicial. Eso valor agregado ayudó a empoderar a los stakeholders por haber sido incorporada (en la mayoría de los casos) su propuesta de valor.

Un tercer impacto tangible está referido a que la metodología que se diseñó fue pensada para cumplir con un objetivo de doble propósito. El primero de ellos se orientó al nivel meso de la organización, es decir, a las estructuras profesionales. El segundo de ellos, está referido a que la metodología fue diseñada de forma neutra. Esto significa que puede aplicarse a cualquier tema (o sector) cambiando los atributos en el Modelo Lógico.

Un cuarto impacto, de mayor escala, está relacionado con la mejora cualitativa de la toma de decisiones, hecho que repercutió de forma directa en las lecciones aprendidas. El haber logrado impactar 
positivamente en la capacidad de generar métodos con instrumentos sencillos para gestionar la información crítica de la organización fue clave. Conocerse mejor a sí misma fue determinante para que los diálogos se realizasen con mejor argumentación. El impacto hacia adentro y hacia fuera de las instituciones fue significativo y esos nuevos procesos van alineados con la innovación abierta, en el sentido de que potenció los diálogos con todos los actores participantes. En esa línea, al conocerse mejor los activos tangibles en el área de la Energía y los mapas diseñados, permitieron visualizar con especificidad las estructuras de producción de conocimientos, se potenció el intercambio de información y su gestión, por ende, fue más sencilla.

Un quinto impacto ya de orden teórico-conceptual, fue el hecho de haber logrado sincronizar de manera comprehensiva los modelos referidos al Capital Intelectual y a la Gestión de Conocimiento, con el enfoque del SNI. Al final terminó siendo un proceso de construcción compleja que puede ser utilizada por quien lo requiera.

El sexto impacto en materia de políticas públicas CTi, fue el hecho de transferir al Ministerio de CyT la metodología y, mejor aún, fue la receptividad inmediata y la conexión con actores como PDVSA e INTEVEP que no conocían varias de las capacidades existentes en los centros generadores de conocimiento como las universidades.

\section{CONCLUSIONES}

La finalidad de la iniciativa en el área de la Energía fue la de mejorar los procesos de toma de decisiones utilizando los diálogos como mecanismos de interacciones dinámicas a distintos niveles, hasta llegar a incidir positivamente en la mejora del diseño y formulación de las políticas institucionales y públicas.

En el caso de Venezuela, se comenzó por diseñar una metodología que les permite a las organizaciones vinculadas a la CTi repensar su modelo lógico en materia de generación de su información, debido a que existe una debilidad no corregida hasta el momento referida a esta problemática en los actores del SNI de ese país. El punto de mejora se debe a la utilización de procesos de diálogos sostenidos entre los stakeholders.

Los resultados obtenidos en el área de energía en el caso de Venezuela permiten establecer que los mecanismos e instrumentos diseñados basados en la gestión del conocimiento y el capital intelectual mejoran significativamente la toma de decisiones al habilitar el manejo de información en todos los niveles de las organizaciones y facilitar su articulación. El hecho de generar la posibilidad de validar la información mediante diálogos con los actores participantes potencia el cambio en la infocultura organizacional. 
El supuesto teórico que se utilizó para el caso de la energía correlaciona a los distintos actores del SNI de Venezuela con el desempeño innovativo, asociado a la mejora sustancial de cada una de ellos (organizaciones) en materia de creación, captura, transformación y uso del conocimiento crítico, con la finalidad de avanzar en la aplicación de los modelos de GC y CI y por esa vía apoyarse en las nuevas tecnologías para aportar argumentos sólidos al diseño de las políticas públicas.

La correlación entre los modelos de la gestión del conocimiento y del capital intelectual a escala organizacional y el enfoque de Sistema Nacional de Innovación sirvieron como referente teórico-conceptual para diseñar y aplicar un modelo lógico dirigido a las organizaciones vinculadas a las actividades de ciencia, tecnología e innovación en Venezuela. El proceso de articulación fue el conjunto de diálogos desarrollados para llegar a consensos.

La iniciativa se delineó partiendo de una prueba piloto en el área de energía y a una escala donde participaron empresas, universidades, institutos de investigación (todos de carácter nacional e internacional), asociaciones petroleras y el Ministerio de Ciencia y Tecnología de Venezuela.

Una lección que se extrae de este proceso de diálogos de CTi, es la referida a la mejora en los mecanismos y herramientas que permiten identificar, capturar, organizar y almacenar el conocimiento de la organización, con la idea de transformarlo en activos de conocimiento que presten beneficios y se puedan compartir (socializar) hasta escalar a la toma de decisiones de los distintos actores del SNI. 


\section{ANEXO I}

ENFOQUE BASE DE LA TAXONOMÍA DISEÑADA PARA ESTA ÁREA

\section{Temas en Energía}

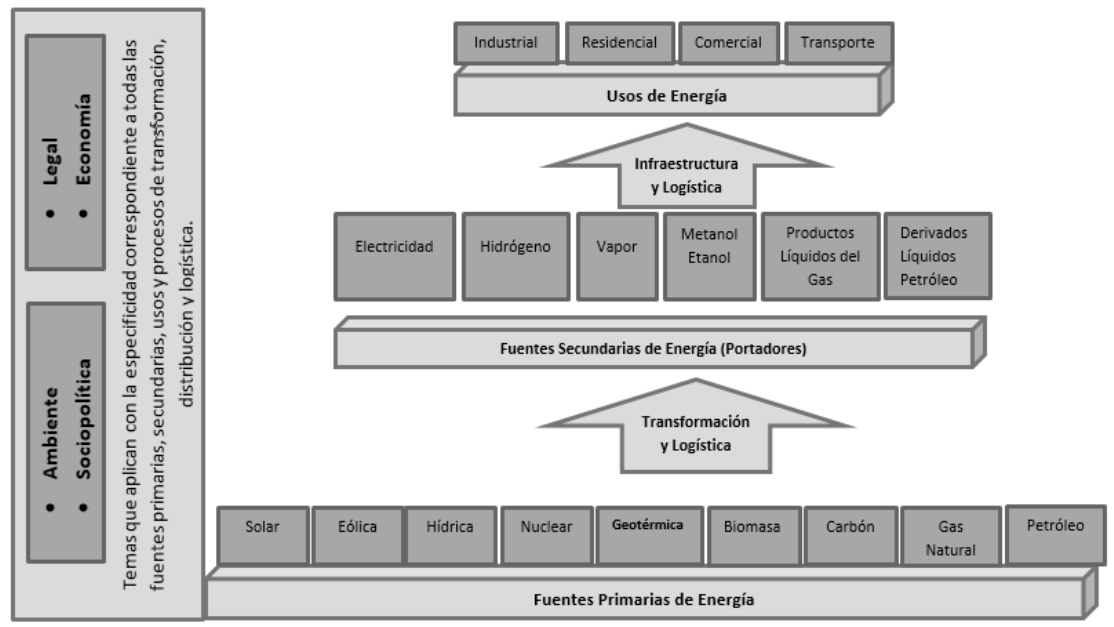





\section{ANEXO II}

\section{ESTRUCTURAS DE PRODUCCIÓN DE CONOCIMIENTO (EPC)}

La Figura muestra la más compleja de las EPC o Nodo de conocimiento.

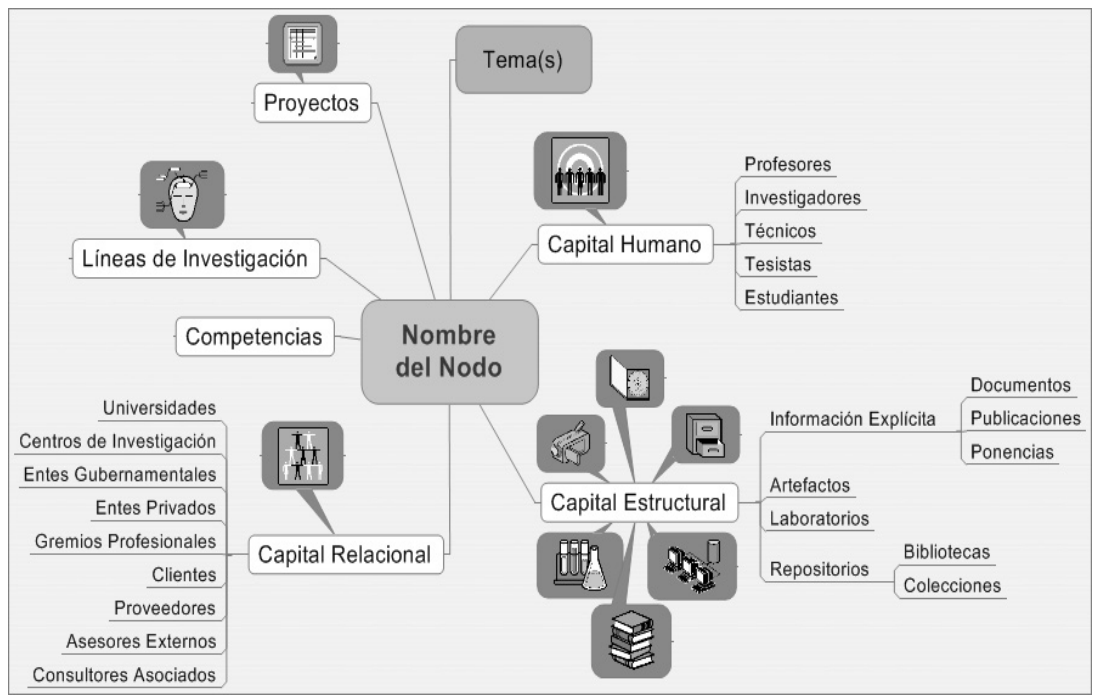





\section{ANEXO III}

\section{DEL CONTEXTO GENERAL A LAS POLÍTICAS PÚBLICAS EN CTI. PERÍODO 1950-2016}

La Venezuela de los años cincuenta del siglo pasado, era en más de un 52\% rural, rondaba el $51 \%$ de personas que sabían leer y escribir y su población era cercana a los 5 millones de habitantes (De la Vega, 2005). Esas características generales permiten inferir que era un país atrasado y con poca tradición en actividades de CyT. No obstante, el país estaba imbuido en un proceso acelerado de desarrollo impulsado por los ingresos provenientes de la extracción y venta de petróleo por parte de multinacionales.

Especialistas en historia de la ciencia coinciden en señalar que la creación de la Asociación Venezolana para el Avance de la Ciencia (ASOVAC) fue el inicio de un proceso de institucionalización sostenida que culminó con la creación del Consejo Nacional de Investigaciones Científicas y Tecnológicas (CONICIT) en el año 1967 como organismo promotor de estas actividades.

La ASOVAC, fundada por Augusto de Venanzi, se instaló en el año 1950 y el Acta Constitutiva la firmaron 50 personas. La Junta Directiva provisional contaba con 7 principales y 7 suplentes, de los cuales en el primer grupo había 3 extranjeros y en el segundo grupo 4, es decir, un 50\% (Ardila, 1981). Ese núcleo de investigadores, junto a los que se 
incorporaron posteriormente a esa asociación, promovió la creación de instituciones que marcaron el rumbo de la ciencia y la tecnología en Venezuela, en plena dictadura de Marcos Pérez Jiménez entre 1952 y 1958.

Augusto De Venanzi y Marcel Roche fundaron el Instituto de Investigaciones Médicas (IMM) en la Fundación Luis Roche y comenzaron a trabajar en equipo de forma privada en el año 1952.

En ciencias básicas solo la Escuela de Biología de la UCV logró funcionar plenamente en los años cincuenta hasta su cambio de orientación hacia campos experimentales y al nuevo plan de estudios en el año implantado en 1957 (Vessuri, 1987; Texera, 1992b).

En el año 1954 se creó el Instituto Venezolano de Investigaciones Neurológicas (IVNIC) debidamente dotado de edificios, materiales y equipos y se trajeron investigadores del exterior que por lapsos variables trabajaron en el instituto. Humberto Fernández Morán fue su primer director y se planteó como objetivo que Venezuela comenzara a participar en la empresa universal del conocimiento (Ruiz Calderón, 1987). Al entrar en la democracia se convirtió en el Instituto Venezolano de Investigaciones Científicas (IVIC) ampliando su rango de acción a múltiples áreas del conocimiento.

A la caída de la dictadura de Pérez Jiménez, en el año 1958, continuó la expansión en cuanto a las áreas del conocimiento y la construcción del tejido socio-institucional en CyT en Venezuela. Entre los principales actores sociales que participaron en el proceso de articulación de esas actividades estaban el Estado, las universidades y las empresas. Ese esfuerzo fue impulsado fundamentalmente por científicos y profesionales que incluso diseñaron y crearon esas y otras instituciones.

Una de las vías para avanzar en la transferencia de conocimiento y la experiencia requerida para cumplir con la misión, objetivos y metas trazados en las instituciones fue la incorporación de profesionales y técnicos cualificados, particularmente científicos, que permitieran dar inicio a las actividades de varias de esas instituciones, debido a la casi nula tradición en materia de investigación que existía en la Venezuela de la época.

El enorme esfuerzo por desarrollar el país necesitaba de mano de obra cualificada. El mundo de la ciencia era todavía incipiente, pero se comenzaba a vislumbrar un mapa que ya contaba con instituciones y científicos nacionales y extranjeros. El contexto nacional de la época, basado en el modelo de acumulación capitalista, que en el caso venezolano contó con recursos importantes provenientes del petróleo, se enmarcaba dentro de la política de sustitución de importaciones y se caracterizó por el intento de creación de un sistema nacional de ciencia y tecnología. Esos procesos siempre se encontraron con problemas por no haber respetado los tiempos mínimos para que pudieran cuajar adecuadamente proyectos de esa naturaleza. Hay escenarios 
donde las ventanas de oportunidad se pueden aprovechar y hay otros que definitivamente deben seguir su curso de aproximaciones sucesivas hasta llegar a la madurez. Un déficit que ha presentado el país en todo el proceso socio-histórico que venimos estudiando tiene que ver con al ámbito educativo nacional en todos sus niveles (Vessuri, 1992).

El éxito de una política social en el período democrático elevó las aspiraciones de la población que encontró obstáculos para el acceso a los diferentes niveles educativos (Hung de León \& Piñango, 1985). Otro indicador ilustrativo se reflejaba en la falta de tradición en las actividades de ciencia y tecnología: a pesar del esfuerzo que se venía efectuando en el país durante las décadas del cincuenta y sesenta, no se realizaron actividades de investigación industrial formales, debido al contexto caracterizado por un muy bajo desarrollo industrial y científico-tecnológico (Ávalos \& Jaffé, 1992). La ausencia de una tradición cultural en materia educativa demarcaba una situación que colocaba al país en la periferia del conocimiento, debido a que el problema no solo se circunscribía a la tasa de asistencia al sistema, sino que abarcaba otras aristas que delineaban una situación bastante más compleja que el hecho cuantitativo, a pesar de los esfuerzos evidentes realizados en esos años por modernizar el país.

En el año 1974 se incrementaron los precios del petróleo a raíz de la coyuntura internacional, lo que en el caso específico de Venezuela significó ingresos fiscales que alteraron los parámetros económicos y obligaron al rediseño de las políticas del gasto público y el reajuste en el sistema económico nacional. Ese nuevo marco tuvo un impacto favorable en el mercado laboral durante esa década, caracterizado por el crecimiento sostenido del empleo con la que se denominó "política de pleno empleo", que bajó los niveles en ese renglón hasta situarse en el año 1979 en un 4,8\% de cesantía (Torrealba \& Oropeza, 1988).

Hacia 1979, los síntomas de crisis económica comenzaron a evidenciarse y se inició un proceso irreversible que tuvo un impacto negativo en lo social y en lo político en los años sucesivos, lo cual hizo disminuir drásticamente la calidad de vida en el país.

Desde la perspectiva de la CTi, prevalecía el modelo lineal. La ideología dominante estaba marcada por la creencia de que los científicos debían tener un papel central en la determinación de los problemas a ser investigados en el país y que muchos problemas importantes de la ciencia no eran de interés social inmediato y debían ser tratados con autonomía y, en consecuencia, los científicos debían establecer las políticas y estrategias del sector (Vessuri, 1992). Ese elemento ideológico imperó y en el horizonte temporal se crearon un número importante de instituciones de diversa índole que pasaron a conformar una suerte de sistema nacional de ciencia y tecnología, donde los científicos tuvieron un papel central en lo concerniente a su diseño y funcionamiento. 
A continuación, se presenta una tabla de instituciones que toma en cuenta a universidades, centros, institutos, y organismos de planificación. La intención es mostrar el proceso acelerado de creación y consolidación que abarcó dos décadas en constante expansión. Esa multiplicación de instituciones no logró una verdadera conjugación de políticas, estrategias, programas, instrumentos y una base de información común para avanzar coordinadamente hacia la consolidación del sistema. Sin embargo, no se puede desconocer el esfuerzo, inversión y logros alcanzados, que, sin ser mucho en términos productivos, constituye una plataforma importante (de la Vega, 2005). Ahora, bien, la tabla no incluye a todas las instituciones de educación superior que se han creado en el país a partir de 1950, por el hecho de que están dedicadas casi exclusivamente al trabajo de formación.

Tabla $\mathbf{N}^{\circ}$ 1. Mapa de las principales instituciones que planifican o realizan actividades de educación, ciencia y tecnología en Venezuela. Período 1950-2016

\begin{tabular}{|c|c|c|c|}
\hline Sector 0 sub sector & $\begin{array}{l}\text { Institución } 0 \\
\text { dependencia }\end{array}$ & Año & Objetivo \\
\hline \multirow{5}{*}{ Сут } & $\begin{array}{l}\text { IVNIC } \\
\text { IVIC }\end{array}$ & $\begin{array}{l}1954 \\
1959\end{array}$ & Investigación básica y aplicada \\
\hline & CIEPE & 1974 & $\begin{array}{l}\text { Investigación tecnológica } \\
\text { industrial }\end{array}$ \\
\hline & INZIT-CICASI & - & $\begin{array}{l}\text { Investigación tecnológica } \\
\text { industrial }\end{array}$ \\
\hline & INTEVEP & 1976 & $\begin{array}{l}\text { Investigación tecnológica } \\
\text { industrial }\end{array}$ \\
\hline & $\begin{array}{l}\text { Fundación Luis Roche } \\
\text { CIDA }\end{array}$ & $\begin{array}{l}1953 \\
1975\end{array}$ & Investigación básica \\
\hline $\begin{array}{l}\text { Universidades } \\
\text { públicas }\end{array}$ & Existen 20 & - & $\begin{array}{l}\text { Académico/investigación en } \\
\text { varios casos, en otros solo } \\
\text { Académico }\end{array}$ \\
\hline $\begin{array}{l}\text { Universidades } \\
\text { Privadas }\end{array}$ & Existen 19 & - & $\begin{array}{l}\text { Académico/investigación en } \\
\text { algunos casos, en la mayoría solo } \\
\text { académico }\end{array}$ \\
\hline \multirow{5}{*}{ Público } & ASOVAC & 1950 & \multirow{5}{*}{$\begin{array}{l}\text { Planificación/coordinación/ } \\
\text { investigación }\end{array}$} \\
\hline & $\begin{array}{l}\text { FUSAGRI } \\
\text { FONAIAP / INIA }\end{array}$ & $\begin{array}{l}1952 \\
2000\end{array}$ & \\
\hline & CORDIPLAN / MPD & 1960 & \\
\hline & $\begin{array}{l}\text { CONICIT / } \\
\text { FONACIT }\end{array}$ & 19672001 & \\
\hline & FONINVES-CIEP & 1972 & \\
\hline
\end{tabular}




\begin{tabular}{|l|l|l|l|}
\hline Sector o sub sector & \multicolumn{1}{|c|}{$\begin{array}{c}\text { Institución o } \\
\text { dependencia }\end{array}$} & \multicolumn{1}{|c|}{ Año } & Objetivo \\
\hline & FUNDAYACUCHO & 1975 & \\
\hline & $\begin{array}{l}\text { MCT / } \\
\text { MPPEUCT }\end{array}$ & 20002016 & \\
\hline
\end{tabular}

Fuente: CNU-OPSU (2004) y MCT y de la Vega (2005) y de la Vega (2016).

(ASOVAC) Asociación Venezolana para el Avance de la Ciencia.

(FUSAGRI) Fundación Servicios para el Agricultor.

(IVNIC) Instituto Venezolano de Neurología e Investigaciones Cerebrales.

IVIC: Instituto Venezolano de Investigaciones Científicas.

FONAIAP: Fondo Nacional de Investigaciones Agrícolas. INIA: Instituto Nacional de Investigaciones Agrícolas.

CORDIPLAN: Oficina de Coordinación y Planificación de la Presidencia de la República.

MPD: Ministerio de Planificación y Desarrollo.

FUNDAYACUCHO: Fundación Gran Mariscal Ayacucho.

CONICIT: Consejo Nacional de Investigaciones Científicas y Tecnológicas / (FONACIT) Fondo Nacional de CyT.

CIEPE: Centro de Investigaciones del Estado para la Producción Experimental Agroindustrial.

INZIT-CICASI: Instituto Zuliano de Investigaciones Tecnológicas.

INTEVEP: Instituto Venezolano de Tecnología del Petróleo.

MCT: Ministerio de Ciencia y Tecnología. Al 2016 se denomina: El Ministerio del Poder Popular para Educación Universitaria Ciencia, Tecnología (MPPEUCT).

Nota: las grandes universidades nacionales cuentan con varios centros de I+D y empresas.

Venezuela fue uno de los contados países latinoamericanos que, en el período comprendido entre 1950 y 1982, se convirtió en una nación atractiva para técnicos, profesionales y científicos. Eso se debió a la expansión económica, principalmente a través del petróleo, y la estabilidad política en el período democrático. La incorporación de esos investigadores extranjeros en la enseñanza de las actividades de investigación científico-tecnológica en la educación superior fue una de las claves para el desarrollo acelerado de las universidades nacionales e institutos de investigación (Vessuri, 1983). El desarrollo que requería el país falló en la aplicación de políticas públicas en CyT dirigidas al diseño de estrategias y mecanismos claros de articulación con los otros actores, limitando todo el entramado que se requería para contar con una plataforma de desarrollo más sólida.

Ya se han mencionado múltiples causas del éxito limitado que se obtuvo en el ámbito científico y que en lo tecnológico fue aún más exiguo. Ello se debió en gran medida a la falta de políticas adecuadas en el primer caso y a la inexistencia de una industria consolidada en el segundo. La política científica y tecnológica del Estado venezolano, de cuya elaboración y ejecución el CONICIT era responsable, quedó centrada exclusivamente en una política para la investigación, dirigida al mundo de la academia, del laboratorio, de la universidad. Como es natural, ese enfoque hizo que los esfuerzos se alejaran mucho del mundo de la economía, de la producción, de la empresa (Ávalos, 1985). 
Otro elemento central se encuentra en las políticas y estrategias utilizadas para elaborar un plan de atracción para jóvenes con vocación científica, a pesar de haberse creado instituciones como el CONICIT, FUNDAYACUCHO, FONINVES y al esfuerzo que venía desempeñando el Consejo de Desarrollo Científico y Humanístico (CDCH) de la Universidad Central de Venezuela desde el año 1959 y, a partir de la década del setenta, sus homólogos comenzaron a funcionar con estrategias similares en la formación de personal en pre y postgrado. Una de las críticas se fundamenta en la proliferación de instituciones con objetivos similares con la insuficiente o inexistente jerarquización de prioridades nacionales (Naím \& Piñango, 1985), y a la ausencia de una verdadera tradición en materia educativa.

El interés por la ciencia más allá del discurso retórico por parte del Estado ha estado signado por dos condiciones centrales. La primera tiene que ver con un profundo desconocimiento de la importancia estratégica de las actividades científicas, tecnológicas y de innovación por parte de la mayoría de las gestiones gubernamentales del período en estudio, y, consecuentemente, con el desinterés que esto conlleva. La segunda, es referida a los recursos financieros destinados a estas actividades que no solo han sido insuficientes según los cánones internacionales, sino que fueron oscilantes, lo que perturbó la posible planificación de cualquier programa y proyecto a desarrollar. Esa tendencia se observó fundamentalmente hacia finales de los setenta y durante todos los años ochenta (CONICIT, 1997).

En los años noventa resurgió el interés por las actividades de ciencia y la tecnología, a pesar del contexto de deterioro general que caracterizó al país en esos años. En materia de CTi se puede afirmar que, en términos generales, mejoró con respecto a la década anterior. Una de las razones fue el importante incremento en el presupuesto que se destinó a esas actividades en ese período (de la Vega, 2001).

El aumento se originó a raíz de una decisión política del Congreso, generada por un trabajo de lobby que realizó la Ministra de Estado para la Ciencia y la Tecnología en esos años. En el año 1990 se creó el Programa de Promoción a la Investigación (PPI), con lo cual se buscaba incentivar a los investigadores por medio del reconocimiento y por la ayuda económica. En 1992 se consiguió aumentar nuevamente la asignación presupuestaria, al haber captado recursos extraordinarios provenientes de la privatización de empresas del Estado. El Megaproyecto de la privatización significó una inyección de recursos sin precedentes que se gastó sin previsión, lo cual trajo resultados inadecuados de un bajo impacto. También ese mismo año se firmó el convenio entre el CONICIT y el Banco Interamericano de Desarrollo (BID), para implementar durante cuatro años el Programa 
Nuevas Tecnologías, el cual contó con un presupuesto compartido de U\$ 94 millones, dirigido a desarrollar capacidades en el país en tres componentes básicos: formación de investigadores, financiamiento a proyectos y fortalecimiento de la infraestructura, en cinco áreas: nuevos materiales, informática, electrónica, química fina y biotecnología.

A partir de 1994, desde el CONICIT se impulsó un cambio en las políticas públicas de CyT, donde apareció de forma explícita la innovación y ese nuevo proceso se orientó hacia un modelo organizado en torno a la idea de que la investigación se justificaba dentro de un contexto de utilidad y aplicación y se realizara en el seno de redes institucionales; integrada por organizaciones muy heterogéneas y dentro de marcos muy flexibles de trabajo que permitieran la multidisciplinariedad y la interdisciplinariedad (Ávalos, 1999). En el marco de ese cambio se realizó un trabajo de consulta nacional que duró un año aproximadamente, en el cual se discutió hacia dónde deberían dirigirse las políticas, denominado "Repensar el CONICIT", con lo cual, se buscó el consenso entre los actores del denominado Sistema Nacional de Innovación que se intentó implantar. En esta dirección, se fomentaron programas como el de Laboratorios Nacionales y Grupos de Investigación que buscaban cambiar en términos relativos y en aquellas instancias posibles el estilo de trabajo de lo individual a lo colectivo (equipos interinstitucionales). También se implantaron las Agendas de Investigación como un cambio cualitativo dirigido a definir problemas nacionales, regionales o locales, donde la participación en la definición de las líneas de trabajo era compartida entre científicos y los actores involucrados en la problemática planteada.

Durante los dos primeros años de la gestión 1994-1999 se consiguió aumentar la asignación del presupuesto del CONICIT a casi el doble del año 1993, para luego disminuir levemente en los siguientes, medido a precios constantes del año 2001 (OCTI, 2003). El aumento total conseguido durante la década permitió que se incrementaran el número de programas implantados, así como el número de subvenciones otorgadas por esa institución.

En líneas generales, en ese período se lograron varios cambios de orden cualitativo, entre los cuales destacan: el Programa de las Agendas dirigidas a dar respuestas a demandas específicas de diversos sectores de la sociedad; programas de Grupos de Investigación y Apoyo a Laboratorios Nacionales; el financiamiento a los Postgrados Integrados, a Universidades Emergentes y el Apoyo a la Formación de Jóvenes Investigadores que buscaban acercar a los actores del llamado sistema nacional de innovación, con la finalidad de acometer soluciones a problemas complejos de interés nacional. 
Las elecciones del 6 de diciembre de 1998, ganadas por Hugo Chávez, cerraron un ciclo de bipartidismo y abrieron otro con unas líneas de acción difusas. Tal vez la más importante fue la Asamblea Nacional Constituyente que tuvo como objetivo generar una nueva Constitución, cuyos primeros elementos fueron el cambio de nombre del país, la extensión del período presidencial a seis años. También, aumentaron a cinco los poderes del Estado, se constituyó la Vicepresidencia de la República y el Consejo Federal de Gobierno. Así mismo, la nueva constitución prevé los referendos consultivo, aprobatorio y derogatorio, tanto del presidente, como de los alcaldes y gobernadores.

La ruptura radical con el pasado que había gobernado el país desde el año 1959, era el primer argumento para captar adeptos, dado el agotamiento de ese modelo político. Con la conquista del poder por parte de la Revolución Bolivariana, desconcertante para todos, irritante para algunos, esperanzadora para otros, se produjeron cambios profundos en la vida socioeconómica, política, institucional y cultural del país, por encima de las discrepancias de intereses y expectativas de distintos sectores, no siempre atenuados por el discurso áspero y pugnaz del gobierno (Calvo, 2003). Al revisar los primeros años del gobierno revolucionario, encontramos que hubo una gran movilización en torno a los cambios políticos que se intentaron adelantar. En el Congreso se discutió la nueva constitución que estaba dirigida a lograr un marco adecuado que permitiera modernizar las estructuras institucionales. Al obtener el triunfo en los comicios de 1998, el gobierno tuvo apoyo de la población en ese primer período, y basó su discurso en la importancia de tener una constitución adecuada a las necesidades del país y del contexto internacional, como herramienta central para avanzar hacia el desarrollo. Pero al pasar el tiempo, los cuadros opositores incrementaron las críticas a la actuación del gobierno y las enfocaron en la falta de resultados que habían sido ofertados desde la campaña electoral. Ese elemento generó una respuesta del gobierno que amplificó la radicalización política del país. La situación, que ya era extremadamente compleja, entró en una dimensión de proporciones insospechadas, cuyo proceso se agudizó a tal punto, que en el país hubo paralizaciones continuas, intentos de golpe de Estado cívico-militar, paro de la industria petrolera, reestructuración de la misma con un saldo de más de 18 mil empleados retirados, entre otros factores que han afectado todas las estructuras (de la Vega et al., 2010). Venezuela inició un proceso de cambios constantes, con profundos problemas, en el que se confrontan dos posiciones que han llegado a ser excluyentes y altamente conflictivas. El resultado, es un país con graves desencuentros, caracterizado por una polarización de 
una parte de la sociedad venezolana, situación que ha traído como consecuencia una nueva caída de la economía, con altos índices de inflación, desempleo, crecimiento de la economía informal, mayor delincuencia, entre otros problemas como lo es la pugnacidad política para demostrar el poder, es decir, todo lo que se hace es en función de capitalizar adeptos, y no verdaderos proyectos con diferentes alcances para resolver las dificultades e inconvenientes que tiene el país (de la Vega, 2014).

\subsection{UNA NUEVA FORMA DE CONCEBIR LAS ACTIVIDADES CTI}

La nueva gestión de gobierno del Presidente Hugo Chávez Frías cambió el enfoque hacia las actividades de CTi en el país. En 1999, se creó el Ministerio de Ciencia y Tecnología (MCT) y el Fondo Nacional de Ciencia y Tecnología (FONACIT). Con esa medida el gobierno intentó que todos los organismos del denominado sistema de CTi se adscribieran a su despacho, con el propósito de unificarlos bajo una organización centralizada. No obstante, el INTEVEP, Instituto que le presta servicios técnicos y realiza investigación para la industria petrolera y, que además se lleva un porcentaje significativo de los recursos destinados a la $\mathrm{I}+\mathrm{D}$, finalmente, no se adscribió, luego de una larga disputa entre los técnicos de la empresa estatal y el gobierno (de la Vega et al., 2010).

El MCT instauró un modelo de organización de tipo vertical, y la presencia del mismo como ente rector del sistema no es mala en sí. La crítica se deriva de la manera en cómo fue estructurado, ya que no permite una coordinación intersectorial, proceso clave cuando no todos los organismos que hacen ciencia y técnica en la sociedad están bajo la égida del ente rector (Requena, 2003). Los organismos locales, Fundaciones para el Desarrollo de la Ciencia y la Tecnología (FUNDACITES) y las comisionadurías fueron reestructuradas para funcionar bajo las nuevas políticas impulsadas por el MCT, con lo cual se pasó de un proceso que tenía varios años desarrollándose como lo fue la descentralización en esa materia, a seguir pautas centralizadas.

El MCT dio importancia a la búsqueda de recursos financieros con la promulgación de varios instrumentos jurídicos, entre los que destaca la Ley de Ciencia, Tecnología e Innovación (2001), la cual permitía honrar el artículo 110 de la Constitución sancionada en 1999, en la que se establecía que el Estado reconocería "el interés público de la ciencia, la tecnología, el conocimiento, la innovación y los servicios de información necesarios" considerándolos como instrumentos fundamentales para el desarrollo económico del país, así como para asegurar la seguridad y defensa nacional". De igual manera, indicaba que el Estado destinaría los fondos necesarios y crearía "el sistema nacional de ciencia y tecnología" de acuerdo a la Ley (de la Vega et al., 2010). 
Una de las premisas fundamentales de la nueva Ley fue la de organizar lo que el gobierno llamó "el Sistema Nacional de Ciencia, Tecnología e Innovación". Con esa estrategia se buscaba no solo unificar a todos los actores, sino impulsar mecanismos para que el sector productivo invirtiera recursos financieros en la actividad de I+D y procesos de transferencia de tecnología, entre otros. Ese conjunto de buenas intenciones que se plasmaron en esa Ley, no difieren mayormente de las que animaron el discurso institucional de tiempos pasados (Bifano, 2004).

El proyecto bandera del MCT durante sus primeros años de funcionamiento fue diseñar un programa para implantar en todo el país infocentros, con lo cual se buscaba "democratizar la ciencia y la tecnología”. El plan, basado en la supuesta Gerencia Social del Conocimiento, consistió en crear más de 240 espacios físicos dotados de plataformas tecnológicas, bajo la idea de propiciar el uso de herramientas informáticas entre la población, así como el acceso a los contenidos existentes en internet. En poco tiempo estos centros fueron desmontados/cerrados.

En el año 2001, se creó un Observatorio Nacional de Ciencia, Tecnología e Innovación (ONCTI), con la misión de organizar la información en la materia, y por esa vía mejorar la toma de decisiones, proceso que hasta el momento ha tenido problemas al no contar con una cultura adecuada en las instituciones del país que suministrara adecuadamente la información requerida. Hoy en día, no publica datos ni informes técnicos.

Entre los años 2002 y 2003, se apreció una merma en los recursos destinados a la CyT, situación que repercutió negativamente en las instituciones adscritas y en el financiamiento de los programas del MCT. Ese problema derivaba fundamentalmente del creciente conflicto político por el que estaba atravesando el país, que incluso paralizó a la industria petrolera nacional cerca de tres meses.

En el año 2005, a raíz de una reforma de dicha Ley, y la aprobación de un Reglamento, se estableció una contribución de parte de las empresas con ingresos brutos superiores a 100.000 unidades tributarias a actividades de CTi: las de hidrocarburos el $2 \%$, las mineras y eléctricas con el $1 \%$, y las demás el $0,5 \%$. Esos recursos se podían utilizar en tres modalidades: utilización de los fondos dentro de la empresa; financiar proyectos a terceros o cediendo el monto correspondiente a los entes competentes del gobierno (de la Vega et al., 2010).

La aplicación del Reglamento de la LOCTI, a partir del año 2006, impulsó un cambio en los actores del SNI venezolano, al incrementarse los recursos financieros de forma significativa en el ámbito de la CTi, pero esa decisión fue modificada y convertida en un tributo 
directo en el año 2010. El gobierno eliminó del Reglamento la inversión en la propia empresa y cesión a terceros el porcentaje de los fondos obligándola a entregar el monto total al ente gubernamental correspondiente, con lo cual se desmovilizó de forma significativa y progresiva a todos los actores, perdiéndose los avances logrados hasta ese momento en el acercamiento del sector productivo a las IES y entes generadores de conocimiento.

Una de las características que distingue el buen funcionamiento de los SNI es la adecuada relación entre oferta y demanda de conocimientos con el soporte de políticas públicas. En el caso venezolano las condiciones para que se de ese equilibrio no están dadas y en los últimos años las existentes han ido desarticulándose. En vez de incorporarse actores al sistema se cierran continuamente empresas e industrias y las pocas universidades, institutos y centros con trayectoria y resultados en CTi están siendo afectadas tanto en sus presupuestos como en el acceso a fondos públicos desmantelando de esa manera un esfuerzo sostenido de más cincuenta años (de la Vega et al., 2010).

En el año 2013 hubo elecciones presidenciales en Venezuela, cuyo resultado se decidió por un total de 224.268 votos ( $50.61 \%$ a $49,12 \%$ ) a favor del partido de gobierno (PSUV) y Nicolás Maduro se proclamó nuevo presidente de la república bolivariana con un país totalmente dividido en ese momento.

Ya en el año 2016, el gobierno actual, aplicando políticas erráticas, ha ido desmantelando el incipiente SNI que tanto esfuerzo ha costado construir desde 1950. Un dato revelador sobre el fracaso del modelo político-económico actual es el que determina que los ingresos que ha obtenido Venezuela por la venta de petróleo en lo que va de siglo XXI supera con creces todo el presupuesto de la nación durante el siglo XX. Algunos datos básicos indican que, durante el año 1998, el precio del barril de crudo venezolano llegó a venderse a U\$S 7,2. A partir del año 1999, el costo por unidad se incrementó de forma sostenida, con algunas fluctuaciones, hasta llegar en el año 2008 a situarse en U\$S 116,57 (U\$S 139,83 el Brent). A partir de 2009 hubo una caída abrupta, donde el Brent se situó a U\$S 45,59, pero hubo un rebote que ubicó el precio entre U\$S 90 y U\$S 120 entre los años 2010 y 2014. Para el mes de enero de 2016, el precio se ubicó en U\$S 27,76, unos U\$S 4 más que en el año 2003. Esto significa que, en los últimos diecisiete años en Venezuela, ambos gobiernos pertenecientes al mismo partido político (PSUV) han quebrado técnicamente al país con el agravante de que lo lograron en la época de mayor bonanza. El asunto es que Venezuela camina hacia lo que se conoce como una espiral hiperinflacionaria, con una variable en la ecuación referida a la escasez de productos de primera necesidad nunca vista antes. Ese marco de 
recesión general afectó drásticamente a las IES en sus presupuestos y fondos para la investigación y formación, y el sector productivo, con una alta mortalidad de empresas.

En un marco de debilidades, como las que se aprecian en Venezuela, una propuesta para ayudar a las organizaciones a mejorar su desempeño en materia de identificación, organización y manejo de datos e información medular es un avance significativo. La metodología propuesta involucra potencialmente a todos los actores del SNI.

\section{BIBLIOGRAFÍA}

Álvarez, I.; Barletta, F.; Suarez, D.; Yoguel G. 2016 “Marco analítico para la tipificación de diálogos para las políticas de CTI" en Working paper 3 (Red CYTED COM-LALICS). En <http://alics. org/images/CYTED/DT3-DimensionesDialogo.pdf> acceso 19 de abril de 2017.

Andreu, R.; Sieber, S. 1999 "La gestión integral del conocimiento y del aprendizaje" en Economía Industrial (España: Ministerio de Ciencia y Tecnología) No 326, pp. 63-72.

Ardila, M. 1981 "Origen y evolución histórica de la asociación venezolana para el avance de la ciencia (ASOVAC)", Tesis de grado en Sociología (Caracas: Universidad Católica Andrés Bello).

Ávalos, I. 1999 "Breve crónica de un cambio anunciado" en Espacios (Caracas) Vol. 20, $\mathrm{N}^{\circ}$ 2, pp. 79-90, Caracas

Ávalos, I. y Jaffé, W. 1985 Breve historia de la política tecnológica venezolana, en El caso de Venezuela. Una ilusión de armonía (Caracas: Ediciones Iesa) pp. 376-394.

Ávalos, I. y Jaffé, W. 1992 "La investigación industrial en Venezuela" en Ruiz Calderón, H. et al. (comp.) La ciencia en Venezuela. Pasado, presente y futuro (Caracas: Lagoven) pp. 103-117.

Barboza, L. 2016 "Algunas consideraciones en torno al concepto de comunidad" en Working paper 6 (Red CYTED COM-LALICS). En <http://lalics.org/images/CYTED/DT6-DefinicionComunidad. pdf $>$ acceso 19 de abril 2017.

Bemporad, M. 2003 "La conciencia del dato" en INTERCIENCIA (Caracas) Vol. 28, $\mathrm{N}^{\mathrm{o}} 7$, pp. 369, julio.

Bifano, C. 2004 Treinta años de ciencia en Venezuela: logros y tropiezos, en Ciencia y uso del conocimiento (Caracas: Fundación Polar) pp. 89-124.

Borja, J.; Castells, C. 1997 "La ciudad multicultural” en La Factoría (Barcelona) Vol. 2, p. 1, febrero.

Bueno, E. 1999 "Gestión del conocimiento, aprendizaje y capital intelectual" en Boletín del Club Intelect (Madrid) $\mathrm{N}^{\mathrm{o}} 1$, enero. 
CONICIT 1997 Sistema de información de becarios del Conicit

(Caracas: Talleres de Litocromo C. A.).

Calvo, A. 2003 "Recursos naturales y deuda pública” en Enciclopedia temática (Caracas: Planeta) tomo II, pp. 427-480.

Davenport, T.; Prusak, L. 1998 Working Knowledge: How organizations manage what they know (Estados Unidos: Harvard Business School Press).

Dutrénit, G.; Álvarez, I.; Ardanche, M.; Barletta, F.; Bianco, M.; Cortés, R.; Cummings, A.; de la Vega, I.; Díaz, I.; Fernández, O.; Gómez, V.; Goñi, M.; Natera, J. M.; Nupia, C.; Orozco, J.; Prada, F.; Puchet, M.; Romero, F.; Simón, L.; Suárez, D.; Suárez, M.; Sutz, J.; Vera-Cruz, A. 2016 “Matriz de Información para el mapeo de procesos de diálogo de CTI en España, América Latina y el Caribe" en Working paper 5 (Red CYTED COM-LALICS). En <http://lalics.org/images/CYTED/DT5-Formulario2.pdf> acceso 18 de abril de 2017.

Dutrénit, G.; Natera, J. M-; Suárez, M. 2014 "Lineamientos para la caracterización de las Comunidades y sus Procesos de Diálogo" en Working paper 1 (Red CYTED COM-LALICS). En <http:// lalics.org/images/CYTED/DT1-ComunidadesDialogo\%201.pdf> acceso 19 de abril de 2017.

Dutrénit, G.; Natera, J. M.; Puchet Anyul, M. O.; Vera-Cruz, A.; Torres, A. 2017 "Dialogue processes on STI policy-making in Latin America and the Caribbean: dimensions and conditions", en Science and Public Policy, 1-16. En <doi: 10.1093/scipol/ scx044>.

de la Vega, I. 2002 "Un observatorio de ciencia, tecnología e innovación para Venezuela” en Cuadernos del Cendes (Caracas) año $19, \mathrm{~N}^{\circ} 51$, pp. 65-81, tercera época, septiembre-diciembre. de la Vega, I. 2005 Mundos en movimiento. El caso de la movilidad y migración de los científicos y tecnólogos venezolanos (Caracas: Fundación Pola).

de la Vega, I. 2014 “Tráfico pesado de venezolanos cualificados hacía múltiples destinos” en Peralta, R.; Lares, C.; Vegas, K. (eds.) Diáspora del talento migración y educación en Venezuela: análisis y propuestas (Venezuela: FUNDACELAC) pp. 57-88.

de la Vega, I.; Troconis, A.; Blanco, F.; Llovera, F. 2010 El rol de la universidad en el desarrollo científico y tecnológico de Iberoamérica (Chile: CINDA-UNIVERSIA).

Drucker, P. 1993 La sociedad poscapitalista (Barcelona: Apóstrofe). Drucker, P. 2003 "Llega una nueva organización a la empresa” en Gestión del conocimiento. Harvard Business Review (Bilbao: Deusto). 
Edvinsson, L.; Malone, M. 1997 Intellectual Capital (Nueva York: Harper Business).

Goñi, M.; Bianco, M.; Puchet, M. 2015 “Elementos para caracterizar los procesos de diálogo en políticas de CTI" en Working paper 7 (Red CYTED COM-LALICS). <http://lalics.org/ images/CYTED/DT7-ConfianzaPoder.pdf > acceso 15 de abril de 2017.

Harman, C.; Brelade, S. 2000 Knowledge Management and the Role of $H R$ (SCH Associates Ltd.).

Hung de León, L.; Piñango, R. 1985 “Crisis de la educación o crisis del optimismo y el igualitarismo?” en Naím, M.; Piñango, R. (comps.) El caso de Venezuela. Una ilusión de armonía (Caracas: Iesa) pp. 422- 450.

Naím, M.; Piñango, R. (comps.) 1985 El caso de Venezuela: una ilusión de armonía", en El caso de Venezuela. Una ilusión de armonía (Caracas: Iesa) pp. 538-579.

Nonaka, I.; Toyama, R.; Byosière, P. 2001 "A theory of organizational knowledge creation: Understanding the dynamic process of creating knowledge" en Dierkes, M.; Berthoin Antal, A.; Child, J.; Nonaka, I. (eds.) Handbook of organizational learning and knowledge (Nueva York: Oxford University Press) pp. 491-516.

Nonaka, I.; Nishiguchi, T. (eds.) 2001 Knowledge emergence: Social, technical, and evolutionary dimensions of knowledge creation (Nueva York: Oxford University Press).

Nonaka, I.; Takeuchi, H. 1995 The Knowledge-Creating Company (Estados Unidos: Oxford University).

Nupia, C.; Martínez A. 2015 "Revisión de metodologías de procesos de diálogo" en Working paper 4 (Red CYTED COM-LALICS). En <http://lalics.org/images/CYTED/DT4-MetodologiasDialogo. pdf $>$ acceso 18 de abril de 2017.

OCTI, MCT 2003 en http://www.octi.gov.ve/indicadores.

OVIT, (2016) http://www.ovtt.org/sistemas_nacionales_de_inovacion [Consultado: 03-06-2016]

Peña-Cedillo, J. 2003 "Cambio tecnológico y sistemas nacionales de innovación: elementos para la teoría y la política del desarrollo socioeconómico" en Argos (Venezuela) No 38, pp. 41-74, julio.

Pérez-Montoro, M. (ed.); Golkhosravi, M. 2010 "Gestión del conocimiento" en Díaz Nafría, J.; Pérez-Montoro, M.; Salto Alemany, F. (eds.) Glosario de conceptos, metáforas, teorías y problemas en torno a la información (León: Universidad de León). 
Quinn, J.; Anderson, P.; Finkelstein, S. 2003 “La gestión del intelecto profesional: sacar el máximo de los mejores" en Gestión del conocimiento. Harvard Business Review (Bilbao: Deusto) p. 203-230.

Rivero, S. 2002 Claves y pautas para comprender e implantar la gestión del conocimiento: un modelo de referencia (Las Arenas: SOCINTEC).

Ruiz Calderón, H. 1987 “Cambio y permanencia en los modelos de institucionalización de la actividad científica en Venezuela: el caso de la física y la energía nuclear en el IVNIC-IVIC" en Vessuri, H. (comp.) Las instituciones científicas en la historia de la ciencia en Venezuela (Caracas: Fondo Editorial Acta Científica Venezolana) pp. 249-272.

Sánchez, M.; González, A.; Pérez, E. 2007 "El concepto de capital intelectual y sus dimensiones" en Investigaciones Europeas de Dirección y Economía de la Empresa (España) vol. 13, № 2, pp. 97-111.

Stewart, T. 1997 Intellectual Capital: The New Wealth of Organizations (Estados Unidos: Currency Dubleday).

Stewart, T. 2001 La nueva riqueza de las organizaciones: el capital intelectual (Barcelona: Granica).

Sveiby, K. 1997 The New Organizational Wealth (Estados Unidos: Berett-Koehler Publishers).

Sveiby, K. 2000 "La nueva riqueza de las empresas" en Gestión 2000 (Barcelona).

Texera, Y. 1992b "La facultad de ciencias de la Universidad Central de Venezuela" en Ruíz Calderón, H. et al. (comp.) La ciencia en Venezuela. Pasado, presente y futuro (Caracas: Lagoven) pp. 51-64.

Torrealba, R.; Oropeza, J. 1988 Estado y migraciones laborales en Venezuela (Caracas: Cabildo).

Valhondo, D. 2003 Gestión del conocimiento. Del mito a la realidad (Madrid: Díaz de Santos). En <http://ediciones.diazdesantos.es>.

Vessuri, H. 1987 Las instituciones científicas en la historia de la ciencia en Venezuela (Caracas: Fondo Editorial Acta Científica Venezolana) pp. 7-12.

Vessuri, H. 1992 "Ciencia, tecnología y modernización en Venezuela" en Ruíz Calderón, H. et al. (comp.) La ciencia en Venezuela. Pasado, presente y futuro (Caracas: Lagoven) pp. 20-33.

Vessuri, H.; Safar, M. 1983b "Elementos para la historia social de la química en Venezuela: la sociedad venezolana de química" en Díaz, E.; Texera, Y.; Vessuri, H. La ciencia periférica. Aspectos sociopolíticos de la formación de la elite científica en Venezuela (Caracas: Monte Ávila) pp. 121-165. 
Viedma Martí, J. 1998 ICBS - Intellectual capital benchmarking system (Intellectual Capital Management Systems).

Wiig, K. 1997 "Integrating Intellectual Capital and Knowledge Management" en Long Range Planning (Países Bajos: Elsevier) vol. 30, $\mathrm{N}^{\mathrm{o}}$ 3, pp. 399-405. 


\title{
DIÁLOGO PARA A CONSTRUÇÃO DE POLÍTICAS DE CTI PARA ATIVIDADES \\ CULTURAIS
}

\section{A EXPERIÊNCIA DOS ARRANJOS PRODUTIVOS LOCAIS DO CARNAVAL NO BRASIL}

\author{
Marcelo Pessoa de Matos, José Eduardo Cassiolato \\ y Helena M. M. Lastres*
}

\section{INTRODUÇÃO}

A propagação, na virada do milênio, de políticas de apoio a sistemas e arranjos produtivos e inovativas pode ser associada ao reconhecimento da importância de promover a acumulação de conhecimentos, mobilizando as interações dos diferentes atores participantes desses sistemas. Com isso, importante experiência tem sido acumulada no Brasil, somando àquela conquistada na esfera da pesquisa e da análise dos resultados alcançados com os diversos casos apoiados por políticas públicas e privadas. Assim, registra-se a grande oportunidade para avançar no aprimoramento e consolidação do referencial que tem pautado a agenda de pesquisa e de política em Sistemas e Arranjos Produtivos e Inovativos Locais, ou simplesmente Arranjos Produtivos Locais - APLs (Lastres et al., 1999; Cassiolato et al., 2003). O desenvolvimento do referencial de sistemas de inovação, ao final dos anos 1980, reforçou a tese de que a inovação é um processo sistêmico, interativo e localizado, em grande parte, circunscrito às fronteiras nacionais e/ou territoriais; e, portanto, não existe um modelo único a ser seguido. Cada caso precisa ser compreendido de acordo com suas particularidades e o contexto específico no qual se insere,

* Universidad Federal de Río de Janeiro. 
de forma a avaliar qual deve ser seu modo específico e próprio de desenvolvimento e quais iniciativas de políticas poderiam contribuir nesta direção. E essas políticas deveriam resultar de um esforço coletivo e capaz de mobilizar os diversos grupos de interesse (Katz, 1996; Lopez e Lugones, 1999; Johnson e Lundvall, 2003; Arocena e Sutz, 2003; Dutrenit e Sutz, 2013). Isto sublinha o importante papel que exerce o processo de diálogo para a concepção, estruturação e implementação de políticas de ciência, tecnologia e inovação (CTI) (Dutrenit et al., 2014). Através de um processo de diálogo bem estruturado, que leve em consideração as especificidades de cada território e seus atores, é possível incorporar um entendimento amplo de desenvolvimento, para muito além da competitividade e do crescimento econômico.

Este capítulo apresenta um conjunto de evidências empíricas e reflexões críticas acerca desta temática, tendo como foco a experiência do processo de diálogo para a criação e implementação de políticas de CTI para os APLs do Carnaval no Brasil. O texto explora o papel da liderança e da capacidade de coordenação e mobilização de consensos no contexto de arranjos institucionais em recorrente alteração. Portanto, o objetivo central é entender a interface da capacidade de agência dos beneficiários, os interesses políticos e as relações de poder e instituições em transformação, provendo uma reflexão crítica acerca das características e determinantes do processo de diálogo.

Este documento foi realizado no marco da Rede Temática para melhorar o diálogo entre as comunidades envolvidas nas políticas de CTI (COM-LALICS), integrada por grupos de pesquisa de Argentina, Brasil, Chile, Colômbia, Costa Rica, Cuba, El Salvador, Espanha, México, Peru, República Dominicana, Uruguai e Venezuela e financiada pelo CYTED. O objetivo desta rede é, precisamente, sistematizar e analisar experiências de diálogos para a política de CTI, com vistas a identificar diretrizes que permitam conduzir processos exitosos de diálogo.

A primeira seção apresenta uma breve revisão da literatura. A segunda seção discute a metodologia de análise empregada. A terceira seção apresenta a política brasileira para arranjos produtivos locais. A quarta seção focaliza as principais características do sistema em torno do Carnaval, destacando a amplo escopo possível para políticas de CTI. A seção subsequente apresenta uma perspective cronológica do processo de diálogo. Na sexta seção são explorados os papéis dos distintos atores e as forças que ajudam a explicar a dinâmica específica deste caso de diálogo. A última seção apresenta alguns fatos estilizados e conclusões. 


\section{O REFERENCIAL DE SISTEMAS E ARRANJOS PRODUTIVOS E INOVATIVOS LOCAIS NA CONSTRUÇÃO DE POLÍTICAS PÚBLICAS}

A partir das contribuições originais de economistas clássicos, no século $\mathrm{XX}$, se consolida o reconhecimento de que a ampliação das capacitações e o uso de conhecimentos na geração de novos processos, produtos, formas organizacionais, etc. constitui um determinante central da transformação do sistema produtivo e do desenvolvimento (List, 1841; Schumpeter, 1942). Diferentes esforços teóricos e analíticos avançaram o entendimento sobre as fontes e os determinantes da inovação, tanto no nível de empresas individuais quanto de regiões e países. Destaca-se o referencial da teoria evolucionária ou neo-schumpeteriana (Nelson e Winter, 1982; Freeman, 1987; Dosi et al., 1988). Baseado na observação das diversidades existentes entre os diferentes países e territórios -em termo de suas especificidades históricas, linguísticas, culturais e sociais- foi elaborado o conceito de Sistemas Nacionais de Inovação (Freeman 1982, 1987; Lundvall, 1985; Nelson, 1992). A constituição deste referencial se beneficiou de muitas influências, destacando-se a convergência com conceitos e contribuições do pensamento estruturalista latinoamericano. Estes identificam na mudança estrutural o potencial de endogeneizar os benefícios e avanços do progresso técnico e entendem que a promoção de tal processo tem que se dar a partir do entendimento das trajetórias históricas específicas e dos contextos sociais, culturais, econômicos, institucionais e políticos de cada sociedade (Prebisch, 1949; Singer, 1950; Myrdal, 1958; Furtado, 1961). Essas abordagens enfatizam que conhecimentos importantes para o desempenho econômico são enraizados e condicionados a trajetória anterior de sua geração e acumulação (path-dependent). Outro fator destacado é a importância das interações e relações entre os agentes, dado que nem indivíduos nem organizações produzem e inovam sozinhos. Como pano de fundo destas interações está o arcabouço institucional particular e os demais elementos sociais e culturais específicos de um país, derivado de seu processo histórico de desenvolvimento (Freeman, 1995).

Inspirados por esta percepção, outros pensadores têm destacado as especificidades de diferentes subconjuntos de sistemas de inovação. Este é o caso de setores, campos tecnológicos e territórios (regiões e localidades). Especialmente relevante para a presente discussão é a perspectiva local dos sistemas de inovação. Diferentes abordagens que partem de um recorte territorial destacam, por um lado, as características específicas de espaços subnacionais e, por outro lado, os aspectos intrínsecos ao conhecimento, ao aprendizado e à inovação que conferem dinâmicas próprias a diferentes 
espaços locais. Destaca-se o referencial de Sistemas e Arranjos Produtivos e Inovativos Locais, desenvolvido pela RedeSist e que tem pautado, desde 1997, um amplo conjunto de estudos e subsidiado a construção de políticas para o desenvolvimento local e regional (Cassiolato e Lastres, 1999). Como dito, estes têm sido chamados simplesmente de Arranjos Produtivos Locais (APLs).

Arranjos Produtivos Locais representam, fundamentalmente, um quadro de referências, a partir do qual se busca compreender os processos de geração, difusão e uso de conhecimentos e da dinâmica produtiva e inovativa. Tal abordagem oferece um novo instrumental para entender e orientar o desenvolvimento industrial e tecnológico. Entende-se a produção e a inovação como processos sistêmicos, que resultam da articulação de distintos atores e competências. Isso explica porque as novas políticas de desenvolvimento produtivo e inovativo visam mobilizar esses elementos, com o objetivo de ampliar a capacidade de gerar, assimilar e usar conhecimentos. $\mathrm{O}$ enfoque abrange conjuntos de atores econômicos, políticos e sociais e suas interações, incluindo: empresas produtoras de bens e serviços finais e fornecedoras de matérias-primas, equipamentos e outros insumos; distribuidoras e comercializadoras; trabalhadores e consumidores; organizações voltadas à formação e treinamento de recursos humanos, informação, pesquisa, desenvolvimento e engenharia; apoio, regulação e financiamento; cooperativas, associações, sindicatos e demais órgãos de representação. Tal visão sistêmica abrange atores e atividades produtivas e inovativas: (i) com distintas dinâmicas e trajetórias, desde as mais intensivas em conhecimentos até aquelas que utilizam conhecimentos endógenos ou tradicionais; (ii) de diferentes portes e funções, originários dos setores primário, secundário e terciário, operando local, nacional ou internacionalmente (Cassiolato et al., 2003; Lastres et al., 2003; Lastres e Cassiolato, 2006; Cassiolato et al., 2008; Matos et al., 2015).

Um recorte territorial para o conceito de sistemas de inovação se justifica pelo reconhecimento das múltiplas dimensões que caracterizam um território e das particularidades que estas conferem às atividades de produção, construção de competências e inovação ali desenvolvidas. Cada território é moldado a partir da combinação de condições e forças internas e externas, devendo ser compreendido como parte de uma totalidade espacial. O território não se reduz à sua dimensão material ou concreta, apresentando uma variedade de dimensões, tais como (Raffestin, 1993; Santos, 2000):

- Física: que diz respeito tanto a suas características e recursos naturais (tais como clima, solo, relevo, vegetação e subsolo), 
quanto àquelas resultantes dos usos e práticas territoriais por parte dos grupos sociais;

- Econômica: através da organização espacial dos processos de produção econômica o que, como e quem nele produz;

- Sócio-política: meio para interações sociais e relações de dominação e poder- quem e como o domina ou influencia;

- Simbólica: incluindo as ligações afetivas, culturais e de identidade do indivíduo ou grupo social com seu espaço geográfico;

- Cognitiva: referentes às condições para a geração, uso e difusão de conhecimentos.

Cabe destacar algumas dimensões, as quais não têm gozado de posição central na literatura de sistemas de inovação. A dimensão simbólica se refere à construção de ligações afetivas, culturais e de identidade do indivíduo ou grupo social com o seu contexto vivido. A cultura figura, ao mesmo tempo, como um pano de fundo, meio e modo de mediação das relações sociais (Castilho et al., 2009; Lima et al., 2007). O espaço local constitui fundamento da territorialidade e da formação de identidades. Neste contexto se desenvolve o conceito de territorialidade, entendido como as relações entre um indivíduo ou grupo social e seu meio de referência, expressando um sentimento de pertencimento e um modo de agir no âmbito de um dado território (Raffestin, 1993). Estes modos de agir são essencialmente culturais e é esta cultura que pode dar credibilidade de existência e identidade a um grupo de pessoas ou comunidade, favorecendo a sua interação a partir de reconhecimento mútuo e conformação de relações de confiança. Conforme também proposto por Santos (2000 e 1996), o local constitui um intermédio entre o mundo e o indivíduo, no qual as pessoas estão ligadas pela identidade de pertencimento e por atividades úteis ao desenvolvimento econômico, social e cultural da coletividade.

No que se refere à dimensão sócio-política, a esfera local constitui a menor unidade na qual são estabelecidas relações interpessoais e se desenvolvem relação de poder. Grande parte das relações sociopolíticas são construídas a partir da interação frequente, direta e presencial entre os agentes, o que pressupõem que ocupem o mesmo espaço físico. A partir desta interação se reforçam tanto forças de convergência quanto de divergência. A convergência está relacionada ao que se convencionou denominar "capital social", entendido como as instituições formais e informais que afetam os níveis de confiança e interação em um sistema social (Albagli e Maciel, 2003). Um elevado nível de capital 
social propicia relações de cooperação, que favorecem o aprendizado interativo, bem como a construção e transmissão de conhecimentos. Facilita ações coletivas geradoras de sistemas produtivos articulados. A divergência está relacionada à constituição da estrutura social como um sistema hierarquizado de poder e privilégio, determinado tanto por relações materiais quanto por relações simbólicas entre os indivíduos. Conforme descortinado por Bourdieu (1987 e 1989), a posição relativa dos grupos sociais nessa estrutura, formada por "campos", deriva da desigual distribuição de recursos e poderes. A dinâmica social no interior de cada campo é regida pelas lutas em que os agentes procuram manter ou alterar as relações de força e a distribuição de recursos e poderes. $\mathrm{O}$ entendimento dos campos como espaços de relações com lógicas próprias evidencia a importância da dimensão local, na qual prevalece um conjunto mais homogêneo de valores e práticas.

Estes aspectos, juntamente com os aspectos já amplamente sublinhados pela literatura de sistemas de inovação -acerca do caráter localizado, sistêmico e interativo do aprendizado e da inovação-, evidenciam a centralidade desta dimensão nos processos de diálogo para a construção de políticas, de forma geral, e de políticas de CTI, de forma específica. As dimensões simbólica e sócio-política são determinantes para a construção de coesão e consenso, que permitem uma atuação concertada em esferas mais amplas, em busca de atenção das organizações de política e mobilização de recursos, em uma lógica "bottom-up" de determinação de agendas e iniciativas. $\mathrm{O}$ caso discutido neste capítulo oferece fortes evidências para centralidade destas dimensões nos processos de diálogo para construção de políticas.

\section{METODOLOGIA}

O estudo que dá base ao presente artigo apoia-se e dialoga com a metodologia geral proposta e continuamente elaborada pelo conjunto de pesquisadores envolvidos no projeto de pesquisa que deu origem a esta publicação (Dutrenit et al., 2014; Goñi et al., 2015; Álvarez et al., 2016; Nupia e Martínez, 2015; Dutrenit et al., 2016, 2017; Barboza, 2016; Goñi et al., 2015). No que se refere ao levantamento das informações relevantes, o método é fundamentado na observação participativa no processo de desenvolvimento do diálogo para a construção de uma política de CTI para os APLs do Carnaval no Brasil. Tal perspectiva é possível devido ao envolvimento direto dos autores no próprio processo, constituindo um dos grupos de interlocutores.

Este processo teve como ponto de partida, a aplicação do referencial metodológico de pesquisa empírica em APLs desenvolvido pela 
RedeSist. Este envolve o mapeamento de atores locais, a esquematização do sistema produtivo e inovativo, a realização de entrevistas semi-estruturadas junto a todos os tipos de atores relevantes, a organização e análise das informações e dados primários e secundários levantados (Matos et al. no prelo). Esta metodologia foi aplicada em cinco regiões metropolitanas: Rio de Janeiro, São Paulo, Vitória, Porto Alegre, Florianópolis, sendo que as duas primeiras se destacam com as escolas de samba e os espetáculos (desfiles) de maior magnitude e destaque.

Além da observação direta, a coleta de informações também contou com o registro, gravação e transcrição, de todos os eventos chave de diálogo, tais como reuniões de trabalho, seminários e apresentações e discussões formais de propostas de política com os órgãos públicos e beneficiários. As informações e dimensões analíticas foram organizadas de acordo com o esquema geral proposto pelos pesquisadores líderes desta pesquisa, empreendendo-se eventuais adaptações pontuais, tendo em vista a especificidade do caso em tela.

\section{A POLÍTICA BRASILEIRA PARA APLS}

O caso específico analisado neste trabalho constitui um exemplo de esforços muito amplos, que têm sido mobilizados no Brasil no escopo do que se pode caracterizar como a política brasileira para APLs. A lógica inerente ao entendimento do objeto e dos processos envolvidos está intimamente associada à forma como tal referencial foi incorporado ao linguajar e à agenda política. Compreender este pano de fundo contribui, portanto, para entender a lógica de organização e evolução dos diálogos para a construção de políticas.

A partir da década de 2000 se consolida no discurso de políticas públicas o reconhecimento da importância de uma abordagem sistêmica para a promoção da inovação e da competitividade das empresas. Em particular, as políticas para promover o desenvolvimento tecnológico e industrial têm reconhecido que a aglomeração de empresas e o melhor aproveitamento das vantagens coletivas geradas por suas interações podem contribuir para constituição de vantagens competitivas sustentáveis (Cassiolato et al., 2003).

A partir da primeira administração Lula, iniciada em 2003, uma posição mais privilegiada foi atribuída às políticas para diminuição das disparidades regionais e locais no país. As políticas para APLs contaram com o protagonismo do Serviço Brasileiro de Apoio às Micro e Pequenas Empresas (SEBRAE) foram incluídas no Plano Plurianual (PPA) para os períodos 2004-2007 e 2008-2011.

Em paralelo, destaca-se a criação, em 2004, de um grupo interministerial para tratar das políticas com este foco, o Grupo de Trabalho 
Permanente para Arranjos Produtivos Locais (GTP-APL), lotada na estrutura organizacional do Ministério do Desenvolvimento, Indústria e Comércio Exterior, com o objetivo de adotar uma metodologia de apoio integrado a APLs, com base na articulação de ações governamentais. O GTP-APL é composto por 33 organizações, incluindo secretarias de 12 ministérios, agências governamentais, cinco bancos de desenvolvimento federais, com âmbitos nacional e regional, uma instituição bancária privada, o SEBRAE e a Confederação Nacional das Indústrias.

O foco principal do grupo é evitar a duplicação de esforços e sobreposição de iniciativas direcionadas para APLs, permitindo a interação e comunicação entre as instituições e, assim, maximizar os recursos, evitar a fragmentação das iniciativas. O GTP-APL também fomentou e apoiou a criação de núcleos estaduais de apoio a APLs, os quais foram criados no âmbito das secretarias de estado.

A especificidade de cada território, associada à interação de fatores sociais, culturais e institucionais ao longo de sua evolução, sublinha a importância de uma perspectiva orientada de baixo para cima (bottomup)daconstruçãodepolíticas. Háumasólida compreensãonas diretrizes do GTP-APL de que os atores locais devem ser mobilizados como interlocutores centrais no diálogo para a construção de iniciativas. Mas, em termos práticos, as experiências variam desde esforços essencialmente impulsionados por atores locais até o extremo oposto de implementação de planos complexos mobilizados por organizações nacionais e internacionais, que são inspirados por uma lógica de benchmark de outras experiências no país ou no exterior. Por um lado, a construção detalhada e colaborativa das iniciativas de política conduz a uma maior chance de sucesso, tanto por causa da maior legitimação entre os beneficiários locais (e conseguinte apoio e adesão), quanto por causa do foco em obstáculos específicos, oportunidades e trajetórias de desenvolvimento viáveis. Por outro lado, um argumento recorrente é de que uma postura orientada por benchmarks poderia permitir a economia de tempo e recursos ao longo do diálogo para a construção de políticas, permitindo uma ação mais rápida. Especialmente considerando a lógica de alternância de poder político, ligada aos ciclos eleitorais, a importância da capacidade de entregar resultados rapidamente se torna evidente. Como mostrado nas seções seguintes, este conflito desempenha um papel central no caso analisado.

Uma segunda característica central da política para APLs é o seu foco na perspectiva sistêmica. Esta parte do entendimento de que, para a efetiva promoção da competitividade e do desenvolvimento sustentável na esfera local, políticas que são normalmente associados a diferentes secretarias e ministérios (CTI, indústria, desenvolvimento 
regional e social, cultura, etc.) devem, idealmente, ser mobilizadas de forma combinada e convergente. Mesmo assim, a experiência prática mostra iniciativas mais ou menos fragmentadas. Não raro, os ministérios ou agências específicas assumem uma posição de liderança como interlocutor com os agentes locais em um APL e mobilizam os seus instrumentos de apoio usuais, sem considerar a interação potencial com outras esferas de ação política. As experiências nas quais se pode observar uma efetiva convergência de políticas estão associadas a impactos muito mais expressivos (Matos et al., 2015). Também tal aspecto é central importância para o caso analisado, como será discutido nas seções seguintes.

\section{O CARNAVAL NO BRASIL COMO UMA REDE DE ARRANJOS PRODUTIVOS LOCAIS}

As escolas de samba são entidades culturais sem fins lucrativos, cuja principal atividade consiste na realização do desfile durante o Carnaval. O número de escolas varia entre as principais cidades. No Rio de Janeiro, principal palco desta manifestação, existem cerca de 80 agremiações. As escolas de samba são organizadas em diferentes grupos e a competição entre as agremiações define a ascensão ou descenso de escolas entre os grupos, de forma similar ao que acontece em diferentes modalidades esportivas.

Cada escola de samba realiza um desfile com 2000 a 4000 participantes e quatro a oito carros alegóricos. Cada apresentação leva de 40 a 80 minutos. A apresentação se estende ao longo de muitos dias durante o Carnaval. Uma parte variável de participantes não integra a organização; eles adquirem o direito de participar do desfile ao comprarem as fantasias. A cada ano cada escola de samba adota um enredo novo, fazendo menção a fatos históricos, lugares, pessoas, culturas etc. A criação dos elementos visuais (fantasias, adereços e alegorias), dos elementos musicais (samba-enredo) e performáticos é orientada pelo enredo adotado, de forma que a cada ano é produzido um Carnaval completamente novo.

A produção, ano após ano, deste Carnaval movimenta um complexo sistema produtivo e inovativo, envolvendo diferentes atividades produtivas, profissionais de diversas áreas de conhecimento de agentes econômicos, sociais, político institucionais e culturais. Dentre as atividades produtivas, o sistema engloba uma gama variada de atividades industriais e de serviços. A figura 1, abaixo, apresenta uma esquematização dos componentes do sistema.

Identificam-se quatro grandes conjuntos de agentes e atividades, os quais também podem ser caracterizados como subsistemas que 
compõe o sistema do Carnaval:

- Subsistema Produtivo: se divide em quatro grandes grupos. Em primeiro lugar, figura o grupo que engloba a produção de insumos e a intermediação comercial. O segundo grupo engloba o conjunto de agentes responsáveis pela transformação de insumos e conceitos, através do trabalho criativo, e desta forma "produzindo" o espetáculo. O Terceiro grupo engloba o conjunto de agentes e atividades econômicas que são mobilizados nos dias do desfile ou durante o período do Carnaval. Estas atividades são fundamentais para fornecer a infraestrutura, os serviços e produtos necessários para que se promova o encontro do público consumidor com os executores do espetáculo. Por fim, um conjunto diversificado de atores de diversos segmentos das industriais culturais e do entretenimento complementam esta complexa rede produtiva;

- Subsistema de Educação e de Ciência e Tecnologia: contempla o conjunto de organizações de ensino e pesquisa que possuem alguma interface com as atividades do Carnaval;

- Subsistema de Coordenação, Representação e Políticas: em todas as capitais pesquisadas neste estudo, identifica-se uma rica parceria estabelecida entre organizações de representação e coordenação e o poder público. A partir desta interação, sobretudo com as pastas de cultura e turismo, é organizado o desfile são mobilizadas muitas dos agentes produtivos que viabilizam a realização do desfile;

- Subsistema de Demanda/Consumo: constituído pelos consumidores dos diversos produtos da economia do Carnaval. Por um lado, destaca-se como produto principal a experiência do desfile das escolas de samba, seja esta como expectador nas arquibancadas ou como participante, que adquiriu mediante compra da fantasia o direito à vivência.

As escolas de samba estão colocadas no centro deste sistema, como principais agentes produtivos. Da mesma forma, o produto final deste sistema, o desfile, encontra-se em posição central, dado que as diversas atividades do sistema convergem para a consecução deste. As setas e traços representam fluxos e relações econômicas entre os agentes, que são descritos na sequência. 


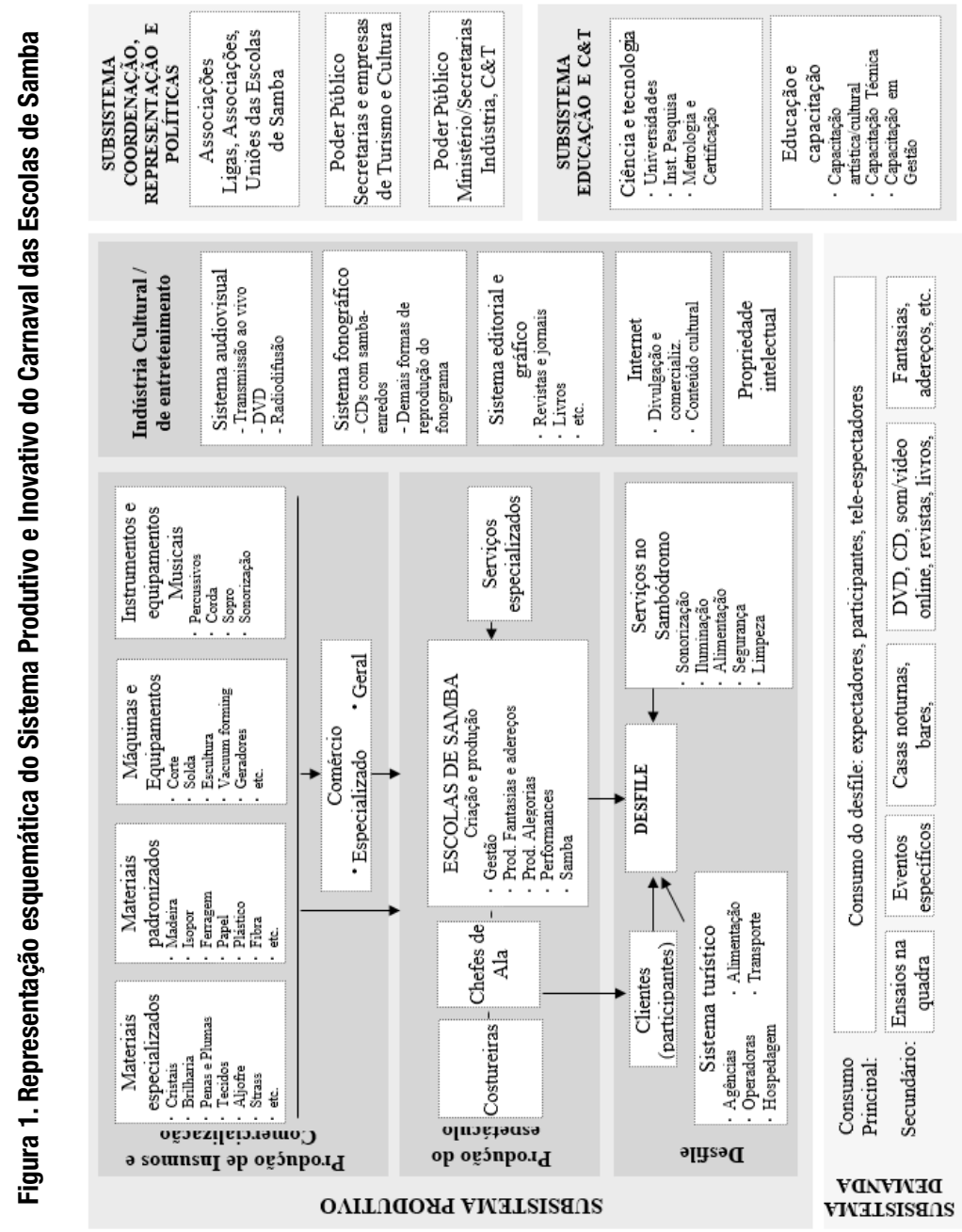

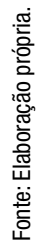


É difícil obter boas estimativas para o volume de recursos mobilizados pela economia do Carnaval, mas os dados existentes evidenciam a complexidade e dimensão do sistema. Em 2015, o Rio de Janeiro atraiu 1,2 milhões de turistas e o Carnaval gerou receitas de aproximadamente US $\$ 470$ milhões, enquanto São Paulo atraiu 900 mil turistas e gerou receitas de US $\$ 354$ milhões (Soares, Prestes Filho, 2013).

Segundo a Secretaria Estadual de Trabalho do Estado do Rio de Janeiro, cerca de $80 \%$ dos postos de trabalho gerados pelas escolas de samba são de caráter temporário e informal. Essa sazonalidade e informalidade se devem ao fato de muitas escolas não terem como manter uma folha de pagamentos fixa, já que não há uma verba destinada especificamente para isso. No que se refere especificamente à produção de fantasias e alegorias, esta porcentagem seria de cerca de 62\% (Araújo, 2002).

Nas principais cidades há uma densa rede de instituições voltadas para a educação e formação profissional em atividades indiretamente relacionadas ao Carnaval. Mas no que se refere à atividade criativa, existe apenas uma infraestrutura de conhecimento em áreas amplas, tais como música, moda e artes visuais, etc. O único projeto formalizado em curso é uma iniciativa de formação de "profissionais de Carnaval", com foco na gestão dessas festividades e eventos (Matos, 2007).

Também se observa uma densa rede de organizações de representação, apoio e promoção, bem como um elevado nível de comprometimento do setor público, com destaque para o âmbito municipal. Cada cidade conta com uma ou mais associações, as quais são responsáveis por interagir com as instituições públicas e em conjunto organizar os desfiles e outras festividades durante o Carnaval. No Rio de Janeiro, por exemplo, a LIESA (Liga Independente das Escolas de Samba do Rio de Janeiro) foi criada em 1980 pelas principais escolas de samba. A AESCRJ (Associação das Escolas de Samba da Cidade do Rio de Janeiro) é a remanescente da associação que representava todas as escolas de samba. Em São Paulo, a Liga SP representa as principais escolas de samba e a UESP representando todas as demais escolas de samba.

Estas organizações desempenham um papel central também no diálogo para a construção de políticas, analisado neste trabalho. Como será mostrado, é a sua capacidade para mobilizar diferentes atores e para levar adiante os processos que explica a extensão e impacto potencial do processo. 


\section{O DIÁlOGO PARA A CONSTRUÇÃO DE UMA POLÍTICA DE CTI PARA APOIAR O CARNAVAL}

Em primeiro lugar, cabe apresentar brevemente o contexto no qual o diálogo para a construção de políticas é estabelecido e se desenvolve. O ponto de partida é percepção de que há uma falta de reconhecimento por parte do poder público das atividades relacionadas ao Carnaval das escolas de samba como um importante e complexo sistema de produção e inovação. Assim, o principal objetivo das escolas de samba e seus órgãos de representação é mobilizar um conjunto de iniciativas de apoio ligadas à política industrial e de Ciência, Tecnologia e Inovação - CTI, direcionado para as escolas de samba.

Embora exista uma relação de longa data entre o governo local com as escolas de samba para a organização dos desfiles, a promoção da capacidade produtiva e de inovação ainda é ausente. Há um vasto conjunto de desafios e oportunidades que se relacionam diretamente com o escopo de atuação da política de CTI, como desafios para avançar na utilização de técnicas e materiais existentes, dada a assimetria de informação entre as áreas técnicas, e o potencial de inovação artística pouco explorado no campo de novos materiais, equipamentos, processos e dispositivos, bem como melhorias organizacionais. A fim de fechar esta lacuna, um interessante processo de diálogo foi estabelecido com as organizações públicas na esfera federal, por iniciativa das próprias escolas de samba. Além disso, a direção em que o diálogo evoluiu fez com que a perspectiva de promoção do desenvolvimento local inclusivo e sustentado também se articulasse ao foco inicial em CTI.

O processo de diálogo pode ser dividido em três fases principais, cronologicamente subsequentes. Nesta seção, descrevem-se estas fases em uma perspectiva factual. Já na seção seguinte, exploram-se considerações detalhadas sobre o processo de diálogo para a construção das políticas de CTI.

\subsection{PRIMEIRA FASE: MOBILIZANDO ATORES}

Partindo da percepção descrita acima, de que há um enorme potencial para a política de CTI fomentar atividades criativas e inovativas ligadas ao sistema de produção e inovação do Carnaval, alguns atores iniciaram um processo de mobilização e geração de consenso entre a comunidade das escolas de samba no país. Este processo teve início no segundo semestre de 2013. A associação das maiores escolas de samba do Rio de Janeiro, a Liga Independente das Escolas de Samba do Rio de Janeiro (LIESA), exerceu um papel de liderança neste processo. Em um primeiro momento, 
a associação mobilizou pessoas em posições de liderança nas escolas de samba do Rio de Janeiro, de forma a construir certo nível de legitimidade para liderar este processo. Em um segundo momento, a LIESA mobilizou o amplo conjunto de associações que representam escolas de samba de diferentes cidades e grupos de todo o país. Ao longo deste processo, um certo nível de consenso foi construído em torno da necessidade e da oportunidade de levar às organizações públicas um conjunto estruturado de reivindicações para a mobilização de políticas de apoio que ultrapassam o âmbito da tradicional política cultural.

Há duas razões intimamente ligadas por que este amplo conjunto de associações atribuiu à LIESA o papel de líder para promover este diálogo com os órgãos governamentais. Primeiro, o desfile das escolas de samba é uma tradição nascida na cidade do Rio de Janeiro no início do século vinte. As escolas de samba desta cidade são as mais conhecidas, mobilizando grande quantidade de recursos para a produção de desfiles continuamente maiores e mais impressionantes. As escolas de samba em outras cidades, de certa maneira, seguiram muitos dos passos destes pioneiros. Assim, as escolas de samba do Rio de Janeiro e sua principal associação representativa têm maior visibilidade e, portanto, capacidade de influenciar a opinião pública. Em segundo lugar, a LIESA, desde a sua criação em 1980, desempenhou um papel importante, apoiando o desenvolvimento das escolas de samba em todo o país e suas respectivas associações representativas, o que ajudou a estabelecer um forte sentimento de solidariedade e de pertença dentro de grande parte desta comunidade cultural.

A LIESA exerceu esse papel de liderança e, juntamente com representantes de associações de outras cidades centrais, iniciou um diálogo com a Comissão de Cultura da Câmara dos Deputados Federais. A apresentação de uma demanda relativamente estruturada (tanto em termos de o que se demanda quanto em termos de constituir a convergência da demanda das escolas de samba de todo o país) foi muito importante para que a Comissão de Cultura fosse capaz de mobilizar esferas específicas do poder público. Como dois aspectos centrais na pauta de reivindicações eram a formação técnica e a difusão tecnológica, o Ministério de Ciência, Tecnologia e Inovação (MCTI) foi identificado como um interlocutor crucial.

Assim, o próximo passo consistiu no estabelecimento de um diálogo entre os representantes das escolas de samba e o alto nível deste ministério. $\mathrm{O}$ apelo encontrou eco significativo neste Ministério devido ao alinhamento ideológico dos atores em posições de liderança (diretor-executivo, primeiro na estrutura hierárquica após 
o ministro), que partem de um amplo entendimento da inovação e do seu papel nos mais diversos segmentos produtivos, em oposição a uma lógica centrada exclusivamente em grandes indústrias de alta tecnologia.

Em uma segunda rodada de reuniões, foi atribuída à Secretaria de Ciência e Tecnologia para Inclusão Social (SECIS) do MCTI a tarefa de aprofundar este diálogo. Esta secretária desenvolve um programa de longo prazo centrado em Centros Vocacionais Tecnológicos (CVTs), que são unidades de formação técnica com algum foco setorial. Muitos CVTs foram estabelecidos em todo o país, sempre em parceria com instituições no nível estadual, com foco na formação profissional em atividades intensivas em trabalho e que não exigem altos níveis de educação formal. Em outros casos, o foco setorial está relacionado com a especialização produtiva de territórios específicos. Em todos os casos, o foco está na formação profissional e algumas iniciativas de difusão de tecnologias maduras, visando oportunidades de emprego e inclusão social.

Assim, mesmo que o foco inicial da demanda estivesse centrado no potencial das escolas de samba enquanto grandes inovadoras e no grande espetáculo do Carnaval comercial, a dimensão social e inclusiva também ganhou relevância neste diálogo. Combinar estas dimensões constituiu um desafio adicional para o diálogo de construção de política. A SECIS mobilizou sua organização parceira no estado do Rio de Janeiro, a Fundação de Apoio à Escola Técnica (FAETEC), para prospectar a possibilidade de criação de um primeiro CVT focado no Carnaval, na cidade do Rio de Janeiro. Isto constituiria uma experiência piloto, que poderia ser replicada nas outras principais cidades do futuro. O projeto formal para este CVT foi apresentado aos representantes das escolas de samba do Rio de Janeiro no final de 2013.

Como relatam muitos dos atores centrais das escolas de samba do Rio de Janeiro, somente se estabeleceu um diálogo muito limitado entre os potenciais beneficiários e a FAETEC, a organização que usaria os recursos fornecidos pelo Ministério para estruturar e operar o CVT do Carnaval. Parcialmente incorporando as demandas expressas pelas escolas de samba, a FAETEC desenvolveu uma proposta de como estruturar este CVT, detalhando os tipos de cursos que deveriam ser oferecidos e sua estrutura. Esta proposta foi fortemente baseada na experiência anterior da FAETEC em setores manufatureiros (carpintaria, confecções, solda, elétrica, mecânica, artesanato, etc.), mas não levou efetivamente em consideração as especificidades da produção do Carnaval. Especificidades estas que estão relacionadas, sobretudo, a forma como a dimensão estética e 
criativa se articula com o lado técnico para a produção de produtos culturais únicos.

A percepção geral de que os especialistas da comunidade do samba não foram suficientemente ouvidos levou à perspectiva de que se tratava de uma proposta orientada de cima para baixo (top-down), a partir de modelos pré-concebidos. Trata-se de uma proposta que foi construída com base em uma transferência relativamente direta de experiências e modelos de política anteriores, possuindo como "vantagem" a agilidade com que esta iniciativa seria capaz de ser colocada em prática. Mas, a percepção de incompatibilidade derivada de uma falta de diálogo levou a uma adesão muito fraca a esta proposta, o que, em última instância, significou seu descarte.

O principal perigo nesta fase era de a mobilização política perder sua força, em associação a uma lógica do tipo "pegar ou largar". Assim, as capacidades de mobilização e coordenação da LIESA foram fundamentais para um renovado engajamento do MCTI. Assim, consolidou-se o entendimento de que era necessário um entendimento muito mais profundo e detalhado das especificidades deste sistema de produção e inovação, para que se construíssem iniciativas de apoio específicas e eficazes. Isso significou dar um passo para trás, para uma fase de reflexão e proposição da política.

\subsection{SEGUNDA FASE: UMA CONSTRUÇÃO DE BAIXO PARA CIMA}

Como notado acima, a capacidade de agência da LIESA foi essencial para novamente mobilizar o Ministério da Ciência, Tecnologia e Inovação, estabelecendo o cenário para um profundo entendimento das necessidades das escolas de samba e a melhor forma de abordá-los. Assim, entre o fim de 2013 e o início de 2014, um grande esforço para construir um programa de política foi mobilizado.

Neste ponto fica claro um desafio adicional que torna este caso diferente e interessante. Mais do que um conjunto diversificado de empresas de diferentes segmentos, o MCTI se via diante do desafio de estabelecer um diálogo com organizações culturais, que não possuem fins lucrativos, mas mesmo assim mobilizam uma complexa rede de valor. As idiossincrasias desta comunidade são muito específicas e divergem de empresas tradicionais. Isto é especialmente relevante quando consideramos os códigos de comunicação e linguagem. Neste contexto, o diálogo direto entre os beneficiários e a organização política pode enfrentar obstáculos significativos. Assim, a opção do ministério foi de mobilizar um grupo muito específico de pesquisadores da universidade, que vem desenvolvendo pesquisas que exploram justamente a interface 
entre as atividades (ou indústrias) culturais e os sistemas de inovação e a política de CTI.

Portanto, o passo seguinte trouxe para o diálogo a RedeSist, um grupo de pesquisa da Universidade Federal do Rio de Janeiro -UFRJ- com foco em sistemas de inovação. Este foi mobilizado por intermédio de Centro de Gestão e Estudos Estratégicos -CGEE-, organização vinculada ao MCTI. Mas, em vez de aceitar que pesquisadores externos realizassem a avaliação dos desafios e oportunidades das escolas de samba e propusessem políticas, a LIESA mais uma vez exerceu um papel decisivo para a construção de um grupo de pesquisa muito específico. A associação propôs a participação de profissionais que estão diretamente ligados às escolas de samba em diferentes áreas: (i) a diretora de uma das principais escolas de samba do Rio de Janeiro e coordenadora de um projeto que visa difundir práticas modernas de gestão nas escolas de samba, a Escola de Carnaval; e (ii) a presidente da principal organização que trabalha com a capacitação de profissionais em atividades artesanais relacionadas à confecção dos desfiles, a AMEBRAS -Associação das Mulheres Empreendedoras do Brasil-, e especialista na gestão de marcas e identidade visual de escolas de samba.

Foi a capacidade deste grupo único de se comunicar e colaborar que permitiu a mobilização de um vasto conjunto de atores chave das escolas de samba do Rio de Janeiro e outras cidades, fornecendo insights importantes sobre os diferentes processos e áreas do sistema de produção e inovação. Nota-se inclusive que a comunidade do samba é fortemente balizada em relações pessoais, sentimentos de confiança e de pertença. Ficou claro também que a disponibilidade de tempo, informações detalhadas e análises foi agilizada pela contribuição dos pesquisadores e analistas externos mobilizados. A fim de replicar este modelo de pesquisa, grupos de pesquisa mistos semelhantes foram estabelecidos nas outras cidades pesquisadas, atuando sob a coordenação da equipe estabelecida no Rio de Janeiro. As entrevistas ocorreram entre fevereiro e setembro de 2014.

Conforme destacado acima, a metodologia utilizada, foi baseado no referencial conceitual e metodológico de Arranjos Produtivos Locais, desenvolvido pela RedeSist. Questionários semiestruturados foram aplicados a presidentes, diretores, carnavalescos (os principais coordenadores artísticos), bem como aos chefes de diferentes áreas de produção, prestadores de serviços especializados, fornecedores, comércio, etc. Todas as entrevistas foram transcritas e um extenso relatório de pesquisa organizou os resultados. Na sequência, foi submetido a cada entrevistado a transcrição da entrevista original e o relatório, solicitando sua validação e opinião. Este processo, 
embora demorado (até o final de 2014), foi essencial para a criação de legitimidade na comunidade de beneficiários sobre os resultados e as proposições de políticas que foram derivadas.

O passo seguinte consistiu em uma rodada adicional de exposição de resultados entre as partes interessadas. Uma vez por ano, dois grandes eventos são organizados em conjunto na cidade do Rio de Janeiro: uma feira dedicada aos produtos e serviços para o Carnaval, chamada Sambacom, e um fórum dedicado às discussões de temas críticos sobre as escolas de samba e os desfiles de Carnaval em todo o território nacional, chamado Carnavália. A edição de 2015 deste evento (no mês de junho) constituiu o palco ideal para apresentar os resultados da pesquisa para a comunidade das escolas de samba de todo o país. Embora, as principais partes interessadas já tivessem sido contatadas para entrevistas e a validação junto a estas já tivesse sido feita, essa fase de exposição e discussão em público provou ser de crucial relevância para gerar ampla consciência e consolidar a legitimidade do documento resultante enquanto instrumento de demanda de ações de política. Dessa forma, com a participação direta de atores beneficiários e com etapas subsequentes de avaliação e ajuste, desenvolveu-se um processo que pode ser caracterizado como uma construção de diálogo sistêmico de baixo para cima, de cima para baixo e lateralmente. O qual foi capaz de alinhavar eixos principais de consensos e encaminhar um conjunto de propostas de política.

Paralelamente, os representantes das principais associações de escolas de samba se comprometeram a levar o relatório e as propostas de políticas para toda a comunidade que representam e aportar considerações e proposições adicionais, que contemplem as características intrínsecas a cada território e a forma como se dá a produção dos desfiles. Embora os aportes adicionais desta fase tenham sido muito tímidos, ela também foi importante para criar consciência e aprofundar o consenso.

O resultado final deste esforço foi um diagnóstico detalhado que explora dificuldades, desafios e oportunidades em áreas como: insumos, novos materiais, equipamentos, máquinas e técnicas de produção, novas soluções tecnológicas, serviços especializados, treinamento, infraestrutura e logística, novos mercados auxiliares, etc. A proposição de política, igualmente detalhada, sugeriu formas concretas para lidar com estas questões, identificando nominalmente potenciais organizações interlocutoras, instrumentos e fontes de recursos.

Em linha coma lógica in trínseca à política para APLs, odocumento prevê a necessidade de se promover a convergência e cooperação 
de iniciativas de política que são geralmente associados a diferentes ministérios e secretarias estaduais. Se, por um lado, as instituições de política já têm avançado na articulação de política de CTI com a política industrial, por outro lado, a articulação destas com políticas das áreas de desenvolvimento social inclusivo e cultura é um terreno pouco explorado. As proposições de política têm como eixo de referência a proposta de criação de Núcleos Coletivos de Capacitação, Produção, Pesquisa e Inovação (denominados de Barracão Escola de Carnaval) em diferentes regiões e sua cooperação em forma de rede. Nestes Núcleos deveriam convergir iniciativas de políticas relacionadas a três campos: (i) trabalho e inclusão produtiva; (ii) manifestação cultural; e (ii) ciência, tecnologia e inovação.

\subsection{TERCEIRA FASE: MUDANÇAS INSTITUCIONAIS}

Quando se chegou ao momento de fazer uso do documento produzido para demandar uma ação concreta por parte do Ministério de Ciência, Tecnologia e Inovação (e parceiros), as proposições encontraram eco muito limitado dentro dessa organização. A razão é que alguns meses antes o ministro havia sido substituído no contexto de mudanças nas relações de poder político. O novo ministro e os diretores atribuíram relevância bastante limitada a uma perspectiva ampla de política de CTI, optando por redirecionar as prioridades políticas para os tradicionais focos, com relação aos quais a incerteza política é bem menor: grandes setores industriais, campos de alta tecnologia, relações universidade-empresa, parques tecnológicos, spin-offs, etc.

Mais uma vez, todo o esforço de promover um diálogo complexo para a construção de uma política de CTI para as escolas de samba correu o risco de perder o seu embalo. E mais uma vez a capacidade de mobilização e coordenação da principal associação das escolas de samba do Rio do Janeiro, a LIESA, foi decisiva para a mobilização dos agentes políticos. Beneficiando-se do diálogo inicial que já havia sido estabelecido com organizações parceiras, necessárias para a implementação do programa de política, a LIESA foi capaz de mobilizar o Ministério da Cultura como novo interlocutor central. A expectativa era de que este ministério fosse capaz de exercer um papel de liderança, mobilizando os recursos necessários e os ministérios e secretarias estaduais. O Ministério da Cultura atribuiu a uma organização subordinada, a Fundação Palmares, a tarefa de se engajar no diálogo com os representantes das escolas de samba.

É claro que, junto com a alternante configuração institucional, os interesses políticos também mudam. Mesmo que baseado em 
amplo processo de pesquisa e validação, dando voz e protagonismo a um vasto conjunto de atores dentro da comunidade das escolas de samba, a Fundação Palmares viu a necessidade de envolver-se em novas rodadas de discussão, se consolidando como novo interlocutor na construção da política a ser elaborada. Na prática, isso significa explorar maneiras de como combinar a proposta de política com o escopo e a lógica de atuação usual desta instituição, de forma a criar legitimidade e obter apoio junto a uma nova configuração de organizações parceiras. Eventualmente, isso também significaria o reequilíbrio de prioridades dadas a diferentes partes da proposta, colocando em primeiro plano os aspectos mais relacionados à política cultural.

Para promover tal rodada de debate, um grande seminário nacional foi marcado para fevereiro de 2016. A LIESA e outras associações desempenharam um papel central como interlocutores no planejamento deste evento, ajudando a definir temas e indicando convidados nas áreas de governo, academia, cultura, sociedade civil e indústria. Mas, mais uma vez, mudanças no cenário político-institucional prejudicaram o processo de diálogo, impedindo que este culminasse na efetiva implementação de ações concretas. A crescente turbulência política no âmbito do governo federal, com o aumento da pressão para derrubar a presidente Dilma Rousseff (mandato 2015 a 2018), levou a uma paralisia e transição política na esfera federal. A oportunidade para avançar com este esforço inovador de estruturação de uma política de CTI sistêmica para uma indústria cultural parece estar perdida no atual contexto de incerteza e reestruturação da relação de poder dentro da política nacional.

A figura abaixo apresenta a linha do tempo com os principais eventos e processos discutidos acima. Conforme detalhado na seção seguinte, as diferentes cores estão associados a eventos que decorrem predominantemente de forças específicas, quais sejam: a capacidade de mobilização e coordenação dos beneficiários (verde); os interesses políticos e relações de poder (azul); e as mudanças institucionais / políticas (vermelho). 


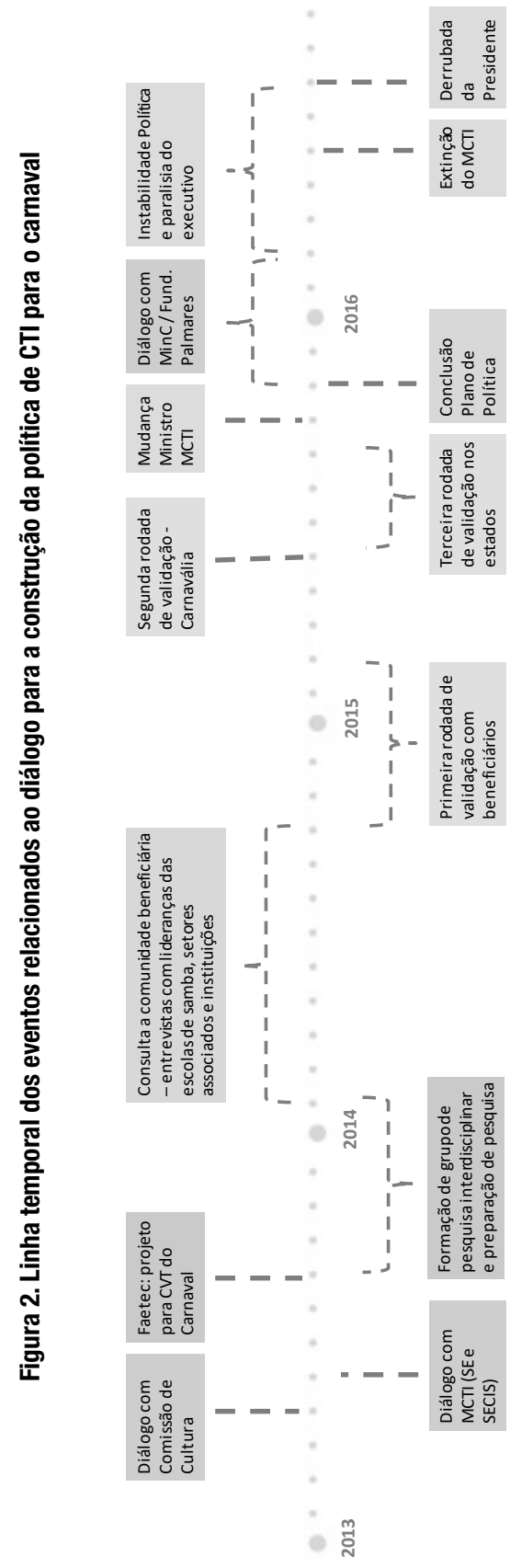

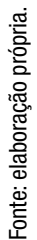




\section{ATORES, FORÇAS E DINÂMICA DO DIÁLOGO}

Duas perspectivas complementares ajudam a analisar esta experiência. Primeiro, são abordadas as diferentes características dos atores e das comunidades a que pertencem, bem como os seus distintos papéis no processo de diálogo. Em segundo lugar, empreende-se uma análise mais profunda da dinâmica do processo e das forças que neste atuaram.

O quadro 1 apresenta os principais atores, as comunidades a que pertencem e o número variável de papéis que desempenharam ao longo do diálogo. Como pode ser visto, as associações de escolas de samba, com a liderança da LIESA, exerceram muitos papéis centrais para o diálogo evoluir. Elas constituíram as principais promotoras, uma vez que foram responsáveis por incentivar e promover o diálogo no seu início e por acompanhar sua implementação. Elas foram as principais líderes, uma vez que orientaram a implementação bem-sucedida do processo de diálogo, especialmente através de sua capacidade de mobilização e coordenação para engajar atores repetidas vezes, quando o diálogo corria o risco de perder sua pujança. Elas foram as principais organizadoras, uma vez que foram responsáveis por identificar atores críticos e tópicos a serem abordados. Em um nível mais limitado, também foram doadoras, proporcionando meios para algumas fases de validação da proposta de política.

O papel de principal doador coube ao MCTI e às organizações subordinadas a esse. O ministério forneceu os recursos para a mobilização do grupo de pesquisadores e para a realização da detalhada pesquisa de campo em diferentes partes do país. Em certa medida, o MCTI também esteve envolvido como um promotor secundário e líder do diálogo. Um papel bastante limitado é atribuído à FAETEC, envolvida apenas na proposição inicial da estrutura de CVT que foi rejeitada.

O grupo de pesquisa, constituído por um conjunto de pesquisadores da universidade e profissionais das escolas de samba e de organizações da sociedade civil, foi responsável pela realização da pesquisa de campo e por traduzir os resultados em proposições que se alinham ao âmbito de atuação das organizações de política. Além disso, este grupo também exerceu o papel de principal facilitador e mediador, se engajando em estreito diálogo com ambos os lados (organizações políticas e grupos de interesse), apresentando, discutindo e adaptando a proposta de política. Ajudando, assim, a lhe aferir maior coerência e legitimidade. 


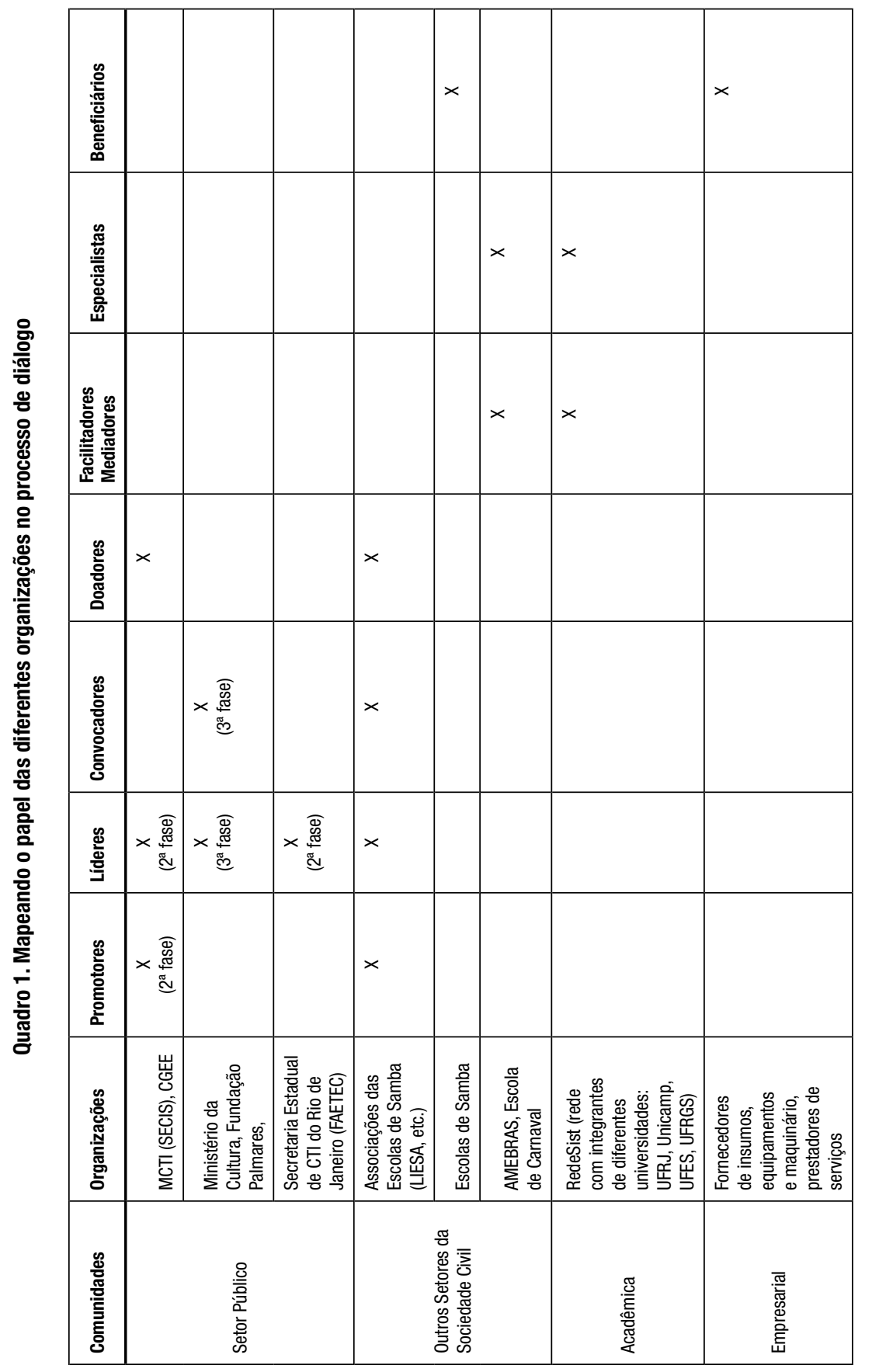

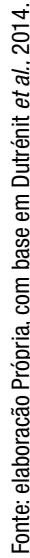


Analisa-se agora a dinâmica do processo de diálogo. A Figura 3 apresenta uma representação esquemática deste. Ao longo da sequência principal representada no esquema, um processo é descrito que, idealmente, começa com a identificação das necessidades ou oportunidades e vai até a implementação de políticas concretas. Três cores são empregadas para representar diferentes tipos de forças que desempenharam papel central para o diálogo evoluir ao longo de um determinado caminho. Estas forças principais são:

- A capacidade de mobilização e coordenação dos beneficiários (verde);

- Os interesses políticos e relações de poder (azul);

- Mudanças institucionais / políticas (vermelho).

Enquanto as duas primeiras são essencialmente endógenas ao processo de diálogo, a terceira representa uma força exógena (aleatória), que eventualmente influencia todo o processo. $\mathrm{O}$ esquema da figura abaixo destaca a principal força determinante para o diálogo passar de uma etapa para outra, o que não significa que outras forças não desempenhem também papéis secundários e simultâneos em cada fase. O esquema constitui, portanto, uma simplificação que torna mais clara a exposição. Como indicado na seção anterior, o processo tem como ponto de partida a tomada de consciência acerca da existência de problemas, necessidades e oportunidades para o melhor desenvolvimento do sistema de produção e inovação das escolas de samba. Mas, o que representa, em um primeiro momento, uma consciência fragmentada só pode levar à mobilização de toda a comunidade de potenciais beneficiários através de um complexo processo de diálogo.

A LIESA exerceu esse papel central, exercendo sua capacidade de mobilização e coordenação para construir um consenso, estabelecendose como principal representante das escolas de samba de todo o país neste processo de diálogo. $\mathrm{O}$ passo subsequente consiste na mobilização das organizações de política. Mais uma vez, a principal força motriz para a exitosa mobilização da Comissão de Cultura da Câmara dos Deputados e, posteriormente, do Ministério de Ciência, Tecnologia e Inovação foi a capacidade de mobilização e coordenação da LIESA. Neste caso, esta capacidade está intimamente ligada à influência política que esta associação tem em certos campos da esfera pública.

A próxima etapa descrita no esquema consiste na especificação das necessidades e na identificação de meios concretos para as organizações de política mobilizadas contribuírem, tendo em vista seu escopo de atuação e missão institucional. $\mathrm{O}$ avanço nesta etapa parece estar 
predominantemente relacionado com a existência de interesse político dentro do MCTI e da capacidade de fazer valer este interesse dentro da estrutura burocrática do ministério (relações de poder). Convergência política e relações de poder também são decisivas para a mobilização de instituições parceiras, como a FATEC no estado do Rio de Janeiro. Em uma primeira rodada, a principal esfera de consulta para a estruturação de uma proposta de política foi limitada às próprias organizações de política. Estas recorreram, fundamentalmente, às suas experiências e rotinas para a construção de um programa de política (a proposta de CVT feita pela FAETEC), a partir de analogias com outros segmentos que normalmente apoiam.

De forma semelhante a uma representação esquemática do processo de inovação, mesmo que exista uma lógica sequencial, o processo de diálogo não pode ser representado como sendo linear. Problemas em uma fase podem implicar na necessidade de se voltar às fases anteriores, redefinindo parcialmente as trajetórias do processo. No caso em tela, a inadequação da primeira proposição de política implicou na necessidade de se voltar a um estágio inicial de concepção e planejamento. Como discutido acima, a sua rejeição deriva do fato de se tratar de uma construção "de cima para baixo", feita pelas organizações de política, com a expectativa implícita de que os beneficiários se adequassem à política pré-definida. Em vez de se chegar a um beco sem saída do tipo "pegar ou largar", ${ }^{1}$ a capacidade de mobilização e coordenação da LIESA e outras associações tornou possível que o dispensar desta proposta não implicasse no fim do processo de diálogo. As associações lograram mobilizar o MCTI novamente e salientar a necessidade de uma construção da política que parta de um entendimento muito mais profundo das especificidades do sistema de produção e inovação das escolas de samba, uma construção de "baixo para cima".

Assim, na segunda rodada de especificação das necessidades e de identificação de iniciativas concretas, provou-se ser necessário recorrer a outras esferas, além das experiências e rotinas das organizações de política. Uma alternativa habitual para as organizações de política é a mobilização de especialistas externos, frequentemente pesquisadores de universidades ou de empresas de consultoria que realizam pesquisas na área e/ou já possuem algum nível de conhecimento sobre o setor ou campo tecnológico. Eventualmente, estes especialistas realizam entrevistas, organizam oficinas ou utilizam outras metodologias para captar a opinião dos potenciais beneficiários. Este tenderia a ser também o caso aqui. Em um primeiro momento, a iniciativa do MCTI e suas organizações subordinadas foi de mobilizar exclusivamente o grupo de pesquisa da Universidade

1 No espanhol "Tómelo o déjelo". 
Federal do Rio de Janeiro. Mais uma vez, foi o poder e a influência dos representantes das escolas de samba que levaram ao entendimento de que uma nova configuração de grupo de pesquisa teria que ser estabelecida. Isto levou à criação deste grupo único, composto por acadêmicos e profissionais das escolas de samba e organizações da sociedade civil que trabalham no âmbito do Carnaval.

Após a detalhada avaliação dos desafios e das oportunidades para as escolas de samba e passando por várias rodadas de apresentação e discussão, chega-se a uma segunda proposta de política, caracterizada como uma construção "de baixo para cima" que detalha atores políticos concretos e as iniciativas a cargo destes. A implementação desta proposta necessariamente dependia da disponibilidade de recursos e da capacidade política de mobilização de diferentes esferas do governo para trabalharem em conjunto. É neste momento que entra em cena a terceira força descrita no esquema abaixo. As mudanças nas posições de liderança dentro do MCTI, que era a organização disposta a mobilizar recursos e parceiros, poderia levar à perda de todo o esforço (seta vermelha no esquema). Mas, mais uma vez a capacidade de mobilização da LIESA revelou-se essencial para a mobilização de novos interlocutores na esfera pública, o Ministério da Cultura, de forma a dar continuidade ao processo. Mesmo que a política para APLs se proponha a ser uma construção de baixo para cima, interesses políticos sempre desempenham um papel. Assim, esse Ministério, enquanto parceiro central que poderia mobilizar recursos para a implementação da política, fez questão de dar seu toque à proposta, o que significou passar por novas rodadas de discussão e adaptação. Este processo moroso acabou por ser interrompido por causa de novos 'choques exógenos', as mudanças no ambiente político-institucional relacionadas com a crise política brasileira.

Figura 3. 0 processo de diálogo as principais forces que influenciam o processo

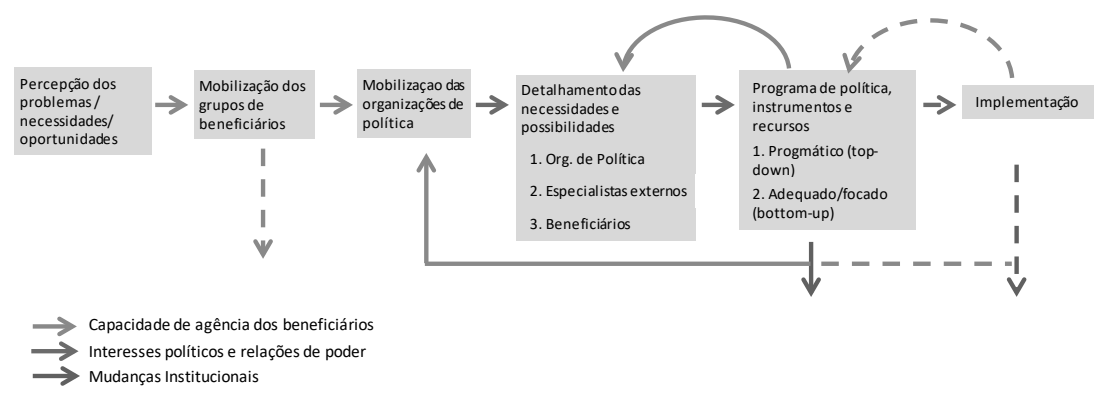

Fonte: elaboração própria. 
$\mathrm{O}$ esquema na figura também descreve as possíveis fases subsequentes, as quais não se chegou na presente experiência, nomeadamente a implementação das políticas. Como mostrou a interrupção do processo, alcançar esta fase também dependeria predominantemente das formas de atendimento de interesses políticos. Como observado em diversas experiências de políticas para APLs, a fase de implementação também pode apontar para a necessidade de se dar um passo para trás, na medida em que os resultados intermédios e obstáculos apontem para a necessidade de reformular as propostas de política e os instrumentos. Outras experiências também apontam para o risco de alterações nas configurações institucionais levarem à interrupção das iniciativas já em sua fase de implantação. Também neste caso, a capacidade de agência dos beneficiários, em uma lógica "de baixo para cima" de construção do diálogo, tende a ser crucial para a mobilização de novas fontes de recursos e parceiros.

\section{CONCLUSÕES}

Uma das conclusões do estudo realizado remete às conclusões gerais resultantes das análises sobre as políticas para APLs e de desenvolvimento implementadas no Brasil e no mundo. De fato, após duas décadas de esforços de concepção e implementação de políticas com o foco de APLs, observa-se que grandes avanços foram feitos e também que há significativo espaço para avanços. Uma importante limitação está relacionada com o uso de modelos baseados nos países mais desenvolvidos e suas organizações (baseadas na concepção de benchmarking), os quais dificilmente são aplicáveis à realidade de países em desenvolvimento e às especificidades de cada território. Uma vez implementados, os requerimentos postos por estes modelos não são cumpridos e se desdobra em um conjunto de críticas a estes atores locais, uma vez que 'seu comportamento não obedece ao padrão definido pelo modelo'. Em vez de reconhecer que o modelo está errado e que formas mais adequadas de promoção destes atores deveriam ser perseguidas, os beneficiários são culpados pelo insucesso da política. Este esforço de impor uma adequação, sem levar em consideração as especificidades, impõe aos atores locais um espécie de "Leito de Procusto" (Lastres, Arroio e Lemos). ${ }^{2}$

Tais conclusões mais gerais indicam também que não raro, os ministérios e agências governamentais específicas assumem uma posição de liderança como interlocutor com os agentes locais em um

2 Na mitologia grega, Procusto era um ferreiro e bandido de Attica, que atacava fisicamente as pessoas, esticando elas ou cortando suas pernas, de forma que coubessem exatamente em uma cama de ferro (Lastres et al 2003). 
APL e mobilizam os seus instrumentos de apoio usuais, sem considerar a interação potencial com outras esferas de ação política. As experiências nas quais se pode observar uma efetiva convergência de políticas estão associadas a impactos muito mais expressivos (Matos et al., 2015). Como discutido acima, tal aspecto também teve importância central para o caso analisado.

Acima de tudo, o caso em foco realça como o processo de diálogo para a construção de uma política de CTI para o sistema produtivo e inovativo do Carnaval das escolas de samba foi capaz de lidar com estes e outros desafios gerais inerentes à política brasileira para APLs e ainda fornece muitos aprendizados interessantes.

Em primeiro lugar, vale destacar as características específicas dos atores envolvidos, o que confere ao caso contornos distintos ao usual escopo das políticas de CTI (Goñi et al., 2015). Em vez de um conjunto diversificado de empresas de diferentes segmentos, este caso tem como atores centrais do sistema organizações culturais, que não possuem fins lucrativos, mas que mobilizam uma ampla e complexa rede de valor. Além disso, os atores políticos não se limitam àqueles associados às áreas de indústria, CTI e competitividade. As esferas da política cultural e social também possuem um papel central. Desta forma, esta experiência põe frente a frente atores que possuem quase nenhuma experiência de trabalhar em conjunto. Estes enfrentam o desafio de encontrar uma linguagem comum e a compreensão sobre o alcance e os possíveis meios para colaborarem. Finalmente, um grupo de pesquisa diversificado é convidado a desempenhar um papel central como interlocutor e mobilizador do diálogo. Este grupo é formado por pesquisadores na temática de desenvolvimento local e APLs de universidades públicas e profissionais vinculados às escolas de samba. Ele exerceu um papel crucial de duas maneiras:

- Foi decisivo para diminuir a brecha cognitiva entre a comunidade de beneficiários das escolas de samba e as organizações públicas (ver capítulo teórico). O não acolhimento da proposta de CVT da FAETEC constitui um desdobramento do grande desafio que constitui a comunicação entre estas 'tribos';

- Foi crucial para acessar as principais partes interessadas e informações críticas, a participação de atores da comunidade beneficiária como parte da equipe que conduziu a avaliação detalhada. Relações dentro da esfera das organizações culturais tendem a ser bastante informais e fortemente baseadas no contato pessoal e na confiança. 
Em segundo lugar, encontramos uma interação muito interessante e complexa entre orientações de construção de políticas do tipo 'de baixo para cima' (bottom-up) e de 'cima para baixo' (top-down) (Alvarez et al., 2016). Mesmo que se reconheça a especificidade e o papel central dos atores locais, em termos práticos as políticas para APLs revelam experiências diversas, que vão desde esforços essencialmente impulsionados a partir do território local até a implementação de planos complexos trazidos por organizações nacionais e internacionais. Neste segundo caso, muitas vezes as propostas são guiadas por uma lógica de benchmark focando em distritos industriais e clusters do mundo desenvolvido e se conectam diretamente com o padrão usual de ação dos órgãos políticos em questão.

Ao longo da experiência analisada neste trabalho, diferentes fases podem ser observadas. Passa-se de iniciativas voluntariosas 'de cima para baixo' para uma reformulação destas a partir de uma lógica de construção coletiva e consensual. Como descrito acima, na medida em que se alteram as configurações institucionais, os interesses políticos também mudam, o que pode levar ao maior ou menor favorecimento de certos tipos de políticas. Assim, a capacidade de mobilização e coordenação dos beneficiários é essencial para se contrapor à tendência de construção de políticas do tipo top-down e à captura por interesses políticos.

Não raro, para que demandas específicas conquistem espaço na agenda política, uma forte capacidade dos grupos demandantes de se organizarem e exercerem lobby junto a altas esferas do poder público é essencial. A experiência em tela demonstra como que todo o diálogo só se iniciou por conta da capacidade das associações das escolas de samba de organizarem um pleito consensual e levá-lo diretamente à Comissão de Cultura da Câmara dos Deputados. O diálogo também evoluiu e passou por diferentes fases e loops para trás graças à capacidade destas associações de mobilizarem a continuamente as diferentes comunidades envolvidas.

Em terceiro lugar, coloca-se a questão relacionada ao tempo. A análise realizada mostra que a intensidade e a velocidade com que os diálogos se traduzem em iniciativas efetivas variam, dependendo de uma série de fatores. O mais importante se refere à capacidade de mobilização/coordenação dos grupos de interesse e a existência de uma organização com disponibilidade de recursos e capacidade de mobilizar as demais. Contudo, o interesse desta organização pode variar consideravelmente, na medida em que ocorram mudanças em posições de liderança e outras devidas às variações dos arranjos políticos.

O caso examinado dos APLs do Carnaval, no período considerado, mostra como o papel protagonista passa do Ministério da Ciência, 
Tecnologia e Inovação para o Ministério da Cultura, realçando a necessidade de aprofundar a compreensão da dinâmica, desafios e oportunidades para o desenvolvimento destes APLs culturais. Tal necessidade e as mudanças políticas ocorridas contribuíram para que a fase de diálogo para a construção da política tomasse muito tempo, não tendo sido ainda concluída. Isso leva à conclusão de que o sucesso do diálogo, capaz de levar à construção e implementação de políticas eficazes, está também ligado à questão de timing. Nesse sentido, a experiência analisada revelou acima de tudo, as especificidades do processo de escolha entre (i) a opção de aproveitar (em certa medida) as iniciativas pré-formatada oferecidas pelo MCTI e seus parceiros; e (ii) a opção de tomar o tempo necessário para a construção de uma política mais adequada, mesmo que correndo o risco de perder essa "janela de oportunidade institucional".

De toda forma, a discussão realizada acima indica que o esforço de dar vida a uma política de Estado de CTI bem estruturada para a atividade cultural do Carnaval parece encontrar-se em uma espécie de "vale da morte do diálogo político". Isso decorre da necessidade de tempo e esforço para a construção de uma proposta detalhada e aderente às realidades dos territórios, seus agentes e atividades. Uma significativa massa crítica de conhecimento foi mobilizada e traduzida em propostas de políticas, as quais podem ser consideradas como resultado formal do diálogo. Mas para que se chegue a resultados práticos, a implementação das ações propostas, o papel de uma organização com a capacidade de mobilizar recursos parece estar ausente. Superar este 'vale' dependerá da capacidade de mobilização e representação e pressão dos beneficiários, apesar do risco de perda de confiança nas organizações de apoio e promoção, especialmente as governamentais.

\section{BIBLIOGRAFIA}

Albagli, S.; Maciel, M. L. 2003 "Capital social e empreendedorismo local” em Lastres, H. M. M., Cassiolato, J. E.; Maciel, M. L. Pequena empresa: cooperação e desenvolvimento local (Rio de Janeiro: Relume Dumará).

Álvarez, I.; Barletta, F.; Suarez, D.; Yoguel, G. 2016 “Marco analítico para la tipificación de diálogos para las políticas de CTI" en Working paper (Red CYTED COM-LALICS) $\mathrm{N}^{\circ}$ 3. En <http:// lalics.org/images/CYTED/DT3-DimensionesDialogo.pdf> acceso 15 de abril de 2017.

Araújo, P. Q. 2002 "Escolas de samba e relações de trabalho: entre a passarela e o barracão" en Earp, F. S. (org.) Pão e circo: fronteiras e perspectivas da economia do entretenimento (Rio de Janeiro: Palavra e Imagem) pp. 165-207. 
Arocena, R.; Sutz, J. 2003 "Learning divides, social capital and the roles of universities" (Rio de Janeiro: 1st Globelics Conference).

Barboza, L. 2016 "Algunas consideraciones en torno al concepto de comunidad" en Working paper (Red CYTED COM-LALICS) $\mathrm{N}^{\circ} 6$. En $<$ http://lalics.org/images/CYTED/DT6-DefinicionComunidad. pdf.> acceso 15 de abril de 2017.

Bourdieu, P. 1987 "What makes a social class?” en Berkeley Journal of Sociology (Berkeley: Universidad de California) $\mathrm{N}^{\circ} 22$, pp. 1 - 18.

Bourdieu, P. 1989 O poder simbólico (Lisboa/Rio de Janeiro: Bertrand).

Britto, J. 2000 Características estruturais dos clusters industriais na economia brasileira. Projeto de pesquisa Arranjos e Sistemas Produtivos Locais e as Novas Politicas de Desenvolvimento Industrial e Tecnológico. Relatório de pesquisa (Rio de Janeiro: Instituto de Economia/UFRJ).

Britto, J.; Albuquerque, E. M. 2000 "Clusters industriais na economia brasileira: uma análise exploratória a partir dos dados da RAIS" en Encontro Nacional de Economia (Campinas: ANPEC) $\mathrm{N}^{\circ} 28$.

Cassiolato, J. E.; Lastres, H. M. M.; Maciel, M. L. (eds) 2003 Systems of innovation and development: evidence from Brazil (Cheltenham: Elgar).

Cassiolato, J. E.; Maciel, M. L. (orgs) 2003 Pequena empresa, cooperação e desenvolvimento local (Rio de Janeiro: Relume Dumará).

Cassiolato, J. E.; Matos, M. P.; Lastres, H. M. M. 2008 Arranjos produtivos locais: uma alternativa para o desenvolvimento: criatividade e cultura (Rio de Janeiro: E-Papers) vol. 1.

Castillo, M. A.; Arenhardt, M. M.; Le Bourlegat, C. A. 2009 "Cultura e identidade: os desafios para o desenvolvimento local no assentamento Aroeira, Chapadão do Sul, MS" en Interações (Campo Grande: Universidade Católica Dom Bosco) N 10 (2), pp. 159-169.

Dosi, G.; Freeman, C.; Nelson R.; Silverberg, G.; Soete, L. (eds) 1988 Technical change and Economic Theory (London: Pinter Publishers) pp. 349-69.

Dutrénit, G.; Álvarez, I.; Ardanche, M.; Barletta, F.; Bianco, M.; Cortés, R.; Cummings, A.; de la Vega, I.; Díaz, I.; Fernández, O.; Gómez, V.; Goñi, M.; Natera, J.M.; Nupia, C.; Orozo, J.; Prada, F.; Puchet, M.; Romero, F.; Simón, L.; Suárez, D.; Suárez, M.; Sutz, J.; Vera-Cruz, A. O. 2016 "Matriz de Información para el mapeo de procesos de diálogo de CTI en España, América Latina y el Caribe" en Working paper (Red CYTED COM-LALICS) $\mathrm{N}^{\circ}$ 5. En $<$ http://lalics.org/images/CYTED/DT5-Formulario2.pdf> acceso 15 de abril de 2017. 
Dutrénit, G.; Natera, J. M.; Suárez, M. 2014 "Lineamientos para la caracterización de las Comunidades y sus Procesos de Diálogo" en Working paper (Red CYTED COM-LALICS) $\mathrm{N}^{\circ} 1$. En <http:// lalics.org/images/CYTED/DT1-ComunidadesDialogo\%201.pdf> acceso 15 de abril de 2017.

Dutrénit, G.; Natera, J. M.; Puchet Anyul, M. O.; Vera-Cruz, A.; Torres, A. 2017 "Dialogue processes on STI policy-making in Latin America and the Caribbean: dimensions and conditions", en Science and Public Policy, 1-16. En <doi: 10.1093/scipol/ scx044>.

Dutrénit, G.; Sutz, J. (ed.) 2013 Sistemas de Innovación para un desarrollo inclusivo: la experiencia latinoamericana (México: Foro Consultivo Cientifico y Tecnológico, A.C).

Freeman, C. 1988 "Japan: a new National System of Innovation?" en Dosi, G.; Freeman, C.; Nelson R.; Silverberg, G.; L. Soete (eds.) Technical change and Economic Theory (London: Pinter Publishers) pp. 349-69.

Freeman, C. 2003 (1982) "Technonological infrastructure and international competitiveness" (Rio de Janeiro: The First Globelics Conference "Innovation Systems and Development Strategies for the Third Millennium").

Freeman, C. 1987 Technology policy and economic performance (London: Pinter).

Freeman, C. 1995 “The 'national system of innovation' in historical perspective" en Journal of Economics (Cambridge: Oxford University Press) $\mathrm{N}^{\circ} 19$.

Furtado, C. 1961 Development and Underdevelopment. Drysdale (Los Angeles: University of California Press).

Goñi, M.; Andarche, M.; Bianco, M.; Puchet, M. 2015

"Caracterización de lãs condiciones de los procesos de diálogo: confianza, conflicto, relaciones de Poder" en Documento de Trabalho (Rede CYTED COM-LALICS) $\mathrm{N}^{\circ} 7$.

Goñi, M.; Bianco, M.; Puchet, M. 2015 "Elementos para caracterizar los procesos de diálogo en políticas de CTI" em Working paper (Red CYTED COM-LALICS) $\mathrm{N}^{\circ}$ 7. En <http://lalics.org/images/ CYTED/DT7-ConfianzaPoder.pdf> acceso 15 de abril de 2017.

Johnson, B.; Lundvall, B-Å. 2003 "Promoting innovation systems as a response to the globalizing learning economy" en Cassiolato, J. E.; Lastres, H. M. M.; Maciel, M. L. (eds.) Systems of innovation and development: evidence from Brazil (Cheltenham: Elgar).

Katz, J. (coord.) 1996 National innovation systems in Latin America (Mimeo. ECLAC) 
Lastres, H. M. M.; Cassiolato, J. E.; Maciel, M. L. 2003 Pequena empresa: cooperação e desenvolvimento local (Rio de Janeiro: Relume Dumará).

Lastres, H. M. M.; Cassiolato, J. 2006 Estratégias para o desenvolvimento: um enfoque sobre arranjos produtivos locais do Norte, Nordeste e Centro-Oeste Brasileiros (Rio de Janeiro: E-Papers).

Lastres, H. M. M.; Cassiolato, J. E.; Lemos, C. R.; Maldonado, J. E.; Vargas, M. A. 1999 "Globalização e inovação localizada" em Cassiolato, J. E.; Lastres, H. M. M. (ed.) Globalização e inovação localizada: experiências de sistemas locais no âmbito do Mercosul (Brasília: IBICT/MCT) pp. 39-71.

Lima, V. R.; Marinho, M.; Brand, A. 2007 "História, identidade e desenvolvimento local: questões e conceitos" em História \& Perspectivas $\mathrm{N}^{\circ} 36-37$, pp. 363-388.

List, F. 1841 Das Nationale System der Politischen Ökonomie (Basel: Kyklos) en Longmans, Green and Co (trad.) 1841 The National System of Political Economy (Londres).

Lopez, A.; Lugones, G. 1999 "Los sistemas locales en el escenario de la globalización" en Globalização e inovação localizada (Brasilia: IBICT/MCT).

Lundvall, B.-Å. 1985 Product Innovation and User-Producer Interaction (Aalborg: Aalborg University Press).

Lundvall, B-Å. (ed.) 1992 National innovation systems: towards a theory of innovation and interactive learning (London: Pinter).

Matos, M. P. 2007 O sistema produtivo e inovativo local do Carnaval carioca. Dissertação de Mestrado em Economia. Programa de Pós-Graduação em Economia, Universidade Federal Fluminense, Niterói.

Matos, M.; Borin, E.; Cassiolato, J. (eds.) 2015 Políticas estratégicas de inovação e mudança estrutural: Uma década de evolução dos Arranjos Produtivos Locais (Rio de Janeiro: E-papers).

Myrdal, G. 1958 Value in Social Theory: A Selection of Essays on Methodology (London: Routledge and Keegan Paul).

Nelson, R. R.; Winter, S. G. 1982 An evolutionary theory of economic change (Cambridge: Harvard University Press).

Nelson, R.R. (ed.) 1992 National Innovation Systems: A Comparative Study (Oxford: Oxford University Press).

Nupia, C.; Martínez, A. 2015 "Revisión de metodologías de procesos de diálogo" em Working paper (Red CYTED COM-LALICS) $\mathrm{N}^{\circ} 4$. En <http://lalics.org/images/CYTED/DT4-MetodologiasDialogo. pdf $>$ acceso 15 de abril de 2017. 
Prebisch, R. 1949 "Problemas teóricos e práticos do crescimento econômico" en Bielschowsky, R. 2000 (ed.) Cinqüenta anos de pensamento na CEPAL (Rio de Janeiro: Editora Record).

Raffestin, C. 1993 Por uma geografia do poder (São Paulo: Ática). Trad. Maria Cecília França.

Reinert, E.; Reinert, S. 2003 “Innovation systems of the past: modern nations - states in a historical perspective: the role of innovation and of systemic effects in economic thought" (Rio de Janeiro: Rio De Janeiro Globelics Conference). En <www.globelics.org>.

Santos, M. 1996 A natureza do espaço: técnica e tempo, razão e emoção (São Paulo: Hucitec).

Santos, M. 2000 Por uma outra globalização - do pensamento único à consciência universal (São Paulo: Record).

Schumpeter, J. A. 1984 (1942) Capitalismo, socialismo e democracia (Rio de Janeiro: Zahar).

Singer, H. 1950 "The Distribution of Gains between Investing and Borrowing Countries" en American Economic Review (Londres: Palgrave Macmillan) $\mathrm{N}^{\circ} 50$.

Soares, C.; Prestes Filho, L. C. 2013 Plano Estratégico da Escola de Carnaval (Rio de Janeiro). 


\title{
DIÁLOGO PARA LA POLÍTICA CTI EN EL SECTOR DE SOFTWARE EN ARGENTINA
}

\section{ORÍGENES, EVOLUCIÓN Y DESAFÍOS DEL FONSFOT COMO HERRAMIENTA DE PROMOCIÓN SECTORIAL}

\author{
Florencia Barletta, Diana Suárez y Gabriel Yoguel*
}

\section{INTRODUCCIÓN}

El sector de Software y Servicios Informáticos (SSI) se encuentra dentro de las industrias denominadas "intensivas en conocimiento". Es un sector con una alta demanda de recursos humanos calificados, con el potencial de producir bienes y servicios de alto valor agregado y con la capacidad de incrementar el contenido tecnológico del resto de los bienes y servicios que conforman la estructura productiva. En la Unión Europea, por ejemplo, más de un tercio del empleo de SSI corresponde a personal con educación universitaria (Eurostat, 2013). En los países de la OECD, el nivel de gasto en investigación y desarrollo (I+D) del sector es superior al $6 \%$ del valor agregado bruto (Galindo-Rueda y Verger, 2016), equivalente al de las industrias de media-alta y alta intensidad tecnológica. En términos de la demanda, se trata de un sector dinámico con tasas de crecimiento mundiales que entre 1995 y 2014 se ubicaron en torno al 18\% promedio anual para las industrias de los servicios de computación e información (WTO, 2015). En este escenario, aunque América Latina

* Centro Interdisciplinario de Estudios en Ciencia, Tecnología e Innovación (CIECTI) Instituto de Industria - Universidad Nacional de General Sarmiento (IdeI-UNGS) 
representa alrededor del $1 \%$ en el mercado mundial, algunos países de la región, como Argentina, Brasil y Uruguay, muestran tasas de crecimiento superiores al promedio, con fuentes de competitividad, tales como los recursos humanos calificados, que dan cuenta de la potencialidad del sector como disparador de procesos de agregación de valor en las exportaciones y la atracción de inversiones externas (López et al., 2009).

En Argentina, el sector se inicia a la par de su desarrollo en el plano internacional, registrándose empresas de SSI ya en la década de 1960, y supo sobrevivir a los vaivenes económicos que caracterizaron la dinámica del país durante la última mitad del siglo pasado. No obstante, hacia fines de los años noventa y principios del año 2000, en un escenario macroeconómico adverso y con una demanda local deprimida, las limitaciones al crecimiento eran evidentes. La posición periférica del sector en términos de infraestructura de soporte y esquemas de promoción industrial lo colocaban en desventaja, tanto respecto de otros sectores productivos como de sus pares en el resto del mundo. En este contexto emerge un diálogo político hacia fines de los años noventa, que se consolida con la constitución del Foro de Competitividad SSI, creado en el marco de una política más amplia orientada a pensar la promoción industrial en una serie de sectores estratégicos. A más de 10 años de esta iniciativa, el sector de SSI ya no ocupa un lugar marginal en la economía argentina debido a que ha venido creciendo, en términos de empleo, empresas y exportaciones, a tasas muy superiores que el promedio de la industria. Es en este marco que nos preguntamos de qué manera la política de ciencia, tecnología e innovación (CTI) acompañó esta trayectoria y contribuyó a la consolidación de una masa crítica empresarial.

El objetivo de este capítulo es analizar el proceso de diálogo para la política de CTI en el sector de SSI. Las motivaciones son, en primer lugar, estudiar y sistematizar las características del diálogo (en términos de organización, equilibrios y asimetrías de poder entre las comunidades involucradas, forma de implementación, etc.) que condujeron al diseño de una política específica de promoción del sector, como fue la creación de este Fondo Fiduciario de Promoción de la Industria del Software (FONSOFT). En segundo lugar, nos preguntamos en qué medida la evolución del fondo respondió a la trayectoria del sector y qué desafíos se plantean para la política sectorial luego de más de una década de promoción.

El análisis del proceso de diálogo reveló que, en sus orígenes, la existencia de niveles homogéneos de capacidades, la ausencia de grupos hegemónicos y el compromiso de actores clave de cada una 
de las comunidades permitió el desarrollo de un espacio plural de interacción, en el cual las necesidades sectoriales se impusieron por encima de las agendas particulares de los actores. Ello dio lugar a recomendaciones de política específicas, que se tradujeron en 2004 en leyes de promoción y fondos de apoyo a la innovación y la generación de capacidades, el FONSOFT entre ellos. Esta herramienta de promoción de la innovación fue guiada inicialmente por una política de "multiplicación de semillas" que se manifestó en la orientación del financiamiento hacia la creación de empresas. No obstante, el análisis del sector de SSI ("objeto" del diálogo) en la actualidad revela que, de cara a los nuevos desafíos tecnológicos y comerciales, el FONSOFT parecería ya no ser relevante para dar respuesta a las necesidades de un sector que se ha expandido significativamente, dentro del cual se fueron conformando múltiples segmentos de actividad con intereses divergentes. En este contexto, la evolución del sector muestra signos de la necesidad de un nuevo proceso de diálogo, ahora más complejo, dada la multiplicidad de dinámicas empresarias al interior del sector .

La metodología consistió en un estudio de caso, siguiendo los lineamientos tradicionales de la literatura (Yin, 2009). Asimismo, el análisis realizado forma parte de las actividades desarrolladas por la "Red temática para mejorar el diálogo entre las comunidades involucradas en las políticas de CTI (COM-LALICS)", financiada por CYTED durante el período 2014-2016. El objetivo de esta red, integrada por equipos de investigación de Argentina, Brasil, Chile, Colombia, Costa Rica, Cuba, El Salvador, España, México, Perú, República Dominicana, Uruguay y Venezuela, es sistematizar y analizar experiencias de diálogos para la política CTI, con vistas a identificar lineamientos que permitan conducir procesos exitosos de diálogo. Las instancias de presentación, discusión y puesta en conjunto de los procesos de diálogo estudiados en los distintos países miembro de la red, permitieron avanzar en la producción de documentos de trabajo de naturaleza metodológica, a partir de los cuales se analizó el caso que ocupa este capítulo, y que nutre el objetivo final de la red, a saber, el desarrollo de lineamientos para la promoción de diálogos para la CTI (Dutrénit et al., 2014).

En consecuencia, en primer lugar se buscó reconstruir la historia del FONSOFT a fin de caracterizar el proceso en términos del poder relativo de cada uno de los actores y comunidades involucradas, la existencia de actores con capacidad de imposición y/o de bloqueo y el nivel de flexibilidad para incorporar las sugerencias de rumbo resultantes del diálogo (Barboza, 2016; Goñi et al., 2015). Esta actividad incluyó la revisión de los documentos oficiales del FONSOFT 
(memorias, bases de convocatorias, informes de gestión y bases de datos de beneficiarios). Asimismo, se realizaron entrevistas a interlocutores clave provenientes de la comunidad académica, del sector público y del sector empresarial. Siguiendo la propuesta de Dutrénit et al. (2016), la sistematización de la información tuvo como eje indagar sobre la evolución de las posiciones de las tres comunidades antes y durante el proceso de diálogo, los hitos del proceso, los aprendizajes para nuevos procesos de diálogo y los nuevos desafíos para la promoción de la CTI desde una perspectiva de comunidades. El análisis posterior dio lugar a la tipificación del diálogo en términos de su origen, organización y resultados (Álvarez et al., 2016). Finalmente, la revisión de estudios más recientes de evaluación del FONSOFT (Barletta et al., 2013b; Baum et al., 2009; Motta et al., 2016; Pereira et al., 2016), así como el análisis directo de sus resultados en términos de promoción a nivel de la firma permitió identificar nuevos desafíos para la política CTI y cada una de las comunidades.

El capítulo se estructura de la siguiente forma. Luego de esta introducción, en la sección 2 se caracteriza el diálogo para la política CTI en el sector SSI en términos de su origen, organización y resultados, con eje en la creación de FONSFOT. A continuación, en la sección 3 , se propone un análisis en etapas que combina el estudio del FONSOFT en términos de la evolución de sus instrumentos y beneficiarios con la descripción de las características que se fueron configurando en el sector en cada período. En la sección 4 se presentan algunas conclusiones sobre la coherencia o divergencia entre la evolución de los instrumentos, la configuración actual del sector y las demandas y necesidades de promoción en CTI.

\section{CARACTERIZACIÓN DEL DIÁLOGO}

\subsection{ORIGEN}

\subsubsection{EL SECTOR DE SOFTWARE Y SERVICIOS INFORMÁTICOS \\ EN ARGENTINA}

El surgimiento de la informática en Argentina fue relativamente contemporáneo a su surgimiento a nivel mundial. Esto contribuyó a que, a la par de los avances internacionales, se generaran capacidades científicas y tecnológicas en informática en forma temprana en el país y la región y a la par de los avances internacionales. Por ejemplo, el Instituto de Cálculo de la Facultad de Ciencias Exactas de la UBA, a través de los proyectos llevados a cabo por Manuel Sadosky, adquirió su primera computadora científica (primera de Latinoamérica) en 1962 y una de las 19 unidades en todo el mundo. Esto 
dio lugar a un largo proceso de experimentación y de aprendizaje en las ciencias computacionales y en la electrónica (Erbes et al., 2004).

Desde la perspectiva privada, los primeros desarrollos de la actividad surgieron de la mano de los departamentos de sistemas de información de las grandes empresas extranjeras y algunos grupos económicos nacionales que realizaban desarrollos in-house. En paralelo, durante las décadas del sesenta y setenta se registraron algunos experimentos de empresas electrónicas con relativo éxito, tales como la experiencia de Fate en la producción de calculadoras, y la producción de impresoras por parte de IBM. Sin embargo, estas experiencias fueron de corto aliento porque los procesos de desindustrialización y crisis económica que marcarían las décadas siguientes frenaron el desarrollo. En ese marco se generó además una fuerte emigración de recursos humanos altamente calificados, lo que se agudizó durante la última dictadura militar a mediados de los setenta.

En materia de software específicamente, durante la década de los ochenta surgieron las primeras empresas desarrolladoras y prestadoras de servicios informáticos, que contabilizaban alrededor de 300 y abastecían al 30\% del mercado local, mientras el $70 \%$ restante era cubierto por importaciones (SECYT, 1987). En el plano las políticas de ciencia y tecnología (CyT), la experiencia de cooperación internacional latinoamericana para la formación de informática (la Escuela Latinoamericana de Informática - ESLAI) alimentaba la formación de capacidades, nuevamente, con el impulso emblemático de Manuel Sadosky.

Aunque, durante la década de 1990, muchas de estas trayectorias se vieron severamente afectadas por el proceso de apertura y achicamiento del Estado, la trayectoria previa fue generando un sentido de pertenencia dentro de la actividad que se desplazaba de la universidad (en la Argentina y el exterior) al sector privado. A la vez, estas mismas políticas de reestructuración del Estado y privatización de empresas de servicios públicos junto a un tipo de cambio bajo y la expansión del sector financiero favorecieron la incorporación de tecnologías de la información por parte de grandes usuarios TIC, lo que paradójicamente permitió la expansión de la actividad informática focalizada en la provisión de servicios que no podía cubrir la oferta extranjera por el alto grado de especificidad. Así, durante esta década, el sector se expandió en términos de ventas y empleo (alrededor del $40 \%$ ), aunque con una fuerte orientación hacia el mercado doméstico (Chudnovsky \& López, 2002).

Hacia fines de los noventa, con el fin de las privatizaciones, la demanda doméstica disminuyó significativamente y el sector de SSI se 
encontró en un escenario de oferta (de alta gama) excedente. En este contexto, empieza a emerger una toma de conciencia sectorial sobre la necesidad de pensar en forma conjunta las alternativas del sector frente al nuevo panorama, que terminó en la profunda crisis económica argentina de principios de siglo. Se fue generando así un grupo de referentes del sector que coincidían en la necesidad de buscar nuevo financiamiento, generar recursos humanos y abrir nuevos mercados ante la caída de la demanda interna, lo que significaba un importante desafío debido a la falta de experiencia en los mercados externos de las empresas locales y al escaso desarrollo del sector. No obstante, el sector dio una respuesta favorable a las nuevas condiciones domésticas que se conjugaron con una creciente internacionalización de la actividad a partir de la proliferación del outsourcing a nivel global. En este nuevo contexto, entre 2003 y 2010 la actividad se expandió nuevamente, con incrementos cercanos al $17 \%$ anual en ventas y empleo (vs. el 3\% registrado en la industria manufacturera), pero esta vez, con una fuerte vocación exportadora, que alcanzó un incremento del 20\% anual (Barletta et al., 2013a).

\subsubsection{LA INSTITUCIONALIZACIÓN DEL DIÁLOGO.}

En una mirada retrospectiva, el diálogo para una política pública de CTI para el sector de software en la Argentina comienza informalmente en los últimos años de la década del noventa y se institucionaliza en 2003, con la creación de los foros de competitividad por parte de la Secretaría de Industria de la Nación (Ministerio de Producción). En este sentido, el diálogo se inicia desde una convocatoria de tipo top-down aunque rápidamente el involucramiento activo de los diferentes actores y comunidades en general lo convirtieron en un proceso de tipo bottom-up (Álvarez et al., 2016), en el sentido que son las comunidades académica y empresarial que, en consonancia con las voluntades políticas, impulsan un proceso proactivo de diagnóstico sectorial y propuesta de política pública de promoción industrial y de innovación.

En relación a las voluntades de la comunidad del sector público, luego de la crisis de 2001, y después de más de tres años de estancamiento económico, se verificaron importantes cambios en la política económica argentina. Por un lado, la salida de la Convertibilidad y la devaluación dieron lugar a una política de tipo de cambio competitivo que generó incentivos para la búsqueda de estrategias exportadoras. Por otro lado, se produjo un cambio en la concepción de las políticas de competitividad, que pasaron de estar basadas en instrumentos horizontales a promover algunas estrategias de intervención sectorial. En este marco se encuadra la creación de los nueve foros 
de competitividad con el objetivo de realizar un diagnóstico sectorial y contribuir al diseño de instrumentos públicos de promoción: Madera y Muebles, Cuero y sus Manufacturas, Textil e Indumentaria, Maquinaria Agrícola, Industrias de Base Cultural, Industrias de Gas Vehicular, Industrias de Base Biotecnológica, Industrias de Materiales para la Construcción Civil y Software y Servicios Informáticos (SSI). En este último convergieron las diferentes instituciones de CyT y empresas que se habían ido desarrollando durante las décadas previas.

En ese contexto, el Foro de Competitividad SSI fue el primer ámbito explícito de discusión público-privado para la articulación de una estrategia de desarrollo y definición de una política sectorial. Entre los principales retos (Dutrénit et al., 2016) se destacaba la necesidad de establecer las bases a partir de las cuales se definiría el perfil de la industria. En este sentido, el sector SSI no formaba parte de tal categoría, lo que impedía a las empresas acceder a los beneficios promocionales existentes.

Un segundo reto se relacionó con la necesidad de establecer mecanismos que otorgaran estabilidad fiscal e incentivos a las empresas para la incorporación de personal. La legislación argentina, nacida a la luz de la industria manufacturera de la industrialización por sustitución de importaciones, resultaba poco adecuada para la expansión de un sector intensivo en la contratación de recursos humanos calificados.

El tercer desafío que se planteó fue el de generar instrumentos específicos para el desarrollo de capacidades (fomento de la I+D, formación de recursos humanos y calidad) acordes a las necesidades generadas por la expansión del sector. Al igual que en el caso de la política industrial, las firmas del sector quedaban excluidas de los instrumentos de la política de CTI, dados los requisitos de antigüedad y estructura.

También se planteó entre los retos del foro la generación de mecanismos que dinamizaran la inserción externa de las firmas del sector. Para ello, se buscó establecer criterios que abrieran posibilidades para la certificación de calidad, el desarrollo de misiones comerciales y especialmente, la instauración de una marca país en desarrollo de software.

Finalmente, en el plano nacional, el foro se propuso definir lineamientos estratégicos para la articulación con la demanda del sector público, así como también el fomento del desarrollo regional y local a partir de la creación de clústeres y polos de SSI.

La identificación de estos desafíos y el diseño de instrumentos específicos para levantar las restricciones existentes para el desarrollo del sector fueron los principales logros del foro. A lo largo de las reuniones, 
se lograron articular diferentes voces, intereses y agendas, así como, también, plantear puntos de tensión y desacuerdos existentes. El foro se constituyó en un espacio de debate con amplia participación de los principales stakeholders y la representación de todas las comunidades. En este sentido, un aspecto diferenciador del foro SSI respecto del resto de los foros fue la naturaleza de sus participantes en términos de capacidades y la existencia de facilitadores clave (Dutrénit et al., 2014), que permitieron avances en todos los frentes planteados. Otro elemento fue el hecho de que la comunicación entre los actores claves estuvo fundada en una comunidad preexistente que mantenía vínculos entre los referentes del sistema universitario y del sector privado.

\subsection{ORGANIZACIÓN}

\subsubsection{ACTORES Y COMUNIDADES}

Una característica distintiva de los foros de competitividad respecto a otros espacios de interacción impulsados desde la esfera pública, fue la búsqueda del involucramiento activo de los actores interesados en el desarrollo y promoción de cada sector. En el caso de SSI, se buscó reconocer no solo los avances realizados en el ámbito empresarial (a través de las principales cámaras del sector: la Cámara de Empresas de Software y Servicios Informáticos -CESSI- y la Cámara de Informática y Comunicaciones de la República Argentina -CICOMRA-) sino además involucrar a los principales grupos de investigación directa o indirectamente vinculados con SSI y a los nuevos espacios de creación, promoción y aplicación de conocimiento. En particular, los nuevos grupos de investigación provenientes de las ciencias sociales, los nuevos empresarios y las áreas de gobierno con intención de promover el sector tuvieron desde el comienzo del foro un involucramiento muy significativo. No participaron asociaciones gremiales de trabajadores informáticos, ya que por ese entonces la sindicalización de la actividad era prácticamente nula. No obstante, la voz de los profesionales de la actividad fue llevada a través de SADIO (Sociedad Argentina de Informática e Investigación Operativa) creada en los sesenta, que vincula a los profesionales de la actividad y promueve actividades de capacitación y diálogo entre sector privado y academia.

En términos generales, la comunidad académica estuvo representada por unas diez universidades nacionales y un gran número de centros orientados a la investigación básica y aplicada. Esto incluyó grupos de investigación en áreas afines a la informática, pero también científicos dedicados al análisis tecnológico, sectorial 
y de los estudios sociales de la ciencia. La comunidad empresarial estuvo representada por dos tipos de actores. Por un lado, las cámaras empresariales oficiaron de representantes de las empresas del sector. Por otro lado, se contó con la participación directa de firmas pequeñas, medianas y grandes. En términos del origen de capital, mientras que las empresas nacionales estaban interesadas en promover el sector, salvo algunas excepciones, la mayoría de las empresas multinacionales no mostraron mucho interés en tanto su actividad se centraba principalmente en la importación de soluciones estándar. Así, el impulso de las empresas nacionales fue decisivo para el proceso de diálogo. Por último, en relación a la comunidad del sector público, participaron activamente tres ministerios nacionales (Ministerio de Trabajo, Ministerio de Ciencia, Tecnología e Innovación Productiva y Ministerio de Industria). Otras organizaciones públicas involucradas en el diálogo fueron las agencias de promoción a nivel local y el Gobierno de la Ciudad de Buenos Aires. Finalmente, el Cluster Córdoba Technology, SADIO, la Fundación Vía Libre, el clúster tecnológico de Rosario y el Polo IT Buenos Aires formaron parte de la comunidad que puede denominarse sociedad civil. ${ }^{1}$

Así, el éxito en la participación y convocatoria del proceso de diálogo se explica no solo por haber logrado la participación de las instituciones más relevantes de la actividad, sino también porque los actores más comprometidos y con experiencia en las distintas dimensiones que hacen a la promoción asumieron el liderazgo del proceso. De esta forma, se consolidó un foro plural, que contó con la participación activa de todos los actores clave.

\subsubsection{LA DINÁMICA DE INTERACCIONES Y EL ROL DE LAS CAPACIDADES}

Una vez convocadas las comunidades a través de sus principales representantes, el liderazgo estuvo a cargo de los coordinadores del foro, los que se constituyeron en personal permanente bajo la modalidad de consultores (rentados) durante todo el proceso. Estos líderes fueron seleccionados entre actores reconocidos y respetados por las diferentes comunidades, especialmente, por su múltiple filiación. Acompañando el liderazgo, aparecieron también actores claves provenientes del mundo académico y empresarial que contribuyeron con una participación activa. Entre ellos vale destacar a Gabriel Baum, Alberto Briozzo, (ambos decisivos en materia de liderazgo) Silvia Bidart, Carlos Pallotti, Rosita Wachenchauzer, Esteban Feuersein, Vanesa Luchessi y Gabriel Yoguel.

1 La lista completa de participantes puede consultarse en MECON (2003). 
El lugar elegido para llevar adelante las actividades del foro fue la Cuidad de Buenos Aires, y tuvo como sede de los encuentros al Ministerio de Industria. No obstante, también se promovió la creación de Foros Locales en diferentes lugares del país dando una dimensión federal al proceso de diálogo. Desde la organización convocante, se decidió que el proceso sería auto-organizado, aunque con la salvedad de haber nombrado antes a los consultores líderes del proceso que oficiaban de traductores y facilitadores del diálogo. Dada esta selección, la metodología (Nupia y Martínez, 2015) se basó en la convocatoria a reuniones regulares, distinguiéndose entre reuniones plenarias, reuniones temáticas y foros regionales, que favorecieron un diálogo más ordenado y en el que los distintos actores de cada comunidad tuvieron voz. Las reuniones se extendieron a lo largo de varios meses, tras las cuales los coordinadores procuraron la compilación de memorias y la redacción de los documentos que servirían de insumo a los resultados finales del foro.

En términos de la gestión del diálogo, que el foro haya alcanzado una propuesta concreta de política, que se materializara en leyes y programas de promoción, se explica en parte por la existencia de coordinadores dedicados de manera exclusiva a la tarea, pero también porque los mismos eran reconocidos por las distintas comunidades. Se trató de actores que combinaban una amplia trayectoria en el sector público y la academia y el sector privado y la academia (de manera combinada), con conocimiento de los habitus de cada comunidad, lo que permitió además que oficiaran de moderadores, facilitadores y traductores de cada una de las voces participantes. Asimismo, fueron estos mismos actores quienes una vez que acordaron los objetivos con todas las comunidades interesadas, fueron capaces de pasar de manera ágil y rápida de reuniones globales multitudinarias a reuniones temáticas con un número reducido de personas, con capacidad de sintetizar las discusiones y realizar recomendaciones.

Otra característica que favoreció el éxito del foro en términos de los productos resultantes se relaciona con la naturaleza y motivaciones de los asistentes. En este caso, cada uno de los convocados supo aprovechar la oportunidad de diálogo, lo que ayudó a que las contradicciones que aparecían a lo largo del proceso fueran minimizadas para dar lugar a propuestas superadoras de las posiciones planteadas. Esto fue posible gracias a la existencia de un umbral mínimo y compartido de capacidades de los participantes, los que entendieron el foro como una oportunidad para el desarrollo sectorial.

Aunque en la narrativa histórica se observa el rol de las capacidades como un atributo clave del foro SSI, que lo distingue de los 
demás foros y que explica sus resultados, al momento de su realización, la diversidad de actores dentro de cada comunidad supuso el reto de articular diferentes voces, intereses y agendas para plantear tanto acuerdos como desacuerdos. Esto fue posible gracias a la existencia de facilitadores, generalmente referidos en la literatura como gatekeepers. Al respecto, así como existió un nivel elevado y homogéneo de capacidades entre los participantes, se verificó un elevado nivel de heterogeneidad intracomunidad, aunque sin la presencia de grupos de poder que pudieran imponer su agenda. Esta pluralidad también contribuyó a desarrollar un capital social que facilitó el intercambio y los flujos de información, recursos y oportunidades y ayudó a los actores a coordinar las interdependencias de las tareas críticas y a superar los dilemas de las acciones colectivas (Gargiulo y Benassi, 1999). Siguiendo las ideas evolucionistas de Noteboom et al. (2007), se podría pensar que las vinculaciones en el marco del foro dieron lugar a procesos de aprendizaje por interacción, que fueron posibles gracias a la existencia de una baja distancia cognitiva entre las comunidades involucradas.

Otro elemento que facilitó las interacciones, y que permitió minimizar las contradicciones que fueron apareciendo a lo largo del proceso y encontrar propuestas superadoras que incluyeran las diferentes posiciones, fue la naturaleza de red del sector y el hecho de tratarse de una actividad relativamente joven. Esto imprimió una dinámica ausente de grupos de poder hegemónicos, que impusieran sus intereses, incluso ante la presencia de grandes empresas transnacionales.

\subsection{RESULTADOS}

A partir de las reuniones y el trabajo en red del foro, se identificaron seis desafíos: i) definir el sector SSI como una industria, a fin de facilitar su acceso a los beneficios promocionales existentes; ii) desarrollar mecanismos para generar estabilidad fiscal e incentivos para las empresas intensivas en recursos humanos calificados; iii) definir programas de capacitación que permitan la expansión del sector; iv) generar instrumentos específicos para promover las actividades de I+D; v) crear mecanismos para mejorar el patrón de especialización comercial de las empresas; y vi) promover la creación de clústeres de SSI orientados a articular la demanda del sector público y fomentar el desarrollo regional.

Sobre la base de este diagnóstico, uno de los principales resultados del foro SSI fue la implementación de un plan estratégico a diez años con metas y actividades específicas que incluyeron un centro de investigación especializado (la Fundación Sadosky, creada en 2009) y el diseño y aprobación de dos leyes clave, que llevarían a la creación 
del FONSOFT. Por un lado, las actividades del foro llevaron a la sanción de la Ley 25.856, aprobada en 2004, que reconoció al sector SSI como industria. También en 2004, se sancionó la Ley 25.922 a partir de la cual se establecieron beneficios fiscales para las empresas SSI que exportaran, realizan inversiones en $\mathrm{I}+\mathrm{D}$ o contaran con certificaciones de calidad. Esta ley también incluyó la creación del FONSOFT bajo la órbita de la Agencia Nacional de Promoción Científica y Tecnológica (ANPCyT). El objetivo de este fondo sería (y es) fortalecer las actividades de producción de software a nivel nacional a través de incentivos fiscales, créditos subsidiados, aportes no reembolsables y becas de formación a empresas y empresarios interesados en crear negocios relacionados con software, crear y mejorar la calidad de sus productos y servicios.

Así, los resultados directos incluyeron la puesta en marcha de una ley de promoción sectorial con instrumentos que a la fecha resultan aún claves para la ventaja competitiva del sector, y es en este sentido que se sostiene que el foro fue exitoso en materia de diálogo para la política CTI. Hasta 2015, el FONSFOT y la Fundación Sadosky fueron los dos pilares de la promoción sectorial. También se identifican resultados indirectos, asociados a la construcción de redes de cooperación que se extendieron más allá de las actividades del foro. No obstante, y tal como se verá en las secciones que sigue, pese a la centralidad del FONSOFT y de la existencia de redes integradas por las diferentes comunidades, a más de una década de lanzado el fondo, la funcionalidad actual de los instrumentos en el contexto del desarrollo sectorial no parece ser tan significativa como en sus inicios.

\subsection{LÍNEA DE TIEMPO DEL DIÁLOGO SSI}

En la figura 1 se esquematiza la línea de tiempo del diálogo para la política CTI del sector SSI. Se incluyen los antecedentes sectoriales, el origen y el desarrollo del diálogo. Tal como puede apreciarse, aunque el diálogo se concentra en el período que va desde 2003 hasta 2006, con la primera convocatoria FONSOFT, este forma parte de un proceso más amplio de desarrollo y promoción sectorial que se inicia a mediados del siglo pasado y se extiende hasta la actualidad. En cada una de las fases del proceso identificadas, se detallan los hitos del diálogo, la temática y las principales comunidades involucradas. 
Figura 1. Línea de tiempo del diálogo para la política CTI en el sector SSI

\begin{tabular}{|c|c|c|c|c|c|c|c|c|c|}
\hline $\begin{array}{l}\text { Inicios de la } \\
\text { industria e } \\
\text { investigación } \\
\text { en SSI }\end{array}$ & $\begin{array}{c}\text { Escuela } \\
\text { latinoamericana } \\
\text { de informática }\end{array}$ & $\begin{array}{c}\text { Desarrollo de la } \\
\text { industria asociado a } \\
\text { las privatizaciones de } \\
\text { servicios públicos }\end{array}$ & \begin{tabular}{|c} 
Emergencia de \\
diálogos \\
informales \\
frente a la crisis \\
del sector \\
\end{tabular} & $\begin{array}{c}\text { Foros de } \\
\text { Competitividad } \\
\text { SSI }\end{array}$ & \begin{tabular}{|c|} 
Ley de \\
promoción del \\
Software \\
(creación del \\
FONSOFT) \\
\end{tabular} & $\begin{array}{c}\text { Primera } \\
\text { convocatoria } \\
\text { FONSOFT }\end{array}$ & $\begin{array}{l}\text { Etapa 1: } \\
\text { Spread } \\
\text { the seed }\end{array}$ & \begin{tabular}{|c|} 
Etapa 2: \\
Límites al \\
crecimiento
\end{tabular} & $\begin{array}{c}\text { Etapa 3: } \\
\text { Viejas y } \\
\text { nuevas } \\
\text { restricciones }\end{array}$ \\
\hline 1960 & 1980 & 1990 & 2000 & 2003 & 2004 & 2006 & 2007-2008 & 2009-2013 & 2014-2015 \\
\hline \multicolumn{3}{|c|}{ Antecedentes } & Origen & Diálogo & Resultados & & Evolución & & Desafios \\
\hline
\end{tabular}

\section{DESCRIPCIÓN Y ANÁLISIS DEL FONSOFT}

\subsection{INSTRUMENTOS Y LÍNEAS DE FINANCIAMIENTO}

Como se mencionó anteriormente, el FONSOFT fue creado en 2004 y se integra con aportes del tesoro nacional y de la cooperación internacional. Desde la primera adjudicación de proyectos en 2006, el objetivo del fondo ha sido promover la innovación tecnológica en el sector SSI a través de instrumentos de financiamiento dirigidos a estudiantes universitarios, emprendedores, empresas PyME, centros de investigación y universidades.

A la fecha, y de acuerdo a los datos oficiales publicados por el FONSOFT, los instrumentos de promoción se organizan en torno a siete líneas de financiamiento para las que se realizan convocatorias sistemáticas cada año, más una línea asociada a la cooperación internacional, la que depende de acuerdos específicos de naturaleza esporádica. Estas líneas se encuentran estructuradas en torno a tres tipos de instrumentos de promoción: i) aportes no reembolsables (ANR); ii) créditos subsidiados; y iii) becas para la finalización de carreras de grado.

En primer lugar, se encuentra la línea “ANR" que data de los orígenes del FONSOFT en 2006 y tiene por objeto financiar proyectos de certificación de calidad (modalidad i) y de desarrollo de nuevos productos y proceso de software (modalidad ii). Los beneficiarios son empresas PyME del sector, a través de la cofinanciación de proyectos por hasta el 50\% del presupuesto o U\$S 50 mil en un plazo de 16 meses y hasta el 50\% o U\$S 141 mil en un plazo de 18 meses para las modalidades i y ii, respectivamente.

La línea "Subsidios a Emprendedores" también son ANR, aunque en este caso destinados a personas físicas, vigente desde 2007. El objetivo es precisamente promover el espíritu emprendedor a través de la cofinanciación de proyectos de innovación tecnológica, definida como 
el desarrollo de nuevos procesos, productos o servicios de software con el potencial de conducir a nuevas empresas. Los proyectos deben contemplar un horizonte de hasta 12 meses y se financia o bien el $60 \%$ del proyecto o bien hasta U\$S 32 mil.

Como continuación de la promoción del emprendedorismo, en 2016 se crea el "ANR empresa joven". Los objetivos de esta línea son similares a los del ANR tradicional, estructurados en torno a tres modalidades: calidad, continuación de proyectos anteriores y desarrollo de nuevos productos, procesos o servicios, pero destinados específicamente a empresas jóvenes (menos de 2 años de edad). A través de esta línea se cofinancian proyectos de hasta U\$S 42, U\$S 64 y U\$S 83 mil, respectivamente, para cada modalidad, con un plazo máximo de ejecución de 14 meses.

Una cuarta línea de financiación es el denominado "ANR I+D". Originalmente, los proyectos centrados en la realización de estas actividades quedaban subsumidos como una modalidad dentro del ANR tradicional. Desde 2013, los proyectos de I+D cuentan con una convocatoria específica, dirigida a empresas PyME, para proyectos de hasta 24 meses y con un monto máximo de financiación de U\$S 160 mil o el $50 \%$ del presupuesto.

El "ANR capacitación" constituye otra línea de financiamiento, destinada a la formación de recursos humanos, lanzada por primera vez en 2009. Se financian proyectos de capacitación llevados adelante por instituciones públicas o privadas que demuestren capacidades técnicas y administrativas. El plazo de ejecución es de 12 meses y se cofinancia hasta el $60 \%$ del proyecto o U $\$$ S 32 mil.

Además de estas líneas se observan otros programas ANR específicos a lo largo del tiempo, que dependen de situaciones particulares en las relaciones internacionales o procesos específicos de desarrollo industrial y tecnológico. En esta modalidad se encuadra el "ANR internacional" que financia proyectos binacionales, los que fueron previamente aprobados por el Ministerio de Ciencia, Tecnología e Innovación Productiva (MINCyT) en el marco de procesos de cooperación bilateral. En este sentido, aunque se trata de una ventanilla permanente, la oportunidad de presentar proyectos depende del lanzamiento de convocatorias específicas (con un país determinado). Este es también el caso del ANR Televisión Digital Terrestre (TDT) de 2010 en el marco de la adopción del sistema brasilero de TDT, el que a su vez se basa en el sistema japonés. Esta convocatoria tuvo por objetivo el desarrollo de productos y procesos de software orientados a la televisión digital a partir de ANR.

Además de los ANR, desde 2012 el FONSOFT cuenta con la línea "Becas", la que consiste en el otorgamiento de un subsidio para el 
desarrollo de proyectos de desarrollo en tecnologías de información y comunicaciones. Son beneficiarios los estudiantes avanzados ( $80 \%$ de la currícula) de carreas de grado afines de universidades nacionales, provinciales o institutos universitarios. Para aplicar a este beneficio, los aspirantes deben presentar una idea proyecto. Una vez aprobada, los beneficiarios se vuelven postulantes y podrán acceder a una beca con un estipendio único de U\$S 8,9 mil una vez finalizados sus estudios, para lo que tienen un plazo máximo de 18 meses desde el momento de cierre de la convocatoria.

Finalmente, se encuentra la línea "Crédito exporta", cuya primera convocatoria data de los inicios del FONSOFT en 2006. Como su nombre lo indica, se trata de créditos subsidiados para la promoción de la actividad exportadora (iniciación o continuación). A través de esta línea se financian actividades vinculadas con la generación de capacidades para la exportación, la adecuación de productos para la inserción externa y la promoción externa y el desarrollo de mercados, con un plazo de ejecución máximo de 12 meses. Resultan beneficiarias las empresas PyMEs del sector TIC, las que pueden aplicar a un financiamiento de hasta el $80 \%$ del proyecto o U\$S 224 mil, con una tasa de interés equivalente a la ofrecida por el European Central Bank ajustada por el Main refinancing operations (fixed rate) y un plazo de gracia de dos años, a pagar en 12 cuotas cuatrimestrales.

En síntesis, se trata de instrumentos de apoyo financiero a la innovación en el sector SSI, con eje en el otorgamiento de subsidios para el desarrollo tecnológico, pero también con instrumentos de promoción de la actividad exportadora y la creación de competencias vía generación de recursos humanos calificados.

\subsection{ANÁLISIS DE LA EVOLUCIÓN DEL FONSOFT VIS A VIS LA DINÁMICA DEL SECTOR}

El objetivo de esta sección es dar cuenta de la evolución de lo que consideramos "resultado del diálogo" (FONSOFT) vis a vis la dinámica del denominado "objeto del diálogo" (la trayectoria del sector de SSI en Argentina). Esta motivación surge del análisis previo del diálogo, donde advertimos que no es posible estudiar (y evaluar) los diálogos de política CTI desde una perspectiva estática cuando "el objeto" constituye un blanco móvil que exige adaptar el diseño de la política a su dinámica. En términos de la literatura evolucionista, la existencia de un blanco móvil demanda del diseño de una política CTI que asuma un carácter experimental (Breznitz \& Ornston, 2014; Metcalfe \& Ramlogan, 2008), sobre todo en un sector de alto dinamismo tecnológico, a nivel local e internacional, donde los procesos de generación de variedad son impulsados por la constante introducción 
de novedad derivada de la centralidad de la destrucción creativa que determinan, a su vez, la dinámica del proceso de competencia. Esa intervención de tipo experimental es central no solo por la dinámica alcanzada por el objeto del diálogo (y target de la política) sino también por los cambios que ocurren en el entorno de ese objeto a partir de numerosos procesos de retroalimentación (positivos y negativos) que afectan las capacidades de las firmas. Es decir, el carácter experimental de la política consiste en entender la dinámica y trayectoria de las firmas y sus interrelaciones y en fomentar los feedbacks positivos, alentar la producción de cambios cuando hay bloqueos de las interacciones entre los componentes del sistema de innovación y en desarrollar las capacidades ausentes (Yoguel et al., 2016). Por lo tanto, desde una perspectiva de redes es posible considerar la dinámica del sector de SSI como un conjunto de nodos (empresas) y conexiones que van cambiando a lo largo del tiempo, y que requiere instrumentos "adaptables" a los cambios de los nodos y de las interacciones del sistema y que tengan en cuenta el proceso de competencia en el que las firmas están embebidas.

Desde esta perspectiva evolucionista proponemos analizar en qué medida el resultado del diálogo se fue adaptando a los cambios ocurridos en el sector de software, desde el momento en que se empieza a implementar la política de promoción sectorial con la creación del FONSOFT. $^{2}$ El análisis, que considera el período 2004-2016, permite identificar 3 etapas que se diferencian por el grado de maduración del sector y por los cambios introducidos en los instrumentos de promoción del FONSOFT.

\subsubsection{ETAPA 1. SPREAD THE SEED ${ }^{3}$ (2004-2008)}

Esta etapa se inicia con la creación del FONSOFT en el año 2004, si bien las primeras convocatorias a la presentación de proyectos comenzaron en 2006 con tres instrumentos: ANR FONSOFT, Subsidio a emprendedores y Crédito Exporta. Denominamos a esta etapa "spread de seed", dado que la racionalidad detrás de la política de promoción del sector fue apoyar en forma generalizada tanto la creación de nuevas empresas como el desarrollo de innovaciones en empresas existentes, más allá de la especialización intrasectorial

2 Si bien los resultados del diálogo también incluyen beneficios impositivos, el análisis se circunscribe a uno de los instrumentos de promoción creados en el marco de la ley de software.

3 A pesar de que denominamos a esta primera etapa como una "multiplicación de semillas", debe señalarse que el sector tiene una larga historia no lineal de avances y retrocesos que se remonta a la década del sesenta, como se describió en la sección 2.1. 
asociada. Así, desde sus comienzos el diseño de la política sectorial se distanciaba de una política centrada en elegir y promocionar ganadores ("picking the winner"). Esta política tenía sentido en el marco de un sector que aún estaba lejos de constituir una masa crítica de empresas y que por lo tanto limitaba la posibilidad de identificar perfiles sectoriales exitosos (Chudnovsky et al., 2001; Lopez, 2003; Perrazo et al., 1999).

En efecto, a inicios de los años 2000,, el sector tenía una participación marginal en el total de empleo y empresas de la economía argentina, por debajo del 1\% en ambas dimensiones (Ver Tabla 1). Sin embargo, y a pesar de esa escasa participación en la estructura productiva, desde mediados de los noventa el sector venía creciendo a un ritmo superior que el promedio de la economía. Esta dinámica se puede explicar por una conjunción de factores internos y externos. Entre los factores internos es relevante mencionar que, como resultado de trayectorias previas (ver sección 2.1.), el sector privado ya mostraba a principios de los noventa un nivel de capacidades tecnológicas y productivas que puso en ventaja a algunas empresas localizadas en el mercado local ante el nuevo escenario macroeconómico. En el marco de una economía ampliamente desregulada, muchos sectores (con predominio del financiero y de los servicios públicos privatizados), iniciaron fuertes procesos de informatización. Estos sectores se caracterizaban por

una importante demanda de software y de servicios informáticos hacia las empresas locales, ya que esta tenía fuertes especificidades locales particularmente con respecto a la escala de las soluciones requeridas y estuvieron acotadas a un número reducido de firmas, en muchos casos empresas extranjeras localizadas en el país. A su vez, el significativo aumento de las importaciones de hardware y software durante este período relegaron los desarrollos de las empresas locales del sector fundamentalmente a la adaptación y adecuación de productos importados y, con algunas excepciones, a desarrollos dirigidos hacia empresas menos dinámicas ya que la demanda de mayor nivel de complejidad de software y servicios informáticos (SSI) se abasteció desde el exterior. (Erbes et al., 2006: 160)

Luego, la devaluación del peso argentino en 2002 fue un factor clave para generar un shock de competitividad en el sector. Entre los factores externos, la difusión del outsourcing global contribuyó a dinamizar el sector, que contaba con algunas ventajas comparativas tales como husos horarios, disponibilidad de recursos humanos y dominio de idioma inglés. 
Tabla 1. Empleo y empresas de software y servicios informáticos. 1996-2005

\begin{tabular}{|c|c|c|c|c|}
\hline Año & Empleo & Empresas & $\begin{array}{c}\text { \% total empleo } \\
\text { registrado }\end{array}$ & $\begin{array}{c}\text { \% total empresas } \\
\text { sector privado }\end{array}$ \\
\hline $\mathbf{1 9 9 6}$ & 13.413 & 1.303 & $0,4 \%$ & $0,3 \%$ \\
\hline $\mathbf{1 9 9 7}$ & 16.034 & 1.479 & $0,4 \%$ & $0,4 \%$ \\
\hline $\mathbf{1 9 9 8}$ & 19.786 & 1.692 & $0,5 \%$ & $0,4 \%$ \\
\hline $\mathbf{1 9 9 9}$ & 22.824 & 1.743 & $0,6 \%$ & $0,4 \%$ \\
\hline $\mathbf{2 0 0 0}$ & 26.538 & 2.015 & $0,7 \%$ & $0,5 \%$ \\
\hline $\mathbf{2 0 0 1}$ & 27.588 & 2.026 & $0,7 \%$ & $0,5 \%$ \\
\hline $\mathbf{2 0 0 2}$ & 24.233 & 1.885 & $0,7 \%$ & $0,5 \%$ \\
\hline $\mathbf{2 0 0 3}$ & 25.726 & 2.120 & $0,7 \%$ & $0,5 \%$ \\
\hline $\mathbf{2 0 0 4}$ & 30.868 & 2.625 & $0,7 \%$ & $0,6 \%$ \\
\hline $\mathbf{2 0 0 5}$ & 38.351 & 3.070 & $0,8 \%$ & $0,6 \%$ \\
\hline
\end{tabular}

Fuente: elaboración propia en base a información del FONSOFT, ANPCyT.

Desde la política pública, la creación del FONSOFT priorizó desde sus inicios el diseño de instrumentos orientados a crear empresas y desarrollar proyectos de innovación en empresas existentes sin definición de prioridades al interior del sector y con flexibilidad en el grado de novedad de los proyectos financiados. Tal como se mencionó anteriormente, entre los primeros instrumentos de promoción de la innovación se encontraban los ANR FONSOFT y los Subsidios a emprendedores, que se mantienen vigentes en la actualidad. Las Tablas 2 y 3 muestran información sobre la cantidad de proyectos presentados, adjudicados y tasa de aprobación para ambos instrumentos. De allí surge, en primer lugar, que la cantidad de empresas que solicitan apoyo al FONSOFT es creciente (en línea con la dinámica propia del sector). En segundo lugar, que en ambos instrumentos (pero mucho más marcadamente en el subsidio a emprendedores), la tasa de aprobación es significativamente elevada. Debe notarse sin embargo que la proporción de firmas que se beneficiaron de proyectos aprobados fue de solo el $2 \%$ de las firmas existentes en 2006, llegó al 4\% en el 2011 (el año de mayor adjudicación) y se estabilizó en el 3\% del total de firmas en los años siguientes.

Un fondo asimilable al FONSOFT, también dependiente de la Agencia, es el FONTAR (Fondo Tecnológico Argentino) que cuenta con instrumentos de financiación semejantes, pero no discrimina sectorialmente. Es decir, los beneficiarios son PyMEs de todos los sectores de actividad económica. Al tomarlo como referencia, la tasa pro- 
medio de aprobación del FONTAR es de aproximadamente un 25\% y del 20\% al considerar únicamente el sector de SSI. En cambio, la tasa de aprobación de los ANR FONSOFT se ubica cerca del 50\% y, en el caso de los subsidios a emprendedores, supera el 60\%. Esta evidencia sobre la elevada tasa de aprobación sustenta la idea que da el nombre a esta etapa, mostrando que la política de promoción estuvo orientada a impulsar y sostener el crecimiento del sector con requisitos de aprobación relativamente laxos, predominando la idea de generar una masa crítica de empresas más que determinar una estrategia sobre qué tipo de empresas fomentar.

Tabla 2. ANR FONSOFT. Principales indicadores.

\begin{tabular}{|c|c|c|c|c|c|c|}
\hline Año & Presentados & Adjudicados & $\begin{array}{c}\text { Tasa de } \\
\text { aprobación }\end{array}$ & $\begin{array}{c}\% \text { de } \\
\text { Cantidad de } \\
\text { empresas } \\
\text { empresas con } \\
\text { presentaciones } \\
\text { a FONSOFT (del } \\
\text { total de empresas } \\
\text { de software) }\end{array}$ & $\begin{array}{c}\% \text { de las empresas } \\
\text { de software con } \\
\text { acceso a FONSOFT }\end{array}$ \\
\hline 2006 & 164 & 80 & $49 \%$ & 3.467 & $5 \%$ & $2 \%$ \\
\hline 2007 & 201 & 89 & $44 \%$ & 3.847 & $6 \%$ & $2 \%$ \\
\hline 2008 & 290 & 138 & $48 \%$ & 4.087 & $8 \%$ & $3 \%$ \\
\hline 2009 & 397 & 182 & $46 \%$ & 4.174 & $11 \%$ & $4 \%$ \\
\hline 2010 & 290 & 128 & $44 \%$ & 4.356 & $8 \%$ & $3 \%$ \\
\hline 2011 & 308 & 155 & $50 \%$ & 4.538 & $9 \%$ & $3 \%$ \\
\hline 2012 & 270 & 120 & $44 \%$ & 4.662 & $8 \%$ & $3 \%$ \\
\hline 2013 & 254 & 145 & $57 \%$ & 4.726 & $7 \%$ & $3 \%$ \\
\hline
\end{tabular}

Fuente: elaboración propia en base a información del FONSOFT (ANPCyT) y del OEDE, Ministerio de Trabajo y Seguridad Social.

Tabla 3. Subsidio a emprendedores. Principales indicadores.

\begin{tabular}{|c|c|c|c|}
\hline Año & Presentados & Adjudicados & Tasa de aprobación \\
\hline 2007 & 110 & $10^{*}$ & $9 \%$ \\
\hline 2008 & 452 & 282 & $62 \%$ \\
\hline 2009 & 359 & 194 & $54 \%$ \\
\hline 2010 & 315 & 196 & $62 \%$ \\
\hline 2011 & 325 & 209 & $64 \%$ \\
\hline 2012 & 192 & 121 & $63 \%$ \\
\hline 2013 & 140 & 96 & $69 \%$ \\
\hline
\end{tabular}

*La mayoría de los resultados de las evaluaciones de la convocatoria 2007 tuvieron lugar en 2008.

Fuente: elaboración propia en base a información del FONSOFT, ANPCyT. 


\subsubsection{ETAPA 2. LÍMITES AL CRECIMIENTO (2008-2013)}

Al poco tiempo de la creación del FONSOFT, empezaron a ser evidentes ciertas restricciones para el crecimiento futuro del sector de SSI. Por un lado, la apreciación del tipo de cambio real disminuyó la competitividad de las firmas en los mercados externos, que venía siendo una estrategia de crecimiento sostenida. Por otro lado, la expansión del sector generó una fuerte demanda de recursos humanos que dio lugar a la aparición de una fuerte demanda laboral insatisfecha asociada a la extensión del tiempo de formación en las carreras de informática y una elevada rotación de los trabajadores informáticos.

Sobre la primera limitante, la respuesta de política fue casi nula en el marco del FONSOFT. Como se describió en la sección previa, desde 2006 se pone en marcha el instrumento "crédito exporta" con el objetivo de apoyar la actividad exportadora, pero los resultados no fueron positivos. La demanda por parte de las empresas de este instrumento fue casi nula: en el período 2007-2014 se presentaron 21 proyectos y se adjudicaron 6 . Sin embargo, más allá del casi nulo uso de este instrumento, el sector de SSI continuó fortaleciendo su competitividad en el mercado mundial y la inserción externa es una de las actividades más significativas del sector (que genera alrededor de 1.600 millones de dólares anuales). ${ }^{4}$ En este sentido, encontramos un primer punto de divergencia entre los instrumentos del FONSOFT y la evolución de la dinámica, en este caso exportadora, del sector.

La segunda limitante se presenta en el Gráfico 1. Desde mediados de los noventa y hasta el año 2008, el sector privado muestra un crecimiento sostenido tanto en términos de la cantidad de empresas como de la generación de empleo, ${ }^{5}$ mientras que el número de estudiantes universitarios en informática se estanca -e incluso cae- a principios del año 2000, para mantenerse en un número en torno a los 80 mil estudiantes. La presencia de estas brechas entre demanda y oferta de personal calificado abre la pregunta acerca de las estrategias seguidas por las firmas para poder captar recursos humanos en un escenario de fuerte competencia entre las empresas por conseguir personal calificado. Por otra parte, mientras la extensión de la carrera fue la consecuencia de una demanda laboral muy elevada y salarios crecientes, la fuerte rotación requiere una consideración adicional. La rotación

4 Fuente: Observatorio de Economía del Conocimiento. Subsecretaría de Servicios Tecnológicos y Productivos. Ministerio de Producción.

5 Es importante aclarar que el empleo corresponde al empleo total de empresas de SSI, que no solo incluye trabajadores informáticos. Sin embargo, esta sobre-estimación del empleo informático se ve atenuada por un importante elemento de subestimación que es la cantidad de trabajadores empleados en áreas de informática de empresas de otros sectores de actividad. 
fue la resultante de una fuerte competencia de las firmas por captar recursos humanos calificados. También pudo estar reflejando que los trabajadores informáticos cambian de lugar de trabajo porque las demandas acerca de sus competencias son en la mayor parte de los casos poco interesantes (Borello et al., 2005). Tal vez una combinación de la demanda excedente y el escaso interés de los trabajos ofertados sea una adecuada explicación sobre la elevada rotación de trabajadores en el sector.

\section{Gráfico 1. Evolución del empleo, estudiantes en informática y cantidad de empresas de SSI. Período 1996-2014.}

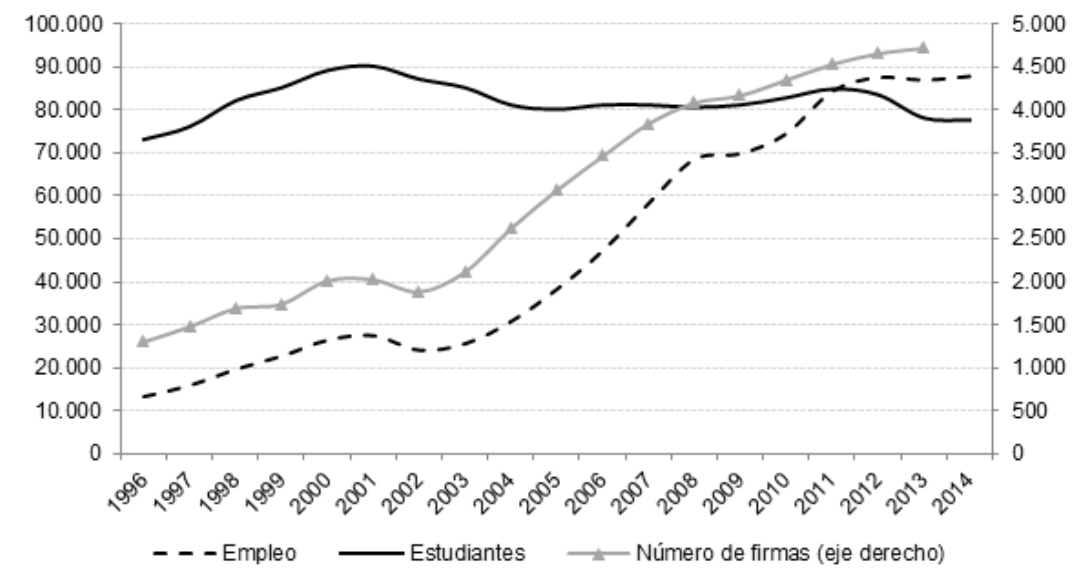

Fuente: elaboración propia en base a información del Ministerio de Trabajo y Seguridad Social de la Nación y de la Secretaría de Políticas Universitarias.

En este marco, desde el sector público nacional la preocupación por la escasez de recursos humanos calificados y por la extensión en los años de formación universitaria se plasmó en el diseño de nuevos instrumentos para generar incentivos orientados a la finalización de los estudios. En el caso particular del FONSOFT, en 2012 se lanza el programa Becas para jóvenes profesionales con el doble objetivo de fomentar el espíritu emprendedor y reducir la deserción de las carreras. ${ }^{6}$ Como se mencionó

6 En otros ámbitos del Estado nacional también se impulsaron programas de capacitación. En 2012 se crea el programa EmplearTec a partir de una iniciativa del Ministerio de Trabajo de la Nación y la Cámara Empresarial de Software y Servicios Informáticos (CESSI) para dar capacitación gratuita a jóvenes en informática. El Estado nacional invirtió U\$S 11 millones en el desarrollo de laboratorios de informática y simuladores, como infraestructura de base para capacitación y la CESSI destinó U\$S 1 millón para otorgar becas para la realización de tres tipos de cursos de formación: i) formación técnica y funcional en diferentes temas (programación, desarrollo de aplicaciones, dis- 
en la sección 3.1., este instrumento financia Ideas Proyecto para la Innovación y Desarrollo de Productos, Servicios, Sistemas o Soluciones en Tecnología de la Información, para la adjudicación de cupos de becas para la finalización de los estudios de grado. La modalidad es de dos convocatorias por año y, de acuerdo a la información disponible, tanto la cantidad de presentaciones como la tasa de aprobación aumentaron significativamente en 2014, reflejando una ampliación en el acceso a la beca. Como se observa en la Tabla 4, el acceso a este nuevo instrumento no fue masivo, sobre todo en las dos primeras convocatorias. En la convocatoria de 2014, luego de algunos años de funcionamiento que contribuye a la difusión, se amplía el acceso en forma significativa, al menos comparativamente al año previo.

Tabla 4. Becas jóvenes profesionales. Principales indicadores.

\begin{tabular}{|c|c|c|c|}
\hline Año & Presentados & Adjudicados & Tasa de aprobación \\
\hline 2012 & 208 & 69 & $33 \%$ \\
\hline 2013 & 137 & 37 & $27 \%$ \\
\hline 2014 & 328 & 172 & $52 \%$ \\
\hline
\end{tabular}

Fuente: elaboración propia en base a información de FONSOFT.

\subsubsection{ETAPA 3. VIEJAS Y NUEVAS RESTRICCIONES (2013-ACTUALIDAD)}

La última etapa del análisis es de final abierto y refiere a la actualidad, por eso la denominamos con un interrogante que invita a pensar, a partir de la configuración actual del sector y de la evolución de los instrumentos del FONSOFT, qué tipo de segmentos dentro del sector de software se desarrollarán (o deberían desarrollarse) en Argentina en los próximos años y sería importante apoyar a través de la política pública. Esta pregunta se fundamenta en una lectura evolucionista de la dinámica del sector. Pensando en términos de un enfoque de ciclo de vida de la tecnología (Perez \& Soete, 1988), el sector de SSI mostró en los últimos 15 años un rápido crecimiento basado en la expansión del mercado (interno y externo), el aumento de la producción y la creación de nuevas empresas ("nuevos entrantes"). En los últimos años, el crecimiento del sector y la competencia por la captura de mayor participación de mercado condujeron a un proceso de concentración que tampoco da cuenta de una masa crítica de empresas produciendo bienes/servicios similares (Ver Tabla 5). Este segmento concentrado convive con un sector altamente heterogéneo en término del perfil de especialización presente en el mercado. En este marco surgen al menos dos preguntas:

eño de páginas web, etc.); ii) formación en conocimientos informáticos básicos o de alfabetización digital; y iii) formación docente en áreas TIC (Motta et al., 2016). 
i) en la fase de maduración que muestra hoy el sector, ¿existen condiciones para identificar y generar incentivos económicos en ciertos segmentos de especialización?; ii) ¿es posible continuar el diálogo para la política CTI tal y como fue pensado en la fase de crecimiento inicial del sector o por el contrario este nuevo escenario impone nuevas condiciones para iniciar un diálogo con cambios metodológicos tanto en la implementación del diálogo como en la intervención en el sector?

Respecto a la configuración actual del sector, se destacan al menos dos fenómenos: un paulatino proceso de concentración y una elevada heterogeneidad sectorial.

El crecimiento del tamaño medio de las firmas de cada estrato reafirma la tendencia a la concentración del empleo en un conjunto pequeño de las firmas de mayor porte. Por ejemplo, el tamaño promedio de las firmas grandes pasó de 77 personas en el 2004 a 138 en el 2013, mostrando un crecimiento de $80 \%$ (Ver Tabla 5). Este aumento de la concentración se evidencia en que mientras que en el 2004 un cuarto del empleo era explicado por el segmento de firmas grandes, la proporción alcanza al 41\% en el 2014 (Tabla 6).

Tabla 5. Tamaño medio de ocupados de las empresas de SSI, por segmento Período 2004-2013.

\begin{tabular}{|c|c|c|c|c|c|c|c|c|c|c|}
\hline & $\mathbf{2 0 0 4}$ & $\mathbf{2 0 0 5}$ & $\mathbf{2 0 0 6}$ & $\mathbf{2 0 0 7}$ & $\mathbf{2 0 0 8}$ & $\mathbf{2 0 0 9}$ & $\mathbf{2 0 1 0}$ & $\mathbf{2 0 1 1}$ & $\mathbf{2 0 1 2}$ & $\mathbf{2 0 1 3}$ \\
\hline Total & 12 & 12 & 14 & 15 & 17 & 17 & 17 & 19 & 19 & 18 \\
\hline Grandes & 77 & 74 & 77 & 87 & 95 & 110 & 114 & 139 & 145 & 138 \\
\hline Medianas & 19 & 20 & 22 & 23 & 25 & 24 & 23 & 24 & 22 & 22 \\
\hline Pequeñas & 12 & 13 & 14 & 15 & 14 & 14 & 14 & 14 & 15 & 15 \\
\hline Micro & 5 & 5 & 5 & 5 & 5 & 5 & 5 & 5 & 5 & 5 \\
\hline
\end{tabular}

Fuente: elaboración propia en base a Ministerio de Trabajo y Seguridad Social.

Tabla 6. Distribución del empleo en empresas de SSI, por segmento. Período 2004-2014.

\begin{tabular}{|c|c|c|c|c|c|c|c|c|c|c|c|}
\hline $\begin{array}{c}\text { Segmento } \\
\text { de empleo }\end{array}$ & $\mathbf{2 0 0 4}$ & $\mathbf{2 0 0 5}$ & $\mathbf{2 0 0 6}$ & $\mathbf{2 0 0 7}$ & $\mathbf{2 0 0 8}$ & $\mathbf{2 0 0 9}$ & $\mathbf{2 0 1 0}$ & $\mathbf{2 0 1 1}$ & $\mathbf{2 0 1 2}$ & $\mathbf{2 0 1 3}$ & $\mathbf{2 0 1 4}$ \\
\hline Grandes & $25 \%$ & $25 \%$ & $27 \%$ & $30 \%$ & $32 \%$ & $34 \%$ & $36 \%$ & $40 \%$ & $42 \%$ & $41 \%$ & $41 \%$ \\
\hline Medianas & $25 \%$ & $25 \%$ & $26 \%$ & $27 \%$ & $27 \%$ & $26 \%$ & $24 \%$ & $23 \%$ & $22 \%$ & $22 \%$ & $21 \%$ \\
\hline Pequeñas & $30 \%$ & $30 \%$ & $29 \%$ & $28 \%$ & $26 \%$ & $26 \%$ & $25 \%$ & $23 \%$ & $23 \%$ & $24 \%$ & $24 \%$ \\
\hline Micro & $21 \%$ & $19 \%$ & $18 \%$ & $16 \%$ & $15 \%$ & $14 \%$ & $14 \%$ & $13 \%$ & $13 \%$ & $13 \%$ & $13 \%$ \\
\hline
\end{tabular}

Fuente: elaboración propia en base a Ministerio de Trabajo y Seguridad Social. 
Por otro lado, el crecimiento del sector en los últimos quince años condujo a una configuración altamente heterogénea en términos de los segmentos y modelos de negocios de las empresas que hoy lo conforman. En términos de incentivos, más allá de los de tipo macroeconómico que favorecieron el desarrollo de actividades vinculadas al factory $^{7}$ con la existencia de un tipo de cambio competitivo en los años posteriores a la devaluación de 2002, no se definieron segmentos estratégicos a favor de cierto tipo de actividad de SSI desde la política pública impulsada por el Estado nacional. Así, tanto en términos de la especialización sectorial de la oferta (a qué sectores proveen las firmas de SSI) como de destino de la oferta (cuál es el área de aplicación) se configuró un sector muy heterogéneo.

Por otro lado, realizar un análisis de la configuración actual del sector no resulta una tarea fácil porque, a partir de las fuentes revisadas y los especialistas consultados, emergen posiciones no homogéneas -entre y al interior de las comunidades- respecto a los siguientes interrogantes: i) cómo caracterizar la cadena de valor de SSI en términos de sus diferentes eslabones; ii) cuál es el perfil de especialización alcanzado por Argentina; iii) dónde se encuentran las principales fuentes de ventaja competitiva; iv) cuáles son las ventajas/desventajas de seguir orientar la política a ciertos segmentos verticales. En esa dirección se presentan diversas percepciones sobre el perfil de especialización del sector elaborados sobre la base de bases de datos, estudios de caso y entrevistas a informantes claves.

En primer lugar, en la Tabla 7 se presenta una taxonomía realizada sobre la base a una encuesta a cerca de 200 empresas de las regiones que concentran la mayor parte de la producción de SSI en Argentina (Barletta et al, 2013). Esta taxonomía combina información sobre los sectores a los que proveen las empresas y el área de aplicación de la oferta de productos y servicios ${ }^{8}$. En términos de la especialización sectorial, los resultados muestran una elevada dispersión de segmentos verticales como clientes de las firmas entrevistadas: industria alimenticia (17\% de las empresas), industria automotriz (11\%), industrias

7 En este caso, se trata sobre todo de un grupo reducido de grandes empresas nacionales y extranjeras, donde se encuentran algunos centros foráneos de desarrollo integrados a las redes globales de producción de software de sus respectivas matrices. Estas empresas se dedican a la provisión de servicios de aplicaciones de software para grandes clientes locales e internacionales y en gran medida a ofrecer servicios de comercialización de productos desarrollados en sus casas matrices u ofrecer servicios informáticos mediante outsourcing (Motta, Morero \& Borrastero, 2016).

8 Las áreas relevadas fueron: a) administración y gestión; b) producción; c) logística; d) publicidad y marketing; e) seguridad informática; f) calidad; g) compras, ventas o medios de pago; h) capacitación; y i) servicio al cliente. 
de proceso (9\%), industria química (8\%), servicios financieros $(13 \%)$, software y servicios informáticos $(9 \%)$. En términos de área de aplicación, predominan las áreas de administración y gestión y, servicios al cliente y compras, ventas y medios de pago. De la combinación de ambas dimensiones, surge que el $43 \%$ de las empresas están diversificadas tanto en términos sectoriales como en área de aplicación y solo el $18 \%$ de las empresas muestra un perfil de especialización total (sectorial y área de aplicación). Sin embargo, incluso en este último grupo de firmas no predomina un sector de actividad, sino que, por el contrario, la oferta provee a segmentos verticales dispersos.

Tabla 7. Taxonomía de empresas

\begin{tabular}{|c|c|c|}
\hline & Diversificación sectorial & Especialización sectorial \\
\hline $\begin{array}{c}\text { Diversificación de área } \\
\text { de aplicación }\end{array}$ & $43 \%$ & $16 \%$ \\
\hline $\begin{array}{c}\text { Especialización área } \\
\text { de aplicación }\end{array}$ & $22 \%$ & $18 \%$ \\
\hline
\end{tabular}

Fuente: Barletta, Pereira y Yoguel (2013) en base a Encuesta del proyecto "Capacidades de absorción y conectividad en sistemas productivos y de innovación locales. El caso de la industria de Software y Servicios Informáticos", financiado por Fundación Carolina.

En segundo lugar, Motta et al. (2016) proponen una segmentación del sector a partir de la identificación de tres grupos de empresas que se caracterizan por la presencia de una marcada relación entre el tamaño y origen del capital de las firmas, y la actividad que desarrollan. Según estos autores existe un número reducido de grandes empresas nacionales y extranjeras de alta especialización dedicadas a proveer servicios de aplicaciones de software para grandes clientes locales e internacionales, a ofrecer servicios de comercialización de productos desarrollados en las casas matrices u ofrecer servicios informáticos mediante outsourcing. El segundo segmento está constituido por empresas medianas de capital nacional, con elevada inserción internacional, que prestan servicios de aplicaciones de software especializados en diversos nichos de mercado: sector financiero y bancos, seguros y servicios públicos, empresas manufactureras y petroleras y del sector de salud (Ginsberg \& Silva Failde, 2009). El tercer segmento se conforma por un gran número de empresas pequeñas de capital local, dedicadas al desarrollo de productos de software y a la prestación de servicios con bajo nivel de especialización. Son empresas que se dedican a una amplia variedad de provisión de servicios informáticos. 
En tercer lugar, siguiendo el análisis planteado en Obaya et al. (2016) es posible identificar en el actual perfil actual de SSI al menos 6 segmentos: i) firmas que ofrecen soluciones customizadas; ii) firmas proveedoras de servicios de consultoría y de servicios vinculados a productos de terceros; iii) firmas que elaboran códigos integrados en cadenas globales y/o con empresas nacionales de SSI; iv) oferentes de servicios semiestandarizados vinculados a productos diseñados por la empresa; v) oferentes de software embebido y vi) productores videojuegos. En este caso, a diferencia del planteo anterior, Obaya et al. (2016) consideran que la asociación entre tamaño y pertenencia a cada uno de esos grupos no es tan clara. Cada uno de esos perfiles se caracterizan por tener diferentes modelos de negocios, lo que se manifiesta en i) una explicitación desigual de cómo construyen y se apropian de rentas; en ii) fuertes diferencias acerca del rol de sus principales activos y sus capacidades centrales, incluyendo la realización o no de las actividades de I+D.

El primer grupo constituye el más numeroso de todos, y es representativo de una proporción importante de empresas. Se trata de firmas más interesadas en dar soluciones que servicios y que reutilizan los códigos fuente generados en diversos proyectos. Este tipo de firmas suele no estar interesadas en los servicios de mantenimiento, porque obtienen su renta de la reutilización de códigos. Adicionalmente, las capacidades se centran no solo en programación sino en la habilidad para entender el funcionamiento de segmentos verticales. En este perfil de empresas la necesidad de desarrollar actividades de $\mathrm{I}+\mathrm{D}$ es escasa. En términos de arquitectura de red, destacan las vinculaciones con clientes con los que se genera una coproducción de los servicios.

El segundo grupo ofrece básicamente servicios de consultoría y mantenimiento de soluciones ofertadas por otros previamente. En este perfil de empresas, las rentas devienen básicamente de la venta de servicios y del mantenimiento de soluciones aportadas por las firmas del primer grupo. En este caso las capacidades necesarias y la arquitectura de red son menos significativas.

El tercer grupo vende servicios de factory y puede estar también oculto en los dos grupos anteriores. Se trata de empresas insertas ya sea en cadenas globales de valor como en provisión de horas de software a otras empresas SSI. La renta se deriva de poder ofertar servicios con salarios inferiores a los del mercado. Las capacidades centrales son las de programación y respuesta a las necesidades de los clientes, que tienen un rol decisivo en los procesos de sub-contratación.

El cuarto grupo representa a las empresas tecnológicamente más avanzadas centradas en el desarrollo de productos propios y venta de 
servicios asociados. En este perfil de empresas, la renta que se genera depende del desarrollo de productos propios en mercados especializados que apunten a aumentar la relación producto/servicios en las ventas. En términos de capacidades centrales destacan el conocimiento sobre el funcionamiento de sectores verticales, el desarrollo de capacidades en diseño y en adaptación de los productos a las necesidades de los clientes y las capacidades de investigación y desarrollo. Finalmente, en términos de la arquitectura de red, este tipo de empresas sobresalen por los vínculos con centros tecnológicos y universidades del sistema nacional de innovación, venture capitals y clientes con elevadas capacidades tecnológicas.

El grupo de software embebido da cuenta de una proporción reducida de empresas que generan rentas derivadas de la capacidad de comprensión de la forma como se integra el software a máquinas y equipos específicos.

El grupo de videojuegos presenta una elevada heterogeneidad entre un grupo reducido de grandes empresas y una elevada proporción de empresas de muy reducido tamaño -en muchos casos informalesque han tenido una dinámica muy positiva en los últimos 10 años fundamentalmente en el mercado externo. Las empresas de este grupo generan rentas a partir de la coevolución de capacidades de programación y de diseño de juegos y de sus capacidades para generar con rapidez nuevos juegos en forma permanente.

En cuarto lugar, y de forma más estilizada, entrevistas con especialistas revelan que alrededor del $40 \%$ de las firmas de SSI argentinas se encuentran en segmentos menos dinámicos o con una menor intensidad relativa de conocimiento y tecnología, entre los que se destacan las empresas que desarrollan códigos y las de testing. El restante $60 \%$ se reparte entre las que implementan y adaptan aplicaciones, las especializadas en segmentos verticales y las de bases de datos. Siguiendo esta fuente, Argentina cuenta con ventajas competitivas en los siguientes sub-segmentos: 1) plataformas dinámicas (animaciones, advert games); 2) servicios profesionales de alto nivel (segmento donde predominan las empresas multinacionales); 3) AgroTICs; 4) salud (se trata de empresas que se benefician de la ausencia de un sistema único de salud); y 5) edición de imágenes.

Más allá de las coincidencias o divergencias sobre la composición del sector, la política de FONSOFT no parece, al menos hasta la actualidad, mantener la coherencia que presentó en la primera y, en menor medida, en la segunda fase en términos del diseño de instrumentos. Al momento, no se crearon ni se tomó conocimiento de proyectos que busquen fortalecer ciertos segmentos de nicho o alguna otra actividad estratégica. En cambio, sí se planteó la 
importancia de impulsar la innovación con el objetivo de complejizar la actividad de las empresas locales, que mantiene un importante componente de factory. Se crea entonces un nuevo instrumento en 2014 denominado ANR I+D con el objetivo de apoyar proyectos de colaboración en $\mathrm{I}+\mathrm{D}$ entre empresas privadas y las instituciones del sistema nacional de innovación. Sin embargo, hasta el momento solo un proyecto fue financiado en el marco de esta línea. En parte, esto puede explicarse por la débil presencia de firmas que requieren hacer I+D formal (Obaya et al, 2016) y por un escaso entendimiento acerca de qué quiere decir hacer I+D e innovar en el sector de software, lo que forma parte de un debate más general sobre las características que asumen los procesos de innovación en sectores intensivos en conocimiento (Coombs \& Miles, 2000; Cusumano, 2010; Djellal \& Gallouj, 1999; Gallouj \& Savona, 2010). El fracaso de este instrumento también refleja un largo debate entre los referentes del sector y los hacedores de política en términos de cómo apoyar la innovación. En un sector donde la compra de bienes de capital no constituye un esfuerzo de innovación relevante como lo es en la manufactura, los recursos humanos pasan a ser casi la única fuente de innovación. Sin embargo, el FONSOFT no financia la incorporación de recursos humanos como insumo del proceso de innovación. ${ }^{9}$ En el marco de este debate, las empresas encuentran en el régimen de promoción de la ley de software una mejor herramienta para financiar la innovación, dado que reciben beneficios fiscales como contrapartida de sus inversiones en I+D. Esta es la posición de algunos especialistas que sostienen que la función del FONSOFT se fue desdibujando por esta decisión de no financiar recursos humanos propios para actividades de innovación, quedando así relegado frente a la ley de software como instrumento de promoción. Sin embargo, no constituye una postura consensuada, reflejando que los intereses y posiciones actuales no son tan homogéneas como en el inicio del diálogo.

\section{REFLEXIONES FINALES}

En el análisis de la evolución del sector vis a vis la dinámica del FONSOFT muestra que, a lo largo de las etapas analizadas, se ha venido produciendo una acumulación en capas de los instrumentos de promoción

9 Si bien el FONSOFT está financiado por el Tesoro Nacional, esta decisión responde a una política de la Agencia Nacional de Promoción Científica y Tecnológica de implementar las mismas condiciones para todos sus fondos, en el marco de ciertas normativas del BID (principal financiador de la Agencia). Entre ellas, no se permite financiar recursos humanos propios, independientemente del fondo o sector de actividad. 
debido a que en las fases estudiadas se observa la aparición de nuevos instrumentos, a veces funcionales a las demandas productivas, sin la desaparición de instrumentos iniciales y sin cambios sustanciales en los programas en ejecución, poniendo de manifiesto la implementación de una política poco experimental.

La figura 2 estiliza, para las 3 etapas identificadas, las características centrales del sector de SSI y los instrumentos diseñados por el FONSOFT para ilustrar en qué medida es posible inferir la existencia o no de esquemas funcionales. Entendemos por un esquema funcional aquel que muestra coherencia y coevolución entre los rasgos emergentes del sector (Nelson, 1994), la demanda de política asociada y la respuesta del FONSOFT en términos del diseño de instrumentos. Predomina en este análisis una visión bottom-up de la política, en línea con la dinámica del diálogo. En este marco, la primera etapa se caracteriza por un esquema funcional que responde a las posibilidades del sector en un contexto de elevada incertidumbre sobre la dinámica futura y la evolución de una posible especialización de segmentos. En esta etapa, de fuerte crecimiento y aparición de gran cantidad de nuevos entrantes, la política horizontal del FONSOFT a través de los aportes no reembolsables y los subsidios a emprendedores orientados a apoyar la creación de empresas nuevas funcionó en el marco de una dinámica coevolutiva entre la demanda sectorial emergente que fue acompañada por la política. En la segunda etapa también se presenta un esquema funcional en el marco de un sector que empieza a presentar límites al crecimiento con la emergencia de una demanda insatisfecha de recursos humanos que retroalimenta en forma negativa al sistema educativo, debido a que comienza a aumentar el tiempo de formación universitaria y la deserción. En este marco, la coevolución con el FONSOFT se manifiesta en el lanzamiento de un nuevo programa de becas de formación de jóvenes profesionales, si bien el impacto es aún reducido. Esta adición de instrumentos parece no responder a la configuración y a las necesidades del sector en la tercera etapa. Esta etapa muestra persistencia de la escasez de recursos humanos y una microheterogeneidad creciente en términos de los segmentos que lo componen, con requerimientos y demandas de política bien diferenciados. Mientras tanto, el FONSOFT continúa centrando la política de promoción en los instrumentos tradicionales que introduce la idea de la existencia de un esquema disfuncional basado, en algunos casos, en demandas actuales del sector que no coinciden con la oferta de instrumentos y, en otros casos, en un aparente diseño inadecuado de la herramienta de política en función de la demanda (como es el caso del instrumento "Crédito exporta"). 
En suma, el análisis de las etapas tomadas en conjunto manifiesta que la coevolución entre el sector SSI y el FONSOFT fue inicialmente importante, se comenzó a debilitar en la segunda etapa, y se convierte en una clara divergencia hacia el final del período. En parte, esto se explicaría por la ausencia de un diseño más experimental de la política que reconozca el sector de software como un blanco móvil, y defina instancias de monitoreo y evaluación, así como también etapas de diagnóstico sobre la evolución del sector. En otras palabras, la falta de continuidad del diálogo en la implementación y evolución de los instrumentos refleja el distanciamiento entre la política y la dinámica sectorial.

Figura 2. Evolución del sector vs FONSOFT, por etapas.

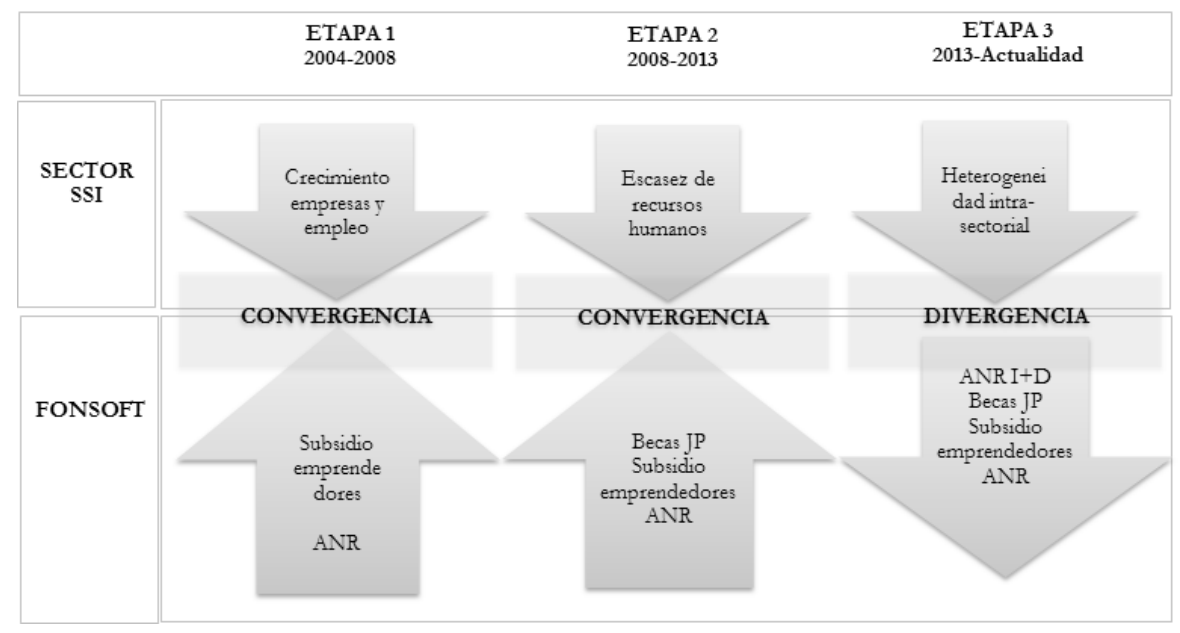

De esta forma, la capacidad del FONSOFT para acompañar la expansión del sector SSI durante la última década parece ahora insuficiente ${ }^{10}$ para promover procesos de complejización tecnológica, especialización productiva e inserción en cadenas globales de valor en el marco de un sector más complejo, con modelos de negocios

10 La pérdida de protagonismo como instrumento de promoción frente al régimen de promoción de la ley se manifiesta en los montos anuales de financiación. Mientras que el FONSOFT tiene un presupuesto de alrededor de 2 millones de dólares anuales, los beneficios de la ley representan alrededor de 45 millones. De todas maneras, es importante destacar que al interior del sector hay un fuerte debate dado que algunos expertos sostienen que los beneficiarios de la ley son pocas y grandes empresas (muchas de ellas multinacionales) y plantean una serie de modificaciones como la restricción de la adhesión a Pymes de capital nacional. 
divergentes y con demandas heterogéneas en materia de formación de recursos humanos y promoción de la innovación.

Este panorama requiere generar un nuevo debate, posiblemente asociado a la necesidad de regenerar el diálogo para la política CTI, que conduzca a establecer nuevos consensos sobre la posición y configuración del sector, las ventajas y desventajas de la especialización en diferentes segmentos y qué tipo de políticas son necesarias en el nuevo escenario.

Reconociendo que la configuración actual del sector dista de la inicial, la dinámica de las comunidades que forman parte del diálogo también fueron configurando características inter e intracomunidad que merecen nuevas consideraciones. Por ejemplo, en la comunidad empresarial, la dispersión de segmentos y el proceso de concentración fueron configurando un espacio con asimetrías de poder más claras y presencia de intereses en conflicto que conducen a demandas diferenciadas, ausentes o débilmente presentes al inicio del diálogo. Frente a este gran crecimiento de la comunidad empresarial, la comunidad académica ha mostrado en los últimos quince años un crecimiento menos sustancial que se reflejaría en cambios en los equilibrios de poder intercomunidades ante un nuevo diálogo. A la vez, con la proliferación del factory en el sector privado -cuya magnitud efectiva sigue siendo tema de debate-, desde el ámbito académico emergen consensos en torno a apreciaciones negativas sobre la calidad de la demanda (lo que limita la complejidad de los problemas a resolver y las soluciones a ofertar) y los desafíos (cognitivos y tecnológicos) que presenta la comunidad empresarial, lo que dificulta el abordaje de la vinculación entre las comunidades empresarial y académica.

Finalmente, en la comunidad política emerge un actor convocante de un nuevo diálogo de la mano del Ministerio de Producción de la Nación con una primera iniciativa ya concretada que reunió a los actores pertenecientes a las distintas comunidades. El informe de esta primera reunión refleja fundamentalmente las demandas actuales de la comunidad empresarial asociadas al debate sobre la especialización y la falta de recursos humanos, como temas que persisten y se repiten. Entre los nuevos temas, surge la necesidad de contar con información más detallada sobre la configuración actual del sector para conocer con más exactitud el peso de los diferentes segmentos, el requerimiento de institucionalizar un diálogo sobre prospectiva donde se genere debate en torno a las posibilidades futuras del sector (a nivel local y global) y la demanda de vinculación de los polos tecnológicos locales con las cadenas de valor regionales. 


\section{BIBLIOGRAFÍA}

Álvarez, I.; Barletta, F.; Suarez, D.; Yoguel, G. 2016 "Marco analítico para la tipificación de diálogos para las políticas de CTI" en Working paper 3 (Red CYTED COM-LALICS). En <http://lalics. org/images/CYTED/DT3-DimensionesDialogo.pdf> acceso $15 \mathrm{de}$ abril de 2017.

Barboza, L., 2016 "Algunas consideraciones en torno al concepto de comunidad" en Working paper 6 (Red CYTED COM-LALICS).

En <http://lalics.org/images/CYTED/DT6-DefinicionComunidad. pdf $>$ acceso 15 de abril de 2017.

Barletta, F.; Pereira, M.; Robert, V.; Yoguel, G.; 2013a “Argentina:

Dinámica reciente del sector de software y servicios informáticos" en Revista de la CEPAL (CEPAL) $\mathrm{N}^{\circ} 110$, pp. 137-155.

Barletta, F.; Yoguel, G.; Pereira, M.; 2013b "Capabilities, linkages, and performance. The recent dynamic of the Argentine software and IT services sector", Ponencia presentada en Globelics 2013 (Ankara).

Baum, G.; Artopoulos, A.; Aguerre, C.; Albornoz, I.; Robert, V.; 2009 Libro Blanco de la prospectiva TIC. Proyecto 2020 (Argentina: Ministry of Science, Technology and Production Innovation).

Borello, J.; Erbes, A.; Robert, V.; Roitter, S.; Yoguel, G.; 2005 "Competencias técnicas de los trabajadores informáticos. El caso de Argentina" en Revista de la CEPAL (CEPAL) N 87, diciembre.

Breznitz, D.; Ornston, D.; 2014 "Scaling up and sustaining experimental innovation policies with limited resources: Peripheral Schumpeterian development agencies" en OECD (ed.) Making Innovation Policy Work (OECD) pp. 247-284.

Coombs, R.; Miles, I.; 2000 "Innovation, measurement and services" en Metcalfe, J.; Miles, I. (eds.) Innovation systems in the service economy: measurement and case study analysis (Boston: Kluwer).

Cusumano, M.; 2010 "Cloud computing and SaaS as new computing platforms", Ponencia presentada en Communications of the ACM CACM (Homepage archive) vol. 53 (4), abril.

Chudnovsky, D.; López, A.; 2002 "The Software and Information Services Sector in Argentina. Pros and Cons of an InwardOriented Development Strategy" en Discussion Paper (World Institute for Development Economics Research - UNU-MERIT) $\mathrm{N}^{\circ} .2002 / 92$. 
Chudnovsky, D.; Lopez, A.; Melitzko, S.; 2001 "El sector de software y servicios informáticos en la Argentina. Situación actual y perspectivas de desarrollo", Documento de trabajo $\mathrm{N}^{\mathrm{o}} 27$ (Buenos Aires: CENIT).

Djellal, F.; Gallouj, F. 1999 "Services and the search for relevant innovation indicators: a review of national and international surveys" en Science and public policy (Reino Unido: Oxford University Press) No 26(4), pp. 218-232.

Dutrénit, G.; Álvarez, I.; Ardanche, M.; Barletta, F.; Bianco, M.; Cortés, R.; Cummings, A.; de la Vega, I.; Díaz, I.; Fernández, O.; Gómez, V.; Goñi, M.; Natera, J. M.; Nupia, C.; Orozco, J.; Prada, F.; Puchet, M.; Romero, F.; Simón, L.; Suárez, D.; Suárez, M., Sutz, J.; Vera-Cruz, A. 2016 "Matriz de Información para el mapeo de procesos de diálogo de CTI en España, América Latina y el Caribe" en Working paper 5 (Red CYTED COM-LALICS). En $<$ http://lalics.org/images/CYTED/DT5-Formulario2.pdf> acceso 15 de abril de 2017.

Dutrénit, G.; Natera, J. M.; Suárez, M. 2014 "Lineamientos para la caracterización de las Comunidades y sus Procesos de Diálogo" en Working paper 1 (Red CYTED COM-LALICS). En <http:// lalics.org/images/CYTED/DT1-ComunidadesDialogo\%201.pdf> acceso 15 de abril de 2017.

Erbes, A.; Robert, V.; Yoguel, G. 2004 El sendero evolutivo y potencialidades del sector de software en Argentina (Argentina: Universidad Nacional de General Sarmiento, LITTEC).

Erbes, A.; Robert, V.; Yoguel, G. 2006 "El sendero evolutivo y potencialidades del sector de software en Argentina" en Borello, J.; Robert, V.; Yoguel, G. (eds.) La informática en la Argentina. Desafíos a la especialización y a la competitividad (Buenos Aires: UNGS-Prometeo Libros.

Eurostat 2013 Science, technology and innovation in Europe, 2013 edition (Luxemburgo: Unión Europea).

Galindo-Rueda, F.; Verger, F. 2016 "OECD Taxonomy of Economic Activities Based on R\&D Intensity" en OECD Science, Technology and Industry Working Papers (París: OECD Publishing) $\mathrm{N}^{\circ}$ 04. En $<$ http://dx.doi.org/10.1787/5jlv73sqqp8r-en>.

Gallouj, F.; Savona, M. 2010 "Towards a theory of innovation in services" en Gallouj, F.; Djellal, F. (eds.) The handbook of innovation and services (Cheltenham: Elgar).

Gargiulo, M.; Benassi, M.; 1999 "The dark side of social capital” en Leenders, R.; Gabbay, S. (eds.) Corporate social capital and liability (Estados Unidos: Springer). 
Ginsberg, M.; Silva Failde, D. 2009 “Análisis del régimen de promoción de la industria del software y servicios informáticos" en Congreso Anual AEDA (Buenos Aires).

Goñi, M.; Bianco, M.; Puchet, M. 2015 “Elementos para caracterizar los procesos de diálogo en políticas de CTI" en Working paper 7 (Red CYTED COM-LALICS). En <http:// lalics.org/images/CYTED/DT7-ConfianzaPoder.pdf> acceso 15 de abril de 2017.

López, A. 2003 "El sector de software y servicios informáticos en la Argentina ¿es posible una inserción exportadora sostenible?" en Boscherini, F.; Novick, M.; Yoguel, G. (eds.) Nuevas tecnologías de información y comunicación. Los límites en la economía del conocimiento (Buenos Aires-Madrid: Miño y Dávila).

López, A.; Ramos, D.; Torre, I. 2009 "Las exportaciones de servicios de América Latina y su integración en las cadenas globales de valor", Documento de proyecto CEPAL (Santiago de Chile).

MECON 2003 Foro de competitividad de software y servicios informáticos (Argentina: Ministerio de Economía y Producción).

Metcalfe, S.; Ramlogan, R. 2008 "Innovation systems and the competitive process in developing economies" en The Quarterly Review of Economics and Finance (Países Bajos: Elsevier) $\mathrm{N}^{\circ}$ 48(2), pp. 433-446.

Motta, J.; Morero, H.; Borrastero, C. 2016 "La política industrial en el sector de software de Argentina durante los años 2000", Ponencia presentada en Seminario Interuniversitario sobre Desarrollo Productivo (Buenos Aires: FCEN, UBA).

Nelson, R. 1994 "The Co-evolution of Technology, Industrial Structure, and Supporting Institutions" en Industrial and Corporate Change (Reino Unido: Oxford University Press) $\mathrm{N}^{\circ}$ 3(1), pp. 47-63.

Nooteboom, B.; Van Haverbeke, W.; Duysters, G.; Gilsing, V.; van den Oord, A. 2007 "Optimal cognitive distance and absorptive capacity” en Research Policy (Países Bajos: Elsevier) No 36(7), pp. 1016-1034.

Nupia, C.; Martínez A. 2015 "Revisión de metodologías de procesos de diálogo" en Working paper 4 (Red CYTED COM-LALICS). En <http://lalics.org/images/CYTED/DT4-MetodologiasDialogo.pdf> acceso 15 de abril de 2017.

Obaya, M.; Yoguel, G.; Robert, V.; Lerena, O. 2016 "R\&D activities in software firms in emerging countries. Four case studies in Argentina", Ponencia presentada en 16th Congress of the International Joseph A. Schumpeter Society (Montreal). 
Pereira, M.; Barletta, F.; Yoguel, G. 2016 "El desempeño del sector de software y servicios informáticos en la Argentina: evidencia microeconométrica sobre los programas públicos de apoyo" en Revista CEPAL (CEPAL).

Pérez, C.; Soete, L. 1988 "Catching Up in Technology: entry Barriers and Windows of Opportunity" en Dosi, G.; Freeman, C.; Nelson, R.; Soete, L. (eds.) Technical Change and Economic Theory (Londres: Francis Pinter).

Perrazo, R.; Delbue, M.; Ordóñez, J.; Ridner, A. 1999 “Oportunidades para la producción y exportación de Software", Documento de Trabajo No 9 (Buenos aires: Agencia Nacional de Promoción Científica y Tecnológica).

SECYT 1987 "Producción y comercio de software en la Argentina. Secretaría de Ciencia y Técnica-/Subsecretaría de Informática y Desarrollo" en Documento SID No 35 (Buenos Aires).

WTO 2015 International Trade Statistics 2015 (World Trade Organization).

Yin, R. 2009 Case study research: Design and methods (SAGE).

Yoguel, G.; Pereira, M.; Barletta, F. 2016 "Los sistemas de innovación y la política industrial y tecnológica" en Erbes, A.; Suarez, D. (eds.) Repensando el desarrollo latinoamericano. Una discusión desde los sistemas de innovación (Buenos Aires: UNGS). 





\section{COLECCIÓN GRUPOS DE TRABAJO}

Este trabajo forma parte de un esfuerzo más amplia de reflexión sobre Ciencia, Tecnología y Sociedad en América Latina, que viene desarrollando el Grupo de trabajo "Ciencia y Sociedad" de CLACSO. En particular, este libro contribuye a alimentar el pensamiento en torno a la generación de políticas de CTI basadas en la evidencia, a partir de la discusión de estudios de caso sobre los procesos de diálogo de las comunidades para construir política pública.

Esperamos que la recopilación de estos casos de estudios, estructurados a través del marco analítico que proponemos, sean considerados como un aporte a la construcción de políticas públicas de CTI, basadas en la participación pública, que logren contribuir al desarrollo de ALC y España.

De la Presentación de Gabriela Dutrénit y José Miguel Natera.

Patrocinado por

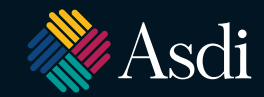

Agencia Sueca

de Desarrollo Internacional
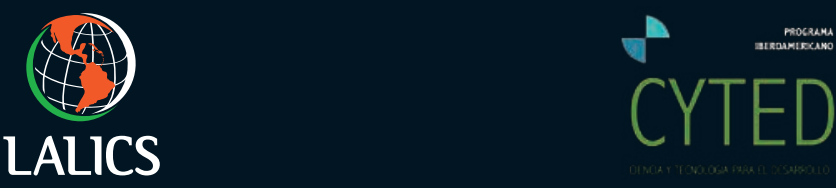

\section{LALICS}

